\title{
Herbaceous Feedstock 2018 State of Technology Report
}

\author{
Mohammad S Roni, Damon S Hartley, \\ Mike Griffel, Hongqiang Hu, Quang A \\ Nguyen, Hao Cai, David N Thompson \\ March 2020
}

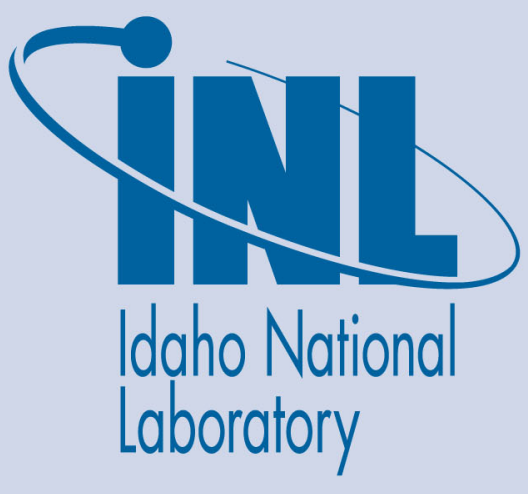

The INL is a U.S. Department of Energy National Laboratory operated by Battelle Energy Alliance 


\title{
Herbaceous Feedstock 2018 State of Technology Report
}

\author{
Mohammad S Roni, Damon S Hartley, Mike Griffel, Hongqiang Hu, Quang A \\ Nguyen, Hao Cai, David N Thompson
}

March 2020

\section{Idaho National Laboratory} Idaho Falls, Idaho 83415

http://www.inl.gov

Prepared for the U.S. Department of Energy

Office of Energy Efficiency and Renewable Energy

Under DOE Idaho Operations Office

Contract DE-AC07-05ID14517 


\title{
HERBACEOUS FEEDSTOCK 2018 STATE OF TECHNOLOGY REPORT
}

\author{
Mohammad Roni, David N. Thompson, \\ Damon Hartley, Mike Griffel, Honqiang Hu, \\ Quang Nguyen, Hao Cai
}

SEPTEMBER 30, 2018 


\begin{tabular}{|l|l|}
\hline BWD\#: 1.1.1.2.DL.1 \\
$\begin{array}{l}\text { Type: Milestone } \\
\text { WBS \#: 1.1.1.2 }\end{array}$ & $\begin{array}{l}\text { Completion Date: September 30, 2018 } \\
\text { Scheduled Completion: September 30, 2018 } \\
\text { Platform Area: Feedstock Supply and Logistics }\end{array}$ \\
\hline Milestone Title: & Herbaceous Feedstock 2018 State of Technology Report \\
\hline Authors: & $\begin{array}{l}\text { Mohammad Roni, David N. Thompson, Damon Hartley, Mike } \\
\text { Griffel, Honqiang Hu, Quang Nguyen, Hao Cai (Argonne) }\end{array}$ \\
\hline $\begin{array}{l}\text { Project Name: } \\
\text { Project Leader: }\end{array}$ & $\begin{array}{l}\text { Feedstock Supply Chain Analysis } \\
\text { David N. Thompson }\end{array}$ \\
\hline Participating Researchers & $\begin{array}{l}\text { Neal Yancey, Jaya Tumuluru, William Smith, Lynn Wendt, Jeffrey } \\
\text { Lacey, and Vicki Thompson }\end{array}$ \\
\hline Key Words: & analysis, state of technology, feedstock, herbaceous \\
\hline
\end{tabular}

\section{EXECUTIVE SUMMARY}

The U.S. Department of Energy (DOE) promotes the production of advanced liquid transportation fuels from lignocellulosic biomass by funding fundamental and applied research that advances the State of Technology (SOT). As part of its involvement with this mission, Idaho National Laboratory (INL) completes an annual SOT report for biomass feedstock logistics. This report summarizes supply system impacts of Bioenergy Technologies Office (BETO)-funded research and development efforts at INL and elsewhere (such as the High-Tonnage Feedstock Logistics projects (Webb et al. 2013a, Webb et al. 2013b, Webb et al. 2013c, Webb and Sokhansanj 2014, Sokhansanj et al. 2014)) that lead to improvements in feedstock supply systems. These include improvements to and observed performance of innovative harvest and collection methods, storage technologies, transportation and handling approaches, and advanced preprocessing technologies. Biomass quality and variability, and the interface between feedstock quality and conversion performance are key drivers in addition to delivered feedstock cost. In this report, we estimate the benefits of R\&D improvements to individual supply system unit operations, and present the status of feedstock logistics technology development for converting biomass into biofuels. These analyses are supported by experimental data where possible, and help to align the SOT relative to the cost goals defined in the Multi-Year Program Plan.

During 2018, the BETO Conversion Platform redefined the time on-stream for their process models to $90 \%$. The 2018 Herbaceous SOT aligns with this change, which reduces the amount of feedstock required to be delivered to the reactor throat from 800,000 dry tons to 725,000 dry tons annually. Biomass availabilities in this SOT were updated to year 2018 data from the 2016 Billion-Ton Report (BT16) (DOE 2016a), with the exception of switchgrass, for which the 2018 Herbaceous SOT utilized the 2019 switchgrass availability data from BT16 (as was done in both the 2016 and 2017 Herbaceous SOTs). This was because BT16 does not project switchgrass availability in 2018, rather, the soonest switchgrass was projected to be available is in 2019. Hence, switchgrass availability for this analysis was that projected for 2019. The 2018 Herbaceous SOT models technologies identical to those modeled in the 2017 Herbaceous SOT. A sensitivity analysis varying the modeled equipment performance over experimentally-observed ranges was added in the 2018 SOT. The 2018 Herbaceous SOT also includes a supply system projection for 2022 that utilizes current BETO Feedstock Supply and Logistics (FSL) R\&D technical targets.

The 2018 Herbaceous SOT predicts a modeled delivered feedstock cost of $\$ 83.67 /$ dry ton (2016\$); 


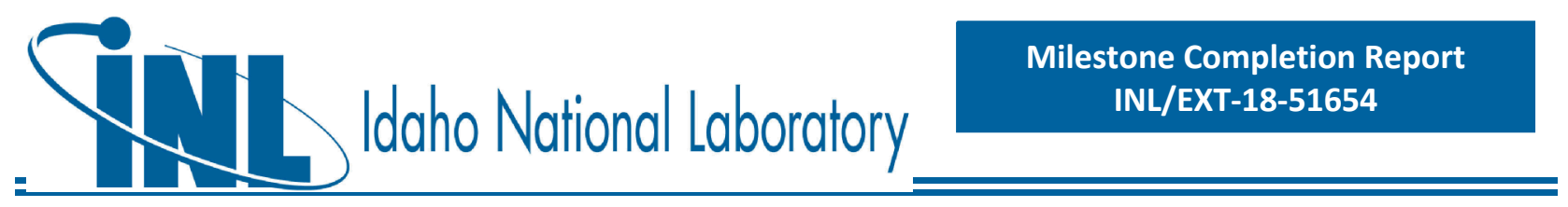

this is a $\$ 0.23$ /dry ton $(2016 \$)$ decrease from the 2017 Herbaceous SOT. The reduction in required biomass supply together with increased BT16-projected biomass availability in the supply shed contributed to this modeled cost reduction. The least-cost formulation model, which optimally sites and scales local preprocessing depots, also contributed to the cost reduction by considering county-level grower payment and distance from the biorefinery as variables in the optimization algorithm. Sensitivity analysis on various process parameters that affect delivered feedstock cost in the 2018 Herbaceous SOT shows that the delivered cost could vary from $\$ 80.45-\$ 88.83 /$ dry ton. The highest impacting factors that could lead to uncertainty in delivered cost included effective baling rate, bale density, hammer mill throughput, interest rate and storage dry matter loss. A modeled net reduction in greenhouse gas emissions (GHG) was completed by Argonne National Laboratory using the 2018 Greenhouse Gases, Regulated Emissions, and Energy use in Transportation model, estimating a decrease of $4.8 \mathrm{~kg} \mathrm{CO}_{2} \mathrm{e} / \mathrm{ton}$ from the $2017 \mathrm{SOT}$ (74.11 $\mathrm{kg} \mathrm{CO}_{2} \mathrm{e} /$ ton in 2017 to $69.27 \mathrm{~kg} \mathrm{CO}_{2} \mathrm{e} /$ ton in 2018). This reduction was attributed to reduced bale transport distance to the distributed depots and to the reduction of delivered biomass from 800,000 dry tons to 725,000 dry tons annually. 


\section{Table of Contents}

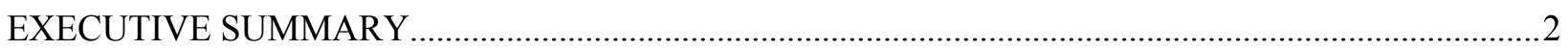

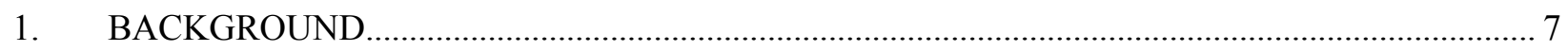

Progression of Feedstock Supply System Designs................................................................. 7

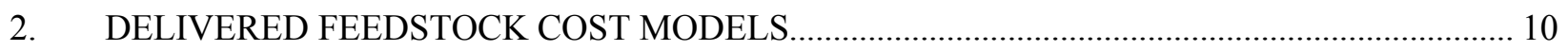

2.12018 Herbaceous Feedstock SOT Cost Analysis............................................................. 10

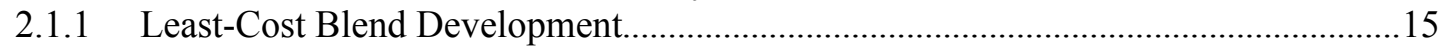

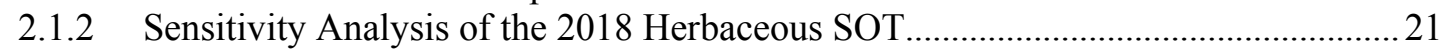

2.2 Comparative Supply Costs and Blends for Centralized Depots and Exclusion of

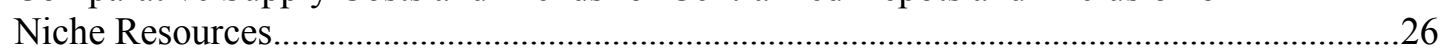

2.2.1 Exclusion of Grass Clippings from the Distributed Depot Case.................................26

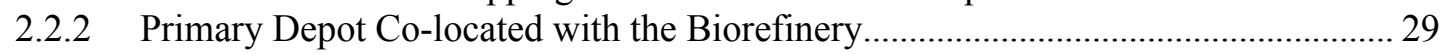

2.2.3 Exclusion of Grass Clippings from the Centralized Depot Case................................. 32

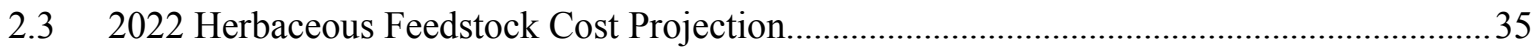

2.3.1 Projected Technology Developments by Supply Chain Element................................ 35

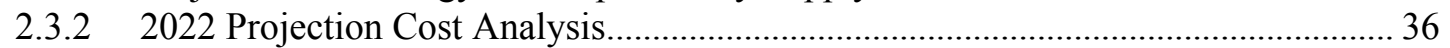

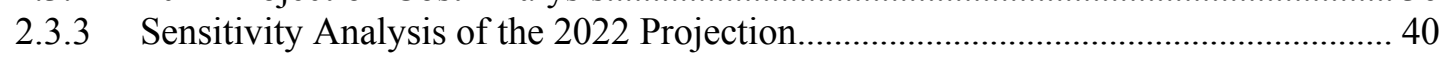

3. INDUSTRIAL RELEVANCE OF THE BLENDSTOCKS........................................................... 45

4. QUALIFICATION OF THE BLENDSTOCKS FOR RENEWABLE IDENTIFICATION

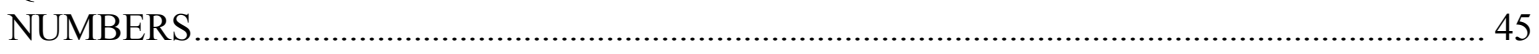

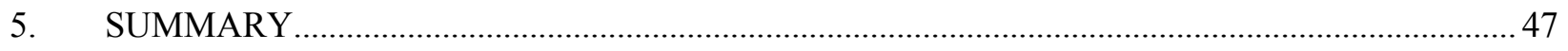

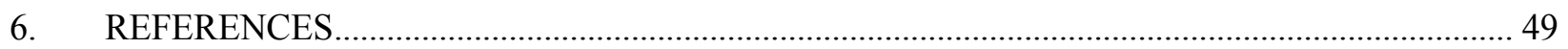

APPENDIX A - 2018 Herbaceous State of Technology Feedstocks Logistics Design and

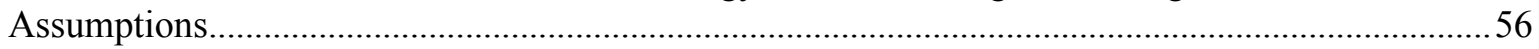

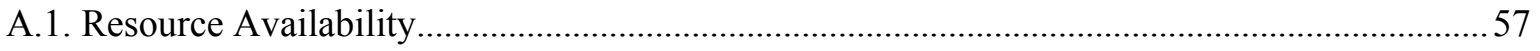

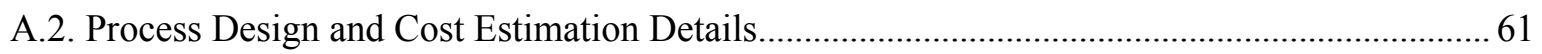

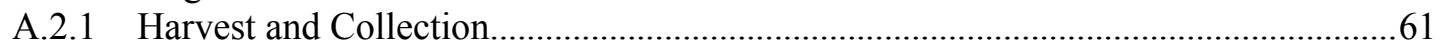

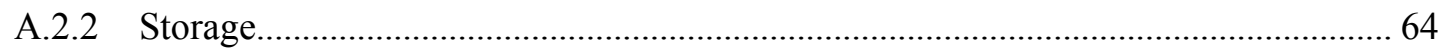

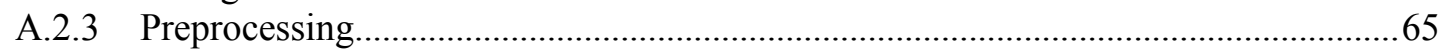

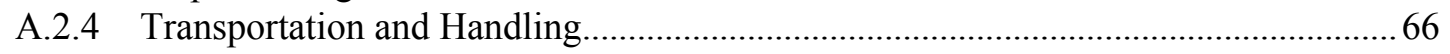

A.2.5 Depot construction cost for different depot sizes........................................................ 73

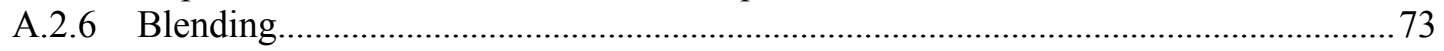

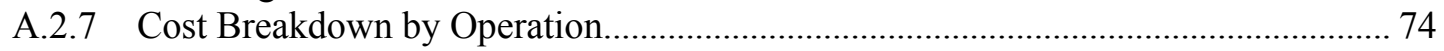


APPENDIX B - Optimization of Blending Based on Quality, Resource Availability, Location

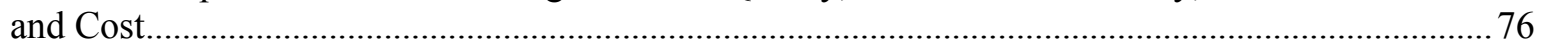

B-1 MILP Model for Distributed Depot Cases.............................................................................. 76

B-2 MILP Model for Centralized Cases (Primary Depot Co-Located with the Biorefinery)

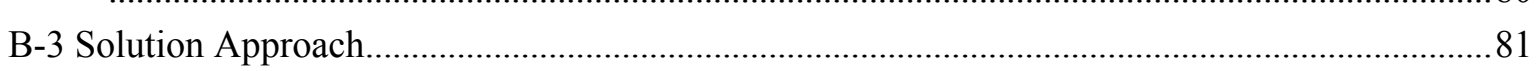

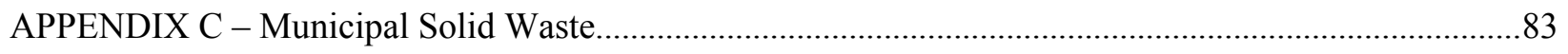

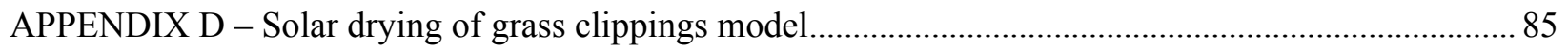

D.1 Design of a solar drying system for drying grass clippings................................................... 85

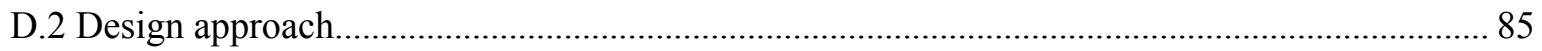

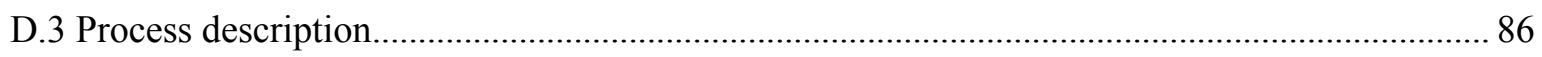

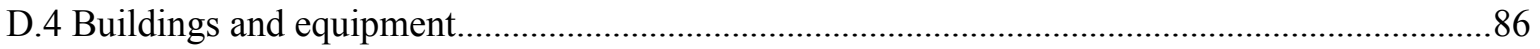

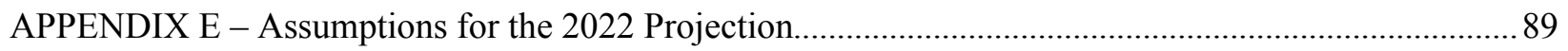

E.1 Incorporation of ILM Strategies to Reduce Grower Payment.................................................. 89

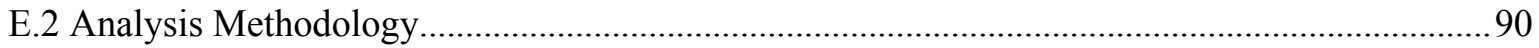

E.3 Logistics Design Assumptions for the 2022 Projection........................................................... 93

APPENDIX F - Process Flow Diagrams and Mass Balances for the 2018 Herbaceous SOT...................100

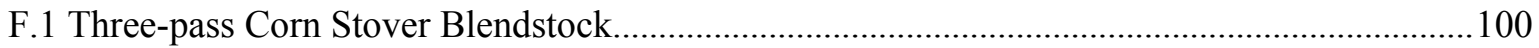

F.2 Two-pass Corn Stover Blendstock...................................................................................... 113

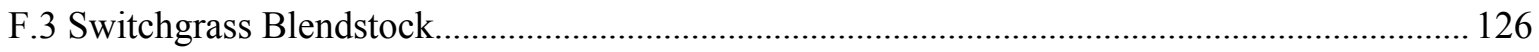

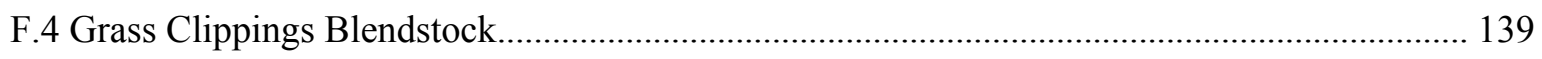

APPENDIX G - Process Flow Diagrams and Mass Balances for the Exclusion of Grass Clippings

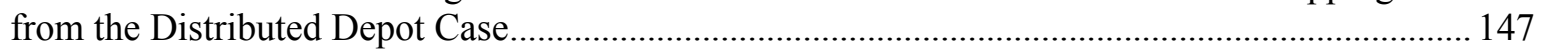

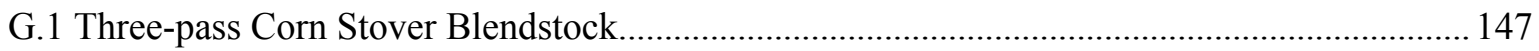

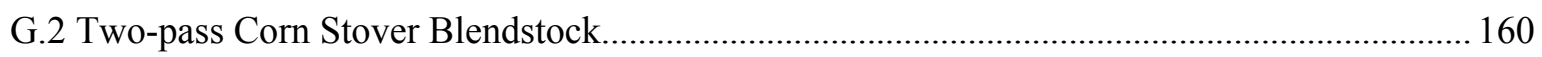

APPENDIX H - Process Flow Diagrams and Mass Balances for the Primary Depot Co-located

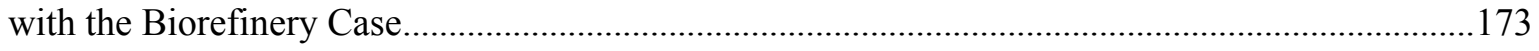

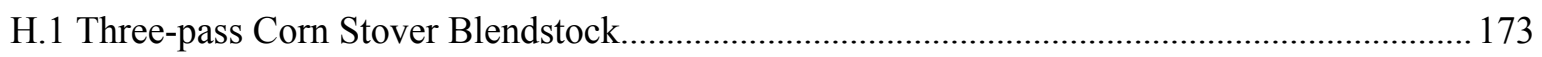

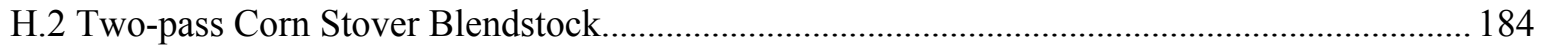

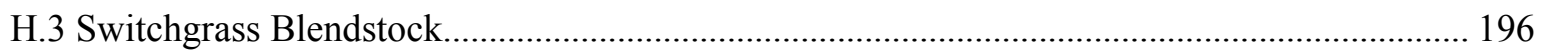

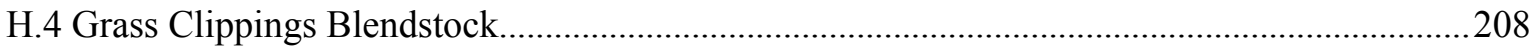

APPENDIX I - Process Flow Diagrams and Mass Balances for the Exclusion of Grass Clippings

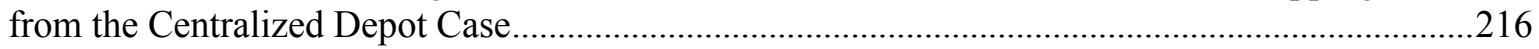

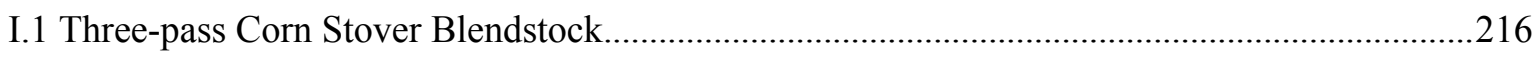




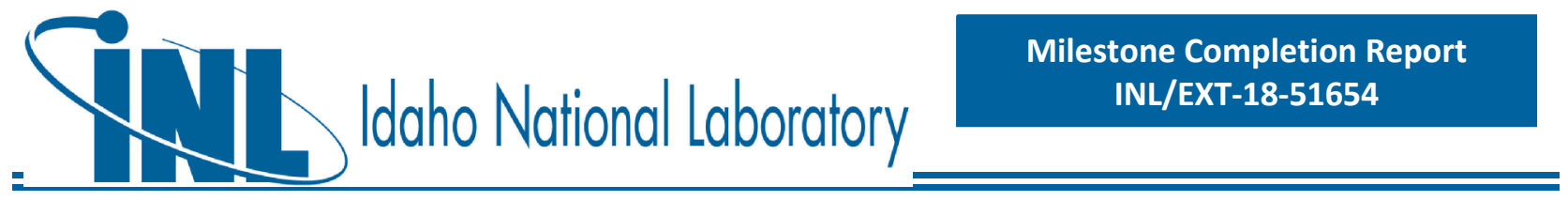

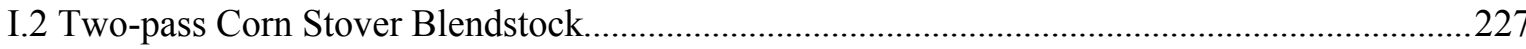

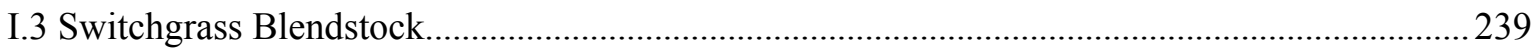

APPENDIX J - Process Flow Diagrams and Mass Balances for the 2022 Herbaceous Projection

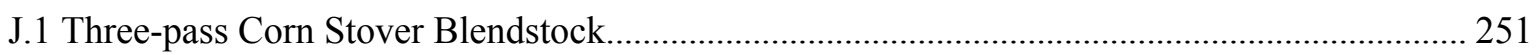

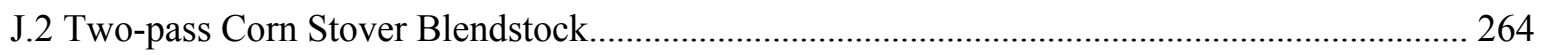

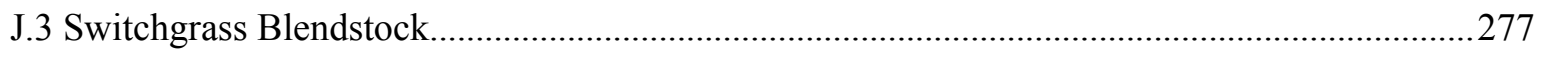

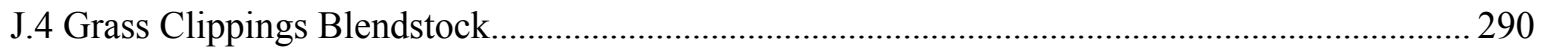




\section{BACKGROUND}

DOE promotes the production of advanced liquid transportation fuels from lignocellulosic biomass by funding fundamental and applied research that advances the SOT to transform renewable biomass into commercially viable biofuels. To track progress toward these DOE objectives, the Bioenergy Technologies Office (BETO) sets cost targets and oversees an annual SOT report that estimated the status of technology development relative to these goals utilizing data and experimental results. The Terrestrial Feedstock Supply and Logistics (FSL) platform within BETO has developed performance targets that are directed toward mobilizing large quantities of biomass. One target is to establish criteria by 2022 under which the emerging industry could operate at $90 \%$ operational reliability, and requires validation of $\mathrm{n}^{\text {th }}$ plant feedstock supply and logistics systems that can deliver feedstock at or below \$85.51/dry ton (2016\$) including grower payment and logistics costs from harvest to the throat of the conversion reactor (DOE 2016b).

Feedstocks are essential to achieving BETO goals, because the cost, quality, and quantity of feedstock available and accessible at any given time limit the maximum amount of biofuels that can be produced. In accordance with the 2016 Multi-Year Program Plan (DOE 2016b), FSL focuses on (1) reducing the delivered cost of sustainably produced biomass, (2) preserving and improving the physical and chemical quality parameters of harvested biomass to meet the individual needs of biorefineries and other biomass users, and (3) expanding the quantity of feedstock materials accessible to the bioenergy industry. This is done by identifying, developing, demonstrating, and validating efficient and economical integrated systems for harvest and collection, storage, handling, transport, and preprocessing raw biomass from a variety of crops to reliably deliver the required supplies of high-quality, affordable feedstocks to biorefineries as the industry expands. The elements of cost, quality, and quantity are key considerations when developing advanced feedstock supply concepts and systems (DOE 2016b).

\section{Progression of Feedstock Supply System Designs}

Feedstock supply systems are highly complex systems of operations required to move and transform biomass from a raw harvested material at the point of production into a formatted, on-spec feedstock at the throat of the conversion reactor. Feedstock logistics can be broken down into individual operations of harvest and collection, storage, transportation, preprocessing, and queuing and handling. Designing economic and environmentally sustainable feedstock supply systems, while providing necessary resource quantities at the appropriate quality, is critical for growth of the bioenergy industry. Research and development on feedstock supply systems aims to reduce delivered cost, improve and preserve feedstock quality, and expand access to biomass resources. Through 2012, BETO-funded research on feedstock supply systems focused on improving conventional feedstock supply systems (CFSS). CFSS designs rely on existing technology and systems to supply feedstock to biorefineries (Hess et al. 2009a). These designs tend to be vertically integrated with a specific conversion process or biorefinery. They also create the requirement to design extremely robust conversion systems capable of handling variability in feedstock quality at the biorefinery. Biorefineries strive to optimize efficiencies and capacities within the constraints of local supply, equipment availability, and permitting requirements. However, this approach makes the system vulnerable to variations in feedstock quality parameters, such as (a) high ash content, which negatively impacts operating costs related to acid consumption and ash disposal; (b) variable composition of convertible carbohydrates, which negatively impacts sugar yields due to suboptimal enzyme loading; and (c) variable moisture, which increases grinding costs and creates handling and flowability problems that significantly reduce reliability of feedstock introduction to the conversion process. 
CFSS designs are currently the backbone of the emerging biofuels industry. However, conventional supply systems have limitations that restrict widespread implementation on a national scale (Hess et al. 2009a, Hess et al. 2009b). Viability of the conventional supply system's design is reliant on geographical areas that have a concentrated supply of abundant, easily accessible, and low-cost biomass resources (such as corn stover in the Midwestern United States). Within these regions, variable weather, inherent compositional variability and harvest practices that are not designed to mitigate quality concerns, such as moisture and ash content, leads to considerable variability in feedstock cost and the biorefinery's ability to process the biomass. Low density bales in conventional systems combined with the short window of availability necessitate large-scale bale storage, leading to greatly increased fire risk. Moving outside these select regions, the feedstock supply system must be further adapted to accommodate a diversity of feedstocks to ensure adequate supply, which leads to changing cost, quality, and conversion yields that are directly tied to the conversion facility's size constraints. CFSS can only address feedstock quality indirectly through passive controls, such as resource selection or best management practices. For example, research at INL has shown that varying harvesting practices and equipment can reduce ash (i.e., dirt) entrainment during harvest and baling (Bonner et al. 2014b). When positioned in a highly productive single resource area, biorefineries can be selective in contracting only biomass that meets their specifications. However, biomass quality (e.g., ash and moisture content) is highly variable both spatially and temporally (Kenney et al. 2013b), and, in any given year, passive controls might not provide sufficient quality control for the feedstock to meet desired specifications. Therefore, biorefineries that rely on conventional designs are constrained to local resources, with cost-prohibitive expansion of the collection radius limiting plant size (Graham et al. 2013). Several analyses have shown that as the biofuels industry expands past the highly productive regions, CFSS will fail to meet supply requirements (Hess et al. 2009b, Bonner et al. 2014a) economically or at the desired price target.

To meet the demands of the future bioenergy industry, the supply system must expand beyond CFSS in certain areas to what has been termed "advanced" feedstock supply systems (Hess et al. 2009a, Hess et al. 2009b, Searcy et al. 2010, Jacobson et al. 2014). For advanced feedstock supply system (AFSS) designs, a distributed network of aggregation and processing centers, termed "depots," are employed near the point of biomass production (i.e., the field or forest) to reduce biomass variability and produce feedstocks of a uniform format, necessary to move toward biomass commoditization (Figure 1). The depots produce a stable, tradable, merchandisable intermediate near the point of biomass production. This reduces downstream conversion inefficiencies and moves the burden of feedstock variability away from the biorefinery. ${ }^{1}$

Advanced concepts have evolved (and continue to evolve) as new research and ideas emerge. Advanced concepts are also guided by input from stakeholders. In February 2015, the Advanced Feedstock Supply System Validation Workshop gathered experts from industry, DOE offices, DOE-funded laboratories, and academia to discuss approaches for addressing challenges associated with an expanding bioenergy industry and assumptions used in the Advanced Feedstock Supply System. The workshop was sponsored by DOE-BETO and feedback received is being considered as advanced concepts evolve (Searcy et al. 2015).

Depots have the ability to provide logistics solutions for sourcing multiple biomass resources to a biorefinery, whether these resources are dispersed or co-located. In such a scenario, depots may emerge as feedstock supply chain business elements to lessen the complexity to a biorefinery of managing a blended feedstock supply system. An economic advantage of a depot in this scenario may be its

1. Advanced systems are discussed further in Jacobson et al. (2014a). 


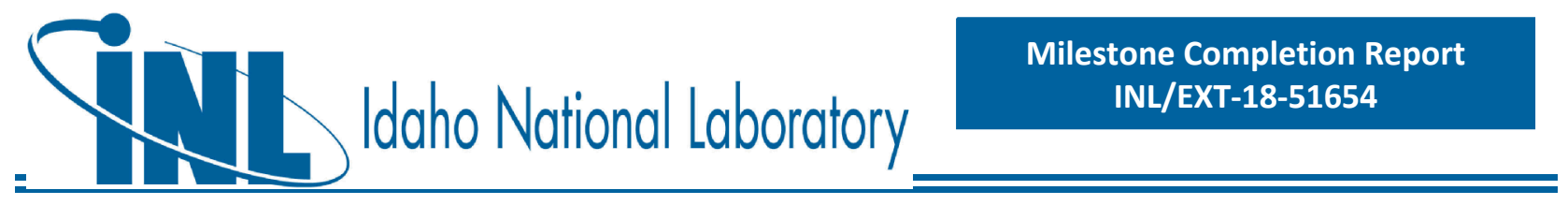

specialization to

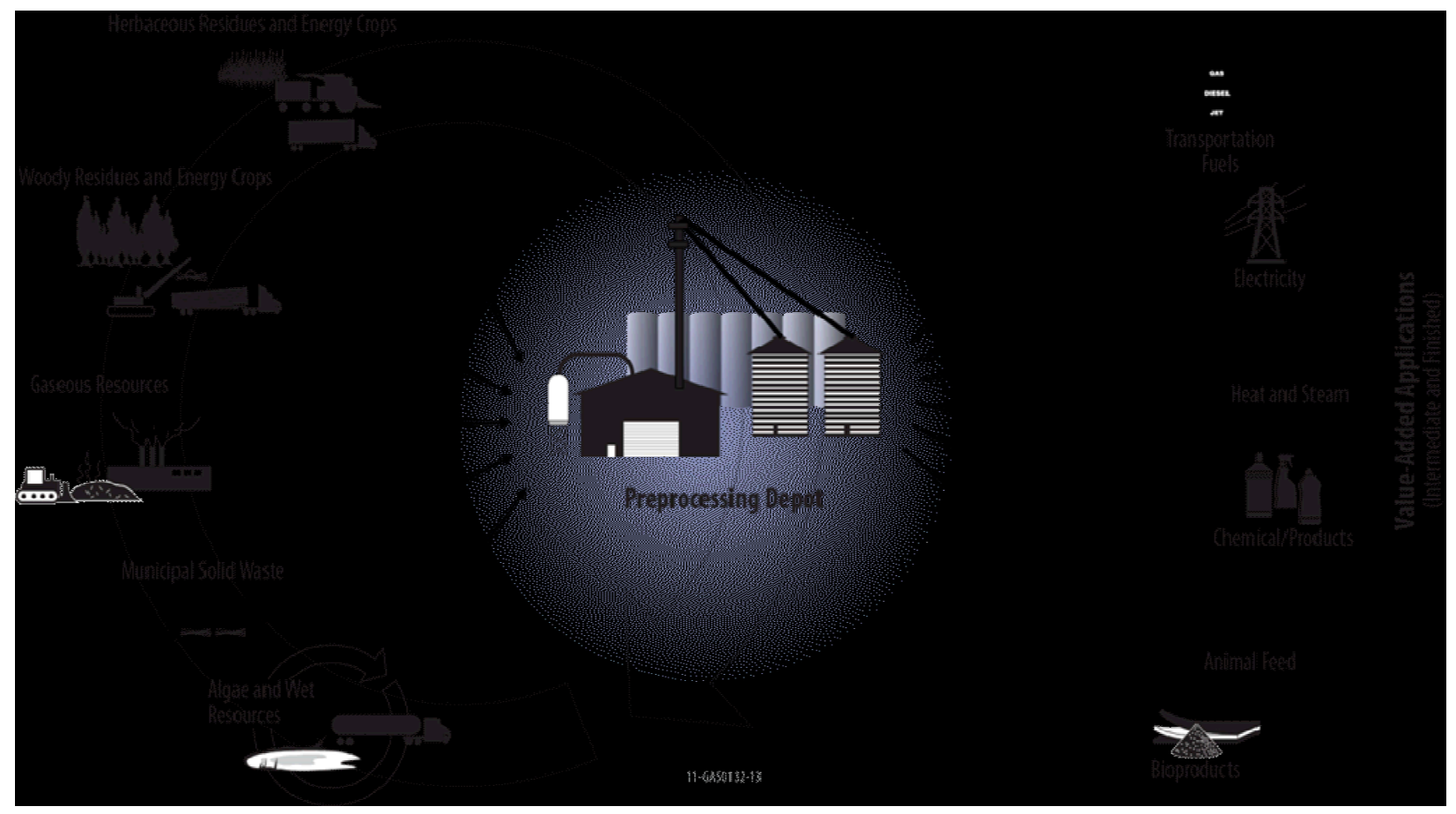

Figure 1. Incorporation of stakeholder feedback has resulted in improvements in advanced feedstock supply systems, evolving depots from being vertically integrated to producing merchandisable intermediates and serving a variety of customers and markets.

supply and preprocess single sources of improved quality, value-added biomass (referred to as a "blendstock") that can be formulated together with blendstocks from other depots to produce costeffective feedstocks meeting the specifications of numerous customers. This specialization eliminates the need for a single entity to make a capital investment and establish expertise to contract, preprocess, and supply a diversity of resources that may have different preprocessing requirements. Relying on multiple biomass types and sources to produce blended feedstocks will also reduce the risk to industry by diversifying reliance on any one feedstock.

The 2018 Herbaceous SOT applies blending of multiple types of herbaceous biomass as a means of increasing access to biomass resources and meeting feedstock quality and cost specifications, which is a critical step toward feedstock commoditization. Blending refers to combining different types of biomass to consistently provide a uniform feedstock of known specifications for a conversion process at the lowest possible cost. The 2017 Herbaceous SOT utilized an expanded least-cost blend optimization model to identify the lowest cost feedstock blend that meets feedstock carbohydrate specifications while optimally siting local distributed depots and optimizing their scales based on minimization of the net delivered blend cost at the reactor throat of the biorefinery. This same optimization tool (Appendix B) was used in the 2018 Herbaceous SOT to determine the least cost blend and the optimal depot locations and sizes. The 2018 Herbaceous SOT incorporates four depots, three of which are located at a distance from the biorefinery in higher-yielding counties that have significant corn stover and switchgrass biomass available lower on the supply curve. The fourth depot, consistent with the 2017 Herbaceous SOT, is 
located in the Denver, CO metropolitan area adjacent to a Municipal Solid Waste (MSW) transfer station that receives and preprocesses the grass clippings.

\section{DELIVERED FEEDSTOCK COST MODELS}

The Biomass Logistics Model (BLM) was used to model feedstock logistics cost and energy consumption estimates for the 2017 Herbaceous SOT design. The BLM incorporates information from a collection of databases that provide (1) engineering performance data for hundreds of equipment systems, (2) spatially explicit labor cost data sets, and (3) local tax and regulation data. The BLM's analytic engine is built in the systems dynamics software package Powersim ${ }^{\mathrm{TM}}$. The BLM is designed to work with thermochemical- and biochemical-based biofuel conversion platforms and to accommodate a range of lignocellulosic biomass types (e.g., herbaceous residues, short-rotation woody and herbaceous energy crops, woody residues, and algae). The BLM simulates the flow of biomass through the entire supply chain while tracking changes in feedstock characteristics (i.e., moisture content, dry matter, ash content, and dry bulk density) and calculating cost and energy consumption (Cafferty et al. 2013b). The energy consumption and other parameters (e.g. transportation distance, density) from BLM are also input to the Greenhouse Gases, Regulated Emissions, and Energy use in Transportation model (GREET 2016) to perform a cursory farm gate-to-plant gate life-cycle assessment on GHG emissions.

The sum of unit operation costs of harvesting and collection, storage, preprocessing, and handling and queuing from the BLM are input to the least-cost blend optimization model (Appendix B). This model is a decision tool developed to formulate minimum cost blended feedstocks based on one or more minimum material quality specifications, the quantity and locations of available biomass resources, and their farmgate costs. The optimization occurs generally as follows. County-level tabular availability and farm gate cost data are taken from BT16 for a selected set of potential biomass sources for a feedstock blend formulation. Grower payments for each biomass source in each county are estimated by subtracting the harvesting and collection costs for each biomass source in each location from the farm gate price at that location. Overall percentage dry matter losses within the individual biomass supply systems for each biomass source, as well as the reactor-throat percentage carbohydrate for each biomass source are estimated using user-defined supply chain unit operation calculator blocks developed in Aspen Plus ${ }^{\circledR}$. Transportation distances for each county-level biomass source to the biorefinery or depot are calculated, including winding factors. The net reactor-throat cost for each county-level biomass source, equal to the grower payment + transportation cost + other logistics costs (including in-plant preprocessing costs), is then calculated. The costs of constructing local distributed depots (as a function of depot scale) are also input to the least-cost blend optimization model. The least cost combination of the various biomass types and quantities from the county-level sources is then determined using Mixed Integer Linear Programming (MILP), allowing the complete set of data for all biomass types and locations to be considered individually for inclusion (or not) in the formulated blend. Constraints include a total of 725,000 dry tons of blended feedstock delivered to the reactor throat at 59\% total carbohydrates. Additional constraints such as limiting the county-level sourced biomass to only what is available, and eliminating mathematical solutions that would source negative quantities of biomass from any county-level biomass source, are also imposed on the optimal solution. A detailed description of the least-cost blend optimization model and the various constraints is provided in Appendix B. 


\subsection{Herbaceous Feedstock SOT Cost Analysis}

The 2018 Herbaceous SOT is reported in $2016 \$$ and includes grower payment, logistics costs, and ash and moisture dockages to reflect a modeled net delivered feedstock supply cost. Building upon the leastcost formulation approach initiated in the 2016 Herbaceous SOT, the 2018 Herbaceous SOT determines the lowest net delivered cost for a blended feedstock comprised of multiple biomass types. The optimization is constrained by BT16 county-level availability, location and farm gate prices, as well as conversion-specified total carbohydrate, ash, moisture and particle size specifications. All unit operations from field to reactor throat, including harvesting and collection, storage, transportation, preprocessing, and handling and queuing are included in the cost assessment. The biomass resources considered in the 2018 Herbaceous SOT include corn stover harvested by two methods (three-pass and two-pass), switchgrass and the grass clippings fraction of MSW yard trimmings. Resource availabilities, yields and improved equipment information were incorporated from data in the BT16 report (DOE 2016a), industry publications (Forest Concepts, 2017), and the DOE Regional Feedstock Partnership (Owens et al. 2016). To be consistent with the 2017 Herbaceous SOT, the 2018 Herbaceous SOT is located in Sheridan County KS, a moderately low-yield area in northwestern Kansas.

The biochemical conversion in-feed feedstock compositional specification is presented in Table 1 (Davis et al. 2013). The shaded rows in Table 1 show the compositional specifications for the feedstock, namely, $59 \%$ carbohydrates, $\leq 5 \%$ ash, and $20 \%$ moisture. An additional specification is $1 / 4$ " mean particle size at the pretreatment reactor throat.

Table 1. Delivered feedstock composition assumptions for dilute-acid pretreatment and enzymatic hydrolysis to sugars followed by biological conversion of sugars to hydrocarbons pathway (Humbird et al. 2011, Davis et al. 2013).

\begin{tabular}{lc}
\hline Component & $\begin{array}{c}\text { Composition } \\
\text { (dry wt. \%) }\end{array}$ \\
\hline Glucan & 35.05 \\
\hline Xylan & 19.53 \\
\hline Lignin & 15.76 \\
\hline Ash & 4.93 \\
\hline Acetate & 1.81 \\
\hline Protein & 3.10 \\
\hline Extractives & 14.65 \\
\hline Arabinan & 2.38 \\
\hline
\end{tabular}




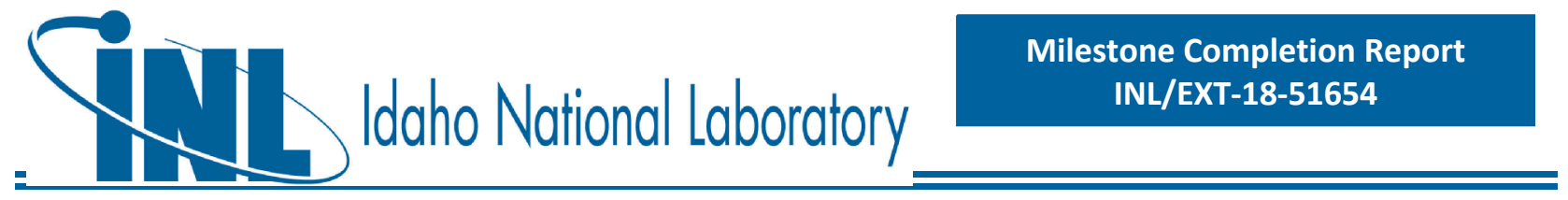

\begin{tabular}{lc}
\hline Galactan & 1.43 \\
\hline Mannan & 0.60 \\
\hline Sucrose & 0.77 \\
\hline Total structural carbohydrate & $\mathbf{5 8 . 9 9}$ \\
\hline Total structural carbohydrate + sucrose & $\mathbf{5 9 . 7 6}$ \\
\hline Moisture (bulk wt.\%) & $\mathbf{2 0 . 0}$ \\
\hline
\end{tabular}

During 2018, the BETO Conversion Platform redefined the time on-stream for their process models to $90 \%$. The 2018 Herbaceous SOT aligns with this change, which reduces the amount of feedstock required to be delivered to the reactor throat from 800,000 dry tons to 725,000 dry tons annually. Biomass availabilities in this SOT were updated to year 2018 data from the 2016 Billion-Ton Report (BT16) (DOE 2016a), with the exception of switchgrass, for which the 2018 Herbaceous SOT utilized the 2019 switchgrass availability data from BT16 (as was done in both the 2016 and 2017 Herbaceous SOTs). This was because BT16 does not project switchgrass availability in 2018, rather, soonest switchgrass is projected to be available is in 2019. Hence, switchgrass availability for this analysis was that projected for 2019. The 2018 Herbaceous SOT models technologies identical to those modeled in the 2017 Herbaceous SOT. A sensitivity analysis varying the modeled equipment performance over experimentally-observed ranges was added in the 2018 SOT.

The modeled net delivered herbaceous feedstock supply system costs for biochemical conversion, inclusive of grower payment, logistics and preprocessing costs, as well as ash and moisture dockages are shown in Table 2 for the Herbaceous SOTs from 2013-2018. The 2018 Herbaceous SOT predicts a modeled delivered feedstock cost of $\$ 83.67$ /dry ton (2016\$); this is a $\$ 0.23 /$ dry ton (2016\$) decrease from the 2017 Herbaceous SOT.

Table 2. Modeled SOT herbaceous feedstock supply costs for 2013-2018. All costs are presented on a per dry ton basis and are in $2016 \$$.

\begin{tabular}{lcccccc}
\hline & \multicolumn{6}{c}{ Delivered Cost (\$/dry ton) (2016\$) } \\
\cline { 2 - 7 } & 2013 SOT & 2014 SOT & 2015 SOT & 2016 SOT & 2017 SOT & 2018 SOT \\
\hline Feedstock & $\begin{array}{c}\text { Corn } \\
\text { Stover }\end{array}$ & $\begin{array}{c}\text { Corn } \\
\text { Stover }\end{array}$ & Blend & Blend & Blend & Blend \\
\hline Net delivered cost & $\$ 149.31$ & $\$ 138.68$ & $\$ 121.45$ & $\$ 95.56$ & $\$ 83.90$ & $\$ 83.67$ \\
\hline Grower payment & $\$ 40.61$ & $\$ 40.61$ & $\$ 32.73$ & $\$ 28.33$ & $\$ 23.24$ & $\$ 23.54$ \\
\hline \multicolumn{1}{c}{12} & & & & & & \\
\hline
\end{tabular}




\begin{tabular}{lcccccc}
\hline Feedstock logistics & $\$ 108.70$ & $\$ 98.07$ & $\$ 88.72$ & $\$ 67.23$ & $\$ 60.66$ & $\$ 60.13$ \\
\hline Harvest \& collection & $\$ 20.52$ & $\$ 24.79$ & $\$ 18.89$ & $\$ 14.84$ & $\$ 16.91$ & $\$ 16.68$ \\
\hline Storage \& queuing & $\$ 4.60$ & $\$ 5.30$ & $\$ 4.39$ & $\$ 4.99$ & $\$ 6.54$ & $\$ 6.55$ \\
\hline $\begin{array}{l}\text { Preprocessing and in- } \\
\text { plant receiving }\end{array}$ & $\$ 46.60$ & $\$ 32.48$ & $\$ 34.86$ & $\$ 30.54$ & $\$ 22.52$ & $\$ 22.40$ \\
\hline $\begin{array}{l}\text { Transportation \& } \\
\text { handling }\end{array}$ & $\$ 15.49$ & $\$ 16.92$ & $\$ 15.24$ & $\$ 14.94$ & $\$ 13.43$ & $\$ 13.23$ \\
\hline Dockage & $\$ 21.49$ & $\$ 18.58$ & $\$ 15.34$ & $\$ 1.92$ & $\$ 1.26$ & $\$ 1.27$ \\
\hline
\end{tabular}

The 2018 Herbaceous SOT represents an update to the supply system design presented in 2017 to account for increased feedstock availability predicted by BT16 for 2018, as well as the decreased feedstock supply requirement. Because the same technologies utilized in the 2017 Herbaceous SOT were modeled, there was not a significant reduction in feedstock delivered cost. The $\$ 0.23 /$ dry ton reduction from the 2017 SOT is a result of increased availability of corn stover in 2018 and the reduction of the feedstock supply requirement from 800,000 to 725,000 dry tons/year. As in the 2017 SOT, removing the constraint on supply radius and allowing preprocessing to pellets to be located near higher-yielding counties (more biomass available at a lower cost on the supply curve) allowed the lowest cost blend to be comprised of biomass that was obtained at lower grower payments. Note that because projected increases in biomass from 2017 to 2018 by BT16 were not necessarily distributed homogeneously across the supply counties in the region, the lowest cost blend ratios have changed from 2017 . The observed $\$ 0.30 /$ dry ton increase in grower payment from 2017 resulted from the increased amount of higher grower payment feedstock such as switchgrass in the lowest cost blend. The $\$ 0.53$ /dry ton increase in harvest and collection from 2017 results from the higher harvesting cost of two-pass corn stover, which is a major component in the blend and is required to meet the carbohydrate specification. The $\$ 0.12 /$ dry ton reduction in preprocessing is a composite result of the change in feedstock blend ratios. The $\$ 0.12 /$ dry ton reduction in transportation and handling cost resulted from a reduction in bale transportation distance due to the utilization of distributed depots together with the lower cost transportation of pellets from the depots to the biorefinery. Dockage totaling $\$ 1.27 /$ dry ton include ash dockage and moisture dockage.

The 2018 Herbaceous SOT least-cost blend consists of $12.74 \%$ three-pass corn stover, $73.22 \%$ twopass stover, $9.83 \%$ switchgrass, and $4.21 \%$ grass clippings. The 2018 Herbaceous SOT cost is based on a weighted average of the individual total costs of producing pellets of each of these biomass sources. The reported total delivered feedstock cost is $\$ 1.84$ /dry ton below the BETO FSL feedstock cost target of $\$ 85.51 /$ dry ton (2016\$) (DOE 2016b).

The largest portion of the blend is composed of a combination of two-pass and three-pass corn stover. The three-pass system modeled in the 2018 Herbaceous SOT is the "conventional" method (also referred to as multi-pass), in which the first pass is grain harvest using a combine with the spreader turned on, the second pass is windrowing using a flail shredder, and the third pass is a baler. This is different than the two-pass harvesting method (currently employed by POET-DSM), in which the first pass is harvest using 
a combine with header raised to just below the ear on the corn stalks and the spreader turned off, and the second pass is a baler (Birrell et al. 2014; Shinners et al. 2012). This eliminates the windrowing step, which is a significant source of soil entrainment in the baled stover. The raised header (higher cut height) leads to a lower harvest yield, but contributes to soil sustainability.

As in 2017, the 2018 Herbaceous SOT includes the energy crop switchgrass as a potential resource for use in the blended feedstock as a strategy to mitigate the lower carbohydrate levels of three-pass and two-pass corn stover. According to the BT16 report, commercialization of energy crops has increased since 2011, with deployment on as many as 20,000 acres (DOE 2016a). Regional USDA switchgrass production statistics for 2012 also show the potential for switchgrass to supply multiple markets (power, fuels, and animal bedding) (DOE 2016a). BT16 switchgrass availability in the modeled region for 2019 was thus used for this analysis, as done in the 2016 and 2017 Herbaceous SOTs.

The 2018 Herbaceous SOT again incorporates MSW grass clippings in the feedstock blend. MSW consists of household items that are used and discarded (e.g., product packaging, clothing, bottles, food scraps, newspapers, appliances, paint, and batteries), as well as yard wastes (e.g., grass clippings, leaves, tree and shrub prunings, etc.) (Environmental Protection Agency 2015). Grass clippings were selected as a blend component due to their basic structural and compositional similarity to other herbaceous biomass sources, as well as the fact that some municipalities collect them separately from other household waste (no sorting costs). Hence, it was assumed that grass clippings from a large metropolitan area were collected separately by the municipality or other third party and delivered to a depot located adjacent to their normal disposal site. The city of Denver, CO, located approximately 220 miles from the biorefinery, separately collects grass clippings for composting (WCDENVER, 2017; Denver, 2017a), using autoloading garbage trucks (Denver, 2017b). It was assumed that the grass clippings (70\% moisture assumption) would be delivered on the day of collection to a transfer station or landfill, and that drying and pelleting of the grass clippings would occur at a small co-located depot. It was assumed that there would be no tipping fee ( $\sim 50$ is U.S. average), and a $\$ 10 /$ dry ton purchase cost to cover collection and delivery of the grass clippings.

As modeled in the 2017 Herbaceous SOT, pellets produced from the various biomass blendstocks are blended prior to conversion. Mass and energy balances and equipment sizes were calculated using Aspen Plus ${ }^{\circledR}$ modules constructed using calculator blocks defined using moisture/throughput and moisture/energy consumption relationships based on INL PDU data. Generally, the feedstock supply system unit operation costs were modeled using the Biomass Logistics Model (BLM) based on the Aspen Plus ${ }^{\circledR}$ outputs. Exceptions include transportation costs and grower payments, which were outputs of the least-cost blend optimization. GHG estimates were based on energy consumption at each unit operation, and were modeled at Argonne National Laboratory using GREET. The 2018 Herbaceous SOT modeled costs and GHG estimates for each individual herbaceous feedstock supply system and the blended feedstock case are shown in Table 3. Design details are presented in Appendix A. The carbohydrate and ash contents of the 2018 Herbaceous SOT blend are 59.22\% and 8.30\%, respectively. The net delivered blend cost therefore includes an ash dockage of $\$ 1.24$ dry ton to offset the additional biorefinery cost of disposing of the additional ash over the $5 \%$ ash specification, and a moisture dockage of $\$ 0.03 /$ dry ton to offset the cost to the biorefinery for additional make-up water to bring the blend to $20 \%$ moisture. Like the 2017 Herbaceous SOT, the impact of blending in the 2018 Herbaceous SOT is that it allowed access to additional feedstocks (grass clippings and switchgrass) that enables the biorefinery to both procure sufficient biomass and also to meet the carbohydrate spec, thereby avoiding a high carbohydrate dockage. 
Table 3. The 2018 Herbaceous SOT modeled cost and GHG estimates for an herbaceous feedstock supply system supplying 725,000 dry tons annually in northwestern Kansas. Grower payments are based on supply curves from BT16 (DOE 2016a) and costs are presented in \$/dry ton (2016\$). Design details are in Appendix A.

\begin{tabular}{|c|c|c|c|c|c|c|}
\hline \multirow[t]{2}{*}{ Cost Element } & \multicolumn{5}{|c|}{ Cost (\$/dry ton) (2016\$) } & \multirow{2}{*}{$\begin{array}{c}\text { GHG } \\
\text { Emissions } \\
(\mathrm{kg} \\
\left.\mathrm{CO}_{2} \mathrm{e} / \text { ton }\right)^{\mathrm{a}}\end{array}$} \\
\hline & $\begin{array}{c}\text { Three- } \\
\text { Pass } \\
\text { Stover }\end{array}$ & $\begin{array}{c}\text { Two- } \\
\text { Pass } \\
\text { Stover }\end{array}$ & $\begin{array}{l}\text { Switch- } \\
\text { grass }\end{array}$ & $\begin{array}{c}\text { Grass } \\
\text { Clippings }\end{array}$ & $\begin{array}{c}\text { Least- } \\
\text { Cost } \\
\text { Blend }^{\text {b }}\end{array}$ & \\
\hline Blend Ratio & $12.74 \%$ & $73.22 \%$ & $9.83 \%$ & $4.21 \%$ & $100.0 \%$ & - \\
\hline Grower payment & $\$ 26.66$ & $\$ 21.71$ & $\$ 38.87$ & $\$ 10.13$ & $\$ 23.54$ & - \\
\hline $\begin{array}{l}\text { Harvest and } \\
\text { collection }\end{array}$ & $\$ 13.84$ & $\$ 18.79$ & $\$ 11.76$ & $\$ 0.00$ & $\$ 16.68$ & 11.00 \\
\hline $\begin{array}{l}\text { Storage and } \\
\text { queuing }\end{array}$ & $\$ 6.40$ & $\$ 6.53$ & $\$ 5.89$ & $\$ 6.57$ & $\$ 6.45$ & 2.64 \\
\hline $\begin{array}{l}\text { Transportation and } \\
\text { handling }\end{array}$ & $\$ 11.35$ & $\$ 13.52$ & $\$ 11.00$ & $\$ 19.18$ & $\$ 13.23$ & 18.01 \\
\hline $\begin{array}{l}\text { In-plant receiving } \\
\text { and preprocessing }\end{array}$ & $\$ 22.65$ & $\$ 22.65$ & $\$ 22.05$ & $\$ 20.23$ & $\$ 22.49$ & 37.62 \\
\hline Dockage & $\$ 2.74$ & $\$ 1.01$ & $\$ 0.56$ & $\$ 3.08$ & $\$ 1.27$ & - \\
\hline Total & $\$ 83.64$ & $\$ 84.21$ & $\$ 90.13$ & $\$ 59.19$ & $\$ 83.67$ & 69.27 \\
\hline
\end{tabular}

a Pesticide and fertilizer emissions incurred during biomass production were attributed to the biomass growth stage of the life cycle and are not included.

b The blend costs are presented as the weighted average of the blend component costs.

c Grower payment taken as the cost assumed for procurement of grass clippings.

It is worth noting that for the grass clippings grower payment, we assumed that although their collection and disposal often carry a tipping fee (negative cost) to the landfill or disposal site, eventually they would be procured at a positive cost once the market develops. Hence, as a conservative assumption, we assumed a positive procurement cost of $\$ 10.00$ /dry ton (in 2014\$) for grass clippings, and assigned this value as the "grower payment." The transportation costs for grass clippings are noticeably higher than for the other blendstocks because the only available source of grass clippings is considerably more distant 
from the biorefinery than the other blendstocks. There was a modeled net reduction in greenhouse gas emissions (GHG) of $4.84 \mathrm{~kg} \mathrm{CO}_{2} \mathrm{e} /$ ton from the $2017 \mathrm{SOT}$ (i.e., from $74.11 \mathrm{~kg} \mathrm{CO}_{2} \mathrm{e} / \mathrm{ton}$ in 2017 to 69.27 $\mathrm{kg} \mathrm{CO}_{2} \mathrm{e} / \mathrm{ton}$ in 2018). This reduction is attributed to reduced bale transport distance to the distributed depots and reduced transportation of pellets from the depots to the biorefinery for the updated biorefinery on-stream time, as well as several updates to the 2018 GREET model.

\subsubsection{Least-Cost Blend Development}

Blending is common practice in many industries (e.g., in the U.S. grain industry) to adjust quality (Hill 1990). Crude oil refiners blend various distillate fractions to meet seasonal regulations for gasoline vapor pressure (Li et al. 2010). Similarly, different grades of coal are blended to achieve compliance with regulations regarding sulfur and nitrogen emissions in the power generation industry (Shih et al. 1995, Boavida et al. 2012). Closer to the biomass industry, the animal feed industry uses a range of biomass and nutrient sources blended together to meet specific nutrient requirements of the target animal (Reddy et al. 2009). Finally, relatively high-ash content biomass sources are mixed with low-ash coal to allow their use in co-fired biopower generation (Sami et al. 2001).

Gains in the projected quantities of biomass available to produce feedstocks at the required cost and conversion in-feed specifications can be realized by transitioning to a blended feedstock approach. This is accomplished by the use of a least-cost formulation approach that considers not only composition and average component costs, but also the combination of individual grower payments and distance from the biorefinery. With this approach, a biomass source that has a very low grower payment but is very far from the biorefinery will in some cases be favored over a higher cost source of biomass that is much closer. The paradigm for the current biorefining industry is that closer is cheaper even if it has a higher grower payment, because of the transportation cost. However, in a least-cost scenario that may not be true in all cases, depending on the feedstock.

Biomass quality is a key consideration when analyzing biomass cost and availability. Formulating a designed feedstock through advanced preprocessing and blending can allow low cost, low quality biomass sources to be blended with biomass of higher cost and quality to achieve in-feed specifications while minimizing the delivered feedstock cost at the conversion facility. In combination with densification, wider sourcing areas can be tapped (including resources that are considered stranded using CFSS. Bringing these additional biomass streams into the feedstock supply creates cost benefits by reducing overall grower payments (Jacobson et al. 2014).

\subsubsection{Modeled Blendstock Compositions}

The trade-offs among feedstock cost, quality and impacts to biorefinery profitability resulting from impacts to operating costs and operational reliability are critical. Failure to adhere to biorefinery quality specifications can have significant impacts on downstream conversion yield and biofuel cost. Thus, choice of biomass sources for biochemical conversion must be guided not only by their cost and availability, but also by compositional quality relative to carbohydrate and ash specifications, and their convertibility via selected pretreatment technologies and subsequent enzymatic hydrolysis. Recognizing that while these factors are interdependent, carbohydrate content and convertibility are more important than ash content. Hence, we selected herbaceous biomass sources that were both higher and lower than the carbohydrate specification of 59\%, and placed less emphasis on ash content. Further, biomass candidates were required to have been tested for conversion performance relative to corn stover both individually and in blends (this was done in WBS 2.2.1.102). Individual preprocessed blendstock cost was considered as an important, but not overriding factor. 
Because of the historic use of corn stover for biochemical conversion R\&D, herbaceous feedstocks were targeted. The selected blendstocks and their compositions as-harvested and as-delivered just prior to blending are shown in Table 4. For this SOT, "as-harvested" corn stover and switchgrass compositions were estimated because of a low number of samples in the INL Bioenergy Feedstock Library that included full wet chemical analysis of carbohydrates, lignin and ash. In Table 4, the as-harvested biomass compositions for corn stover and switchgrass represent the average compositions of harvested bales at the

Table 4. Harvested biomass and compositions for as-harvested biomass (David and Ragauskas 2010, Liu et al. 2010, INL 2016), and for as delivered blendstocks to be blended before introduction to the pretreatment reactor throat.

\begin{tabular}{|c|c|c|c|c|}
\hline & \multicolumn{4}{|c|}{ Harvested Biomass/Preprocessed Blendstock } \\
\hline & Corn Stover & Corn Stover & Switchgrass & $\begin{array}{c}\text { Grass } \\
\text { Clippings }\end{array}$ \\
\hline Harvest Method & Three-Pass & Two-Pass & Two-Pass & Bulk \\
\hline \multicolumn{5}{|c|}{ As-Harvested Biomass Compositions ${ }^{a, b}$} \\
\hline Moisture Content ( \% wb) & $30.0 \%$ & $30.0 \%$ & $20.0 \%$ & $70.0 \%$ \\
\hline Total Carbohydrates (\% db) & $55.2 \%$ & $57.6 \%$ & $64.7 \%$ & $28.1 \%$ \\
\hline \multicolumn{5}{|l|}{ Composition (all \% db) } \\
\hline total anhydro-C6 & $35.5 \%$ & $37.0 \%$ & $35.6 \%$ & $19.6 \%$ \\
\hline total anhydro-C5 & $20.5 \%$ & $21.4 \%$ & $29.1 \%$ & $8.5 \%$ \\
\hline lignin & $14.8 \%$ & $14.8 \%$ & $17.8 \%$ & $16.7 \%$ \\
\hline ash & $11.0 \%$ & $7.0 \%$ & $6.2 \%$ & $12.8 \%$ \\
\hline other & $18.3 \%$ & $19.8 \%$ & $11.4 \%$ & $42.4 \%$ \\
\hline \multicolumn{5}{|c|}{ Delivered Blendstock Compositions } \\
\hline Dry Matter Loss $(\% \mathrm{db})^{\mathrm{c}}$ & $13.76 \%$ & $13.76 \%$ & $9.84 \%$ & $2.49 \%$ \\
\hline Moisture Content $(\% \mathrm{wb})$ & $11.50 \%$ & $11.50 \%$ & $9.00 \%$ & $10.00 \%$ \\
\hline Total Carbohydrates $(\% \mathrm{db})$ & $57.4 \%$ & $60.3 \%$ & $66.6 \%$ & $28.7 \%$ \\
\hline \multicolumn{5}{|l|}{ Composition (all \% db) } \\
\hline total anhydro-C6 & $38.0 \%$ & $39.8 \%$ & $37.3 \%$ & $20.0 \%$ \\
\hline total anhydro-C5 & $19.4 \%$ & $20.5 \%$ & $29.4 \%$ & $8.7 \%$ \\
\hline lignin & $15.9 \%$ & $16.6 \%$ & $18.7 \%$ & $17.0 \%$ \\
\hline ash & $12.2 \%$ & $7.6 \%$ & $6.4 \%$ & $13.1 \%$ \\
\hline other & $14.5 \%$ & $15.5 \%$ & $8.3 \%$ & $41.2 \%$ \\
\hline
\end{tabular}

a As-harvested biomass compositions for corn stover and switchgrass indicate compositions of harvested bales at the time they are placed into field-side storage. For grass clippings, as-harvested biomass composition indicates the composition of the bulk grass clipping when they are delivered for drying and preprocessing at a small depot (Depot B), which is assumed to be the same day they are cut.

b As-harvested corn stover compositions taken from Table 3 and adjusted for additional soil ash contamination. Average ash contents for three-pass and two-pass corn stover harvested in Kansas were taken from the INL Bioenergy feedstock library. Switchgrass composition is for the Blackwell cultivar, which is adapted for maximum yields in Kansas (David and Ragauskas 2010). Harvested grass clippings composition is for grass clippings collected in Idaho Falls, ID (data in the INL Bioenergy Feedstock Library).

c Calculated by mass balances based on losses in storage and preprocessing. Detailed losses are described in Appendix A. 
time they are placed into field-side storage. For grass clippings, as-harvested biomass composition represents the composition of the bulk grass clippings when they are delivered for drying and preprocessing at the depot in the Denver Metropolitan area, which is assumed to be the same day they are cut. The as-harvested compositions were estimated as follows. As-harvested corn stover compositions were taken from Table 3 and adjusted for additional soil ash contamination consistent with the average ash contents observed for Kansas-sourced three-pass and two-pass harvested corn stover samples in the INL Bioenergy Feedstock Library (11\% and 7\%, respectively). Switchgrass as-harvested composition is for the Blackwell cultivar, which is adapted for maximum yields in Kansas (David and Ragauskas 2010). The as-harvested grass clippings composition is for grass clippings collected in Idaho Falls, ID (data in the INL Bioenergy Feedstock Library).

Comparisons of the variability of ash and total carbohydrates in the small number of completely characterized samples in the Feedstock Library are shown in Figure 2. The library metadata for multi-pass corn stover did not identify whether they were three-pass or two-pass. The error bars shown for the library samples represent the $95 \%$ Confidence Interval using the Student's t-distribution with $n=7$ for multi-pass corn stover, and $n=4$ for both switchgrass and grass clippings. Except for total ash on the switchgrass library sample, the estimated as-harvested biomass compositions are within the ranges measured for the small number of completely characterized samples in the feedstock library.

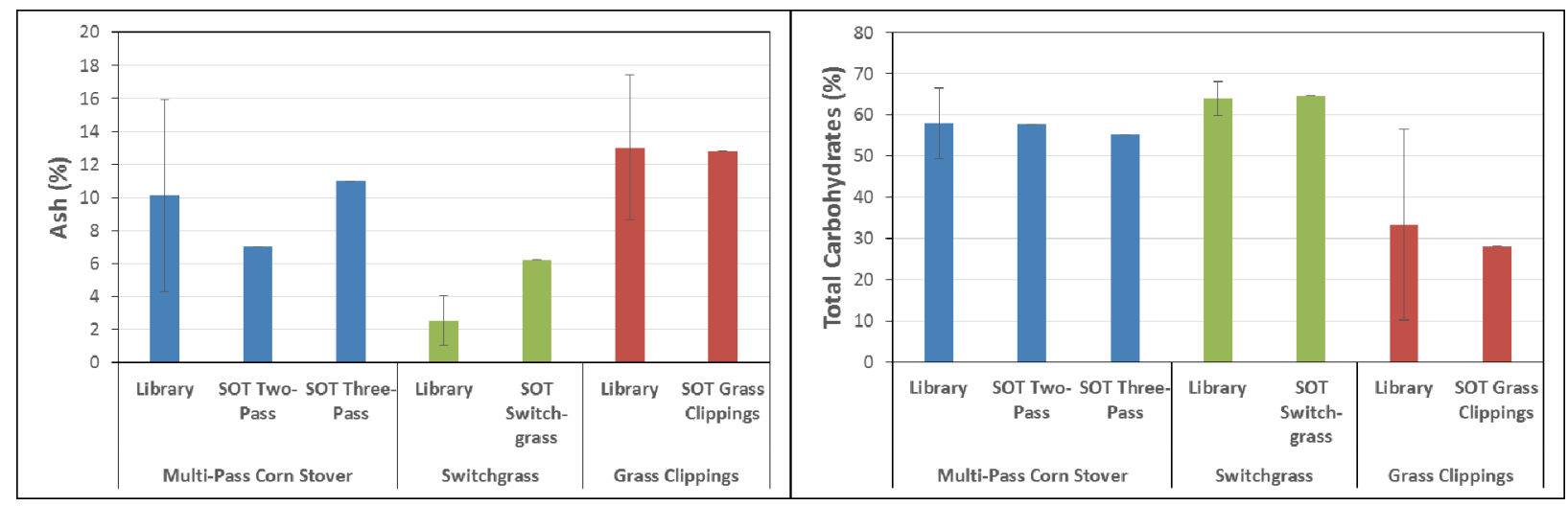

Figure 2. Comparison of the variability of ash and total carbohydrates in the small number of completely characterized samples in the Feedstock Library. The error bars shown for the library samples represent the 95\% Confidence Interval using the Student's t-distribution with $n=7$ for multipass corn stover, and $n=4$ for both switchgrass and grass clippings.

Delivered blendstock compositions shown in Table 4 indicate that two-pass corn stover and switchgrass are above 59\% total carbohydrate, while three-pass corn stover and grass clippings are below $59 \%$ total carbohydrates. Hence, the feedstock carbohydrate specification can be met by blending higher carbohydrate blendstocks with lower carbohydrate blendstocks. Similarly, feedstock ash content can be adjusted by replacing higher ash blendstocks with lower ash blendstocks. If the blended feedstock does not meet the conversion in-feed ash specification $(\leq 5 \%)$, an ash dockage is incurred that is equivalent to the additional ash disposal cost incurred by the biorefinery. The moisture content of the blended feedstock $(11.19 \%)$ is lower than the moisture specification of $20 \%$; this is necessary to keep the pellets stable to aerobic degradation during storage (Bonner et al. 2016), and to facilitate flowability in feedstock handling systems. Delivering the feedstock blend at $10 \%$ rather than $20 \%$ moisture would incur a cost of $\$ 0.03 /$ dry ton $(2016 \$)$ to the biorefinery in the form of additional make-up water. This value was calculated from 
the assumed make-up water cost of $\$ 0.31 /$ ton $(2016 \$)$ of water used by Davis et al. (2013).

Conversion performance is a critical consideration when selecting a blend and it depends on the quality and conversion performance of the blendstocks that comprise the feedstock blend. The performance of various feedstock blends in different conversion processes is the subject of past and ongoing work. Results to date are promising. For example, Karki et al. (2010) investigated the enzymatic hydrolysis of switchgrass and tall wheatgrass mixtures - two chemically similar feedstocks - following dilute acid and aqueous ammonia pretreatments. They found that glucose yields for the blends, a critical performance parameter for biochemical conversion, were significantly higher than for switchgrass alone but were lower than for wheatgrass alone. Furthermore, they found they were able to predict hydrolysis results for the mixtures based on the results of the individual components.

Shi et al. (2013) studied four biomass blends representing the general classes of available biomass, including hardwoods, softwoods, herbaceous, and agricultural residues, and applied pretreatments to investigate enzymatic digestibility. They found sugar yields of the pretreated blends reached $90 \%$ within 24 hours of saccharification, indicating the potential for mixed feedstocks to be a significant resource to biorefineries producing biofuels. Another study found that with knowledge of the feedstock blend composition and the conversion performance of the constituents in the blend, the conversion performance of the feedstock blends could be reasonably predicted, with the overall performance aligning with the weighted average of the conversion performance of the individual constituents (Nagle et al. 2014).

Prior BETO-funded work at INL under WBS 2.2.1.102 indicated that it is possible to formulate blends that are capable of meeting quality targets and conversion metrics and performing similarly to corn stover in laboratory-scale screening experiments. Glucose release was measured after combined diluteacid pretreatment and enzymatic hydrolysis for blends of single-pass corn stover, switchgrass, and MSW grass clippings. Total glucose release per gram of biomass (on a dry-weight basis) for blends of corn stover/switchgrass (80/20 and 50/50) and corn stover/switchgrass/grass (60/35/5) were statistically equivalent to $100 \%$ corn stover (Figure 3). Maximizing sugar yields from biomass is critical for biochemical conversion processes that rely on sugars derived from cellulose for biological and catalytic upgrading to hydrocarbons (Figure 3).

\subsubsection{Modeled Blendstock Availability}

After quality, the next considerations for blendstock selection are quantity and availability. The available corn stover in 2018 was projected from data presented in the BT16 report (DOE 2016a). To maximize the utilization of corn stover from low-yielding counties surrounding the biorefinery, we assumed that these counties would utilize only three-pass harvest. It was further assumed that two-pass corn stover would only be available from high-yielding counties, which we assumed to be counties yielding 2 tons/acre or more. Noting that the BT16 report (DOE 2016a) data for corn stover availability are reported from three-pass harvest only, it was necessary to adjust the three-pass yields reported in the BT16 report to yields that would be expected from two-pass harvest. A case study in Emmetsburg, IA (Smith et al. 2014) found that two-pass harvesting averaged 0.95 dry tons/acre, while the three-pass system averaged 1.95 dry tons/acre, for a relative two-pass/three-pass yield of 0.487 dry tons of two-pass per dry ton of three-pass. Hence, for high-yielding corn stover-producing counties, we assumed that only $48.7 \%$ of the corn stover presented as available in the BT16 report (DOE 2016a) would be available as two-pass corn stover. While this is a large reduction in the amount of available corn stover for the biorefinery, the two-pass corn stover is of higher quality than three-pass corn stover. Another benefit is that two-pass corn stover provides another biomass source besides switchgrass that exceeds the carbohydrate spec following storage and preprocessing (there were relatively low amounts of switchgrass 


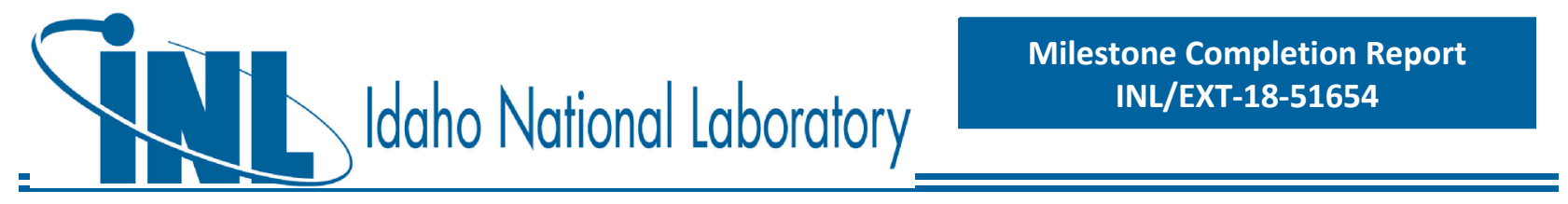

assumed to be available).

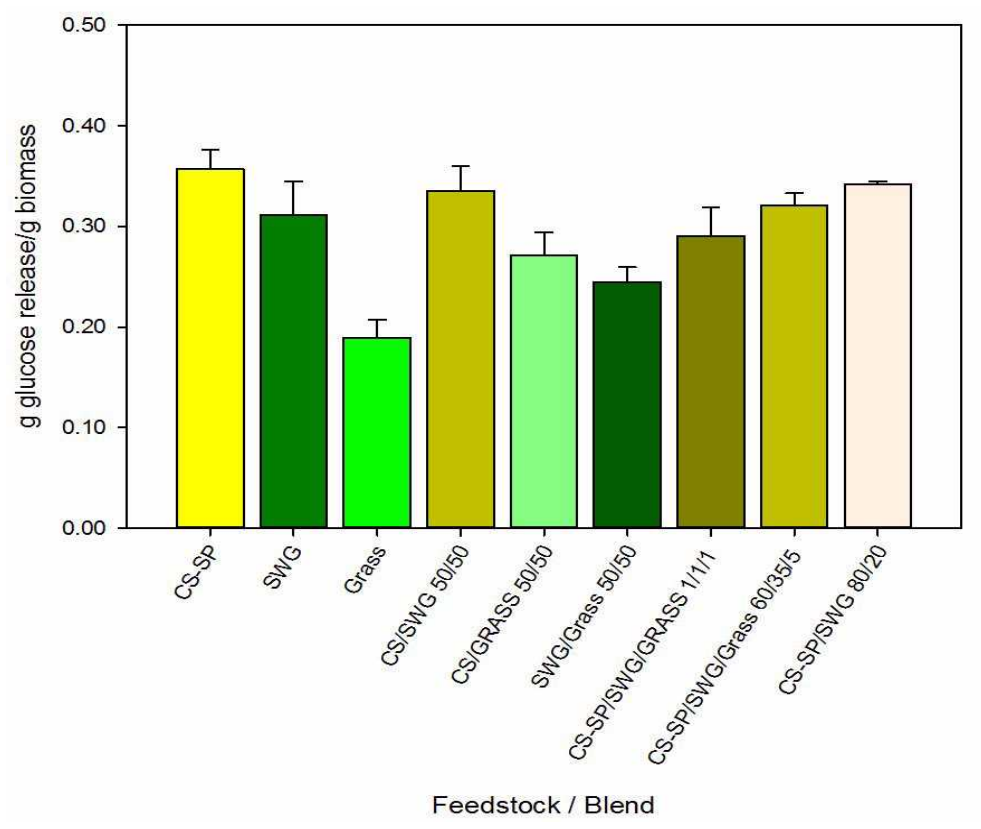

Figure 3. Total glucose release from combined dilute-acid pretreatment and enzymatic hydrolysis for corn stover, switchgrass, and MSW (grass clippings fraction) and blends. CS = corn stover, $S P=$ single-pass corn stover, Grass = grass clippings fraction of $M S W, S W G=$ switchgrass. Blending composition tested at $1600^{\circ} \mathrm{C}$.

\subsubsection{Modeled Blendstock Cost and Optimal Supply System}

The last consideration for blendstock selection is the delivered feedstock cost. A least-cost formulation model that utilizes Mixed-Integer Linear Programming was developed (see Appendix B) to identify the least-cost blend given grower payments, transportation distances to the biorefinery, logistics costs, depot location, depot size with construction costs, and compositional data. The model minimizes the total delivered cost of the blended feedstock while meeting the carbohydrate spec in the delivered feedstock blend, and defines which biomass sources will be used, from which counties, number and locations of depots and the individual depot sizes, and the blend ratios of the various blendstocks. The net delivered feedstock blend cost consists of a grower payment, extracted from BT16 data, and logistics costs extracted from the BLM. Logistics costs include harvesting and collection costs, transportation costs, storage costs, preprocessing costs, biomass replacement costs to account for cost of dry matter losses, and handling and queuing costs.

As stated above, the least-cost blend for this analysis consisted of $12.74 \%$ three-pass corn stover, $73.22 \%$ two-pass stover, $9.83 \%$ switchgrass, and $4.21 \%$ grass clippings. The amounts of harvested biomass (prior to storage) required to produce this blend are shown in Table 5, along with their compositions, and individual delivered costs. The depot locations, biomass source counties and biorefinery location are shown pictorially in Figure 4, and are listed in Table 6. The least cost supply chain network utilized four distributed depots (Nodes 5, 6, 9, 13 in Figure 4) when the biorefinery is 


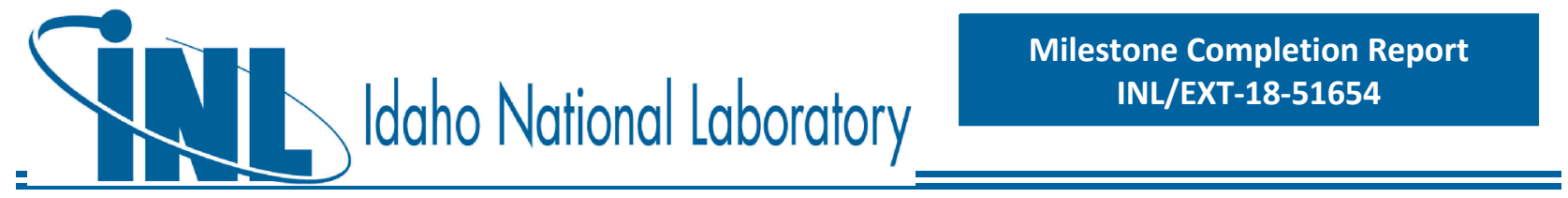

located in Sheridan county, Kansas. The results also show that a biorefinery with a design capacity of 725,000 dry tons/year, would need to procure at least 832,995 dry tons of biomass annually to account for losses in the system.

Table 5. Delivered (reactor-throat) costs and compositions of the herbaceous biomass sources, the preprocessed blendstocks produced from these biomass sources, and the least-cost blend. The modeled cost estimates are for delivery of 725,000 dry tons/year of blended feedstock at $59.22 \%$ carbohydrate, $8.30 \%$ ash and $11.19 \%$ moisture, and are discussed in detail in Appendix A. An ash dockage of \$1.24/dry ton and a moisture dockage of \$0.03/dry ton are included in the total delivered blend cost. All costs are in $2016 \$$.

\begin{tabular}{lccccc}
\hline \multicolumn{1}{c}{ Biomass Type } & $\begin{array}{c}\text { Raw } \\
\text { Biomass } \\
\text { Purchased } \\
\text { (dry tons) }\end{array}$ & $\begin{array}{c}\text { Pelleted } \\
\text { Blendstocks } \\
\text { Produced } \\
\text { (dry tons) }\end{array}$ & $\begin{array}{c}\text { Total } \\
\text { Carbohydrates } \\
(\mathbf{w t \%} \mathbf{d b})\end{array}$ & $\begin{array}{c}\text { Ash } \\
(\mathbf{w t} \% \mathbf{d b})\end{array}$ & $\begin{array}{c}\text { Delivered } \\
\text { Cost } \\
\text { (\$/dry ton) }\end{array}$ \\
\hline Three-pass corn stover & 107,084 & 92,349 & $57.40 \%$ & $12.20 \%$ & $\$ 83.64$ \\
\hline Two-pass corn stover & 615,563 & 530,862 & $60.30 \%$ & $7.60 \%$ & $\$ 84.20$ \\
\hline Switchgrass & 79,026 & 71,250 & $66.60 \%$ & $6.40 \%$ & $\$ 90.13$ \\
\hline Grass clippings & 31,322 & 30,539 & $28.70 \%$ & $13.10 \%$ & $\$ 59.19$ \\
\hline Totals & 832,995 & 725,000 & $59.22 \%$ & $8.30 \%$ & $\$ 83.67$ \\
\hline
\end{tabular}

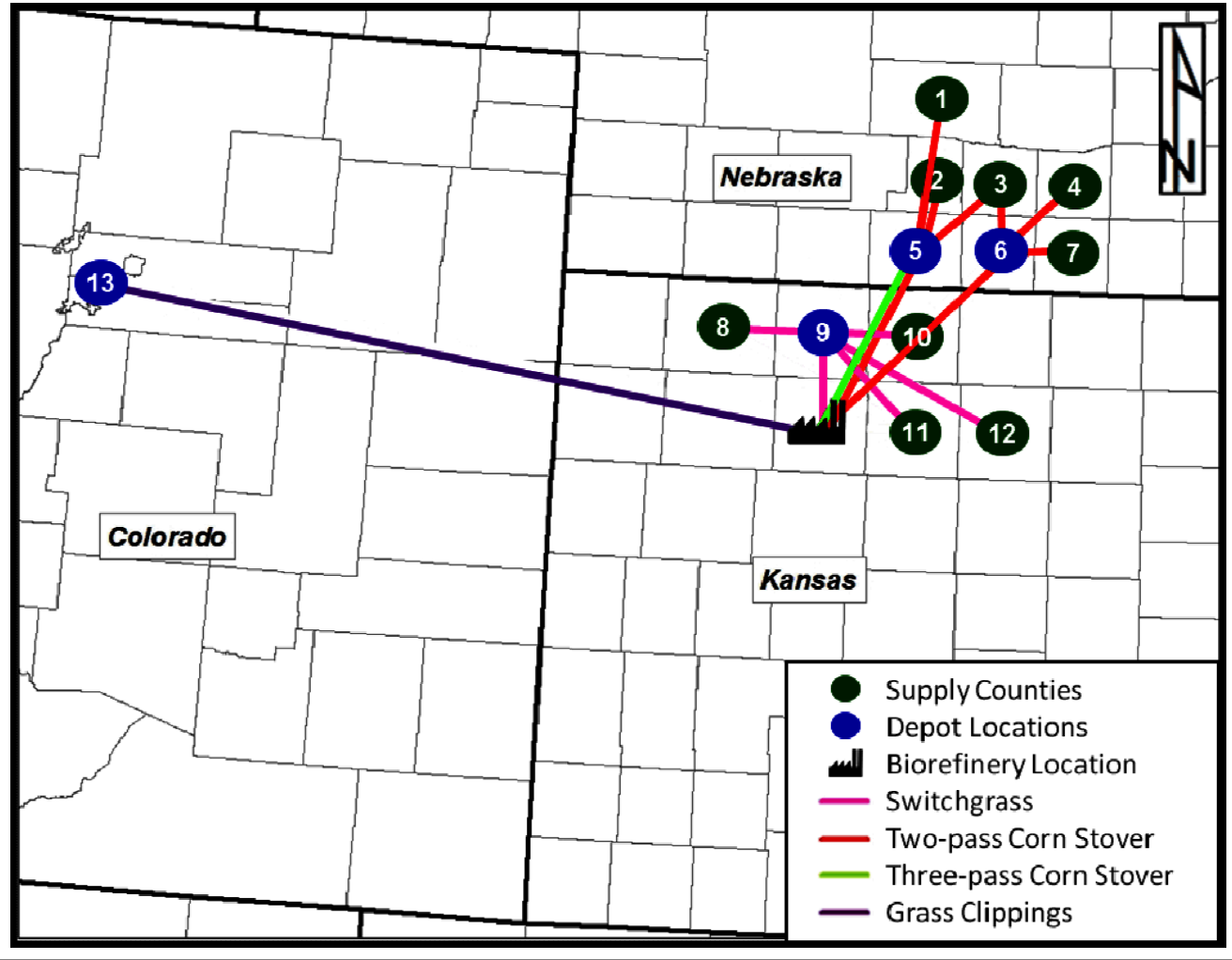


Figure 4. Supply chain network design for the 2018 Herbaceous SOT. The supply chain has 4 distributed depots (Nodes $=5,6,9,13)$ with the biorefinery located in Sheridan County, Kansas. Threepass corn stover is sourced from Node 5, two-pass corn stover from Nodes 1, 2, 3, 4, 6 and 7, switchgrass from Nodes 8, 9, 10,11 and 12, and grass clippings from Node 13.

Table 6. Optimal locations and sizes of distributed depots for least cost delivery of 725,000 dry tons/year of blended feedstock to Sheridan County, KS.

\begin{tabular}{|c|c|c|c|c|c|}
\hline Node & Identifier & County & $\begin{array}{c}\text { Capacity } \\
\text { (dry tons/yr) }\end{array}$ & Biomass Type & $\begin{array}{c}\text { Biomass Source } \\
\text { Nodes } \\
\end{array}$ \\
\hline- & Biorefinery & Sheridan, KS & 725,000 & Blend & $5,6,9,13$ \\
\hline 9 & Depot & Decatur, KS & 75,000 & Switchgrass & $8,9,10,11,12$ \\
\hline \multirow[t]{2}{*}{5} & Depot & Furnas, NE & 250,000 & $\begin{array}{l}\text { three-pass } \\
\text { corn stover }\end{array}$ & 5 \\
\hline & & & & $\begin{array}{l}\text { two-pass } \\
\text { corn stover }\end{array}$ & $1,2,3$ \\
\hline 6 & Depot & Harlan, NE & 425,000 & $\begin{array}{l}\text { two-pass } \\
\text { corn stover }\end{array}$ & $3,4,6,7$ \\
\hline 13 & Depot & Denver, CO & 32,000 & $\begin{array}{c}\text { grass } \\
\text { clippings }\end{array}$ & $\begin{array}{c}\text { Denver } \\
\text { metropolitan } \\
\text { area }\end{array}$ \\
\hline
\end{tabular}

\subsubsection{Sensitivity Analysis of the $\mathbf{2 0 1 8}$ Herbaceous SOT}

Sensitivity analysis was performed to determine the impact of uncertainty in values for key operational parameters on the delivered cost on the static $\mathrm{n}^{\text {th }}$-plant design presented as the 2018 Herbaceous SOT. In the analysis, the locations of the distributed depots were kept fixed, but their sizes were allowed to vary in order to capture not only the impacts of increased or decreased capital and operating costs, but also the impacts on depot construction and financing costs.

Critical process parameters that affect delivered feedstock were investigated to determine the impact of uncertainty in their values on the delivered feedstock cost. The parameters are shown in Table 7; each parameter was varied based on actual variations observed in experimental, field data. Equipment performance parameters such as throughput and energy consumption are known to impact cost in each area of the supply chain (harvest and collection, transportation, preprocessing, etc.), so these formed the initial set of targets for sensitivity analysis. Bulk density is well known as a cost factor in transportation, so the assumed bulk density of bales and the measured bulk densities of pellets of the various biomass blendstocks were also varied in the analysis. Costs such the interest rate were varied to understand the relative impact of some factors that may vary with the state of the economy. Finally, the farm gate cost and the gross quantity of biomass that must be purchased in order to supply 725,000 dry tons of feedstock to the biorefinery forms a large proportion of the delivered cost; since the largest source of dry matter loss is during storage, the assumed dry matter losses for each biomass type were varied in the sensitivity analysis. Noticeably missing from the set of parameters that were varied are ash and moisture contents. Ash content was not varied because this would alter input sugar compositions and require the blend composition to change, which would lead to the need to alter depot and resource draw locations in order 


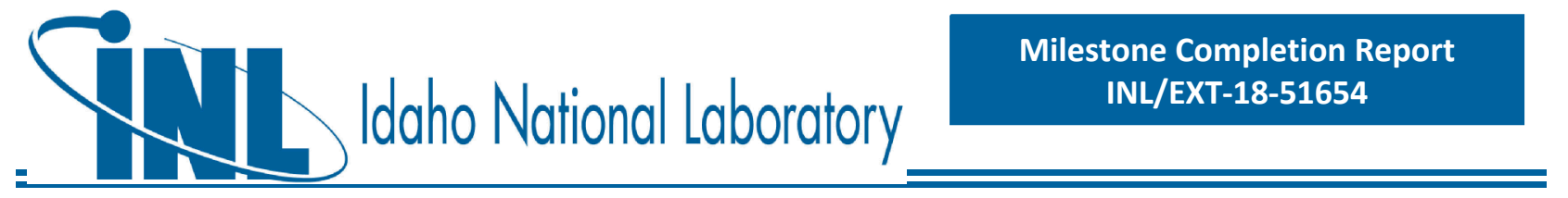

to achieve the least cost (and so the result would not be directly comparable to the static 2017 Herbaceous SOT design). Moisture was not varied because this would require the preprocessing design to add a dryer in order to meet the delivered feedstock specifications required by the conversion process, and this would make it not directly comparable to the static 2018 Herbaceous SOT design.

Table 7. Model parameters varied for the sensitivity analysis. Each parameter was varied independently based on actual variations observed in experiment, field data.

\begin{tabular}{|c|c|c|c|c|c|}
\hline Parameter & Units & Biomass Type & Minimum & $\begin{array}{l}\text { Average } \\
\text { (SOT) }\end{array}$ & Maximum \\
\hline \multirow{4}{*}{$\begin{array}{l}\text { Effective } \\
\text { windrowing rate }\end{array}$} & \multirow[t]{4}{*}{ acres $/ \mathrm{hr}$} & Three-pass corn stover & 10.78 & 11.5 & 12.51 \\
\hline & & Two-pass corn stover & n.a. & n.a. & n.a. \\
\hline & & Switchgrass & 8.25 & 8.8 & 9.57 \\
\hline & & Grass clippings & n.a. & n.a. & n.a. \\
\hline \multirow{4}{*}{$\begin{array}{l}\text { Effective baling } \\
\text { rate }^{\mathrm{b}}\end{array}$} & \multirow[t]{4}{*}{ dry ton $/ \mathrm{hr}$} & Three-pass corn stover & 16.14 & 26.18 & 28.10 \\
\hline & & Two-pass corn stover & 8.88 & 14.4 & 24.7 \\
\hline & & Switchgrass & 24.04 & 27.36 & 28.10 \\
\hline & & Grass clippings & n.a. & n.a. & n.a. \\
\hline \multirow{4}{*}{$\begin{array}{l}\text { Field side storage } \\
\text { dry matter loss }{ }^{\mathrm{c}}\end{array}$} & \multirow[t]{4}{*}{$\%$} & Three-pass corn stover & $5 \%$ & $12 \%$ & $20 \%$ \\
\hline & & Two-pass corn stover & $5 \%$ & $12 \%$ & $20 \%$ \\
\hline & & Switchgrass & $4 \%$ & $8 \%$ & $12 \%$ \\
\hline & & Grass clippings & n.a. & n.a. & n.a. \\
\hline \multirow{4}{*}{$\begin{array}{l}\text { Bale transport } \\
\text { loading/unloading } \\
\text { time }^{\mathrm{d}}\end{array}$} & \multirow[t]{4}{*}{ minutes } & Three-pass corn stover & 39 & 42 & 45 \\
\hline & & Two-pass corn stover & 39 & 42 & 45 \\
\hline & & Switchgrass & 39 & 42 & 45 \\
\hline & & Grass clippings & n.a. & n.a. & n.a. \\
\hline \multirow[t]{4}{*}{ Bale density ${ }^{e}$} & \multirow[t]{4}{*}{$\mathrm{lb} / \mathrm{ft}^{3}$} & Three-pass corn stover & 11 & 12 & 13 \\
\hline & & Two-pass corn stover & 11 & 12 & 13 \\
\hline & & Switchgrass & 9 & 12 & 13 \\
\hline & & Grass clippings & n.a. & n.a. & n.a. \\
\hline $\begin{array}{l}\text { Hammer mill } \\
\text { throughput }^{f}\end{array}$ & $\begin{array}{l}\text { dry tons } / \mathrm{hr} / \\
\text { machine }\end{array}$ & Three-pass corn stover & 2.44 & 3.34 & 4.92 \\
\hline 23 & & & & & \\
\hline
\end{tabular}




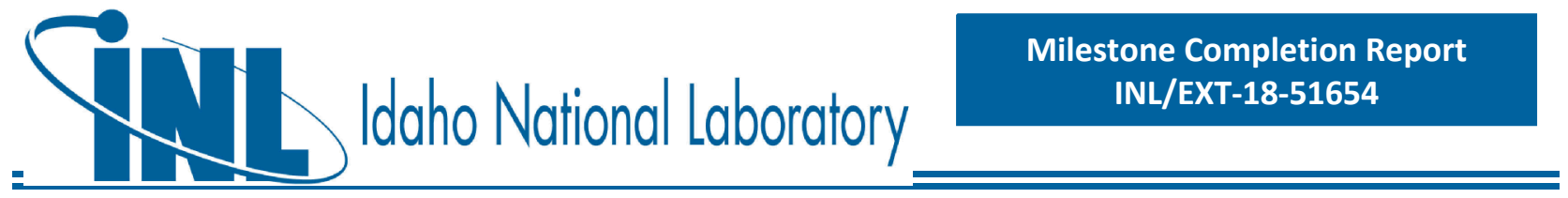

\begin{tabular}{lllll}
\hline $\begin{array}{l}\text { (Shredder for } \\
\text { Grass clippings) }\end{array}$ & Two-pass corn stover & 2.44 & 3.34 & 4.92 \\
\cline { 2 - 5 } & Switchgrass & 3.82 & 4.54 & 5.05 \\
\cline { 2 - 5 } & Grass clippings & 4.63 & 5.50 & 6.12 \\
\hline
\end{tabular}




\section{YWL Idaho Notiond labocidory}

Table 7. (continued)

\begin{tabular}{|c|c|c|c|c|c|}
\hline Parameter & Units & Biomass Type & Minimum & $\begin{array}{c}\text { Average } \\
\text { (SOT) }\end{array}$ & Maximum \\
\hline \multirow{2}{*}{$\begin{array}{l}\text { Hammer mill } \\
\text { energy } \\
\text { consumption }^{\mathrm{f}}\end{array}$} & \multirow[t]{4}{*}{$\mathrm{kWh} /$ dry ton } & Three-pass corn stover & 8.239 & 12.86 & 15.96 \\
\hline & & Two-pass corn stover & 8.239 & 12.86 & 15.96 \\
\hline \multirow{2}{*}{$\begin{array}{l}\text { (Shredder for } \\
\text { Grass clippings) }\end{array}$} & & Switchgrass & 16.79 & 19.91 & 26.53 \\
\hline & & Grass clippings & 3.31 & 3.92 & 5.22 \\
\hline \multirow{4}{*}{$\begin{array}{l}\text { Rotary shear } \\
\text { throughput }^{\mathrm{f}}\end{array}$} & \multirow{4}{*}{$\begin{array}{c}\text { dry } \\
\text { tons } / \text { hr/machine }\end{array}$} & Three-pass corn stover & 11.95 & 12.58 & 13.21 \\
\hline & & Two-pass corn stover & 11.95 & 12.58 & 13.21 \\
\hline & & Switchgrass & 12.95 & 13.63 & 14.31 \\
\hline & & Grass clippings & n.a. & n.a. & n.a. \\
\hline \multirow{4}{*}{$\begin{array}{l}\text { Rotary shear } \\
\text { energy } \\
\text { consumption }^{\mathrm{f}}\end{array}$} & \multirow[t]{4}{*}{$\mathrm{kWh} / \mathrm{dry}$ ton } & Three-pass corn stover & 8.26 & 8.69 & 9.12 \\
\hline & & Two-pass corn stover & 8.26 & 8.69 & 9.12 \\
\hline & & Switchgrass & 1.43 & 1.50 & 1.58 \\
\hline & & Grass clippings & n.a. & n.a. & n.a. \\
\hline \multirow{4}{*}{$\begin{array}{l}\text { Pelleting } \\
\text { throughput }^{\mathrm{f}}\end{array}$} & \multirow{4}{*}{$\begin{array}{c}\text { dry } \\
\text { tons/hr/machine }\end{array}$} & Three-pass corn stover & 3.24 & 3.38 & 3.51 \\
\hline & & Two-pass corn stover & 3.24 & 3.38 & 3.51 \\
\hline & & Switchgrass & 3.32 & 3.50 & 3.63 \\
\hline & & Grass clippings & 3.80 & 4.00 & 4.15 \\
\hline \multirow{4}{*}{$\begin{array}{l}\text { Pelleting energy } \\
\text { consumption }^{\mathrm{f}}\end{array}$} & \multirow[t]{4}{*}{$\mathrm{kWh} /$ dry ton } & Three-pass corn stover & 34.84 & 36.24 & 37.20 \\
\hline & & Two-pass corn stover & 34.84 & 36.24 & 37.20 \\
\hline & & Switchgrass & 57.9 & 60.2 & 61.8 \\
\hline & & Grass clippings & 78.8 & 82.0 & 84.2 \\
\hline
\end{tabular}




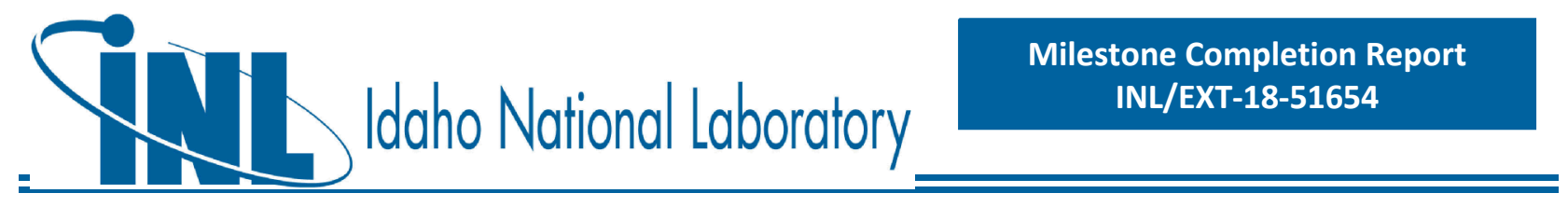

Table 7. (continued)

\begin{tabular}{llllll}
\hline \multirow{2}{*}{ Parameter } & Units & \multicolumn{1}{c}{ Biomass Type } & $\begin{array}{c}\text { Minimum } \\
(\text { SOT })\end{array}$ & $\begin{array}{c}\text { Average } \\
(\text { SOT) }\end{array}$ & $\begin{array}{c}\text { Maximum } \\
\text { (SOT) }\end{array}$ \\
\hline $\begin{array}{l}\text { By pass during } \\
\text { fractional milling }\end{array}$ & $\%$ & Three-pass corn stover & $35.01 \%$ & $40.39 \%$ & $44.00 \%$ \\
\cline { 2 - 5 } & & Two-pass corn stover & $35.01 \%$ & $40.39 \%$ & $44.00 \%$ \\
\cline { 2 - 5 } & Switchgrass & $38.50 \%$ & $44.98 \%$ & $46.00 \%$ \\
\cline { 2 - 5 } & Grass clippings & n.a. & n.a. & n.a. \\
\hline Interest rate $^{\mathrm{h}}$ & Three-pass corn stover & 4.0 & 8.0 & 12.0 \\
\cline { 2 - 5 } & Two-pass corn stover & 4.0 & 8.0 & 12.0 \\
\cline { 2 - 5 } & Switchgrass & 4.0 & 8.0 & 12.0 \\
\cline { 2 - 5 } & Grass clippings & 4.0 & 8.0 & 12.0 \\
\hline
\end{tabular}

a: Effective windrowing rate is variated based on variation of field efficiency measured from time series data(Roni, M. et al., 2018).

b: Depends on variation of yield and equipment capacity. Empirical field data from DOE co-sponsored Biomass Alliance for Logistics Efficiency and Specifications (BALES) project (Comer, 2017) and DOE-sponsored "Growing Bioeconomy Markets: Farm-to-Fuel in Southside Virginia" project.(DOE.,2017).were utilized to measure the variation in two-pass corn stover and switchgrass .The variation in threepass corn stover was estimated by normalizing the two-pass corn stover data by applying actual baling rate during three-pass corn stover baling.

c: Assumed based on observed variation during storage

d: Bale load time variation is measured from variation of bale loads by Stinger ALSS (STINGER,2015).

e: Variation is measured based on empirical data from DOE funded integrated landscape design project (Roni, M. et al., 2018).

f: INL PDU data, Forest concept data were utilized to measure the variation in throughput and energy consumption under base case process conditions (e.g. moisture, screen size ) for corn stover and switchgrass. Switchgrass percentage variation of throughput and energy consumption from base case is utilized to estimate the grass clippings variations

g: INL PDU data were utilized to measure the variation in percentage of material by bypassed during second stage grinding under base case process conditions (e.g. moisture, screen size ) for corn stover and switchgrass

$\mathrm{h}$ : Assumptions based on expected variations

Figure 5 shows the results of the sensitivity analysis. Sensitivity analysis on various process parameters that affect delivered feedstock cost in the 2018 Herbaceous SOT shows that the delivered cost could vary from $\$ 80.45$ - $\$ 88.83 /$ dry ton. The top factors that caused such variations are: effective baling rate, bale density, hammer mill throughput, interest rate and storage dry matter loss. In the current design, increasing baling rate and bale density may have the greatest potential to reduce delivered feedstock cost. Based on observed variation, improvement of hammer mill throughput could 


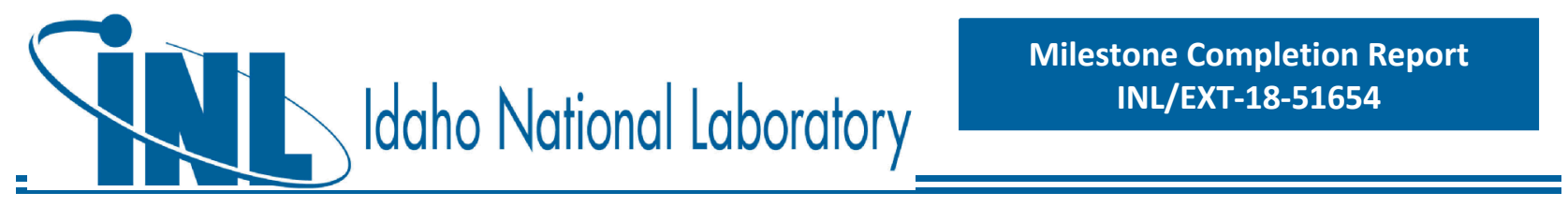

reduce the delivered feedstock by $\$ 2.64$ /dry ton, whereas reduced hammer mill throughput would increase the delivered feedstock by $\$ 3.12$ /dry ton. If storage dry matter loss of corn stover and switchgrass can be improved from $12 \%$ to $8 \%$ and $8 \%$ to $4 \%$ respectively, the delivered feedstock could be reduced by $\$ 1.22 /$ dry ton. Additional parameters that have measurable effects on the uncertainty in delivered feedstock price include hammer mill energy consumption, pelleting throughput and percentage of bypassed material during fractional milling.

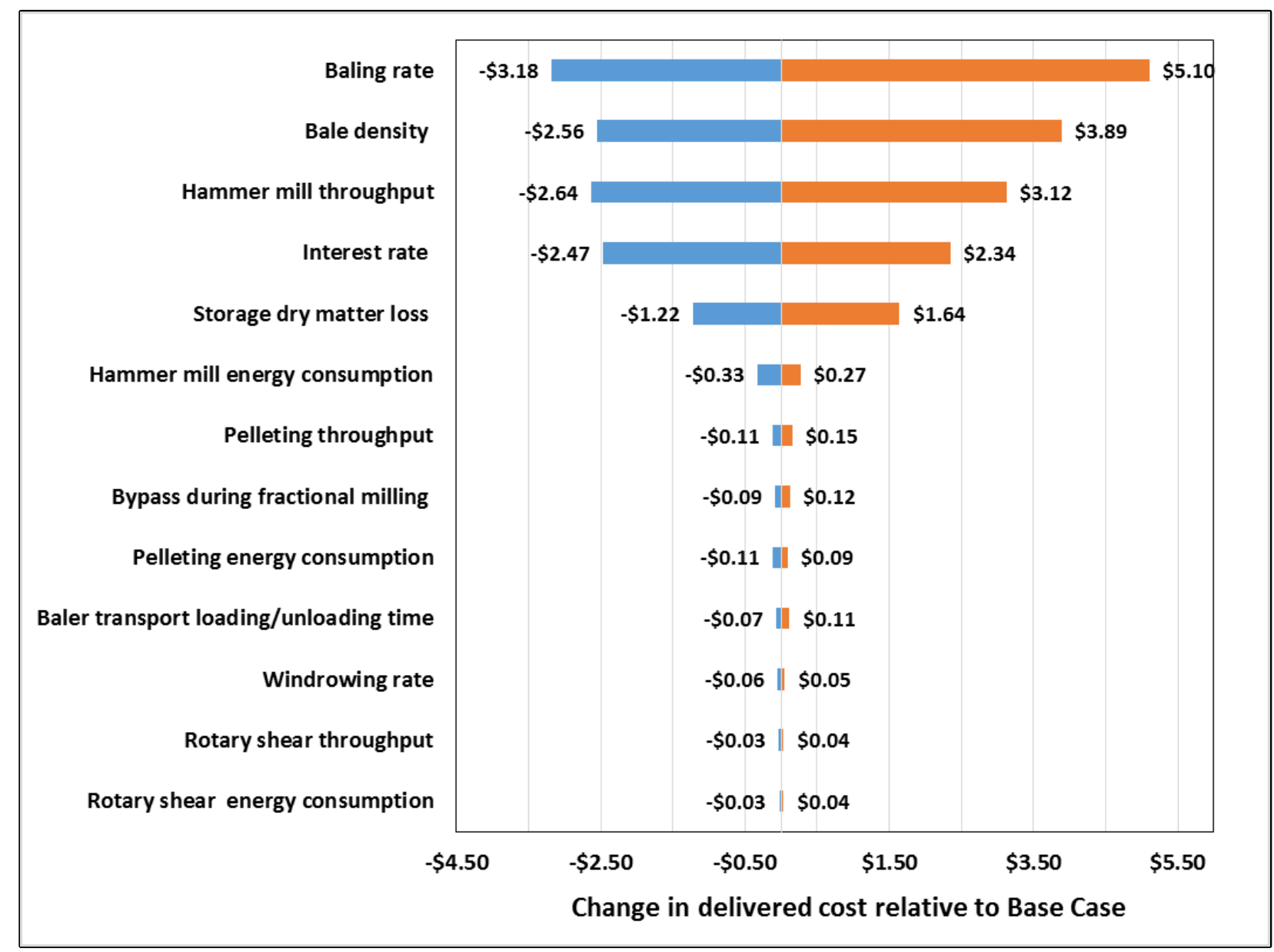

Figure 5. Tornado chart showing sensitivity of cost to operational parameters used to model the 2018 SOT Design. 


\subsection{Comparative Supply Costs and Blends for Centralized Depots and Exclusion of Niche Resources}

Three additional logistics designs were considered for comparison to the optimal least-cost herbaceous feedstock supply chain design represented by the 2018 Herbaceous SOT, which resulted in four distributed depots. The additional designs were defined by placing traditional constraints on:

1. Whether distant, low quality but low cost niche grass clippings would be utilized in a blend at lower than $5 \%$, in a distributed depot scenario. This case is equivalent to the SOT case, except that grass clippings are not made available as a biomass source for the least cost optimization.

2. Where the high-volume biomass sources are preprocessed. For this case, grass clippings are available, but the depot location for the primary components of the blend is forced to colocate with the biorefinery.

3. Whether distant, low quality but low cost niche grass clippings would be utilized in a blend at lower than $5 \%$, in a centralized depot scenario. This case is equivalent to case 2 , except that grass clippings are not made available as a biomass source for the least cost optimization.

The first and third cases assume the conventional belief that distant resources will always be too costly to transport, and that if they are not available in quantities larger enough to comprise more than $5 \%$ of the blend, that they will not be utilized. The second case assumes the conventional approach of vertically integrating the feedstock supply and siting all preprocessing operations at the biorefinery, which is widely believed to always be the most cost effective solution for feedstock supply because of economies of scale. These cases are presented below.

\subsubsection{Exclusion of Grass Clippings from the Distributed Depot Case}

The exclusion of grass clippings from the distributed depot case utilizes identical assumptions used in the 2018 Herbaceous SOT, except that grass clippings are excluded. The modeled least cost for each individual herbaceous feedstock supply systems and the blend composition are shown Table 8 . The leastcost blend for this case consisted of 33.34\% three-pass corn stover and 66.67\% two-pass corn stover, with the higher-cost switchgrass also excluded because the carbohydrate specification could be met with only the two lower cost sources of corn stover. The optimized least-cost delivered cost increases from $\$ 83.67 /$ dry ton to $\$ 83.83 /$ dry ton if grass clippings are excluded from the blend, a $\$ 0.16$ dry ton increase relative to the SOT case, which amounts to $\$ 116,000$ in additional cost for feedstock supply to the biorefinery.

The amounts of harvested biomass (prior to storage) required to produce this blend are shown in Table 9, along with their compositions, and individual delivered costs. The depot locations, biomass source counties and biorefinery location are shown pictorially in Figure 6, and are listed in Table 10. The least cost supply chain network utilized two distributed depots (Nodes 5 and 7 in Figure 6) when the biorefinery is located in Sheridan county, Kansas. The results also show that a biorefinery located in Sheridan County, Kansas with a design capacity of 725,000 dry tons/year, would need to procure at least 840,677 dry tons of biomass annually to account for losses in the system, an increase of 7,682 dry tons compared to the 2018 Herbaceous SOT. 
Table 8. Modeled cost and GHG estimates for an herbaceous feedstock supply system supplying 725,000 dry tons annually in northwestern Kansas, if grass clippings are excluded from the blend based on low availability and distance from the biorefinery. Grower payments are based on supply curves from BT-16 (DOE 2016a) and costs are presented in \$/dry ton (2016\$). Design details are in Appendix $A$.

\begin{tabular}{|c|c|c|c|c|c|c|}
\hline \multirow[t]{2}{*}{ Cost Element } & \multicolumn{5}{|c|}{ Cost (\$/dry ton) } & \multirow{2}{*}{$\begin{array}{c}\text { GHG } \\
\text { Emissions } \\
\left(\mathrm{kg} \mathrm{CO}_{2} \mathrm{e} / \mathrm{ton}\right)\end{array}$} \\
\hline & $\begin{array}{l}\text { Three- } \\
\text { Pass } \\
\text { Stover }\end{array}$ & $\begin{array}{c}\text { Two- } \\
\text { Pass } \\
\text { Stover }\end{array}$ & $\begin{array}{l}\text { Switch- } \\
\text { grass }\end{array}$ & $\begin{array}{l}\text { Grass } \\
\text { Clippings }\end{array}$ & $\begin{array}{c}\text { Least- } \\
\text { Cost } \\
\text { Blend }^{\mathrm{a}}\end{array}$ & \\
\hline Blend Ratio & $33.33 \%$ & $66.67 \%$ & $0.00 \%$ & - & $100 \%$ & - \\
\hline Grower payment & $\$ 26.66$ & $\$ 21.71$ & $\$ 0.00$ & - & $\$ 23.36$ & - \\
\hline $\begin{array}{l}\text { Harvest and } \\
\text { collection }\end{array}$ & $\$ 13.84$ & $\$ 18.79$ & $\$ 0.00$ & - & $\$ 17.14$ & 11.38 \\
\hline $\begin{array}{l}\text { Storage and } \\
\text { queuing }\end{array}$ & $\$ 6.40$ & $\$ 6.53$ & $\$ 0.00$ & - & $\$ 6.49$ & 2.66 \\
\hline $\begin{array}{l}\text { Transportation and } \\
\text { handling }\end{array}$ & $\$ 11.42$ & $\$ 13.65$ & $\$ 0.00$ & - & $\$ 12.91$ & 15.63 \\
\hline $\begin{array}{l}\text { In-plant receiving } \\
\text { and preprocessing }\end{array}$ & $\$ 22.35$ & $\$ 22.35$ & $\$ 0.00$ & - & $\$ 22.35$ & 35.84 \\
\hline Dockage & $\$ 2.74$ & $\$ 1.00$ & $\$ 0.00$ & - & $\$ 1.58$ & - \\
\hline Total & $\$ 83.41$ & $\$ 84.04$ & $\$ 0.00$ & - & $\$ 83.83$ & 65.50 \\
\hline
\end{tabular}

a Blend costs are presented as the weighted average of the blend component costs.

Table 9. Procured biomass and composition of the blended feedstock in the least-cost blend if grass clippings are excluded from the blend based on low availability and distance from the biorefinery.

\begin{tabular}{|c|c|c|c|c|c|}
\hline \multirow[t]{2}{*}{ Biomass Type } & \multirow{2}{*}{$\begin{array}{c}\text { Raw } \\
\text { Biomass } \\
\text { Purchased } \\
\text { (dry tons) }\end{array}$} & \multirow{2}{*}{$\begin{array}{c}\text { Pelleted } \\
\text { - Blendstocks } \\
\text { Delivered } \\
\text { (dry tons) }\end{array}$} & \multicolumn{3}{|c|}{ Pelleted Blendstocks } \\
\hline & & & $\begin{array}{c}\text { Total } \\
\text { Carbohydrates } \\
(\mathrm{wt} \% \mathrm{db})\end{array}$ & $\begin{array}{c}\text { Ash } \\
(w t \% \text { db) }\end{array}$ & $\begin{array}{c}\text { Delivered } \\
\text { Cost } \\
\text { (\$ } / \text { drv ton) }\end{array}$ \\
\hline
\end{tabular}




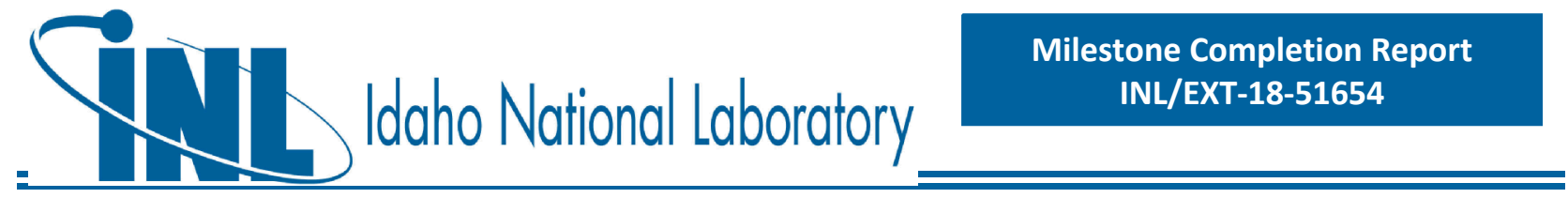

\begin{tabular}{lccccc}
\hline Three-pass corn stover & 280,227 & 241,668 & $57.40 \%$ & $12.20 \%$ & $\$ 83.41$ \\
\hline Two-pass corn stover & 560,450 & 483,332 & $60.30 \%$ & $7.60 \%$ & $\$ 84.04$ \\
\hline Switchgrass & 0 & 0 & $66.60 \%$ & $6.40 \%$ & $\$ 90.13$ \\
\hline Grass clippings & - & - & - & - & - \\
\hline Totals & 840,677 & 725,000 & $59.33 \%$ & $9.13 \%$ & $\$ 83.83$ \\
\hline
\end{tabular}

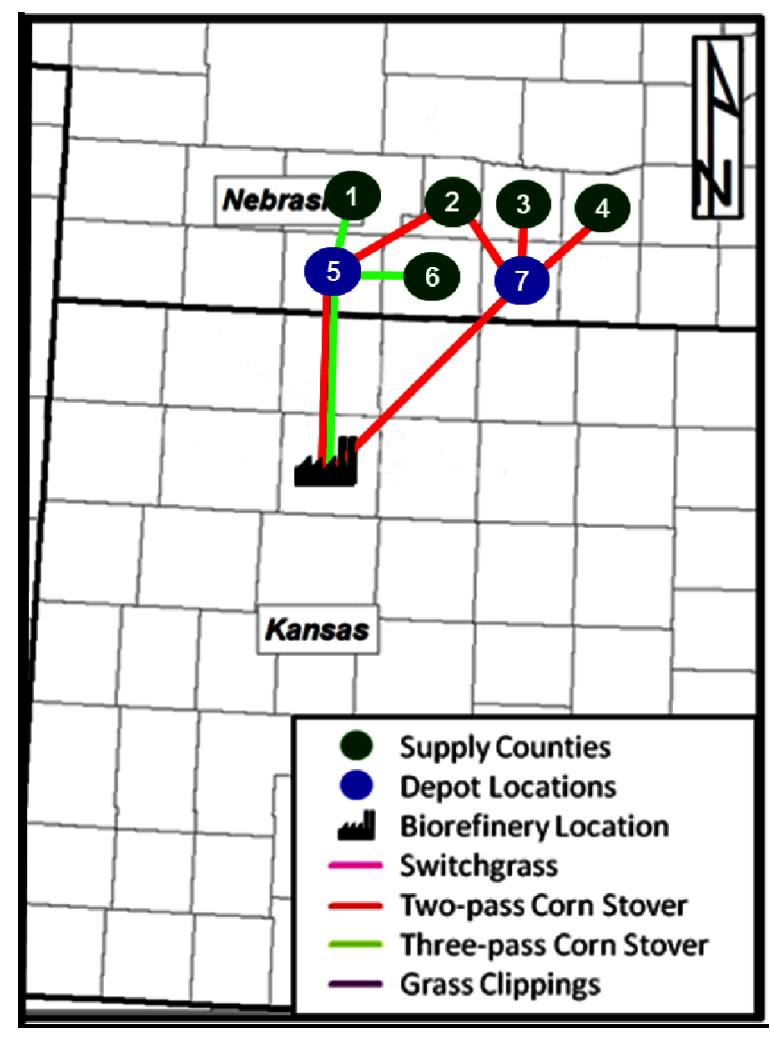

Figure 6. Supply chain network design for the case where grass clippings are excluded from the blend based on low availability and/or distance from the biorefinery. The supply chain has 2 distributed depots (Nodes $=5$ and 7) with the biorefinery located in Sheridan County, Kansas. Three-pass corn stover is sourced from Nodes 1, 5 and 6, and two-pass corn stover from Nodes 2, 3, 4 and 7 .

Table 10. Optimal locations and sizes of distributed depots for least cost delivery of 725,000 dry tons/year of blended feedstock to Sheridan County, KS, when grass clippings are excluded from the blend.

\begin{tabular}{cccccc}
\hline Node & Identifier & County & $\begin{array}{c}\text { Capacity } \\
(\text { dry tons/yr) }\end{array}$ & Biomass Type & $\begin{array}{c}\text { Biomass Source } \\
\text { Nodes }\end{array}$ \\
\hline- & Biorefinery & Sheridan, KS & 725,000 & Blend & 5,7 \\
\hline
\end{tabular}




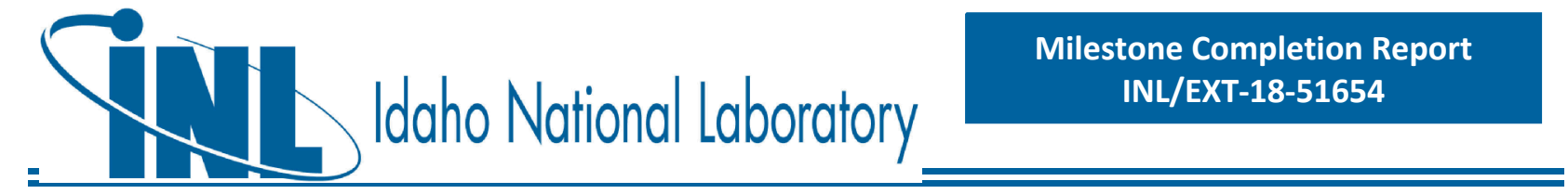

\begin{tabular}{|c|c|c|c|c|c|}
\hline 7 & Depot & Harlan, NE & 475,000 & $\begin{array}{l}\text { two-pass } \\
\text { corn stover }\end{array}$ & $2,3,4,7$ \\
\hline \multirow[t]{2}{*}{5} & \multirow[t]{2}{*}{ Depot } & \multirow[t]{2}{*}{ Red Willow, NE } & \multirow[t]{2}{*}{300,000} & $\begin{array}{l}\text { two-pass } \\
\text { corn stover }\end{array}$ & 2 \\
\hline & & & & $\begin{array}{l}\text { three-pass } \\
\text { corn stover }\end{array}$ & $1,5,6$ \\
\hline
\end{tabular}




\subsubsection{Primary Depot Co-located with the Biorefinery}

The primary depot co-located with the biorefinery case utilizes the depot location assumptions used in the 2016 Herbaceous SOT. Two depots are available in this case, with the primary depot co-located with the biorefinery, and a second, small grass clippings depot located in the Denver Metropolitan area. In this case, baled two-pass corn stover, three-pass corn stover and switchgrass are trucked to the depot. The only difference in the least-cost optimization in comparison to the SOT case is that depot siting is fixed and not considered in the cost optimization. The modeled least cost for each individual herbaceous feedstock supply systems and the blend composition are shown Table 11. The least-cost blend for this case consisted of $36.85 \%$ three-pass corn stover, $51.20 \%$ two-pass corn stover, $10.03 \%$ switchgrass and $1.92 \%$ grass clippings. The optimized least-cost delivered cost increases from $\$ 83.67 /$ dry ton to $\$ 84.21 /$ dry ton if grass clippings are excluded from the blend, an increase of $\$ 0.54$ /dry ton relative to the SOT case, which amounts to $\$ 391,000$ in additional cost for feedstock supply to the biorefinery.

Table 11. Modeled cost and GHG estimates for an herbaceous feedstock supply system supplying 725,000 dry tons annually in northwestern Kansas, with depot location assumptions used in the 2016 Herbaceous SOT. Two depots are available in this case, with the primary depot co-located with the biorefinery, and a second, small grass clippings depot located in the Denver Metropolitan area. Grower payments are based on supply curves from BT16 (DOE 2016a) and costs are presented in \$/dry ton (2016\$). Design details are in Appendix A.

\begin{tabular}{|c|c|c|c|c|c|c|}
\hline \multirow[t]{2}{*}{ Cost Element } & \multicolumn{5}{|c|}{ Cost (\$/dry ton) } & \multirow{2}{*}{$\begin{array}{c}\text { GHG } \\
\text { Emissions } \\
\text { (kg CO} \mathrm{CO}_{2} \mathrm{e} / \mathrm{ton} \text { ) }\end{array}$} \\
\hline & $\begin{array}{l}\text { Three- } \\
\text { Pass } \\
\text { Stover }\end{array}$ & $\begin{array}{c}\text { Two- } \\
\text { Pass } \\
\text { Stover }\end{array}$ & $\begin{array}{l}\text { Switch- } \\
\text { grass }\end{array}$ & $\begin{array}{c}\text { Grass } \\
\text { Clippings }\end{array}$ & $\begin{array}{c}\text { Least- } \\
\text { Cost } \\
\text { Blend }^{\mathrm{a}}\end{array}$ & \\
\hline Blend Ratio & $36.85 \%$ & $51.20 \%$ & $10.03 \%$ & $1.92 \%$ & $100 \%$ & - \\
\hline Grower payment & $\$ 26.66$ & $\$ 21.71$ & $\$ 38.87$ & $\$ 10.13$ & $\$ 25.03$ & - \\
\hline $\begin{array}{l}\text { Harvest and } \\
\text { collection }\end{array}$ & $\$ 13.84$ & $\$ 18.79$ & $\$ 11.76$ & $\$ 0.00$ & $\$ 15.90$ & 10.74 \\
\hline $\begin{array}{l}\text { Storage and } \\
\text { queuing }\end{array}$ & $\$ 6.40$ & $\$ 6.53$ & $\$ 5.89$ & $\$ 6.57$ & $\$ 6.42$ & 2.65 \\
\hline $\begin{array}{l}\text { Transportation and } \\
\text { handling }\end{array}$ & $\$ 11.90$ & $\$ 14.67$ & $\$ 8.99$ & $\$ 19.18$ & $\$ 13.17$ & 17.96 \\
\hline $\begin{array}{l}\text { In-plant receiving } \\
\text { and preprocessing }\end{array}$ & $\$ 22.14$ & $\$ 22.14$ & $\$ 21.55$ & $\$ 20.23$ & $\$ 22.05$ & 37.33 \\
\hline Dockage & $\$ 2.74$ & $\$ 1.00$ & $\$ 0.56$ & $\$ 3.08$ & $\$ 1.64$ & - \\
\hline
\end{tabular}




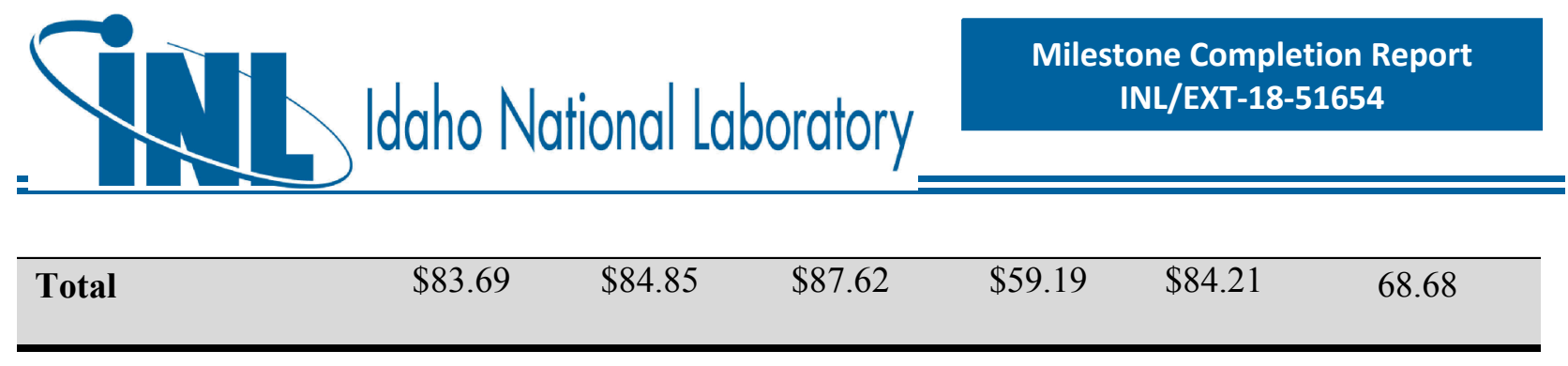

a The blend costs are presented as the weighted average of the blend component costs.

b Grower payment taken as the cost assumed for procurement of grass clippings.

The amounts of harvested biomass (prior to storage) required to produce this blend are shown in Table 12, along with their compositions, and individual delivered costs. The depot locations, biomass source counties and biorefinery location are shown pictorially in Figure 7, and are listed in Table 13. The least cost supply chain network utilized one centralized depot (Node 11 in Figure 7) when the biorefinery

Table 12. Procured biomass and compositions of the blended feedstock in the least-cost blend for the centralized depot case.

\begin{tabular}{lccccc}
\hline \multicolumn{1}{c}{ Biomass Type } & $\begin{array}{c}\text { Raw } \\
\text { Biomass } \\
\text { Purchased } \\
\text { (dry tons) }\end{array}$ & $\begin{array}{c}\text { Pelleted } \\
\text { Blendstocks } \\
\text { Delivered } \\
\text { (dry tons) }\end{array}$ & $\begin{array}{c}\text { Total } \\
\text { Carbohydrates } \\
\text { (wt\% db) }\end{array}$ & $\begin{array}{c}\text { Ash } \\
\text { (wt\% db) }\end{array}$ & $\begin{array}{c}\text { Delivered } \\
\text { Cost } \\
\text { (\$/dry ton) }\end{array}$ \\
\hline Three-pass corn stover & 309,780 & 267,154 & $57.40 \%$ & $12.20 \%$ & $\$ 83.69$ \\
\hline Two-pass corn stover & 430,413 & 371,188 & $60.30 \%$ & $7.60 \%$ & $\$ 84.85$ \\
\hline Switchgrass & 80,642 & 72,707 & $66.60 \%$ & $6.40 \%$ & $\$ 87.62$ \\
\hline Grass clippings & 14,309 & 13,951 & $28.70 \%$ & $13.10 \%$ & $\$ 59.19$ \\
\hline Totals & 835,144 & 725,000 & $59.26 \%$ & $9.28 \%$ & $\$ 84.21$ \\
\hline
\end{tabular}



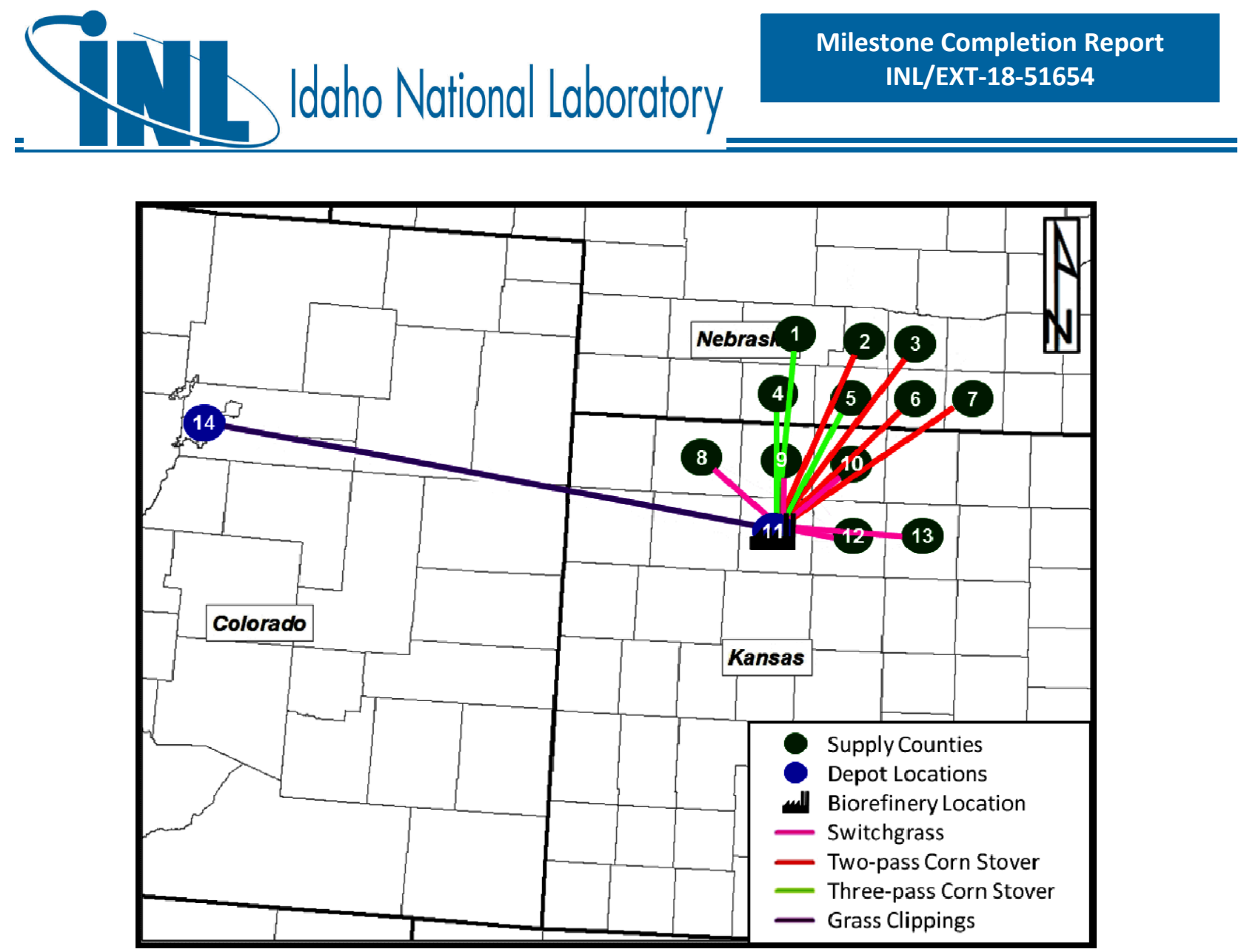

Figure 7. Supply chain network design for the centralized primary depot case. The supply chain has a centralized primary depot (Node 11) and a distant grass clippings depot (Node 14) with the biorefinery located in Sheridan County, Kansas. Three-pass corn stover is sourced from Nodes 1, 4 and 5, two-pass corn stover from Nodes 2, 3, 6 and 7, switchgrass from Nodes 8, 9, 10, 12 and 13, and grass clippings from Node 14.

is located in Sheridan county, Kansas. The results also show that a biorefinery located in Sheridan County, Kansas with a design capacity of 725,000 dry tons/year, would need to procure at least 835,144 dry tons of biomass annually to account for losses in the system, an increase of 2,149 dry tons compared to the 2018 Herbaceous SOT.

Table 13. Locations and sizes of depots for least cost delivery of 725,000 dry tons/year of blended feedstock to Sheridan County, KS in the centralized primary depot case.

\begin{tabular}{cccccc}
\hline Node & Identifier & County & $\begin{array}{c}\text { Capacity } \\
\text { (dry tons/yr) }\end{array}$ & Biomass Type & $\begin{array}{c}\text { Biomass Source } \\
\text { Nodes }\end{array}$ \\
\hline- & Biorefinery & Sheridan, KS & 725,000 & Blend & 11,14 \\
\hline 11 & Depot & Sheridan, KS & 788,469 & $\begin{array}{c}\text { three-pass } \\
\text { corn stover }\end{array}$ & $1,4,5$ \\
\cline { 3 - 5 } & & & two-pass & $2,3,6,7$ \\
\cline { 3 - 5 } & & & & & \\
& & & &
\end{tabular}




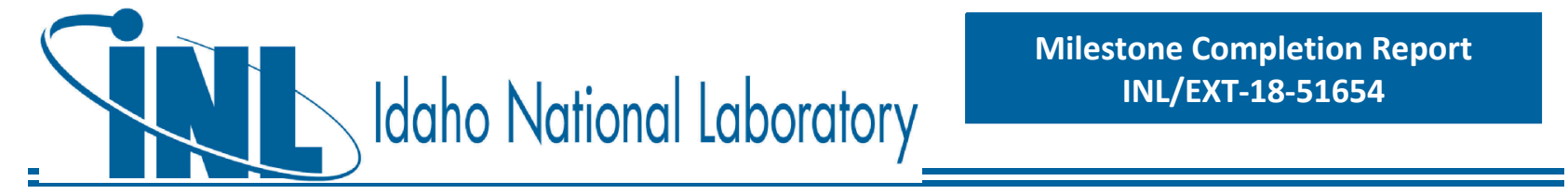

\begin{tabular}{|c|c|c|c|c|c|}
\hline & & & & \\
\hline & & & & switchgrass & $8,9,10,12,13$ \\
\hline 14 & Depot & Denver, CO & 11,531 & $\begin{array}{l}\text { grass } \\
\text { clippings }\end{array}$ & $\begin{array}{c}\text { Denver } \\
\text { metropolitan } \\
\text { area }\end{array}$ \\
\hline
\end{tabular}




\subsubsection{Exclusion of Grass Clippings from the Centralized Depot Case}

The exclusion of grass clippings from the centralized depot case utilizes identical assumptions when the primary depot is co-located with the biorefinery, except that grass clippings are excluded. The modeled least cost for each individual herbaceous feedstock supply systems and the blend composition are shown Table 14. The least-cost blend for this case consisted of $51.37 \%$ three-pass corn stover and $40.9 \%$ two-pass corn stover, and $7.73 \%$ switchgrass. Switchgrass was used in this case (as compared to the no grass clippings distributed case) because bales are being transported, and the switchgrass is closer to the co-located biorefinery than the two-pass corn stover sources. The optimized least-cost delivered cost increases from $\$ 83.67$ /dry ton to $\$ 84.63$ /dry ton if grass clippings are excluded from the blend, a $\$ 0.96 /$ dry ton increase relative to the SOT case, which amounts to $\$ 696,000$ in additional cost for feedstock supply to the biorefinery.

Table 14. Modeled cost and GHG estimates for an herbaceous feedstock supply system supplying 725,000 dry tons annually in northwestern Kansas, with a single depot co-located with the biorefinery (grass clippings are excluded). Grower payments are based on supply curves from BT16 (DOE 2016a) and costs are presented in \$/dry ton (2016\$). Design details are in Appendix A.

\begin{tabular}{|c|c|c|c|c|c|c|}
\hline \multirow[t]{2}{*}{ Cost Element } & \multicolumn{5}{|c|}{ Cost (\$/dry ton) } & \multirow{2}{*}{$\begin{array}{c}\text { GHG } \\
\text { Emissions } \\
\left(\mathrm{kg} \mathrm{CO}_{2} \mathrm{e} / \text { ton }\right)\end{array}$} \\
\hline & $\begin{array}{c}\text { Three- } \\
\text { Pass } \\
\text { Stover }\end{array}$ & $\begin{array}{c}\text { Two- } \\
\text { Pass } \\
\text { Stover }\end{array}$ & $\begin{array}{l}\text { Switch- } \\
\text { grass }\end{array}$ & $\begin{array}{l}\text { Grass } \\
\text { Clippings }\end{array}$ & $\begin{array}{c}\text { Least- } \\
\text { Cost } \\
\text { Blend }^{\mathrm{a}}\end{array}$ & \\
\hline Blend Ratio & $51.37 \%$ & $40.90 \%$ & $7.73 \%$ & - & $100 \%$ & - \\
\hline Grower payment & $\$ 26.66$ & $\$ 21.71$ & $\$ 38.87$ & - & $\$ 25.58$ & - \\
\hline $\begin{array}{l}\text { Harvest and } \\
\text { collection }\end{array}$ & $\$ 13.84$ & $\$ 18.79$ & $\$ 11.76$ & - & $\$ 15.71$ & 10.73 \\
\hline $\begin{array}{l}\text { Storage and } \\
\text { queuing }\end{array}$ & $\$ 6.40$ & $\$ 6.53$ & $\$ 5.89$ & - & $\$ 6.41$ & 2.65 \\
\hline $\begin{array}{l}\text { Transportation and } \\
\text { handling }\end{array}$ & $\$ 12.44$ & $\$ 14.51$ & $\$ 8.40$ & - & $\$ 12.98$ & 17.53 \\
\hline $\begin{array}{l}\text { In-plant receiving } \\
\text { and preprocessing }\end{array}$ & $\$ 22.14$ & $\$ 22.14$ & $\$ 21.55$ & - & $\$ 22.10$ & 36.79 \\
\hline Dockage & $\$ 2.74$ & $\$ 1.00$ & $\$ 0.56$ & - & $\$ 1.86$ & - \\
\hline Total & $\$ 84.23$ & $\$ 84.69$ & $\$ 87.03$ & - & $\$ 84.63$ & 67.70 \\
\hline
\end{tabular}




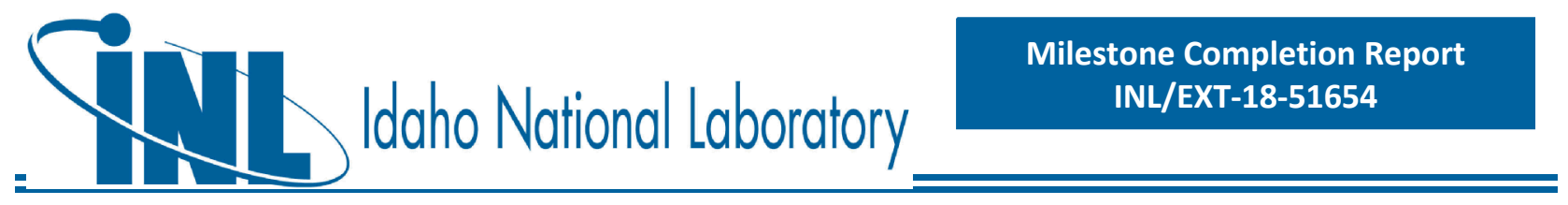

a Blend costs are presented as the weighted average of the blend component costs.

The amounts of harvested biomass (prior to storage) required to produce this blend are shown in Table 15, along with their compositions, and individual delivered costs. The depot locations, biomass source counties and biorefinery location are shown pictorially in Figure 8, and are listed in Table 16. The least cost supply chain network utilized a single co-located depot (Node 13 in Figure 8) when the biorefinery is located in Sheridan county, Kansas. The results also show that a biorefinery located in Sheridan County, Kansas with a design capacity of 725,000 dry tons/year, would need to procure at least 837,851 dry tons of biomass annually to account for losses in the system, an increase of 4,856 dry tons compared to the 2018 Herbaceous SOT.

Table 15. Procured biomass and composition of the blended feedstock in the least-cost blend if grass clippings are excluded from the blend based on low availability and distance from the biorefinery (single co-located depot).

\begin{tabular}{lccccc}
\hline \multicolumn{1}{c}{ Biomass Type } & $\begin{array}{c}\text { Raw } \\
\text { Biomass } \\
\text { Purchased } \\
\text { (dry tons) }\end{array}$ & $\begin{array}{c}\text { Pelleted } \\
\text { Blendstocks } \\
\text { Delivered } \\
\text { (dry tons) }\end{array}$ & $\begin{array}{c}\text { Total } \\
\text { Carbohydrates } \\
\text { (wt\% db) }\end{array}$ & $\begin{array}{c}\text { Ash } \\
\text { (wt\% db) }\end{array}$ & $\begin{array}{c}\text { Delivered } \\
\text { Cost } \\
\text { (\$/dry ton) }\end{array}$ \\
\hline Three-pass corn stover & 431,876 & 372,450 & $57.40 \%$ & $12.20 \%$ & $\$ 84.23$ \\
\hline Two-pass corn stover & 343,808 & 296,500 & $60.30 \%$ & $7.60 \%$ & $\$ 84.69$ \\
\hline Switchgrass & 62,167 & 56,050 & $66.60 \%$ & $6.40 \%$ & $\$ 87.03$ \\
\hline Grass clippings & - & - & - & - & - \\
\hline Totals & 837,851 & 725,000 & $59.30 \%$ & $9.87 \%$ & $\$ 84.63$ \\
\hline
\end{tabular}



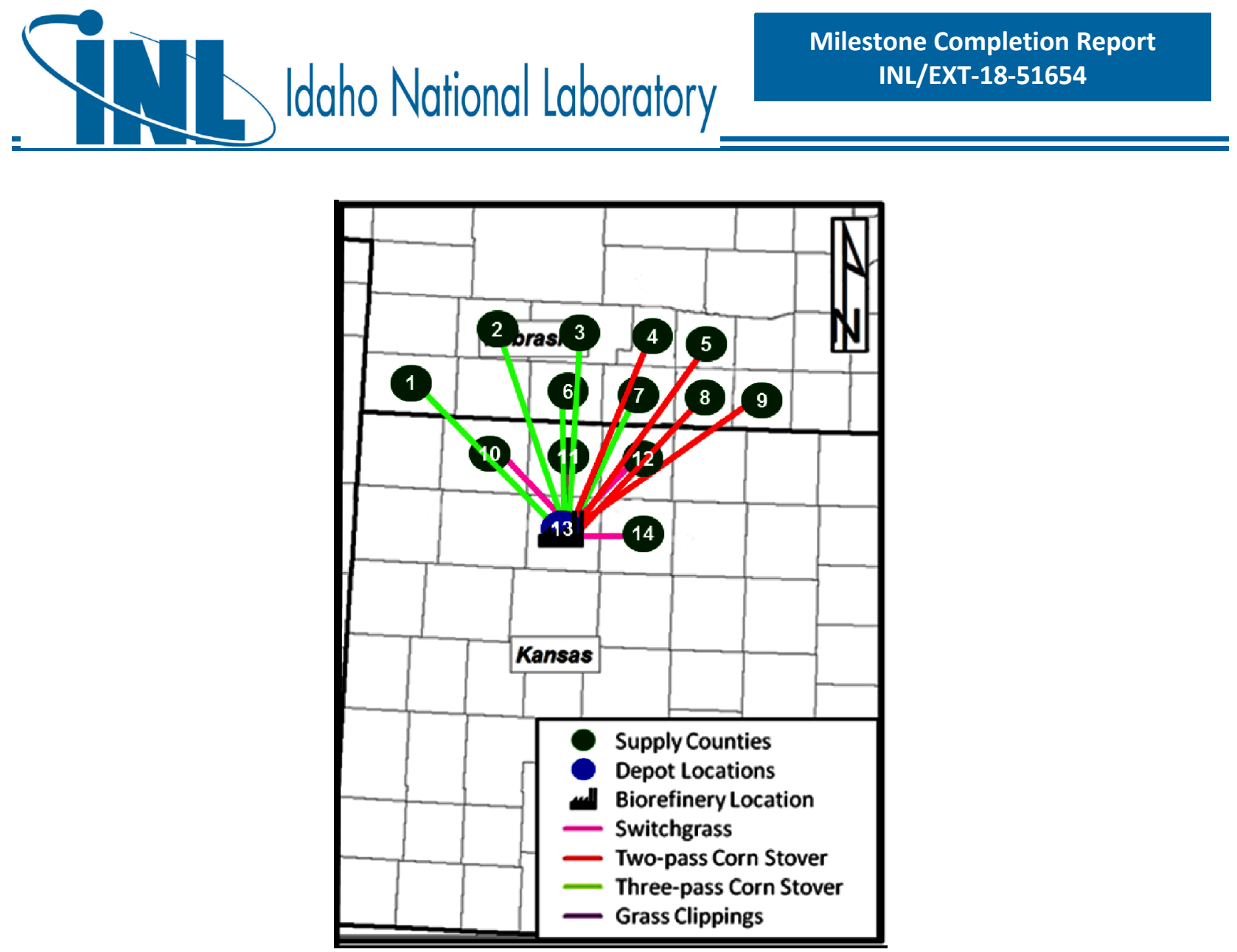

Figure 8. Supply chain network design for the centralized depot case with grass clippings excluded. The supply chain has a single centralized depot (Node 13) co-located with the biorefinery in Sheridan.

Table 16. Optimal locations of sourced biomass for a centralized depot adjacent to the biorefinery for least cost delivery of 725,000 dry tons/year of blended feedstock to the biorefinery Sheridan County, KS, with grass clippings excluded from the blend.

\begin{tabular}{cccccc}
\hline Node & Identifier & County & $\begin{array}{c}\text { Capacity } \\
(\text { dry tons/yr) }\end{array}$ & Biomass Type & $\begin{array}{c}\text { Biomass Source } \\
\text { Nodes }\end{array}$ \\
\hline- & Biorefinery & Sheridan, KS & 725,000 & Blend & 13 \\
\hline 13 & Depot & Sheridan, KS & 800,000 & $\begin{array}{c}\text { three-pass } \\
\text { corn stover }\end{array}$ & $1,2,3,6,7$ \\
\cline { 3 - 5 } & & & $\begin{array}{c}\text { two-pass } \\
\text { corn stover }\end{array}$ & $4,5,8,9$ \\
\cline { 3 - 5 } & & & switchgrass & $10,11,12,14$ \\
\hline
\end{tabular}




\subsection{Herbaceous Feedstock Cost Projection}

\subsubsection{Projected Technology Developments by Supply Chain Element}

The 2022 Projection for biochemical conversion establishes the pathway from the 2018 SOT to meet a projected delivered feedstock cost of $\$ 79.07 /$ dry ton $(2016 \$$ ) by defining technical targets that must be achieved to meet the goal. In this section, we outline assumptions and technical requirements throughout the supply chain. This includes biomass availability and the individual supply chain operations needed to achieve the $\$ 79.07 /$ dry ton cost target. The following sections briefly discuss updates that would occur to the 2018 SOT in order to achieve the $\$ 79.07 /$ dry ton cost target; detailed descriptions and assumptions used are described in Appendix E.

\subsubsection{Grower payment}

The 2022 Projection incorporates Integrated Landscape Management (ILM) within the least-cost blended feedstock optimization strategy to reduce biomass access cost. ILM introduces opportunities to further reduce the grower payment portion of biomass access costs, while maintaining or improving grower profitability. Grower payment is comprised of three elements: (1) an establishment cost, i.e., the basic labor, machinery, fertilizer and land costs to produce the biomass; (2) a nutrient replacement cost, i.e., the cost of replacing nutrients that are removed with the biomass (to maintain sustainable productivity of the soil); and (3) a profit for the producer, i.e., a monetary incentive to produce the biomass for sale to biorefineries. ILM considers subfield management strategies to reduce biomass production costs either through gains in operational efficiencies, or through improvement of field-level profitability by maximizing the profitability of both grain production and biomass production. Although seeming contradictory, this provides a mechanism to reduce overall grower payment while either maintaining or improving overall grower profitability. This is achieved by replacing grain crops in "traditionally" low grain-yielding (unprofitable) subfield areas with high biomass-yielding dedicated energy crops such as Panicum virgatum (switchgrass) and Miscanthus $\times$ giganteus (miscanthus) which require fewer nutrient inputs and are more efficient with regard to water requirements. In this way, the more expensive crop input costs are reallocated to lower biomass production costs. Additional improvements to grower profitability occur when crop residue is removed from the high grain-yielding areas, due to reduced tillage requirements for incorporating the residues into the soil. The 2022 Projection incorporates the ILM target of reducing biomass grower payment by at least $20 \%$ at the field level.

\subsubsection{Harvest and Collection}

The 2022 Projection incorporates improvements to two-pass harvesting using variable rate harvesting (Birrell et al, 2017). Variable rate harvesting typically utilizes a biomass-specific corn head such as the Straeter "Corn Rower." Because the Straeter header lays the lower stalk onto the ground prior to windrow formation, the material other than grain (MOG) is dropped onto this bed of biomass resulting in improved collection yield in addition to the decreased incorporation of soil into bales that is normally seen with twopass harvesting systems. The 2022 Projection incorporates a 35\% improvement in two-pass harvesting yield through the use of the Straeter header. There is also potential to reduce the actual amount of soil collection because soil-stover contact is reduced compared to other two-pass harvesting methods.

\subsubsection{Storage and Queuing}

The 2022 Projection also considers strategies for reducing dry matter losses and moisture during 
storage. The analysis projects a reduction of corn stover dry matter loss from $12 \%$ to $7 \%$ and switchgrass dry matter loss from $8 \%$ to $7 \%$ (these are WBS 1.2.1.1 technical targets). Dry matter losses are decreased by utilizing/storing corn stover harvested during different periods of the harvest with different methods that are tailored toward the moisture contents characteristic of the individual harvest periods (harvested moisture content generally decreases as the harvest season progresses). Scenarios and experimental data utilized included storage using fermentation and/or exhaust stack gases rich in $\mathrm{CO}_{2}$ to inhibit respiratory activity of indigenous microbes and fungi during storage of high-moisture bales on-site. The 2022 Projection also included the WBS 1.2.1.1 technical target to reduce corn stover mean bale moisture from $25 \%$ to $20 \%$ as a result of the utilization/storage management approach. This magnitude of reduction could potentially be achieved through the use of drying methods including passive ventilation in stacks oriented to use prevailing winds, active ventilation using low-power mechanical ventilation under ambient temperature and relative humidity conditions, and/or active ventilation using available exhaust gases available either on-site or at industrial operations such as power plants, incinerators, and/or pulp and paper plants adjacent to satellite storage facilities.

\subsubsection{Transportation and Handling}

The 2022 Projection incorporates both bale and pellet transportation. Baled biomass is shipped from field-side storage to the depots, while pelleted blendstocks are shipped from depots to the biorefinery. The analysis projects to improved transportation and handling efficiency through transportation of high density pellets and utilization of the MILP optimization model to minimize transportation distance by identifying optimal depot locations and sizes, and optimal biomass source locations.

\subsubsection{In-plant Receiving and Preprocessing}

One of the significant issues faced by preprocessing using a horizontal bale grinder in the 2018 SOT is uneven flow from the grinder. This was made especially clear during the Feedstock-Conversion Interface Consortium's (FCIC) low-temperature pathway corn stover preprocessing baselining runs during FY18, as the uneven flow from the first stage grinder led to many downstream failures of the screw conveyor exiting the second stage grinder. Uneven flow also makes it very difficult to achieve consistent particle size distributions over time. The 2022 Projection incorporates the use of a bale processor/debaler immediately upstream of the horizontal bale grinder used in the 2018 Herbaceous SOT, to break apart the bale and create a more even flow of biomass into the grinder and downstream equipment. This improvement thus has the potential to improve Stage-1 grinding throughput and reduce energy consumption. The preprocessing design assumptions in the 2018 Herbaceous SOT were revised based on this change as well as the projected reduction in entering moisture content (from utilization storage management improvements) to estimate preprocessing costs for the 2022 Projection.

\subsubsection{Dockage}

The 2022 Projection includes both ash and moisture dockages. An update to the MILP optimization model for the 2022 Projection was that ash and moisture dockages are now inputs to the least-cost blend optimization.

\subsubsection{Projection Cost Analysis}

Table 17 shows the detailed cost breakdown comprising the 2013, 2017 and 2018 SOTs together with the projected 2022 cost breakdown; the modeled SOT herbaceous feedstock supply cost progression is 


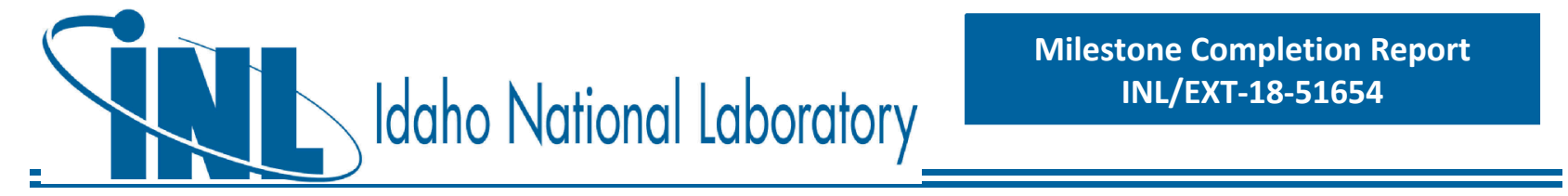

also shown in a waterfall chart in Figure 9. 


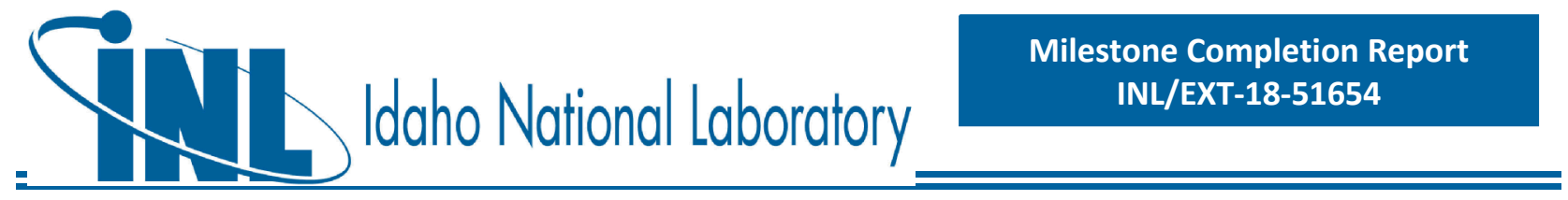

Table 17. Comparison of modeled costs (\$/Dry Ton) (2016\$) among the 2013 SOT, 2017 SOT, 2018 SOT, 2022 Projection, and 2030 Design Case projection.

\begin{tabular}{|c|c|c|c|c|c|}
\hline & \multicolumn{5}{|c|}{ Cost } \\
\hline & 2013 SOT & 2017 SOT & 2018 SOT & $\begin{array}{c}2022 \\
\text { Projection }\end{array}$ & $\begin{array}{c}2030 \\
\text { Projection }\end{array}$ \\
\hline Feedstock & $\begin{array}{l}\text { Corn } \\
\text { Stover }\end{array}$ & Blend & Blend & Blend & TBD \\
\hline Net delivered cost & $\$ 149.31$ & $\$ 83.90$ & $\$ 83.67$ & $\$ 79.07$ & $\$ 71.26$ \\
\hline Grower payment & $\$ 40.61$ & $\$ 23.24$ & $\$ 23.54$ & $\$ 22.37$ & TBD \\
\hline Harvest \& collection & $\$ 20.52$ & $\$ 16.91$ & $\$ 16.68$ & $\$ 12.79$ & TBD \\
\hline Harvesting & $\$ 17.00$ & $\$ 13.59$ & $\$ 13.37$ & $\$ 9.48$ & \\
\hline Collection & $\$ 3.52$ & $\$ 3.32$ & $\$ 3.31$ & $\$ 3.31$ & \\
\hline Storage \& queuing & $\$ 4.60$ & $\$ 6.54$ & $\$ 6.45$ & $\$ 8.35$ & \\
\hline $\begin{array}{l}\text { In-plant receiving and } \\
\text { Preprocessing }\end{array}$ & $\$ 46.60$ & $\$ 22.52$ & $\$ 22.49$ & $\$ 21.44$ & TBD \\
\hline Bale processor & - & - & - & $\$ 1.99$ & \\
\hline Grinder 1 & $\$ 17.95$ & $\$ 9.93$ & $\$ 9.85$ & $\$ 7.84$ & \\
\hline $\begin{array}{l}\text { Grinder 2/ rotary } \\
\text { shear }\end{array}$ & $\$ 12.39$ & $\$ 1.41$ & $\$ 1.40$ & $\$ 1.25$ & \\
\hline Drying & $\$ 16.25$ & $\$ 0.20$ & $\$ 0.22$ & $\$ 0.25$ & \\
\hline Densification & - & $\$ 6.36$ & $\$ 6.34$ & $\$ 6.42$ & \\
\hline $\begin{array}{l}\text { Blending and other } \\
\text { equipment }^{\text {b }}\end{array}$ & - & $\$ 1.64$ & $\$ 1.64$ & $\$ 1.36$ & \\
\hline $\begin{array}{l}\text { Depot construction } \\
\text { cost }\end{array}$ & - & $\$ 2.98$ & $\$ 3.04$ & $\$ 2.33$ & \\
\hline $\begin{array}{l}\text { Transportation \& } \\
\text { handling }\end{array}$ & $\$ 15.49$ & $\$ 13.43$ & $\$ 13.23$ & $\$ 12.43$ & TBD \\
\hline
\end{tabular}




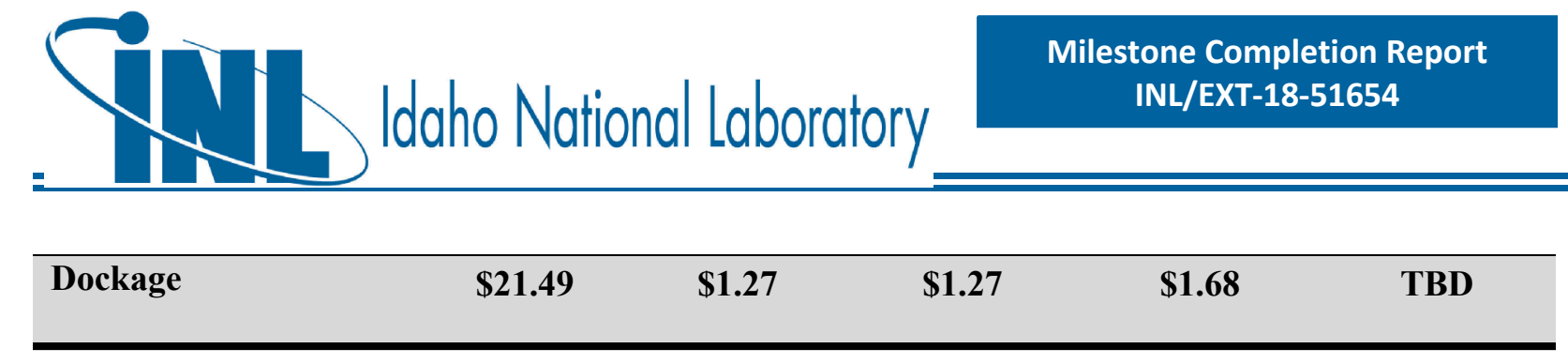

The modeled delivered feedstock cost for the 2022 Projection is $\$ 79.07$, a decrease of $\$ 4.60 /$ dry ton from the 2018 Herbaceous SOT. This reduction is attributed to projected technical advances in various areas (details of the technical targets are given in Appendix E). The reduction of $\$ 1.17 /$ dry ton in grower payment from the 2018 SOT is a result of increased availability of ILM-derived switchgrass in the supply shed, and to the optimal selection of biomass resource locations and depot sizes for the blend using the MILP least-cost blend optimization. The \$3.89/dry ton reduction in harvest and collection from 2018 SOT results from incorporation of variable rate two-pass harvesting. The $\$ 1.53 /$ dry ton increase in storage and queuing results from increased storage and handling activities to reduce dry matter loss and decrease moisture content exiting storage. The net $\$ 1.05 /$ dry ton reduction in preprocessing is a composite result of the use of the bale processor prior to feeding the first stage grinder (to improve first stage grinding throughput and energy consumption), the improvement of throughput and energy consumption for high moisture pelleting due to lower moisture biomass resulting from storage improvements, and the elimination of the pellet cooler following high moisture densification (also a benefit derived from lower

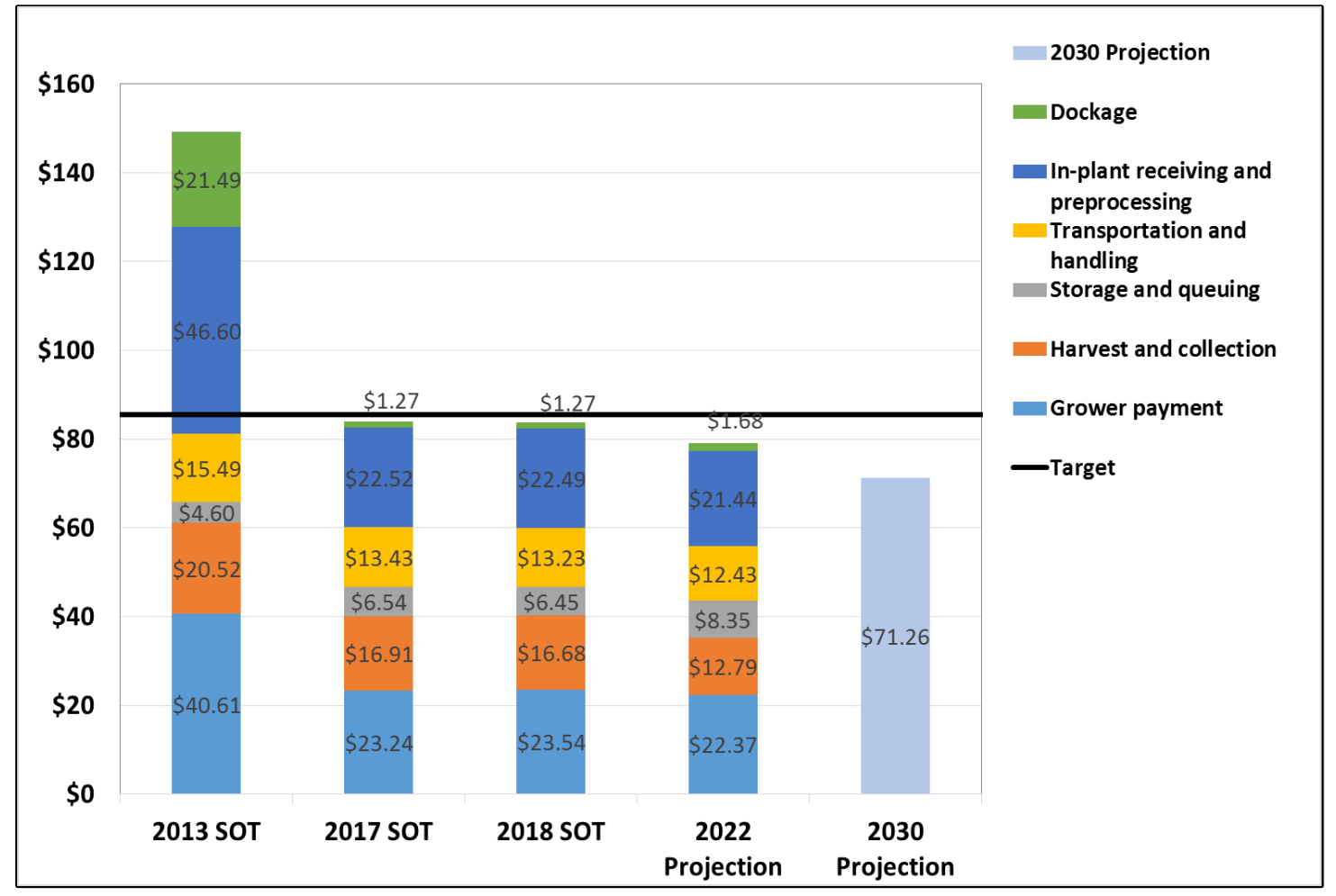

Figure 9: Waterfall chart showing the modeled SOT herbaceous feedstock supply cost progression for 2013, 2017, 2018 and the delivered feedstock cost target for 2022 and 2030

moisture content exiting storage). The $\$ 0.80 /$ dry ton reduction in transportation and handling costs resulted from a reduction in bale transportation distance due to the utilization of additional switchgrass available from ILM, the use of distributed depots, and the lower cost transportation of pellets from the depots to the biorefinery. An increase of $\$ 0.41 /$ dry ton in dockage is attributed to the increased amount of 


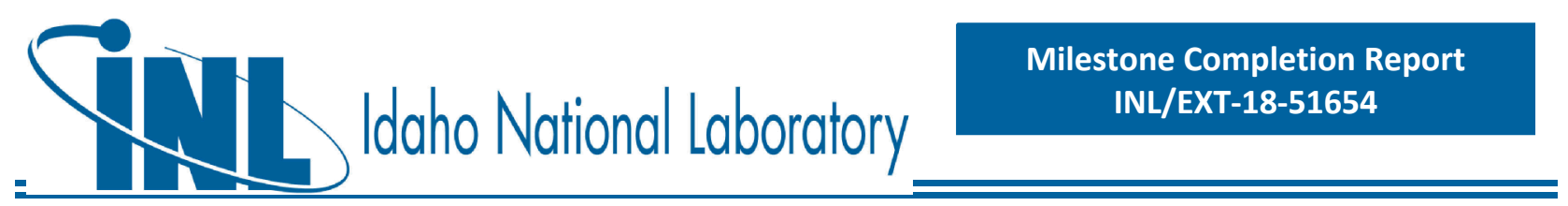

higher ash biomass in the blend (three-pass corn stover and grass clippings); this increase was a direct result of including the trade-off of dockage applied for not meeting quality and the use of lower cost (but lower quality) biomass sources in the MILP least-cost optimization model.

The least-cost blend in the 2022 Projection is comprised of $49.95 \%$ three-pass corn stover, $12.23 \%$ two-pass stover, $33.03 \%$ switchgrass, and $4.79 \%$ grass clippings. The increased availability of switchgrass from the inclusion of ILM-derived switchgrass for the 2022 Projection led to an increased amount of switchgrass in the projected 2022 blend compared to the 2018 SOT blend. The projected quantities of harvested biomass (prior to storage) required to produce this blend are shown in Table 18, along with their delivered blendstock quantities, compositions, individual delivered costs and GHG emissions. The results show that a biorefinery located in Sheridan County, Kansas with a design capacity of 725,000 dry tons/year, would need to procure at least 832,995 dry tons of biomass annually to account for losses in the system. Depot locations, biomass source counties and biorefinery location are shown in Figure 10, and are listed in Table 19. The least cost supply chain network utilized three distributed depots (Nodes 7, 17, 23 in Figure 10) with the biorefinery located in Sheridan County, Kansas. 


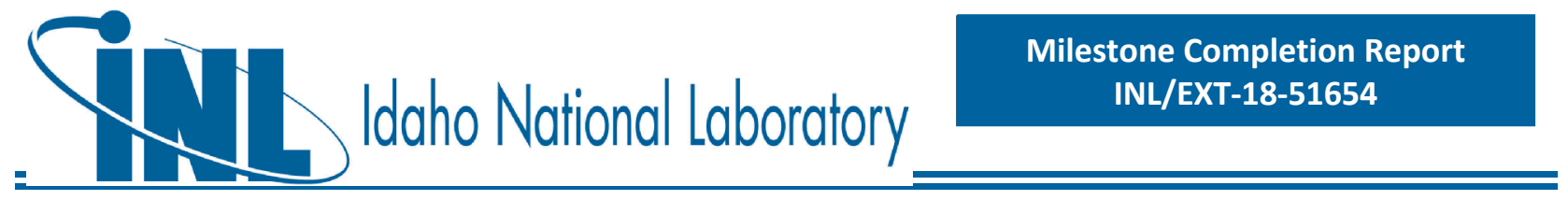

Table 18. Projected delivered (reactor-throat) costs and compositions of the herbaceous biomass sources, the preprocessed blendstocks produced from these biomass sources, and the least-cost blend for the 2022 Design Case.

\begin{tabular}{|c|c|c|c|c|c|c|}
\hline \multirow[t]{2}{*}{ Biomass Type } & \multirow{2}{*}{$\begin{array}{c}\text { Raw } \\
\text { Biomass } \\
\text { Purchased } \\
\text { (dry tons) }\end{array}$} & \multirow{2}{*}{$\begin{array}{c}\text { Pelleted } \\
\text { Blendstocks } \\
\text { Produced } \\
\text { (dry tons) }\end{array}$} & \multicolumn{3}{|c|}{ Pelleted Blendstocks } & \multirow[b]{2}{*}{$\begin{array}{c}\text { GHG } \\
\text { Emissions }\end{array}$} \\
\hline & & & $\begin{array}{c}\text { Total } \\
\text { Carbohydrates } \\
(\mathbf{w t} \% \mathrm{db})\end{array}$ & $\begin{array}{c}\text { Ash } \\
\text { (wt\% db) }\end{array}$ & $\begin{array}{l}\text { Delivered Cost } \\
\text { (\$/dry ton) }\end{array}$ & \\
\hline $\begin{array}{l}\text { Three-pass } \\
\text { corn stover }\end{array}$ & 397,366 & 362,159 & $56.90 \%$ & $11.60 \%$ & $\$ 78.58$ & $\left(\mathrm{~kg} 6.53^{2 / \mathrm{dt})}\right.$ \\
\hline $\begin{array}{l}\text { Two-pass } \\
\text { corn stover }\end{array}$ & 97,284 & 88,665 & $59.60 \%$ & $7.20 \%$ & $\$ 81.63$ & 67.78 \\
\hline Switchgrass & 262,766 & 239,485 & $66.40 \%$ & $6.30 \%$ & $\$ 81.73$ & 66.36 \\
\hline $\begin{array}{l}\text { Grass } \\
\text { clippings }\end{array}$ & 35,581 & 34,692 & $28.70 \%$ & $13.10 \%$ & $\$ 59.20$ & 57.76 \\
\hline Totals & 792,997 & 725,000 & $59.02 \%$ & $9.38 \%$ & $\$ 79.07$ & 66.21 \\
\hline
\end{tabular}

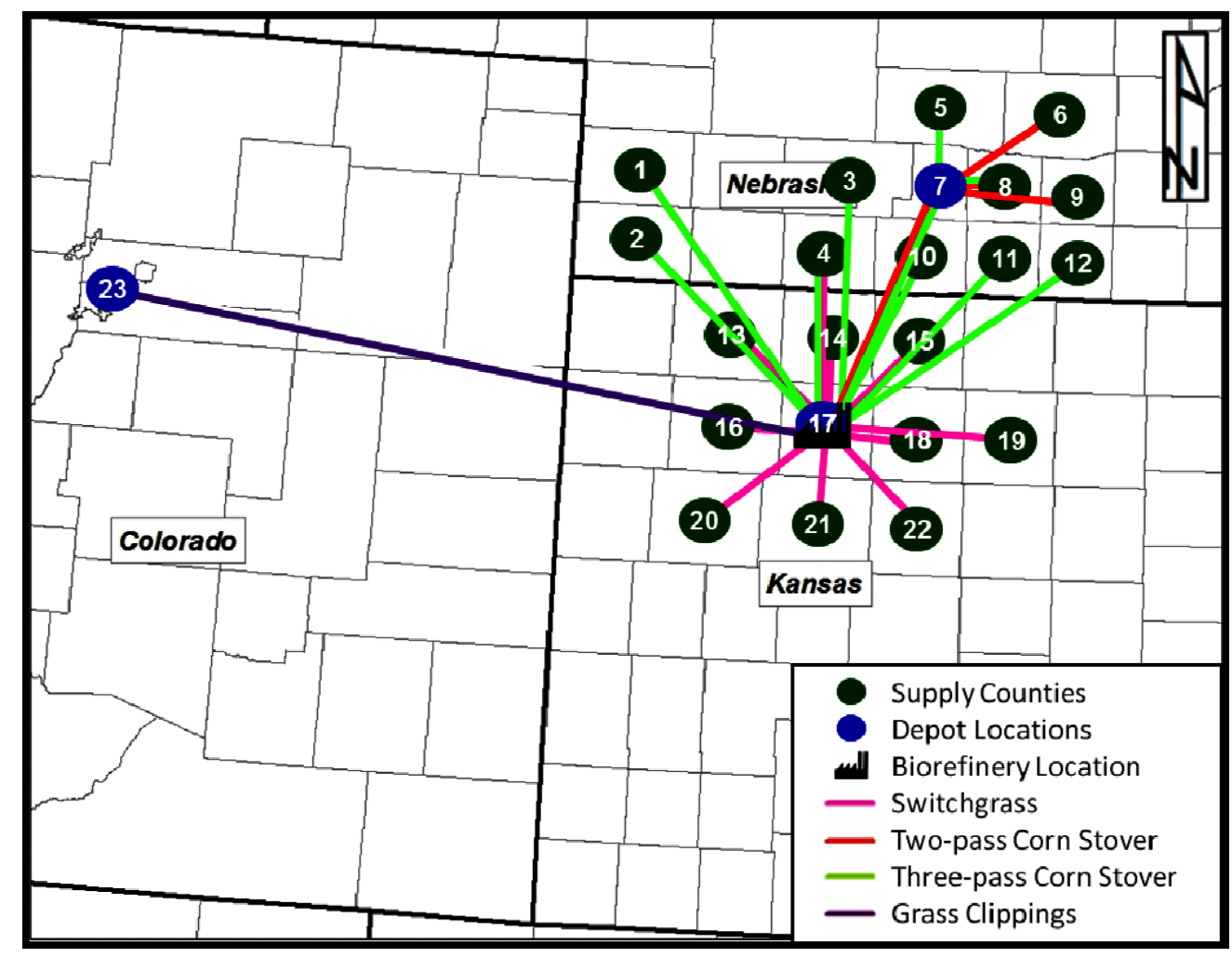

Figure 10. Supply chain network design for the 2022 Herbaceous Design Case Projection. The supply chain has 3 distributed depots (Nodes $=7,17,23$ ) with the biorefinery located in Sheridan County, Kansas. Three-pass corn stover is sourced from Nodes 1, 2, 3, 4, 5, 7, 8, 10, 11, 12 and 17, two-pass corn stover from Nodes 6, 7, 8 and 9, and switchgrass from Nodes 4, 13, 14, 15, 


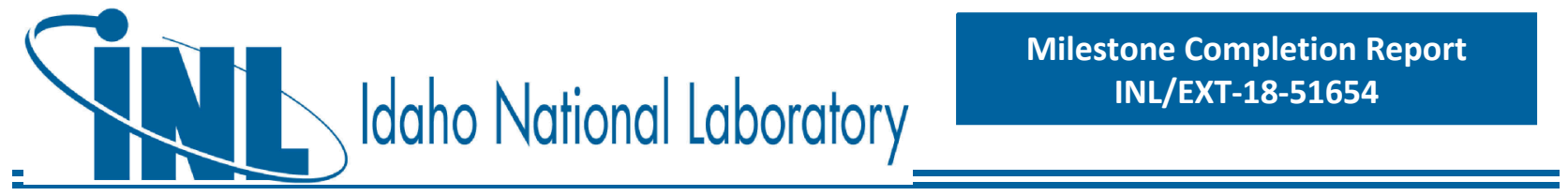

16, 17, 18, 19, 20, 21 and 22, and grass clippings from Node 23. 
Table 19. Optimal locations and sizes of distributed depots for least cost delivery of 725,000 dry tons/year of blended feedstock to Sheridan County, KS for the 2022 Herbaceous Feedstock Projection.

\begin{tabular}{|c|c|c|c|c|c|}
\hline Node & Identifier & County & $\begin{array}{c}\text { Capacity } \\
\text { (dry tons/yr) }\end{array}$ & Biomass Type & $\begin{array}{c}\text { Biomass Source } \\
\text { Nodes } \\
\end{array}$ \\
\hline- & Biorefinery & Sheridan, KS & 725,000 & Blend & $7,17,23$ \\
\hline \multirow[t]{2}{*}{17} & \multirow[t]{2}{*}{ Depot } & \multirow[t]{2}{*}{ Sheridan, KS } & \multirow[t]{2}{*}{425,000} & Switchgrass & $\begin{array}{c}4,13,14,15 \\
16,17,18,19 \\
20,21,22\end{array}$ \\
\hline & & & & $\begin{array}{l}\text { three-pass } \\
\text { corn stover }\end{array}$ & $\begin{array}{c}1,2,3,4,10 \\
11,12,17\end{array}$ \\
\hline \multirow[t]{2}{*}{7} & \multirow[t]{2}{*}{ Depot } & \multirow[t]{2}{*}{ Gosper, NE } & \multirow[t]{2}{*}{325,000} & $\begin{array}{l}\text { two-pass } \\
\text { corn stover }\end{array}$ & $6,7,8,9$ \\
\hline & & & & $\begin{array}{l}\text { three-pass } \\
\text { corn stover }\end{array}$ & $5,7,8$ \\
\hline 23 & Depot & Denver, CO & 36,000 & $\begin{array}{l}\text { grass } \\
\text { clippings }\end{array}$ & $\begin{array}{c}\text { Denver } \\
\text { metropolitan } \\
\text { area }\end{array}$ \\
\hline
\end{tabular}

\subsubsection{Sensitivity Analysis of the $\mathbf{2 0 2 2}$ Projection}

Sensitivity analysis was performed to determine the impact of uncertainty in values for key operational parameters on the delivered cost on the static $n^{\text {th }}$-plant design presented as the 2022 Projection. Critical process parameters that affect delivered feedstock were investigated to determine the impact of uncertainty in their values on the delivered feedstock cost. Newly added process parameters in the 2022 Projection include bale processor throughput and energy consumption. The parameters varied in the sensitivity analysis are shown in Table 20.

Figure 11 shows the results of the sensitivity analysis; delivered cost was found to vary from $\$ 77.27$ $\$ 81.94$ dry ton. The factors impacting delivered cost the most included the interest rate, hammer mill throughput, baling rate, bale density, and storage dry matter loss. Based on the observed variation, further improvement of hammer mill throughput to its maximum value would reduce the delivered feedstock by $\$ 1.12$ dry ton, whereas reducing hammer mill throughput to its minimum would increase the delivered feedstock by $\$ 2.12$ /dry ton. Uncertainties in baling rate and bale density led to ranges of $-\$ 0.32 /$ dry ton to $+\$ 2.87 /$ dry ton, and $-\$ 0.90 /$ dry ton to $+\$ 1.17 /$ dry ton, respectively. Additional parameters that had measurable effects on the uncertainty in delivered feedstock price included bale processor throughput, hammer mill energy consumption, pelleting throughput, and percentage of bypassed material during fractional milling. 


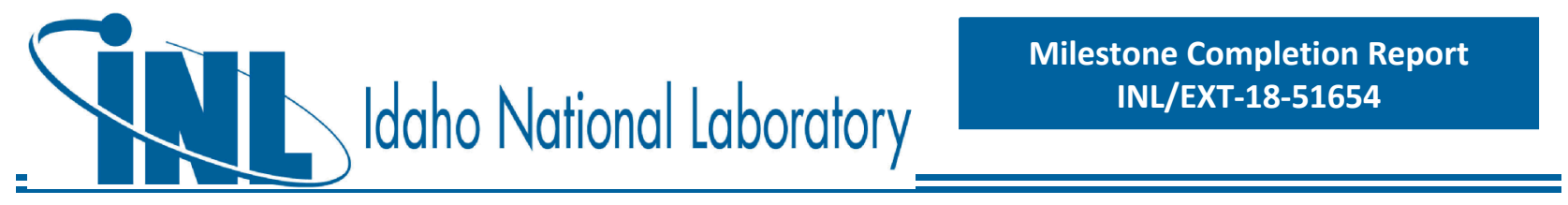

Table 20. Model parameters varied for the sensitivity analysis. Each parameter was varied independently according to percentage changes used for the base case observed in the 2018 Herbaceous SOT.

\begin{tabular}{|c|c|c|c|c|c|}
\hline Parameter & Units & Biomass Type & Minimum & $\begin{array}{c}\text { Average } \\
\text { (Projection) }\end{array}$ & Maximum \\
\hline \multirow{4}{*}{$\begin{array}{l}\text { Effective } \\
\text { windrowing rate }\end{array}$} & \multirow[t]{4}{*}{ acres $/ \mathrm{hr}$} & Three-pass corn stover & 10.78 & 11.50 & 12.51 \\
\hline & & Two-pass corn stover & n.a. & n.a. & n.a. \\
\hline & & Switchgrass & 8.25 & 8.8 & 9.57 \\
\hline & & Grass clippings & n.a. & n.a. & n.a. \\
\hline \multirow{4}{*}{$\begin{array}{l}\text { Effective baling } \\
\text { rate }\end{array}$} & \multirow[t]{4}{*}{ dry ton $/ \mathrm{hr}$} & Three-pass corn stover & 16.14 & 26.18 & 28.10 \\
\hline & & Two-pass corn stover & 11.70 & 19.00 & 28.10 \\
\hline & & Switchgrass & 24.04 & 27.36 & 28.10 \\
\hline & & Grass clippings & n.a. & n.a. & n.a. \\
\hline \multirow{4}{*}{$\begin{array}{l}\text { Field side storage } \\
\text { dry matter loss }\end{array}$} & \multirow[t]{4}{*}{$\%$} & Three-pass corn stover & $5 \%$ & $7 \%$ & $12 \%$ \\
\hline & & Two-pass corn stover & $5 \%$ & $7 \%$ & $12 \%$ \\
\hline & & Switchgrass & $4 \%$ & $7 \%$ & $12 \%$ \\
\hline & & Grass clippings & n.a. & n.a. & n.a. \\
\hline \multirow{4}{*}{$\begin{array}{l}\text { Bale transport } \\
\text { loading/unloading } \\
\text { time }\end{array}$} & \multirow[t]{4}{*}{ minutes } & Three-pass corn stover & 39 & 42 & 45 \\
\hline & & Two-pass corn stover & 39 & 42 & 45 \\
\hline & & Switchgrass & 39 & 42 & 45 \\
\hline & & Grass clippings & 39 & 42 & 45 \\
\hline \multirow[t]{4}{*}{ Bale density } & \multirow[t]{4}{*}{$\mathrm{lb} / \mathrm{ft}^{3}$} & Three-pass corn stover & 11 & 12 & 13 \\
\hline & & Two-pass corn stover & 11 & 12 & 13 \\
\hline & & Switchgrass & 9 & 12 & 13 \\
\hline & & Grass clippings & n.a. & n.a. & n.a. \\
\hline
\end{tabular}




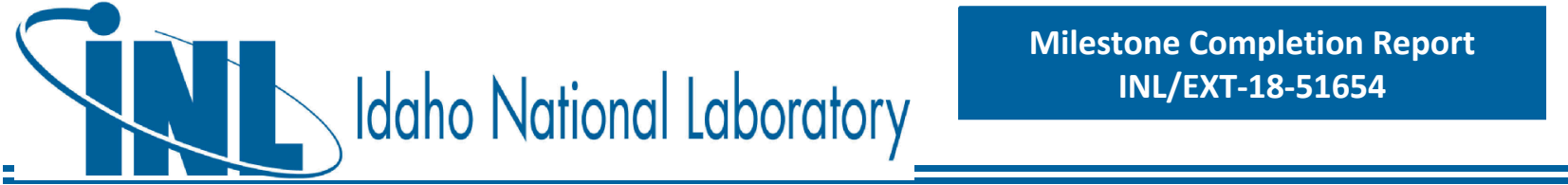

Table 20. (continued)

\begin{tabular}{|c|c|c|c|c|c|}
\hline Parameter & Units & Biomass Type & Minimum & $\begin{array}{c}\text { Average } \\
\text { (Projection) }\end{array}$ & Maximum \\
\hline \multirow{4}{*}{$\begin{array}{l}\text { Hammer mill } \\
\text { throughput }^{\mathrm{f}} \\
\text { (Shredder for } \\
\text { Grass clippings) }\end{array}$} & \multirow{4}{*}{$\begin{array}{l}\text { dry tons } / \mathrm{hr} / \\
\text { machine }\end{array}$} & Three-pass corn stover & 2.93 & 4 & 4.47 \\
\hline & & Two-pass corn stover & 2.93 & 4 & 4.47 \\
\hline & & Switchgrass & 4.37 & 5 & 5.56 \\
\hline & & Grass clippings & 4.63 & 5.50 & 6.12 \\
\hline \multirow{4}{*}{$\begin{array}{l}\text { Hammer mill } \\
\text { energy } \\
\text { consumption } \\
\text { (Shredder for } \\
\text { Grass clippings) }\end{array}$} & \multirow[t]{4}{*}{$\mathrm{kWh} /$ dry ton } & Three-pass corn stover & 5.77 & 9.00 & 11.17 \\
\hline & & Two-pass corn stover & 5.77 & 9.00 & 11.17 \\
\hline & & Switchgrass & 11.81 & 14.00 & 18.65 \\
\hline & & Grass clippings & 3.31 & 3.92 & 5.22 \\
\hline \multirow{4}{*}{$\begin{array}{l}\text { Rotary shear } \\
\text { throughput }\end{array}$} & \multirow{4}{*}{$\begin{array}{c}\text { dry } \\
\text { tons/hr/machine }\end{array}$} & Three-pass corn stover & 11.95 & 12.58 & 13.21 \\
\hline & & Two-pass corn stover & 11.95 & 12.58 & 13.21 \\
\hline & & Switchgrass & 12.95 & 13.63 & 14.31 \\
\hline & & Grass clippings & n.a. & n.a. & n.a. \\
\hline \multirow{4}{*}{$\begin{array}{l}\text { Rotary shear } \\
\text { energy } \\
\text { consumption }\end{array}$} & \multirow[t]{4}{*}{$\mathrm{kWh} /$ dry ton } & Three-pass corn stover & 8.26 & 8.69 & 9.12 \\
\hline & & Two-pass corn stover & 8.26 & 8.69 & 9.12 \\
\hline & & Switchgrass & 1.43 & 1.50 & 1.58 \\
\hline & & Grass clippings & n.a. & n.a. & n.a. \\
\hline \multirow{5}{*}{$\begin{array}{l}\text { Pelleting } \\
\text { throughput }\end{array}$} & \multirow{5}{*}{$\begin{array}{c}\text { dry } \\
\text { tons/hr/machine }\end{array}$} & Three-pass corn stover & 3.57 & 3.72 & 3.86 \\
\hline & & Two-pass corn stover & 3.57 & 3.72 & 3.86 \\
\hline & & Switchgrass & 3.32 & 3.50 & 3.63 \\
\hline & & Grass clippings & 3.80 & 4.00 & 4.15 \\
\hline & & Grass clippings & 78.8 & 82.0 & 84.2 \\
\hline
\end{tabular}




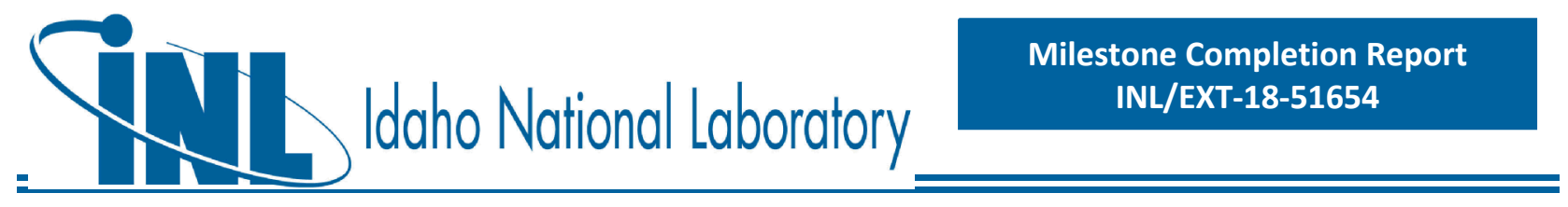

Table 20. (continued)

\begin{tabular}{|c|c|c|c|c|c|}
\hline Parameter & Units & Biomass Type & Minimum & $\begin{array}{c}\text { Average } \\
\text { (Projection) }\end{array}$ & Maximum \\
\hline \multirow{3}{*}{$\begin{array}{l}\text { Pelleting energy } \\
\text { consumption }\end{array}$} & \multirow[t]{3}{*}{$\mathrm{kWh} / \mathrm{dry}$ ton } & Three-pass corn stover & 31.36 & 32.62 & 33.48 \\
\hline & & Two-pass corn stover & 31.36 & 32.62 & 33.48 \\
\hline & & Switchgrass & 57.90 & 60.20 & 61.80 \\
\hline \multirow{4}{*}{$\begin{array}{l}\text { By pass during } \\
\text { fractional milling }\end{array}$} & \multirow[t]{4}{*}{$\%$} & Three-pass corn stover & $35.01 \%$ & $40.39 \%$ & $44.00 \%$ \\
\hline & & Two-pass corn stover & $35.01 \%$ & $40.39 \%$ & $44.00 \%$ \\
\hline & & Switchgrass & $38.50 \%$ & $44.98 \%$ & $46.00 \%$ \\
\hline & & Grass clippings & n.a. & n.a. & n.a. \\
\hline \multirow[t]{4}{*}{ Interest rate } & \multirow[t]{4}{*}{$\%$} & Three-pass corn stover & 4.0 & 8.0 & 12.0 \\
\hline & & Two-pass corn stover & 4.0 & 8.0 & 12.0 \\
\hline & & Switchgrass & 4.0 & 8.0 & 12.0 \\
\hline & & Grass clippings & 4.0 & 8.0 & 12.0 \\
\hline \multirow{4}{*}{$\begin{array}{l}\text { Bale processor } \\
\text { throughput }^{\text {a }}\end{array}$} & \multirow[t]{4}{*}{ tons/hr } & Three-pass corn stover & 4 & 5 & 6 \\
\hline & & Two-pass corn stover & 4 & 5 & 6 \\
\hline & & Switchgrass & 4 & 5 & 6 \\
\hline & & Grass clippings & n.a. & n.a. & n.a. \\
\hline \multirow{4}{*}{$\begin{array}{l}\text { Bale processor } \\
\text { energy } \\
\text { consumption }\end{array}$} & \multirow[t]{4}{*}{ hp } & Three-pass corn stover & 60 & 75 & 90 \\
\hline & & Two-pass corn stover & 60 & 75 & 90 \\
\hline & & Switchgrass & 60 & 75 & 90 \\
\hline & & Grass clippings & n.a. & n.a. & n.a. \\
\hline
\end{tabular}

a For the bale processor only, minimum and maximum for sensitivity analysis assumed at $\pm 20 \%$ variation. 

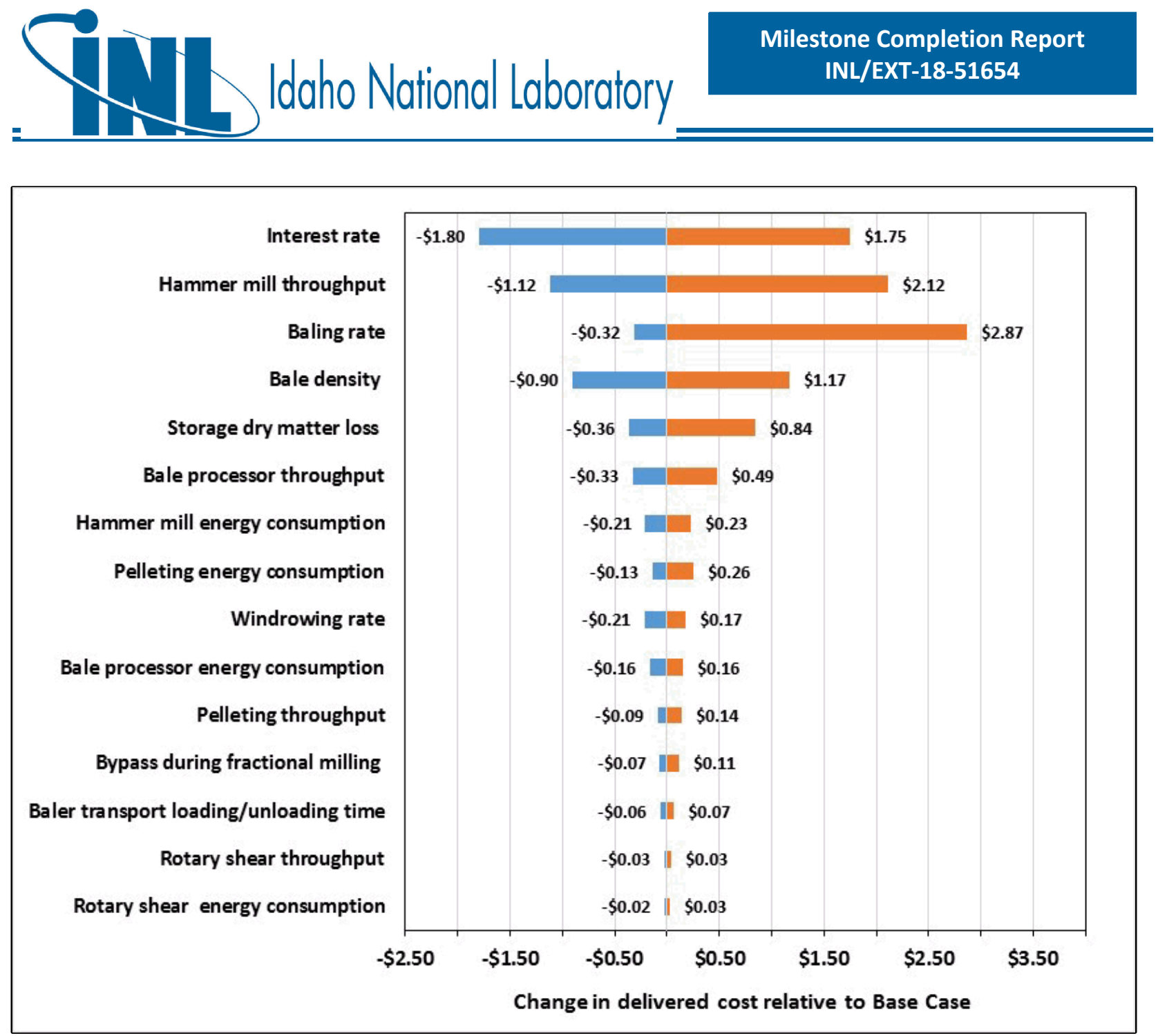

Figure 11. Tornado chart showing sensitivity of cost to operational parameters used to model the 2022 Design Case. 


\section{INDUSTRIAL RELEVANCE OF THE BLENDSTOCKS}

The availability of a biomass resource is not static, nor does it have a single definition. For the purposes of this report, availability is defined as the quantity of biomass materials that can be mobilized into the supply chain at a price that meets current cost targets. More specifically, resource availability assumed in this report is the quantity of two-pass and three-pass corn stover that can be purchased at average grower payments of $\$ 21.71$ dry ton and $\$ 26.66 /$ dry ton, respectively; the quantity of switchgrass with a grower payment of $\$ 38.87 /$ dry ton, and the quantity of grass clippings that can be purchased with a grower payment of $\$ 10.13 /$ dry ton. The current availability of the blendstocks has been primarily determined through use of the 2016 Billion Ton Report. While BT16 primarily presents projections of how the market will develop based on sustained investment and technology improvement, the 2016 estimates in BT16 represented the currently economically available resources in the calendar year 2016. In 2016 it was estimated that there were 114,072,663 dry tons of corn stover available nationally, with 1,095,021 dry tons of corn stover within 100 miles of the study area. Although the BT16 report (DOE 2016a) does not project any switchgrass to be available until 2019, this report also indicated that as many as 20,000 acres have been planted since 2011 (DOE 2016a). However, the current crop availability for the study region is not known; thus, for the purpose of the analysis in this SOT, we used the 2019 switchgrass projection of 358,714 dry/tons within 100 miles of the study area. The quantity of available grass clippings available nationally is estimated at 3,008,250 dry tons nationally and the estimated current availability for the Denver, CO metropolitan area from EPA data on per capita MSW generation data and the percentage of grass clippings in the MSW (Environmental Protection Agency 2015), together with U.S. Census data for the Denver metropolitan area (Appendix A). The region of interest for the 2018 herbaceous SOT remains the same as the 2015, 2016, and 2017 SOTs, with the assumed biorefinery location in Sheridan County, KS. Northwest Kansas was chosen to demonstrate the barriers and cost of operating outside the niche, high-yield areas, which are more representative of yield conditions encountered when operating a national-scale bioenergy industry. However, the feedstock properties that are important to the conversion process, (i.e. ash, moisture, and carbohydrate content) were conservatively assumed to maintain applicability of the supply chain operations at a national scale.

\section{QUALIFICATION OF THE BLENDSTOCKS FOR RENEWABLE IDENTIFICATION NUMBERS}

The Environmental Protection Agency revised the National Renewable Fuel Standard Program to implement the requirements of the Energy Security and Independence Act of 2007 (EISA), in 2010. The revision of the program became known as RFS2, and mandated the use of 36 billion gallons of renewable fuel by 2022. As part of the revised rules, definitions of qualified biofuel feedstocks were outlined; the revised rules stipulated that "renewable fuels" had to be made from materials that qualify as renewable biomass. To be considered renewable biomass the materials must conform to the specified types and land types from where they are harvested as directed by EISA. From the final rule published in Vol 75, No. 58 of the Federal Register on page 14681. 
"The definition includes:

- Planted crops and crop residue from agricultural land cleared prior to December 19, 2007 and actively managed or fallow on that date.

- $\quad$ Planted trees and tree residue from tree plantations cleared prior to December 19 , 2007 and actively managed on that date.

- Animal waste material and byproducts.

- Slash and pre-commercial thinnings from non-federal forestlands that are neither oldgrowth nor listed as critically imperiled or rare by a State Natural Heritage program.

- Biomass cleared from the vicinity of buildings and other areas at risk of wildfire.

- Algae.

- Separated yard waste and food waste."

Biochemical conversion focuses primarily on herbaceous materials. Specifically the qualification must be examined for the three potential feedstock sources that were considered: corn stover, switchgrass and grass clippings.

Both corn stover and switchgrass qualify as a renewable material under Section II.B.4.a.i on page 14691. This section states that “... planted crops and crop residue harvested from agricultural land cleared or cultivated at any time prior to December 19,2007, that is either actively managed or fallow, and nonforested." This section goes on to further define both planted crops and crop residue. The definition of planted crops is the following:

"All annual or perennial agricultural crops from existing agricultural land that may be used as feedstock for renewable fuel, such as grains, oilseeds, and sugarcane, as well as energy crops, such as switchgrass, prairie grass, duckweed and other species (but not including algae species or planted trees), providing that they were intentionally applied by humans to the ground, a growth medium, or a pond or tank, either by direct application as seed or plant, or through intentional natural seeding or vegetative propagation by mature plants introduced or left undisturbed for that purpose."

While crop residue is defined as the following:

"The biomass left over from the harvesting or processing of planted crops from existing agricultural land and any biomass removed from existing agricultural land that facilitates crop management (including biomass removed from such lands in relation to invasive species control or fire management), whether or not the biomass includes any portion of a crop or crop plant."

In addition to the definitions of planted crops and crop residue, the qualification as a renewable material stipulates that the biomass must be harvested from "existing agricultural land", which is limited to three land types: cropland, pastureland and Conservation Reserve Program land.

Cropland is defined for the purposes of EISA and RFS2 as, "land used for the production of crops for 
harvest, including cultivated cropland for row crops or close-grown crops and non-cultivated cropland for horticultural crops". While pastureland is defined as, "land managed primarily for the production of indigenous or introduced forage plants for livestock grazing or hay production, and to prevent succession to other plant types." Another caveat for the qualification of agricultural land is that the land must have been cleared or cultivated prior to December 19, 2007 and actively managed or fallow and non-forested since December 19, 2007. Under normal conditions, both corn stover and switchgrass will meet the conditions necessary to be deemed a renewable material and qualify for RINS.

Grass clippings are a form of separated yard waste and were grandfathered into the RFS2 material qualification. The grandfathering provisions are highlighted in Section I.A.6 on page 14682. In the provision it states, the new renewable biomass definition in EISA modified the ability for MSW-derived fuels to qualify under the RFS program by restricting it to "separated yard waste or food waste". To qualify as a separated waste, the materials must contain no more than the presence of incidental, de minimus contaminants, which are unintentionally included and impractical to separate. In our analysis, the grass clippings are collected separately from other waste streams and as such meet the qualifying characteristics.

Ultimately, the qualification of biomass as renewable is subject to verification that the feedstocks meet the requirements specified by EISA. Currently, there are three mechanisms that provide this verification. First, the individual fuel production facilities can perform their own recordkeeping and reporting. Second, renewable fuel producers can form a consortium that funds third-party audit of quality assurance, based on an EPA approved plan. The final method only is only available to producers sourcing their biomass entirely from within the United States. This method uses an aggregate compliance approach using USDA publicly available data about agricultural land to form the basis of determination on feedstock renewability. In the case of non-agricultural products, producers must obtain sufficient documentation from their suppliers to prove compliance with EISA definitions.

\section{SUMMARY}

The Terrestrial Feedstock Supply and Logistics platform within BETO focuses on (1) reducing the delivered cost of sustainably produced biomass; (2) preserving and improving the physical and chemical quality parameters of harvested biomass to meet the individual needs of biorefineries and other biomass users; and (3) expanding the quantity of feedstock materials accessible to the bioenergy industry. To support BETO and its bioenergy production goals, INL completes annual SOT reports for herbaceous and woody biomass feedstock logistics. This report provides the status of technology development of feedstock logistics for herbaceous biomass to biofuels, experiment-based results and data, and provides a relative comparison to technical targets and costs goals from design cases.

Although CFSS form the backbone of the emerging biofuels industry, they have limitations that restrict widespread implementation on a national scale. To meet the demands of the future industry, the feedstock supply system must shift from the conventional system to what has been termed "advanced" supply systems. In advanced designs, a distributed network of aggregation and processing centers, termed "depots," are employed near the point of biomass production (i.e., the field or forest) to reduce feedstock variability and produce feedstocks of a uniform format, moving toward biomass commoditization. The 2018 Herbaceous SOT is part of a longer-term vision of achieving an implemented advanced feedstock supply system, which produces a stable, tradable commodity at the decentralized distributed depot. 
During 2018, the BETO Conversion Platform redefined the time on-stream for their process models to $90 \%$. The 2018 Herbaceous SOT aligns with this change, which reduces the amount of feedstock required to be delivered to the reactor throat from 800,000 dry tons to 725,000 dry tons annually. Biomass availabilities in this SOT were updated to year 2018 data from the 2016 Billion-Ton Report (BT16) (DOE 2016a), with the exception of switchgrass, for which the 2018 Herbaceous SOT utilized the 2019 switchgrass availability data from BT16 (as was done in both the 2016 and 2017 Herbaceous SOTs). This was because BT16 does not project switchgrass availability in 2018, rather, the soonest switchgrass was projected to be available is in 2019. Hence, switchgrass availability for this analysis was that projected for 2019. The 2018 Herbaceous SOT models technologies identical to those modeled in the 2017 Herbaceous SOT. A sensitivity analysis varying the modeled equipment performance over experimentally-observed ranges was added in the 2018 SOT. The 2018 Herbaceous SOT also includes a supply system projection for 2022 that utilizes current BETO Feedstock Supply and Logistics (FSL) R\&D technical targets.

The 2018 Herbaceous SOT predicts a modeled delivered feedstock cost of $\$ 83.67 /$ dry ton (2016 $\$$ ); this is a $\$ 0.23$ dry ton $(2016 \$)$ decrease from the 2017 Herbaceous SOT. The reduction in required biomass supply together with increased BT16-projected biomass availability in the supply shed contributed to this modeled cost reduction. The least-cost formulation model, which optimally sites and scales local preprocessing depots, also contributed to the cost reduction by considering county-level grower payment and distance from the biorefinery as variables in the optimization algorithm. Sensitivity analysis on various process parameters that affect delivered feedstock cost in the 2018 Herbaceous SOT shows that the delivered cost could vary from $\$ 80.45-\$ 88.83 /$ dry ton. The highest impacting factors that could lead to uncertainty in delivered cost included effective baling rate, bale density, hammer mill throughput, interest rate and storage dry matter loss. A modeled net reduction in greenhouse gas emissions (GHG) was completed by Argonne National Laboratory using the 2018 Greenhouse Gases, Regulated Emissions, and Energy use in Transportation model, estimating a decrease of $4.8 \mathrm{~kg} \mathrm{CO}_{2} \mathrm{e} / \mathrm{ton}$ from the $2017 \mathrm{SOT}$ (74.11 $\mathrm{kg} \mathrm{CO}_{2} \mathrm{e} /$ ton in 2017 to $69.27 \mathrm{~kg} \mathrm{CO}_{2} \mathrm{e} / \mathrm{ton}$ in 2018). This reduction was attributed to reduced bale transport distance to the distributed depots and to the reduction of delivered biomass from 800,000 dry tons to 725,000 dry tons annually. 


\section{REFERENCES}

Anderson, E. K., Parrish, A. S., Voigt, T. B., Owens, V. N., Hong, C.-H. and Lee, D. (2013). "Nitrogen fertility and harvest management of switchgrass for sustainable bioenergy feedstock production in Illinois." Industrial Crops and Products 48: 19-27.

Aqa, S. and Bhattacharya, S. (1992). "Densification of preheated sawdust for energy conservation." Energy 17(6): 575-578.

Bhattacharya, S. (1993). "State-of-the-art of utilizing residues and other types of biomass as an energy source." RERIC International Energy Journal 15(1): 1-21.

Bhattacharya, S., Sett, S. and Shrestha, R. M. (1989). "State of the art for biomass densification." Energy Sources 11(3): 161-182.

Bioplastics. (2015). "Report studies factors affecting cost of cellulosic feedstocks for biochemicals." bio plastics magazine .com Retrieved 16/9/2015, 2015, from

http://www.bioplasticsmagazine.com/en/news/meldungen/20150109Cellulosics-feedstocks.php.

Birrell, S. J. and Karlen, D. L. (2017). " Corn Stover Residue Management:Site Specific Stover Collection and Site Specific Tillage." Presentation at 2017 Annual Meeting for DOE project "Enabling Sustainable Landscape Design for Continual Improvement of Operating Bioenergy Supply Systems"

Birrell, S. J., Karlen, D. L. and Wirt, A. (2014). "Development of sustainable corn stover harvest strategies for cellulosic ethanol production." BioEnergy Research 7(2): 509-516.

Bizjournals (2016). "Bizjournals, Here's where metro Denver ranks on population growth." http://www.bizjournals.com/denver/news/2016/06/06/heres-where-metro-denvers-population-growthranks.html, (accessed 12/12/2016.2016).

Boavida, D., Abelha, P., Gulyurtlu, I., Valentim, B. and Sousa, M. J. L. D. (2012). "A study on coal blending for reducing NOx and N2O levels during fluidized bed combustion." Clean Air 5: 175-191.

Bonner, I. J., Muth Jr, D. J., Koch, J. B. and Karlen, D. L. (2014a). "Modeled impacts of cover crops and vegetative barriers on corn stover availability and soil quality." BioEnergy Research 7(2): 576-589.

Bonner, I. J., Smith, W. A., Einerson, J. J. and Kenney, K. L. (2014b). "Impact of harvest equipment on ash variability of baled corn stover biomass for bioenergy." BioEnergy Research 7(3): 845-855.

Bonner I. J., Thompson, D. N., Plummer, M. A., Dee, M. R., Tumuluru, J. S., Pace, D. P., Teymouri, F., Campbell, T., Bals, B. (2016). "Impact of ammonia fiber expansion (AFEX) pretreatment on energy consumption during drying, grinding, and pelletization of corn stover." Drying Technology, 34(11): 1319-1329.

Bonner, I., McNunn, G., Muth, D., Tyner, W., Leirer, J. and Dakins, M. (2016). "Development of integrated bioenergy production systems using precision conservation and multicriteria decision analysis techniques." Journal of Soil and Water Conservation 71(3): 182-193.

Bonner, I. J., Cafferty, K. G., Muth, D. J., Tomer, M. D., James, D. E., Porter, S. A. and Karlen, D. L. (2014a). "Opportunities for Energy Crop Production Based on Subfield Scale Distribution of 
Profitability." Energies 7(10): 6509-6526.

Bonner, I. J., Cafferty, K. G., Muth, D. J., Tomer, M. D., James, D. E., Porter, S. A. and Karlen, D. L. (2014b). "Opportunities for enrgy crop production based on subfield scale distribution of profitability." Under Review at 'Energies' 7(1).

Brue, J. D., Darr, M. J., Bergman, R. W. and Webster, K. (2015). "Understanding management practices for biomass harvest equipment for commercial scale operation." 2015 ASABE Annual International Meeting, American Society of Agricultural and Biological Engineers, DOI 10.13031/aim.20152189505.

Cafferty, K., Jacobson, J. and Kenney, K. (2013a). "Herbaceous/Biochem Feedstock 2013 State of Technology Report." Idaho National Laboratory, Idaho Falls, ID.

Cafferty, K. G., Muth, D. J., Jacobson, J. J. and Bryden, K. M. (2013b). "Model Based Biomass System Design of Feedstock Supply Systems for Bioenergy Production." ASME 2013 International Design Engineering Technical Conferences and Computers and Information in Engineering Conference, Portland, OR, USA, ASME.

Carnohan, S., Jacobson, J. J., Ford, A. and Beall, A. (2014). "Simulating Pelletization Strategies to Reduce the Biomass Supply Risk at America's Biorefineries." Presented at the 2014 International System Dynamics Conference, Delft University, Netherlands, INL/CON-14-32503.

Comer, K. (2017). "BALES Project Review 2017. Presentation at DOE Bioenergy Technologies Office (BETO) 2017 Project Peer Review Feedstock Supply \& Logistics Session".

CurrentResults. (2016). "Current Results weather and science facts." Retrieved 9/16/2016, 2016, from https://www.currentresults.com/Weather/US/humidity-city-annual.php.

David, K. and Ragauskas, A. J. (2010). "Switchgrass as an energy crop for biofuel production: A review of its ligno-cellulosic chemical properties." Energy \& Environmental Science 3(9): 1182-1190.

Davis, R., Tao, L., Tan, E. C. D., Biddy, M. J., Beckham, G. T., Scarlata, C., Jacobson, J., Cafferty, K., Ross, J., Lukas, J., Knorr, D. and Schoen, P. (2013). "Process Design and Economics for the Conversion of Lignocellulosic Biomass to Hydrocarbons: Dilute-Acid and Enzymatic Deconstruction of Biomass to Sugars and Biological Conversion of Sugars to Hydrocarbons." National Renewable Energy Laboratory, Golden, CO, NREL/TP-5100-60223.

Denver (2016). "Metro Denver Population." from http://www.metrodenver.org/dobusiness/demographics/population/.

Denver (2017a), “Composting Food \& Yard Waste" retrieved in 9/30/2017 from https://www.denvergov.org/content/denvergov/en/trash-and-recycling/composting.html

Denver (2017b), "Discover Denver's Compost Collection Program” retrieved in 9/30//2017 from https:/www.denvergov.org/content/denvergov/en/trash-and-recycling/composting/compost-collectionprogram.html

Dobos, R.R., Sinclair, H.R. and Robotham, M.P., 2008. User Guide for the National Commodity Crop Productivity Index (NCCPI). USDA-Natural Resources Conservation Service (Available from: ftp://ftp-fc. sc. egov. usda. gov/NSSC/NCCPI/NCCPI_user_guide.pdf).

DOE (2011). "U.S. Billion-Ton Update: Biomass Supply for a Bioenergy and Bioproducts Industry." R. 
D. Perlack and B. J. Stokes (Leads). Oak Ridge National Laboratory, Oak Ridge, TN, ORNL/TM$2011 / 224$.

DOE (2016a). " 2016 Billion-Ton Report: Advancing Domestic Resources for a Thriving Bioeconomy, Volume 1: Economic Availability of Feedstocks." M. H. Langholtz, B. J. Stokes, and L. M. Eaton (Leads). Oak Ridge National Laboratory, Oak Ridge, TN, ORNL/TM-2016/160.

DOE (2016b). "Multi-Year Program Plan." U.S. Department of Energy, Bioenergy Technologies Office, Washington, DC, DOE/EE-1385, March 2016.

DOE. (2017). "Growing Bioeconomy Markets: Farm-to-Fuel in Southside Virginia." from https://www.youtube.com/watch?v=1yjx9wHmiTY

Dutta, A., Talmadge, M., Hensley, J., Worley, M., Dudgeon, D., Barton, D., Groenendijk, P., Ferrari, D., Stears, B., Searcy, E., Wright, C. and Hess, J. (2011). "Process Design and Economics for Conversion of Lignocellulosic Biomass to Ethanol - Thermochemical Pathway by Indirect Gasification and Mixed Alcohol Synthesis." National Renewable Energy Laboratory, Golden, CO, NREL/TP-510051400 .

Environmental Protection Agency, E. (2015). "Municipal Solid Waste." Retrieved 9/11/2015, 2015, from http://www.epa.gov/wastes/nonhaz/municipal/.

Forest Concept "Summary Report of Comminution Energy for Processing Herbaceous Biomass with Forest Concepts’ Rotary Shear Equipment" Technical Report, May 31, 2017.

Graham, R., Langholtz, M., Eaton, L., Jacobson, J., Wright, C., Muth, M., Inman, D., Tan, E., Wu, M., Chiu, Y., Jones, S., Snowden-Swan, L. and Argo, A. (2013). "Investigation of Biochemical Biorefinery Sizing and Environmental Sustainability Impacts for Conventional Bale System and Advanced Uniform Biomass Logistics Designs." Biofuels, Bioproducts and BioPower, DOI: 10.1002/bbb.1391.

GREET. (2016). "Greenhouse Gas, Regulated Emissions and Energy Use in Transportation (GREET) model." Retrieved 09.05.2016, 2016, from https:/greet.es.anl.gov/.

Gustafson, R., Bura, R., Cooper, J., McMahon, R., Schmitt, E. and Vajzovic, A. (2009). "Converting Washington lignocellulosic rich urban waste to ethanol." Ecology Publication: Washington State University. 09-07-060.

Hess, J. R., Kenney, K., Ovard, L., Searcy, E. and Wright, C. (2009a). "Uniform-format solid feedstock supply system: a commodity-scale design to produce an infrastructure-compatible bulk solid from lignocellulosic biomass." INL/EXT-08-14752, Idaho National Laboratory.

Hess, J. R., Kenney, K. L., Ovard, L. P., Searcy, E. M. and Wright, C. T. (2009b). "Commodity-scale production of an infrastructure-compatible bulk solid from herbaceous lignocellulosic biomass." Uniform-format Bioenergy feedstock supply system design report series, Idaho National Laboratory, Idaho Falls, ID, INL/EXT-09-17527.

Hill, L. D. (1990). "Grain grades and standards: Historical issues shaping the future." University of Illinois Press, Chicago and Urbana, IL.

Hoskinson, R. L., Karlen, D. L., Birrell, S. J., Radtke, C. W. and Wilhelm, W. W. (2007). "Engineering, nutrient removal, and feedstock conversion evaluations of four corn stover harvest scenarios." Biomass and Bioenergy(31): 126-136. 
Humbird, D., Davis, R., Tao, L., Kinchin, C., Hsu, D., Aden, A., Schoen, P., Lukas, J., Olthof, B., Worley, M., Sexton, D. and Dudgeon, D. (2011). "Process Design and Economics for the Conversion of Lignocellulosic Biomass to Ethanol: Dilute-Acid Pretreatment and Enzymatic Hydrolysis of Corn Stover." National Renewable Energy Laboratory, Golden, CO, NREL/TP-5100-47764.

INL. (2016). "Bioenergy Feedstock Library." Retrieved 09/07/2016, 2016.

Jacobson, J. J., Roni, M. S., Cafferty, K., Kenney, K., Searcy, E. and Hansen, J. K. (2014). "Biomass feedstock supply system design and analysis." Idaho National Laboratory, Idaho Falls, Idaho, INL/EXT-14-33227.

Jones, S., Meyer, P., Snowden-Swan, L. Padmaperuma, A., Tan, E., Dutta, A., Jacobson, J, Cafferty, K. (2013). "Process design and economics for the conversion of lignocellulosic biomass to hydrocarbon fuels: Fast Pyrolysis and Hydrotreating Bio-oil Pathway." Pacific Northwest National Laboratory, Richland, WA, PNNL-23053.

Karki, B., Nahar, N. and Pryor, S. (2010). "Enzymatic hydrolysis of switchgrass and tall wheatgrass mixtures using dilute sulfuric acid and aqueous ammonia pretreatments." Biological Engineering 3(3): 163-171.

Kenney, K., Cafferty, C., Jacobson, J., Bonner, I., G., G., Hess, R., Ovard, L., Smith, W., Thompson, D., Thompson, V., J., T. and Yancey, N. (2013a). "Conversion Pathway: Biological Conversion of Sugars to Hydrocarbons - The 2017 Design Case." Idaho National Laboratory, Idaho Falls, ID, INL/EXT-13-30342.

Kenney, K. L., Smith, W. A., Gresham, G. L. and Westover, T. L. (2013b). "Understanding biomass feedstock variability." Biofuels 4(1): 111-127.

Li, J., Karimi, I. and Srinivasan, R. (2010). "Recipe determination and scheduling of gasoline blending operations." AIChE journal 56(2): 441-465.

Lindsey, K., Johnson, A., Kim, P., Jackson, S. and Labbé, N. (2013). "Monitoring switchgrass composition to optimize harvesting periods for bioenergy and value-added products." Biomass and Bioenergy 56: 29-37.

Liu, L., Ye, X. P., Womac, A. R. and Sokhansanj, S. (2010). "Variability of biomass chemical composition and rapid analysis using FT-NIR techniques." Carbohydrate Polymers 81(4): 820-829.

Mathanker, S. K. and Hansen, A. C. (2014). "Harvesting system design and performance." Book Chapter, pp. 85-139, DOI: 10.1007/978-1-4899-8014-4_5.

Muth, D. J., Bryden, K. M. and Nelson, R. G. (2013). "Sustainable agricultural residue removal for bioenergy: A spatially comprehensive US national assessment." Applied Energy 102: 403-417.

Muth, D. J., McCorkle, D. S., Koch, J. B. and Bryden, K. M. (2012). "Modeling sustainable agricultural residue removal at the subfield scale." Agronomy Journal 104(4): 970-981.

Nagle, N. J., Wolfrum, E., Ness, R., Peterson, D. and Ray, A. E. (2014). "Complete pretreatment and enzymatic hydrolysis of 10-INL study materials." National Renewable Energy Laboratory, Golden, CO, Milestone Completion Report-2.2.1.100.

NREL. (2016). "NREL Dynamic Maps, GIS Data, \& Analysis Tools." Retrieved 9/20/2016, 2016, from www.nrel.gov/gis/solar.html. 
Owens, V. N., Karlen, D. L. and Lacey, J. (2016). "Regional Feedstock Partnership Report: Enabling the Billion-Ton Vision." Idaho National Laboratory, Idaho Falls, Idaho, INL/EXT-15-37477.

Peters, M. S., C. D. Timmerhaus and West, R. E. (1968). Plant Design and Economics for Chemical Engineers. New York, NY, McGraw-Hill.

Pordesimo, L., Hames, B., Sokhansanj, S. and Edens, W. (2005). "Variation in corn stover composition and energy content with crop maturity." Biomass and Bioenergy 28(4): 366-374.

Ray, A., Schaller, K., Fillerup, E., Park, S., Hoeger, I. and Nagle., N. (2016). "Biochem Blended Feedstock Development." Idaho National Laboratory, Idaho Falls, ID, Quarterly Progress Report2.2.1.102, June 30, 2013.

Reddy, D. V. and Krishna, N. (2009). "Precision animal nutrition: A tool for economic and eco-friendly animal production in ruminants." Livestock Research for Rural Development 21(3), Article \#36.

Robbins, J. A. and Gu, M. (2013). "Cost of Constructing a Metal Hoop High Tunnel." Arkansas, USA, University of Arkansas.

Roni, M., Hartley, D. and Searcy, E. (2015). "Herbaceous Feedstock 2015 State of Technology Report." Idaho National Laboratory, Idaho Falls, ID, INL/EXT-15-36595.

Roni, M., Hansen, J., Griffel, M., Hartley, D., Mamun, S. and Vazhnik, V. (2018). "Enabling Sustainable Landscape Design for Continual Improvement of Operating Bioenergy Supply Systems". Idaho Falls, Idaho, USA, Idaho National Laboratory INL/MIS-18-51176

Roni, M., Thompson, D. N., Hu, H., Hartley, D., Nguyen, Q., Cai, H.. 2017. Herbaceous Feedstock 2017 State of Technology Report. Idaho National Laboratory.

Sami, M., Annamalai, K. and Wooldridge, M. (2001). "Co-firing of coal and biomass fuel blends." Progress in Energy and Combustion Science 27(2): 171-214.

Schmitt, E., Bura, R., Gustafson, R., Cooper, J. and Vajzovic, A. (2012). "Converting lignocellulosic solid waste into ethanol for the State of Washington: an investigation of treatment technologies and environmental impacts." Bioresource Technology 104: 400-409.

Searcy, E. and Hess, J. (2010). "Uniform-format feedstock supply system: A commodity-scale design to produce an infrastructure-compatible biocrude from lignocellulosic biomass." Idaho National Laboratory, Idaho Falls, Idaho, INL/EXT-10-20372.

Searcy, E., Lamers, P., Hansen, J., Jacobson, J., Hess, J.R. and Webb, E. (2015). "Advanced Feedstock Supply System Validation Workshop SUMMARY REPORT." Idaho National Laboratory, Idaho Falls, ID. INL/EXT-15-50315.

Shah, A., Darr, M. J., Webster, K. and Hoffman, C. (2011). "Outdoor storage characteristics of singlepass large square corn stover bales in Iowa." Energies 4(10): 1687-1695.

Shi, J., Thompson, V., Yancey, N., Stavila, V., Simmons, B. A. and Singh, S. (2013). "Impact of mixed feedstocks and feedstock densification on ionic liquid pretreatment efficiency." Biofuels 4(1): 63-72.

Shih, J.-S. and Frey, H. C. (1995). "Coal blending optimization under uncertainty." European Journal of Operational Research 83(3): 452-465.

Shinners, K. J., Bennett, R. G. and Hoffman, D. S. (2012). "Single and two-pass corn grain and stover harvesting." Transactions of the ASABE 55(2): 341-350. 
Smith, W. and Bonner, I. (2012). "Demonstrate through integrated model analysis using field and PDUscale data from dry corn stover a total feedstock logistics cost of $\$ 35.00$ per dry ton (excluding grower payment, in 2007\$)." Idaho National Laboratory Idaho Falls, ID, Milestone Completion Report-1.2.1.1.

Smith, W. and Bonner, I. (2014). "Evaluation of two multi-pass stover harvest systems and their impacts on the interactions between yield and ash on the delivered feedstock price." Idaho National Laboratory, Idaho Falls, ID, Milestone Completion Report, Biomass Engineering-1.2.1.1 Harvest, Collection, \& Storage; Award Number 15076, March 31, 2014.

Smith, W., Bonner, I. and Kenney, K. (2013). "INL-AGCO Field Activities--2010-2012." Idaho National Laboratory, Idaho Falls, ID, INL/LTD-13-28431.

Sokhansanj, S., Webb, E. and Turhollow Jr, A. F. (2014). "Simulation of the DOE High-Tonnage Biomass Logistics Demonstration Projects: Auburn University." Oak Ridge National Laboratory, Oak Ridge, TN, ORNL/TM-2014/505.

Springer, T. L. (2012). "Biomass yield from an urban landscape." Biomass and Bioenergy 37: 82-87.

STINGER (2015). "Baled biomass from field to factory., Stinger.

Subahana, K., Mathew, M., Awasthi, A., Muralidharan, N. and Natarajan, R. (2015). "Experimental investigation of convective drying kinetics of switchgrass leaf in open sun and in a forced convection solar dryer." International Journal of ChemTech Research 7(5): 2399-2407.

Swaploader. (2016). "Swaploader USA Ltd." Retrieved 9/16/2016, 2016, from www.swaploader.com.

Thompson, D., Roni, M., Hartley, D. and Nguyen, Q. (2016). "Herbaceous Feedstock 2016 State of Technology Report." Idaho National Laboratory, Idaho Falls, ID, INL/LTD-16-40097

Thompson, V., Ray, A., Stevens, D., Daubaras, D., Hoover, A., Emerson, R., Ukaew, S., Klemetsrud, B., Klinger, J., Eatherton, D. and Shonnard., D. (2015a). "Assessment of municipal solid waste for biochemical and thermochemical conversion pathways." Presented at the 37th Symposium on Biotechnology for Fuels and Chemicals, San Diego, CA.

Thompson, V., Ray, A., Stevens, D., Daubaras, D., Hoover, A., Emersion, R., Klemetsrud, B., Klinger, J., Ukaew, S. and Shonnard, D. R. (2015b). "Characterization of Products from Fast Pyrolysis of Municipal Solid Waste (MSW): Preliminary Analyses Using Micro-Pyrolysis." Presented at the 37th Symposium on Biotechnology for Fuels and Chemicals, San Diego, CA.

Tumuluru, J. S. (2014). "Effect of process variables on the density and durability of the pellets made from high moisture corn stover." Biosystems Engineering 119: 44-57.

Tumuluru, J. S. (2015). "High moisture corn stover pelleting in a flat die pellet mill fitted with a $6 \mathrm{~mm}$ die: physical properties and specific energy consumption." Energy Science \& Engineering 3(4): 327341.

Tumuluru, J. S., Wright, C. T., Kenny, K. L. and Hess, J. R. (2010). "A review on biomass densification technologies for energy application." Idaho National Laboratory, Idaho Falls, ID, INL/EXT-18420.

Undersander, D. (2016). "Drying Forage for Hay and Haylage." Retrieved 9/16/2016, 2016, from http://www.uwex.edu/ces/forage/pubs/drying_forage.pdf.

Webb, E., Sokhansanj, S. and Turhollow Jr, A. F. (2013a). "Simulation of the DOE High-Tonnage 
Biomass Logistics Demonstration Projects: AGCO Corporation." Oak Ridge National Laboratory, Oak Ridge, TN, ORNL/TM-2013/323.

Webb, E., Sokhansanj, S. and Turhollow Jr, A. F. (2013b). "Simulation of the DOE High-Tonnage Biomass Logistics Demonstration Projects: FDC Enterprises." Oak Ridge National Laboratory, Oak Ridge, TN, ORNL/TM-2013/338.

Webb, E., Sokhansanj, S. and Turhollow Jr, A. F. (2013c). "Simulation of the DOE High-Tonnage Biomass Logistics Demonstration Projects: State University of New York College of Environmental Science and Forestry." Oak Ridge National Laboratory, Oak Ridge, TN, ORNL/TM-2013/376.

Webb, E. and Sokhansanj, S. (2014). "Sensitivity Analysis of Biomass High-Tonnage Logistics Demonstration Projects." Oak Ridge National Laboratory, Oak Ridge, TN, ORNL/TM-2013/568.

Wendt, L., Bonner, I., Smith, W., Plummer, M. and Earl, J. (2013). "Quantify structural sugar loss in storage relative to initial moisture content and oxygen availability." Idaho National Laboratory Idaho Falls, ID, Milestone Completion Report-1.2.1.1000.

WCDENVER, "Waste Connections of Colorado" Retrieved 9/30/2017, from http://www.epa.gov/wastes/nonhaz/municipal/.http://www.wcdenver.com/residential\#Recycling

Wendt, L. M., Bonner, I. J., Hoover, A. N., Emerson, R. M. and Smith, W. A. (2014). "Influence of airflow on laboratory storage of high moisture corn stover." BioEnergy Research 7(4): 1212-1222.

Wolfrum, E. J., Ness, R. M., Nagle, N. J., Peterson, D. J. and Scarlata, C. J. (2013). "A laboratory-scale pretreatment and hydrolysis assay for determination of reactivity in cellulosic biomass feedstocks." Biotechnology for Biofuels 6(1): 1.

Womac, A., Hart, W., Bitra, V. and Kraus, T. (2012). "Biomass harvesting of high-yield low-moisture switchgrass: Equipment performance and moisture relations." Applied Engineering in Agriculture 28(6): 775-786.

Yancey, N. and Tumuluru, J. S. (2015). "Size Reduction, Drying and Densification of High Moisture Biomass." Idaho National Laboratory, Idaho Falls, ID.

Yancey, N. A., Wright, C. T., Conner, C. C. and Hess, J. R. (2009). "Preprocessing moist lignocellulosic biomass for biorefinery feedstocks." Paper presented at the 2009 ASABE Annual International Meeting. Reno, NV, INL/CON-08-14983. 


\section{APPENDIX A - 2018 Herbaceous State of Technology Feedstocks Logistics Design and Assumptions}

The 2018 Herbaceous SOT provides an annual herbaceous feedstock supply to a biorefinery located in Sheridan County, Kansas (northwestern Kansas). The feedstock supply consists of 725,000 dry tons of an herbaceous biomass blend consisting of $12.74 \%$ three-pass stover, $73.22 \%$ two-pass stover, $9.83 \%$ switchgrass and $4.21 \%$ grass clippings, for biochemical conversion. The 2018 Herbaceous SOT incorporates four depots (identified as Nodes 5, 6, 9 and 13 in Figure 4 and Table 6 of the main document, and Figure A-1 in this appendix), three of which are located at a distance from the biorefinery in high-yielding counties that have significant corn stover and switchgrass biomass available lower on the supply curve. The fourth depot, consistent with the 2016 and 2017 Herbaceous SOTs, is located adjacent to a Municipal Solid Waste (MSW) transfer station in the Denver, CO metropolitan area that receives and preprocesses a separately-collected grass clippings fraction of yard trimmings MSW from surrounding counties.

The 2018 Herbaceous SOT couples feedstock logistics with resource availability, reflected as grower payment, to estimate the delivered feedstock cost required to supply the 725,000 dry ton/year biorefinery. The 2018 Herbaceous SOT design is located in an area of relatively low biomass productivity, consistent with the 2017 Herbaceous SOT, to acknowledge the barriers and cost implications for meeting national targets for a national-scale biorefinery industry, when biomass must be sourced in locations where there is sufficient biomass supply, but there is also a diversity of biomass types available, which offers blending options to assist in meeting conversion specifications. Grower payments were calculated from farm gate prices reported in the BT16 report (DOE 2016a) by subtracting modeled harvest and collection costs and scaling to the appropriate year. For the grass clippings fraction of the blend, we conservatively assumed no associated tipping fee ( $\sim 50.63 /$ dry ton is the U.S. average), and a delivered cost of $\$ 10.13 /$ dry ton at the depot in the Denver metropolitan area. This provides a net of $\$ 60.76 /$ dry ton to reimburse the cost of curb-side collection of the grass clippings separately from aggregated yard trimmings MSW. As noted in the main body of this report, the city of Denver separately collects grass clippings for composting (WCDENVER, 2017; Denver, 2017a), using auto-loading garbage trucks (Denver, 2017b).

The three-pass corn stover harvest and collection method assumed for this analysis is consistent with those used in conventional systems and also referred to as "multi-pass harvesting systems." The two-pass corn stover harvesting and collection method assumed for the analysis is an advanced harvest method that is currently utilized by Poet-DSM to harvest corn stover for its Emmetsburg, IA facility. In this method, the first pass is grain harvest using a combine with header raised to just below the ear on the corn stalks and the spreader turned off, and the second pass is a baler (Birrell et al. 2014; Shinners et al. 2012). This eliminates the windrowing step, which is a significant source of soil entrainment in the baled corn stover. The raised header (higher cut height) leads to a lower harvest yield, and is generally a conservative approach to ensure soil sustainability. The three-pass stover and two-pass corn stover are harvested, collected, and then stored fieldside (tarped) until being transported by truck to the main depot in bales.

Like the 2017 Herbaceous SOT, the 2018 Herbaceous SOT incorporates the energy crop switchgrass in the blended feedstock to mitigate the low carbohydrate/high ash contents of three-pass corn stover and the low-cost grass clippings. According to the BT16 report, commercialization of energy crops has increased since 2011, with deployment on as many as 20,000 acres (DOE 2016a). Regional USDA 
switchgrass production statistics for 2012 also show the potential for switchgrass to supply multiple markets (e.g., power, fuels, and animal bedding) (DOE 2016a). Switchgrass is assumed to be harvested using two-pass harvest. The switchgrass is harvested, collected, and then stored fieldside (tarped) until being transported by truck to the main depot in bales.

The modeled supply chain for the 2018 Herbaceous SOT is shown in Figure A-1. The depots at Nodes 5, 6 and 9 in Figure 4 and Table 6 of the main document, and in Figure A-1, are general purpose depots in the sense that they employ identical preprocessing equipment in each, and can receive any of the sources of agricultural biomass or switchgrass, although two of these depots receive only a single biomass type in the least-cost scenario (see Table 6 and Figure A-1). The baled biomass delivered from road-side storage at the farm gates of the supplying counties is size reduced using hammer milling/fractional milling followed by rotary shear, densified using high moisture pelleting, and then cooled and placed into temporary depot storage until shipping to the biorefinery when needed. Grass clippings are preprocessed utilizing solar drying followed by shredding and pelleting (see Appendix D), and immediately trucked approximately 220 miles to the biorefinery. Pellets shipped from these depots to the biorefinery are placed into silos (separated by biomass type) when received, and blended to the correct ratio immediately prior to feeding to the reactor throat. The silos serve as the metering bin for the conversion process, as the pellets are blended as they are conveyed to the feeding system for the pretreatment reactor.

\section{A.1. Resource Availability}

The geographic area chosen for the 2018 Herbaceous SOT is northwestern Kansas, with the biorefinery located in Sheridan County. It was assumed that all of the biomass as identified in the BT16 report located in Kansas, Nebraska and Colorado would be potentially available to meet the demand of 725,000 dry tons delivered to the pretreatment reactor throat at the biorefinery. The available corn stover in 2018 was estimated from the county-level data in the BT16 report (DOE 2016a); corn stover availability in BT16 is representative of conventional three-pass harvesting. We assumed that two-pass harvesting would be limited to high-yielding counties (defined as stover yields $\geq 2.0$ dry tons/acre), however, three-pass harvesting could also be utilized in these counties. We further assumed that only three-pass harvest would be used in low-yielding counties (stover yields $<2.0$ tons/acre). This was done to maximize yields of corn stover from the low-yielding counties, which are significantly greater in number than high-yielding counties.

Because two-pass harvesting cuts higher on the stalk, less stover is collected by the baler. In a multiyear study, Birrell et al. (2014) showed that two-pass harvest of material other than grain (MOG) reached about $35 \%$ of the collection efficiency of conventional three-pass harvest. In another study (Smith et al. 2014), it was observed that the specific two-pass harvest method assumed in this SOT achieved slightly less than half the yield observed for the flail shred three-pass harvest method assumed for this study (Table A-1). Three-pass harvesting with a flail shredder and square bales achieved 1.9-2.0 dry tons/acre, while the two-pass system achieved 0.9-1.0 dry tons per acre. The average ratio of two-pass yield/threepass yield is then 0.487 . Hence, for the high-yielding counties, we adjusted the BT16 three-pass availabilities for corn stover down by a factor of 0.487 to give the two-pass availability numbers for the analysis.

The BT16 report (DOE 2016a) does not project switchgrass availability in 2018; the soonest switchgrass is available in the BT16 report is 2019. Therefore, availability of switchgrass for this analysis was that projected for 2019 (this was done in the 2016 Herbaceous SOT as well). The availability of grass 

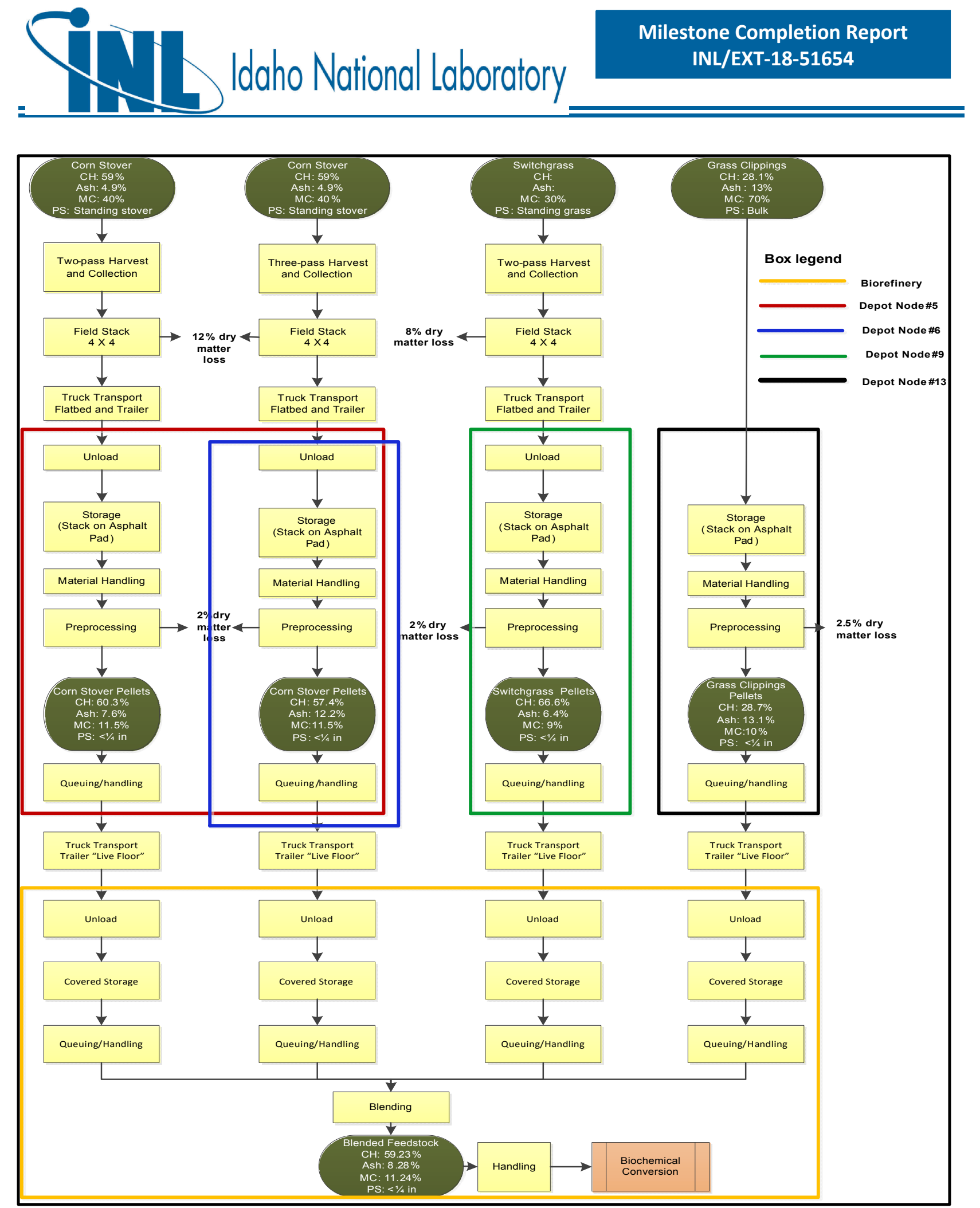

Figure A-1. The modeled 2018 Herbaceous SOT feedstock supply system. CH=Carbohydrate content, $M C=$ moisture content, $P S=$ Particle size. Depots are identified as nodes 5, 6, 9 and 13. Optimal locations and sizes of these nodes are listed in Figure 4 and Table 6 of the main body of this report. 
Table A-1. Baled corn stover yield and mean ash contents in three-pass harvesting (Rake, Flail), and twopass harvesting (MOG) (Smith et al. 2014). We assumed square bales for transportation; relevant treatments in the table are in bolded text. The flail treatment (ISU '12 3.2) was not used because its low ash content is inconsistent with the other flail treatments.

\begin{tabular}{|c|c|c|c|c|}
\hline Windrow & Bale Type & ID & $\begin{array}{c}\text { Yield } \\
\text { (DMT/acre) }\end{array}$ & $\begin{array}{c}\text { Ash } \\
\left(w t^{\%} \% d b\right)\end{array}$ \\
\hline $\mathrm{MOG}^{\mathrm{a}}$ & Round & MOG-1 & 0.5 & 4.9 \\
\hline MOG & Round & MOG-2 & 0.6 & 3.8 \\
\hline $\mathrm{MOG}$ & Round & MOG-3 & 0.7 & 7.6 \\
\hline $\mathrm{MOG}$ & Round & MOG-4 & 0.7 & 6.8 \\
\hline $\mathrm{MOG}$ & Round & MOG-5 & 0.7 & 5.6 \\
\hline MOG & Round & MOG-6 & 0.8 & 6.3 \\
\hline MOG & Square & MOG-7 & 0.9 & 5.8 \\
\hline MOG & Square & MOG-8 & 1.0 & 5.3 \\
\hline Rake & Square & RAKE-1 ${ }^{b}$ & $0.9^{\mathrm{b}}$ & 8.1 \\
\hline Rake & Square & $\mathrm{RAKE}^{\mathrm{b}}$ & $1.4^{\mathrm{b}}$ & 7.6 \\
\hline G-hoff & Square & G-HOF & 1.9 & 8.0 \\
\hline 1-P & Square & $1-\mathrm{PASS}^{\mathrm{c}}$ & 1.9 & 5.7 \\
\hline Flail & Square & FLAIL $^{c}$ & 2.0 & 13.9 \\
\hline Rake & Square & ISU '12 3.1 & 1.4 & 14.6 \\
\hline Flail & Square & ISU '12 3.2 & 1.4 & 7.6 \\
\hline Rake & Square & ISU '12 3.3 & 1.9 & 15.6 \\
\hline Flail & Square & ISU '12 3.4 & 1.9 & 12.1 \\
\hline
\end{tabular}

a The combine drops the material other than grain (MOG) into a loose windrow, which is followed by a separate baler. Drawbacks to this method are reduced collection efficiency and field "striping" as a result of uneven residue removal.

b Assumed average bale weight from previous co-located studies

c Provided by Matt Darr, Iowa State University

clippings was estimated as follows: The U.S. EPA publishes per capita MSW generation (Figure A-2(a)) and the percentages of food and yard wastes, paper, metals, and electronics (Figure A-2(b)) that on average contribute to MSW generation (Environmental Protection Agency 2015). Using this information and the population in the Denver metropolitan area (Denver 2016) adjusted by $2.1 \%$ for annualized growth (Bizjournals, 2016), the estimated projected per capita MSW generation in 2018 would be about $4.23 \mathrm{lb} /$ person/day. We then conservatively assumed that $10 \%$ of the dry weight of the yard wastes consisted of grass clippings. With these assumptions, projected grass clippings availability in the Denver Metropolitan area is shown in Table A-2. 

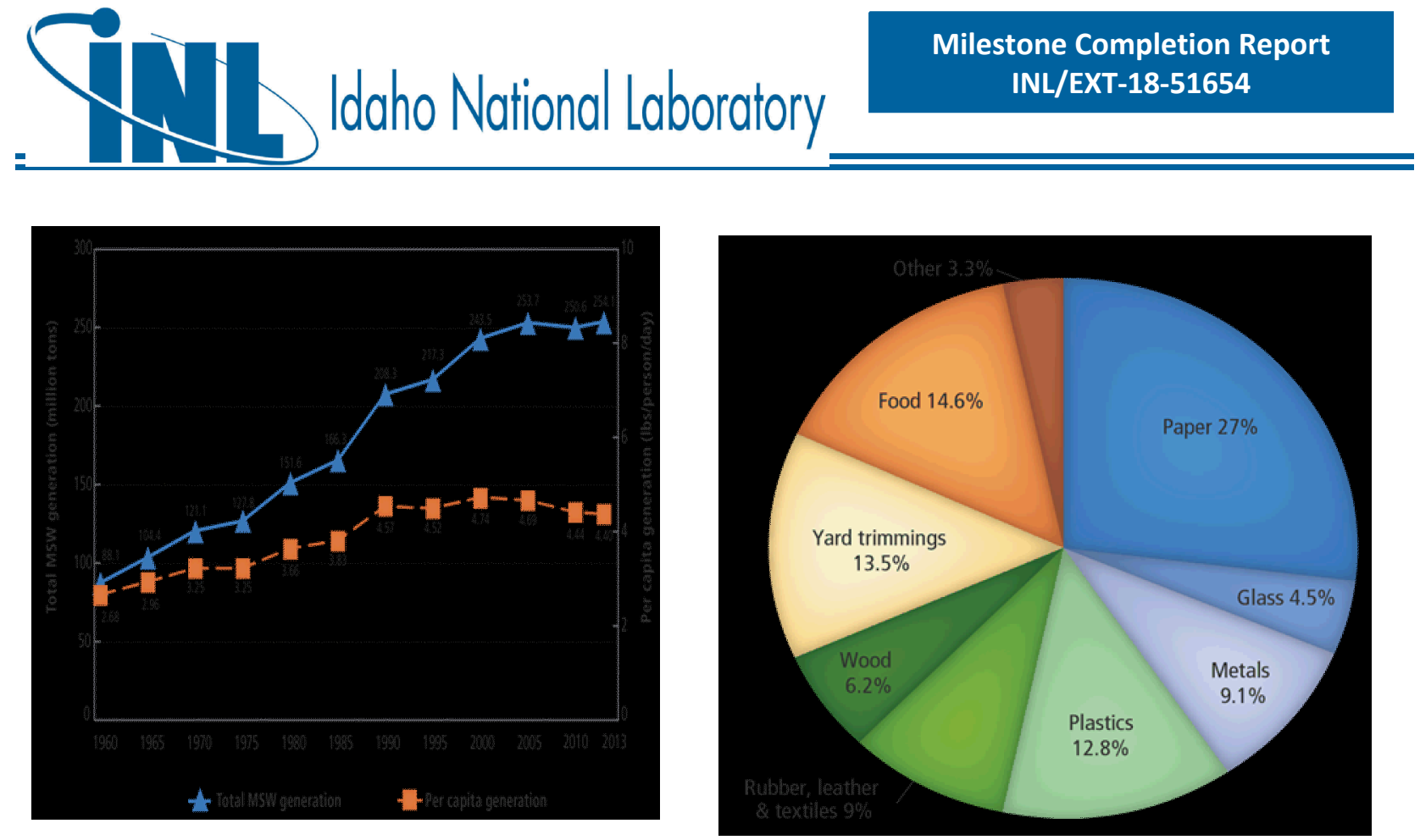

Figure A-2. EPA estimated annual municipal solid waste generation in the United States and its average composition. (a) Per capita MSW generation (1960-2013); and (b) Average compositional breakdown of municipal waste (Environmental Protection Agency 2015).

Table A-2. Projected grass clippings supply from the Denver Metropolitan area estimated from per capita MSW generation, population in the Denver metropolitan area (Denver 2016), and average percentage of yard wastes and grass in MSW (Environmental Protection Agency 2015).

\begin{tabular}{lcc}
\hline $\begin{array}{c}\text { Metro-Denver } \\
\text { County }\end{array}$ & Population (2016) & $\begin{array}{c}\text { Purchased grass clippings } \\
\text { tons) })^{\mathrm{a}}\end{array}$ \\
\hline Adams & 480,317 & (dry \\
\hline Arapahoe & 618,341 & 6,7222 \\
\hline Boulder & 313,708 & 3,411 \\
\hline Broomfield & 61,826 & 672 \\
\hline Denver & 664,220 & 7,222 \\
\hline Douglas & 314,592 & 3,420 \\
\hline Jefferson & 558,532 & 6,073 \\
\hline \hline TOTAL & $3,011,536$ & 32,743 \\
\hline \hline
\end{tabular}

a Assumes 2.1\% annual population growth in the Denver Metropolitan Counties (Bizjournals, 2016).

\section{A.2. Process Design and Cost Estimation Details}


In this section, the costs of different supply chain operations are described along with assumptions and input parameters. Table A-3 shows the 2018 costs of energy inputs for the 2018 Herbaceous SOT as compared to the assumptions used for the 2017 Herbaceous SOT.

Table A-3. Updated energy prices and interest rates used to model herbaceous feedstock logistics costs for the 2018 Herbaceous SOT.

\begin{tabular}{lcc}
\hline \multicolumn{1}{c}{ Component } & 2017 Assumptions & 2018 Assumptions \\
\hline Interest Rate & $8 \%$ & $8 \% \%^{\mathrm{a}}$ \\
\hline Electricity Price & $\$ 0.0675 / \mathrm{kWh}$ & $\$ 0.0672 / \mathrm{kWh}^{\mathrm{b}}$ \\
\hline Natural Gas Price & $\$ 3.38 / \mathrm{MMBtu}$ & $\$ 3.36 / \mathrm{MMBtu}^{\mathrm{b}}$ \\
\hline Off-Road Diesel Price & $\$ 2.02 / \mathrm{gal}$ & $\$ 2.011 / \mathrm{gal}^{\mathrm{b}}$ \\
\hline
\end{tabular}

a See Jones et al. (2013)

b See EIA (2017). Updated from the 2017 Herbaceous SOT using producer price index

\section{A.2.1 Harvest and Collection}

The 2018 Herbaceous SOT design incorporates corn stover, switchgrass and grass clippings into the blended feedstock. Corn stover harvest is assumed to be available via two different harvesting methods, three-pass (conventional) harvesting and two-pass harvesting (advanced). Conventional three-pass harvesting has the advantage of high yield, but the disadvantage of low quality with respect to carbohydrates (lower) and ash (higher). Two-pass harvesting allows better quality, but decreases the harvesting yield. Conventional three-pass systems involve cutting the feedstock, collecting the material into a windrow, and then baling the windrowed material (Figure A-3). The two-pass collection method eliminates the windrowing step and thereby reduces the potential for soil contamination (Shinners et al. 2012, Birrell et al. 2014). In this method, the combine drops the material other than grain (MOG) into a loose windrow, which is followed by a separate baler. The two-pass method assumed here is that utilized by POET-DSM's Advanced Biofuels' Project Liberty. Drawbacks to this method are reduced collection efficiency (due to a higher cut height) and field "striping" (Birrell et al. 2014) as a result of uneven residue removal. Two-pass collection does not increase the required throughput to the combine or hinder its operation, but requires some minor operational modifications. Combine operation is altered by disengaging the straw choppers at the rear of the combine to allow the MOG to drop behind the combine into a loose windrow. The combine is modified by adding "stalk-stompers" or by mounting rollers under the header to bend the lower stalk over in the rows on which the MOG will be dropped. These devices are commonly (but not universally) used under the wheel-track rows to reduce the risk of tire punctures. They are optional equipment but are relatively inexpensive.

Because of the higher cutting height in two-pass harvest, the stover yields are limited to the upper stalk, husk, cob, and some leaves, which (stated above) amount to about, or less than, 1 ton/acre. 


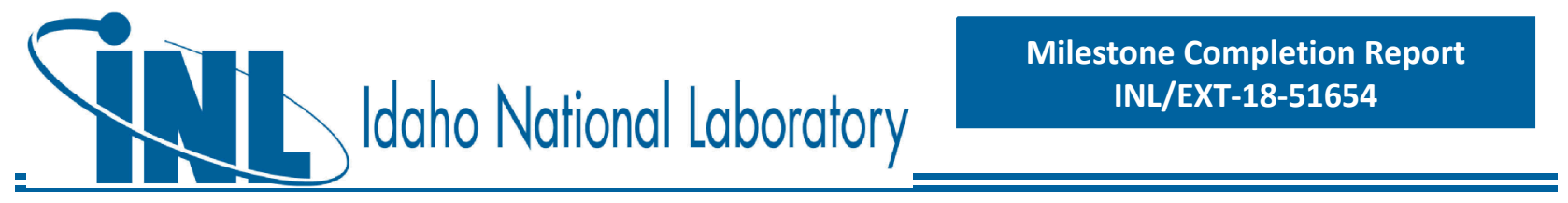

However, it is purported that MOG is lower in moisture and ash content (Hoskinson et al. 2007). Most of the ash variability is introduced from soil during baling. Corn stover yield could be potentially increased in the two-pass harvest and collection method by cutting stover lower in the stalk. This could be accomplished by using a stalk-chopping head, reducing the cutting height. However, with lower stalk comes more moisture and ash and the stalk chopping head requires more power and increases cost.

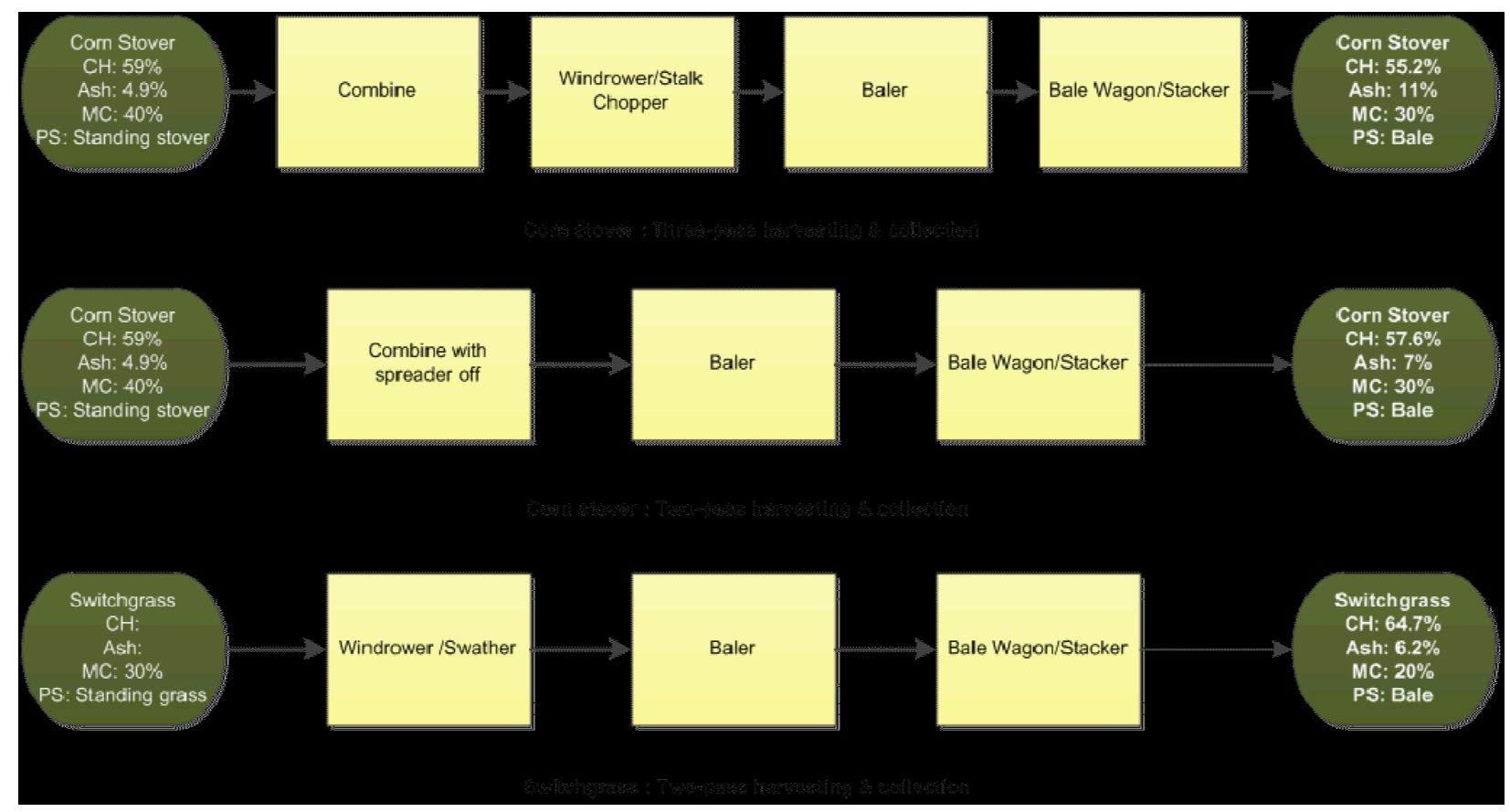

Figure A-3. The 2018 Herbaceous SOT harvest and collection operations for corn stover and switchgrass. It is assumed that prior to baling there is some amount of field drying to reach $30 \%$ moisture for corn stover and 20\% moisture for the switchgrass. $\mathrm{CH}=$ Carbohydrate content, $M C=$ moisture content, and PS=Particle size.

It is assumed that two-pass harvesting will be limited to high-yielding areas as a result of this stover yield limitation. Our reasoning is as follows: Pordesimo et al. (2005) demonstrated that at grain maturity, the above-ground stover mass fraction is approximately equal to the grain mass, in that case 6.7 dry tons/acre and 207 bushels/acre for the stover and the grain, respectively. In a multi-year study (Birrell et al. 2014), two-pass baling resulted in 35\% stover yield with 186 bushels/acre grain yield. To recover 0.7 dry tons/acre (the experimentally-validated average two-pass yield used for estimating harvesting costs for two-pass harvest; see Table A-4) or more, it would be necessary to have grain yields of 372 bushels/acre, which is unlikely on low-yielding fields. This represents an average yield in the Corn Belt, meaning that half of the available fields will have yields below this value, thus, corn stover yields less than 0.7 dry tons/acre. Part of the quality benefit from two-pass harvest arises from lower levels of inorganics higher up the stalk. Hoskinson et al. (2007) showed elevated inorganic nutrient and total ash contents in the lower stalk materials relative to the upper stalk. Additionally, an analysis by Birrell et al. (2014) showed that a greater quantity of ash forming minerals (Al, B, Cu, Fe, Mn) were present in multipass bales relative to two-pass MOG bales collected from the same experimental plots. Hence, while upper stalk collection via two-pass baling yields less stover, the total ash content of the stover is lower, and there is a sustainability benefit since inorganic nutrient removal from the field is lower as well. 
Switchgrass harvesting is assumed to utilize a two-pass harvesting system typically used for energy grasses (Mathanker et al. 2014). In the first pass, grasses are cut and windrowed by a selfpropelled windrower fitted with a rotary disk header, such as is typically used to cut hay. In the second pass, the windrowed material in the field is picked up by a baler. Large square balers are assumed to be used to bale the windrowed material. This two-pass system is consistent with switchgrass harvest after killing-frost where moisture contents are sufficiently low to reach a stable storage moisture content in the windrow (Womac et al. 2012).

Table A-4 summarizes the harvest and collection design assumptions for the 2018 Herbaceous SOT. The assumed yield, capacity and efficiency of harvest and collections equipment, moisture content, and ash content have been estimated based on published data (Anderson et al. 2013, Lindsey et al. 2013, Bonner et al. 2014b, DOE 2016a, Owens et al. 2016), data from field trials (Smith et al. 2012, Smith et al. 2014, Brue et al. 2015), data taken from the INL Bioenergy Feedstock Library (INL 2016), and from personal communications ${ }^{2,3}$.

Table A-4. Harvest and collection design assumptions in the 2018 Herbaceous SOT for three-pass corn stover, two-pass corn stover and switchgrass.

\begin{tabular}{|c|c|c|c|}
\hline \multirow[t]{2}{*}{ Component } & \multicolumn{2}{|c|}{ Corn stover } & \multirow[t]{2}{*}{ Switchgrass } \\
\hline & $\begin{array}{c}\text { Three-Pass } \\
\text { Harvest }\end{array}$ & $\begin{array}{l}\text { Two-Pass } \\
\text { Harvest }\end{array}$ & \\
\hline \multicolumn{4}{|l|}{ Harvest time } \\
\hline Operational hours & $\begin{array}{l}6 \text { weeks/year, } \\
6 \text { days/week, } \\
14 \text { hour/days }\end{array}$ & $\begin{array}{l}6 \text { weeks/year, } \\
6 \text { days/week, } \\
14 \text { hour/days }\end{array}$ & $\begin{array}{l}6 \text { weeks/year, } \\
6 \text { days/week, } \\
14 \text { hour/days }\end{array}$ \\
\hline \multicolumn{4}{|l|}{ Combine } \\
\hline Capacity & 41 tons/hour & 41 tons/hour & $\mathrm{N} / \mathrm{A}^{\mathrm{a}}$ \\
\hline Field efficiency & $70 \%$ & $70 \%$ & N/A \\
\hline Collection efficiency & $43 \%$ & $43 \%$ & $\mathrm{~N} / \mathrm{A}$ \\
\hline \multicolumn{4}{|l|}{$\begin{array}{l}\text { Stalk chopping } \\
\text { windrower }\end{array}$} \\
\hline Capacity & 11.5 acres/hour & N/A & 8.8 acres/hour \\
\hline
\end{tabular}

${ }^{2}$ Personal communication from Magen E. Shedden, a researcher at Oak Ridge National Laboratory (ORNL)

${ }^{3}$ Personal communication from William Smith, INL researcher 


\begin{tabular}{|c|c|c|c|}
\hline & & \multicolumn{2}{|c|}{$\begin{array}{l}\text { Milestone Completion Report } \\
\text { INL/EXT-18-51654 }\end{array}$} \\
\hline Efficiency & $80 \%$ & N/A & $79 \%$ \\
\hline \multicolumn{4}{|c|}{ Bale wagon/stacker } \\
\hline Capacity & 12 bales/load & 12 bales/load & 12 bales/load \\
\hline \multicolumn{4}{|l|}{ Baler } \\
\hline Capacity & 50 bales/hour & 25 bales/hour & 50 bales/hour \\
\hline Harvest yield & 1.2 tons/acre & 0.7 tons/acre & 3.5 tons/acre \\
\hline
\end{tabular}

a N/A, not applicable.

\section{A.2.2 Storage}

Field storage design assumptions for corn stover and switchgrass are included in the 2018 Herbaceous SOT. The current industry standard for assessing storage performance depends on the measure of dry matter loss. While losses occur during physical handling, such losses are minimized by best practices and are not considered a major factor for improvements within the storage operation. In contrast, dry matter losses via biological decomposition are highly variable, difficult to measure, and difficult to control. The primary factors that drive biological dry matter loss are moisture content of the biomass entering storage, the temperature and relative humidity as a function of time, oxygen availability, $\mathrm{pH}$, and the presence of inhibitory substances. The 2018 Herbaceous SOT assumes that $30 \%$ moisture content bales in storage for one year will result in an average 12\% dry matter loss (Cafferty et al. 2013a), identical to the assumption used for the 2017 Herbaceous SOT for corn stover. In the 2018 Herbaceous SOT, the dry matter losses are partitioned to individual corn stover components using the average losses of individual corn stover components observed in 3-month storage tests (Wendt et al. 2013) in the INL storage simulators at initial moisture contents ranging from $20-52 \%$ (Table A-5).

Table A-5. Average distribution of dry matter losses among corn stover components observed in 3-month storage tests in the INL storage simulators at initial moisture contents ranging from $20-52 \%$ (Wendt et al. 2013).

\begin{tabular}{cc}
\hline Component & $\begin{array}{c}\text { Fraction of Dry } \\
\text { Matter Lost (\%) }\end{array}$ \\
\hline Total C6 & $18.46 \%$ \\
\hline Total C5 & $28.93 \%$ \\
\hline Lignin & $6.45 \%$ \\
\hline Ash & $0.00 \%$ \\
\hline
\end{tabular}




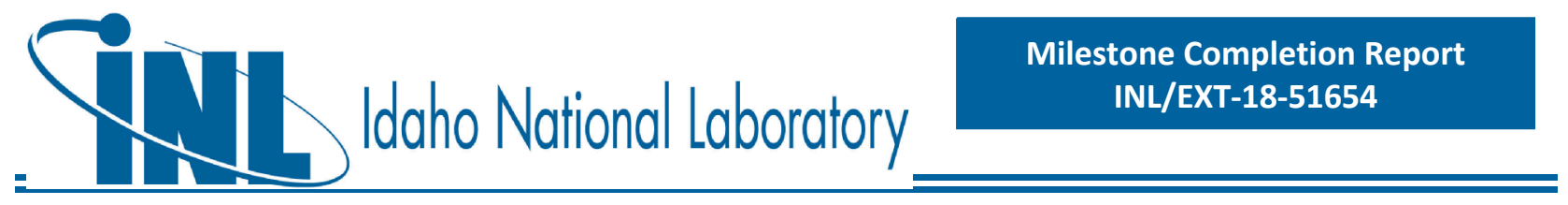

\begin{tabular}{cc}
\hline Protein & $3.00 \%$ \\
\hline Extractives & $29.99 \%$ \\
\hline Acetate & $13.18 \%$ \\
\hline \hline SUM & $100.00 \%$ \\
\hline
\end{tabular}

Additional storage assumptions are shown in Table A-6. The 2018 Herbaceous SOT assumes moisture loss of 5\% moisture from 30\% moisture corn stover bales during storage, which is a conservative estimate in comparison to the $10-14 \%$ moisture losses during bale storage observed in a storage study conducted by Shah et al. (2011). The 2018 Herbaceous SOT assumes 20\% moisture content bales resulting in $8 \%$ dry matter loss for switchgrass (because of its lower moisture content entering storage, the storage dry matter loss for switchgrass would be lower than that for corn stover). We assumed a conservative $2.5 \%$ moisture loss for switchgrass bales, again in line with its lower entering moisture content. Finally, we assumed the distribution of dry matter losses among compositional components to be identical to that observed for corn stover (Table A-5).

Table A-6. Field storage design assumptions for the 2018 Herbaceous SOT.

\begin{tabular}{lcc}
\hline \multicolumn{1}{c}{ Component } & Corn stover & Switchgrass \\
\hline Storage moisture content & $30 \%$ & $20 \%$ \\
\hline Storage dry matter loss & $12 \% /$ year & $8 \% /$ year \\
\hline Storage moisture loss & $5 \% /$ year & $2.5 \% /$ year \\
\hline Stack configuration & $4 \times 4$ tarped & $4 \times 4$ tarped \\
\hline
\end{tabular}

\section{A.2.3 Preprocessing}

The 2018 Herbaceous SOT incorporates several preprocessing technology changes (and improved measured data) from those used in the 2017 Herbaceous SOT, as well as improved pilot-scale data to guide moisture-loss assumptions during grinding and pelleting. The second-stage hammer mill was replaced with rotary shear, which is less sensitive to moisture content than hammer milling and has higher throughput with lower energy consumption.

The 2018 Herbaceous SOT design incorporates high moisture pelleting into corn stover and switchgrass preprocessing. In high moisture pelleting, the biomass is preheated to approximately $110^{\circ} \mathrm{C}$ for short durations (typically $5 \mathrm{~min}$ ) prior to pelleting. Depending on the temperature used, preconditioning biomass by preheating it can affect both its chemical composition and its behavior during mechanical densification processes such as pelleting. When these changes impact mechanical properties, thereby changing the way the feedstock responds during densification, the overall quality of the pellets 
can be improved (Bhattacharya et al. 1989, Tumuluru et al. 2010). Preheating can also increase the throughput of the pellet mill and reduce the energy requirement per kilogram of biomass pellets produced. When the preheat temperature is high enough to impact chemical composition, preheating can also enable production of higher-quality densified products for multiple end-use applications (Aqa et al. 1992, Bhattacharya 1993). Preheating in the presence of moisture can also promote softening of the natural binders in the biomass, including starch, lignin, and protein (Tumuluru 2014). Laboratory experiments performed under INL WBS 1.2.1.2 using flat-die and round-die pellet mills has shown that high durability pellets can be produced at an intermediate moisture content of 33-34\% (wet basis), preheating temperatures $>70^{\circ} \mathrm{C}$, and die speeds $>50 \mathrm{~Hz}$ (Tumuluru 2014).

The 2018 Herbaceous SOT eliminates the drying step during preprocessing of corn stover and switchgrass. Pilot-scale testing of high moisture pelleting and cooling performed under INL WBS 1.2.1.2 indicated that the conservative moisture loss assumptions used in 2016 during grinding and pelleting could be increased, which eliminated the need for drying the pelleted biomass. Reduced energy consumption for high moisture pelleting was also observed in the pilot-scale ring die pellet mill tests, as compared to the lab-scale flat die pellet mill values utilized in the 2016 Herbaceous SOT.

The 2018 Herbaceous SOT updates the percentage of material bypassed during fractional milling based on the pilot-scale testing performed under INL WBS 1.2.1.2. As shown in Figure A-4, fractional milling inserts a screening operation (disk screen) between the first-stage and second-stage grinding operations (the horizontal grinder and hammer mill, respectively) to remove the material that already meets the size specification before the material enters second-stage comminution. This reduces the amount of material that flows through the second-stage comminution, thereby reducing its size (cost) and energy consumption. In addition, fewer fines are produced because the material already meeting the particle size specification is not further ground. Hence, a tighter particle size distribution is achieved. Results from the pilot-scale testing performed under INL WBS 1.2.1.2 showed that $40.39 \%$ of the corn stover material meets particle size requirements after the first-stage grinder and can bypass the secondstage size reduction, thereby leading to significant savings. Pilot-scale testing with switchgrass performed specifically for this SOT analysis (was not required for the milestone) showed that $44.98 \%$ of the switchgrass material meets particle size requirements after the first-stage grinder and can bypass the second-stage size reduction. Experiments performed in the Biomass Feedstock User Facility (BFNUF) at INL (WBS 1.2.3.3) have shown that $1-2 \%$ of feedstock dry matter that arrives at the biorefinery gate is lost as dust during grinding, of which as much as $25 \%$ is ash. ${ }^{4}$ The organic fraction is generally comprised of fines generated from the leaves, which are thin and brittle and shatter from the hammer impacts during grinding.

Corn stover preprocessing for the 2018 Herbaceous SOT design is shown Figure A-4(a) for three-pass corn stover preprocessing, and in Figure A-4(b) for two-pass harvesting. Although the preprocessing operations are identical for both corn stover sources, they have been shown separately because their initial and intermediate moisture contents and compositions are different (these are shown at various stages within the figures). Input parameters (such as throughput and energy consumption) have been updated in Table A-7 for corn stover, based on pilot-scale results (WBS\# 1.2.1.2). Switchgrass preprocessing for the 2018 Herbaceous SOT design is shown Figure A-4(c). Again, although its preprocessing steps are identical to those of the corn stover types, it is shown separately to allow differences among the biomass sources' moisture and compositions to be shown throughout preprocessing. Input parameters for switchgrass are also presented in Table A-7.

${ }^{4}$ Personal communication regarding dust collection during preprocessing from Neal Yancey, INL researcher 


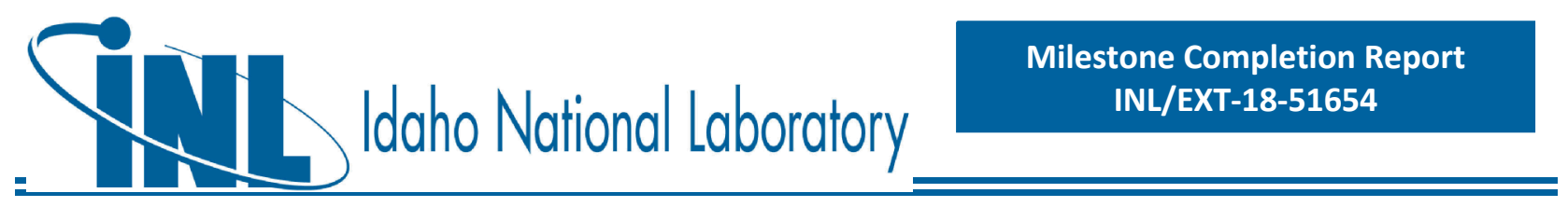

Figure A-4(d) shows the preprocessing steps for grass clippings. Grass clippings have been shown to have high ash content (Springer 2012, Thompson et al. 2015a, Thompson et al. 2015b), which typically varies from $12-15 \%$. Moisture content varies by location weather, and ranges from $60 \%-90 \%$ (Thompson et al. 2015a). It was assumed for this analysis that grass clippings would arrive at the grass clippings depot at an intermediate $70 \%$ moisture content nearer to the lower end of the range because of the relatively low humidity experienced in the Denver Metropolitan area (CurrentResults 2016). A solar dryer is assumed to dry the grass clippings from $70 \%$ to $15 \%$ moisture. Solar drying equipment and facilities costs were estimated based on several publicly available articles and technical descriptions of system requirements for drying similar biomass types (Robbins et al. 2013, Subahana et al. 2015). The design and assumptions for the solar drying system are provided in Appendix D. Shredding and densifying performance and energy usage for preprocessing grass clippings were estimated based on switchgrass preprocessing performance data from the INL PDU.

\section{A.2.4 Transportation and Handling}

The 2018 Herbaceous SOT incorporates both bale and pellet transportation. Baled biomass is shipped from field side storage to the depots, while pelleted blendstocks are shipped from depots to the biorefinery. Transportation operations include truck transportation and loading/unloading. Design assumptions for transportation and handling are outlined in Table A-8.

Transportation and handling includes all steps involved in the movement of biomass from multiple local locations to a centralized location (such as a preprocessing facility or biomass depot), including loading, trucking, and unloading. Like the 2017 Herbaceous SOT, the 2018 SOT uses the faster and more 

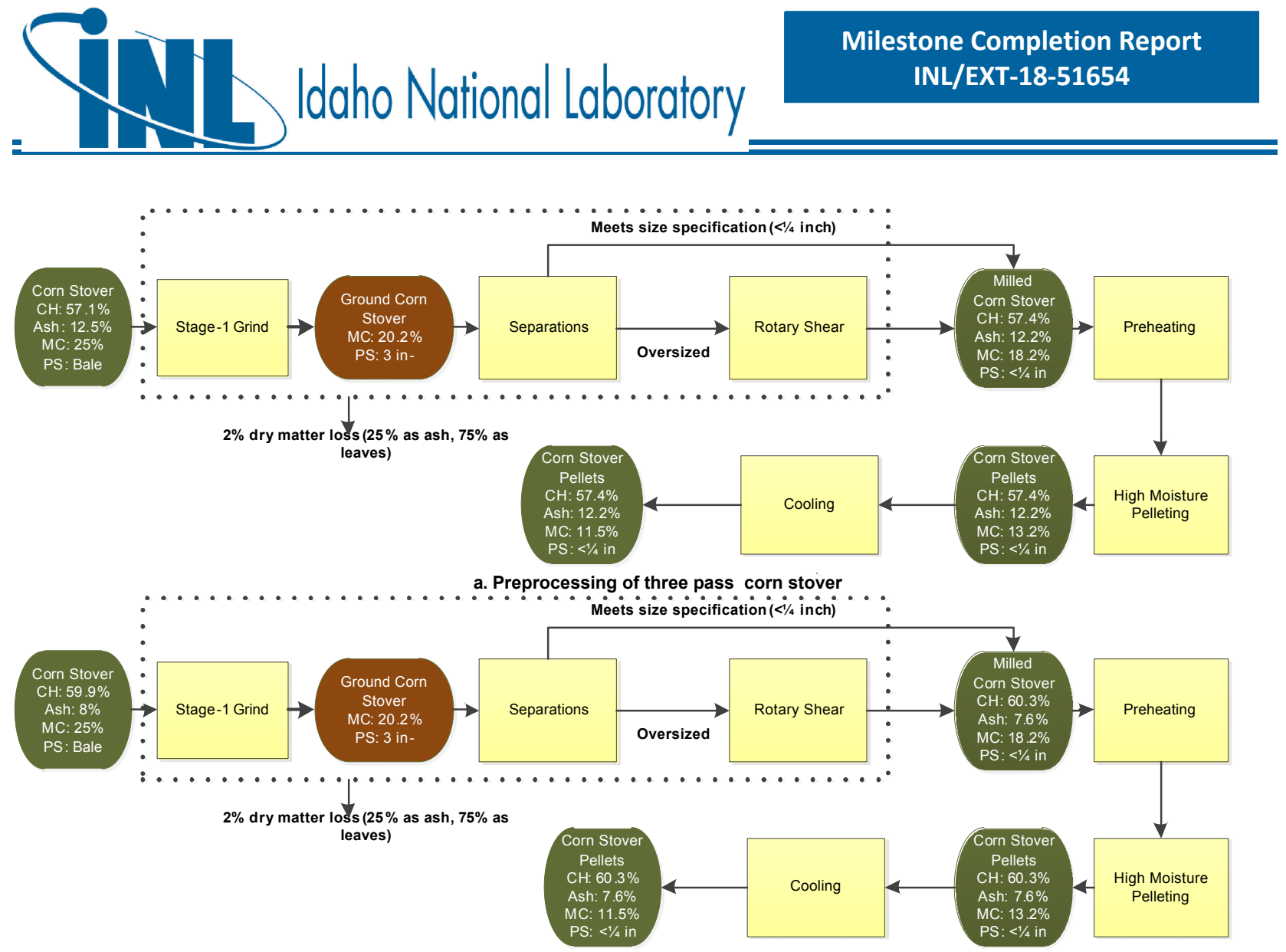

b. Preprocessing of two pass corn stover

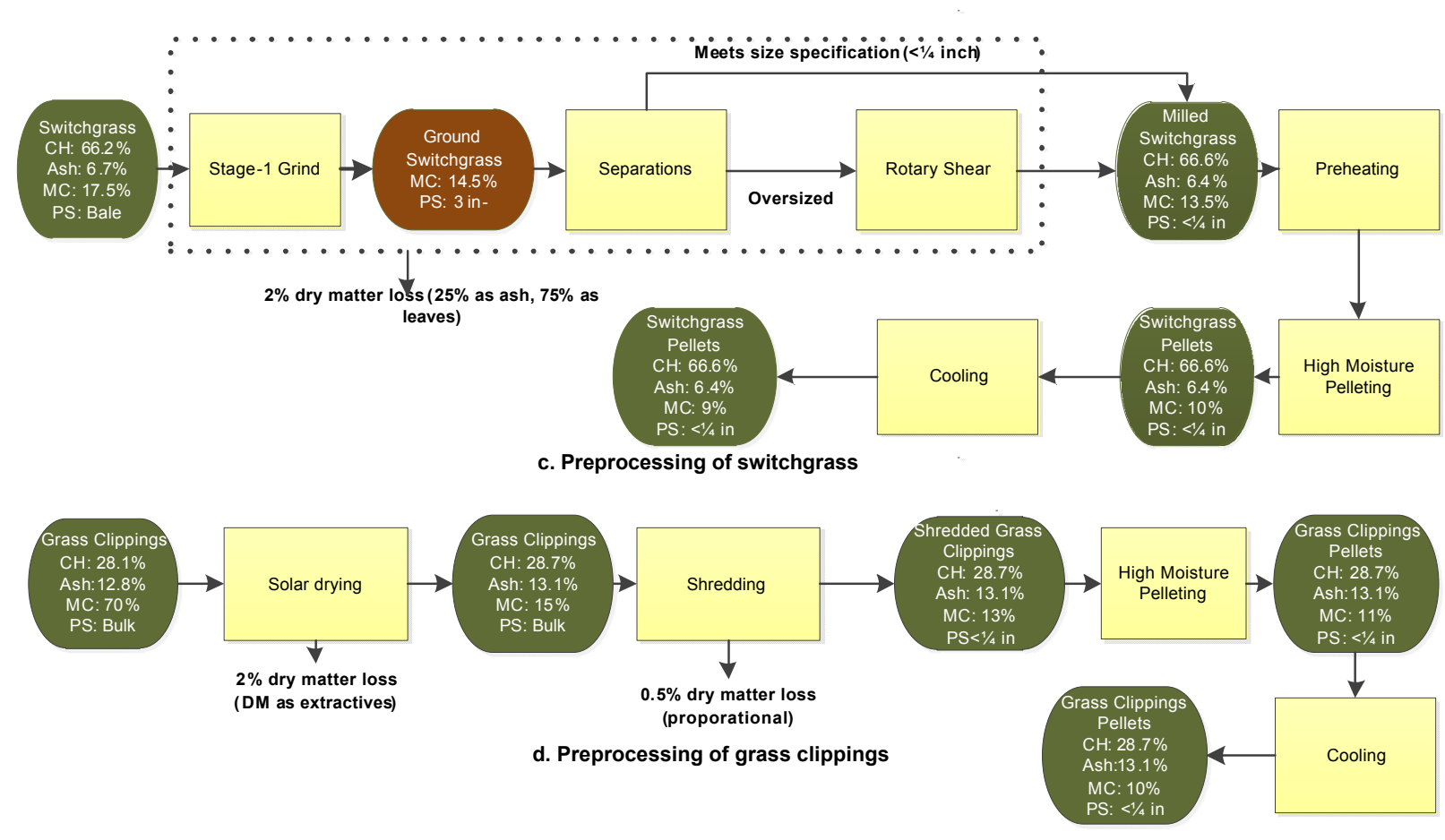

Figure A-4. 2018 Herbaceous SOT preprocessing configurations for corn stover, switchgrass and grass clippings. $C H=$ Carbohydrate content,$M C=$ moisture content,$P S=$ particle size. 


\section{NIIdaho National Laboratory \\ Milestone Completion Report \\ INL/EXT-18-51654}

Table A-7. Summary of 2018 Herbaceous SOT preprocessing assumptions. The benefit of fractional milling is included by adjusting the throughput and energy consumption of 2nd stage grinding.

\begin{tabular}{|c|c|c|c|}
\hline Component & $\begin{array}{l}\text { Three-Pass \& Two- } \\
\text { Pass Corn Stover }\end{array}$ & Switchgrass & Grass Clippings \\
\hline Location of operation & Depot Nodes 4, 6,12 & Depot Node 12 & Depot Node 14 \\
\hline \multicolumn{4}{|l|}{ Stage 1 size reduction } \\
\hline Grinder type & Hammer mill & Hammer mill & Shredder \\
\hline Screen Size (inch) & 3 & 3 & $1 / 4$ \\
\hline Energy (kWh/dry ton) & 12.86 & 19.91 & 3.92 \\
\hline Throughput (dry ton/hour/machine) & 3.336 & 4.54 & 7.8 \\
\hline Operating conditions (moisture \%) & $25.00 \%$ & $17.50 \%$ & $15.00 \%$ \\
\hline \multicolumn{4}{|l|}{ Separations } \\
\hline Screen type & Disk screen & Disk screen & N/A \\
\hline Energy (kWh/dry ton) & Minimal electricity & Minimal electricity & N/A \\
\hline Throughput (dry ton/hour/machine) & 5 & 5 & N/A \\
\hline Operating conditions (moisture \%) & $20.23 \%$ & $14.50 \%$ & N/A \\
\hline Bypass & $40.39 \%$ & $44.98 \%$ & N/A \\
\hline \multicolumn{4}{|l|}{ Stage 2 Grinder } \\
\hline Comminution method & Rotary shear & Rotary shear & $\mathrm{N} / \mathrm{A}$ \\
\hline Screen Size ( inch) & $0.25^{\mathrm{a}}$ & $0.25^{\mathrm{a}}$ & N/A \\
\hline Energy (kWh/dry ton) & $14.57\left(8.69^{b}\right)$ & $2.72\left(1.50^{c}\right)$ & N/A \\
\hline Throughput (dry ton/hour/machine) & $7.5\left(12.58^{\mathrm{b}}\right)$ & $7.5\left(13.63^{\mathrm{c})}\right.$ & N/A \\
\hline 76 & & & \\
\hline
\end{tabular}




\begin{tabular}{|c|c|c|c|}
\hline Operating conditions (moisture \%) & $18.23 \%$ & $13.50 \%$ & $\mathrm{~N} / \mathrm{A}$ \\
\hline \multicolumn{4}{|l|}{ Densifier } \\
\hline Densifier type & Pellet mill & Pellet mill & Pellet mill \\
\hline Energy (kWh/dry ton) & 36.24 & 60.2 & 82 \\
\hline Throughput (dry ton/hour/machine) & 3.38 & 3.5 & 4 \\
\hline Operating conditions (moisture \%) & $18.23 \%$ & $13.50 \%$ & $13.00 \%$ \\
\hline Pellet density $\left(\mathrm{lb} / \mathrm{ft}^{3}\right)$ & 39.42 & 41.56 & 35.00 \\
\hline Pellet durability & $98.70 \%$ & $97.60 \%$ & $97.60 \%$ \\
\hline \multicolumn{4}{|l|}{ Cooler } \\
\hline Moisture removed & $1.70 \%$ & $1.00 \%$ & $1.00 \%$ \\
\hline Energy (kWh/dry ton) & 3.02 & 3.02 & 3.02 \\
\hline Throughput (dry ton/hour/machine) & 5 & 5 & 5 \\
\hline
\end{tabular}


Table A-7. (Continued).

\begin{tabular}{llcc}
\hline \multicolumn{1}{c}{ Component } & $\begin{array}{c}\text { Three-Pass \& Two- } \\
\text { Pass Corn Stover }\end{array}$ & Switchgrass & Grass Clippings \\
\hline Dryer & N/A & N/A & $50 \%$ \\
\hline Moisture removed & N/A & N/A & 0 \\
\hline Energy (kWh/dry ton) & N/A & N/A & 5.55 \\
\hline Throughput (dry ton/hour/machine) & & & \\
\hline
\end{tabular}

a: Particle size after rotary shear was below 0.25 inch

b: The effective energy consumption is reduced because only $59.61 \%$ of the material is processed in Stage 2 due to fractional milling. The effective throughput is improved because only $59.61 \%$ of the material is processed in Stage 2 due to fractional milling

c: The effective energy consumption is reduced because only $55.02 \%$ of the material is processed in Stage 2 due to fractional milling. The effective throughput is improved because only $55.02 \%$ of the material is processed in Stage 2 due to fractional

efficient Advanced Load Securing System (ALSS) developed in the AGCO-led High-Tonnage Feedstock Logistics project (Webb et al. 2013a), and ensures that each load meets transportation regulations (Figure A-5) using industry data for loading and unloading times. By automating the operation, the ALSS allows the load to be secured without the driver leaving the cab of the tractor (STINGER 2015). The ALSS is reported to load an entire truck in as little as 6 minutes (STINGER 2015). Additional handling operations are required to transfer and queue biomass during preprocessing, and to transfer the blended feedstock to the pretreatment reactor. Surge bins, conveyors, and tipper are used in handling operations.

Flowability is defined as the relative movement of bulk particles in comparison to neighboring particles, and is a measurement of the cohesion and shear stresses in bulk materials. Ground materials (such as bulk corn stover) tend to bridge and clog openings. Flow obstruction, bridging, or arching in addition to inconsistent and unreliable movement of material are common problems in biomass handling and reactor feeding. Figure A-6 shows three common issues experienced in material handling. Arching (bridging) occurs when an arch-shaped obstruction forms above the hopper outlet and stops flow. Ratholing (funneling) occurs when discharge takes place only in a flow channel located above the outlet; once the central flow channel is empty, flow stops. Finally, incomplete clean-out is when not all of the material empties from the sides of the holding container. To address these characteristics, the 2018 Herbaceous SOT incorporates densification to improve feedstock flowability. 


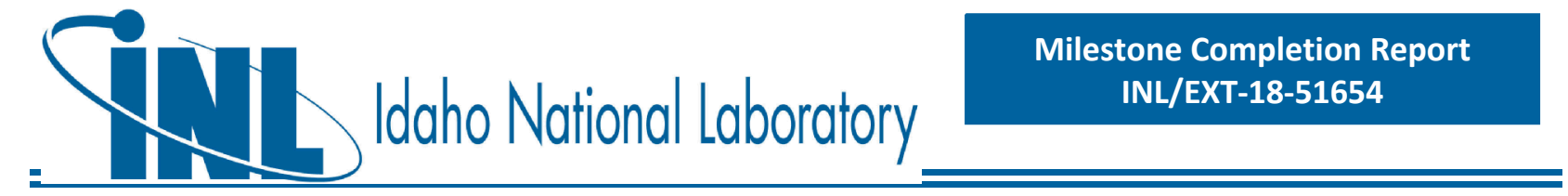




\section{YId Idaho National laboratory}

Table A-8. Transportation and handling design assumptions in the 2018 Herbaceous SOT.

\begin{tabular}{lcccc}
\hline Component & $\begin{array}{c}\text { Three-pass corn } \\
\text { Stover }\end{array}$ & $\begin{array}{c}\text { Two-pass corn } \\
\text { Stover }\end{array}$ & Switchgrass & Grass Clippings \\
\hline \multicolumn{2}{l}{ Biomass characteristics during transportation from field to depot } \\
Format & Bale & Bale & Bale & n.a \\
\hline Density & $121 \mathrm{~b} / \mathrm{ft}^{3}$ & $12 \mathrm{lb} / \mathrm{ft}^{3}$ & $12 \mathrm{lb} / \mathrm{ft}^{3}$ & $\mathrm{n} . \mathrm{a}$ \\
\hline $\begin{array}{l}\text { Moisture } \\
\text { content }\end{array}$ & $25 \%$ & $25 \%$ & $17.5 \%$ & $\mathrm{n} . \mathrm{a}$ \\
\hline
\end{tabular}

\begin{tabular}{|c|c|c|c|c|}
\hline Format & Bulk pellets & Bulk pellets & Bulk pellets & Bulk pellets \\
\hline Density & $39.42 \mathrm{lb} / \mathrm{ft}^{3}$ & $39.42 \mathrm{lb} / \mathrm{ft}^{3}$ & $41.56 \mathrm{lb} / \mathrm{ft}^{3}$ & $35 \mathrm{lb} / \mathrm{ft}^{3}$ \\
\hline $\begin{array}{l}\text { Moisture } \\
\text { content }\end{array}$ & $11.53 \%$ & $11.53 \%$ & $9.00 \%$ & $10.00 \%$ \\
\hline
\end{tabular}

\begin{tabular}{lcccc}
\hline \multicolumn{4}{l}{ Truck used during both } \\
transportation from field to depot and depot to biorefinery \\
Speed & 50 miles/hour & 50 miles/hour & 50 miles/hour & n.a \\
\hline Type & Day cab & Day cab & Day cab & n.a
\end{tabular}

\begin{tabular}{|c|c|c|c|c|}
\hline \multicolumn{5}{|c|}{ Trailer used during transportation from field to depot } \\
\hline Type & $\begin{array}{l}\text { 53-ft flatbed with } \\
\text { ALSS }\end{array}$ & $\begin{array}{c}\text { 53-ft flatbed with } \\
\text { ALSS }\end{array}$ & $\begin{array}{c}\text { 53-ft flatbed with } \\
\text { ALSS }\end{array}$ & n.a \\
\hline Volume & $3,600 \mathrm{ft}^{3}$ & $3,600 \mathrm{ft}^{3}$ & $3,600 \mathrm{ft}^{3}$ & n.a \\
\hline
\end{tabular}

Trailer used during transportation from depot to biorefinery

Type Trailer "Live Trailer "Live Trailer "Live Floor" Trailer "Live Floor"

Floor" 48 feet 2- $\quad$ Floor" 48 feet 2- $\quad 48$ feet 2-axle $\quad 48$ feet 2-axle axle axle 


\begin{tabular}{|c|c|c|c|c|}
\hline & & & \multicolumn{2}{|c|}{$\begin{array}{l}\text { Milestone Completion Report } \\
\text { INL/EXT-18-51654 }\end{array}$} \\
\hline Volume & $3,600 \mathrm{ft}^{3}$ & $3,600 \mathrm{ft}^{3}$ & $3,600 \mathrm{ft}^{3}$ & $3,600 \mathrm{ft}^{3}$ \\
\hline \multicolumn{5}{|c|}{ Bale Loader } \\
\hline Capacity & 120 tons/hour & 120 tons/hour & 120 tons/hour & 120 tons/hour \\
\hline
\end{tabular}

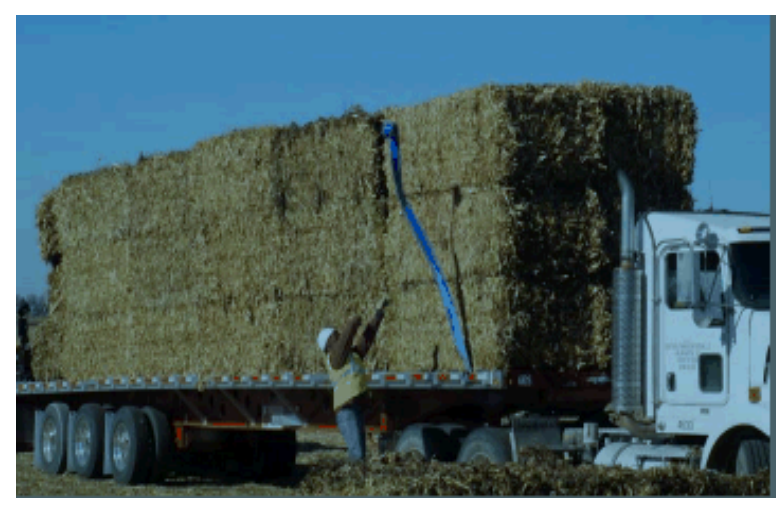

(a) Manual bale securing system

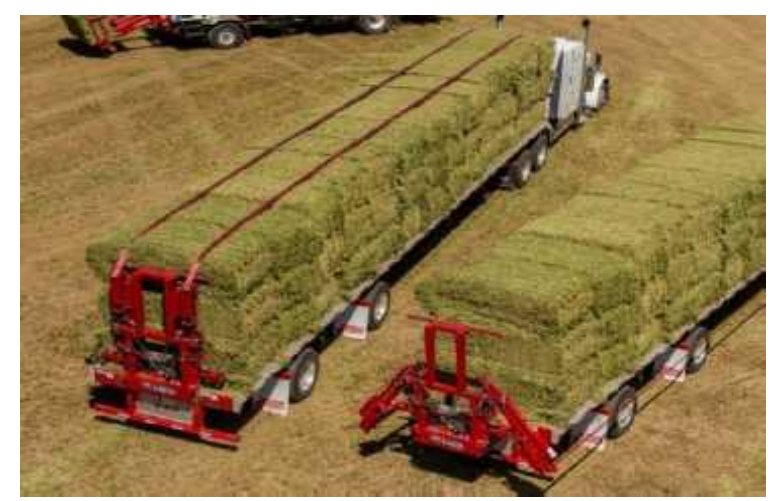

(b) Advanced load securing system

Figure A-5. Advanced Load Securing System (ALSS) replacing intense physical requirements to secure a load of bales in 2016 SOT (Source: Stinger)

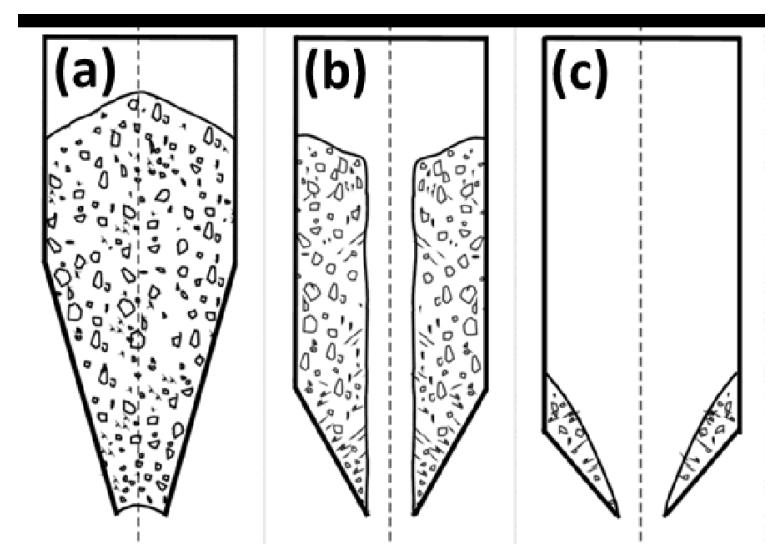

Figure A-6. Common flow and handling issues encountered when handling biomass. (a) Cohesive arch; (b) Rathole; and (c) Incomplete cleanout. (Source: www.pharmtech.com)

The 2018 Herbaceous SOT estimates transportation cost based on biomass physical characteristics and equipment used during transportation. Transportation cost has two components, the distance variable cost (DVC) and the distance fixed cost (DFC). The distance variable cost includes the cost of fuel and 


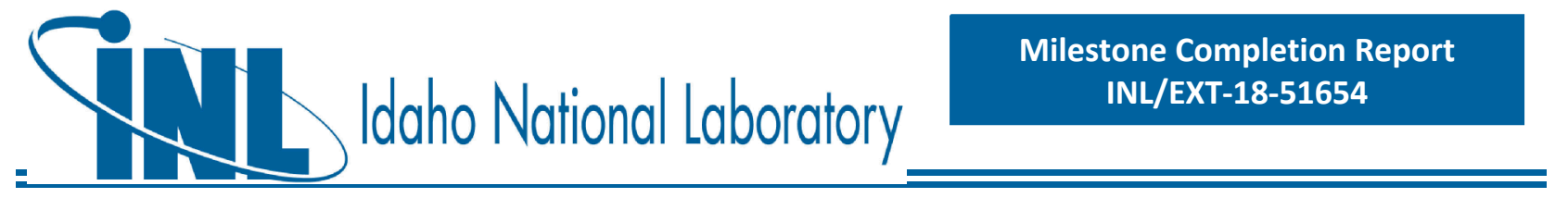

labor, while the distance fixed cost includes the cost of loading and unloading the truck. Linear regressions were performed to estimate DVC and DFC for each of the biomass bale and blendstock pellet types based on the transportation and handling design assumptions shown above in Table A-8. The regression models were used to estimate the DVC of corn stover and switchgrass bales at $\$ 0.114$ dry ton/mile, while the DFC for bale transportation was estimated at $\$ 3.42 /$ dry ton. The DVC for corn stover, switchgrass and grass clippings pellets were estimated to be $\$ 0.082 /$ dry ton $/ \mathrm{mile}, \$ 0.081 / \mathrm{dry}$ ton $/ \mathrm{mile}$, $\$ 0.081 /$ dry ton/mile respectively, with the DFC estimated at $\$ 0.829 /$ dry ton, $\$ 0.792 /$ dry ton, and $\$ 0.827 /$ dry ton, respectively. The values of DVC and DFC were utilized in the expanded least cost optimization model described in Appendix B, to determine the cost-optimum resource usage based on both transportation distance and grower payment. The total transportation costs for bales and pellets (including loading and unloading) are shown as a function of distance from the biorefinery in Table A-9.

Table A-9. Total transportation costs for biomass bales and blendstock pellets.

\begin{tabular}{|c|c|c|c|c|}
\hline \multirow[t]{2}{*}{$\begin{array}{l}\text { Distance } \\
\text { (mi) }\end{array}$} & \multirow{2}{*}{$\begin{array}{c}\text { Corn Stover \& } \\
\text { Switchgrass Bale } \\
\text { Transportation } \\
\text { Costs }\end{array}$} & \multicolumn{3}{|c|}{ Pelleted Blendstock Transportation Costs } \\
\hline & & $\begin{array}{l}\text { Corn Stover } \\
\text { (\$/dry ton) }\end{array}$ & $\begin{array}{l}\text { Switchgrass } \\
\text { (\$/dry ton) }\end{array}$ & $\begin{array}{c}\text { Grass Clippings } \\
\text { (\$/dry ton) }\end{array}$ \\
\hline 10 & $\$ 4.57$ & $\$ 1.66$ & $\$ 1.61$ & $\$ 1.64$ \\
\hline 20 & $\$ 5.72$ & $\$ 2.49$ & $\$ 2.48$ & $\$ 3.28$ \\
\hline 30 & $\$ 6.83$ & $\$ 3.33$ & $\$ 3.30$ & $\$ 3.99$ \\
\hline 40 & $\$ 8.00$ & $\$ 4.17$ & $\$ 4.02$ & $\$ 4.71$ \\
\hline 50 & $\$ 9.12$ & $\$ 4.96$ & $\$ 4.84$ & $\$ 5.44$ \\
\hline 60 & $\$ 10.24$ & $\$ 5.79$ & $\$ 5.65$ & $\$ 6.17$ \\
\hline 70 & $\$ 11.40$ & $\$ 6.63$ & $\$ 6.47$ & $\$ 6.90$ \\
\hline 80 & $\$ 12.52$ & $\$ 7.47$ & $\$ 7.29$ & $\$ 7.62$ \\
\hline 90 & $\$ 13.69$ & $\$ 8.26$ & $\$ 8.11$ & $\$ 8.35$ \\
\hline 100 & $\$ 14.80$ & $\$ 9.10$ & $\$ 8.93$ & $\$ 9.08$ \\
\hline 120 & $\$ 17.09$ & $\$ 10.77$ & $\$ 10.47$ & $\$ 11.67$ \\
\hline 140 & $\$ 19.37$ & $\$ 12.40$ & $\$ 12.10$ & $\$ 13.13$ \\
\hline 160 & $\$ 21.66$ & $\$ 14.08$ & $\$ 13.74$ & $\$ 14.60$ \\
\hline 180 & $\$ 23.95$ & $\$ 15.72$ & $\$ 15.28$ & $\$ 16.06$ \\
\hline 200 & $\$ 26.23$ & $\$ 17.39$ & $\$ 16.92$ & $\$ 17.52$ \\
\hline 220 & $\$ 28.46$ & $\$ 19.02$ & $\$ 18.55$ & $\$ 18.97$ \\
\hline 240 & $\$ 30.74$ & $\$ 20.70$ & $\$ 20.01$ & $\$ 20.42$ \\
\hline
\end{tabular}

Once the optimum resource supply, volume and depot locations were determined, an average weighted transportation distance was calculated for the different types of biomass and the pelleted blendstocks. Table A-10 summarizes the transported biomass, weighted transportation distance and 


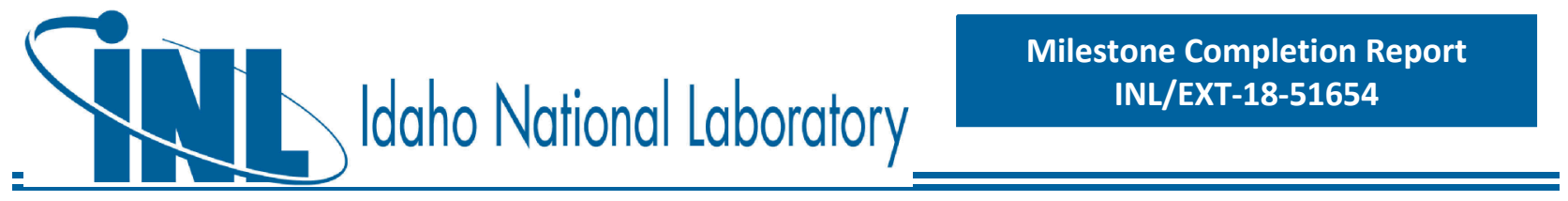

average transportation cost for various biomass and pellet from field to depot and depot to biorefinery in the 2018 Herbaceous SOT. The average weighted transportation distances from field to biorefinery of three-pass corn stover, two-pass corn stover and switchgrass were 80.68 miles, 104.01 miles and 66 miles respectively. 
Table A-10. Summary of transported biomass, weighted transportation distance and average transportation cost for various biomass and pellet from field to depot and depot to biorefinery in the 2018 Herbaceous SOT case.

\begin{tabular}{lccccccc}
\hline Biomass & Raw & \multicolumn{3}{c}{ Fields to Depots } & \multicolumn{3}{c}{ Depots to Biorefinery } \\
\cline { 3 - 8 } & $\begin{array}{c}\text { Biomass } \\
\text { Purchased } \\
\text { (dry tons) }\end{array}$ & $\begin{array}{c}\text { Biomass } \\
\text { Trans- } \\
\text { ported } \\
\text { (dry tons) }\end{array}$ & $\begin{array}{c}\text { Weighted } \\
\text { Trans- } \\
\text { portation } \\
\text { Distance } \\
\text { (miles) }\end{array}$ & $\begin{array}{c}\text { Average } \\
\text { Trans- } \\
\text { portation } \\
\text { cost } \mathbf{\$} / \\
\text { dry ton) }\end{array}$ & $\begin{array}{c}\text { Pellets } \\
\text { Trans- } \\
\text { ported } \\
\text { (dry tons) }\end{array}$ & $\begin{array}{c}\text { Weighted } \\
\text { Trans- } \\
\text { portation } \\
\text { Distance } \\
\text { (miles) }\end{array}$ & $\begin{array}{c}\text { Average } \\
\text { Trans- } \\
\text { portation } \\
\text { cost (\$/ } \\
\text { dry ton) }\end{array}$ \\
\hline $\begin{array}{l}\text { Three-pass } \\
\text { corn stover }\end{array}$ & 107,084 & 94,234 & 15.15 & $\$ 5.14$ & 92,349 & 64.60 & $\$ 6.20$ \\
\hline $\begin{array}{l}\text { Two-pass } \\
\text { corn stover }\end{array}$ & 615,563 & 541,696 & 26.24 & $\$ 6.40$ & 530,862 & 75.68 & $\$ 7.12$ \\
\hline Switchgrass & 79,026 & 72,704 & 38.10 & $\$ 7.74$ & 71,250 & 29.94 & $\$ 3.25$ \\
\hline $\begin{array}{l}\text { Grass } \\
\text { clippings }\end{array}$ & 31,322 & - & - & - & 30,539 & 220.00 & $\$ 19.18$ \\
\hline Blended & 832,995 & 708,634 & 24.88 & $\$ 6.10$ & 725,000 & 75.85 & $\$ 7.13$ \\
\hline
\end{tabular}

\section{A.2.5 Depot construction cost for different depot sizes}

Construction and infrastructure costs for depots were estimated as follows. For a fixed depot size, the total installed capital investment cost per ton was estimated for the preprocessing, storage and handling operations in the depot. The installed capital cost included all preprocessing, handling and storage equipment; the estimate included instrumentation and control, piping and electrical installation, yard improvement, engineering and supervision, contractor fees, construction and contingency. To estimate the capital layout for construction and infrastructure for individual preprocessing equipment similar to the equipment in this design, an installation factor value of 1.49 was applied, estimated based on Peters et al. (1968). Land cost was calculated assuming 160 acres per distributed depot (including onsite bale storage) at a cost of $\$ 500 /$ acre, and was added to the capital cost to determine the loan amount. The required acreage for a 725,000 dry tons/year depot (including onsite bale storage) was estimated at 226 acres. The total cost was amortized over 30 years, assuming a $20 \%$ down payment and an $8 \%$ interest rate, and divided by the number of delivered tons to give the per ton cost of depot construction and infrastructure, which totaled $\$ 2.68$ /dry ton for a depot scaled to 725,000 dry tons/year. The above steps were repeated for depot scales ranging from 25,000-700,000 dry tons/year, and the results are shown in Figure A-7.

\section{A.2.6 Blending}

Pellets of each individual blendstock are conveyed into separate storage bins upon receipt from the depots. Pellets are blended in the biorefinery just prior to introduction to the pretreatment reactor feeding system, and are blended to the desired ratio during conveyance to the feeder. The three-pass corn stover, two-pass corn stover, switchgrass and grass clippings pellets are blended at a ratio of $12.74 \% / 73.22 \%$ / $9.83 \% / 4.21 \%$, respectively, and the blend is conveyed to the throat of the pretreatment reactor. 

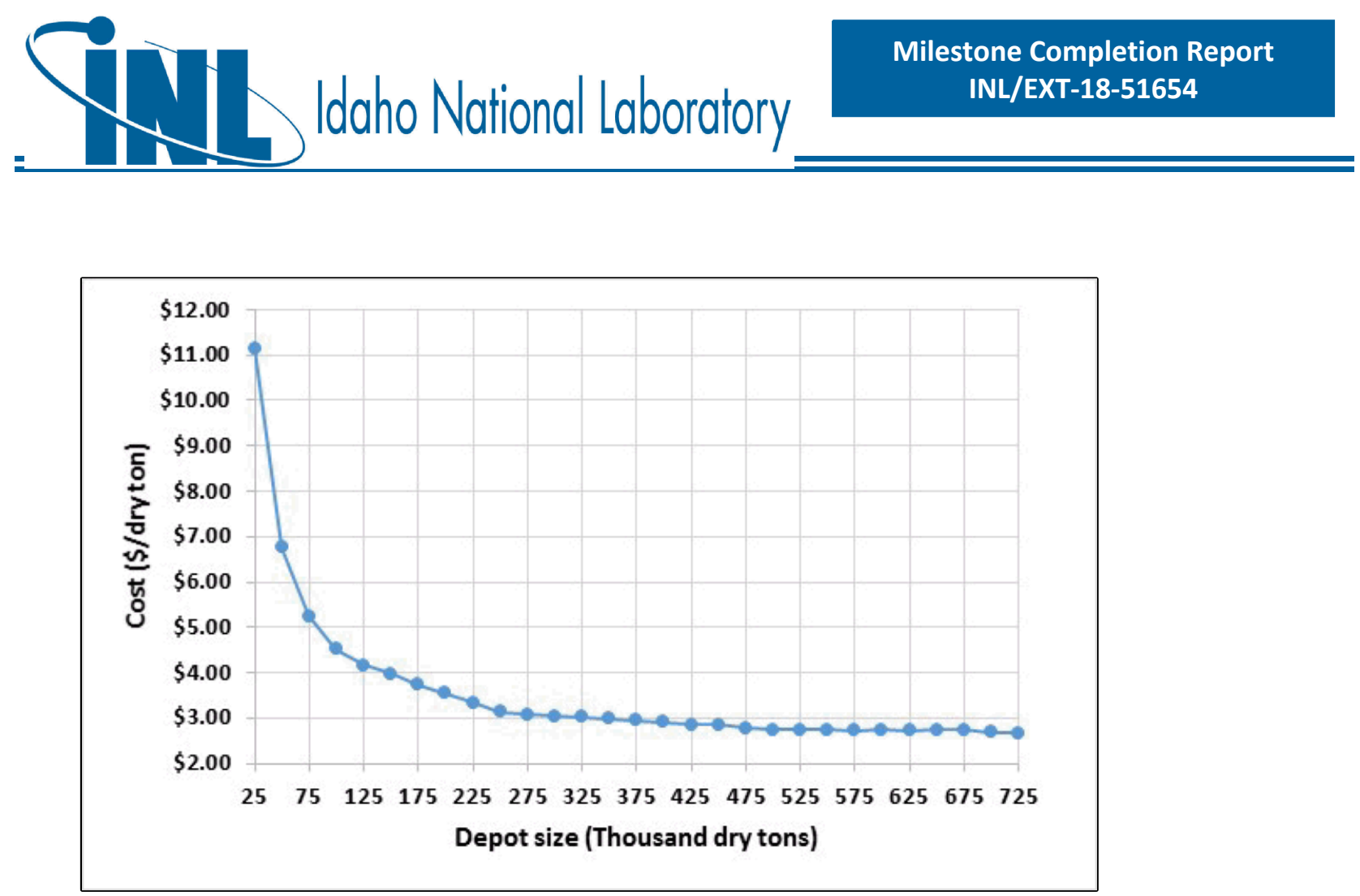

Figure A-7. Estimated depot construction costs as a function of depot scale.

\section{A.2.7 Cost Breakdown by Operation}

As described above, an ash dockage equivalent to the biorefinery cost of disposing of ash in excess of the ash specification is applied in the 2017 Herbaceous SOT. Ash disposal costs are assumed to be $\$ 37.63$ dry ton of ash (Davis et al. 2013). Delivering the feedstock blend at $10 \%$ rather than $20 \%$ moisture would incur a cost of to the biorefinery in the form of additional make-up water. This value was calculated from the assumed make-up water cost of $\$ 0.31 /$ ton of water used by Davis et al. (2013). Table A-11 shows the cost breakdown by operation for the individual blendstocks 


\section{NIIdaho National Laboratory

Table A-11. 2018 Herbaceous SOT modeled costs for production of blendstock pellets, by operation.

\begin{tabular}{|c|c|c|c|c|}
\hline Cost Element & $\begin{array}{c}\text { Three-Pass } \\
\text { Corn Stover } \\
\text { (\$/dry ton) }\end{array}$ & $\begin{array}{l}\text { Two-Pass } \\
\text { Corn Stover } \\
\text { (\$/dry ton) }\end{array}$ & $\begin{array}{l}\text { Switchgrass } \\
\text { (\$/dry ton) }\end{array}$ & $\begin{array}{c}\text { Grass } \\
\text { Clippings } \\
\text { (\$/dry ton) } \\
\end{array}$ \\
\hline Grower payment $t^{a}$ & $\$ 26.66$ & $\$ 21.71$ & $\$ 38.87$ & $\$ 10.13$ \\
\hline Harvest and collection & $\$ 13.84$ & $\$ 18.79$ & $\$ 11.76$ & $\$ 0.00$ \\
\hline Combine & $\$ 0.00$ & $\$ 0.00$ & $\$ 0.00$ & $\$ 0.00$ \\
\hline Shredder & $\$ 4.10$ & $\$ 4.10$ & $\$ 1.85$ & $\$ 0.00$ \\
\hline Baler & $\$ 6.29$ & $\$ 11.24$ & $\$ 6.38$ & $\$ 0.00$ \\
\hline Stacker & $\$ 3.45$ & $\$ 3.45$ & $\$ 3.53$ & $\$ 0.00$ \\
\hline Storage \& queuing & $\$ 6.40$ & $\$ 6.53$ & $\$ 5.89$ & $\$ 6.57$ \\
\hline Field side storage & $\$ 3.97$ & $\$ 4.10$ & $\$ 3.02$ & $\$ 0.00$ \\
\hline Depot storage & $\$ 0.88$ & $\$ 0.88$ & $\$ 0.88$ & $\$ 0.61$ \\
\hline Refinery storage & $\$ 0.12$ & $\$ 0.12$ & $\$ 0.22$ & $\$ 0.15$ \\
\hline Handling and queuing at depot & $\$ 1.21$ & $\$ 1.21$ & $\$ 1.34$ & $\$ 4.50$ \\
\hline Handling and queuing at refinery & $\$ 0.22$ & $\$ 0.22$ & $\$ 0.43$ & $\$ 1.31$ \\
\hline Transportation and handling & $\$ 11.35$ & $\$ 13.52$ & $\$ 11.00$ & $\$ 19.18$ \\
\hline Transportation from field to depot & $\$ 5.14$ & $\$ 6.40$ & $\$ 7.75$ & $\$ 0.00$ \\
\hline Transportation from depot to refinery & $\$ 6.21$ & $\$ 7.12$ & $\$ 3.25$ & $\$ 19.18$ \\
\hline In-plant receiving and preprocessing & $\$ 22.65$ & $\$ 22.65$ & $\$ 22.05$ & $\$ 20.23$ \\
\hline Depot construction cost & $\$ 3.18$ & $\$ 3.18$ & $\$ 3.18$ & $\$ 0.00$ \\
\hline Drying & $\$ 0.00$ & $\$ 0.00$ & $\$ 0.00$ & $\$ 5.17$ \\
\hline 86 & & & & \\
\hline
\end{tabular}




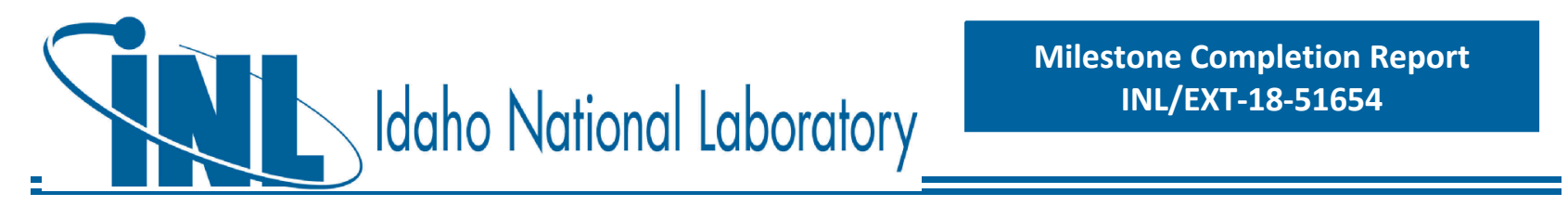

\begin{tabular}{|c|c|c|c|c|}
\hline Grinder 1/shredder & $\$ 10.41$ & $\$ 10.41$ & $\$ 8.51$ & $\$ 1.69$ \\
\hline Rotary shear & $\$ 1.52$ & $\$ 1.52$ & $\$ 0.91$ & $\$ 0.00$ \\
\hline Densifier & $\$ 5.99$ & $\$ 5.99$ & $\$ 7.77$ & $\$ 10.06$ \\
\hline Cooling & $\$ 0.32$ & $\$ 0.32$ & $\$ 0.32$ & $\$ 0.32$ \\
\hline Conveyors & $\$ 0.15$ & $\$ 0.15$ & $\$ 0.20$ & $\$ 0.86$ \\
\hline Dust collection & $\$ 0.74$ & $\$ 0.74$ & $\$ 0.78$ & $\$ 0.69$ \\
\hline Surge bin & $\$ 0.05$ & $\$ 0.05$ & $\$ 0.06$ & $\$ 0.41$ \\
\hline Misc. Equipment ${ }^{\mathrm{b}}$ & $\$ 0.22$ & $\$ 0.22$ & $\$ 0.22$ & $\$ 0.49$ \\
\hline Blending & $\$ 0.07$ & $\$ 0.07$ & $\$ 0.10$ & $\$ 0.54$ \\
\hline Dockage & $\$ 2.74$ & $\$ 1.01$ & $\$ 0.56$ & $\$ 3.08$ \\
\hline Ash dockage & $\$ 2.71$ & $\$ 0.98$ & $\$ 0.53$ & $\$ 3.05$ \\
\hline Moisture dockage & $\$ 0.03$ & $\$ 0.03$ & $\$ 0.03$ & $\$ 0.03$ \\
\hline Total delivered blendstock cost & $\$ 83.64$ & $\$ 84.21$ & $\$ 90.13$ & $\$ 59.19$ \\
\hline
\end{tabular}

a The grower payment cost for MSW implies the cost of procuring grass clippings.

b Miscellaneous equipment consists of destringers, moisture meters, bale rejecters, electromagnets, etc. 


\section{APPENDIX B - Optimization of Blending Based on Quality, Resource Availability, Location and Cost}

By combining analyses using farm gate price assumptions from the BT16 report with quality specifications and compositional variability obtained from the Bioenergy Feedstock Library, gains in the projected volumes of available biomass capable of meeting cost and biorefinery requirements can be realized by transitioning to a blended feedstock approach. Feedstock blending allows a conversion facility to collect less of any one biomass source, thus paying a lower average price for each feedstock by moving down the supply cost curve. Biomass quality is a key consideration when analyzing cost and volume availability of blended feedstocks. Formulating a feedstock through blending and other advanced preprocessing methods allows low cost and low quality biomass to be blended with biomass of higher cost and higher quality to achieve in-feed specifications of a conversion facility. The use of low cost biomass can enable the supply chain to implement additional preprocessing technologies to actively control feedstock quality, while also bringing more biomass into the system.

The technique that was utilized to determine the least-cost blend was Mixed-Integer Linear Programming (MILP). MILP is a method of mathematical optimization in which some of the decision variables are restricted to integer values. Through this approach the single-feedstock paradigm is challenged by allowing multiple available resources to be chosen based on net total cost, quantity and quality considerations. The 2018 Herbaceous SOT incorporates improvements in the MILP models over the 2016 and 2017 models, including the incorporation of local distributed preprocessing depots to deliver biomass to the biorefinery. Because local distributed preprocessing depots produce a tradable commodity that is stable, dense and flowable, deploying locally-distributed preprocessing depots result in cost efficient transportation to the biorefinery. The incorporation of local distributed preprocessing depots also creates an opportunity to access isolated and low-yield areas. The MILP model has captured local distributed preprocessing depots in the supply chain network modeling to determine the least cost blend while identifying optimal depot numbers, locations and sizes. The 2018 Herbaceous SOT showed a delivered feedstock cost benefit for decentralized depots by decoupling the biorefinery and feedstock locations, in comparison to centralized preprocessing co-located with the biorefinery. Delivered feedstock costs were estimated from two MILP models developed for the decentralized depots and centralized depot cases. The definitions of the sets, parameters and variables used in the formulation of the optimization problem are described in Table B-1.

\section{B-1 MILP Model for Distributed Depot Cases}

The model developed in this case uses a distributed depot structure to design the in-bound feedstock supply chain of a biorefinery. The goal of the MILP model in this case is to determine a least-cost blended feedstock from multiple biomass sources to meet conversion specifications, while also identifying appropriate depot locations and size. For the 2018 SOT case where grass clippings are allowed in the blend, it was assumed that depot location for grass clippings is predetermined, and therefore the model does not identify the depot location for the grass clippings; this was done because the grass clippings are concentrated at a single location distant from the biorefinery and must be pelleted for 


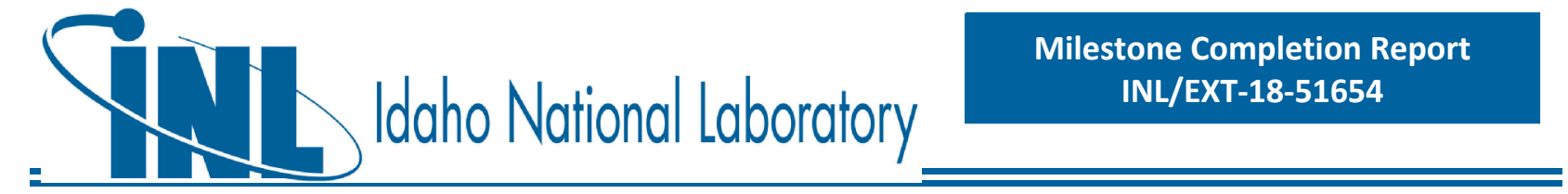

efficient transport. 


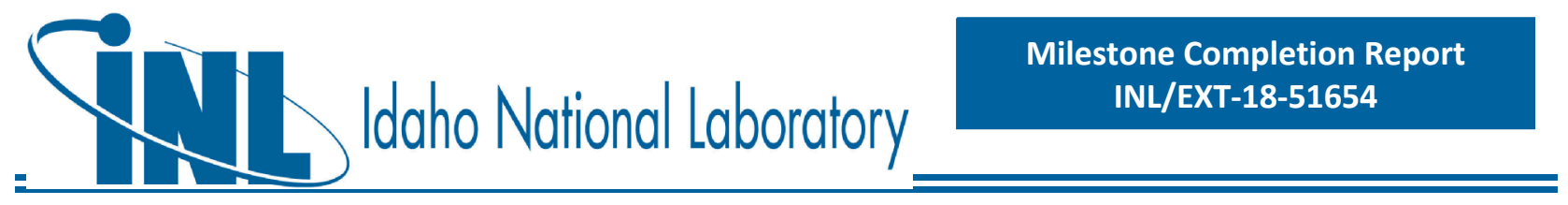

Table B-1. Summary of the definitions of sets, parameters and decision variables used in this analysis.

\section{Set definitions}

$\begin{array}{ll}\boldsymbol{H} & \text { Set of field sites } \\ \boldsymbol{I} & \text { Set of feedstock storage locations } \\ \boldsymbol{F} & \text { Set of feedstocks } \\ \boldsymbol{P} & \text { Set of feedstock prices } \\ \boldsymbol{J} & \text { Set of candidate locations of depots } \\ \boldsymbol{B} & \text { Set of biorefinery locations }\end{array}$

\section{Parameters}

\section{Feedstock Quality}

Percent dry matter loss at location $i$ for feedstock type $f$

Percent carbohydrate content (dry basis) in feedstock type $f$

\section{Field side}

Supply quantity (dry basis) of feedstock $f$, at location $i$ at price

Grower payment at location $i$ for feedstock $f$

Harvesting and collection cost at field side $i$ for feedstock $f$ 


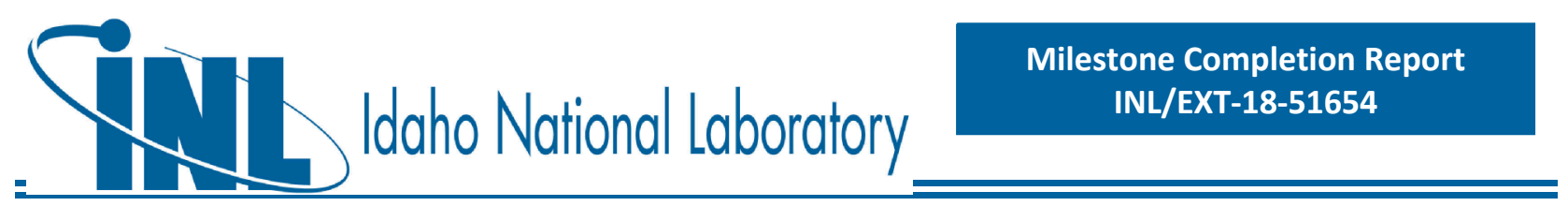

Storage cost at field side $i$ for feedstock $f$

Field side to depot

Transportation cost from location $i$ to depot $j$ for feedstock type $f$

\section{Depot}

Capacity $k$ of depot at location $j$

Construction cost of depot at location $j$ with capacity $\mathrm{k}$

Preprocessing cost of feedstock $f$, at location $i$

Storage cost at $\operatorname{depot} j$ for feedstock $f$

Handling and queuing cost at depot $j$ for feedstock $f$

Capacity utilization of depot at location $j$

Depot to biorefinery reactor throat

Demand quantity for dry biomass at location $j$

Required percent of carbohydrate content in blended feedstock

Transportation cost from depot location $i$ to the selected biorefinery $j$ for feedstock type $f$

Storage cost at biorefinery $j$ for feedstock $f$

Handling and queuing cost at biorefinery $j$ for feedstock $f$

Blending cost at biorefinery $j$ for feedstock $f$ 


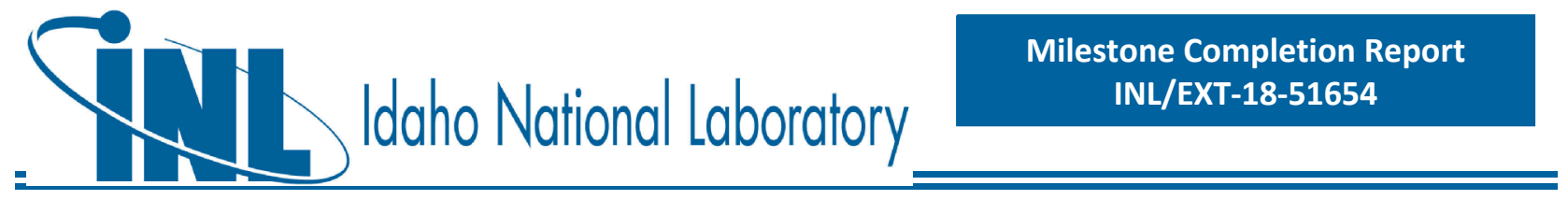

\section{Other parameter}

Distance from supply location $i$ to the selected biorefinery for feedstock $f$

Depot capacity utilization factor

Two-pass corn stover resource availability factor

\section{Decision variables}

Supplied biomass of type $f$ at price from location $i$ to $j$

The decentralized depot MILP model contains three decision variables. The variable is a

continuous variable that represents the flow of biomass type from location $i$ to $j$ at purchase price $p$.

is a binary variable used to select a specific farm gate price $p$ of biomass $f$ from location $i$. is a binary 


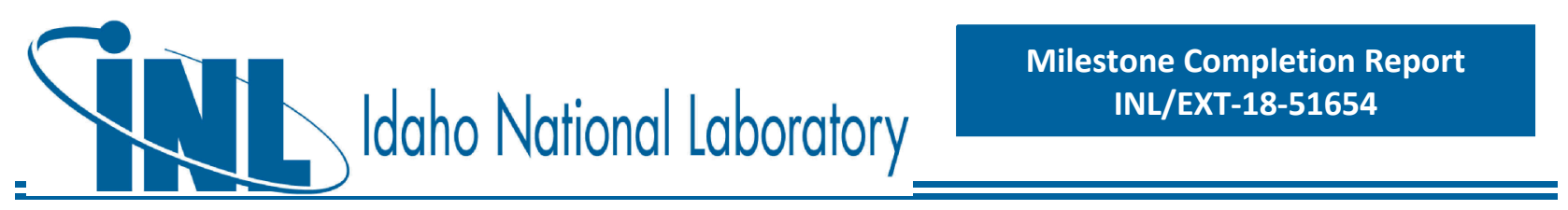

variable used to select a depot at location $j$ with capacity $k$.

The objective of the optimization model is to minimize the total cost of the feedstock delivered to the throat of the reactor. The total cost is the summation of the farm gate cost, transportation cost from field to depot, amortized depot construction and capital costs, depot operating costs, transportation of pellets from the depot to the biorefinery, and handling and feeding costs to the biorefinery reactor throat. The total farm gate cost is shown in Eq. B-1, where $g_{i f p}$ is the grower payment for feedstock $f$ purchased at

location $i$ at a specific farm gate price $p$, is the harvesting and collection cost at field-side $i$ for

feedstock $f$, and is the storage cost at field-side $i$ for feedstock $f$. The grower payment is the BT16 farm

gate cost minus the harvesting cost.

The cost from field-side to depot is shown in Eq. B-2, where is the transportation cost from location $i$

to depot $j$ for feedstock type $f$, is the handling and queuing cost at depot $j$ for feedstock $f$, is the

preprocessing cost of feedstock $f$ at depot location $i$ (including both amortized capital and operating costs), is the storage cost at depot $j$ for feedstock $f$, and is the amortized construction cost of a depot 


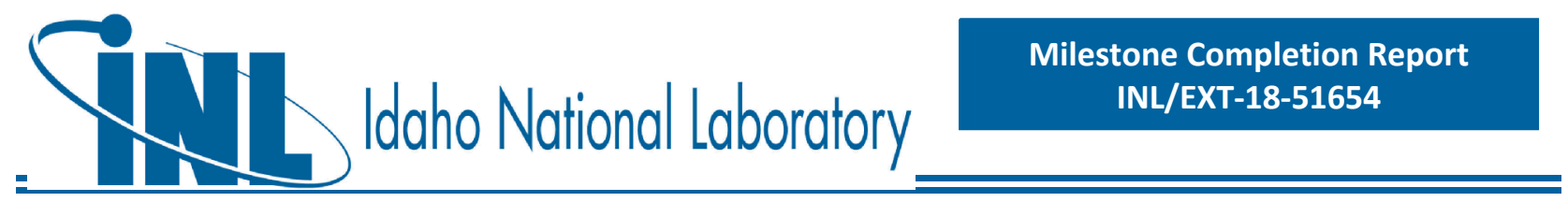

at location $j$ with capacity $k$.

The cost from depot to biorefinery reactor throat is shown in Eq. B-3, where is the transportation cost

from depot location $i$ to the selected biorefinery $j$ for feedstock type $f$, is the storage cost at biorefinery $j$

for feedstock $f$, is the handling and queuing cost at biorefinery $j$ for feedstock $f$ and is the blending cost at biorefinery $j$ for feedstock $f$.

Transportation cost from a depot to the biorefinery, $t_{i f}$, is based on truck transportation and considers that a distance-variable cost, , occurs per ton-mile and per ton shipped due to fuel consumption. 


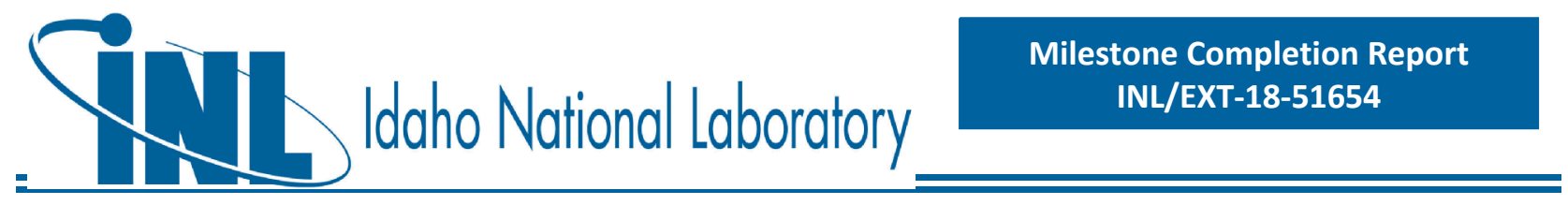

Additionally, a distance-fixed cost, , occurs for each ton loaded/unloaded in the truck for feedstock

typef. Defining as the distance traveled from location $i$ to the selected biorefinery for feedstock $f$, the

transportation cost/ton shipped from a depot to the biorefinery is equal to (Eq. B-4):

The cost objective function that minimizes the total cost of the feedstock delivered to the throat of the reactor is then defined as follows (Eq. B-5):

Let the set of feedstocks, where denotes three-pass corn stover, denotes two-pass corn stover,

denotes switchgrass, and denotes grass clippings. The MILP model (referring to this formulation as 


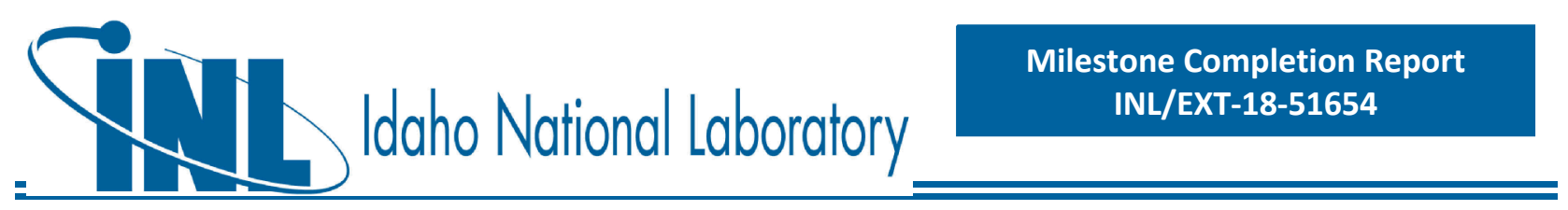

$P-1)$ is bound by a number of constraints on the solution. The first constraints (B-6) are a limit on the

amount of biomass that can be shipped from a supply location, and are tied to county-level farm gate availability from the BT16 report. Constraint B-7 limits the total access of two-pass and three-pass corn stover availability from a county at a specific farm gate price from the BT16 report. Constraint B-8 limits the access to biomass feedstocks in a supply location to what is available at one point along the supply curve. Constraint B-9 limits the biomass flow from field storage to depot after counting losses in the field storage. Constraints B-10 are the total biomass flow balance constraints at depots. Constraints B-11 are the flow balance constraints for a specific biomass at depots.

These flow balances accounted the biomass losses during preprocessing. Constraints B-12 set a limit on the capacity of a depot. Constraints B-13 enforce a minimum depot capacity utilization. Constraints B14 set a limit on the number of depot at a particular location. Constraint B-15 enforces that the total quantity of all delivered feedstock, accounting for losses, must at a minimum meet the required demand of the biorefinery. Constraint B-16 requires that the delivered feedstock, after accounting for compositional changes due to dry matter loss in the supply chain, meet a minimum specified carbohydrate content requirement. Constraints B-17 are a non-negativity constraint on the decision variables. Finally constraints B-18 and B-19 are the binary constraints on the decision variables. 


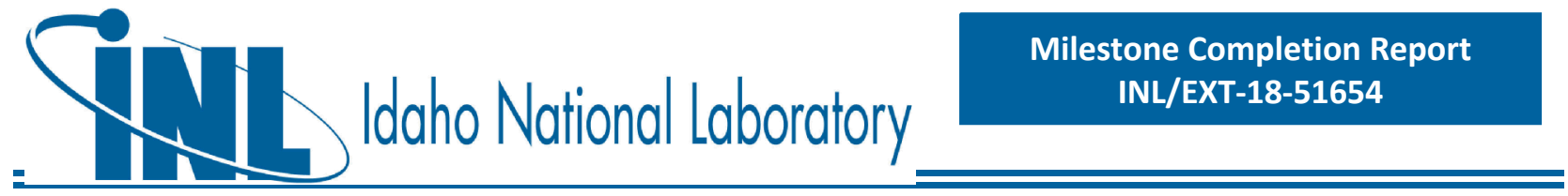

B-9

B-10

B-11

B-12

B-13

B-14

B-15

B-16

B-17 


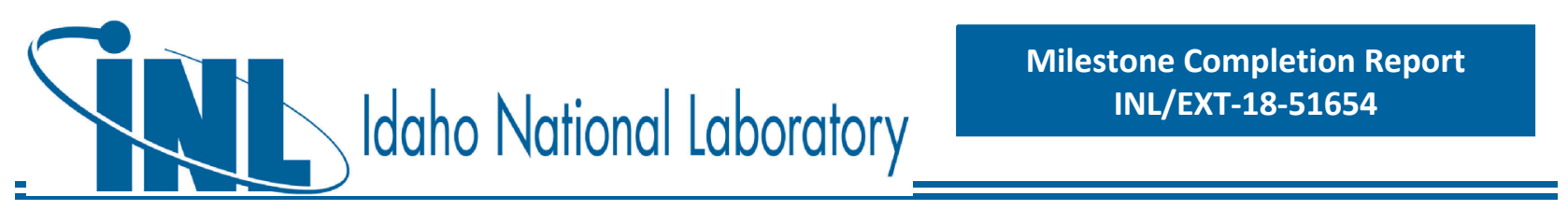

B-18

B-19

\section{B-2 MILP Model for Centralized Cases (Primary Depot Co-Located with the Biorefinery)}

The centralized depot model assumes that corn stover and switchgrass formatted in large square bales are be delivered to a primary depot located alongside the biorefinery, where they are processed into pellets. Pellets of the blendstocks (i.e., three-pass corn stover, two-pass corn stover, and switchgrass) are then conveyed from the primary depot into the conversion facility to blend with grass clippings pellets. Preprocessing of grass clippings occurs at a preprocessing depot located at the source of grass clippings and trucked to the biorefinery. The pellets of the four blendstocks are blended prior to conversion. Because the depot locations are known, the decision variable that identifies depot locations and depot size is excluded from the distributed depot MILP formulation P-1. Therefore, the objective function developed in $\mathrm{P}-1$ is reduced as follows (B-20):

The new formulation P-2 for a centralized depot is follows as follows. Constraint B-21 limits the biomass flow from field storage to depot located at the biorefinery after counting losses in the field storage. Constraints B-22 are the total biomass flow balance constraints at the centralized primary depot. Constraints B-23 are the flow balance constraints for a specific biomass at the centralized primary depot. Constraint B-24 enforces that the total quantity of all delivered feedstock, accounting for losses, must at a minimum meet the required demand of the biorefinery. Constraint B-25 requires that the delivered feedstock, after accounting for compositional changes due to dry matter loss in the supply chain, meets a 


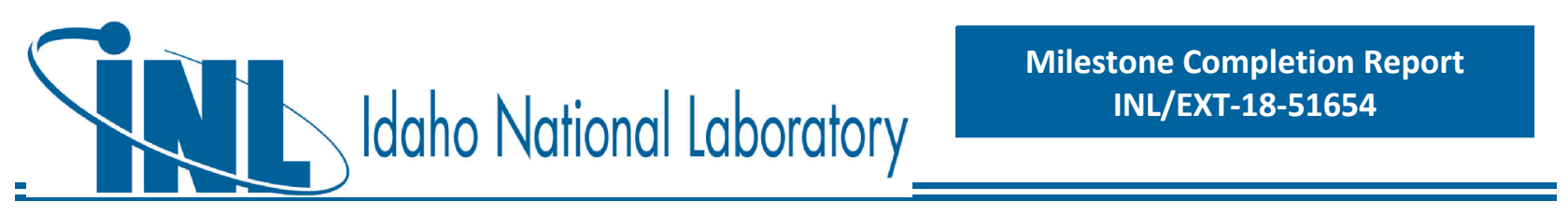

minimum specified carbohydrate content requirement.

P-2

Subject to : (B-5) to (B-7), (B-16), B(17)

\section{B-3 Solution Approach}

Input cost data such as the unit operation costs of harvesting and collection, storage, preprocessing, and handling and queuing used in the MILP model are calculated from the Biomass Logistics Model (BLM), using equipment sizing requirements derived from mass and energy balances performed using steady state Aspen Plus process simulations from standing crop through to the reactor throat of the conversion process. The Aspen Plus process simulations incorporate the input design assumptions of harvesting and collection, storage, preprocessing, and handling and queuing described in Appendix A. IBM CPLEX 12.6.2 Concert Technology with C++ was used to solve the MILP models. The solution of this model results in a minimum cost blend for a single biorefinery location that meets a specified quality specification. Figure B-1 shows the optimization framework with data preparation. 

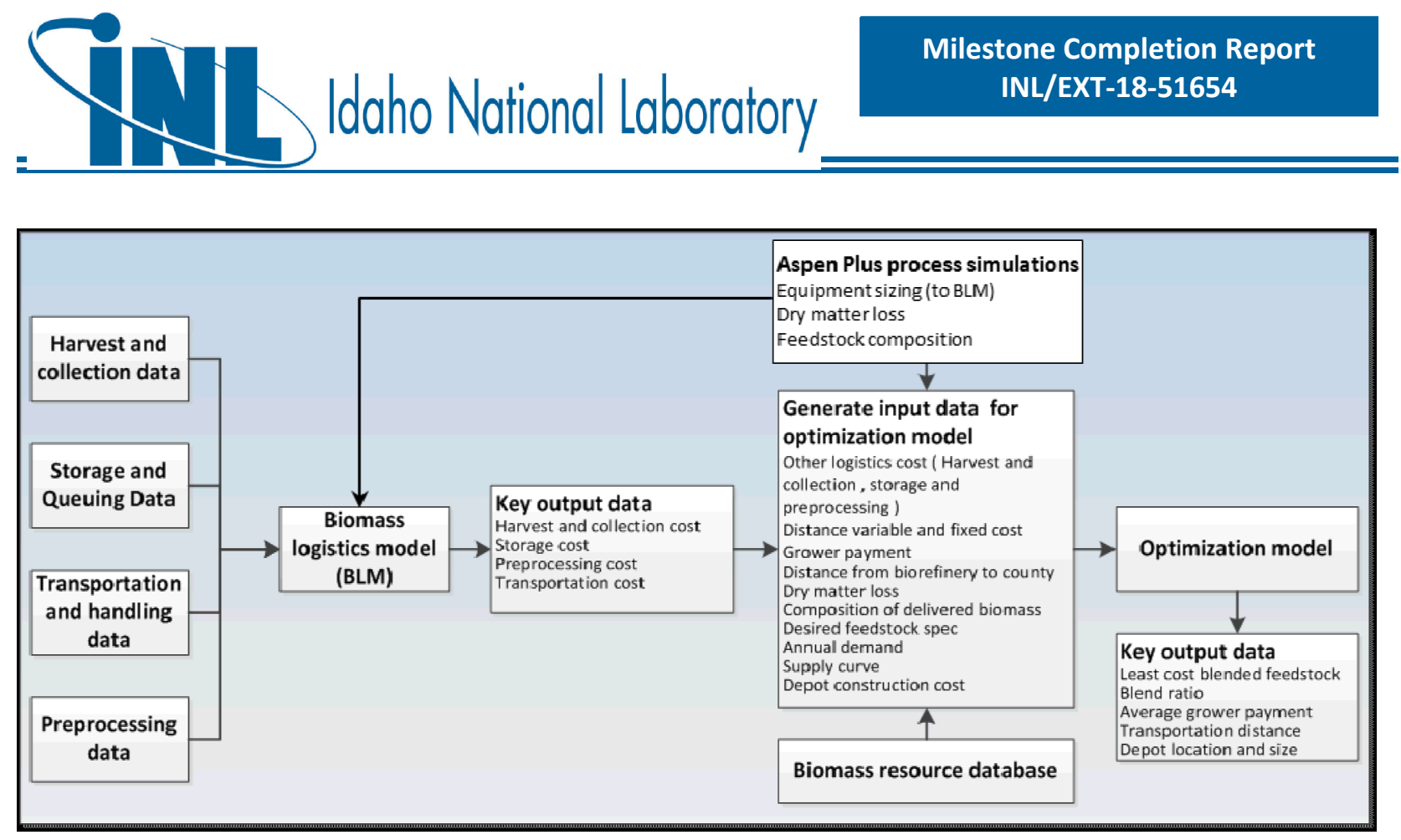

Figure B-1. Representation of the optimization framework with data preparation. 


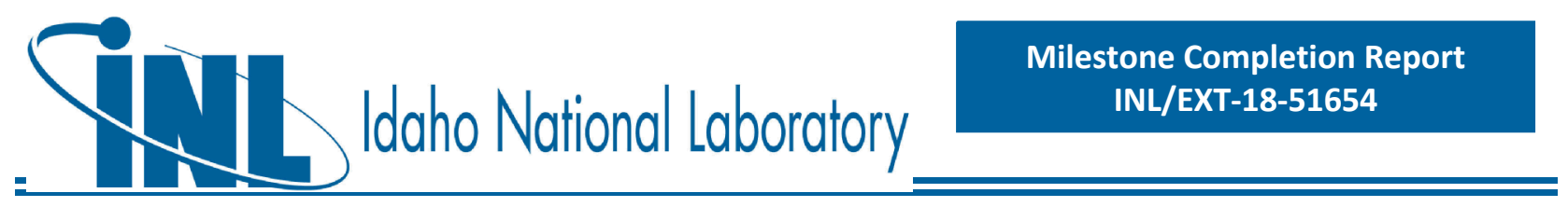

\section{APPENDIX C - Municipal Solid Waste}

Municipal solid waste (MSW) is attractive as a potential biomass source for biofuels because it is available year-round, has an already established infrastructure for collection and handling, and has potential to be low cost. MSW currently can have negative costs of up to $\$ 49.88 /$ dry ton due to tipping fees (Bioplastics 2015). However, it is unlikely that MSW will be available to a biorefinery at negative costs, because MSW will require processing to separate out the fractions of interest and will require other types of preprocessing to upgrade the quality. Even so, it is likely that MSW will still be available at a lower cost than other biomass feedstocks. An average composition of MSW is provided in Table C-1.

Table C-1. National average MSW proportions (Environmental Protection Agency 2015). Paper and paperboard, food and yard trimmings, comprising more than half of the MSW, are potential candidates for conversion to biofuels via various conversion pathways.

\begin{tabular}{ll}
\multicolumn{1}{c}{ Material } & \% of Total MSW \\
\hline Paper and paperboard & $\mathbf{2 8 . 5 \%}$ \\
\hline Glass & $4.6 \%$ \\
\hline Steel & $6.8 \%$ \\
\hline Aluminum & $1.4 \%$ \\
\hline Other nonferrous metals & $0.8 \%$ \\
\hline Plastics & $12.4 \%$ \\
\hline Rubber and leather & $3.1 \%$ \\
\hline Textiles & $\mathbf{1 3 . 4 \%}$ \\
\hline Wood & \\
\hline Other materials & $1.9 \%$ \\
\hline Food & \\
\hline Yard trimmings & \\
\hline
\end{tabular}




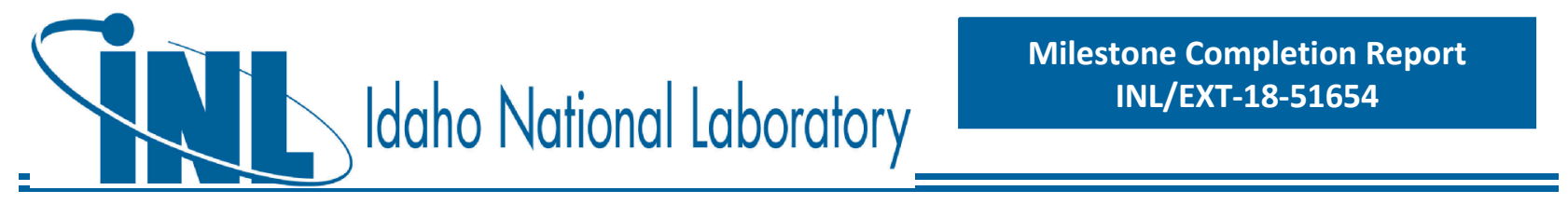

Miscellaneous inorganic waste $\quad 1.5 \%$

Candidate MSW materials for the biochemical pathway include paper and paperboard, food, and yard waste. Of these, paper and paperboard are likely to have more value when recycled than as a feedstock for biofuels. However, a significant fraction of paper and paperboard are considered non-recyclable, including coated paper and cardboard; polycoat material; glossy papers, such as magazines; foodcontaminated papers and cardboards; and any material with added binding agents such as phone books. Of these fractions, food waste has the highest rate of generation and will be available year-round. Nonrecyclable paper has the next highest generation rate and also would be available year-round. Yard waste has the lowest rate of generation and may not be available year-round depending on location, however, yard wastes will have compositions closest to other herbaceous biomass sources. Common components of yard wastes include grass clippings, leaves, twigs and branches. Grass clippings can be a good source of MSW for biofuels production, because if the grass clippings are collected in bins, there are little or no contaminants such as paper or plastic bags. Hence, grass clippings were considered as a feedstock blend component in the 2016 Herbaceous SOT. Grass clippings tend to be high moisture (60-90\%) when collected. Hence, keeping the carbohydrate content stable during collection, storage, and preprocessing is a requirement, and cost-effective drying methods would need to be employed.

An established infrastructure is in place for collection and handling of MSW, which is already paid for by the waste generators. In many locations, recycling programs also are in place to separate out various materials by consumers. Additionally, many municipalities transport MSW to material recovery facilities for further sorting to increase recycling. In these locations, fractions considered here would likely be available at low cost to the biorefinery. Yard waste, in particular, is often collected separately by communities and would need no further separation.

Currently, there are few studies investigating how any of these materials will respond to downstream biorefinery operations such as pretreatment, saccharification, and fermentation. Gustafson et al. (2009) examined yard waste as a potential feedstock for ethanol production, and found that sugar yields after saccharification were very low and attributed this to insufficient pretreatment severity due to the presence of woody materials in the waste stream (Gustafson et al. 2009). However, another study (Schmitt et al. 2012) assessed technical and environmental challenges of converting three lignocellulosic waste streams to ethanol: municipal solid waste, low grade mixed waste paper, and organic yard waste such as leaves and grass, and showed high conversion yields for all three streams using suitable conversion methods. 


\section{APPENDIX D - Solar drying of grass clippings model}

Solar drying of cereals and herbaceous biomass has been practiced for millennia by farmers, especially in areas where the weather is sunny and less humid. Corn stover, straw and hay are often spread in the field to dry before baling. Alfalfa can be field dried in the Arlington (near Madison), WI area from $80 \%$ moisture (wet weight basis) to $20 \%$ moisture in about 32 hours in July, when the material is spread in wide swaths (i.e., windrow width/cut width $>70 \%$ ). When using narrow windrows (windrow width/cut width $<40 \%$ ), drying can take as much as 56 hours (Undersander 2016).

In July, the average relative humidity in the Madison, WI area ranges from 53\% to $86 \%$ (CurrentResults 2016), and the concentrating solar power radiation ( $6.2 \mathrm{miles}$ ) is about $3.5 \mathrm{kWh} / \mathrm{m}^{2} /$ day (NREL 2016). In comparison, in the Denver area during the month of July, the relative humidity ranges from $34 \%$ to $68 \%$, and the concentrating solar power radiation $(6.2 \mathrm{miles})$ is about $7 \mathrm{kWh} / \mathrm{m}^{2} /$ day. Based on this information, one can assume that solar drying of grass clippings can be readily achieved in the Denver area when properly carried out (i.e., spread out the grass clippings and occasionally turn), and the drying time would be expected to be less than that reported for drying alfalfa in Wisconsin.

Commercially, partially-dried grass clippings are usually used in compost. INL has developed a least-cost biomass feedstock blend that includes pellets manufactured from dried grass clippings.

\section{D.1 Design of a solar drying system for drying grass clippings}

Like all herbaceous sources of biomass, grass clippings are seasonally available. Because the supply of grass clippings occurs from May until about the end of October, it was determined that using a conventional natural gas-fired dryer to dry grass clippings for only 6 months out of the year is not cost effective, unless the dryer can be utilized for other purposes. To minimize transportation costs and efficiently utilize resources (personnel, equipment, and infrastructure), the grass drying and pelleting facility would be best located near a landfill or major waste-sorting facility. The estimated quantity of grass clippings available in the Denver Metropolitan area is 32,070 dry tons/year, at 70\% moisture content (wet basis) (Appendix A). It was assumed that delivery of grass clippings to the drying facility takes place 5 days per week using self-unloading trucks. It is assumed that the average bulk density of uncompacted grass clippings is $2.6 \mathrm{lb} / \mathrm{ft}^{3}$ based on available literature (Swaploader 2016). The grass clippings are to be dried to $15 \%$ moisture (wet basis).

\section{D.2 Design approach}

The following design strategies and features are utilized to ensure achieving consistent production rate and moisture content of the dried grass clippings:

- Two days of queued grass clippings on hand in the storage yard to ensure uninterrupted drying operation over the weekend 
- Solar drying occurs in the storage yard to lower the moisture content to ca. $30 \%$ (to stabilize degradation)

- Grass clippings at ca. 30\% moisture are transferred to a greenhouse for further solar drying to quickly dry the partially-dried grass clippings to the required $15 \%$ moisture content. The greenhouse could also be used as temporary storage for partially-dried grass in case of very wet weather.

- Tedding and raking both in the storage yard and the greenhouse to ensure uniform drying and to facilitate quick transfer of material.

The concentrating solar power radiation (6.2 miles) for the Denver area ranges from about 6.5 $\mathrm{kWh} / \mathrm{m}^{2} /$ day to about $8 \mathrm{kWh} / \mathrm{m}^{2} /$ day from May through October. For this design, the available average solar power over this same period is conservatively assumed to be $6.5 \mathrm{kWh} / \mathrm{m}^{2} /$ day. Furthermore, it is assumed that the energy utilization efficiency is $70 \%$ for field drying (with tedding) and $85 \%$ for the greenhouse solar dryers.

\section{D.3 Process description}

Self-loading/unloading delivery trucks unload grass clippings into windrows or small piles. The grass clippings are immediately spread into a $0.3048 \mathrm{~m}$-high $(1 \mathrm{ft}$ ) layer in the storage yard using front end loaders equipped with tedders. The storage yard could consist of a level grassy field or a clearing of compacted dirt and gravel with good water drainage. For two-day storage, the area of the storage yard would be about 1.74 hectares ( 4.3 acres). The yard is tedded (fluffed) 2-3 times per day (morning, afternoon, and early evening) to ensure even drying of grass clippings. The flow of grass clippings through the storage yard is first-in-first-out so that the average drying time is 2 days. It is expected that the moisture of grass clippings at the end of the 2-day drying period would be about $30 \%$. The storage yard is large enough to provide $14 \%$ excess drying capacity using $6.5 \mathrm{kWh} / \mathrm{m}^{2} /$ day solar power radiation and $70 \%$ energy utilization efficiency. The actual drying capacity would normally be higher, because drying continues overnight.

The partially-dried (30\% MC) grass clippings are transferred from the storage yard into four greenhouse solar dryers for further drying to the target $15 \%$ moisture. The greenhouse dryers, with a total drying area of about $5,945.8 \mathrm{~m}^{2}\left(64,000 \mathrm{ft}^{2}\right)$, are equipped with ventilation fans which help increase the drying rate (in comparison with the drying rate in the storage yard). Tedding and raking of the material inside the greenhouse is performed as needed. The greenhouse dryers have $9 \%$ excess drying capacity, not including drying capability overnight. It is estimated that two batches of $30 \%$ moisture grass clippings can be dried down to $15 \% \mathrm{MC}$ in each greenhouse over a period of $24 \mathrm{hrs}$.

The greenhouse can also be used as temporary storage for partially-dried grass clippings from the storage yard in case of heavy rain. The greenhouses, filled to $1.524 \mathrm{~m}(5 \mathrm{ft})$ deep with partially dried grass clippings from the storage yard, could store $270 \%$ of the daily throughput.

When drying is complete, the $15 \%$ moisture grass clippings are raked and transferred (using a front-end loader and conveyors) from the greenhouse to the shredding and pellet production area

\section{D.4 Buildings and equipment}

The greenhouses are designed with a metal hoop high tunnel design (Robbins et al. 2013). Each greenhouse measures approximately $12.19 \mathrm{~m} \times 121.9 \mathrm{~m} \times 4.57 \mathrm{~m}(w \times l \times h)(40 \mathrm{ft} \times 400 \mathrm{ft} \times 15 \mathrm{ft})$. The 


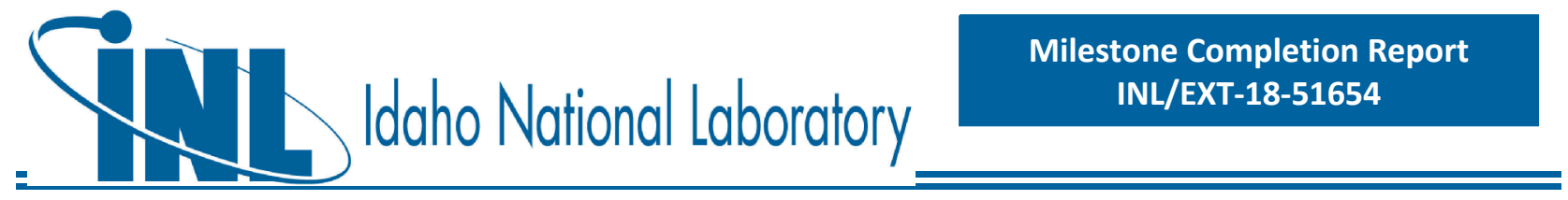

floor is paved with asphalt, and is slightly sloped to prevent water from collecting. The location of the greenhouse is selected with consideration for optimal sunlight and wind exposure to effect a high drying rate. The frame is constructed of galvanized structure steel tubing, and clear greenhouse film covers the sides and the top. Each greenhouse is equipped with lighting, ventilation fans and is tedded 4 times a day to achieve even drying of the grass clippings. The plastic cover is rolled up/down during the winter months (when the greenhouse is not used) to prevent damage from snow load.

Two front-end loaders equipped with rake and tedder attachments are needed for the handling the grass clippings, each with a lifting capacity of about 1.1 ton. A tedder, pulled by the tractor, is used to fluff the grass clippings periodically to ensure even drying. Raking is performed when dried grass clippings are ready to be transferred to the next operation (e.g., from the storage yard to the greenhouses, or from the greenhouses to the shredding and pelleting operation). The installed cost of the solar dryers was estimated at \$530,138 (2014\$) (Tables D-1, D-2 and D-3).

Table D-1. Global assumptions and calculated values used in estimating the installed cost of solar dryers.

\begin{tabular}{lc}
\hline \multicolumn{1}{c}{ Parameter } & Value \\
\hline Available quantity of grass clippings (dry tons) & 27,586 \\
\hline Time period of collection (months) & 6 \\
\hline Number of collection days/month & 20 \\
\hline Total number of collection days & 120 \\
\hline Rate of collection (dry tons/day) & 230 \\
\hline Number of drying days & 180 \\
\hline Average moisture content of delivered grass clippings $(\mathrm{wt} \%$, wet basis) & 70 \\
\hline Average moisture content of final dried grass clippings $(\mathrm{wt} \%$, wet basis) & 15 \\
\hline Bulk density of grass clippings (dry lb/ $\left.\mathrm{ft}^{3}\right)$ & 2.6 \\
\hline Dryer throughput (dry tons/day) & 153.26 \\
\hline Volume of grass clippings processed per day $\left(\mathrm{ft}^{3}\right)$ & 118,226 \\
\hline
\end{tabular}


Table D-2. Assumptions and calculated values used in estimating the installed cost of solar dryers: Firststage drying in the field storage area (from $70 \%$ moisture to about $30 \%$ moisture (wet basis)).

\begin{tabular}{lc}
\multicolumn{1}{c}{ Parameter } & Value \\
\hline Average inventory, day & 2 \\
\hline Volume of grass in inventory $\left(\mathrm{m}^{3}\right)$ & $6,695.5$ \\
\hline Average thickness of grass layer in field (for field drying) $(\mathrm{m})$ & 0.3048 \\
\hline Minimum area for field drying $\left(\mathrm{m}^{2}\right)$ & 21,967 \\
\hline Minimum area for field drying $($ hectares $)$ & 2.197 \\
\hline Length of storage area $(\mathrm{m})$ & 182.9 \\
\hline Width of storage area $(\mathrm{m})$ & 121.9 \\
\hline Design storage area $\left(\mathrm{m}^{2}\right)$ & 22,297 \\
\hline Design storage area $($ hectares $)$ & 2.23 \\
\hline
\end{tabular}

Table D-3. Assumptions and calculated values used in estimating the installed cost of solar dryers: Second-stage drying in greenhouse solar dryers (from about 30\% moisture to $15 \%$ moisture (wet basis)).

\section{Parameter Value}

Time to dry in greenhouse dryer (including loading \& unloading) (days) 0.5

Total volume of grass clippings in dryers $\left(\mathrm{m}^{3}\right)$

$1,673.9$

Average thickness of grass clippings layer in the dryer $(\mathrm{m}) \quad 0.3048$

$\begin{array}{lr}\text { Required active floor area of the dryers }\left(\mathrm{m}^{2}\right) & 5,492\end{array}$

$\begin{array}{ll}\text { Length of each dryer }(\mathrm{m}) & 121.9\end{array}$

$\begin{array}{lr}\text { Width of each dryer }(\mathrm{m}) & 12.19\end{array}$

$\begin{array}{ll}\text { Area of each dryer }\left(\mathrm{m}^{2}\right) & 1,486.4\end{array}$

Number of dryers 4

Total drying area in green house $\left(\mathrm{m}^{2}\right) \quad 5,495.8$

$\%$ overdesign for drying area (\%) $8 \%$

$\begin{array}{ll}\text { Cost of buildings (including fans \& lighting) }\left(\$ / \mathrm{m}^{2}\right) & 72.34\end{array}$

$\begin{array}{ll}\text { Cost of buildings }(2014 \$) & \$ 430,138\end{array}$

$\begin{array}{ll}\text { Tedders and Rakes }(2014 \$) & \$ 100,000\end{array}$

Total installed cost of solar drvers (2014\$) $\$ 530.138$ 


\section{APPENDIX E - Assumptions for the 2022 Projection}

\section{E.1 Incorporation of ILM Strategies to Reduce Grower Payment}

ILM introduces opportunities to further reduce the grower payment portion of biomass access costs, while maintaining or improving grower profitability. Grower payment is comprised of three elements: (1) an establishment cost, i.e., the basic labor, machinery, fertilizer and land costs to produce the biomass; (2) a nutrient replacement cost, i.e., the cost of replacing nutrients that are removed with the biomass (to maintain sustainable productivity of the soil); and (3) a profit for the producer, i.e., a monetary incentive to produce the biomass for sale to biorefineries. ILM considers subfield management strategies to reduce biomass production costs either through gains in operational efficiencies, or through improvement of fieldlevel profitability by maximizing the profitability of both grain production and biomass production. Although seeming contradictory, this provides a mechanism to reduce overall grower payment while either maintaining or improving overall grower profitability. This is achieved by replacing grain crops in "traditionally" low grain-yielding (unprofitable) subfield areas with high biomass-yielding dedicated energy crops such as Panicum virgatum (switchgrass) and Miscanthus $\times$ giganteus (miscanthus) which require fewer nutrient inputs and are more efficient with regard to water requirements. In this way, the more expensive crop input costs are reallocated to lower biomass production costs. Additional improvements to grower profitability occur when crop residue is removed from the high grain-yielding areas, due to reduced tillage requirements for incorporating the residues into the soil.

Over the past several years, analyses have shown ILM as a viable strategy to integrate biomass production practices into agricultural production fields. Muth et al. (2012) developed a computational strategy and examined stover removal schemas at a subfield resolution on three fields in Iowa, and found that USDA Natural Resources Conservation Service (NRCS) conservation management planning guidelines can exceed sustainable removal thresholds for portions of the field (Muth et al. 2012). Applying this strategy and integrating USDA Revised Universal Soil Loss Equation version 2 (RUSLE2) and Wind Erosion Prediction System (WEPS) models within a computational framework revealed more than 150 million metric tons of crop residue could be sustainably harvested as a biomass resource (Muth et. al. 2013). Bonner et al. (2016) modeled the integration of switchgrass into a corn-producing field in Iowa and showed significant gains in total biomass availability and soil organic carbon, while reducing total soil erosion resulting in environmental improvements valued at $\$ 64$ per acre (Bonner et al. 2016). Researchers at INL developed the Landscape Environmental Assessment Framework (LEAF) to model economic and soil loss outcomes relative to traditional and ILM practices. LEAF analysis has shown that switchgrass integration into subfield areas producing net economic losses when utilized for corn production increases both total available biomass and aggregate field profitability while minimizing soil losses (Bonner et al. 2014).

Currently, researchers at INL are conducting analyses in WB 4.2.1.20 to develop strategies by which ILM can reduce biomass grower payments by at least $20 \%$ at a field level based on values listed in the Herbaceous Feedstock 2017 State of Technology Report (Roni et al. 2017). Additional analysis was conducted to derive biomass estimates from ILM sources relative to the 2022 Projection targets using a soil productivity index to segregate ILM-derived switchgrass and high-yielding crop residue subfield areas. These additional sources are in addition to BT16 assumptions (Langholtz et al. 2016). 


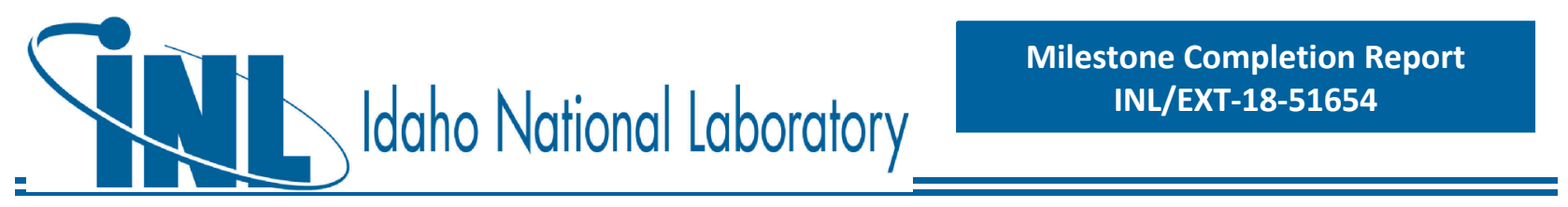

\section{E.2 Analysis Methodology}

An initial fuelshed area was defined spanning 50 counties in northwest Kansas, southwest Nebraska, and eastern Colorado that encompass the analysis area used for the Herbaceous Feedstock 2017 State of Technology report (Figure E-1).

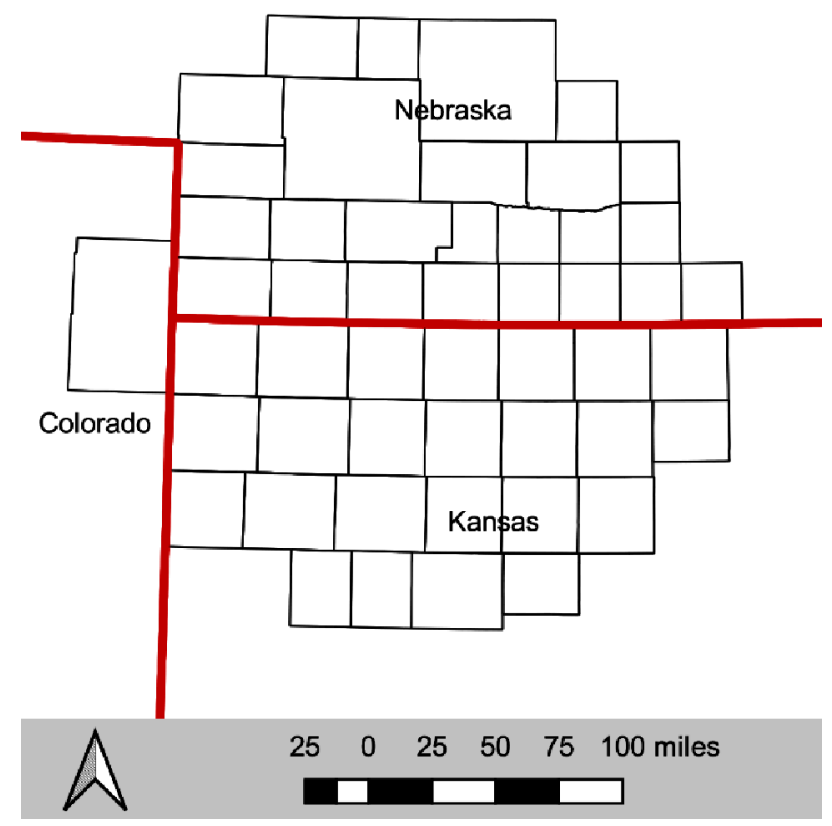

Figure E-1. Spatial distribution of the 50-county fuelshed used for the 2022 Projection. The black polygons symbolize the individual counties and the red lines denote state boundaries.

Agricultural production systems at the field level were delineated using publically-available county and state boundary data from the United States Census Bureau and United States Department of Agriculture (USDA) field boundary, soil, land management, and agricultural statistics data. Common Land Unit (CLU) data was used to define field boundaries and represents the smallest unit of land that has a permanent, contiguous boundary with a common land cover and management schema. Although updated annually, only data as current as 2008 was available since enactment of the Food, Conservation, and Energy Act of 2008 which prohibits the release of more current CLU data on a public basis. USDA Cropland Data Layers (CDL) which show land cover type (i.e. corn, winter wheat, soybeans, etc.) at a 30meter spatial resolution on an annual basis were spatially intersected with CLU boundaries to determine a crop rotation for all fields within the fuelshed for years ranging from 2010 to 2017. Fields producing common agricultural crops for the region including corn, soybeans, winter wheat, sorghum, sunflowers, and dry beans were used for the analysis as well as those incorporating fallow seasons in the rotation as it is a common practice in the region. After down selection of the fields, spatial Soil Survey Geographic (SSURGO) data were intersected with the field boundaries to delineate the subfield areas based on soil characteristics each with a National Commodity Crop Productivity Index (NCCPI) value (Dobos et al. 


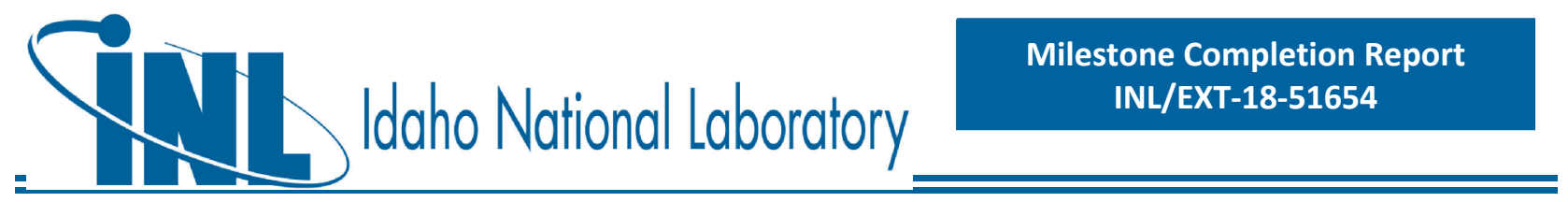

2008). The NCCPI is a method of quantifying potential soil productivity for non-irrigated production systems based on inherent soil properties. The rating consists of a value ranging from 0 to 1 and reflect gradations between the point at which the combination of soil, location, and climate features influence crop productivity (Figure E-2).
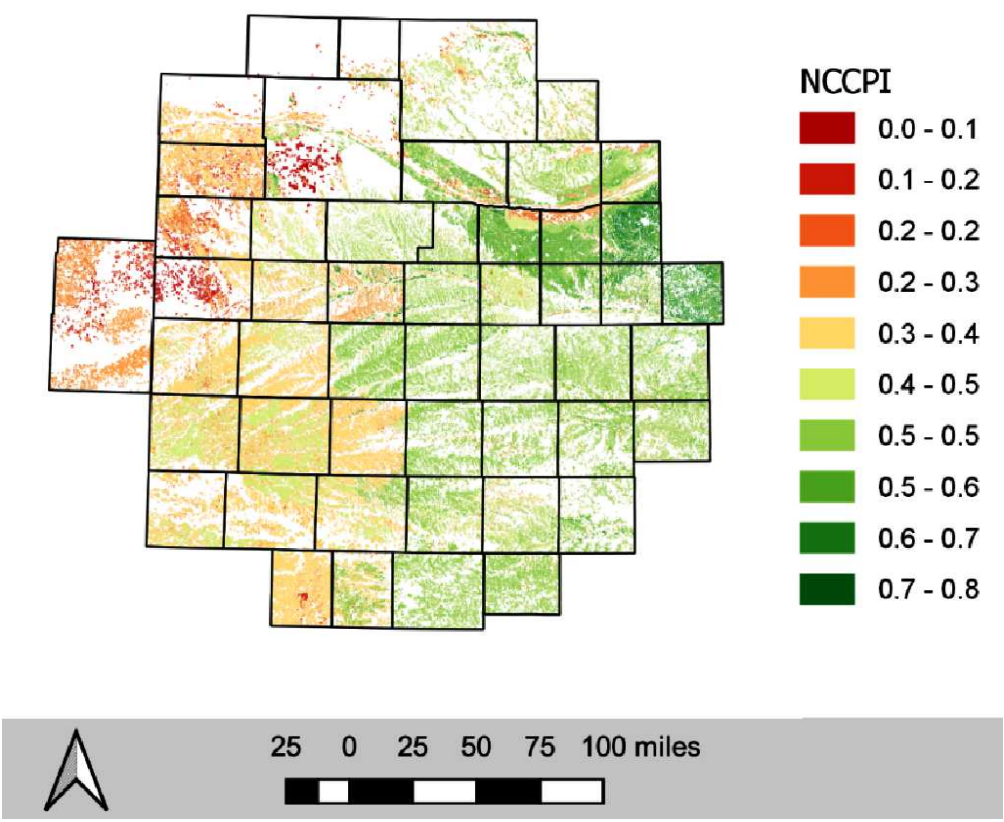

Figure E-2. Soil productivity variability as symbolized by SSURGO NCCPI values. Only soil areas intersecting fields after the crop rotation down-selection process are shown.

Estimation of potential switchgrass acres was performed by aggregating all NCCPI values at a county level and selecting only those subfields with NCCPI values less than one standard deviation of the county NCCPI values below the county NCCPI mean. A grower participation factor of $20 \%$ was applied further reducing available acres. County yield values from BT16 for 2022 were used to estimate total county dry tons of switch grass available. In some cases, county-level yields were not available from BT16 so a value of 3.819 dry tons/acre (the dataset mean value) was used (Table E-1).

Estimation of potential high crop residue areas was achieved by aggregating subfield NCCPI values as was done for the switchgrass analysis. However, only subfield areas with NCCPI values greater than one standard deviation of the county NCCPI values above the county NCCPI mean were included. A grower participation factor of $100 \%$ was used in this case given the potential economic benefits of removing excess crop residue on overall field profitability improving the likelihood of adoption. 


\section{TI Idaho National labocitory}

Table E-1. Switchgrass yields in dry tons/acre derived from BT16 data for 2022.

\begin{tabular}{|c|c|c|c|}
\hline $\begin{array}{l}\text { County } \\
\text { GEOID }\end{array}$ & Switchgrass Yield (dt/acre) & County GEOID & Switchgrass Yield (dt/acre) \\
\hline 8125 & 2.995 & 31001 & 3.819 \\
\hline 20023 & 3.304 & 31019 & 3.819 \\
\hline 20039 & 3.667 & 31029 & 3.819 \\
\hline 20051 & 4.034 & 31041 & 3.819 \\
\hline 20063 & 3.704 & 31047 & 3.819 \\
\hline 20065 & 3.758 & 31057 & 3.819 \\
\hline 20089 & 4.649 & 31061 & 3.819 \\
\hline 20101 & 3.533 & 31063 & 3.819 \\
\hline 20109 & 3.334 & 31065 & 4.025 \\
\hline 20123 & 4.778 & 31073 & 3.819 \\
\hline 20135 & 3.837 & 31079 & 3.819 \\
\hline 20137 & 3.785 & 31083 & 3.819 \\
\hline 20141 & 4.436 & 31085 & 3.819 \\
\hline 20147 & 4.023 & 31087 & 3.584 \\
\hline 20153 & 3.539 & 31099 & 3.819 \\
\hline 20163 & 4.042 & 31101 & 3.819 \\
\hline 20165 & 4.052 & 31111 & 3.819 \\
\hline 20167 & 4.464 & 31113 & 3.819 \\
\hline 20171 & 3.124 & 31117 & 3.819 \\
\hline 20179 & 3.761 & 31129 & 3.819 \\
\hline
\end{tabular}




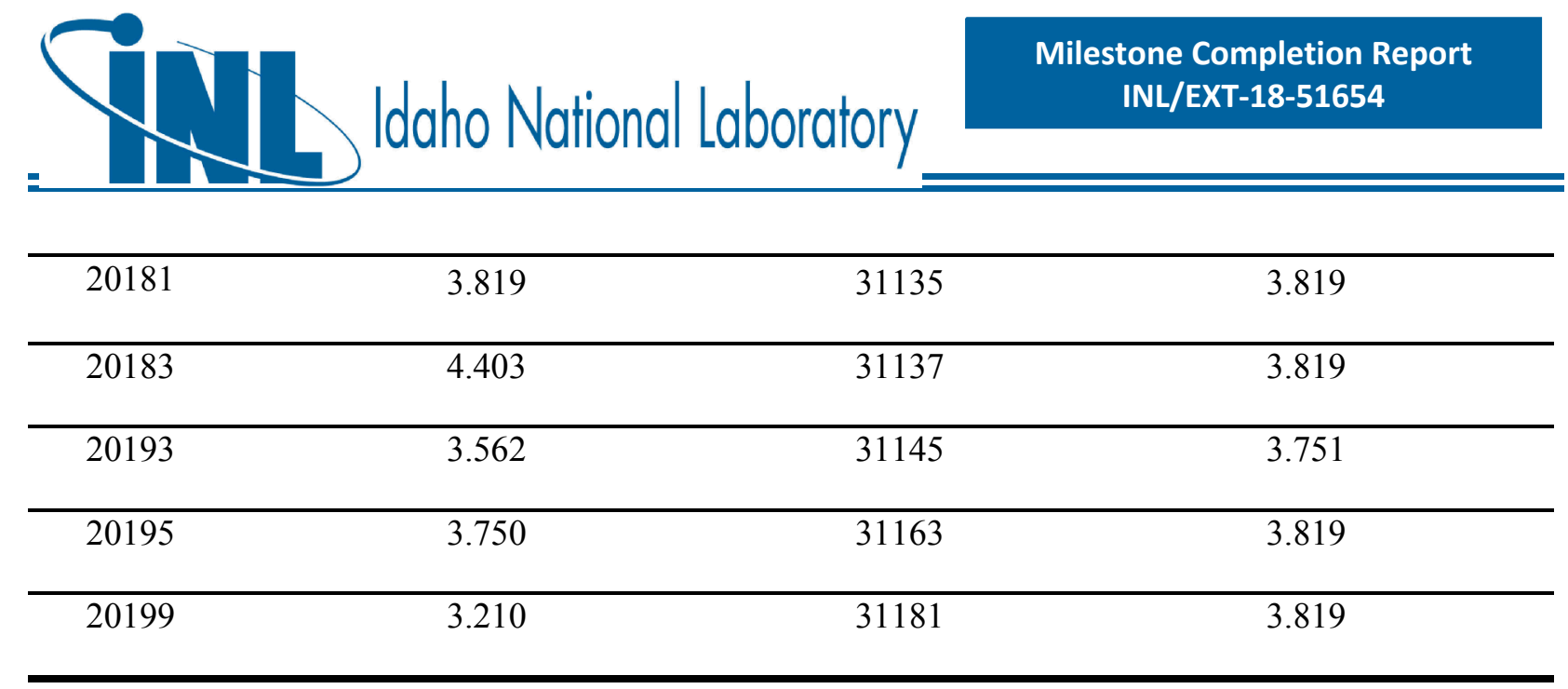




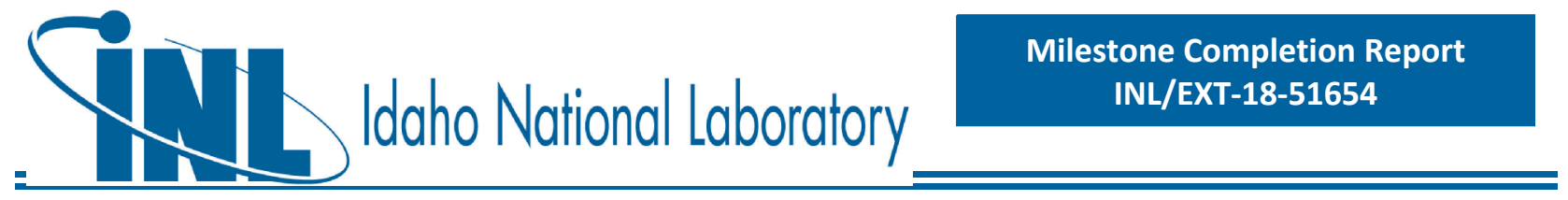

\section{E.3 Logistics Design Assumptions for the 2022 Projection}

The technical targets for harvest and collection in the 2022 Projection are shown in Table E-2.

Table E-2. Technical targets for harvest and collection of herbaceous resources for the 2022 Projection.

\begin{tabular}{|c|c|c|c|c|c|c|c|c|}
\hline \multirow[b]{2}{*}{$\begin{array}{l}\text { Biomass } \\
\text { Source }\end{array}$} & \multicolumn{2}{|c|}{$\begin{array}{l}\text { Ash Content } \\
\text { (\% dry basis) }\end{array}$} & \multicolumn{2}{|c|}{$\begin{array}{l}\text { Baled Moisture } \\
\text { (\% wet basis) }\end{array}$} & \multicolumn{2}{|c|}{$\begin{array}{c}\text { Bulk Density } \\
\left(\mathrm{lb} / \mathrm{ft}^{3}\right)\end{array}$} & \multicolumn{2}{|c|}{$\begin{array}{l}\text { Average yield } \\
\text { (dry tons/acre) }\end{array}$} \\
\hline & $\begin{array}{l}2018 \\
\text { SOT }\end{array}$ & $\begin{array}{c}2022 \\
\text { Target }\end{array}$ & $\begin{array}{l}2018 \\
\text { SOT }\end{array}$ & $\begin{array}{c}2022 \\
\text { Target }\end{array}$ & $\begin{array}{l}2018 \\
\text { SOT }\end{array}$ & $\begin{array}{c}2022 \\
\text { Target }\end{array}$ & $\begin{array}{l}2018 \\
\text { SOT }\end{array}$ & $\begin{array}{c}2022 \\
\text { Target }\end{array}$ \\
\hline $\begin{array}{l}\text { Three-pass } \\
\text { corn stover }\end{array}$ & 11 & 11 & 30 & 30 & 12 & 12 & 1.2 & 1.2 \\
\hline $\begin{array}{l}\text { Two-pass } \\
\text { corn stover }\end{array}$ & 7 & 7 & 30 & 30 & 12 & 12 & 0.7 & 0.95 \\
\hline Switchgrass & 6.2 & 6.2 & 20 & 20 & 12 & 12 & 3.5 & 3.5 \\
\hline
\end{tabular}

The design basis for storage is shown in Table E-3.

Table E-3. Storage design basis for the 2022 Projection.

\begin{tabular}{lcccc}
\hline Feedstock & \multicolumn{2}{c}{ Dry matter loss } & \multicolumn{2}{c}{ Mean bale moisture leaving storage } \\
& 2018 SOT & 2022 Target & 2018 SOT & 2022 Target \\
Three-pass & $12 \%$ & $7 \%^{*}$ & $25 \%$ & $20 \%$ \\
corn stover & & & & $20 \%$ \\
\hline Two-pass & $12 \%$ & $7 \%^{*}$ & $25 \%$ & \\
corn stover & & & & $17.3 \%$ \\
\hline Switchgrass & $8 \%$ & $7 \%{ }^{*}$ & $17.5 \%$ & \\
\hline
\end{tabular}




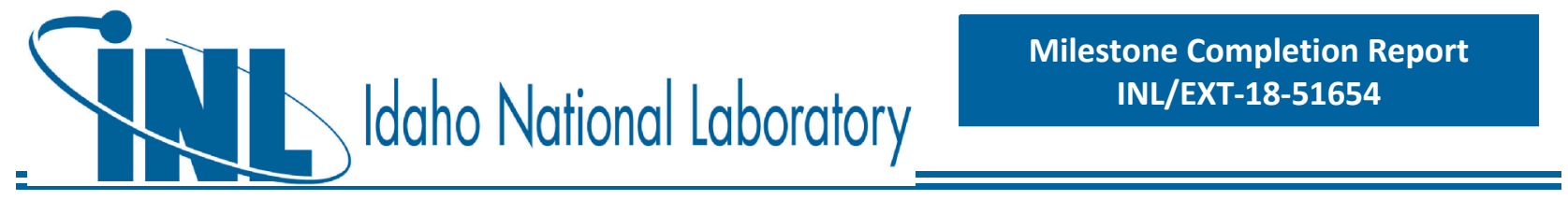

The design bases for size reduction are shown in Tables E-4 and E-5 for corn stover and switchgrass, respectively.

Table E-4. Size-reduction design basis for corn stover.

\begin{tabular}{ccc}
\hline Component & 2018 SOT & 2022 Target \\
\hline Location of operation & Depot & Depot
\end{tabular}

\section{Stage 1 size reduction}

\begin{tabular}{lcc}
\hline Bale processor & n.a & Bale processor \\
\hline Energy consumption & n.a & Estimate based on HP \\
\hline Throughput & n.a & 5 tons $/ \mathrm{hr}$. \\
\hline Grinder type & Hammer mill & $\begin{array}{c}\text { Hammer mill with bale } \\
\text { fluff/processor }\end{array}$ \\
\hline Screen Size (inch) & 3 & 3 \\
\hline $\begin{array}{l}\text { Energy (kWh/dry ton) } \\
\text { Throughput (dry } \\
\text { ton/hour/machine) }\end{array}$ & 12.86 & 9.002 \\
\hline $\begin{array}{l}\text { Operating conditions } \\
\text { (moisture \%) }\end{array}$ & 3.336 & 4 \\
\hline
\end{tabular}

\section{Separations 1}

\begin{tabular}{lcc}
\hline Screen type 1 & Disk screen & Disk screen \\
\hline Energy (kWh/dry ton) & Minimal electricity & Minimal electricity \\
\hline $\begin{array}{l}\text { Throughput (dry } \\
\text { ton/hour/machine) }\end{array}$ & 5 & 5 \\
\hline $\begin{array}{l}\text { Operating conditions } \\
\text { (moisture \%) }\end{array}$ & $20.23 \%$ & $16.18 \%$ \\
\hline \hline
\end{tabular}




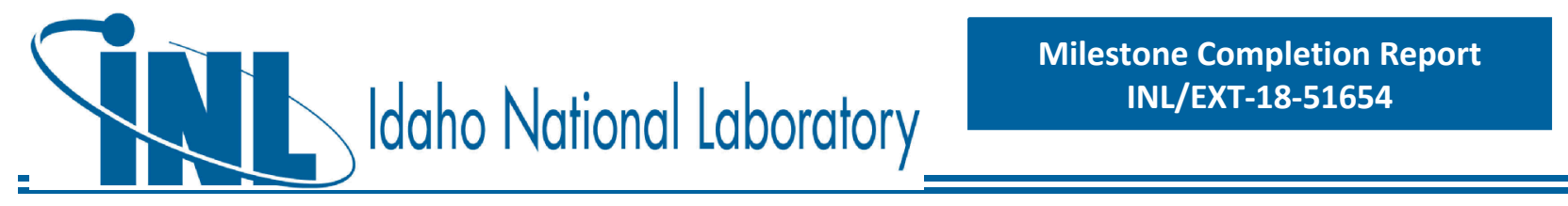

\begin{tabular}{|c|c|c|}
\hline Bypass & $40.39 \%$ & $40.39 \%$ \\
\hline \multicolumn{3}{|l|}{ Stage 2 Grinder } \\
\hline Comminution method & Rotary shear & $\begin{array}{l}\text { Optimize (Rotary Shear or Hammer } \\
\text { mill) }\end{array}$ \\
\hline Screen Size ( inch) & $0.25^{*}$ & $1 / 4$ in Screen in Hammer mill \\
\hline Energy (kWh/dry ton) & $14.57\left(8.69^{* *}\right)$ & $14.57\left(8.69^{* *}\right)$ \\
\hline $\begin{array}{l}\text { Throughput (dry } \\
\text { ton/hour/machine) }\end{array}$ & $7.5\left(12.58^{* * *}\right)$ & $7.5\left(12.58^{* * *}\right)$ \\
\hline $\begin{array}{l}\text { Operating conditions } \\
\text { (moisture \%) }\end{array}$ & $18.23 \%$ & $14.58 \%$ \\
\hline
\end{tabular}

* Particle size after rotary shear was below 0.25 inch.

** The effective energy consumption is reduced because only $59.61 \%$ of the material is processed in Stage 2 due to fractional milling.

*** The effective throughput is improved because only $59.61 \%$ of the material is processed in Stage 2 due to fractional milling. 


\section{NIIdaho National Laboratory

Table E-5. Size-reduction design basis for switchgrass.

\begin{tabular}{|c|c|c|}
\hline Component & 2018 SOT & 2022 Target \\
\hline Location of operation & Depot & Depot \\
\hline \multicolumn{3}{|l|}{ Stage 1 size reduction } \\
\hline Bale processor & N/A & Bale processor \\
\hline Energy consumption & N/A & Estimate based on HP \\
\hline Throughput & N/A & 5 tons $/ \mathrm{hr}$. \\
\hline Grinder type & Hammer mill & $\begin{array}{l}\text { Hammer mill with bale } \\
\text { fluff/processor }\end{array}$ \\
\hline Screen Size (inch) & 3 & 3 \\
\hline Energy (kWh/dry ton) & 19.91 & 14 \\
\hline $\begin{array}{l}\text { Throughput (dry } \\
\text { ton/hour/machine) }\end{array}$ & 4.54 & 5 \\
\hline $\begin{array}{l}\text { Operating conditions } \\
\text { (moisture \%) }\end{array}$ & $17.50 \%$ & $17.3 \%$ \\
\hline
\end{tabular}

\section{Separations 1}

\begin{tabular}{lcc}
\hline Screen type 1 & Disk screen & Disk screen \\
\hline Screen type 2 & Not applicable & Not applicable \\
\hline Energy (kWh/dry ton) & Minimal electricity & Minimal electricity \\
\hline
\end{tabular}

\begin{tabular}{lcc}
\hline $\begin{array}{l}\text { Throughput (dry } \\
\text { ton/hour/machine) }\end{array}$ & 5 & 5 \\
\hline $\begin{array}{l}\text { Operating conditions } \\
\text { (moisture \%) }\end{array}$ & $14.50 \%$ & $14.33 \%$ \\
\hline
\end{tabular}




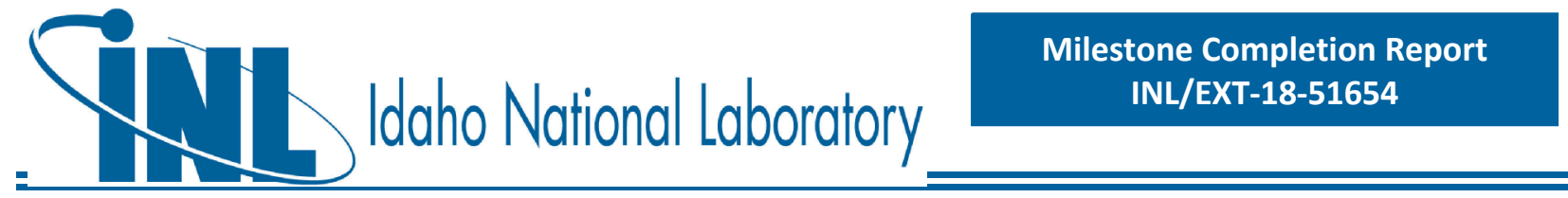

\begin{tabular}{lcc}
\hline Bypass & $44.98 \%$ & $44.98 \%$ \\
\hline Stage 2 Grinder & Rotary shear & Optimize (Rotary Shear or Hammer \\
mill $)$
\end{tabular}

The design bases for densification are shown in Tables E-6 and E-7 for corn stover and switchgrass, respectively.

Table E-6. Densification design basis for corn stover.

\begin{tabular}{lcc}
\multicolumn{1}{c}{ Component } & 2018 SOT & 2022 Target \\
\hline $\begin{array}{l}\text { Screen size used at Stage-2 Size } \\
\text { reduction }\end{array}$ & $1 / 4$ inch & $1 / 4$ inch \\
\hline Densifier & Pellet mill & Pellet mill \\
\hline Densifier type & 36.24 & 32.62 \\
\hline Energy (kWh/dry ton) & 3.38 & 3.72 \\
\hline $\begin{array}{l}\text { Throughput (dry } \\
\text { ton/hour/machine) }\end{array}$ & & \\
\hline \hline
\end{tabular}




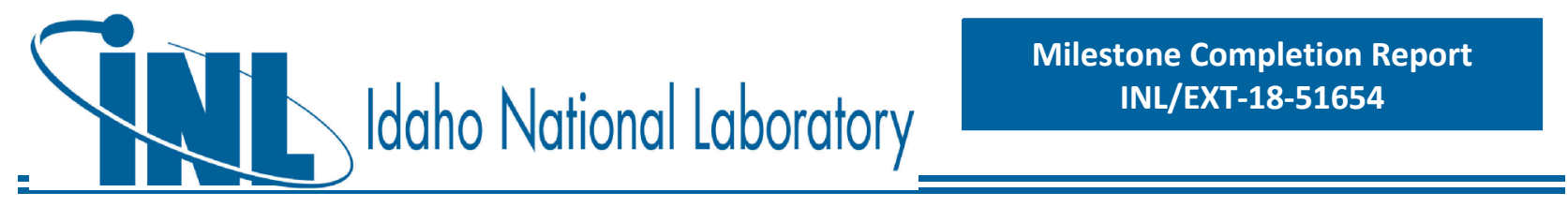

\begin{tabular}{lcc}
\hline $\begin{array}{l}\text { Operating conditions (moisture } \\
\%)\end{array}$ & $18.23 \%$ & $14.58 \%$ \\
\hline Pellet density $\left(\mathrm{lb} / \mathrm{ft}^{3}\right)$ & 39.42 & 39.42 \\
\hline Pellet durability & $98.70 \%$ & $>97.5$ \\
\hline Moisture after pelleting & $13.2 \%$ & $10.56 \%$ \\
\hline $\begin{array}{l}\text { Fines in the pelleted material } \\
\text { No control }(35 \% \text { of material is } \\
\text { lost as fines during conversion) }\end{array}$ & $\begin{array}{c}\text { Reduce the fines in the pellet } \\
\text { bo compared to the } \\
35 \% \text { what is currently } \\
\text { observed }\end{array}$ \\
\hline $\begin{array}{l}\text { Cooler } \\
\text { Moisture after cooling }\end{array}$ & $11.5 \%$ & N/A \\
\hline $\begin{array}{l}\text { Energy (kWh/dry ton) } \\
\text { ton/hour/machine) }\end{array}$ & 3.02 & N/A \\
\hline
\end{tabular}




\section{TII Idaho National Laboratory}

Table E-7. Densification design basis for switchgrass.

\begin{tabular}{|c|c|c|}
\hline Component & 2018 SOT & 2022 Target \\
\hline $\begin{array}{l}\text { Screen size used at Stage- } 2 \text { Size } \\
\text { reduction }\end{array}$ & $1 / 4$ inch & $1 / 4$ inch \\
\hline \multicolumn{3}{|l|}{ Densifier } \\
\hline Densifier type & Pellet mill & Pellet mill \\
\hline Energy (kWh/dry ton) & 60.2 & 60.2 \\
\hline $\begin{array}{l}\text { Throughput (dry } \\
\text { ton/hour/machine) }\end{array}$ & 3.5 & 3.5 \\
\hline $\begin{array}{l}\text { Operating conditions (moisture } \\
\% \text { ) }\end{array}$ & $13.50 \%$ & $13.34 \%$ \\
\hline Pellet density $\left(\mathrm{lb} / \mathrm{ft}^{3}\right)$ & 41.56 & 41.56 \\
\hline Pellet durability & $97.60 \%$ & $97.60 \%$ \\
\hline Moisture after pelleting & $10 \%$ & $9.88 \%$ \\
\hline Fines in the pelleted material & $\begin{array}{c}\text { No control ( } 35 \% \text { of material is } \\
\text { lost as fines during } \\
\text { conversion) }\end{array}$ & $\begin{array}{l}\text { Reduce the fines in the pellet by } \\
80 \% \text { compared to the } 35 \% \text { what } \\
\text { is currently observed }\end{array}$ \\
\hline \multicolumn{3}{|l|}{ Cooler } \\
\hline Moisture after cooling & $9 \%$ & $\mathrm{~N} / \mathrm{A}$ \\
\hline Energy (kWh/dry ton) & 3.02 & $\mathrm{~N} / \mathrm{A}$ \\
\hline $\begin{array}{l}\text { Throughput (dry } \\
\text { ton/hour/machine) }\end{array}$ & 5 & N/A \\
\hline
\end{tabular}




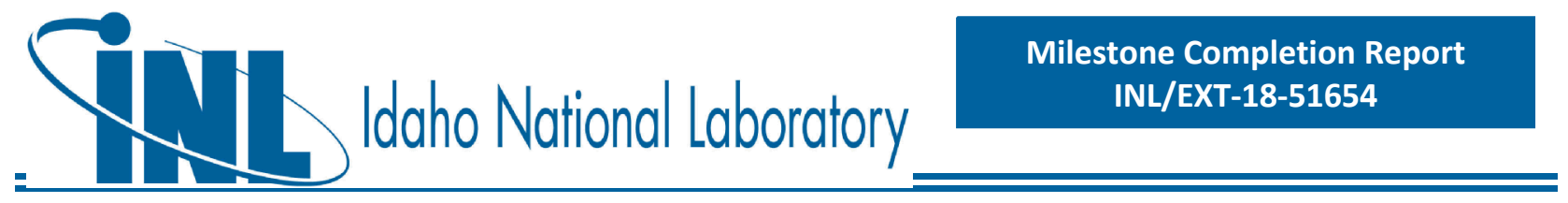

The design bases for transportation are shown in Tables E-8 for corn stover and switchgrass.

Table E-8. Transportation design basis for corn stover and switchgrass.

\begin{tabular}{|c|c|c|c|c|}
\hline \multirow[t]{2}{*}{ Component } & \multicolumn{2}{|c|}{ Corn Stover } & \multicolumn{2}{|c|}{ Switchgrass } \\
\hline & 2018 SOT & 2022 Target & 2018 SOT & 2022 Target \\
\hline \multicolumn{5}{|c|}{ Biomass characteristics during transportation from field to depot } \\
\hline Format & Bale & Bale & Bale & Bale \\
\hline Density & $12 \mathrm{lb} / \mathrm{ft}^{3}$ & $12 \mathrm{lb} / \mathrm{ft}^{3}$ & $12 \mathrm{lb} / \mathrm{ft} 3$ & $12 \mathrm{lb} / \mathrm{ft}^{3}$ \\
\hline Moisture content & $25 \%$ & $20 \%$ & $17.5 \%$ & $17.3 \%$ \\
\hline \multicolumn{5}{|c|}{ Biomass characteristics during transportation from depot to biorefinery } \\
\hline Format & Bulk pellets & Bulk pellets & Bulk pellets & Bulk pellets \\
\hline Density & $39.42 \mathrm{lb} / \mathrm{ft}^{3}$ & $39.42 \mathrm{lb} / \mathrm{ft}^{3}$ & $41.56 \mathrm{lb} / \mathrm{ft}^{3}$ & $41.56 \mathrm{lb} / \mathrm{ft}^{3}$ \\
\hline Moisture content & $11.53 \%$ & $10.56 \%$ & $9.00 \%$ & $9.89 \%$ \\
\hline
\end{tabular}




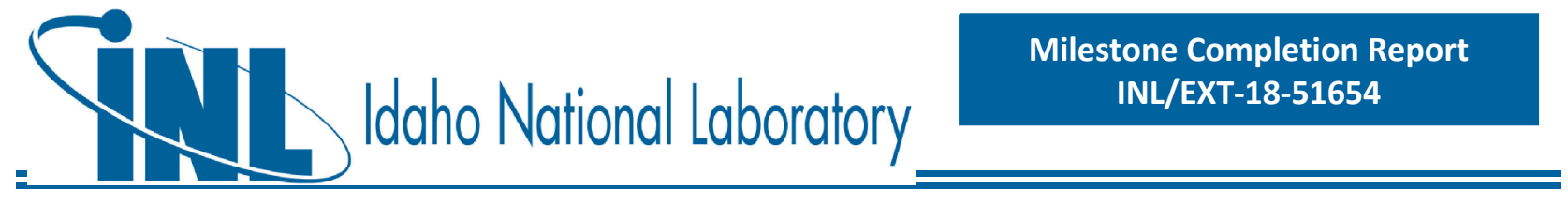

The as-harvested compositions of the biomass sources and the modeled delivered compositions of the individual blendstocks are shown in Table E-9.

Table E-9. Harvested biomass and compositions for as-harvested biomass (David and Ragauskas 2010, Liu et al. 2010, INL 2016), and for as delivered blendstocks to be blended before introduction to the pretreatment reactor throat for the 2022 Projection.

\begin{tabular}{|c|c|c|c|c|}
\hline & \multicolumn{4}{|c|}{ Harvested Biomass/Preprocessed Blendstock } \\
\hline & Corn Stover & Corn Stover & Switchgrass & $\begin{array}{c}\text { Grass } \\
\text { Clippings }\end{array}$ \\
\hline Harvest Method & Three-Pass & Two-Pass & Two-Pass & Bulk \\
\hline \multicolumn{5}{|c|}{ As-Harvested Biomass Compositions ${ }^{a, b}$} \\
\hline Moisture Content ( \% wb) & $30.0 \%$ & $30.0 \%$ & $20.0 \%$ & $70.0 \%$ \\
\hline Total Carbohydrates $(\% \mathrm{db})$ & $55.2 \%$ & $57.6 \%$ & $64.7 \%$ & $28.1 \%$ \\
\hline \multicolumn{5}{|l|}{ Composition (all \% db) } \\
\hline total anhydro-C6 & $35.5 \%$ & $37.0 \%$ & $35.6 \%$ & $19.6 \%$ \\
\hline total anhydro-C5 & $20.5 \%$ & $21.4 \%$ & $29.1 \%$ & $8.5 \%$ \\
\hline lignin & $14.8 \%$ & $14.8 \%$ & $17.8 \%$ & $16.7 \%$ \\
\hline ash & $11.0 \%$ & $7.0 \%$ & $6.2 \%$ & $12.8 \%$ \\
\hline other & $18.3 \%$ & $19.8 \%$ & $11.4 \%$ & $42.4 \%$ \\
\hline \multicolumn{5}{|c|}{ Delivered Blendstock Compositions } \\
\hline Dry Matter Loss $(\% \mathrm{db})^{\mathrm{c}}$ & $8.9 \%$ & $8.9 \%$ & $8.9 \%$ & $2.49 \%$ \\
\hline Moisture Content $(\% \mathrm{wb})$ & $10.56 \%$ & $10.56 \%$ & $9.89 \%$ & $10.00 \%$ \\
\hline Total Carbohydrates (\% db) & $56.9 \%$ & $59.6 \%$ & $66.4 \%$ & $28.7 \%$ \\
\hline \multicolumn{5}{|l|}{ Composition (all \% db) } \\
\hline total anhydro-C6 & $36.9 \%$ & $38.6 \%$ & $37.1 \%$ & $20.0 \%$ \\
\hline total anhydro-C5 & $19.9 \%$ & $20.9 \%$ & $29.4 \%$ & $8.7 \%$ \\
\hline lignin & $15.3 \%$ & $16.0 \%$ & $18.6 \%$ & $17.0 \%$ \\
\hline ash & $11.6 \%$ & $7.2 \%$ & $6.3 \%$ & $13.1 \%$ \\
\hline other & $16.2 \%$ & $17.2 \%$ & $8.7 \%$ & $41.2 \%$ \\
\hline
\end{tabular}

a As-harvested biomass compositions for corn stover and switchgrass indicate compositions of harvested bales at the time they are placed into field-side storage. For grass clippings, as-harvested biomass composition indicates the composition of the bulk grass clipping when they are delivered for drying and preprocessing at a small depot (Depot B), which is assumed to be the same day they are cut.

b As-harvested corn stover compositions taken from Table 3 and adjusted for additional soil ash contamination. Average ash contents for threepass and two-pass corn stover harvested in Kansas were taken from the INL Bioenergy feedstock library. Switchgrass composition is for the Blackwell cultivar, which is adapted for maximum yields in Kansas (David and Ragauskas 2010). Harvested grass clippings composition is for grass clippings collected in Idaho Falls, ID (data in the INL Bioenergy Feedstock Library).

c Calculated by mass balances based on losses in storage and preprocessing. Detailed losses are described in Appendix $\mathrm{J}$ 


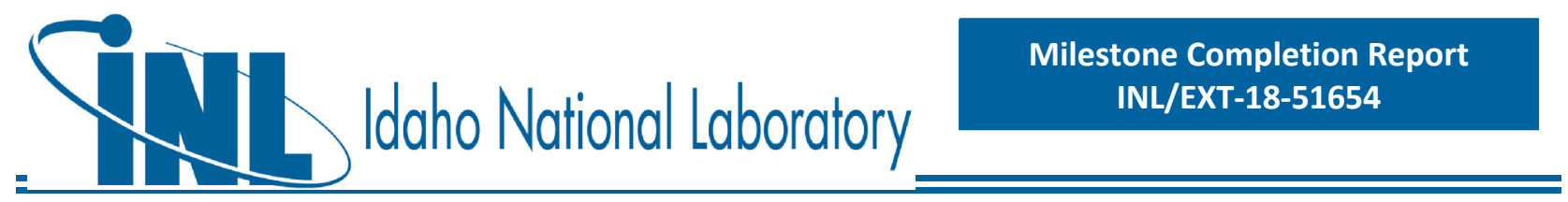

\section{APPENDIX F - Process Flow Diagrams and Mass Balances for the 2018 Herbaceous SOT}

\section{F.1 Three-pass Corn Stover Blendstock}

High-level stream table information from Aspen Plus modeling output follows, for key streams associated with each process operation area. This is followed by high-level PFDs for the associated process areas. Space for stream tables was limited; below is a key to lumped components. As the stream table information focuses primarily on the high-level overall process and does not include every individual modeled stream within each process area, mass balance closure around a given unit area may not be $100 \%$.

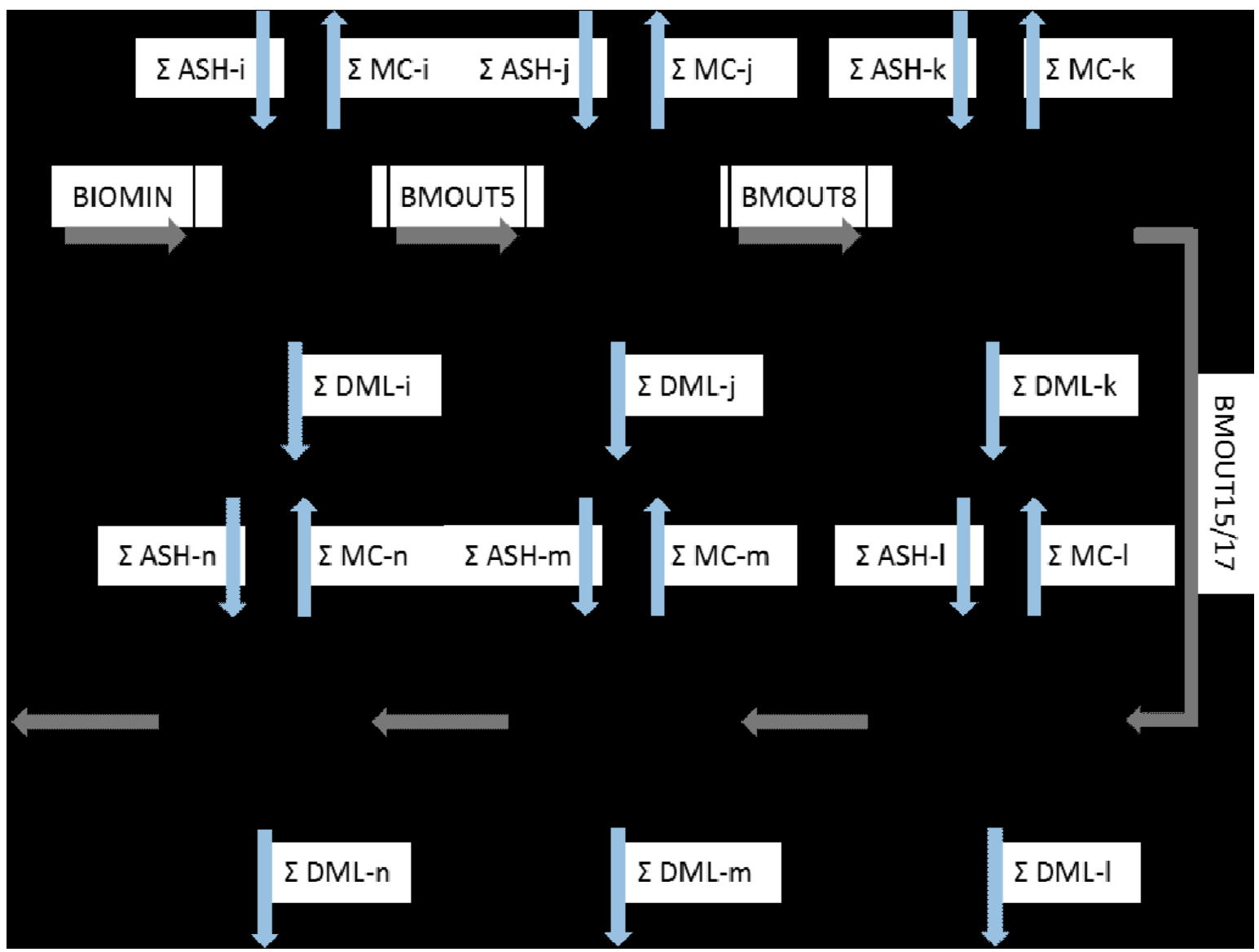

Figure F-1. High-level flowsheet showing key process areas for the three-pass corn stover blendstock in the 2018 Herbaceous SOT. 


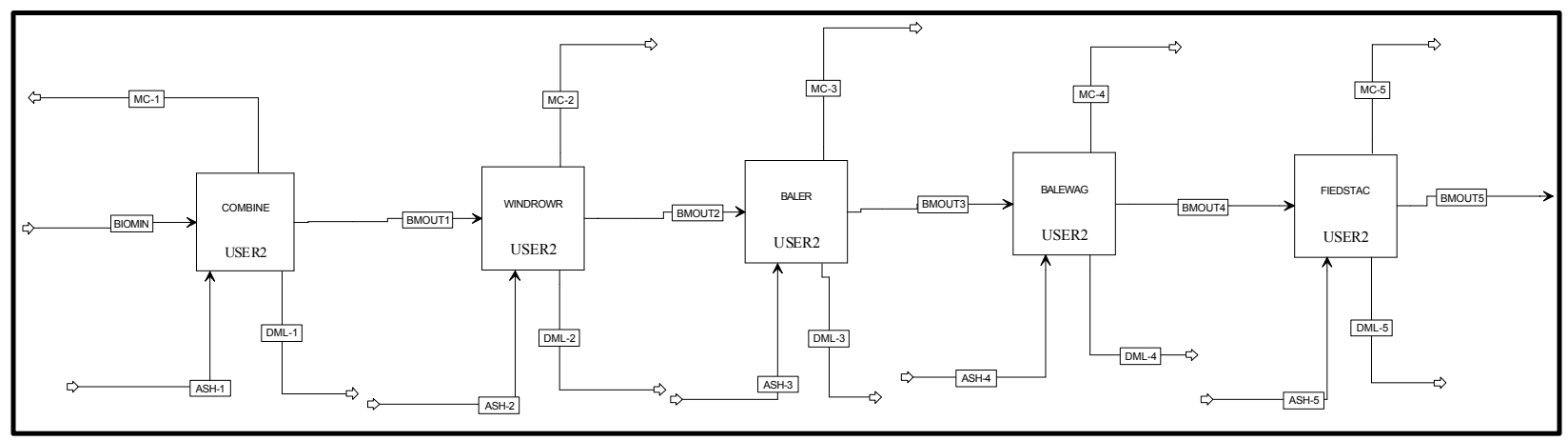

Figure F-2. Detailed process flow diagram for area A100 - Harvesting to Storage.

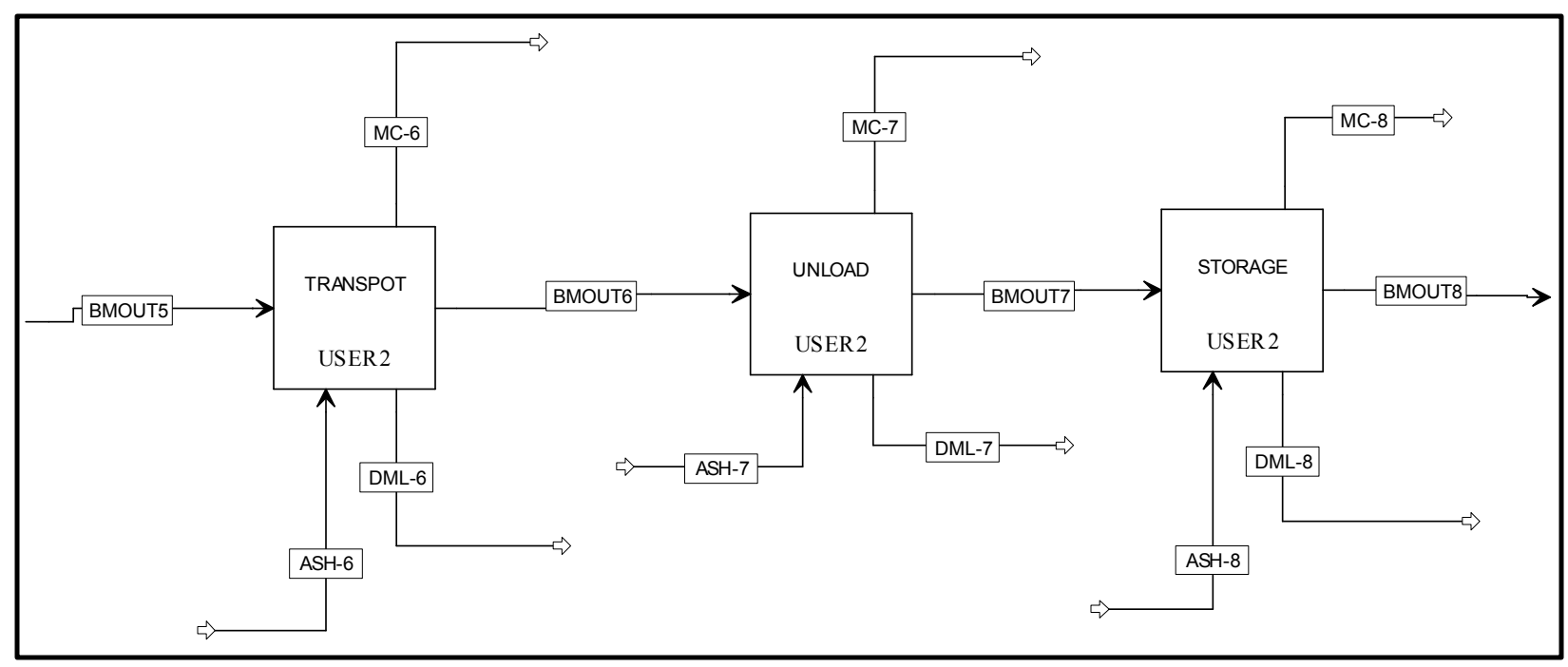

Figure F-3. Detailed process flow diagram for area A200 - Transport to Depot \& Handling. 


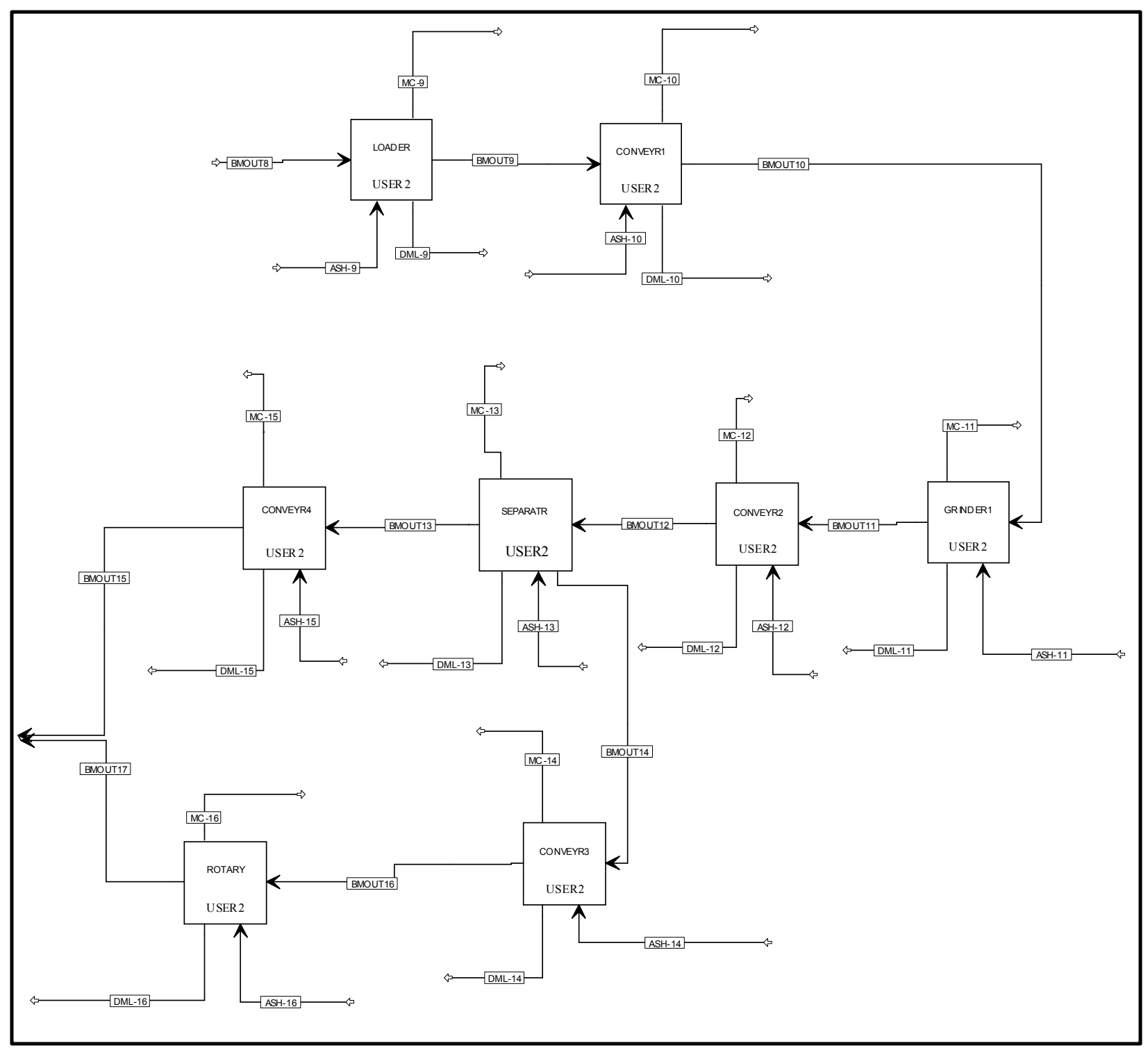

Figure F-4. Detailed process flow diagram for area A300 - Preprocessing - Size Reduction. 

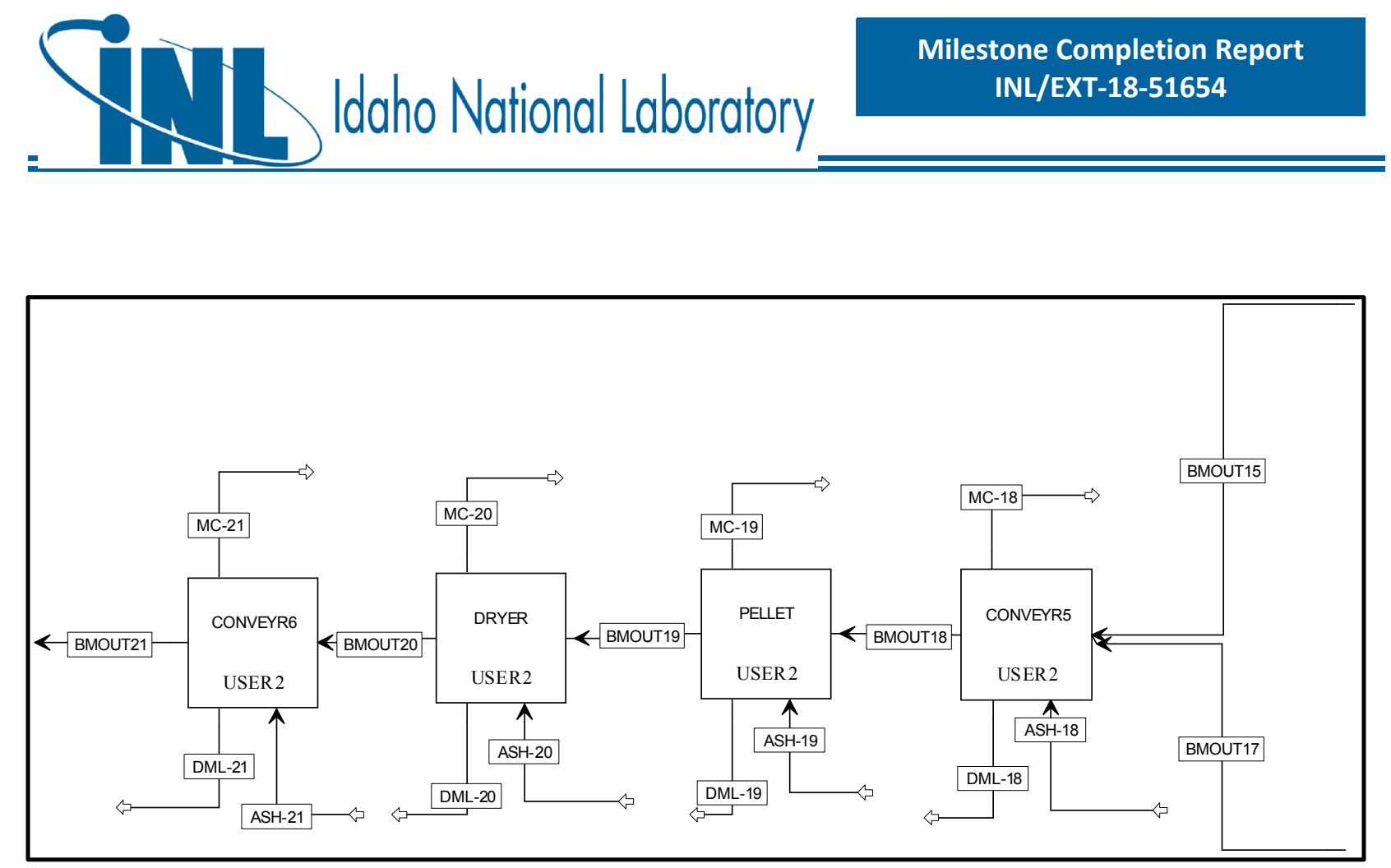

Figure F-5. Detailed process flow diagram for area A400 - Preprocessing - Pelleting.

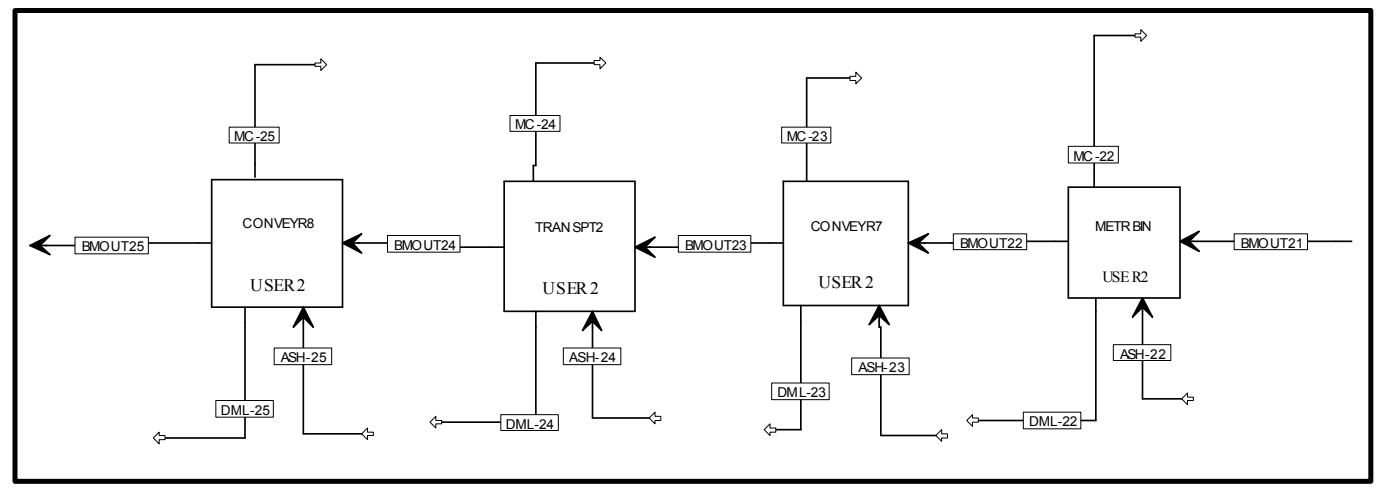

Figure F-6. Detailed process flow diagram for area A500 - Transport to Biorefinery. 

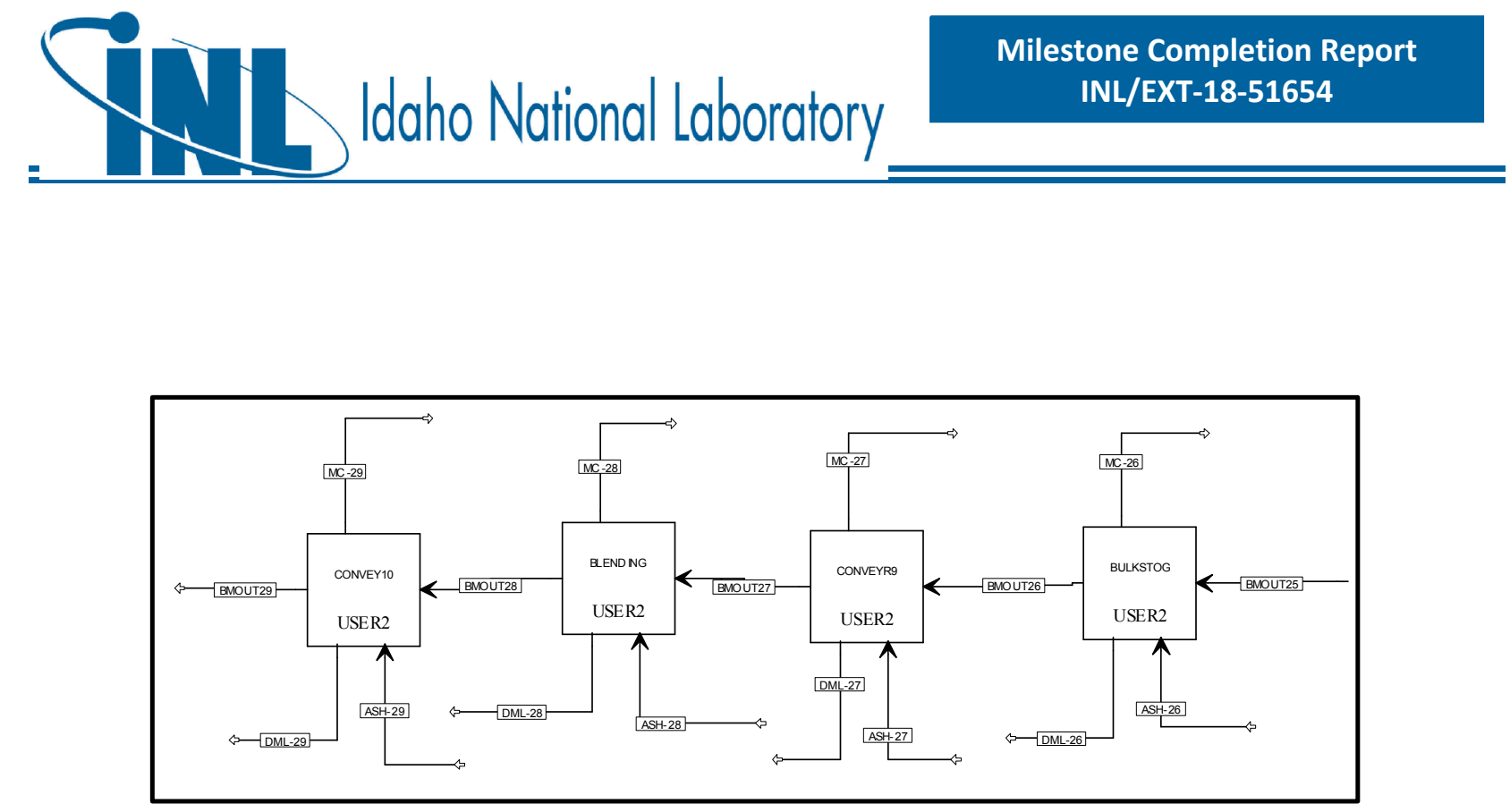

Figure F-7. Detailed process flow diagram for area A600 - Feeding. 


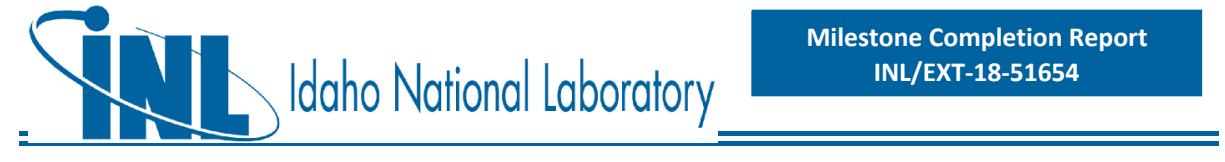

Table F-1. Aspen Plus mass balances from harvest to field-side storage (Area A100) for the three-pass corn stover blendstock in the 2018 Herbaceous SOT. Harvest is assumed to take place within a 6 week period, working 14 hours/day, 6 days per week.

\begin{tabular}{|c|c|c|c|c|c|c|c|c|c|c|c|c|c|c|c|}
\hline Component & unit & BIOMIN & $\begin{array}{c}\text { DML- } \\
1\end{array}$ & MC-1 & $\begin{array}{c}\text { BMOUT } \\
1\end{array}$ & DML-2 & MC-2 & $\begin{array}{c}\text { BMOUT } \\
2\end{array}$ & $\begin{array}{c}\text { DML- } \\
3\end{array}$ & MC-3 & ASH-3 & BMOUT3 & $\begin{array}{c}\text { DML- } \\
4\end{array}$ & $\begin{array}{l}\text { MC- } \\
4\end{array}$ & BMOUT4 \\
\hline $\begin{array}{l}\text { Overall Flow } \\
\text { (moisture and dry } \\
\text { matter) }\end{array}$ & $\mathrm{kg} / \mathrm{hr}$ & 275,298 & 0 & 10 & 275,289 & 0 & 0 & 275,289 & 0 & 0 & 11,697 & 275,289 & 0 & 0 & 275,289 \\
\hline Moisture Flow & $\mathrm{kg} / \mathrm{hr}$ & 82,596 & 0 & 10 & 82,587 & 0 & 0 & 82,587 & 0 & 0 & 0 & 82,587 & 0 & 0 & 82,587 \\
\hline $\begin{array}{l}\text { Total Flow (dry } \\
\text { matter) }\end{array}$ & $\mathrm{kg} / \mathrm{hr}$ & 192,702 & 0 & 0 & 192,702 & 0 & 0 & 192,702 & 0 & 0 & 11,697 & 192,702 & 0 & 0 & 192,702 \\
\hline C6 & $\mathrm{kg} / \mathrm{hr}$ & 68,340 & 0 & 0 & 68,340 & 0 & 0 & 68,340 & 0 & 0 & 0 & 68,340 & 0 & 0 & 68,340 \\
\hline C5 & $\mathrm{kg} / \mathrm{hr}$ & 39,488 & 0 & 0 & 39,488 & 0 & 0 & 39,488 & 0 & 0 & 0 & 39,488 & 0 & 0 & 39,488 \\
\hline LIGNIN & $\mathrm{kg} / \mathrm{hr}$ & 28,489 & 0 & 0 & 28,489 & 0 & 0 & 28,489 & 0 & 0 & 0 & 28,489 & 0 & 0 & 28,489 \\
\hline ASH & $\mathrm{kg} / \mathrm{hr}$ & 9,500 & 0 & 0 & 9,500 & 0 & 0 & 9,500 & 0 & 0 & 11,697 & 21,197 & 0 & 0 & 21,197 \\
\hline PROTEIN & $\mathrm{kg} / \mathrm{hr}$ & 5,589 & 0 & 0 & 5,589 & 0 & 0 & 5,589 & 0 & 0 & 0 & 5,589 & 0 & 0 & 5,589 \\
\hline EXTRACTIVES & $\mathrm{kg} / \mathrm{hr}$ & 26,506 & 0 & 0 & 26,506 & 0 & 0 & 26,506 & 0 & 0 & 0 & 26,506 & 0 & 0 & 26,506 \\
\hline OTHERS & $\mathrm{kg} / \mathrm{hr}$ & 3,093 & 0 & 0 & 3,093 & 0 & 0 & 3,093 & 0 & 0 & 0 & 3,093 & 0 & 0 & 3,093 \\
\hline Temperature & K & 298 & 298 & 298 & 298 & 298 & 298 & 298 & 298 & 298 & 298 & 298 & 298 & 298 & 298 \\
\hline Pressure & $\mathrm{atm}$ & 1 & 1 & 1 & 1 & 1 & 1 & 1 & 1 & 1 & 1 & 1 & 1 & 1 & 1 \\
\hline Vapor Frac & & 0 & 0 & 0 & 0 & 0 & 0 & 0 & 0 & 0 & 0 & 0 & 0 & 0 & 0 \\
\hline
\end{tabular}




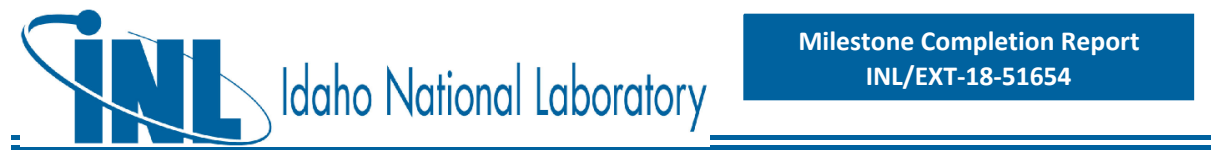

Table F-2. Aspen Plus mass balances from field-side storage to feeding (Areas A200-A600) for the three-pass corn stover blendstock in the 2018 Herbaceous SOT. Depot operation is assumed to take place within 350 day period, working 24 hours/day, 7 days per week.

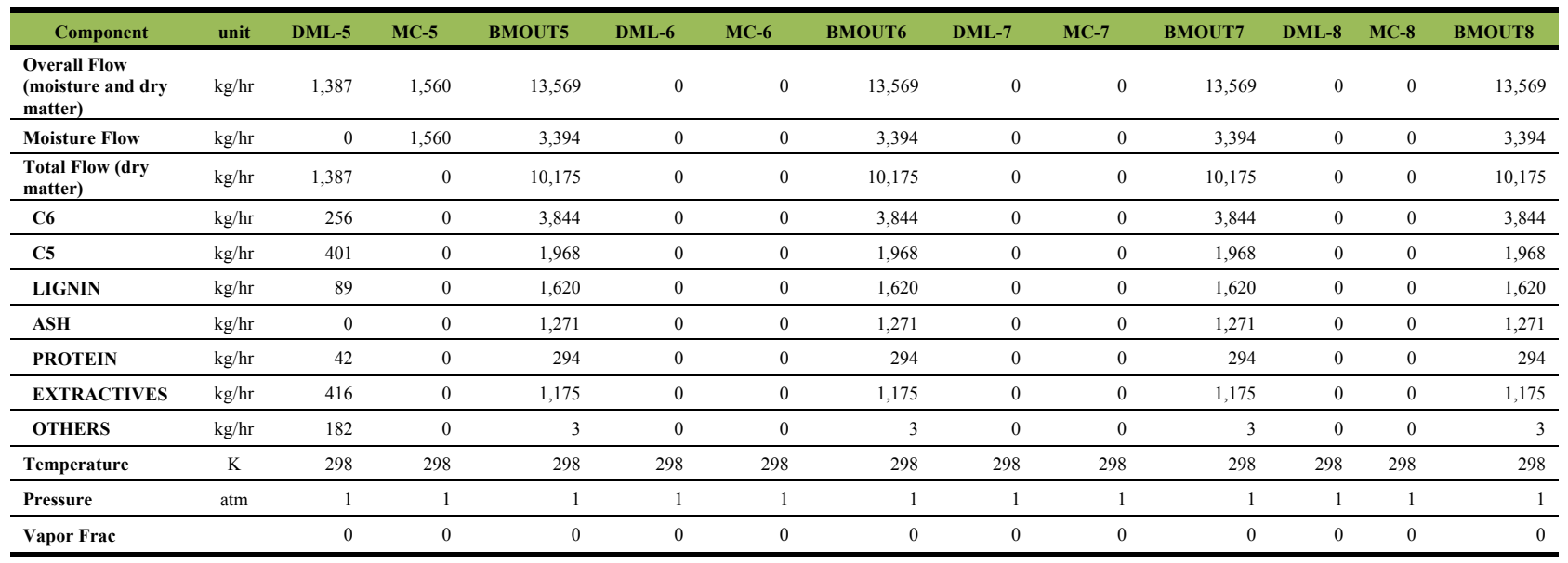

127 


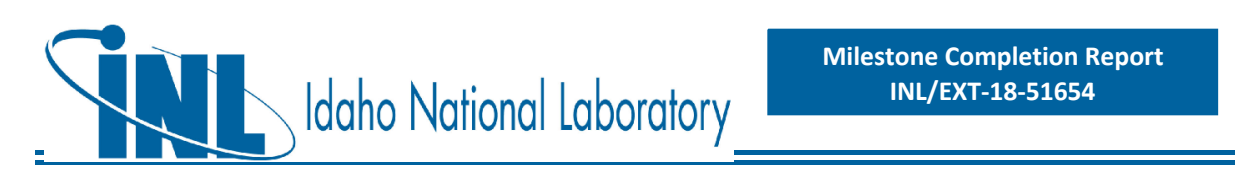

Table F-2. (continued)

\begin{tabular}{|c|c|c|c|c|c|c|c|c|c|c|c|c|c|}
\hline Component & unit & DML-9 & MC-9 & BMOUT9 & DML-10 & MC-10 & BMOUT10 & DML-11 & MC-11 & BMOUT11 & $\begin{array}{c}\text { DML- } \\
12\end{array}$ & $\begin{array}{l}\text { MC- } \\
12\end{array}$ & BMOUT12 \\
\hline $\begin{array}{l}\text { Overall Flow } \\
\text { (moisture and dry } \\
\text { matter) }\end{array}$ & $\mathrm{kg} / \mathrm{hr}$ & 0 & 0 & 13,569 & 0 & 0 & 13,569 & 102 & 838 & 12,629 & 0 & 0 & 12,629 \\
\hline Moisture Flow & $\mathrm{kg} / \mathrm{hr}$ & 0 & 0 & 3,394 & 0 & 0 & 3,394 & 0 & 838 & 2,556 & 0 & 0 & 2,556 \\
\hline $\begin{array}{l}\text { Total Flow (dry } \\
\text { matter) }\end{array}$ & $\mathrm{kg} / \mathrm{hr}$ & 0 & 0 & 10,175 & 0 & 0 & 10,175 & 102 & 0 & 10,073 & 0 & 0 & 10,073 \\
\hline C6 & $\mathrm{kg} / \mathrm{hr}$ & 0 & 0 & 3,844 & 0 & 0 & 3,844 & 29 & 0 & 3,816 & 0 & 0 & 3,816 \\
\hline C5 & $\mathrm{kg} / \mathrm{hr}$ & 0 & 0 & 1,968 & 0 & 0 & 1,968 & 16 & 0 & 1,952 & 0 & 0 & 1,952 \\
\hline LIGNIN & $\mathrm{kg} / \mathrm{hr}$ & 0 & 0 & 1,620 & 0 & 0 & 1,620 & 20 & 0 & 1,600 & 0 & 0 & 1,600 \\
\hline ASH & $\mathrm{kg} / \mathrm{hr}$ & 0 & 0 & 1,271 & 0 & 0 & 1,271 & 26 & 0 & 1,247 & 0 & 0 & 1,247 \\
\hline PROTEIN & $\mathrm{kg} / \mathrm{hr}$ & 0 & 0 & 294 & 0 & 0 & 294 & 0 & 0 & 294 & 0 & 0 & 294 \\
\hline EXTRACTIVES & $\mathrm{kg} / \mathrm{hr}$ & 0 & 0 & 1,175 & 0 & 0 & 1,175 & 12 & 0 & 1,161 & 0 & 0 & 1,161 \\
\hline OTHERS & $\mathrm{kg} / \mathrm{hr}$ & 0 & 0 & 3 & 0 & 0 & 3 & 0 & 0 & 3 & 0 & 0 & 3 \\
\hline Temperature & $\mathrm{K}$ & 298 & 298 & 298 & 298 & 298 & 298 & 298 & 298 & 298 & 298 & 298 & 298 \\
\hline Pressure & atm & 1 & 1 & 1 & 1 & 1 & 1 & 1 & 1 & 1 & 1 & 1 & 1 \\
\hline Vapor Frac & & 0 & 0 & 0 & 0 & 0 & 0 & 0 & 0 & 0 & 0 & 0 & 0 \\
\hline
\end{tabular}




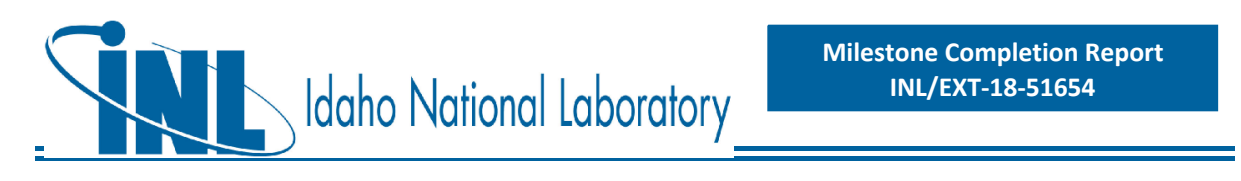

Table F-2. (continued)

\begin{tabular}{|c|c|c|c|c|c|c|c|c|c|c|c|c|}
\hline Component & unit & $\begin{array}{c}\text { DML- } \\
13\end{array}$ & MC-13 & BMOUT13 & BMOUT14 & DML-14 & MC-14 & DML-15 & $\begin{array}{l}\text { MC- } \\
15\end{array}$ & BMOUT15 & $\begin{array}{c}\text { DML- } \\
16\end{array}$ & $\begin{array}{l}\text { MC- } \\
16\end{array}$ \\
\hline $\begin{array}{l}\text { Overall Flow } \\
\text { (moisture and dry } \\
\text { matter) }\end{array}$ & $\mathrm{kg} / \mathrm{hr}$ & 309 & 0 & 5,469 & 0 & 0 & 6,852 & 0 & 0 & 5,469 & 56 & 12 \\
\hline Moisture Flow & $\mathrm{kg} / \mathrm{hr}$ & 309 & 0 & 998 & 0 & 0 & 1,250 & 0 & 0 & 998 & 0 & 12 \\
\hline $\begin{array}{l}\text { Total Flow (dry } \\
\text { matter) }\end{array}$ & $\mathrm{kg} / \mathrm{hr}$ & 0 & 0 & 4,471 & 0 & 0 & 5,602 & 0 & 0 & 4,471 & 56 & 0 \\
\hline $\mathrm{C} 6$ & $\mathrm{~kg} / \mathrm{hr}$ & 0 & 0 & 1,694 & 0 & 0 & 2,122 & 0 & 0 & 1,694 & 15 & 0 \\
\hline C5 & $\mathrm{kg} / \mathrm{hr}$ & 0 & 0 & 867 & 0 & 0 & 1,085 & 0 & 0 & 867 & 9 & 0 \\
\hline LIGNIN & $\mathrm{kg} / \mathrm{hr}$ & 0 & 0 & 710 & 0 & 0 & 889 & 0 & 0 & 710 & 10 & 0 \\
\hline ASH & $\mathrm{kg} / \mathrm{hr}$ & 0 & 0 & 553 & 0 & 0 & 693 & 0 & 0 & 553 & 14 & 0 \\
\hline PROTEIN & $\mathrm{kg} / \mathrm{hr}$ & 0 & 0 & 130 & 0 & 0 & 163 & 0 & 0 & 130 & 0 & 0 \\
\hline EXTRACTIVES & $\mathrm{kg} / \mathrm{hr}$ & 0 & 0 & 516 & 0 & 0 & 646 & 0 & 0 & 516 & 7 & 0 \\
\hline OTHERS & $\mathrm{kg} / \mathrm{hr}$ & 0 & 0 & 1 & 0 & 0 & 2 & 0 & 0 & 1 & 0 & 0 \\
\hline Temperature & $\mathrm{K}$ & 298 & 298 & 298 & 298 & 298 & 298 & 298 & 298 & 298 & 298 & 298 \\
\hline Pressure & atm & 1 & 1 & 1 & 1 & 1 & 1 & 1 & 1 & 1 & 1 & 1 \\
\hline Vapor Frac & & 0 & 0 & 0 & 0 & 0 & 0 & 0 & 0 & 0 & 0 & 0 \\
\hline
\end{tabular}




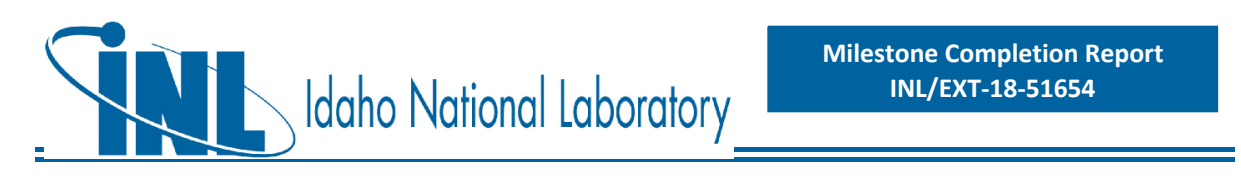

Table F-2. (continued)

\begin{tabular}{|c|c|c|c|c|c|c|c|c|c|c|c|c|}
\hline Component & unit & BMOUT16 & BMOUT17 & DML-18 & MC-18 & BMOUT18 & DML-19 & MC-19 & BMOUT19 & DML-20 & $\begin{array}{l}\text { MC- } \\
20\end{array}$ & BMOUT20 \\
\hline $\begin{array}{l}\text { Overall Flow } \\
\text { (moisture and dry } \\
\text { matter) }\end{array}$ & $\mathrm{kg} / \mathrm{hr}$ & 6,852 & 6,783 & 0 & 0 & 12,252 & 0 & 706 & 11,545 & 0 & 222 & 11,324 \\
\hline Moisture Flow & $\mathrm{kg} / \mathrm{hr}$ & 1,250 & 1,237 & 0 & 0 & 2,235 & 0 & 706 & 1,529 & 0 & 222 & 1,307 \\
\hline $\begin{array}{l}\text { Total Flow (dry } \\
\text { matter) }\end{array}$ & $\mathrm{kg} / \mathrm{hr}$ & 5,602 & 5,546 & 0 & 0 & 10,017 & 0 & 0 & 10,017 & 0 & 0 & 10,017 \\
\hline C6 & $\mathrm{kg} / \mathrm{hr}$ & 2,122 & 2,107 & 0 & 0 & 3,800 & 0 & 0 & 3,800 & 0 & 0 & 3,800 \\
\hline C5 & $\mathrm{kg} / \mathrm{hr}$ & 1,085 & 1,077 & 0 & 0 & 1,943 & 0 & 0 & 1,943 & 0 & 0 & 1,943 \\
\hline LIGNIN & $\mathrm{kg} / \mathrm{hr}$ & 889 & 879 & 0 & 0 & 1,589 & 0 & 0 & 1,589 & 0 & 0 & 1,589 \\
\hline ASH & $\mathrm{kg} / \mathrm{hr}$ & 693 & 679 & 0 & 0 & 1,233 & 0 & 0 & 1,233 & 0 & 0 & 1,233 \\
\hline PROTEIN & $\mathrm{kg} / \mathrm{hr}$ & 163 & 163 & 0 & 0 & 294 & 0 & 0 & 294 & 0 & 0 & 294 \\
\hline EXTRACTIVES & $\mathrm{kg} / \mathrm{hr}$ & 646 & 640 & 0 & 0 & 1,155 & 0 & 0 & 1,155 & 0 & 0 & 1,155 \\
\hline OTHERS & $\mathrm{kg} / \mathrm{hr}$ & 2 & 2 & 0 & 0 & 3 & 0 & 0 & 3 & 0 & 0 & 3 \\
\hline Temperature & $\mathrm{K}$ & 298 & 298 & 298 & 298 & 298 & 298 & 298 & 298 & 298 & 298 & 298 \\
\hline Pressure & $\mathrm{atm}$ & 1 & 1 & 1 & 1 & 1 & 1 & 1 & 1 & 1 & 1 & 1 \\
\hline Vapor Frac & & 0 & 0 & 0 & 0 & 0 & 0 & 0 & 0 & 0 & 0 & 0 \\
\hline
\end{tabular}




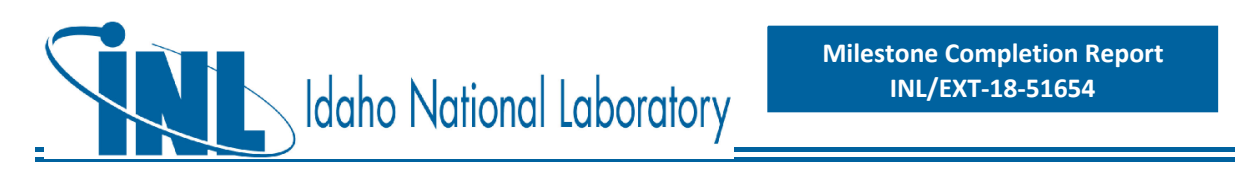

Table F-2. (continued)

\begin{tabular}{|c|c|c|c|c|c|c|c|c|c|c|c|}
\hline Component & unit & $\begin{array}{c}\text { DML- } \\
21\end{array}$ & MC-21 & BMOUT21 & DML-22 & MC-22 & BMOUT22 & DML-23 & MC-23 & BMOUT23 & $\begin{array}{c}\text { DML- } \\
24\end{array}$ \\
\hline $\begin{array}{l}\text { Overall Flow } \\
\text { (moisture and dry } \\
\text { matter) }\end{array}$ & $\mathrm{kg} / \mathrm{hr}$ & 0 & 0 & 11,324 & 0 & 0 & 11,324 & 0 & 0 & 11,324 & 0 \\
\hline Moisture Flow & $\mathrm{kg} / \mathrm{hr}$ & 0 & 0 & 1,307 & 0 & 0 & 1,307 & 0 & 0 & 1,307 & 0 \\
\hline $\begin{array}{l}\text { Total Flow (dry } \\
\text { matter) }\end{array}$ & $\mathrm{kg} / \mathrm{hr}$ & 0 & 0 & 10,017 & 0 & 0 & 10,017 & 0 & 0 & 10,017 & 0 \\
\hline C6 & $\mathrm{kg} / \mathrm{hr}$ & 0 & 0 & 3,800 & 0 & 0 & 3,800 & 0 & 0 & 3,800 & 0 \\
\hline C5 & $\mathrm{kg} / \mathrm{hr}$ & 0 & 0 & 1,943 & 0 & 0 & 1,943 & 0 & 0 & 1,943 & 0 \\
\hline LIGNIN & $\mathrm{kg} / \mathrm{hr}$ & 0 & 0 & 1,589 & 0 & 0 & 1,589 & 0 & 0 & 1,589 & 0 \\
\hline ASH & $\mathrm{kg} / \mathrm{hr}$ & 0 & 0 & 1,233 & 0 & 0 & 1,233 & 0 & 0 & 1,233 & 0 \\
\hline PROTEIN & $\mathrm{kg} / \mathrm{hr}$ & 0 & 0 & 294 & 0 & 0 & 294 & 0 & 0 & 294 & 0 \\
\hline EXTRACTIVES & $\mathrm{kg} / \mathrm{hr}$ & 0 & 0 & 1,155 & 0 & 0 & 1,155 & 0 & 0 & 1,155 & 0 \\
\hline OTHERS & $\mathrm{kg} / \mathrm{hr}$ & 0 & 0 & 3 & 0 & 0 & 3 & 0 & 0 & 3 & 0 \\
\hline Temperature & $\mathrm{K}$ & 298 & 298 & 298 & 298 & 298 & 298 & 298 & 298 & 298 & 298 \\
\hline Pressure & $\mathrm{atm}$ & 1 & 1 & 1 & 1 & 1 & 1 & 1 & 1 & 1 & 1 \\
\hline Vapor Frac & & 0 & 0 & 0 & 0 & 0 & 0 & 0 & 0 & 0 & 0 \\
\hline
\end{tabular}




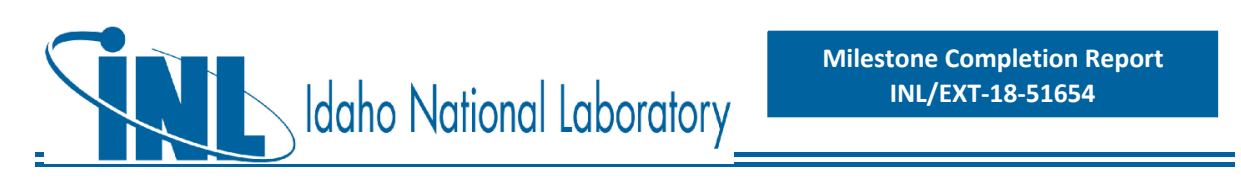

Table F-2. (continued)

\begin{tabular}{|c|c|c|c|c|c|c|c|c|c|c|c|c|}
\hline Component & unit & $\begin{array}{l}\text { MC- } \\
24\end{array}$ & BMOUT24 & DML-25 & MC-25 & BMOUT25 & DML-26 & MC-26 & BMOUT26 & $\begin{array}{c}\text { DML- } \\
27\end{array}$ & $\begin{array}{l}\text { MC- } \\
27\end{array}$ & BMOUT27 \\
\hline $\begin{array}{l}\text { Overall Flow } \\
\text { (moisture and dry } \\
\text { matter) }\end{array}$ & $\mathrm{kg} / \mathrm{hr}$ & 0 & 11,324 & 0 & 0 & 11,324 & 0 & 0 & 11,324 & 0 & 0 & 11,324 \\
\hline Moisture Flow & $\mathrm{kg} / \mathrm{hr}$ & 0 & 1,307 & 0 & 0 & 1,307 & 0 & 0 & 1,307 & 0 & 0 & 1,307 \\
\hline $\begin{array}{l}\text { Total Flow (dry } \\
\text { matter) }\end{array}$ & $\mathrm{kg} / \mathrm{hr}$ & 0 & 10,017 & 0 & 0 & 10,017 & 0 & 0 & 10,017 & 0 & 0 & 10,017 \\
\hline C6 & $\mathrm{kg} / \mathrm{hr}$ & 0 & 3,800 & 0 & 0 & 3,800 & 0 & 0 & 3,800 & 0 & 0 & 3,800 \\
\hline C5 & $\mathrm{kg} / \mathrm{hr}$ & 0 & 1,943 & 0 & 0 & 1,943 & 0 & 0 & 1,943 & 0 & 0 & 1,943 \\
\hline LIGNIN & $\mathrm{kg} / \mathrm{hr}$ & 0 & 1,589 & 0 & 0 & 1,589 & 0 & 0 & 1,589 & 0 & 0 & 1,589 \\
\hline ASH & $\mathrm{kg} / \mathrm{hr}$ & 0 & 1,233 & 0 & 0 & 1,233 & 0 & 0 & 1,233 & 0 & 0 & 1,233 \\
\hline PROTEIN & $\mathrm{kg} / \mathrm{hr}$ & 0 & 294 & 0 & 0 & 294 & 0 & 0 & 294 & 0 & 0 & 294 \\
\hline EXTRACTIVES & $\mathrm{kg} / \mathrm{hr}$ & 0 & 1,155 & 0 & 0 & 1,155 & 0 & 0 & 1,155 & 0 & 0 & 1,155 \\
\hline OTHERS & $\mathrm{kg} / \mathrm{hr}$ & 0 & 3 & 0 & 0 & 3 & 0 & 0 & 3 & 0 & 0 & 3 \\
\hline Temperature & $\mathrm{K}$ & 298 & 298 & 298 & 298 & 298 & 298 & 298 & 298 & 298 & 298 & 298 \\
\hline Pressure & atm & 1 & 1 & 1 & 1 & 1 & 1 & 1 & 1 & 1 & 1 & 1 \\
\hline Vapor Frac & & 0 & 0 & 0 & 0 & 0 & 0 & 0 & 0 & 0 & 0 & 0 \\
\hline
\end{tabular}




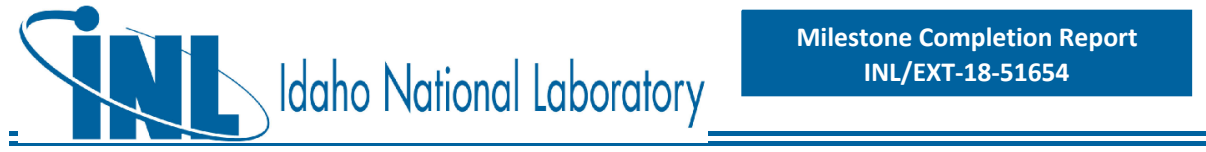

Table F-2. (continued)

\begin{tabular}{lcrrrrrr}
\multicolumn{1}{c}{ Component } & unit & $\begin{array}{c}\text { DML- } \\
\mathbf{2 8}\end{array}$ & MC-28 & BMOUT28 & DML-29 & MC-29 & BMOUT29 \\
\hline $\begin{array}{l}\text { Overall Flow } \\
\text { (moisture and dry } \\
\text { matter) }\end{array}$ & $\mathrm{kg} / \mathrm{hr}$ & 0 & 0 & 11,324 & 0 & 0 & 11,324 \\
\hline Moisture Flow & $\mathrm{kg} / \mathrm{hr}$ & 0 & 0 & 1,307 & 0 & 0 & 1,307 \\
\hline $\begin{array}{l}\text { Total Flow (dry } \\
\text { matter) }\end{array}$ & $\mathrm{kg} / \mathrm{hr}$ & 0 & 0 & 10,017 & 0 & 0 & 10,017 \\
\hline C6 & $\mathrm{kg} / \mathrm{hr}$ & 0 & 0 & 3,800 & 0 & 0 & 3,800 \\
\hline C5 & $\mathrm{kg} / \mathrm{hr}$ & 0 & 0 & 1,943 & 0 & 0 & 1,943 \\
\hline LIGNIN & $\mathrm{kg} / \mathrm{hr}$ & 0 & 0 & 1,589 & 0 & 0 & 1,589 \\
\hline ASH & $\mathrm{kg} / \mathrm{hr}$ & 0 & 0 & 1,233 & 0 & 0 & 1,233 \\
\hline PROTEIN & $\mathrm{kg} / \mathrm{hr}$ & 0 & 0 & 294 & 0 & 0 & 294 \\
\hline EXTRACTIVES & $\mathrm{kg} / \mathrm{hr}$ & 0 & 0 & 1,155 & 0 & 0 & 1,155 \\
\hline OTHERS & $\mathrm{kg} / \mathrm{hr}$ & 0 & 0 & 3 & 0 & 0 & 3 \\
\hline Temperature & $\mathrm{K}$ & 298 & 298 & 298 & 298 & 298 & 298 \\
\hline Pressure & $\mathrm{atm}$ & 1 & 1 & 1 & 1 & 1 & 1 \\
\hline Vapor Frac & & 0 & 0 & 0 & 0 & 0 & 0 \\
\hline
\end{tabular}




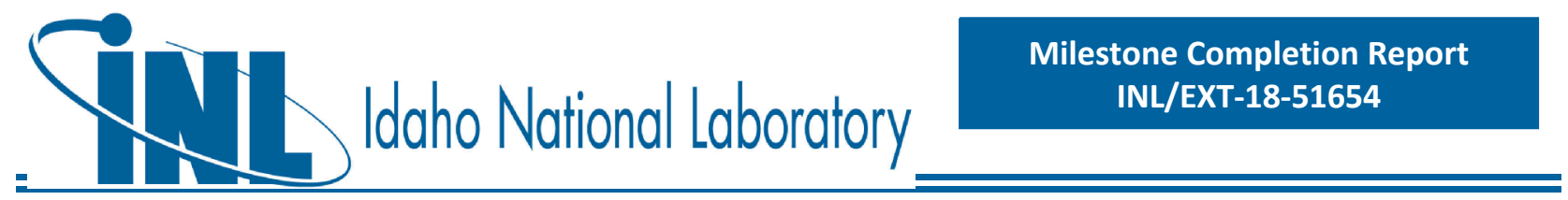

\section{F.2 Two-pass Corn Stover Blendstock}

High-level stream table information from Aspen Plus modeling output follows, for key streams associated with each process operation area. This is followed by high-level PFDs for the associated process areas. Space for stream tables was limited; below is a key to lumped components. As the stream table information focuses primarily on the high-level overall process and does not include every individual modeled stream within each process area, mass balance closure around a given unit area may not be $100 \%$.

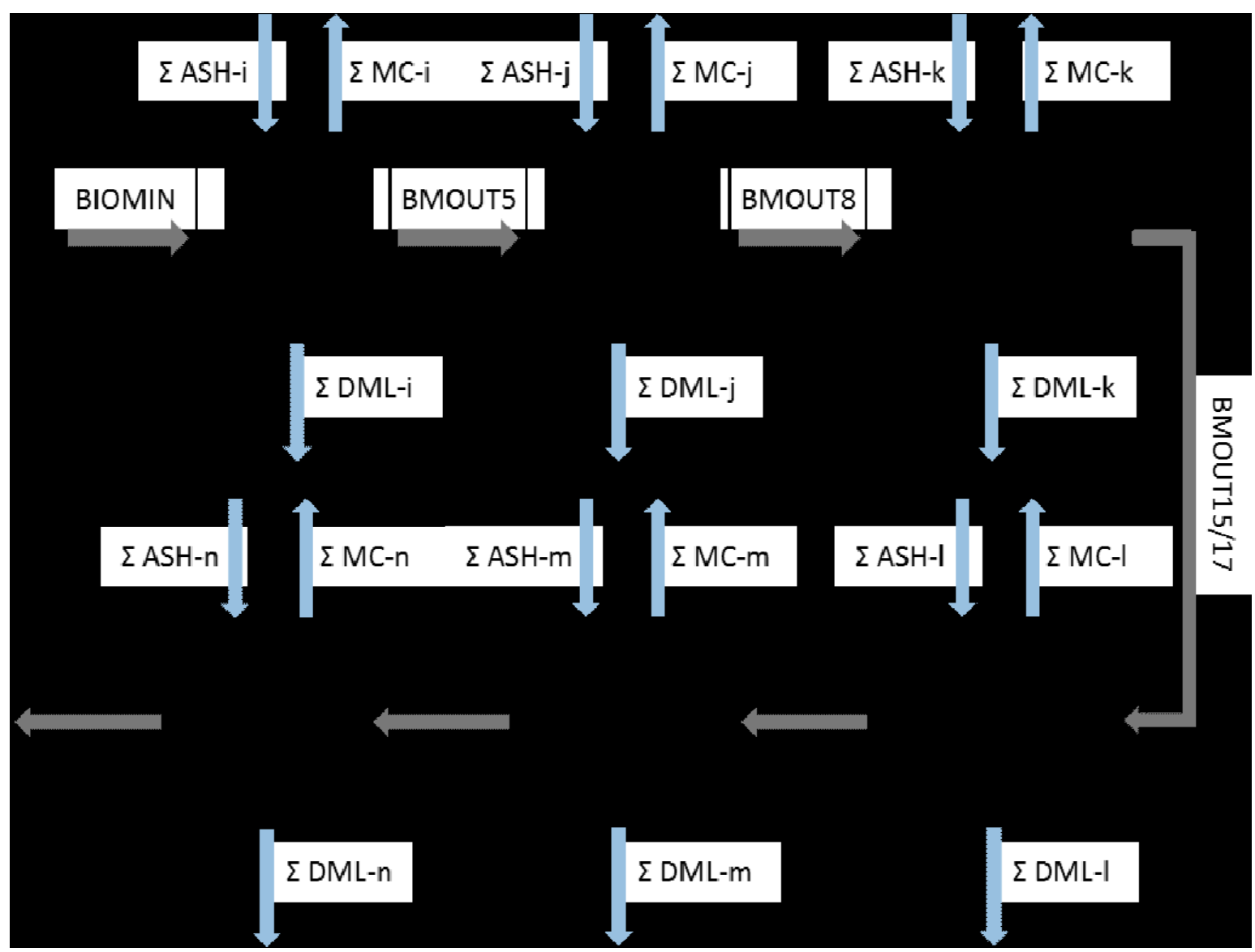

Figure F-8. High-level flowsheet showing key process areas for the two pass corn stover blendstock in the 2018 Herbaceous SOT. 

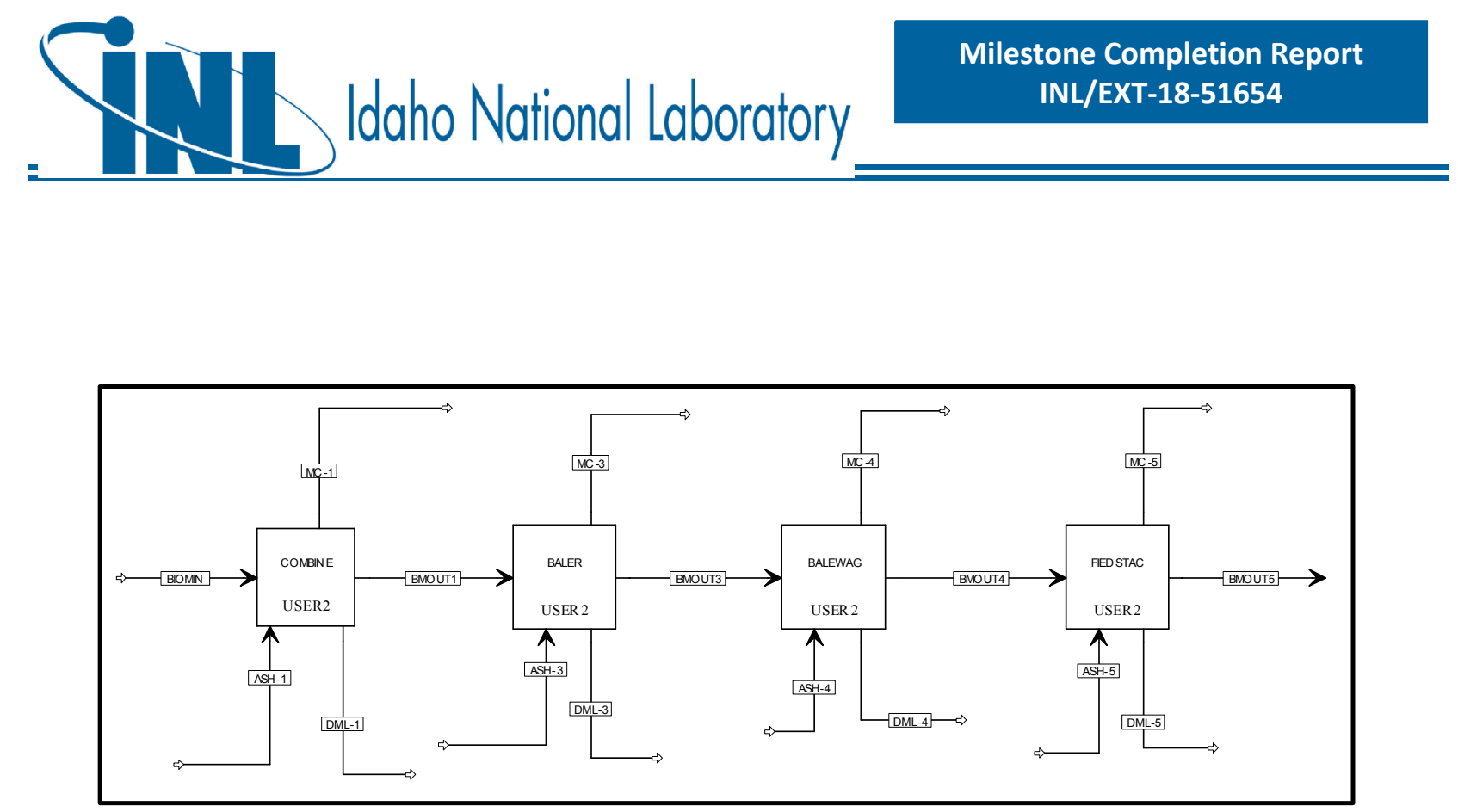

Figure F-9. Detailed process flow diagram for area B100 - Harvesting to Storage.

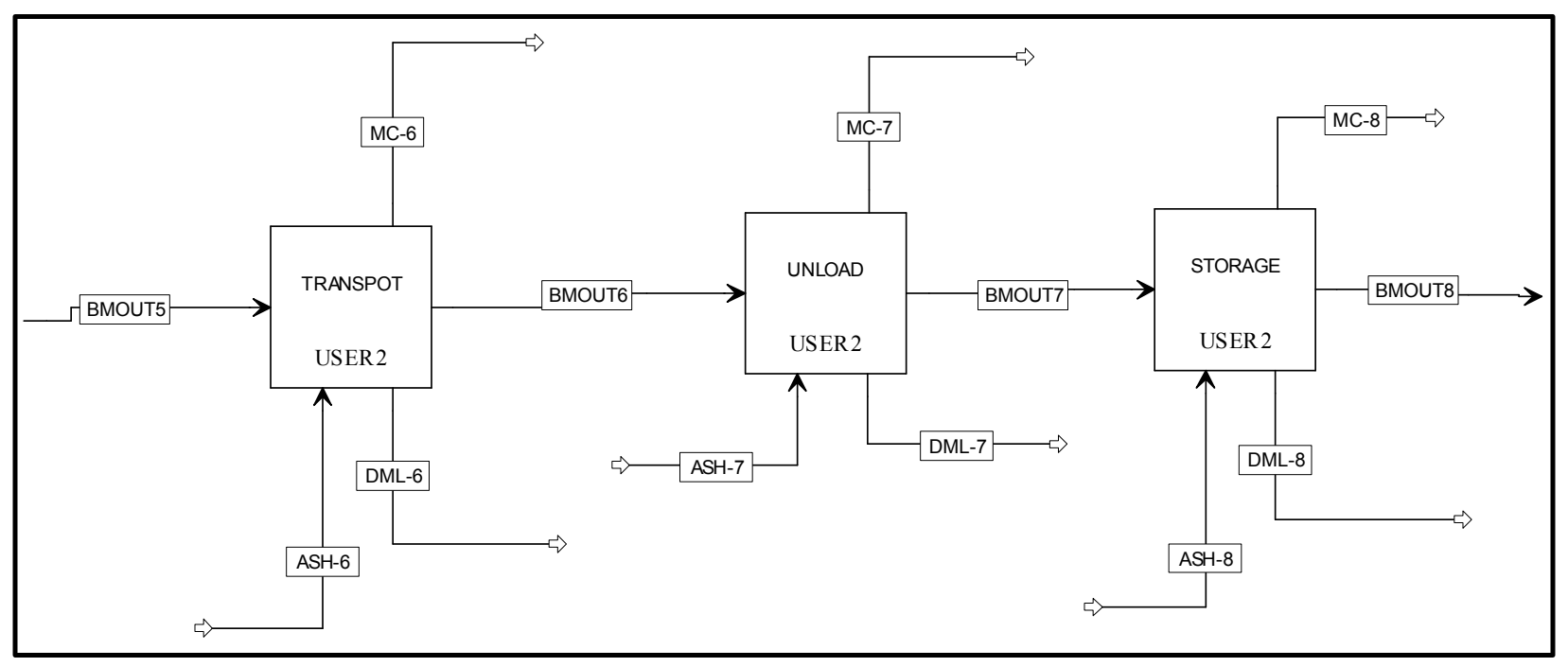

Figure F-10. Detailed process flow diagram for area B200 - Transport to Depot \& Handling. 


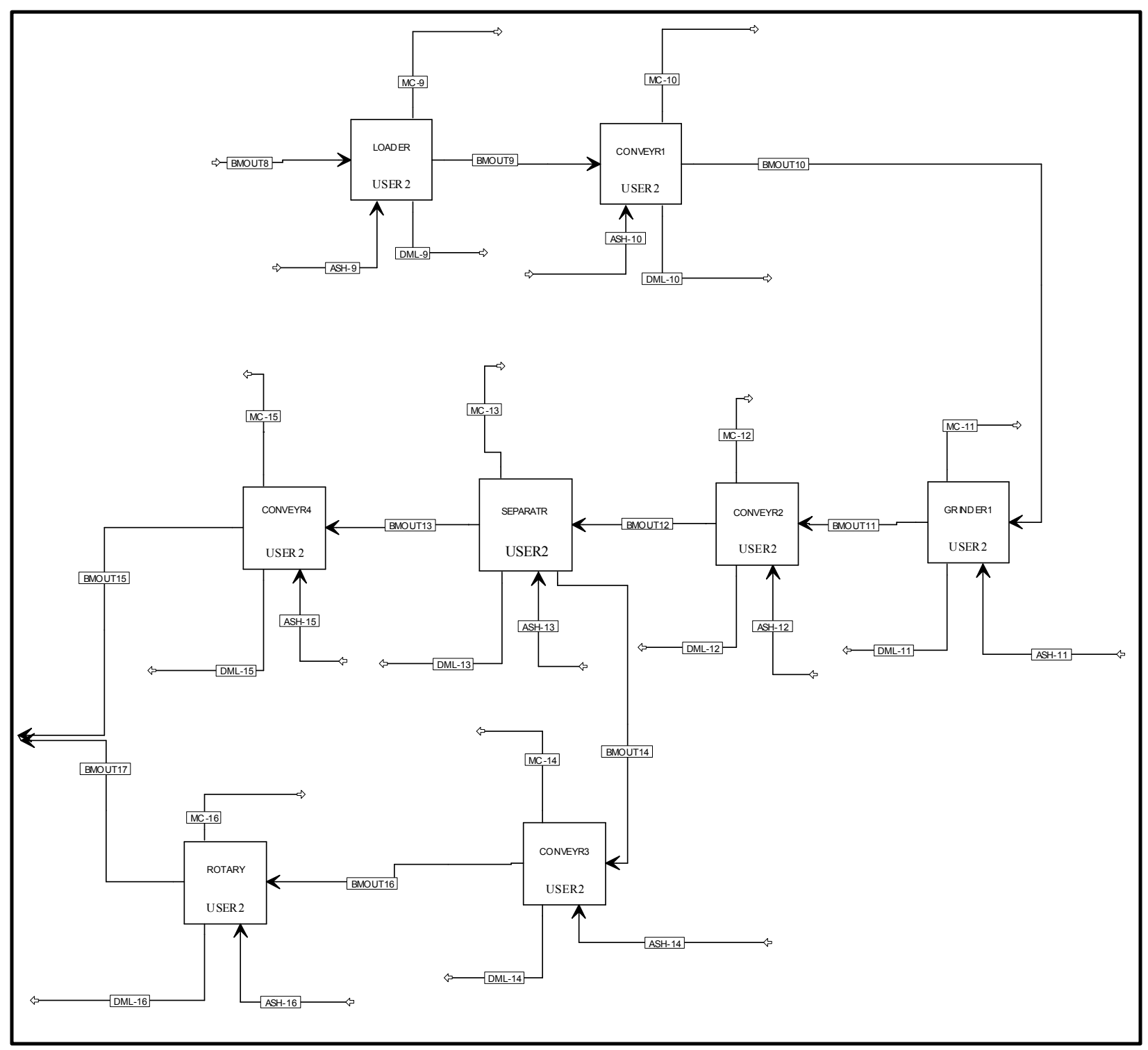

Figure F-11. Detailed process flow diagram for area B300 - Preprocessing - Size Reduction. 

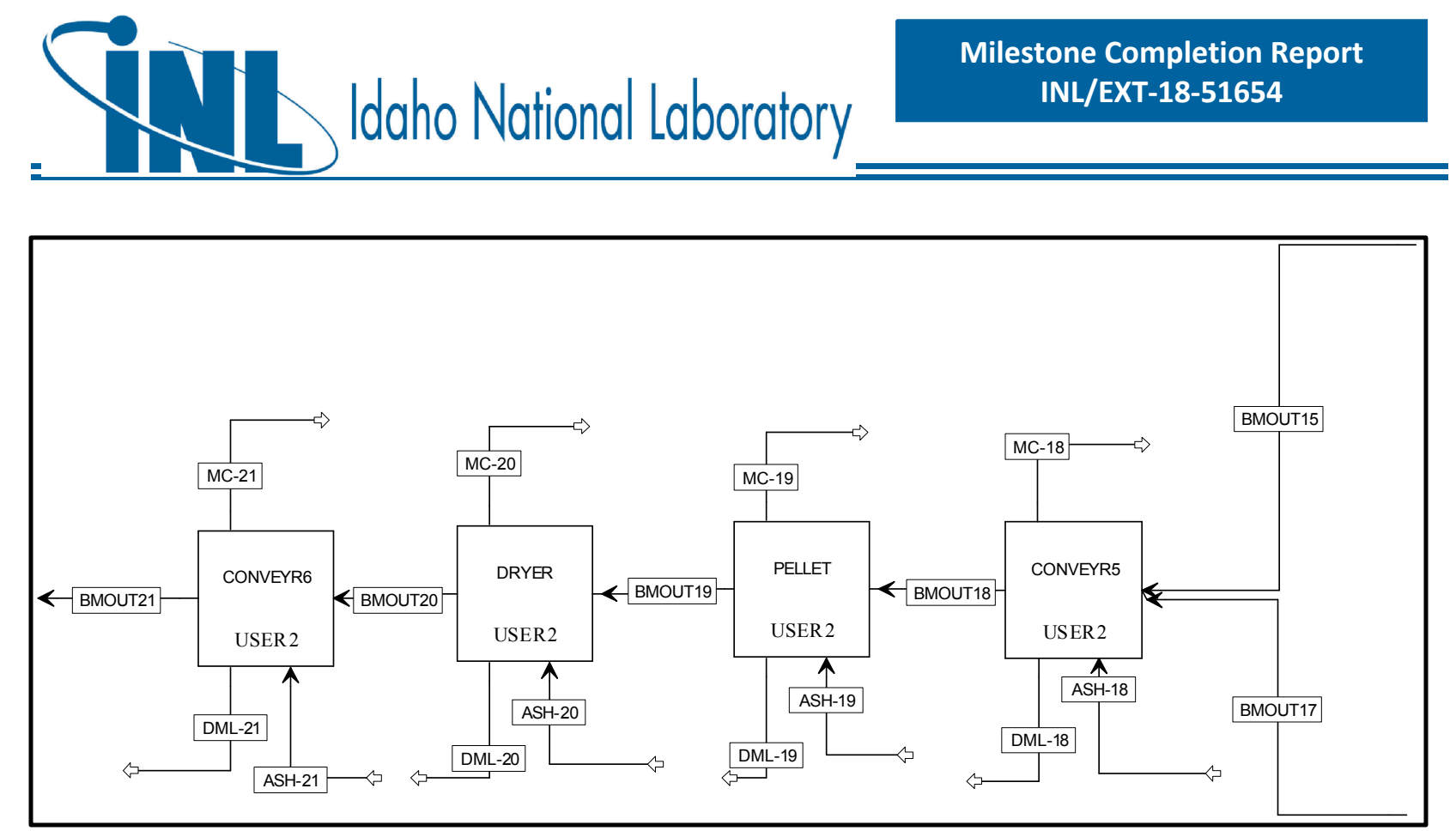

Figure F-12. Detailed process flow diagram for area B400 - Preprocessing - Pelleting.

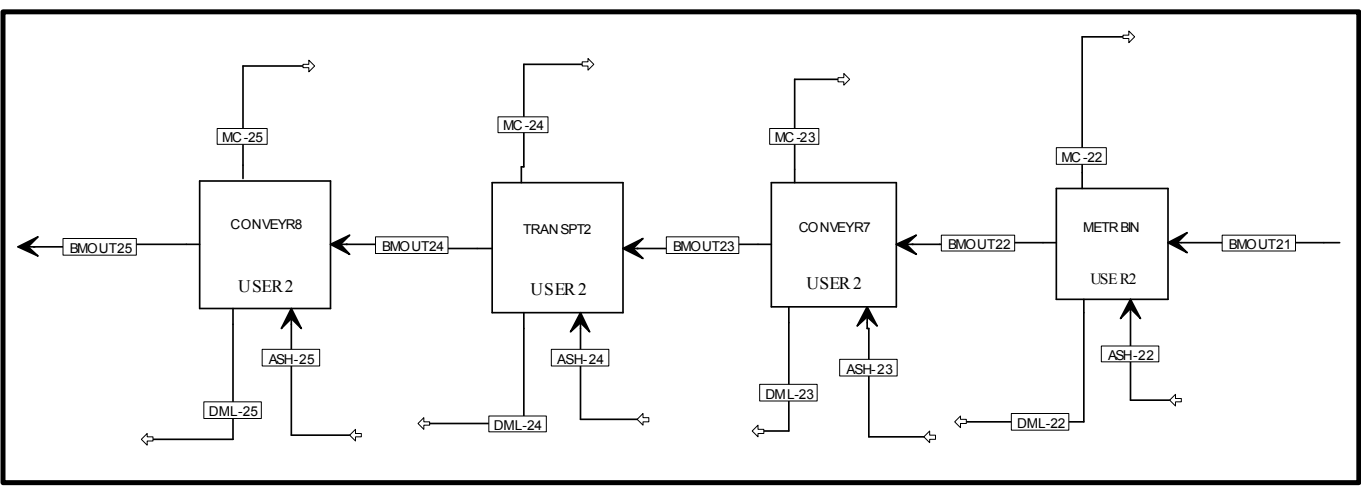

Figure F-13. Detailed process flow diagram for area B500 - Transport to Biorefinery. 

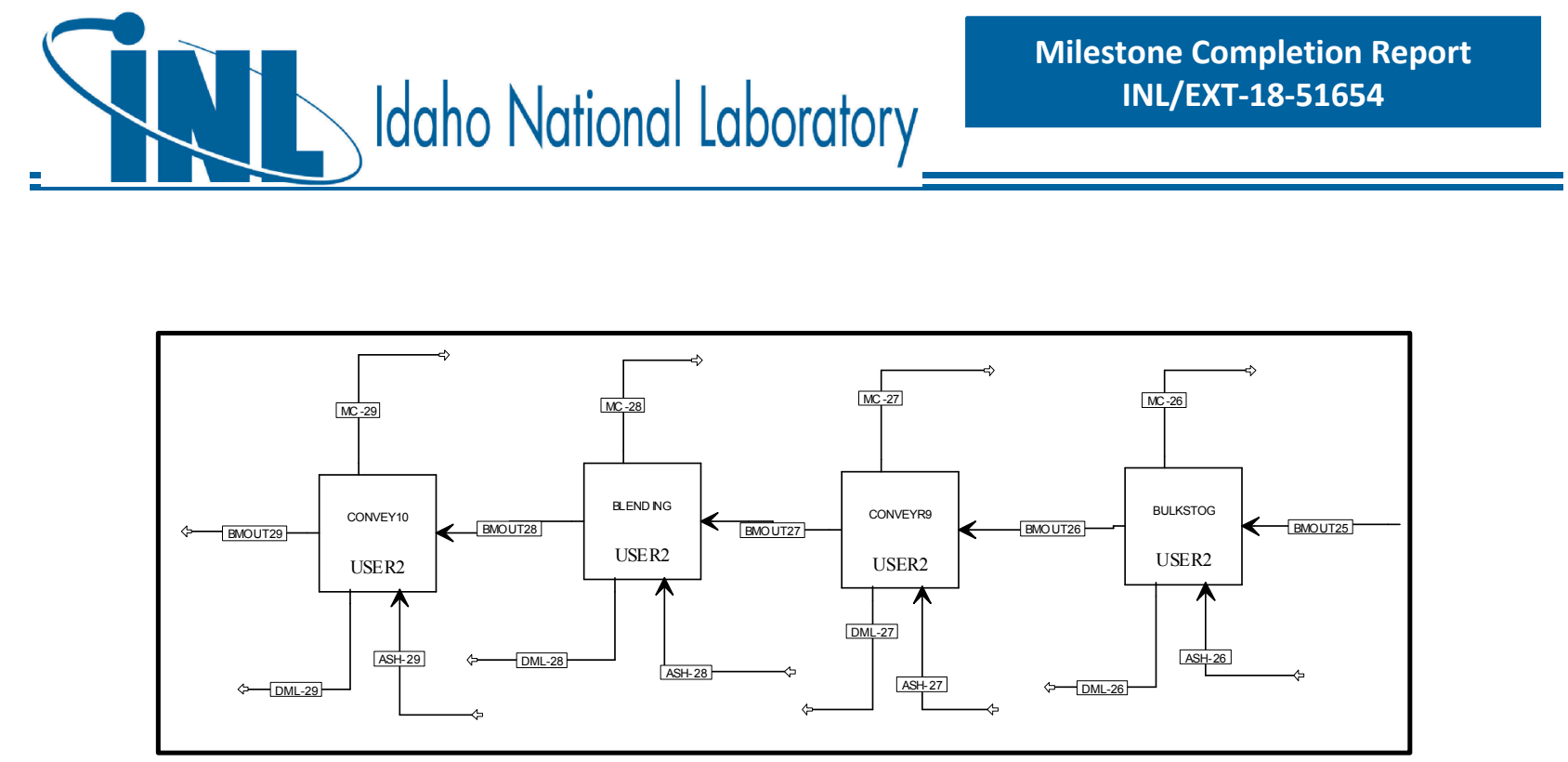

Figure F-14. Detailed process flow diagram for area B600-Feeding. 
Table F-3. Aspen Plus mass balances from harvest to field-side storage (Area B100) for the two-pass corn stover blendstock in the 2018 Herbaceous SOT. Harvest is assumed to take place within a 6 week period, working 14 hours/day, 6 days per week.

\begin{tabular}{|c|c|c|c|c|c|c|c|c|c|c|c|c|}
\hline Component & unit & BIOMIN & DML-1 & MC-1 & BMOUT1 & DML-3 & MC-3 & ASH-3 & BMOUT3 & DML-4 & MC-4 & BMOUT4 \\
\hline $\begin{array}{l}\begin{array}{l}\text { Overall Flow } \\
\text { (moisture and } \\
\text { dry matter) }\end{array} \\
\end{array}$ & $\mathrm{kg} / \mathrm{hr}$ & $1,582,540$ & 0 & 15 & $1,582,525$ & 0 & 0 & 22,932 & $1,582,525$ & 0 & 0 & $1,582,525$ \\
\hline Moisture Flow & $\mathrm{kg} / \mathrm{hr}$ & 474,768 & 0 & 15 & 474,753 & 0 & 0 & 0 & 474,753 & 0 & 0 & 474,753 \\
\hline $\begin{array}{l}\text { Total Flow (dry } \\
\text { matter) }\end{array}$ & $\mathrm{kg} / \mathrm{hr}$ & $1,107,772$ & 0 & 0 & $1,107,772$ & 0 & 0 & 22,932 & $1,107,772$ & 0 & 0 & $1,107,772$ \\
\hline C6 & $\mathrm{kg} / \mathrm{hr}$ & 410,205 & 0 & 0 & 410,205 & 0 & 0 & 0 & 410,205 & 0 & 0 & 410,205 \\
\hline C5 & $\mathrm{kg} / \mathrm{hr}$ & 237,070 & 0 & 0 & 237,070 & 0 & 0 & 0 & 237,070 & 0 & 0 & 237,070 \\
\hline LIGNIN & $\mathrm{kg} / \mathrm{hr}$ & 171,047 & 0 & 0 & 171,047 & 0 & 0 & 0 & 171,047 & 0 & 0 & 171,047 \\
\hline ASH & $\mathrm{kg} / \mathrm{hr}$ & 54,616 & 0 & 0 & 54,616 & 0 & 0 & 22,932 & 77,548 & 0 & 0 & 77,548 \\
\hline PROTEIN & $\mathrm{kg} / \mathrm{hr}$ & 33,567 & 0 & 0 & 33,567 & 0 & 0 & 0 & 33,567 & 0 & 0 & 33,567 \\
\hline $\begin{array}{l}\text { EXTRACTIVE } \\
\text { S } \\
\end{array}$ & $\mathrm{kg} / \mathrm{hr}$ & 159,069 & 0 & 0 & 159,069 & 0 & 0 & 0 & 159,069 & 0 & 0 & 159,069 \\
\hline OTHERS & $\mathrm{kg} / \mathrm{hr}$ & 19,281 & 0 & 0 & 19,281 & 0 & 0 & 0 & 19,281 & 0 & 0 & 19,281 \\
\hline Temperature & $\mathrm{K}$ & 298 & 298 & 298 & 298 & 298 & 298 & 298 & 298 & 298 & 298 & 298 \\
\hline Pressure & atm & 1 & 1 & 1 & 1 & 1 & 1 & 1 & 1 & 1 & 1 & 1 \\
\hline Vapor Frac & & 0 & 0 & 0 & 0 & 0 & 0 & 0 & 0 & 0 & 0 & 0 \\
\hline
\end{tabular}


Table F-4. Aspen Plus mass balances from field-side storage to feeding (Areas B200-B600) for the two-pass corn stover blendstock in the 2018 Herbaceous SOT. Depot operation is assumed to take place within 350 day period, working 24 hours/day, 7 days per week.

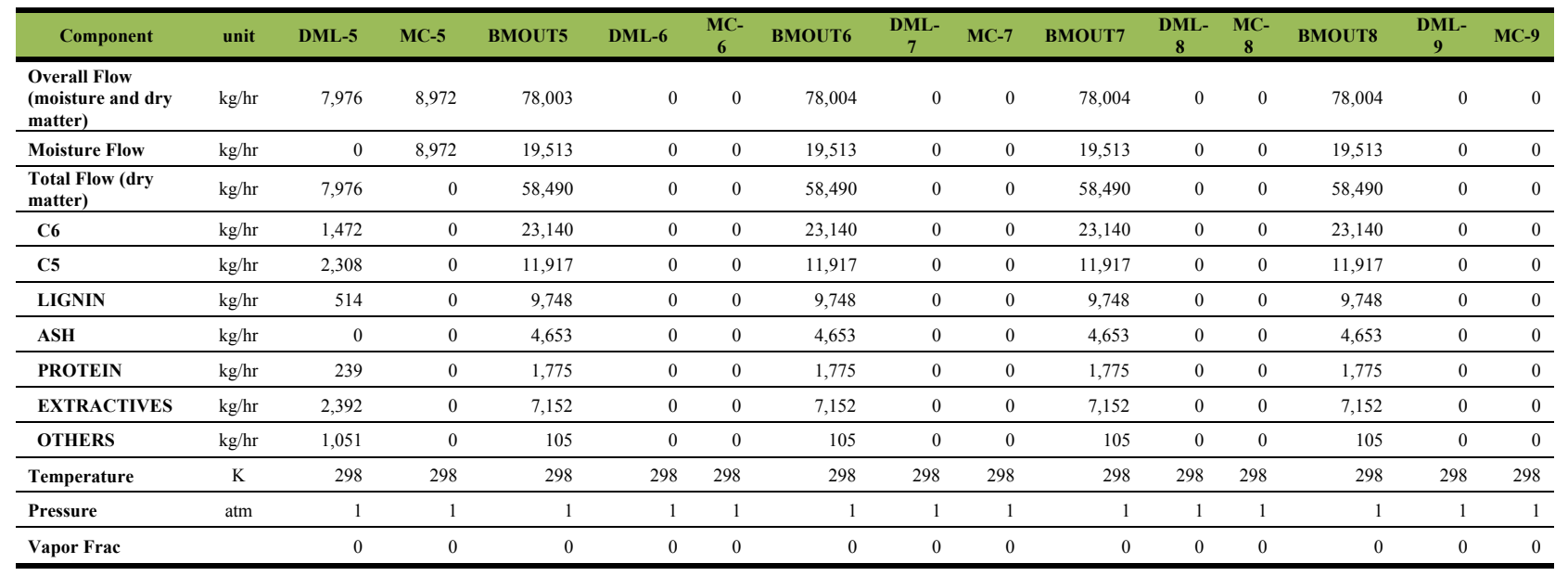


Table F-4. (continued)

\begin{tabular}{|c|c|c|c|c|c|c|c|c|c|c|c|}
\hline Component & unit & BMOUT9 & DML-10 & MC-10 & BMOUT10 & DML-11 & MC-11 & BMOUT11 & DML-12 & $\begin{array}{l}\text { MC- } \\
12\end{array}$ & BMOUT12 \\
\hline $\begin{array}{l}\text { Overall Flow } \\
\text { (moisture and dry } \\
\text { matter) }\end{array}$ & $\mathrm{kg} / \mathrm{hr}$ & 78,004 & 0 & 0 & 78,004 & 585 & 4,816 & 72,602 & 0 & 0 & 72,602 \\
\hline Moisture Flow & $\mathrm{kg} / \mathrm{hr}$ & 19,513 & 0 & 0 & 19,513 & 0 & 4,816 & 14,697 & 0 & 0 & 14,697 \\
\hline $\begin{array}{l}\text { Total Flow (dry } \\
\text { matter) }\end{array}$ & $\mathrm{kg} / \mathrm{hr}$ & 58,490 & 0 & 0 & 58,490 & 585 & 0 & 57,905 & 0 & 0 & 57,905 \\
\hline C6 & $\mathrm{kg} / \mathrm{hr}$ & 23,140 & 0 & 0 & 23,140 & 162 & 0 & 22,979 & 0 & 0 & 22,979 \\
\hline $\mathrm{C} 5$ & $\mathrm{~kg} / \mathrm{hr}$ & 11,917 & 0 & 0 & 11,917 & 91 & 0 & 11,825 & 0 & 0 & 11,825 \\
\hline LIGNIN & $\mathrm{kg} / \mathrm{hr}$ & 9,748 & 0 & 0 & 9,748 & 113 & 0 & 9,635 & 0 & 0 & 9,635 \\
\hline ASH & $\mathrm{kg} / \mathrm{hr}$ & 4,653 & 0 & 0 & 4,653 & 146 & 0 & 4,507 & 0 & 0 & 4,507 \\
\hline PROTEIN & $\mathrm{kg} / \mathrm{hr}$ & 1,775 & 0 & 0 & 1,775 & 0 & 0 & 1,775 & 0 & 0 & 1,775 \\
\hline EXTRACTIVES & $\mathrm{kg} / \mathrm{hr}$ & 7,152 & 0 & 0 & 7,152 & 72 & 0 & 7,081 & 0 & 0 & 7,081 \\
\hline OTHERS & $\mathrm{kg} / \mathrm{hr}$ & 105 & 0 & 0 & 105 & 0 & 0 & 105 & 0 & 0 & 105 \\
\hline Temperature & $\mathrm{K}$ & 298 & 298 & 298 & 298 & 298 & 298 & 298 & 298 & 298 & 298 \\
\hline Pressure & $\mathrm{atm}$ & 1 & 1 & 1 & 1 & 1 & 1 & 1 & 1 & 1 & 1 \\
\hline Vapor Frac & & 0 & 0 & 0 & 0 & 0 & 0 & 0 & 0 & 0 & 0 \\
\hline
\end{tabular}




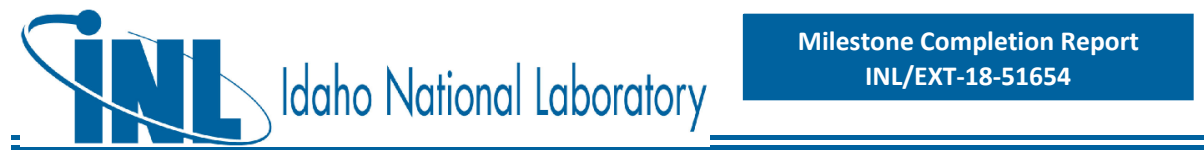

Table F-4. (continued)

\begin{tabular}{|c|c|c|c|c|c|c|c|c|c|c|c|}
\hline Component & unit & $\begin{array}{c}\text { DML- } \\
13\end{array}$ & MC-13 & BMOUT13 & BMOUT14 & DML-14 & MC-14 & DML-15 & $\begin{array}{l}\text { MC- } \\
15\end{array}$ & BMOUT15 & $\begin{array}{c}\text { DML- } \\
16\end{array}$ \\
\hline $\begin{array}{l}\begin{array}{l}\text { Overall Flow } \\
\text { (moisture and dry } \\
\text { matter) }\end{array} \\
\end{array}$ & $\mathrm{kg} / \mathrm{hr}$ & 1,777 & 0 & 31,440 & 39,386 & 0 & 0 & 0 & 0 & 31,440 & 322 \\
\hline Moisture Flow & $\mathrm{kg} / \mathrm{hr}$ & 1,777 & 0 & 5,735 & 7,185 & 0 & 0 & 0 & 0 & 5,735 & 0 \\
\hline $\begin{array}{l}\text { Total Flow (dry } \\
\text { matter) }\end{array}$ & $\mathrm{kg} / \mathrm{hr}$ & 0 & 0 & 25,704 & 32,201 & 0 & 0 & 0 & 0 & 25,704 & 322 \\
\hline C6 & $\mathrm{kg} / \mathrm{hr}$ & 0 & 0 & 10,200 & 12,778 & 0 & 0 & 0 & 0 & 10,200 & 89 \\
\hline C5 & $\mathrm{kg} / \mathrm{hr}$ & 0 & 0 & 5,249 & 6,576 & 0 & 0 & 0 & 0 & 5,249 & 50 \\
\hline LIGNIN & $\mathrm{kg} / \mathrm{hr}$ & 0 & 0 & 4,277 & 5,358 & 0 & 0 & 0 & 0 & 4,277 & 62 \\
\hline ASH & $\mathrm{kg} / \mathrm{hr}$ & 0 & 0 & 2,000 & 2,506 & 0 & 0 & 0 & 0 & 2,000 & 81 \\
\hline PROTEIN & $\mathrm{kg} / \mathrm{hr}$ & 0 & 0 & 788 & 987 & 0 & 0 & 0 & 0 & 788 & 0 \\
\hline EXTRACTIVES & $\mathrm{kg} / \mathrm{hr}$ & 0 & 0 & 3,143 & 3,938 & 0 & 0 & 0 & 0 & 3,143 & 39 \\
\hline OTHERS & $\mathrm{kg} / \mathrm{hr}$ & 0 & 0 & 46 & 59 & 0 & 0 & 0 & 0 & 46 & 0 \\
\hline Temperature & $\mathrm{K}$ & 298 & 298 & 298 & 298 & 298 & 298 & 298 & 298 & 298 & 298 \\
\hline Pressure & $\mathrm{atm}$ & 1 & 1 & 1 & 1 & 1 & 1 & 1 & 1 & 1 & 1 \\
\hline Vapor Frac & & 0 & 0 & 0 & 0 & 0 & 0 & 0 & 0 & 0 & 0 \\
\hline
\end{tabular}


daho Nafional Laboratory

Table F-4. (continued)

\begin{tabular}{|c|c|c|c|c|c|c|c|c|c|c|c|c|}
\hline Component & unit & MC-16 & BMOUT16 & BMOUT17 & DML-18 & MC-18 & BMOUT18 & DML-19 & MC-19 & BMOUT19 & $\begin{array}{c}\text { DML- } \\
20\end{array}$ & $\begin{array}{l}\text { MC- } \\
20\end{array}$ \\
\hline $\begin{array}{l}\text { Overall Flow } \\
\text { (moisture and dry } \\
\text { matter) }\end{array}$ & $\mathrm{kg} / \mathrm{hr}$ & 72 & 39,386 & 38,993 & 0 & 0 & 70,431 & 0 & 4,061 & 66,370 & 0 & 1,276 \\
\hline Moisture Flow & $\mathrm{kg} / \mathrm{hr}$ & 72 & 7,185 & 7,113 & 0 & 0 & 12,848 & 0 & 4,061 & 8,787 & 0 & 1,276 \\
\hline $\begin{array}{l}\text { Total Flow (dry } \\
\text { matter) }\end{array}$ & $\mathrm{kg} / \mathrm{hr}$ & 0 & 32,201 & 31,879 & 0 & 0 & 57,583 & 0 & 0 & 57,583 & 0 & 0 \\
\hline C6 & $\mathrm{kg} / \mathrm{hr}$ & 0 & 12,778 & 12,689 & 0 & 0 & 22,889 & 0 & 0 & 22,889 & 0 & 0 \\
\hline C5 & $\mathrm{kg} / \mathrm{hr}$ & 0 & 6,576 & 6,526 & 0 & 0 & 11,776 & 0 & 0 & 11,776 & 0 & 0 \\
\hline LIGNIN & $\mathrm{kg} / \mathrm{hr}$ & 0 & 5,358 & 5,295 & 0 & 0 & 9,572 & 0 & 0 & 9,572 & 0 & 0 \\
\hline ASH & $\mathrm{kg} / \mathrm{hr}$ & 0 & 2,506 & 2,426 & 0 & 0 & 4,426 & 0 & 0 & 4,426 & 0 & 0 \\
\hline PROTEIN & $\mathrm{kg} / \mathrm{hr}$ & 0 & 987 & 987 & 0 & 0 & 1,775 & 0 & 0 & 1,775 & 0 & 0 \\
\hline EXTRACTIVES & $\mathrm{kg} / \mathrm{hr}$ & 0 & 3,938 & 3,897 & 0 & 0 & 7,040 & 0 & 0 & 7,040 & 0 & 0 \\
\hline OTHERS & $\mathrm{kg} / \mathrm{hr}$ & 0 & 59 & 59 & 0 & 0 & 105 & 0 & 0 & 105 & 0 & 0 \\
\hline Temperature & K & 298 & 298 & 298 & 298 & 298 & 298 & 298 & 298 & 298 & 298 & 298 \\
\hline Pressure & $\mathrm{atm}$ & 1 & 1 & 1 & 1 & 1 & 1 & 1 & 1 & 1 & 1 & 1 \\
\hline
\end{tabular}


Table F-4. (continued)

\begin{tabular}{|c|c|c|c|c|c|c|c|c|c|c|}
\hline Component & unit & BMOUT20 & DML-21 & MC-21 & BMOUT21 & DML-22 & MC-22 & BMOUT22 & DML-23 & $\begin{array}{l}\text { MC- } \\
23\end{array}$ \\
\hline $\begin{array}{l}\text { Overall Flow } \\
\text { (moisture and dry } \\
\text { matter) }\end{array}$ & $\mathrm{kg} / \mathrm{hr}$ & 65,094 & 0 & 0 & 65,094 & 0 & 0 & 65,094 & 0 & 0 \\
\hline Moisture Flow & $\mathrm{kg} / \mathrm{hr}$ & 7,511 & 0 & 0 & 7,511 & 0 & 0 & 7,511 & 0 & 0 \\
\hline $\begin{array}{l}\text { Total Flow (dry } \\
\text { matter) }\end{array}$ & $\mathrm{kg} / \mathrm{hr}$ & 57,583 & 0 & 0 & 57,583 & 0 & 0 & 57,583 & 0 & 0 \\
\hline C6 & $\mathrm{kg} / \mathrm{hr}$ & 22,889 & 0 & 0 & 22,889 & 0 & 0 & 22,889 & 0 & 0 \\
\hline $\mathrm{C} 5$ & $\mathrm{~kg} / \mathrm{hr}$ & 11,776 & 0 & 0 & 11,776 & 0 & 0 & 11,776 & 0 & 0 \\
\hline LIGNIN & $\mathrm{kg} / \mathrm{hr}$ & 9,572 & 0 & 0 & 9,572 & 0 & 0 & 9,572 & 0 & 0 \\
\hline ASH & $\mathrm{kg} / \mathrm{hr}$ & 4,426 & 0 & 0 & 4,426 & 0 & 0 & 4,426 & 0 & 0 \\
\hline PROTEIN & $\mathrm{kg} / \mathrm{hr}$ & 1,775 & 0 & 0 & 1,775 & 0 & 0 & 1,775 & 0 & 0 \\
\hline EXTRACTIVES & $\mathrm{kg} / \mathrm{hr}$ & 7,040 & 0 & 0 & 7,040 & 0 & 0 & 7,040 & 0 & 0 \\
\hline OTHERS & $\mathrm{kg} / \mathrm{hr}$ & 105 & 0 & 0 & 105 & 0 & 0 & 105 & 0 & 0 \\
\hline Temperature & K & 298 & 298 & 298 & 298 & 298 & 298 & 298 & 298 & 298 \\
\hline Pressure & atm & 1 & 1 & 1 & 1 & 1 & 1 & 1 & 1 & 1 \\
\hline Vapor Frac & & 0 & 0 & 0 & 0 & 0 & 0 & 0 & 0 & 0 \\
\hline
\end{tabular}


Table F-4. (continued)

\begin{tabular}{|c|c|c|c|c|c|c|c|c|c|c|c|}
\hline Component & unit & BMOUT23 & DML-24 & MC-24 & BMOUT24 & DML-25 & MC-25 & BMOUT25 & DML-26 & $\begin{array}{l}\text { MC- } \\
26\end{array}$ & BMOUT26 \\
\hline $\begin{array}{l}\text { Overall Flow } \\
\text { (moisture and dry } \\
\text { matter) }\end{array}$ & $\mathrm{kg} / \mathrm{hr}$ & 65,094 & 0 & 0 & 65,094 & 0 & 0 & 65,094 & 0 & 0 & 65,094 \\
\hline Moisture Flow & $\mathrm{kg} / \mathrm{hr}$ & 7,511 & 0 & 0 & 7,511 & 0 & 0 & 7,511 & 0 & 0 & 7,511 \\
\hline $\begin{array}{l}\text { Total Flow (dry } \\
\text { matter) }\end{array}$ & $\mathrm{kg} / \mathrm{hr}$ & 57,583 & 0 & 0 & 57,583 & 0 & 0 & 57,583 & 0 & 0 & 57,583 \\
\hline C6 & $\mathrm{kg} / \mathrm{hr}$ & 22,889 & 0 & 0 & 22,889 & 0 & 0 & 22,889 & 0 & 0 & 22,889 \\
\hline $\mathrm{C} 5$ & $\mathrm{~kg} / \mathrm{hr}$ & 11,776 & 0 & 0 & 11,776 & 0 & 0 & 11,776 & 0 & 0 & 11,776 \\
\hline LIGNIN & $\mathrm{kg} / \mathrm{hr}$ & 9,572 & 0 & 0 & 9,572 & 0 & 0 & 9,572 & 0 & 0 & 9,572 \\
\hline ASH & $\mathrm{kg} / \mathrm{hr}$ & 4,426 & 0 & 0 & 4,426 & 0 & 0 & 4,426 & 0 & 0 & 4,426 \\
\hline PROTEIN & $\mathrm{kg} / \mathrm{hr}$ & 1,775 & 0 & 0 & 1,775 & 0 & 0 & 1,775 & 0 & 0 & 1,775 \\
\hline EXTRACTIVES & $\mathrm{kg} / \mathrm{hr}$ & 7,040 & 0 & 0 & 7,040 & 0 & 0 & 7,040 & 0 & 0 & 7,040 \\
\hline OTHERS & $\mathrm{kg} / \mathrm{hr}$ & 105 & 0 & 0 & 105 & 0 & 0 & 105 & 0 & 0 & 105 \\
\hline Temperature & K & 298 & 298 & 298 & 298 & 298 & 298 & 298 & 298 & 298 & 298 \\
\hline Pressure & atm & 1 & 1 & 1 & 1 & 1 & 1 & 1 & 1 & 1 & 1 \\
\hline Vapor Frac & & 0 & 0 & 0 & 0 & 0 & 0 & 0 & 0 & 0 & 0 \\
\hline
\end{tabular}


daho National Laboratory

Table F-4. (continued)

\begin{tabular}{|c|c|c|c|c|c|c|c|c|c|c|}
\hline Component & unit & $\begin{array}{c}\text { DML- } \\
27\end{array}$ & MC-27 & BMOUT27 & DML-28 & MC-28 & BMOUT28 & DML-29 & MC-29 & BMOUT29 \\
\hline $\begin{array}{l}\text { Overall Flow } \\
\text { (moisture and dry } \\
\text { matter) }\end{array}$ & $\mathrm{kg} / \mathrm{hr}$ & 0 & 0 & 65,094 & 0 & 0 & 65,094 & 0 & 0 & 65,094 \\
\hline Moisture Flow & $\mathrm{kg} / \mathrm{hr}$ & 0 & 0 & 7,511 & 0 & 0 & 7,511 & 0 & 0 & 7,511 \\
\hline $\begin{array}{l}\text { Total Flow (dry } \\
\text { matter) }\end{array}$ & $\mathrm{kg} / \mathrm{hr}$ & 0 & 0 & 57,583 & 0 & 0 & 57,583 & 0 & 0 & 57,583 \\
\hline C6 & $\mathrm{kg} / \mathrm{hr}$ & 0 & 0 & 22,889 & 0 & 0 & 22,889 & 0 & 0 & 22,889 \\
\hline $\mathrm{C} 5$ & $\mathrm{~kg} / \mathrm{hr}$ & 0 & 0 & 11,776 & 0 & 0 & 11,776 & 0 & 0 & 11,776 \\
\hline LIGNIN & $\mathrm{kg} / \mathrm{hr}$ & 0 & 0 & 9,572 & 0 & 0 & 9,572 & 0 & 0 & 9,572 \\
\hline ASH & $\mathrm{kg} / \mathrm{hr}$ & 0 & 0 & 4,426 & 0 & 0 & 4,426 & 0 & 0 & 4,426 \\
\hline PROTEIN & $\mathrm{kg} / \mathrm{hr}$ & 0 & 0 & 1,775 & 0 & 0 & 1,775 & 0 & 0 & 1,775 \\
\hline EXTRACTIVES & $\mathrm{kg} / \mathrm{hr}$ & 0 & 0 & 7,040 & 0 & 0 & 7,040 & 0 & 0 & 7,040 \\
\hline OTHERS & $\mathrm{kg} / \mathrm{hr}$ & 0 & 0 & 105 & 0 & 0 & 105 & 0 & 0 & 105 \\
\hline Temperature & $\mathrm{K}$ & 298 & 298 & 298 & 298 & 298 & 298 & 298 & 298 & 298 \\
\hline Pressure & atm & 1 & 1 & 1 & 1 & 1 & 1 & 1 & 1 & 1 \\
\hline Vapor Frac & & 0 & 0 & 0 & 0 & 0 & 0 & 0 & 0 & 0 \\
\hline
\end{tabular}




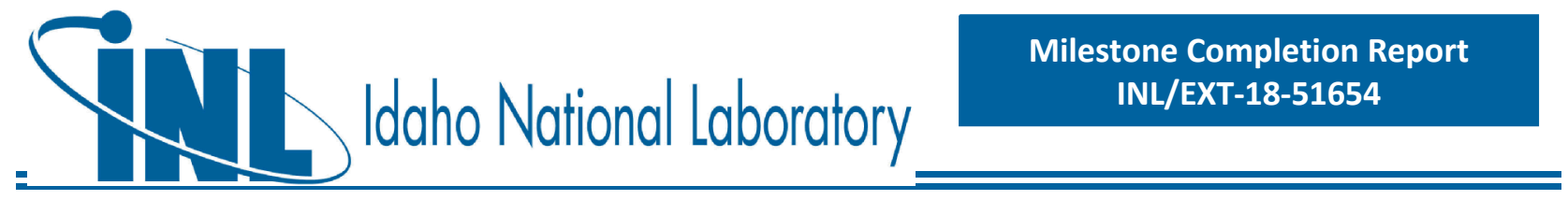

\section{F.3 Switchgrass Blendstock}

High-level stream table information from Aspen Plus modeling output follows, for key streams associated with each process operation area. This is followed by high-level PFDs for the associated process areas. Space for stream tables was limited; below is a key to lumped components. As the stream table information focuses primarily on the high-level overall process and does not include every individual modeled stream within each process area, mass balance closure around a given unit area may not be $100 \%$.

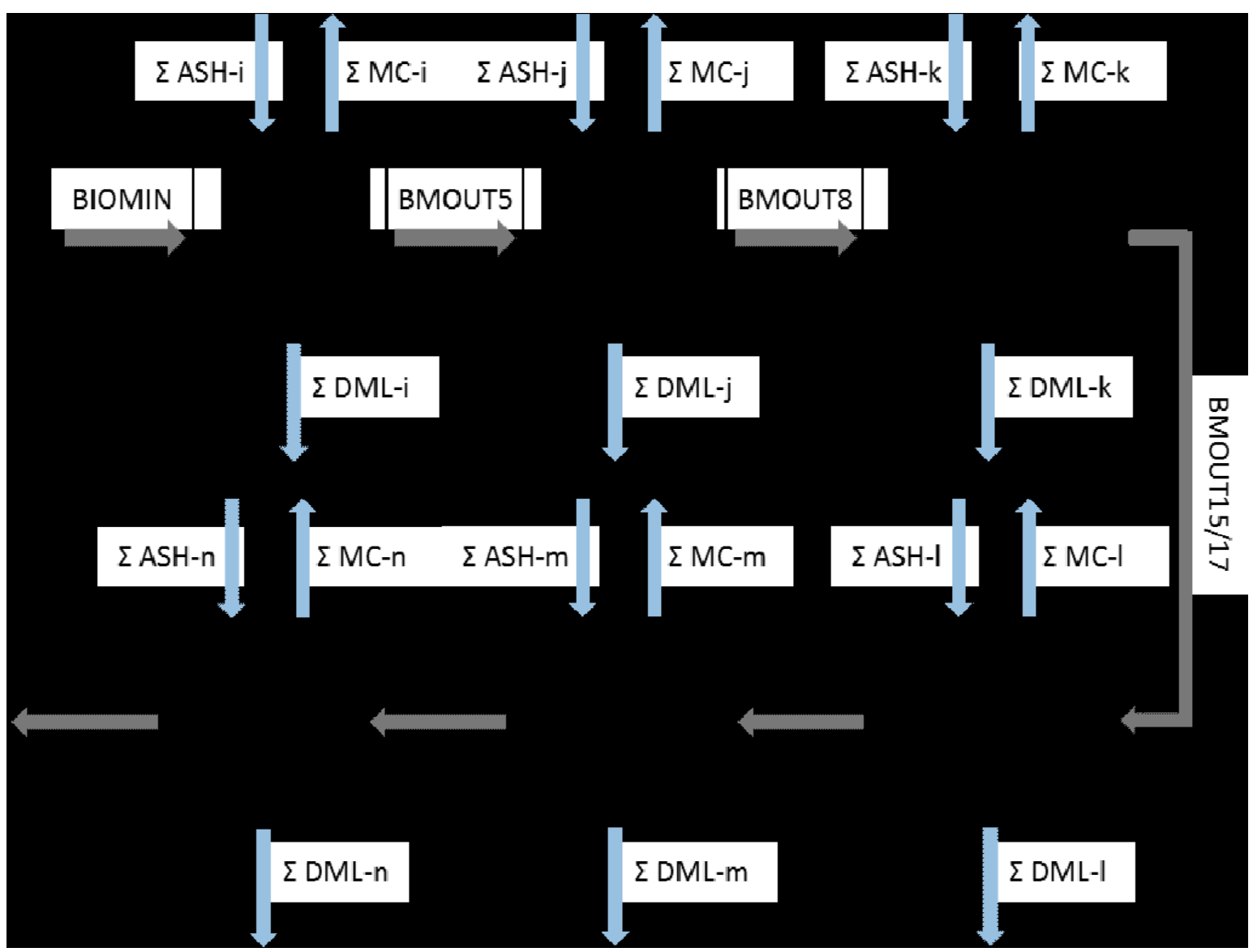

Figure F-15. High-level flowsheet showing key process areas for the switchgrass blendstock in the 2018 Herbaceous SOT. 

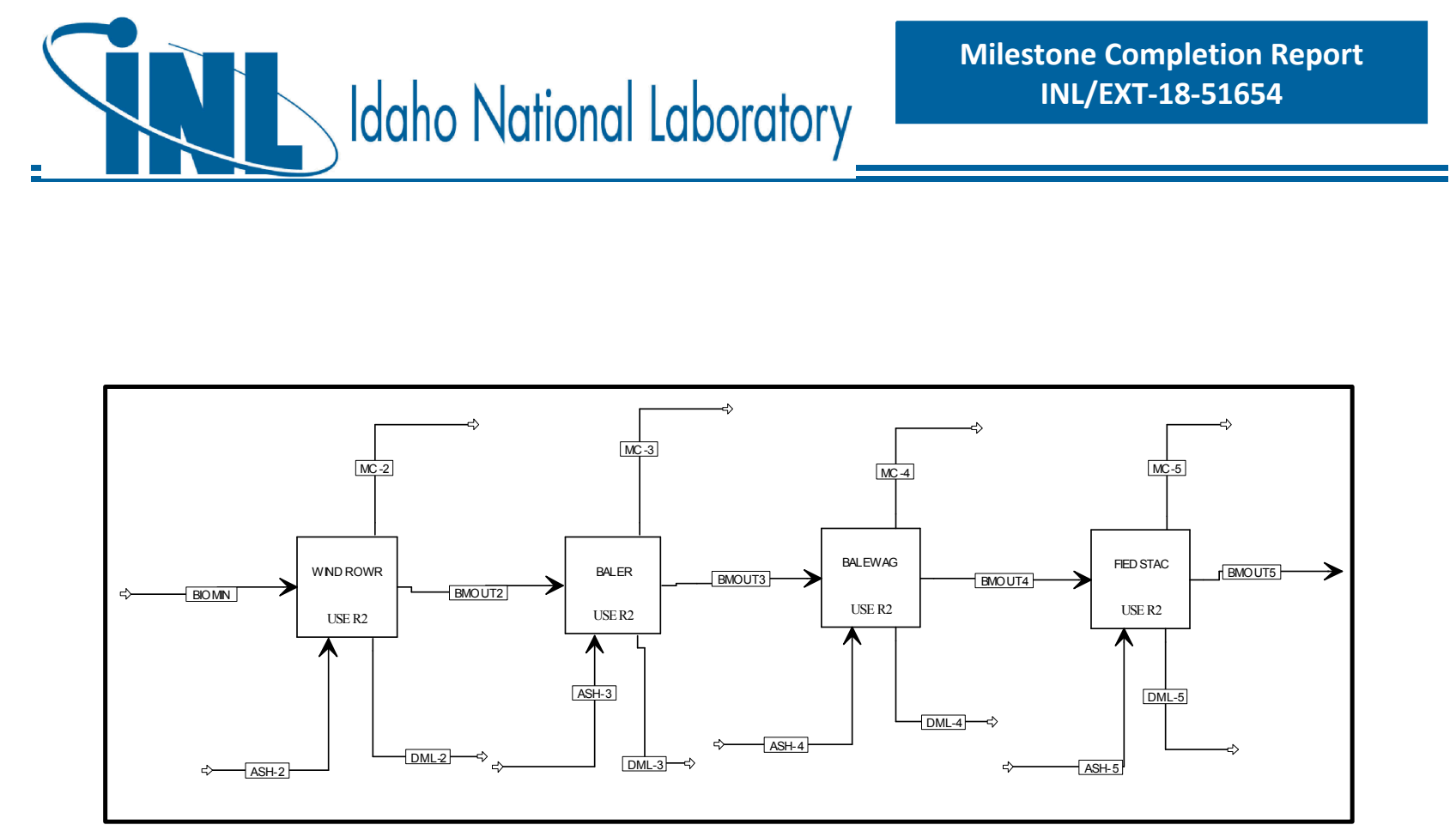

Figure F-16. Detailed process flow diagram for area C100 - Harvesting to Storage.

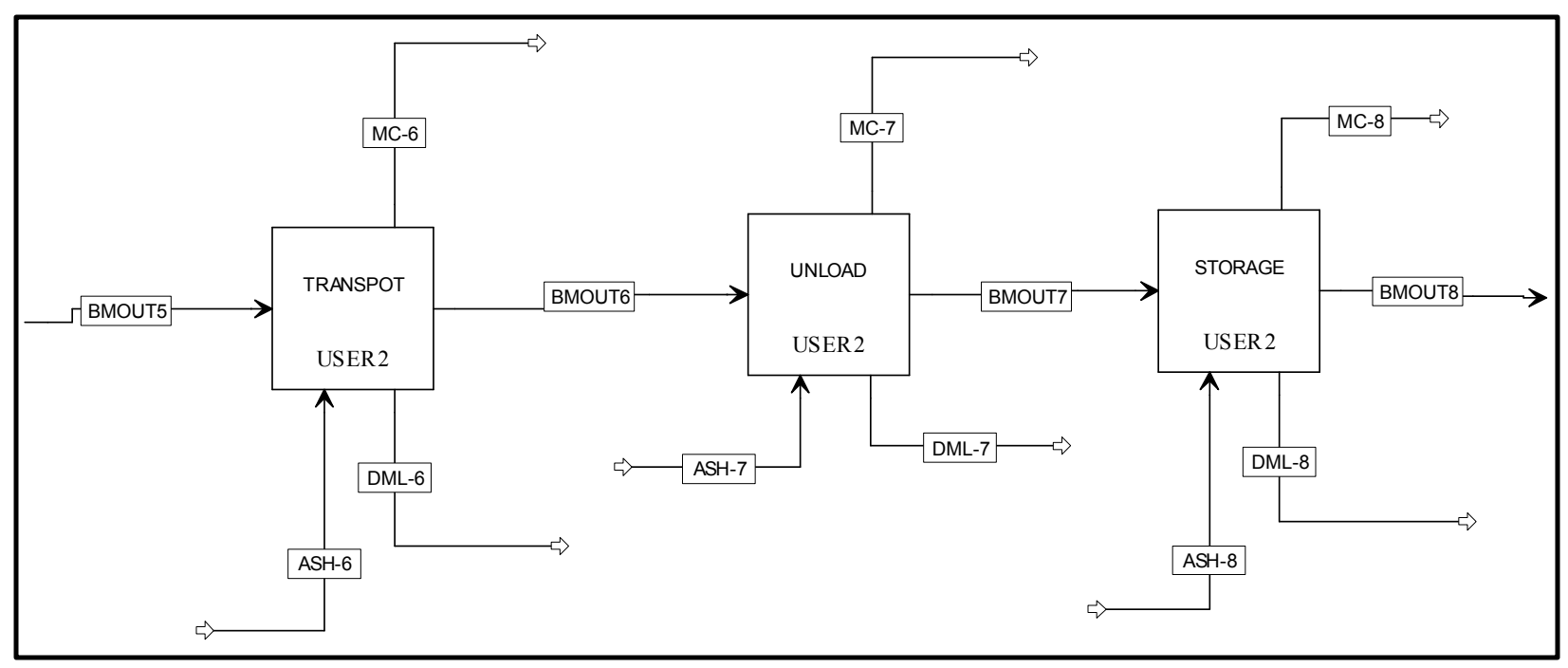

Figure F-17. Detailed process flow diagram for area C200 - Transport to Depot \& Handling. 

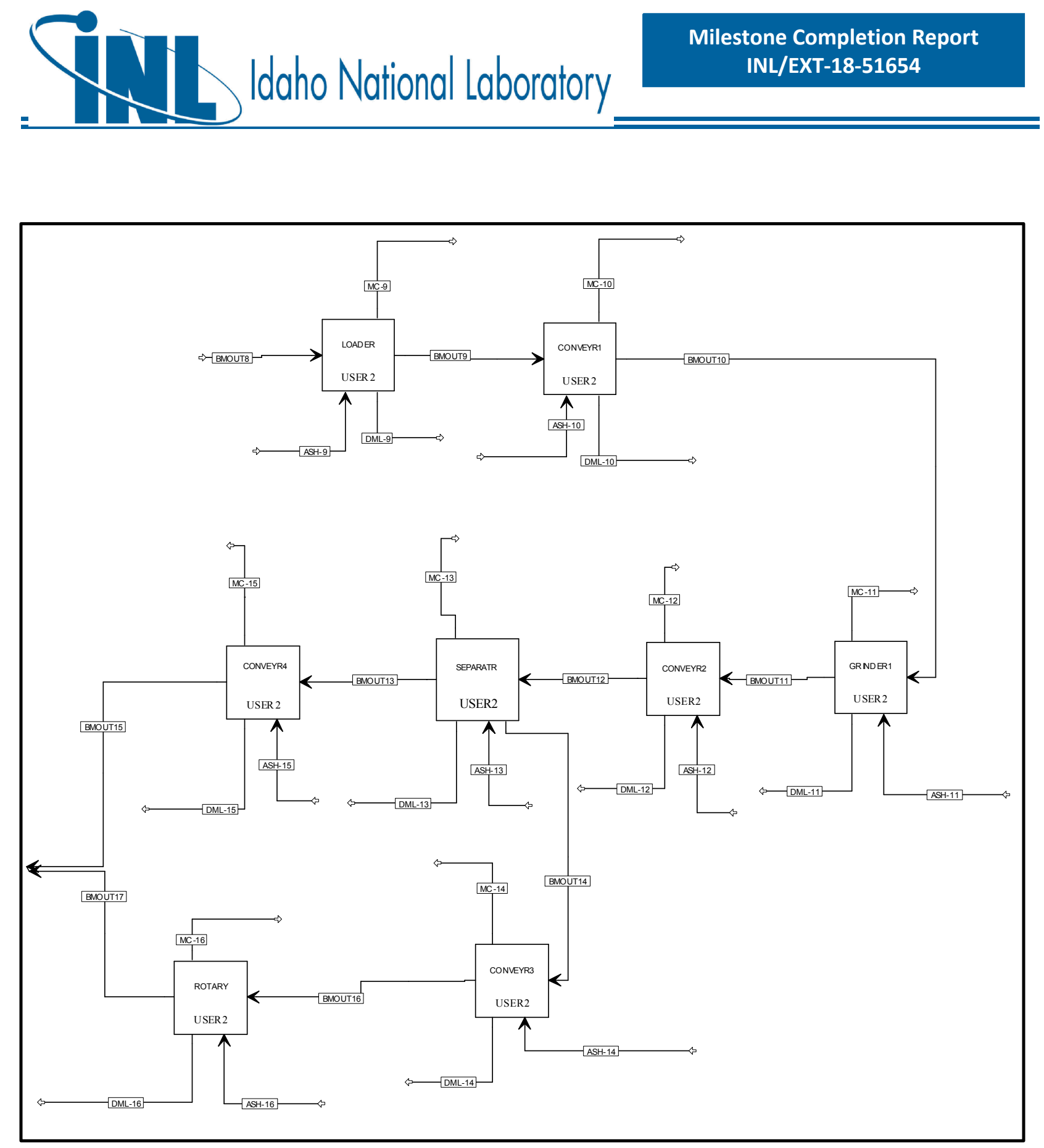

Figure F-18. Detailed process flow diagram for area C300 - Preprocessing - Size Reduction. 

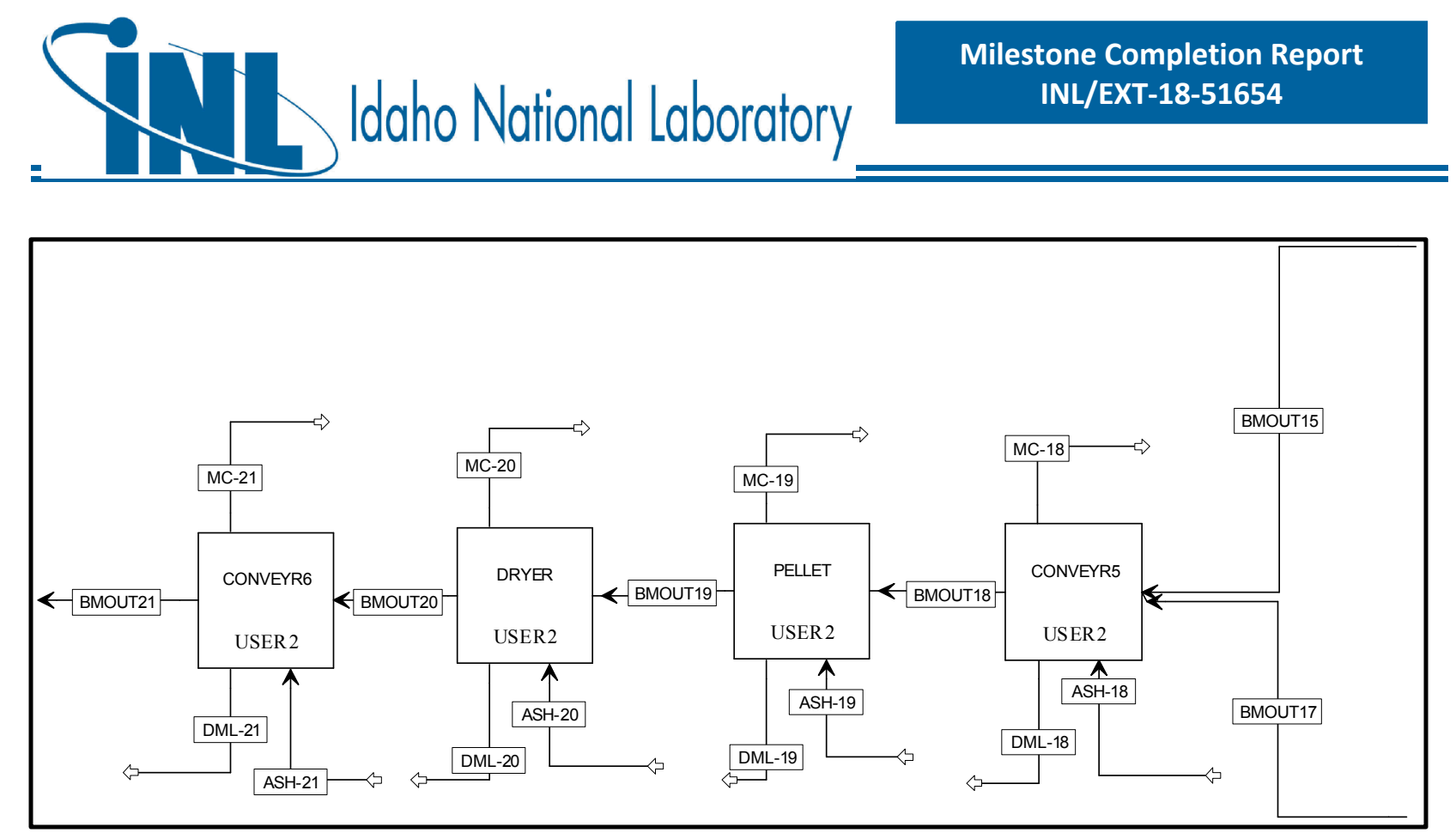

Figure F-19. Detailed process flow diagram for area C400 - Preprocessing - Pelleting.

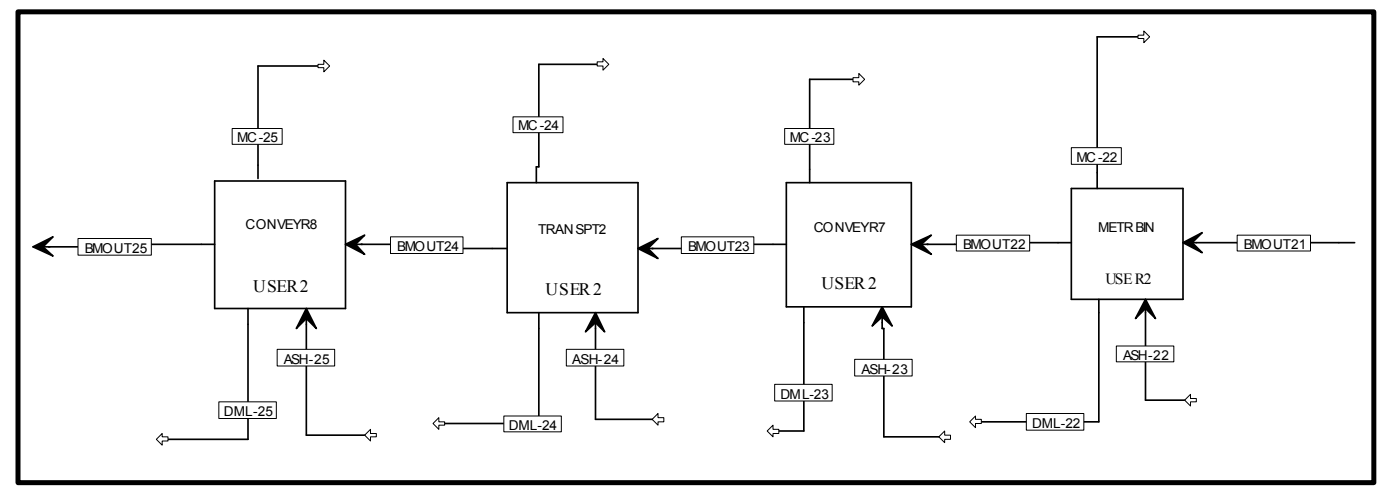

Figure F-20. Detailed process flow diagram for area C500 - Transport to Biorefinery. 

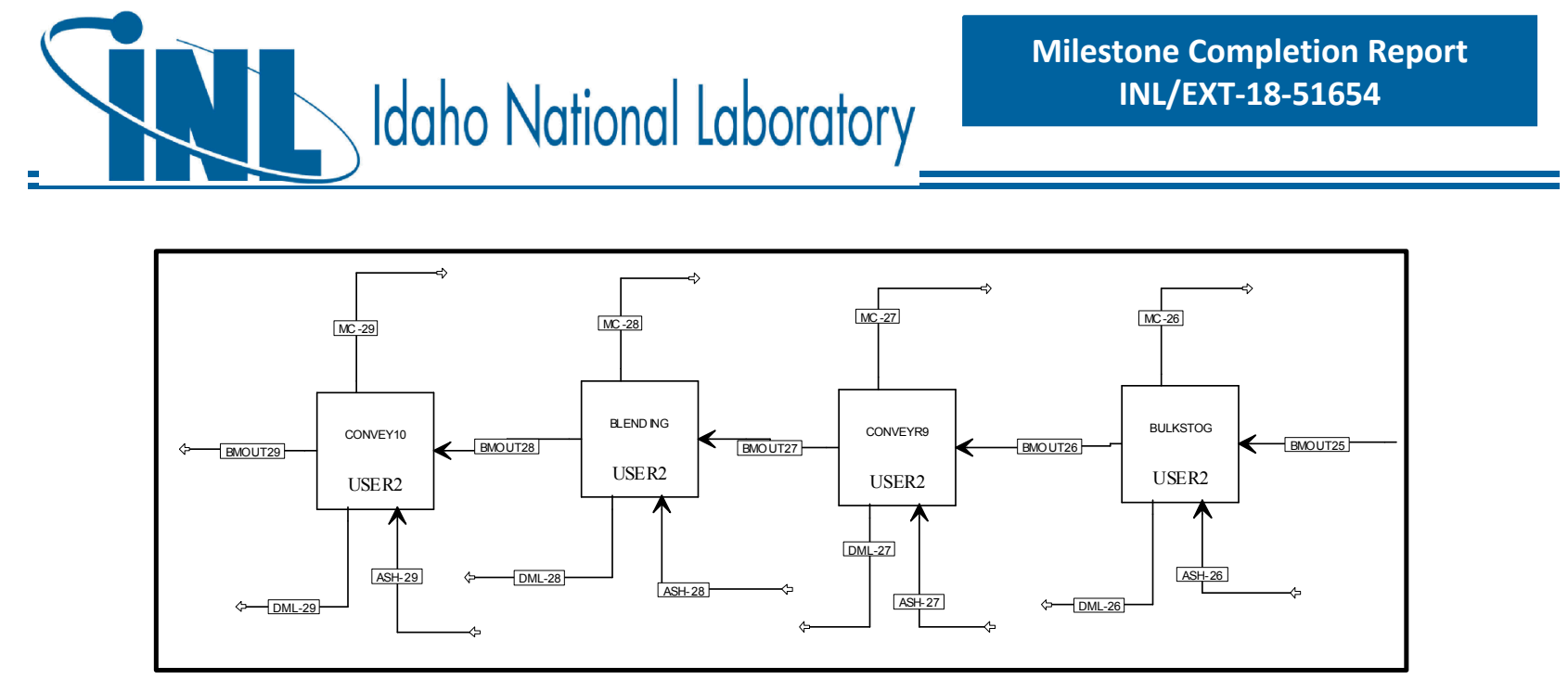

Figure F-21. Detailed process flow diagram for area C600-Feeding. 
Table F-5. Aspen Plus mass balances from harvest to field-side storage (Area C100) for the switchgrass blendstock in the 2018 Herbaceous SOT. Harvest is assumed to take place within a 6 week period, working 14 hours/day, 6 days per week.

\begin{tabular}{|c|c|c|c|c|c|c|c|c|c|c|c|c|c|c|}
\hline Component & unit & BIOMIN & DML-2 & & MC-2 & & BMOUT2 & DML-3 & MC-3 & & BMOUT3 & DML-4 & MC-4 & BMOUT4 \\
\hline $\begin{array}{l}\text { Overall Flow } \\
\text { (moisture and } \\
\text { dry matter) }\end{array}$ & $\mathrm{kg} / \mathrm{hr}$ & 151,761 & & 0 & & 0 & 151,761 & 0 & & 0 & 151,761 & 0 & 0 & 151,761 \\
\hline Moisture Flow & $\mathrm{kg} / \mathrm{hr}$ & 30,352 & & 0 & & 0 & 30,352 & 0 & & 0 & 30,352 & 0 & 0 & 30,352 \\
\hline $\begin{array}{l}\text { Total Flow (dry } \\
\text { matter) }\end{array}$ & $\mathrm{kg} / \mathrm{hr}$ & 121,409 & & 0 & & 0 & 121,409 & 0 & & 0 & 121,409 & 0 & 0 & 121,409 \\
\hline C6 & $\mathrm{kg} / \mathrm{hr}$ & 43,195 & & 0 & & 0 & 43,195 & 0 & & 0 & 43,195 & 0 & 0 & 43,195 \\
\hline C5 & $\mathrm{kg} / \mathrm{hr}$ & 35,326 & & 0 & & 0 & 35,326 & 0 & & 0 & 35,326 & 0 & 0 & 35,326 \\
\hline LIGNIN & $\mathrm{kg} / \mathrm{hr}$ & 21,575 & & 0 & & 0 & 21,575 & 0 & & 0 & 21,575 & 0 & 0 & 21,575 \\
\hline ASH & $\mathrm{kg} / \mathrm{hr}$ & 7,530 & & 0 & & 0 & 7,530 & 0 & & 0 & 7,530 & 0 & 0 & 7,530 \\
\hline PROTEIN & $\mathrm{kg} / \mathrm{hr}$ & 0 & & 0 & & 0 & 0 & & 0 & 0 & 0 & 0 & 0 & 0 \\
\hline $\begin{array}{l}\text { EXTRACTIVE } \\
\text { S }\end{array}$ & $\mathrm{kg} / \mathrm{hr}$ & 13,783 & & 0 & & 0 & 13,783 & 0 & & 0 & 13,783 & 0 & 0 & 13,783 \\
\hline OTHERS & $\mathrm{kg} / \mathrm{hr}$ & 0 & & 0 & & 0 & 0 & & 0 & 0 & 0 & 0 & 0 & 0 \\
\hline Temperature & K & 298 & & 298 & & 298 & 298 & 298 & & 298 & 298 & 298 & 298 & 298 \\
\hline Pressure & $\mathrm{atm}$ & 1 & & 1 & & 1 & 1 & 1 & & 1 & 1 & 1 & 1 & 1 \\
\hline Vapor Frac & & 0 & & 0 & & 0 & 0 & 0 & ) & 0 & 0 & 0 & 0 & 0 \\
\hline
\end{tabular}


Table F-6. Aspen Plus mass balances from field-side storage to feeding (Areas C200-C600) for the switchgrass blendstock in the 2018 Herbaceous SOT. Depot operation is assumed to take place within 350 day period, working 24 hours/day, 7 days per week.

\begin{tabular}{|c|c|c|c|c|c|c|c|c|c|c|c|c|c|c|c|}
\hline Component & unit & DML-5 & MC-5 & BMOUT5 & $\begin{array}{l}\text { DML- } \\
6\end{array}$ & $\begin{array}{l}\text { MC- } \\
6\end{array}$ & BMOUT6 & $\begin{array}{l}\text { DML- } \\
7\end{array}$ & MC-7 & BMOUT7 & $\begin{array}{l}\text { DML- } \\
8\end{array}$ & MC-8 & BMOUT8 & $\begin{array}{l}\text { DML- } \\
9\end{array}$ & $\begin{array}{l}\text { MC- } \\
9\end{array}$ \\
\hline $\begin{array}{l}\text { Overall Flow } \\
\text { (moisture and dry } \\
\text { matter) }\end{array}$ & $\mathrm{kg} / \mathrm{hr}$ & 683 & 466 & 9,517 & 0 & 0 & 9,517 & 0 & 0 & 9,517 & 0 & 0 & 9,517 & 0 & 0 \\
\hline Moisture Flow & $\mathrm{kg} / \mathrm{hr}$ & 0 & 466 & 1,667 & 0 & 0 & 1,667 & 0 & 0 & 1,667 & 0 & 0 & 1,667 & 0 & 0 \\
\hline $\begin{array}{l}\text { Total Flow (dry } \\
\text { matter) }\end{array}$ & $\mathrm{kg} / \mathrm{hr}$ & 683 & 0 & 7,850 & 0 & 0 & 7,850 & 0 & 0 & 7,850 & 0 & 0 & 7,850 & 0 & 0 \\
\hline C6 & $\mathrm{kg} / \mathrm{hr}$ & 126 & 0 & 2,910 & 0 & 0 & 2,910 & 0 & 0 & 2,910 & 0 & 0 & 2,910 & 0 & 0 \\
\hline $\mathrm{C} 5$ & $\mathrm{~kg} / \mathrm{hr}$ & 197 & 0 & 2,286 & 0 & 0 & 2,286 & 0 & 0 & 2,286 & 0 & 0 & 2,286 & 0 & 0 \\
\hline LIGNIN & $\mathrm{kg} / \mathrm{hr}$ & 44 & 0 & 1,472 & 0 & 0 & 1,472 & 0 & 0 & 1,472 & 0 & 0 & 1,472 & 0 & 0 \\
\hline ASH & $\mathrm{kg} / \mathrm{hr}$ & 0 & 0 & 529 & 0 & 0 & 529 & 0 & 0 & 529 & 0 & 0 & 529 & 0 & 0 \\
\hline PROTEIN & $\mathrm{kg} / \mathrm{hr}$ & 21 & 0 & 0 & 0 & 0 & 0 & 0 & 0 & 0 & 0 & 0 & 0 & 0 & 0 \\
\hline EXTRACTIVES & $\mathrm{kg} / \mathrm{hr}$ & 205 & 0 & 764 & 0 & 0 & 764 & 0 & 0 & 764 & 0 & 0 & 764 & 0 & 0 \\
\hline OTHERS & $\mathrm{kg} / \mathrm{hr}$ & 90 & 0 & 0 & 0 & 0 & 0 & 0 & 0 & 0 & 0 & 0 & 0 & 0 & 0 \\
\hline Temperature & $\mathrm{K}$ & 298 & 298 & 298 & 298 & 298 & 298 & 298 & 298 & 298 & 298 & 298 & 298 & 298 & 298 \\
\hline Pressure & atm & 1 & 1 & 1 & 1 & 1 & 1 & 1 & 1 & 1 & 1 & 1 & 1 & 1 & 1 \\
\hline Vapor Frac & & 0 & 0 & 0 & 0 & 0 & 0 & 0 & 0 & 0 & 0 & 0 & 0 & 0 & 0 \\
\hline
\end{tabular}


Table F-6. (continued)

\begin{tabular}{|c|c|c|c|c|c|c|c|c|c|c|c|c|c|}
\hline Component & unit & BMOUT9 & DML-10 & MC-10 & & BMOUT10 & DML-11 & MC-11 & & BMOUT11 & DML-12 & $\begin{array}{l}\text { MC- } \\
12\end{array}$ & BMOUT12 \\
\hline $\begin{array}{l}\text { Overall Flow } \\
\text { (moisture and dry } \\
\text { matter) }\end{array}$ & $\mathrm{kg} / \mathrm{hr}$ & 9,517 & 0 & & 0 & 9,517 & 67 & & 347 & 9,102 & 0 & 0 & 9,103 \\
\hline Moisture Flow & $\mathrm{kg} / \mathrm{hr}$ & 1,667 & 0 & & 0 & 1,667 & 0 & & 347 & 1,319 & 0 & 0 & 1,320 \\
\hline $\begin{array}{l}\text { Total Flow (dry } \\
\text { matter) }\end{array}$ & $\mathrm{kg} / \mathrm{hr}$ & 7,850 & 0 & & 0 & 7,850 & 67 & & 0 & 7,784 & 0 & 0 & 7,784 \\
\hline C6 & $\mathrm{kg} / \mathrm{hr}$ & 2,910 & 0 & & 0 & 2,910 & 24 & & 0 & 2,886 & 0 & 0 & 2,886 \\
\hline $\mathrm{C5}$ & $\mathrm{kg} / \mathrm{hr}$ & 2,286 & 0 & & 0 & 2,286 & 1 & & 0 & 2,285 & 0 & 0 & 2,285 \\
\hline LIGNIN & $\mathrm{kg} / \mathrm{hr}$ & 1,472 & 0 & & 0 & 1,472 & 15 & & 0 & 1,457 & 0 & 0 & 1,457 \\
\hline ASH & $\mathrm{kg} / \mathrm{hr}$ & 529 & 0 & & 0 & 529 & 19 & & 0 & 510 & 0 & 0 & 510 \\
\hline PROTEIN & $\mathrm{kg} / \mathrm{hr}$ & 0 & 0 & & 0 & 0 & 0 & & 0 & 0 & 0 & 0 & 0 \\
\hline EXTRACTIVES & $\mathrm{kg} / \mathrm{hr}$ & 764 & 0 & & 0 & 764 & 8 & & 0 & 757 & 0 & 0 & 757 \\
\hline OTHERS & $\mathrm{kg} / \mathrm{hr}$ & 0 & 0 & & 0 & 0 & 0 & & 0 & 0 & 0 & 0 & 0 \\
\hline Temperature & K & 298 & 298 & & 298 & 298 & 298 & & 298 & 298 & 298 & 298 & 298 \\
\hline Pressure & atm & 1 & 1 & & 1 & 1 & 1 & & 1 & 1 & 1 & 1 & 1 \\
\hline Vapor Frac & & 0 & 0 & & 0 & 0 & 0 & & 0 & 0 & 0 & 0 & 0 \\
\hline
\end{tabular}


latano National Laboratory

Table F-6. (continued)

\begin{tabular}{|c|c|c|c|c|c|c|c|c|c|c|c|}
\hline Component & unit & $\begin{array}{l}\text { DML- } \\
13\end{array}$ & MC-13 & BMOUT13 & BMOUT14 & DML-14 & MC-14 & DML-15 & $\begin{array}{l}\text { MC- } \\
15\end{array}$ & BMOUT15 & $\begin{array}{l}\text { DML- } \\
16 \\
\end{array}$ \\
\hline $\begin{array}{l}\text { Overall Flow } \\
\text { (moisture and dry } \\
\text { matter) }\end{array}$ & $\mathrm{kg} / \mathrm{hr}$ & 104 & 0 & 4,048 & 4,952 & 0 & 0 & 0 & 0 & 4,048 & 47 \\
\hline Moisture Flow & $\mathrm{kg} / \mathrm{hr}$ & 104 & 0 & 547 & 669 & 0 & 0 & 0 & 0 & 547 & 0 \\
\hline $\begin{array}{l}\text { Total Flow (dry } \\
\text { matter) }\end{array}$ & $\mathrm{kg} / \mathrm{hr}$ & 0 & 0 & 3,501 & 4,283 & 0 & 0 & 0 & 0 & 3,501 & 47 \\
\hline $\mathrm{C} 6$ & $\mathrm{~kg} / \mathrm{hr}$ & 0 & 0 & 1,299 & 1,588 & 0 & 0 & 0 & 0 & 1,299 & 13 \\
\hline C5 & $\mathrm{kg} / \mathrm{hr}$ & 0 & 0 & 1,027 & 1,257 & 0 & 0 & 0 & 0 & 1,027 & 8 \\
\hline LIGNIN & $\mathrm{kg} / \mathrm{hr}$ & 0 & 0 & 656 & 802 & 0 & 0 & 0 & 0 & 656 & 9 \\
\hline ASH & $\mathrm{kg} / \mathrm{hr}$ & 0 & 0 & 229 & 280 & 0 & 0 & 0 & 0 & 229 & 11 \\
\hline PROTEIN & $\mathrm{kg} / \mathrm{hr}$ & 0 & 0 & 0 & 0 & 0 & 0 & 0 & 0 & 0 & 0 \\
\hline EXTRACTIVES & $\mathrm{kg} / \mathrm{hr}$ & 0 & 0 & 340 & 417 & 0 & 0 & 0 & 0 & 340 & 9 \\
\hline OTHERS & $\mathrm{kg} / \mathrm{hr}$ & 0 & 0 & 0 & 0 & 0 & 0 & 0 & 0 & 0 & 0 \\
\hline Temperature & $\mathrm{K}$ & 298 & 298 & 298 & 298 & 298 & 298 & 298 & 298 & 298 & 298 \\
\hline Pressure & $\mathrm{atm}$ & 1 & 1 & 1 & 1 & 1 & 1 & 1 & 1 & 1 & 1 \\
\hline Vapor Frac & & 0 & 0 & 0 & 0 & 0 & 0 & 0 & 0 & 0 & 0 \\
\hline
\end{tabular}


a daho National Laboratory

Table F-6. (continued)

\begin{tabular}{|c|c|c|c|c|c|c|c|c|c|c|c|c|c|c|}
\hline Component & unit & MC-16 & BMOUT16 & BMOUT17 & DML-18 & MC-18 & & BMOUT18 & DML-19 & MC-19 & & BMOUT19 & $\begin{array}{l}\text { DML- } \\
20\end{array}$ & $\begin{array}{l}\text { MC- } \\
20\end{array}$ \\
\hline $\begin{array}{l}\text { Overall Flow } \\
\text { (moisture and dry } \\
\text { matter) }\end{array}$ & $\mathrm{kg} / \mathrm{hr}$ & 6 & 4,952 & 4,897 & 0 & & 0 & 8,945 & 0 & & 349 & 8,597 & 0 & 94 \\
\hline Moisture Flow & $\mathrm{kg} / \mathrm{hr}$ & 6 & 669 & 662 & 0 & & 0 & 1,209 & 0 & & 349 & 860 & 0 & 94 \\
\hline $\begin{array}{l}\text { Total Flow (dry } \\
\text { matter) }\end{array}$ & $\mathrm{kg} / \mathrm{hr}$ & 0 & 4,283 & 4,235 & 0 & & 0 & 7,736 & 0 & & 0 & 7,736 & 0 & 0 \\
\hline C6 & $\mathrm{kg} / \mathrm{hr}$ & 0 & 1,588 & 1,576 & 0 & & 0 & 2,874 & 0 & & 0 & 2,874 & 0 & 0 \\
\hline $\mathrm{C} 5$ & $\mathrm{~kg} / \mathrm{hr}$ & 0 & 1,257 & 1,250 & 0 & & 0 & 2,277 & 0 & & 0 & 2,277 & 0 & 0 \\
\hline LIGNIN & $\mathrm{kg} / \mathrm{hr}$ & 0 & 802 & 793 & 0 & & 0 & 1,449 & 0 & & 0 & 1,449 & 0 & 0 \\
\hline ASH & $\mathrm{kg} / \mathrm{hr}$ & 0 & 280 & 269 & 0 & & 0 & 499 & 0 & & 0 & 499 & 0 & 0 \\
\hline PROTEIN & $\mathrm{kg} / \mathrm{hr}$ & 0 & 0 & 0 & 0 & & 0 & 0 & 0 & & 0 & 0 & 0 & 0 \\
\hline EXTRACTIVES & $\mathrm{kg} / \mathrm{hr}$ & 0 & 417 & 408 & 0 & & 0 & 748 & 0 & & 0 & 748 & 0 & 0 \\
\hline OTHERS & $\mathrm{kg} / \mathrm{hr}$ & 0 & 0 & 0 & 0 & & 0 & 0 & 0 & & 0 & 0 & 0 & 0 \\
\hline Temperature & K & 298 & 298 & 298 & 298 & & 298 & 298 & 298 & & 298 & 298 & 298 & 298 \\
\hline Pressure & atm & 1 & 1 & 1 & 1 & & 1 & 1 & 1 & & 1 & 1 & 1 & 1 \\
\hline Vapor Frac & & 0 & 0 & 0 & 0 & & 0 & 0 & 0 & & 0 & 0 & 0 & 0 \\
\hline
\end{tabular}


lacho National Laboratory

Table F-6. (continued)

\begin{tabular}{|c|c|c|c|c|c|c|c|c|c|c|c|c|}
\hline Component & unit & BMOUT20 & DML-21 & MC-21 & & BMOUT21 & DML-22 & MC-22 & & BMOUT22 & DML-23 & $\begin{array}{l}\text { MC- } \\
23\end{array}$ \\
\hline $\begin{array}{l}\text { Overall Flow } \\
\text { (moisture and dry } \\
\text { matter) }\end{array}$ & $\mathrm{kg} / \mathrm{hr}$ & 8,503 & 0 & & 0 & 8,503 & 0 & & 0 & 8,503 & 0 & 0 \\
\hline Moisture Flow & $\mathrm{kg} / \mathrm{hr}$ & 766 & 0 & & 0 & 766 & 0 & & 0 & 766 & 0 & 0 \\
\hline $\begin{array}{l}\text { Total Flow (dry } \\
\text { matter) }\end{array}$ & $\mathrm{kg} / \mathrm{hr}$ & 7,736 & 0 & & 0 & 7,736 & 0 & & 0 & 7,736 & 0 & 0 \\
\hline C6 & $\mathrm{kg} / \mathrm{hr}$ & 2,874 & 0 & & 0 & 2,874 & 0 & & 0 & 2,874 & 0 & 0 \\
\hline $\mathrm{C} 5$ & $\mathrm{~kg} / \mathrm{hr}$ & 2,277 & 0 & & 0 & 2,277 & 0 & & 0 & 2,277 & 0 & 0 \\
\hline LIGNIN & $\mathrm{kg} / \mathrm{hr}$ & 1,449 & 0 & & 0 & 1,449 & 0 & & 0 & 1,449 & 0 & 0 \\
\hline ASH & $\mathrm{kg} / \mathrm{hr}$ & 499 & 0 & & 0 & 499 & 0 & & 0 & 499 & 0 & 0 \\
\hline PROTEIN & $\mathrm{kg} / \mathrm{hr}$ & 0 & 0 & & 0 & 0 & 0 & & 0 & 0 & 0 & 0 \\
\hline EXTRACTIVES & $\mathrm{kg} / \mathrm{hr}$ & 748 & 0 & & 0 & 748 & 0 & & 0 & 748 & 0 & 0 \\
\hline OTHERS & $\mathrm{kg} / \mathrm{hr}$ & 0 & 0 & & 0 & 0 & 0 & & 0 & 0 & 0 & 0 \\
\hline Temperature & K & 298 & 298 & & 298 & 298 & 298 & & 298 & 298 & 298 & 298 \\
\hline Pressure & atm & 1 & 1 & & 1 & 1 & 1 & & 1 & 1 & 1 & 1 \\
\hline Vapor Frac & & 0 & 0 & & 0 & 0 & 0 & & 0 & 0 & 0 & 0 \\
\hline
\end{tabular}


Table F-6. (continued)

\begin{tabular}{|c|c|c|c|c|c|c|c|c|c|c|c|}
\hline Component & unit & BMOUT23 & DML-24 & MC-24 & BMOUT24 & DML-25 & MC-25 & BMOUT25 & DML-26 & $\begin{array}{l}\text { MC- } \\
26\end{array}$ & BMOUT26 \\
\hline $\begin{array}{l}\text { Overall Flow } \\
\text { (moisture and dry } \\
\text { matter) }\end{array}$ & $\mathrm{kg} / \mathrm{hr}$ & 8,503 & 0 & 0 & 8,503 & 0 & 0 & 8,503 & 0 & 0 & 8,503 \\
\hline Moisture Flow & $\mathrm{kg} / \mathrm{hr}$ & 766 & 0 & 0 & 766 & 0 & 0 & 766 & 0 & 0 & 766 \\
\hline $\begin{array}{l}\text { Total Flow (dry } \\
\text { matter) }\end{array}$ & $\mathrm{kg} / \mathrm{hr}$ & 7,736 & 0 & 0 & 7,736 & 0 & 0 & 7,736 & 0 & 0 & 7,736 \\
\hline C6 & $\mathrm{kg} / \mathrm{hr}$ & 2,874 & 0 & 0 & 2,874 & 0 & 0 & 2,874 & 0 & 0 & 2,874 \\
\hline $\mathrm{C} 5$ & $\mathrm{~kg} / \mathrm{hr}$ & 2,277 & 0 & 0 & 2,277 & 0 & 0 & 2,277 & 0 & 0 & 2,277 \\
\hline LIGNIN & $\mathrm{kg} / \mathrm{hr}$ & 1,449 & 0 & 0 & 1,449 & 0 & 0 & 1,449 & 0 & 0 & 1,449 \\
\hline ASH & $\mathrm{kg} / \mathrm{hr}$ & 499 & 0 & 0 & 499 & 0 & 0 & 499 & 0 & 0 & 499 \\
\hline PROTEIN & $\mathrm{kg} / \mathrm{hr}$ & 0 & 0 & 0 & 0 & 0 & 0 & 0 & 0 & 0 & 0 \\
\hline EXTRACTIVES & $\mathrm{kg} / \mathrm{hr}$ & 748 & 0 & 0 & 748 & 0 & 0 & 748 & 0 & 0 & 748 \\
\hline OTHERS & $\mathrm{kg} / \mathrm{hr}$ & 0 & 0 & 0 & 0 & 0 & 0 & 0 & 0 & 0 & 0 \\
\hline Temperature & $\mathrm{K}$ & 298 & 298 & 298 & 298 & 298 & 298 & 298 & 298 & 298 & 298 \\
\hline Pressure & atm & 1 & 1 & 1 & 1 & 1 & 1 & 1 & 1 & 1 & 1 \\
\hline Vapor Frac & & 0 & 0 & 0 & 0 & 0 & 0 & 0 & 0 & 0 & 0 \\
\hline
\end{tabular}


a daho National Laboratory

Table F-6. (continued)

\begin{tabular}{|c|c|c|c|c|c|c|c|c|c|c|c|}
\hline Component & unit & $\begin{array}{l}\text { DML- } \\
27\end{array}$ & MC-27 & BMOUT27 & DML-28 & MC-28 & BMOUT28 & DML-29 & MC-29 & & BMOUT29 \\
\hline $\begin{array}{l}\text { Overall Flow } \\
\text { (moisture and dry } \\
\text { matter) }\end{array}$ & $\mathrm{kg} / \mathrm{hr}$ & 0 & 0 & 8,503 & 0 & 0 & 8,503 & 0 & & 0 & 8,503 \\
\hline Moisture Flow & $\mathrm{kg} / \mathrm{hr}$ & 0 & 0 & 766 & 0 & 0 & 766 & 0 & & 0 & 766 \\
\hline $\begin{array}{l}\text { Total Flow (dry } \\
\text { matter) }\end{array}$ & $\mathrm{kg} / \mathrm{hr}$ & 0 & 0 & 7,736 & 0 & 0 & 7,736 & 0 & & 0 & 7,736 \\
\hline C6 & $\mathrm{kg} / \mathrm{hr}$ & 0 & 0 & 2,874 & 0 & 0 & 2,874 & 0 & & 0 & 2,874 \\
\hline C5 & $\mathrm{kg} / \mathrm{hr}$ & 0 & 0 & 2,277 & 0 & 0 & 2,277 & 0 & & 0 & 2,277 \\
\hline LIGNIN & $\mathrm{kg} / \mathrm{hr}$ & 0 & 0 & 1,449 & 0 & 0 & 1,449 & 0 & & 0 & 1,449 \\
\hline ASH & $\mathrm{kg} / \mathrm{hr}$ & 0 & 0 & 499 & 0 & 0 & 499 & 0 & & 0 & 499 \\
\hline PROTEIN & $\mathrm{kg} / \mathrm{hr}$ & 0 & 0 & 0 & 0 & 0 & 0 & 0 & & 0 & 0 \\
\hline EXTRACTIVES & $\mathrm{kg} / \mathrm{hr}$ & 0 & 0 & 748 & 0 & 0 & 748 & 0 & & 0 & 748 \\
\hline OTHERS & $\mathrm{kg} / \mathrm{hr}$ & 0 & 0 & 0 & 0 & 0 & 0 & 0 & & 0 & 0 \\
\hline Temperature & K & 298 & 298 & 298 & 298 & 298 & 298 & 298 & & 298 & 298 \\
\hline Pressure & atm & 1 & 1 & 1 & 1 & 1 & 1 & 1 & & 1 & 1 \\
\hline Vapor Frac & & 0 & 0 & 0 & 0 & 0 & 0 & 0 & & 0 & 0 \\
\hline
\end{tabular}




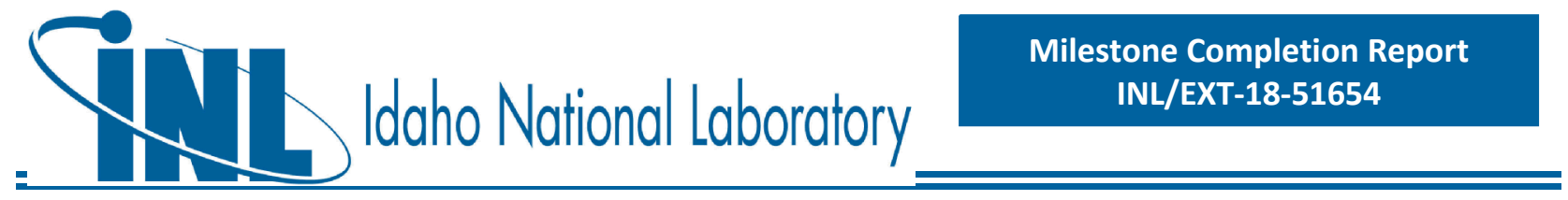

\section{F.4 Grass Clippings Blendstock}

High-level stream table information from Aspen Plus modeling output follows, for key streams associated with each process operation area. This is followed by high-level PFDs for the associated process areas. Space for stream tables was limited; below is a key to lumped components. As the stream table information focuses primarily on the high-level overall process and does not include every individual modeled stream within each process area, mass balance closure around a given unit area may not be $100 \%$.

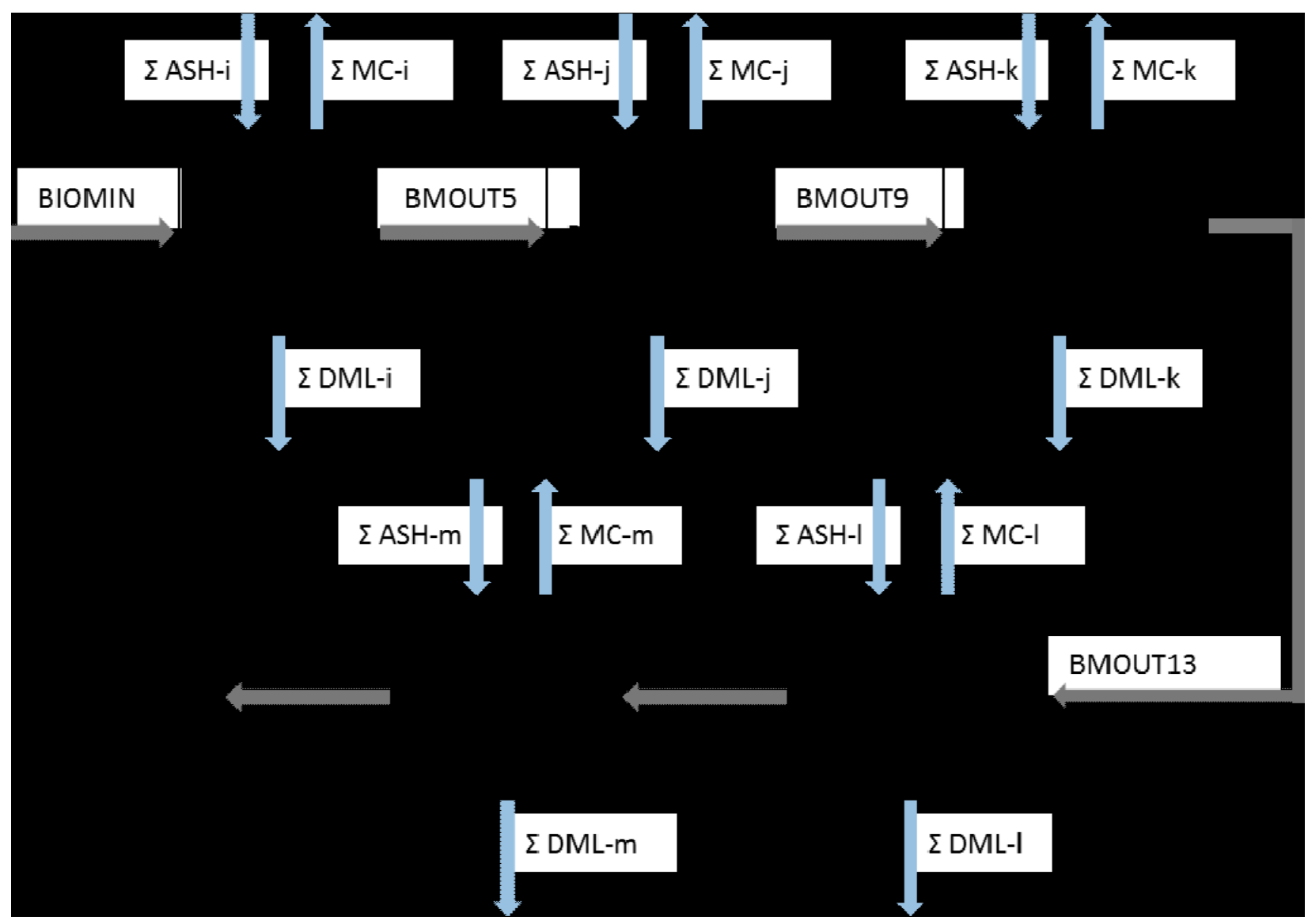

Figure F-22. High-level flowsheet showing key process areas for the grass clippings blendstock in the 2018 Herbaceous SOT. 

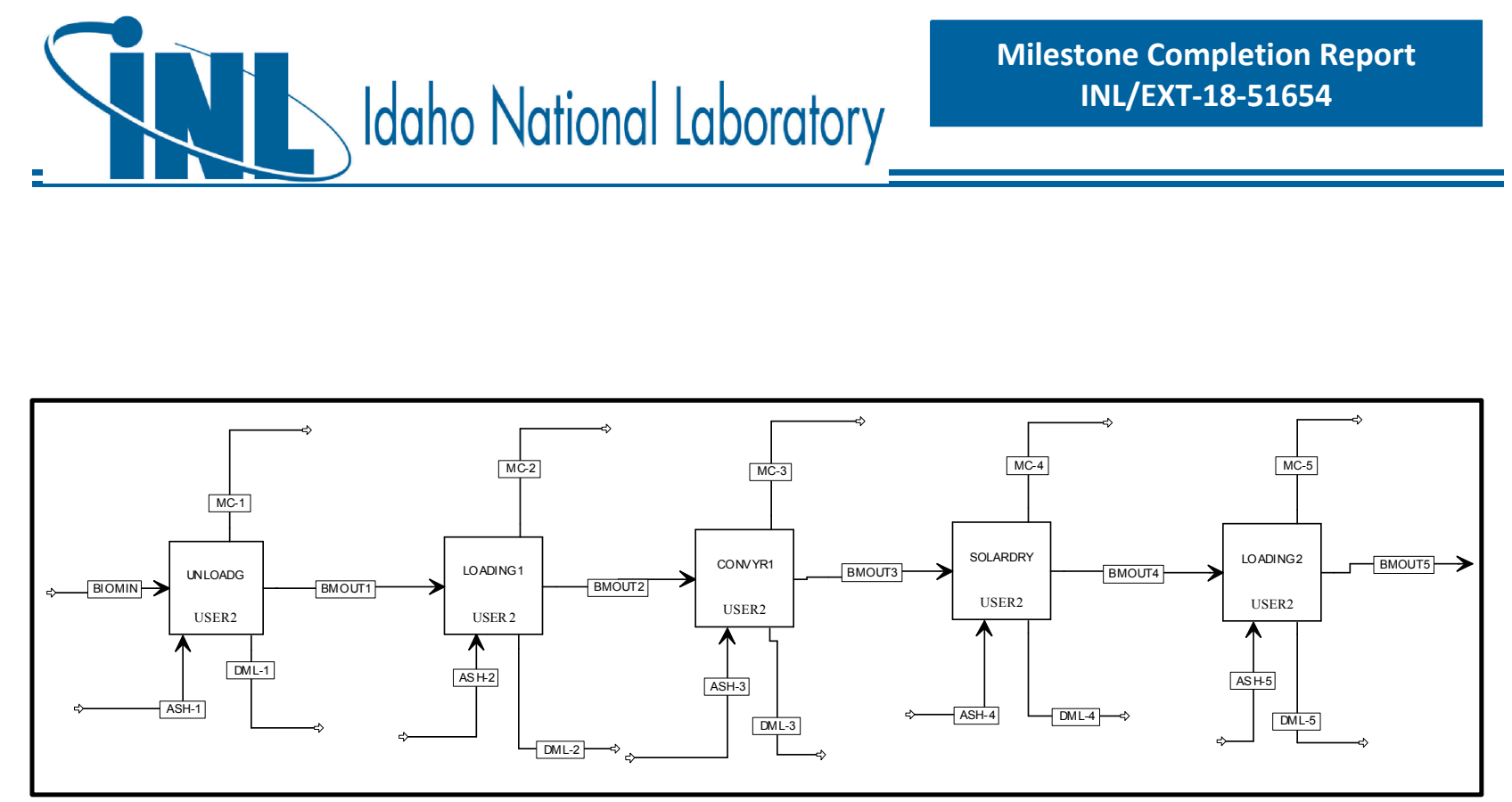

Figure F-23. Detailed process flow diagram for area D100 - Solar Drying.

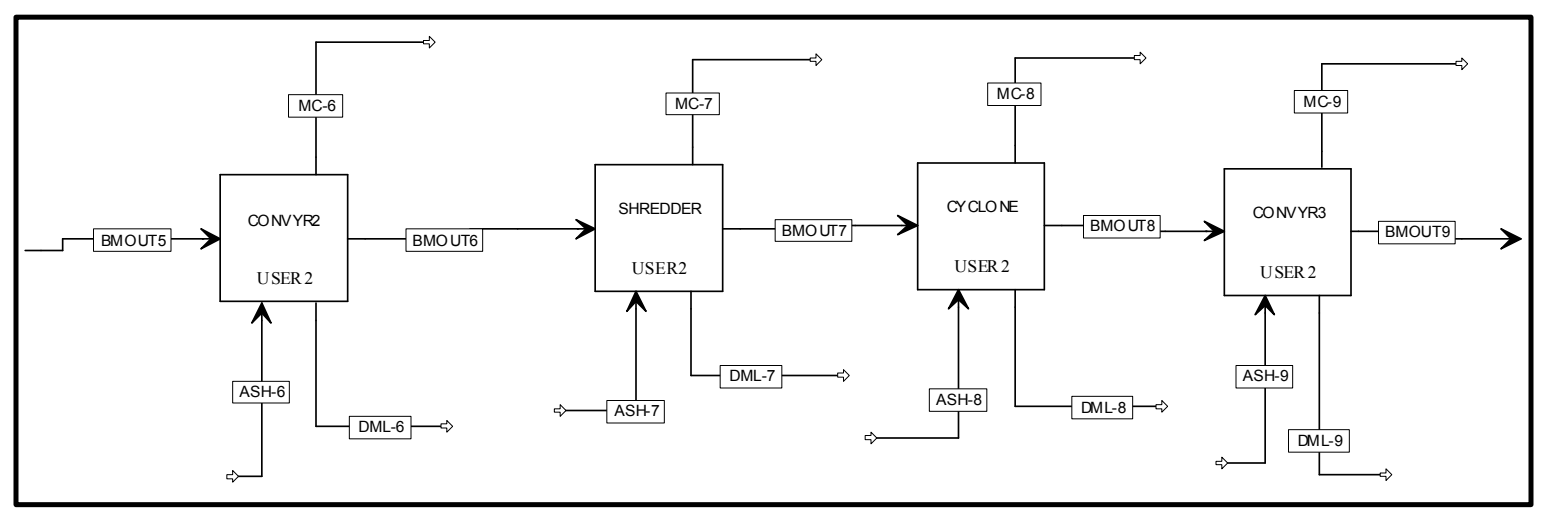

Figure F-24. Detailed process flow diagram for area D200 - Preprocessing - Size Reduction.

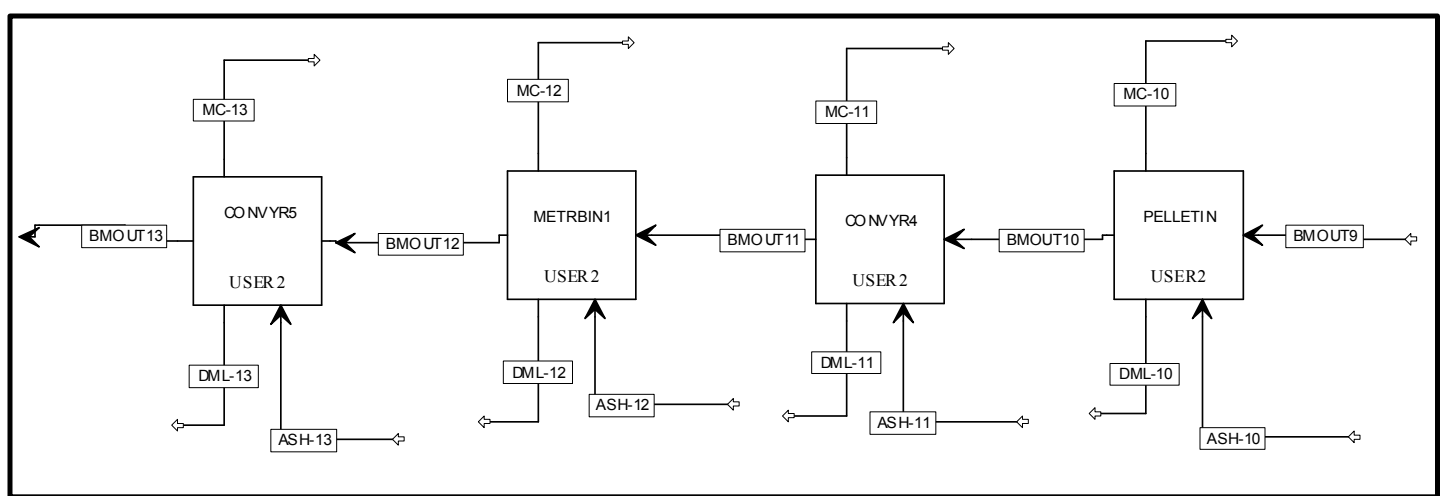

Figure F-25. Detailed process flow diagram for area D300 - Preprocessing - Pelleting. 


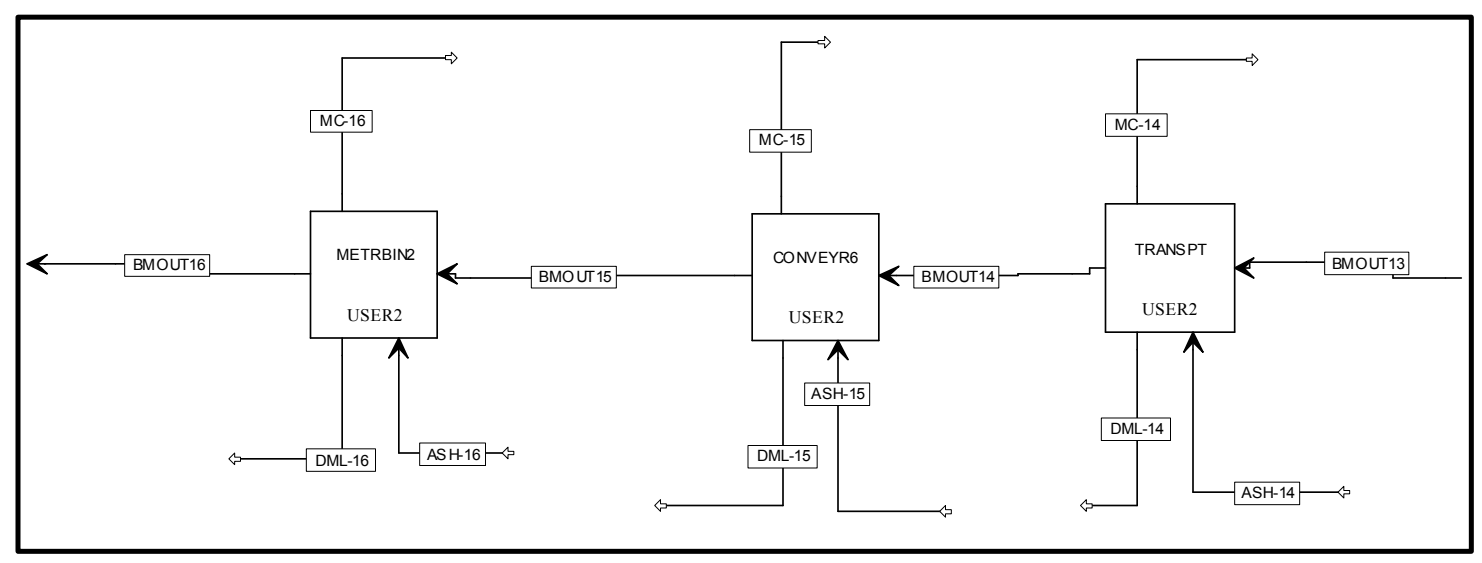

Figure F-26. Detailed process flow diagram for area D400 - Transportation to Biorefinery.

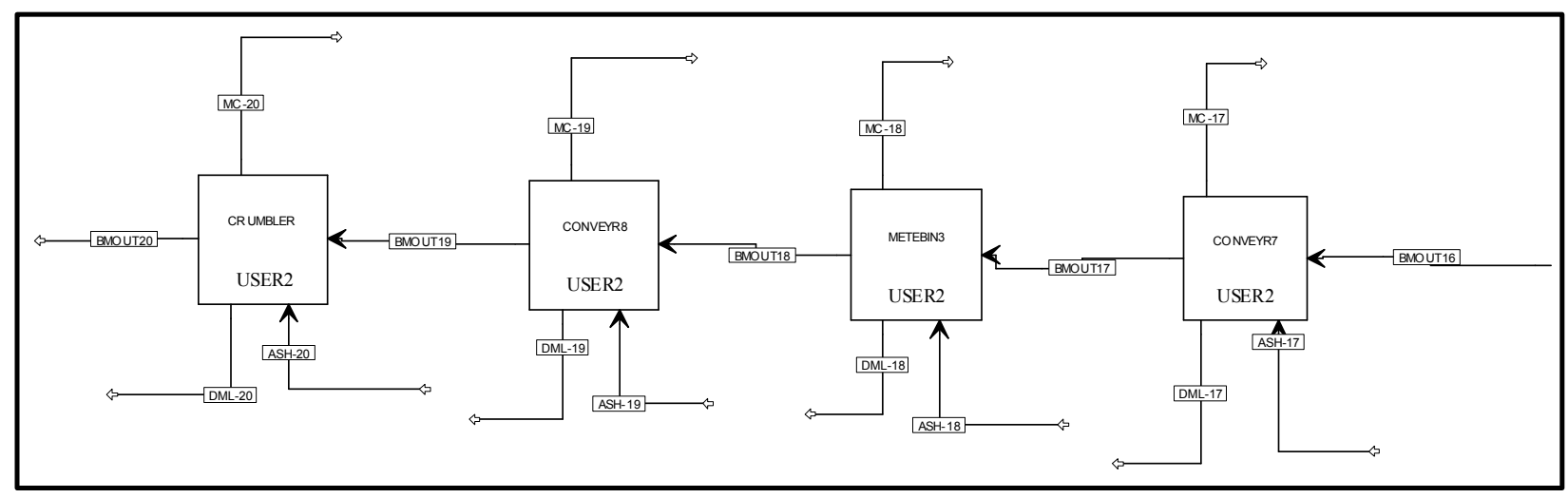

Figure F-27. Detailed process flow diagram for area D500 - Feeding. 
Table F-7. Aspen Plus mass balances for the grass clippings blendstock in the 2018 Herbaceous SOT. Depot operation is assumed to take place within a 25 week period, working 24 hours/day, 7 days per week.

\begin{tabular}{|c|c|c|c|c|c|c|c|c|c|c|c|c|c|}
\hline Component & unit & BIOMIN & DML-1 & MC-1 & BMOUT1 & DML-2 & MC-2 & BMOUT2 & DML-3 & MC-3 & BMOUT3 & DML-4 & MC-4 \\
\hline $\begin{array}{l}\text { Overall Flow } \\
\text { (moisture and } \\
\text { dry matter) }\end{array}$ & $\mathrm{kg} / \mathrm{hr}$ & 22,546 & 0 & 4 & 22,542 & 0 & 0 & 22,542 & 0 & 0 & 22,542 & 41 & 14,594 \\
\hline Moisture Flow & $\mathrm{kg} / \mathrm{hr}$ & 15,784 & 0 & 4 & 15,780 & 0 & 0 & 15,780 & 0 & 0 & 15,780 & 0 & 14,594 \\
\hline $\begin{array}{l}\text { Total Flow (dry } \\
\text { matter) }\end{array}$ & $\mathrm{kg} / \mathrm{hr}$ & 6,763 & 0 & 0 & 6,763 & 0 & 0 & 6,763 & 0 & 0 & 6,763 & 41 & 0 \\
\hline C6 & $\mathrm{kg} / \mathrm{hr}$ & 1,326 & 0 & 0 & 1,326 & 0 & 0 & 1,326 & 0 & 0 & 1,326 & 0 & 0 \\
\hline $\mathrm{C5}$ & $\mathrm{kg} / \mathrm{hr}$ & 574 & 0 & 0 & 574 & 0 & 0 & 574 & 0 & 0 & 574 & 0 & 0 \\
\hline LIGNIN & $\mathrm{kg} / \mathrm{hr}$ & 1,129 & 0 & 0 & 1,129 & 0 & 0 & 1,129 & 0 & 0 & 1,129 & 0 & 0 \\
\hline ASH & $\mathrm{kg} / \mathrm{hr}$ & 865 & 0 & 0 & 865 & 0 & 0 & 865 & 0 & 0 & 865 & 0 & 0 \\
\hline PROTEIN & $\mathrm{kg} / \mathrm{hr}$ & 690 & 0 & 0 & 690 & 0 & 0 & 690 & 0 & 0 & 690 & 0 & 0 \\
\hline $\begin{array}{l}\text { EXTRACTIVE } \\
\text { S }\end{array}$ & $\mathrm{kg} / \mathrm{hr}$ & 1,461 & 0 & 0 & 1,461 & 0 & 0 & 1,461 & 0 & 0 & 1,461 & 41 & 0 \\
\hline OTHERS & $\mathrm{kg} / \mathrm{hr}$ & 717 & 0 & 0 & 717 & 0 & 0 & 717 & 0 & 0 & 717 & 0 & 0 \\
\hline Temperature & $\mathrm{K}$ & 298 & 298 & 298 & 298 & 298 & 298 & 298 & 298 & 298 & 298 & 298 & 298 \\
\hline Pressure & $\mathrm{atm}$ & 1 & 1 & 1 & 1 & 1 & 1 & 1 & 1 & 1 & 1 & 1 & 1 \\
\hline Vapor Frac & & 0 & 0 & 0 & 0 & 0 & 0 & 0 & 0 & 0 & 0 & 0 & 0 \\
\hline
\end{tabular}


Iano National Laboratory

Table F-7. (continued)

\begin{tabular}{|c|c|c|c|c|c|c|c|c|c|c|c|c|c|c|}
\hline Component & unit & BMOUT4 & DML-5 & MC-5 & BMOUT5 & DML-6 & MC-6 & BMOUT6 & $\begin{array}{l}\text { DML- } \\
7\end{array}$ & MC-7 & BMOUT7 & $\begin{array}{l}\text { DML- } \\
8\end{array}$ & MC-8 & BMOUT8 \\
\hline $\begin{array}{l}\text { Overall Flow } \\
\text { (moisture and } \\
\text { dry matter) }\end{array}$ & $\mathrm{kg} / \mathrm{hr}$ & 7,909 & 0 & 0 & 7,909 & 0 & 0 & 7,909 & 33 & 188 & 7,689 & 0 & 0 & 7,689 \\
\hline Moisture Flow & $\mathrm{kg} / \mathrm{hr}$ & 1,186 & 0 & 0 & 1,186 & 0 & 0 & 1,186 & 0 & 188 & 1,000 & 0 & 0 & 1,000 \\
\hline $\begin{array}{l}\text { Total Flow (dry } \\
\text { matter) }\end{array}$ & $\mathrm{kg} / \mathrm{hr}$ & 6,722 & 0 & 0 & 6,722 & 0 & 0 & 6,722 & 33 & 0 & 6,689 & 0 & 0 & 6,689 \\
\hline C6 & $\mathrm{kg} / \mathrm{hr}$ & 1,326 & 0 & 0 & 1,326 & 0 & 0 & 1,326 & 6 & 0 & 1,321 & 0 & 0 & 1,321 \\
\hline C5 & $\mathrm{kg} / \mathrm{hr}$ & 574 & 0 & 0 & 574 & 0 & 0 & 574 & 2 & 0 & 572 & 0 & 0 & 572 \\
\hline LIGNIN & $\mathrm{kg} / \mathrm{hr}$ & 1,129 & 0 & 0 & 1,129 & 0 & 0 & 1,129 & 4 & 0 & 1,125 & 0 & 0 & 1,125 \\
\hline ASH & $\mathrm{kg} / \mathrm{hr}$ & 865 & 0 & 0 & 865 & 0 & 0 & 865 & 8 & 0 & 858 & 0 & 0 & 858 \\
\hline PROTEIN & $\mathrm{kg} / \mathrm{hr}$ & 690 & 0 & 0 & 690 & 0 & 0 & 690 & 4 & 0 & 688 & 0 & 0 & 688 \\
\hline $\begin{array}{l}\text { EXTRACTIVE } \\
\text { S } \\
\end{array}$ & $\mathrm{kg} / \mathrm{hr}$ & 1,420 & 0 & 0 & 1,420 & 0 & 0 & 1,420 & 6 & 0 & 1,414 & 0 & 0 & 1,414 \\
\hline OTHERS & $\mathrm{kg} / \mathrm{hr}$ & 717 & 0 & 0 & 717 & 0 & 0 & 717 & 4 & 0 & 713 & 0 & 0 & 713 \\
\hline Temperature & K & 298 & 298 & 298 & 298 & 298 & 298 & 298 & 298 & 298 & 298 & 298 & 298 & 298 \\
\hline Pressure & atm & 1 & 1 & 1 & 1 & 1 & 1 & 1 & 1 & 1 & 1 & 1 & 1 & 1 \\
\hline Vapor Frac & & 0 & 0 & 0 & 0 & 0 & 0 & 0 & 0 & 0 & 0 & 0 & 0 & 0 \\
\hline
\end{tabular}


Table F-7. (continued)

\begin{tabular}{|c|c|c|c|c|c|c|c|c|c|c|c|c|c|c|}
\hline Component & unit & $\begin{array}{l}\text { DML- } \\
9\end{array}$ & MC-9 & BMOUT9 & DML-10 & MC-10 & BMOUT10 & DML-11 & MC-11 & BMOUT11 & DML-12 & MC-12 & BMOUT12 & DML-13 \\
\hline $\begin{array}{l}\begin{array}{l}\text { Overall Flow } \\
\text { (moisture and } \\
\text { dry matter) }\end{array} \\
\end{array}$ & $\mathrm{kg} / \mathrm{hr}$ & 0 & 0 & 7,689 & 0 & 256 & 7,431 & 0 & 0 & 7,431 & 0 & 0 & 7,431 & 0 \\
\hline Moisture Flow & $\mathrm{kg} / \mathrm{hr}$ & 0 & 0 & 1,000 & 0 & 256 & 742 & 0 & 0 & 742 & 0 & 0 & 742 & 0 \\
\hline $\begin{array}{l}\text { Total Flow (dry } \\
\text { matter) }\end{array}$ & $\mathrm{kg} / \mathrm{hr}$ & 0 & 0 & 6,689 & 0 & 0 & 6,689 & 0 & 0 & 6,689 & 0 & 0 & 6,689 & 0 \\
\hline C6 & $\mathrm{kg} / \mathrm{hr}$ & 0 & 0 & 1,321 & 0 & 0 & 1,321 & 0 & 0 & 1,321 & 0 & 0 & 1,321 & 0 \\
\hline $\mathrm{C5}$ & $\mathrm{kg} / \mathrm{hr}$ & 0 & 0 & 572 & 0 & 0 & 572 & 0 & 0 & 572 & 0 & 0 & 572 & 0 \\
\hline LIGNIN & $\mathrm{kg} / \mathrm{hr}$ & 0 & 0 & 1,125 & 0 & 0 & 1,125 & 0 & 0 & 1,125 & 0 & 0 & 1,125 & 0 \\
\hline ASH & $\mathrm{kg} / \mathrm{hr}$ & 0 & 0 & 858 & 0 & 0 & 858 & 0 & 0 & 858 & 0 & 0 & 858 & 0 \\
\hline PROTEIN & $\mathrm{kg} / \mathrm{hr}$ & 0 & 0 & 688 & 0 & 0 & 688 & 0 & 0 & 688 & 0 & 0 & 688 & 0 \\
\hline $\begin{array}{l}\text { EXTRACTIVE } \\
\text { S }\end{array}$ & $\mathrm{kg} / \mathrm{hr}$ & 0 & 0 & 1,414 & 0 & 0 & 1,414 & 0 & 0 & 1,414 & 0 & 0 & 1,414 & 0 \\
\hline OTHERS & $\mathrm{kg} / \mathrm{hr}$ & 0 & 0 & 713 & 0 & 0 & 713 & 0 & 0 & 713 & 0 & 0 & 713 & 0 \\
\hline Temperature & K & 298 & 298 & 298 & 298 & 298 & 298 & 298 & 298 & 298 & 298 & 298 & 298 & 298 \\
\hline Pressure & atm & 1 & 1 & 1 & 1 & 1 & 1 & 1 & 1 & 1 & 1 & 1 & 1 & 1 \\
\hline Vapor Frac & & 0 & 0 & 0 & 0 & 0 & 0 & 0 & 0 & 0 & 0 & 0 & 0 & 0 \\
\hline
\end{tabular}


Table F-7. (continued)

\begin{tabular}{|c|c|c|c|c|c|c|c|c|c|c|c|c|c|}
\hline Component & unit & MC-13 & BMOUT13 & DML-14 & MC-14 & BMOUT14 & DML-15 & MC-15 & BMOUT15 & DML-16 & MC-16 & BMOUT16 & DML-17 \\
\hline $\begin{array}{l}\text { Overall Flow } \\
\text { (moisture and } \\
\text { dry matter) }\end{array}$ & $\mathrm{kg} / \mathrm{hr}$ & 0 & 7,431 & 0 & 0 & 7,431 & 0 & 0 & 7,431 & 0 & 0 & 7,431 & 0 \\
\hline Moisture Flow & $\mathrm{kg} / \mathrm{hr}$ & 0 & 742 & 0 & 0 & 742 & 0 & 0 & 742 & 0 & 0 & 742 & 0 \\
\hline $\begin{array}{l}\text { Total Flow (dry } \\
\text { matter) }\end{array}$ & $\mathrm{kg} / \mathrm{hr}$ & 0 & 6,689 & 0 & 0 & 6,689 & 0 & 0 & 6,689 & 0 & 0 & 6,689 & 0 \\
\hline C6 & $\mathrm{kg} / \mathrm{hr}$ & 0 & 1,321 & 0 & 0 & 1,321 & 0 & 0 & 1,321 & 0 & 0 & 1,321 & 0 \\
\hline C5 & $\mathrm{kg} / \mathrm{hr}$ & 0 & 572 & 0 & 0 & 572 & 0 & 0 & 572 & 0 & 0 & 572 & 0 \\
\hline LIGNIN & $\mathrm{kg} / \mathrm{hr}$ & 0 & 1,125 & 0 & 0 & 1,125 & 0 & 0 & 1,125 & 0 & 0 & 1,125 & 0 \\
\hline ASH & $\mathrm{kg} / \mathrm{hr}$ & 0 & 858 & 0 & 0 & 858 & 0 & 0 & 858 & 0 & 0 & 858 & 0 \\
\hline PROTEIN & $\mathrm{kg} / \mathrm{hr}$ & 0 & 688 & 0 & 0 & 688 & 0 & 0 & 688 & 0 & 0 & 688 & 0 \\
\hline $\begin{array}{l}\text { EXTRACTIVE } \\
\text { S }\end{array}$ & $\mathrm{kg} / \mathrm{hr}$ & 0 & 1,414 & 0 & 0 & 1,414 & 0 & 0 & 1,414 & 0 & 0 & 1,414 & 0 \\
\hline OTHERS & $\mathrm{kg} / \mathrm{hr}$ & 0 & 713 & 0 & 0 & 713 & 0 & 0 & 713 & 0 & 0 & 713 & 0 \\
\hline Temperature & K & 298 & 298 & 298 & 298 & 298 & 298 & 298 & 298 & 298 & 298 & 298 & 298 \\
\hline Pressure & atm & 1 & 1 & 1 & 1 & 1 & 1 & 1 & 1 & 1 & 1 & 1 & 1 \\
\hline Vapor Frac & & 0 & 0 & 0 & 0 & 0 & 0 & 0 & 0 & 0 & 0 & 0 & 0 \\
\hline
\end{tabular}


Table F-7. (continued)

\begin{tabular}{|c|c|c|c|c|c|c|c|c|c|c|c|c|}
\hline Component & unit & MC-17 & BMOUT17 & DML-18 & MC-18 & BMOUT18 & DML-19 & MC-19 & BMOUT19 & DML-20 & MC-20 & BMOUT20 \\
\hline $\begin{array}{l}\text { Overall Flow } \\
\text { (moisture and } \\
\text { dry matter) }\end{array}$ & $\mathrm{kg} / \mathrm{hr}$ & 0 & 7,431 & 0 & 0 & 7,431 & 0 & 0 & 7,431 & 0 & 0 & 7,431 \\
\hline Moisture Flow & $\mathrm{kg} / \mathrm{hr}$ & 0 & 742 & 0 & 0 & 742 & 0 & 0 & 742 & 0 & 0 & 742 \\
\hline $\begin{array}{l}\text { Total Flow (dry } \\
\text { matter) }\end{array}$ & $\mathrm{kg} / \mathrm{hr}$ & 0 & 6,689 & 0 & 0 & 6,689 & 0 & 0 & 6,689 & 0 & 0 & 6,689 \\
\hline C6 & $\mathrm{kg} / \mathrm{hr}$ & 0 & 1,321 & 0 & 0 & 1,321 & 0 & 0 & 1,321 & 0 & 0 & 1,321 \\
\hline $\mathrm{C} 5$ & $\mathrm{~kg} / \mathrm{hr}$ & 0 & 572 & 0 & 0 & 572 & 0 & 0 & 572 & 0 & 0 & 572 \\
\hline LIGNIN & $\mathrm{kg} / \mathrm{hr}$ & 0 & 1,125 & 0 & 0 & 1,125 & 0 & 0 & 1,125 & 0 & 0 & 1,125 \\
\hline ASH & $\mathrm{kg} / \mathrm{hr}$ & 0 & 858 & 0 & 0 & 858 & 0 & 0 & 858 & 0 & 0 & 858 \\
\hline PROTEIN & $\mathrm{kg} / \mathrm{hr}$ & 0 & 688 & 0 & 0 & 688 & 0 & 0 & 688 & 0 & 0 & 688 \\
\hline $\begin{array}{l}\text { EXTRACTIVE } \\
\mathrm{S} \\
\end{array}$ & $\mathrm{kg} / \mathrm{hr}$ & 0 & 1,414 & 0 & 0 & 1,414 & 0 & 0 & 1,414 & 0 & 0 & 1,414 \\
\hline OTHERS & $\mathrm{kg} / \mathrm{hr}$ & 0 & 713 & 0 & 0 & 713 & 0 & 0 & 713 & 0 & 0 & 713 \\
\hline Temperature & $\mathrm{K}$ & 298 & 298 & 298 & 298 & 298 & 298 & 298 & 298 & 298 & 298 & 298 \\
\hline Pressure & $\mathrm{atm}$ & 1 & 1 & 1 & 1 & 1 & 1 & 1 & 1 & 1 & 1 & 1 \\
\hline Vapor Frac & & 0 & 0 & 0 & 0 & 0 & 0 & 0 & 0 & 0 & 0 & 0 \\
\hline
\end{tabular}




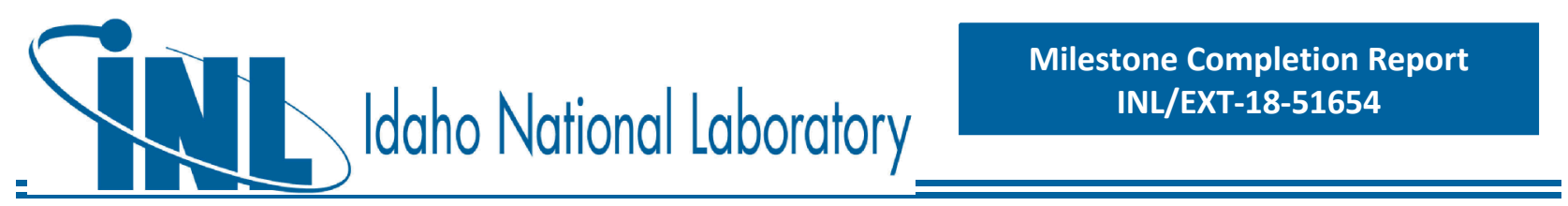

\section{APPENDIX G - Process Flow Diagrams and Mass Balances for the Exclusion of Grass Clippings from the Distributed Depot Case}

\section{G.1 Three-pass Corn Stover Blendstock}

High-level stream table information from Aspen Plus modeling output follows, for key streams associated with each process operation area. This is followed by high-level PFDs for the associated process areas. Space for stream tables was limited; below is a key to lumped components. As the stream table information focuses primarily on the high-level overall process and does not include every individual modeled stream within each process area, mass balance closure around a given unit area may not be $100 \%$.

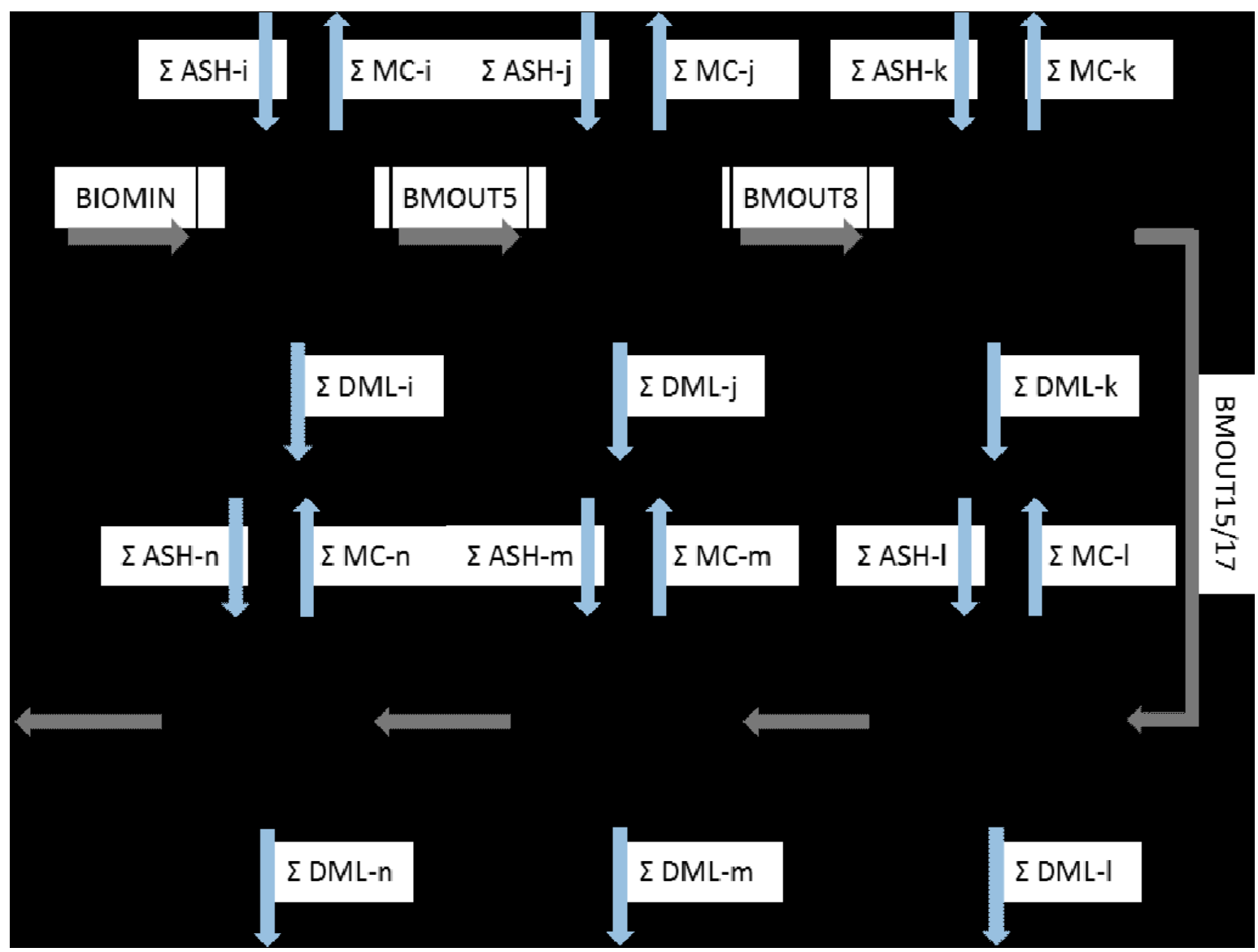

Figure G-1. High-level flowsheet showing key process areas for the three-pass corn stover blendstock in the Exclusion of Grass Clippings from the Distributed Depot Case. 


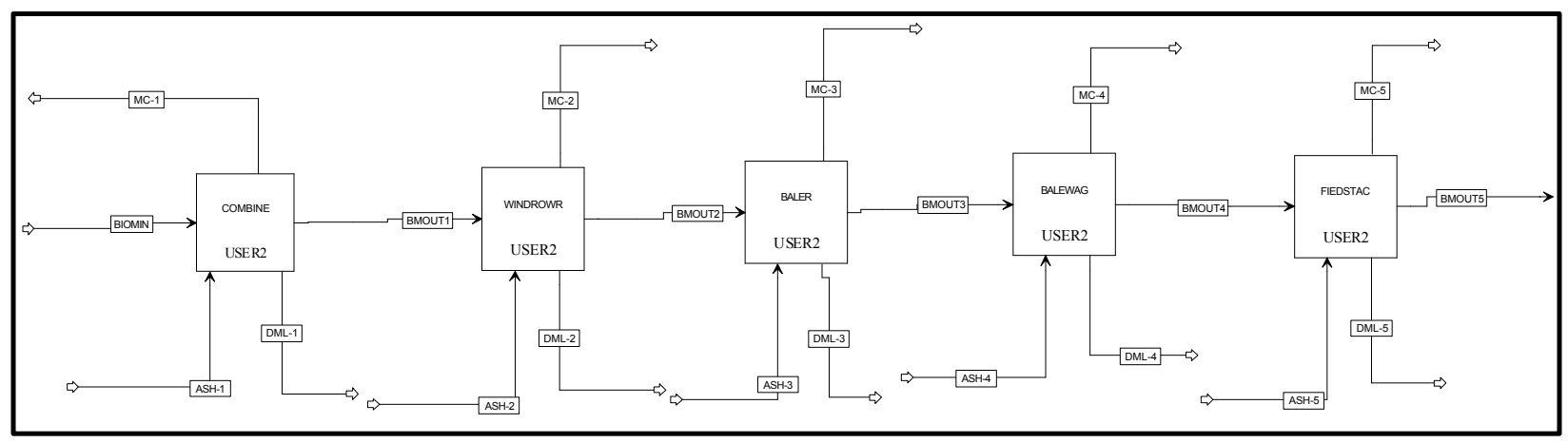

Figure G-2. Detailed process flow diagram for area A100 - Harvesting to Storage.

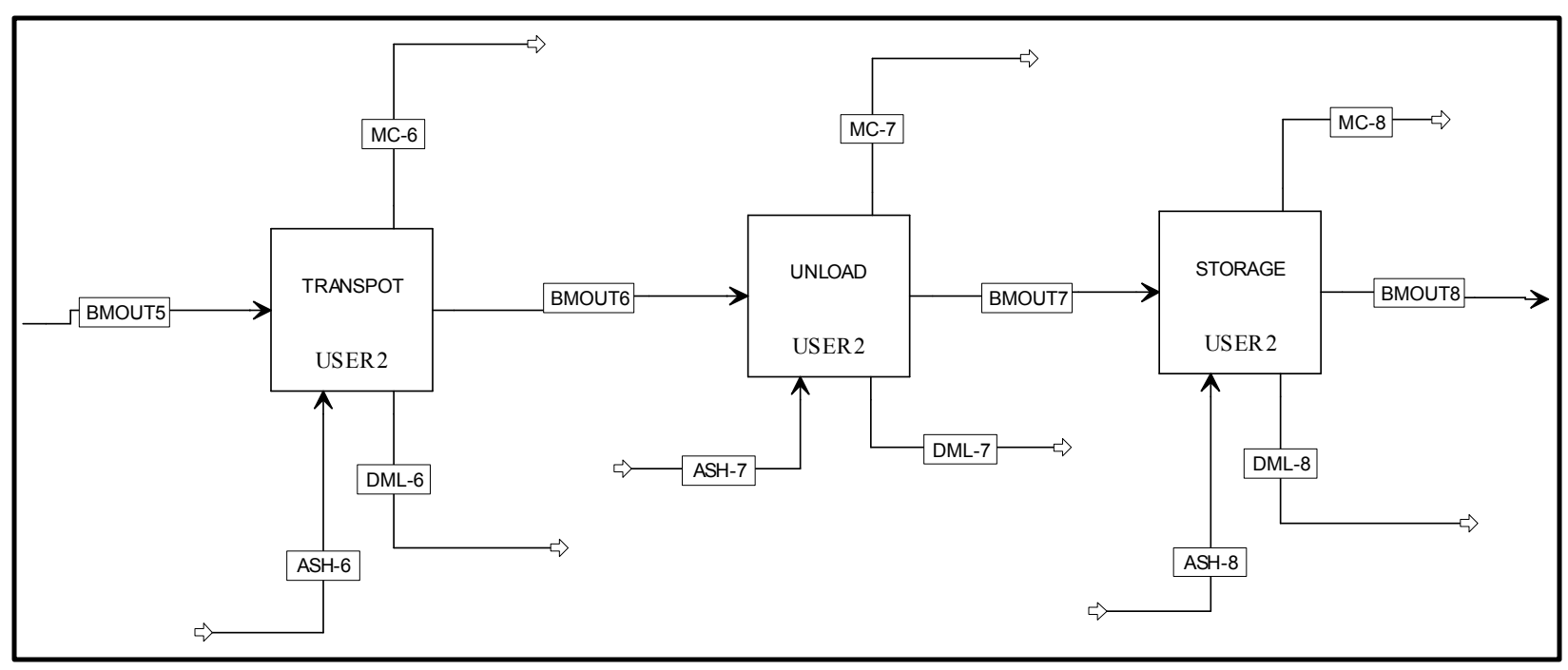

Figure G-3. Detailed process flow diagram for area A200 - Transport to Depot \& Handling. 

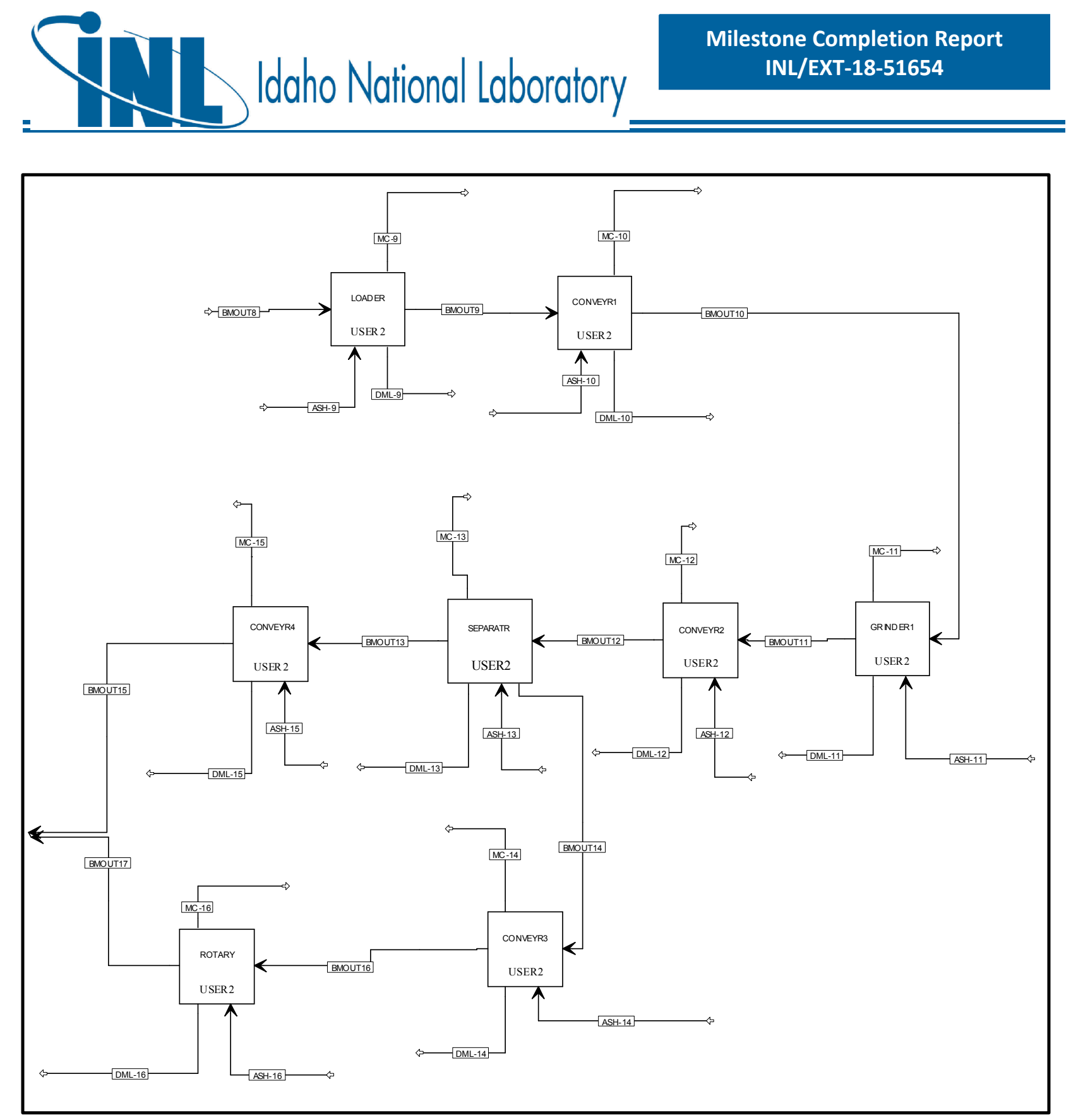

Figure G-4. Detailed process flow diagram for area A300 - Preprocessing - Size Reduction. 

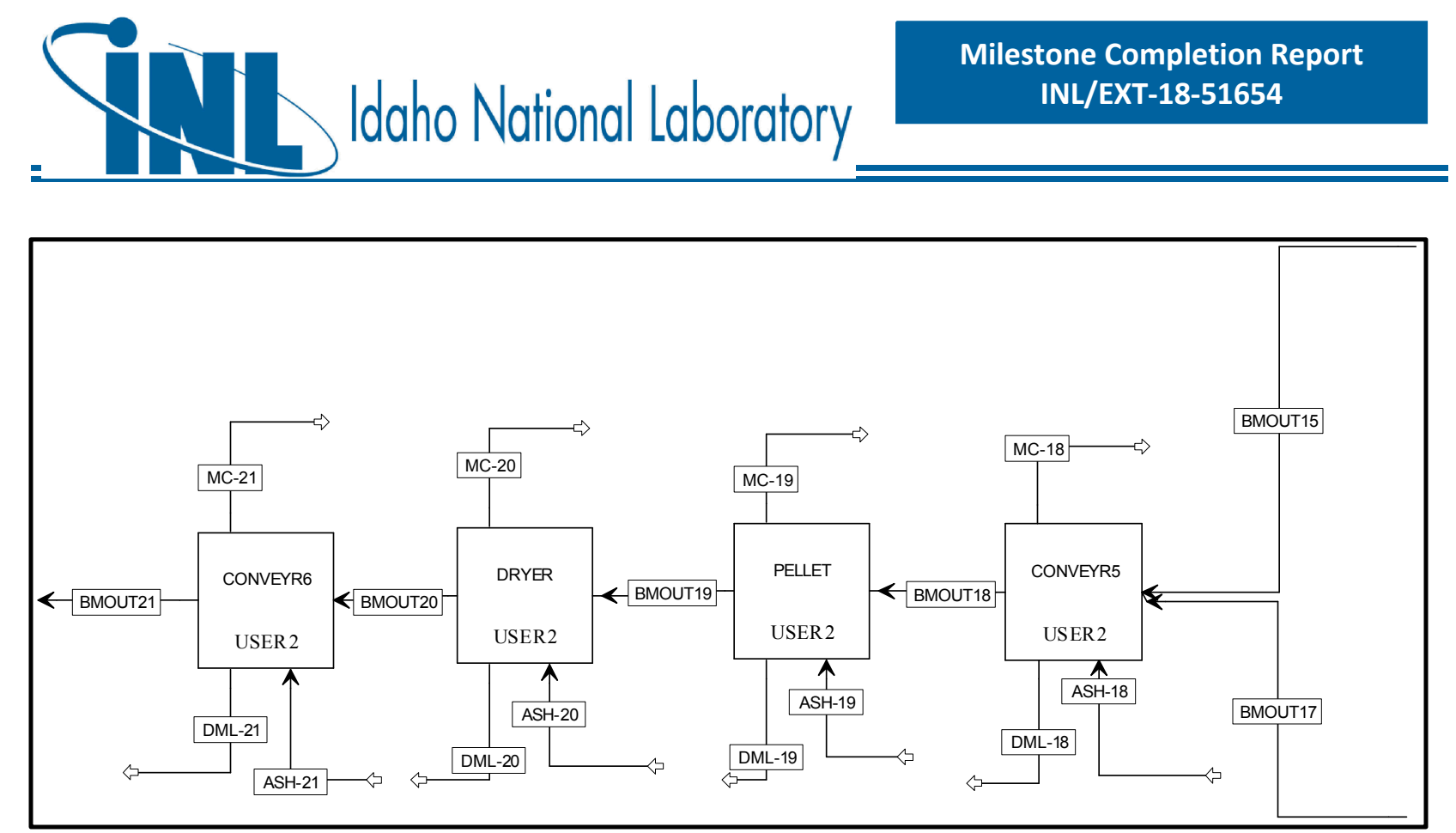

Figure G-5. Detailed process flow diagram for area A400 - Preprocessing - Pelleting.

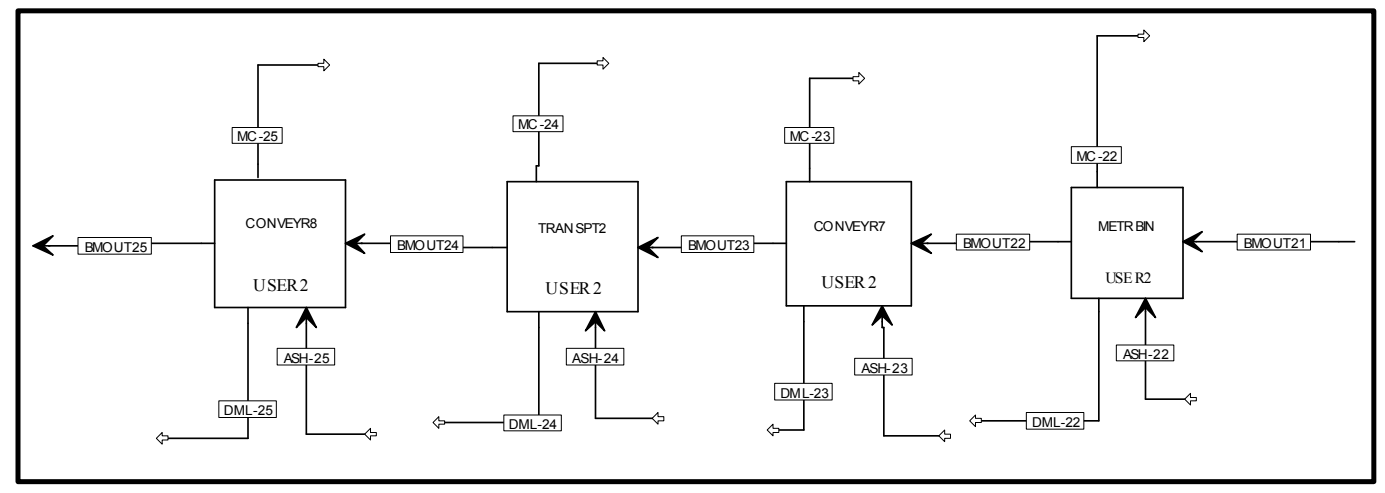

Figure G-6. Detailed process flow diagram for area A500 - Transport to Biorefinery. 

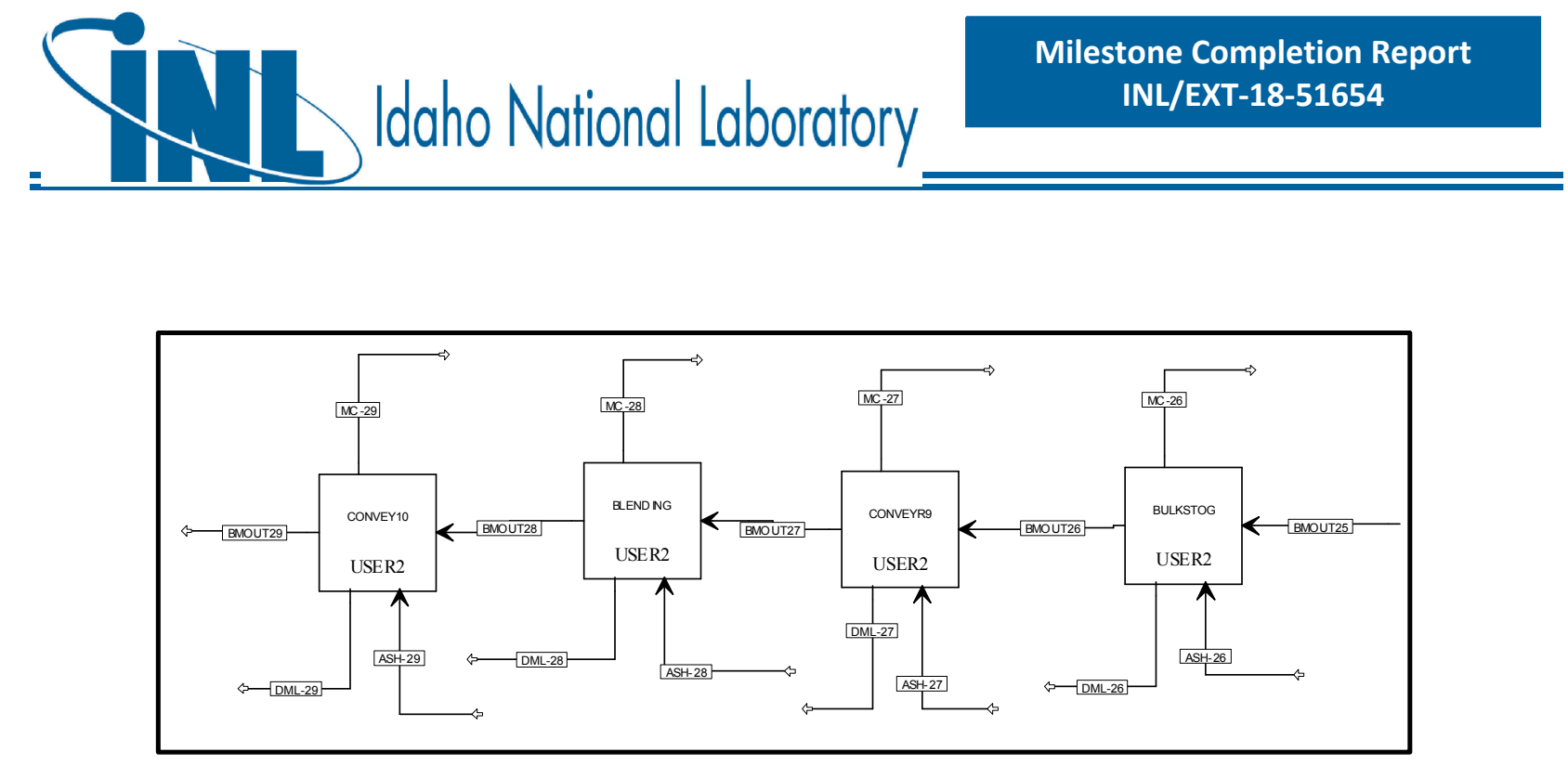

Figure G-7. Detailed process flow diagram for area A600 - Feeding. 
Table G-1. Aspen Plus mass balances from harvest to field-side storage (Area A100) for the three-pass corn stover blendstock in the Exclusion of Grass Clippings from the Distributed Depot Case. Harvest is assumed to take place within a 6 week period, working 14 hours/day, 6 days per week.

\begin{tabular}{|c|c|c|c|c|c|c|c|c|c|c|c|c|c|c|c|}
\hline Component & unit & BIOMIN & $\begin{array}{c}\text { DML- } \\
1\end{array}$ & MC-1 & BMOUT1 & $\begin{array}{l}\text { DML- } \\
2\end{array}$ & $\begin{array}{c}\text { MC- } \\
2\end{array}$ & BMOUT2 & $\begin{array}{l}\text { DML- } \\
3\end{array}$ & $\begin{array}{c}\text { MC- } \\
3\end{array}$ & ASH-3 & BMOUT3 & DML-4 & MC-4 & BMOUT4 \\
\hline $\begin{array}{l}\begin{array}{l}\text { Overall Flow } \\
\text { (moisture and } \\
\text { dry matter) }\end{array} \\
\end{array}$ & $\mathrm{kg} / \mathrm{hr}$ & 720,439 & 0 & 13 & 720,425 & 0 & 0 & 720,425 & 0 & 0 & 30,611 & 720,425 & 0 & 0 & 720,425 \\
\hline Moisture Flow & $\mathrm{kg} / \mathrm{hr}$ & 216,141 & 0 & 13 & 216,128 & 0 & 0 & 216,128 & 0 & 0 & 0 & 216,128 & 0 & 0 & 216,128 \\
\hline $\begin{array}{l}\text { Total Flow (dry } \\
\text { matter) }\end{array}$ & $\mathrm{kg} / \mathrm{hr}$ & 504,298 & 0 & 0 & 504,298 & 0 & 0 & 504,298 & 0 & 0 & 30,611 & 504,298 & 0 & 0 & 504,298 \\
\hline C5 & $\mathrm{kg} / \mathrm{hr}$ & 103,341 & 0 & 0 & 103,341 & 0 & 0 & 103,341 & 0 & 0 & 0 & 103,341 & 0 & 0 & 103,341 \\
\hline LIGNIN & $\mathrm{kg} / \mathrm{hr}$ & 74,555 & 0 & 0 & 74,555 & 0 & 0 & 74,555 & 0 & 0 & 0 & 74,555 & 0 & 0 & 74,555 \\
\hline ASH & $\mathrm{kg} / \mathrm{hr}$ & 24,862 & 0 & 0 & 24,862 & 0 & 0 & 24,862 & 0 & 0 & 30,611 & 55,472 & 0 & 0 & 55,472 \\
\hline PROTEIN & $\mathrm{kg} / \mathrm{hr}$ & 14,625 & 0 & 0 & 14,625 & 0 & 0 & 14,625 & 0 & 0 & 0 & 14,625 & 0 & 0 & 14,625 \\
\hline EXTRACTIVES & $\mathrm{kg} / \mathrm{hr}$ & 69,366 & 0 & 0 & 69,366 & 0 & 0 & 69,366 & 0 & 0 & 0 & 69,366 & 0 & 0 & 69,366 \\
\hline OTHERS & $\mathrm{kg} / \mathrm{hr}$ & 8,094 & 0 & 0 & 8,094 & 0 & 0 & 8,094 & 0 & 0 & 0 & 8,094 & 0 & 0 & 8,094 \\
\hline Pressure & $\mathrm{atm}$ & 1 & 1 & 1 & 1 & 1 & 1 & 1 & 1 & 1 & 1 & 1 & 1 & 1 & 1 \\
\hline Vapor Frac & & 0 & 0 & 0 & 0 & 0 & 0 & 0 & 0 & 0 & 0 & 0 & 0 & 0 & 0 \\
\hline
\end{tabular}


Table G-2. Aspen Plus mass balances from field-side storage to feeding (Areas A200-A600) for the three-pass corn stover blendstock in the Exclusion of Grass Clippings from the Distributed Depot Case. Depot operation is assumed to take place within 350 day period, working 24 hours/day, 7 days per week.

\begin{tabular}{|c|c|c|c|c|c|c|c|c|c|c|c|c|c|}
\hline Component & unit & DML-5 & MC-5 & BMOUT5 & DML-6 & MC-6 & BMOUT6 & DML-7 & MC-7 & BMOUT7 & DML-8 & MC-8 & BMOUT8 \\
\hline $\begin{array}{l}\text { Overall Flow } \\
\text { (moisture and dry } \\
\text { matter) }\end{array}$ & $\mathrm{kg} / \mathrm{hr}$ & 3,631 & 4,084 & 35,510 & 0 & 0 & 35,510 & 0 & 0 & 35,510 & 0 & 0 & 35,510 \\
\hline Moisture Flow & $\mathrm{kg} / \mathrm{hr}$ & 0 & 4,084 & 8,883 & 0 & 0 & 8,883 & 0 & 0 & 8,883 & 0 & 0 & 8,883 \\
\hline $\begin{array}{l}\text { Total Flow (dry } \\
\text { matter) }\end{array}$ & $\mathrm{kg} / \mathrm{hr}$ & 3,631 & 0 & 26,627 & 0 & 0 & 26,627 & 0 & 0 & 26,627 & 0 & 0 & 26,627 \\
\hline C6 & $\mathrm{kg} / \mathrm{hr}$ & 671 & 0 & 10,060 & 0 & 0 & 10,060 & 0 & 0 & 10,060 & 0 & 0 & 10,060 \\
\hline C5 & $\mathrm{kg} / \mathrm{hr}$ & 1,050 & 0 & 5,150 & 0 & 0 & 5,150 & 0 & 0 & 5,150 & 0 & 0 & 5,150 \\
\hline LIGNIN & $\mathrm{kg} / \mathrm{hr}$ & 234 & 0 & 4,239 & 0 & 0 & 4,239 & 0 & 0 & 4,239 & 0 & 0 & 4,239 \\
\hline ASH & $\mathrm{kg} / \mathrm{hr}$ & 0 & 0 & 3,329 & 0 & 0 & 3,329 & 0 & 0 & 3,329 & 0 & 0 & 3,329 \\
\hline PROTEIN & $\mathrm{kg} / \mathrm{hr}$ & 109 & 0 & 769 & 0 & 0 & 769 & 0 & 0 & 769 & 0 & 0 & 769 \\
\hline EXTRACTIVES & $\mathrm{kg} / \mathrm{hr}$ & 1,089 & 0 & 3,073 & 0 & 0 & 3,073 & 0 & 0 & 3,073 & 0 & 0 & 3,073 \\
\hline OTHERS & $\mathrm{kg} / \mathrm{hr}$ & 479 & 0 & 7 & 0 & 0 & 7 & 0 & 0 & 7 & 0 & 0 & 7 \\
\hline Temperature & $\mathrm{K}$ & 298 & 298 & 298 & 298 & 298 & 298 & 298 & 298 & 298 & 298 & 298 & 298 \\
\hline Pressure & $\mathrm{atm}$ & 1 & 1 & 1 & 1 & 1 & 1 & 1 & 1 & 1 & 1 & 1 & 1 \\
\hline
\end{tabular}


Table G-2. (continued)

\begin{tabular}{|c|c|c|c|c|c|c|c|c|c|c|c|c|c|}
\hline Component & unit & DML-9 & MC-9 & BMOUT9 & DML-10 & MC-10 & BMOUT10 & DML-11 & MC-11 & BMOUT11 & $\begin{array}{l}\text { DML- } \\
12\end{array}$ & $\begin{array}{l}\text { MC- } \\
12\end{array}$ & BMOUT12 \\
\hline $\begin{array}{l}\text { Overall Flow } \\
\text { (moisture and dry } \\
\text { matter) }\end{array}$ & $\mathrm{kg} / \mathrm{hr}$ & 0 & 0 & 35,510 & 0 & 0 & 35,510 & 266 & 2,192 & 33,051 & 0 & 0 & 33,051 \\
\hline Moisture Flow & $\mathrm{kg} / \mathrm{hr}$ & 0 & 0 & 8,883 & 0 & 0 & 8,883 & 0 & 2,192 & 6,691 & 0 & 0 & 6,691 \\
\hline $\begin{array}{l}\text { Total Flow (dry } \\
\text { matter) }\end{array}$ & $\mathrm{kg} / \mathrm{hr}$ & 0 & 0 & 26,627 & 0 & 0 & 26,627 & 266 & 0 & 26,360 & 0 & 0 & 26,360 \\
\hline C6 & $\mathrm{kg} / \mathrm{hr}$ & 0 & 0 & 10,060 & 0 & 0 & 10,060 & 73 & 0 & 9,987 & 0 & 0 & 9,987 \\
\hline $\mathrm{C} 5$ & $\mathrm{~kg} / \mathrm{hr}$ & 0 & 0 & 5,150 & 0 & 0 & 5,150 & 42 & 0 & 5,109 & 0 & 0 & 5,109 \\
\hline LIGNIN & $\mathrm{kg} / \mathrm{hr}$ & 0 & 0 & 4,239 & 0 & 0 & 4,239 & 52 & 0 & 4,188 & 0 & 0 & 4,188 \\
\hline ASH & $\mathrm{kg} / \mathrm{hr}$ & 0 & 0 & 3,329 & 0 & 0 & 3,329 & 66 & 0 & 3,262 & 0 & 0 & 3,262 \\
\hline PROTEIN & $\mathrm{kg} / \mathrm{hr}$ & 0 & 0 & 769 & 0 & 0 & 769 & 0 & 0 & 769 & 0 & 0 & 769 \\
\hline EXTRACTIVES & $\mathrm{kg} / \mathrm{hr}$ & 0 & 0 & 3,073 & 0 & 0 & 3,073 & 33 & 0 & 3,040 & 0 & 0 & 3,040 \\
\hline OTHERS & $\mathrm{kg} / \mathrm{hr}$ & 0 & 0 & 7 & 0 & 0 & 7 & 0 & 0 & 7 & 0 & 0 & 7 \\
\hline Temperature & $\mathrm{K}$ & 298 & 298 & 298 & 298 & 298 & 298 & 298 & 298 & 298 & 298 & 298 & 298 \\
\hline Pressure & $\mathrm{atm}$ & 1 & 1 & 1 & 1 & 1 & 1 & 1 & 1 & 1 & 1 & 1 & 1 \\
\hline Vapor Frac & & 0 & 0 & 0 & 0 & 0 & 0 & 0 & 0 & 0 & 0 & 0 & 0 \\
\hline
\end{tabular}


- lacho National Laboratory

Table G-2. (continued)

\begin{tabular}{|c|c|c|c|c|c|c|c|c|c|c|c|c|c|}
\hline Component & unit & $\begin{array}{c}\text { DML- } \\
13\end{array}$ & MC-13 & BMOUT13 & BMOUT14 & DML-14 & MC-14 & DML-15 & $\begin{array}{l}\text { MC- } \\
15\end{array}$ & BMOUT15 & $\begin{array}{c}\text { DML- } \\
16\end{array}$ & $\begin{array}{c}\text { MC- } \\
16\end{array}$ & BMOUT16 \\
\hline $\begin{array}{l}\text { Overall Flow } \\
\text { (moisture and dry } \\
\text { matter) }\end{array}$ & $\mathrm{kg} / \mathrm{hr}$ & 809 & 0 & 14,312 & 0 & 0 & 17,930 & 0 & 0 & 14,312 & 147 & 33 & 17,930 \\
\hline Moisture Flow & $\mathrm{kg} / \mathrm{hr}$ & 809 & 0 & 2,611 & 0 & 0 & 3,271 & 0 & 0 & 2,611 & 0 & 33 & 3,271 \\
\hline $\begin{array}{l}\text { Total Flow (dry } \\
\text { matter) }\end{array}$ & $\mathrm{kg} / \mathrm{hr}$ & 0 & 0 & 11,702 & 0 & 0 & 14,659 & 0 & 0 & 11,702 & 147 & 0 & 14,659 \\
\hline C6 & $\mathrm{kg} / \mathrm{hr}$ & 0 & 0 & 4,433 & 0 & 0 & 5,554 & 0 & 0 & 4,433 & 41 & 0 & 5,554 \\
\hline C5 & $\mathrm{kg} / \mathrm{hr}$ & 0 & 0 & 2,267 & 0 & 0 & 2,841 & 0 & 0 & 2,267 & 23 & 0 & 2,841 \\
\hline LIGNIN & $\mathrm{kg} / \mathrm{hr}$ & 0 & 0 & 1,859 & 0 & 0 & 2,329 & 0 & 0 & 1,859 & 28 & 0 & 2,329 \\
\hline ASH & $\mathrm{kg} / \mathrm{hr}$ & 0 & 0 & 1,448 & 0 & 0 & 1,814 & 0 & 0 & 1,448 & 36 & 0 & 1,814 \\
\hline PROTEIN & $\mathrm{kg} / \mathrm{hr}$ & 0 & 0 & 341 & 0 & 0 & 428 & 0 & 0 & 341 & 0 & 0 & 428 \\
\hline EXTRACTIVES & $\mathrm{kg} / \mathrm{hr}$ & 0 & 0 & 1,349 & 0 & 0 & 1,691 & 0 & 0 & 1,349 & 18 & 0 & 1,691 \\
\hline OTHERS & $\mathrm{kg} / \mathrm{hr}$ & 0 & 0 & 3 & 0 & 0 & 4 & 0 & 0 & 3 & 0 & 0 & 4 \\
\hline Temperature & K & 298 & 298 & 298 & 298 & 298 & 298 & 298 & 298 & 298 & 298 & 298 & 298 \\
\hline Pressure & atm & 1 & 1 & 1 & 1 & 1 & 1 & 1 & 1 & 1 & 1 & 1 & 1 \\
\hline Vapor Frac & & 0 & 0 & 0 & 0 & 0 & 0 & 0 & 0 & 0 & 0 & 0 & 0 \\
\hline
\end{tabular}

176 


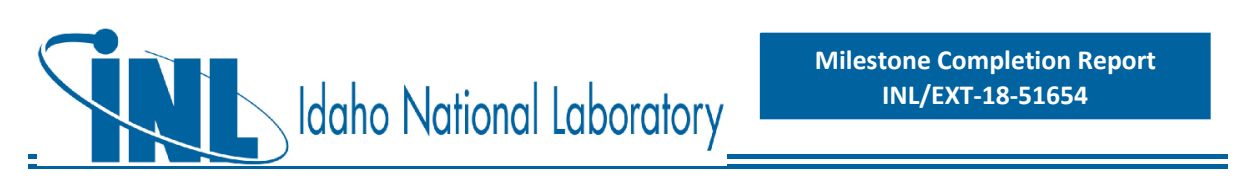

Table G-2. (continued)

\begin{tabular}{|c|c|c|c|c|c|c|c|c|c|c|c|}
\hline Component & unit & BMOUT17 & DML-18 & MC-18 & BMOUT18 & DML-19 & MC-19 & BMOUT19 & DML-20 & $\begin{array}{c}\text { MC- } \\
20\end{array}$ & BMOUT20 \\
\hline $\begin{array}{l}\text { Overall Flow } \\
\text { (moisture and dry } \\
\text { matter) }\end{array}$ & $\mathrm{kg} / \mathrm{hr}$ & 17,751 & 0 & 0 & 32,063 & 0 & 1,849 & 30,214 & 0 & 581 & 29,633 \\
\hline Moisture Flow & $\mathrm{kg} / \mathrm{hr}$ & 3,238 & 0 & 0 & 5,849 & 0 & 1,849 & 4,000 & 0 & 581 & 3,419 \\
\hline $\begin{array}{l}\text { Total Flow (dry } \\
\text { matter) }\end{array}$ & $\mathrm{kg} / \mathrm{hr}$ & 14,513 & 0 & 0 & 26,214 & 0 & 0 & 26,214 & 0 & 0 & 26,214 \\
\hline C6 & $\mathrm{kg} / \mathrm{hr}$ & 5,513 & 0 & 0 & 9,946 & 0 & 0 & 9,946 & 0 & 0 & 9,946 \\
\hline $\mathrm{C} 5$ & $\mathrm{~kg} / \mathrm{hr}$ & 2,818 & 0 & 0 & 5,086 & 0 & 0 & 5,086 & 0 & 0 & 5,086 \\
\hline LIGNIN & $\mathrm{kg} / \mathrm{hr}$ & 2,300 & 0 & 0 & 4,159 & 0 & 0 & 4,159 & 0 & 0 & 4,159 \\
\hline ASH & $\mathrm{kg} / \mathrm{hr}$ & 1,777 & 0 & 0 & 3,225 & 0 & 0 & 3,225 & 0 & 0 & 3,225 \\
\hline PROTEIN & $\mathrm{kg} / \mathrm{hr}$ & 428 & 0 & 0 & 769 & 0 & 0 & 769 & 0 & 0 & 769 \\
\hline EXTRACTIVES & $\mathrm{kg} / \mathrm{hr}$ & 1,673 & 0 & 0 & 3,022 & 0 & 0 & 3,022 & 0 & 0 & 3,022 \\
\hline OTHERS & $\mathrm{kg} / \mathrm{hr}$ & 4 & 0 & 0 & 7 & 0 & 0 & 7 & 0 & 0 & 7 \\
\hline Temperature & $\mathrm{K}$ & 298 & 298 & 298 & 298 & 298 & 298 & 298 & 298 & 298 & 298 \\
\hline Pressure & atm & 1 & 1 & 1 & 1 & 1 & 1 & 1 & 1 & 1 & 1 \\
\hline Vapor Frac & & 0 & 0 & 0 & 0 & 0 & 0 & 0 & 0 & 0 & 0 \\
\hline
\end{tabular}


lacho National Laboratory

Table G-2. (continued)

\begin{tabular}{|c|c|c|c|c|c|c|c|c|c|c|c|}
\hline Component & unit & $\begin{array}{l}\text { DML- } \\
21\end{array}$ & MC-21 & BMOUT21 & DML-22 & MC-22 & BMOUT22 & DML-23 & MC-23 & BMOUT23 & $\begin{array}{c}\text { DML- } \\
24\end{array}$ \\
\hline $\begin{array}{l}\text { Overall Flow } \\
\text { (moisture and dry } \\
\text { matter) }\end{array}$ & $\mathrm{kg} / \mathrm{hr}$ & 0 & 581 & 29,633 & 0 & 581 & 29,633 & 0 & 581 & 29,633 & 0 \\
\hline Moisture Flow & $\mathrm{kg} / \mathrm{hr}$ & 0 & 581 & 3,419 & 0 & 581 & 3,419 & 0 & 581 & 3,419 & 0 \\
\hline $\begin{array}{l}\text { Total Flow (dry } \\
\text { matter) }\end{array}$ & $\mathrm{kg} / \mathrm{hr}$ & 0 & 0 & 26,214 & 0 & 0 & 26,214 & 0 & 0 & 26,214 & 0 \\
\hline C6 & $\mathrm{kg} / \mathrm{hr}$ & 0 & 0 & 9,946 & 0 & 0 & 9,946 & 0 & 0 & 9,946 & 0 \\
\hline C5 & $\mathrm{kg} / \mathrm{hr}$ & 0 & 0 & 5,086 & 0 & 0 & 5,086 & 0 & 0 & 5,086 & 0 \\
\hline LIGNIN & $\mathrm{kg} / \mathrm{hr}$ & 0 & 0 & 4,159 & 0 & 0 & 4,159 & 0 & 0 & 4,159 & 0 \\
\hline ASH & $\mathrm{kg} / \mathrm{hr}$ & 0 & 0 & 3,225 & 0 & 0 & 3,225 & 0 & 0 & 3,225 & 0 \\
\hline PROTEIN & $\mathrm{kg} / \mathrm{hr}$ & 0 & 0 & 769 & 0 & 0 & 769 & 0 & 0 & 769 & 0 \\
\hline EXTRACTIVES & $\mathrm{kg} / \mathrm{hr}$ & 0 & 0 & 3,022 & 0 & 0 & 3,022 & 0 & 0 & 3,022 & 0 \\
\hline OTHERS & $\mathrm{kg} / \mathrm{hr}$ & 0 & 0 & 7 & 0 & 0 & 7 & 0 & 0 & 7 & 0 \\
\hline Temperature & K & 298 & 298 & 298 & 298 & 298 & 298 & 298 & 298 & 298 & 298 \\
\hline Pressure & atm & 1 & 1 & 1 & 1 & 1 & 1 & 1 & 1 & 1 & 1 \\
\hline Vapor Frac & & 0 & 0 & 0 & 0 & 0 & 0 & 0 & 0 & 0 & 0 \\
\hline
\end{tabular}


Table G-2. (continued)

\begin{tabular}{|c|c|c|c|c|c|c|c|c|c|c|c|c|}
\hline Component & unit & $\begin{array}{l}\text { MC- } \\
24\end{array}$ & BMOUT24 & DML-25 & MC-25 & BMOUT25 & DML-26 & MC-26 & BMOUT26 & $\begin{array}{c}\text { DML- } \\
27\end{array}$ & $\begin{array}{l}\text { MC- } \\
27\end{array}$ & BMOUT27 \\
\hline $\begin{array}{l}\text { Overall Flow } \\
\text { (moisture and dry } \\
\text { matter) }\end{array}$ & $\mathrm{kg} / \mathrm{hr}$ & 581 & 29,633 & 0 & 581 & 29,633 & 0 & 581 & 29,633 & 0 & 581 & 29,633 \\
\hline Moisture Flow & $\mathrm{kg} / \mathrm{hr}$ & 581 & 3,419 & 0 & 581 & 3,419 & 0 & 581 & 3,419 & 0 & 581 & 3,419 \\
\hline $\begin{array}{l}\text { Total Flow (dry } \\
\text { matter) }\end{array}$ & $\mathrm{kg} / \mathrm{hr}$ & 0 & 26,214 & 0 & 0 & 26,214 & 0 & 0 & 26,214 & 0 & 0 & 26,214 \\
\hline C6 & $\mathrm{kg} / \mathrm{hr}$ & 0 & 9,946 & 0 & 0 & 9,946 & 0 & 0 & 9,946 & 0 & 0 & 9,946 \\
\hline $\mathrm{C} 5$ & $\mathrm{~kg} / \mathrm{hr}$ & 0 & 5,086 & 0 & 0 & 5,086 & 0 & 0 & 5,086 & 0 & 0 & 5,086 \\
\hline LIGNIN & $\mathrm{kg} / \mathrm{hr}$ & 0 & 4,159 & 0 & 0 & 4,159 & 0 & 0 & 4,159 & 0 & 0 & 4,159 \\
\hline ASH & $\mathrm{kg} / \mathrm{hr}$ & 0 & 3,225 & 0 & 0 & 3,225 & 0 & 0 & 3,225 & 0 & 0 & 3,225 \\
\hline PROTEIN & $\mathrm{kg} / \mathrm{hr}$ & 0 & 769 & 0 & 0 & 769 & 0 & 0 & 769 & 0 & 0 & 769 \\
\hline EXTRACTIVES & $\mathrm{kg} / \mathrm{hr}$ & 0 & 3,022 & 0 & 0 & 3,022 & 0 & 0 & 3,022 & 0 & 0 & 3,022 \\
\hline OTHERS & $\mathrm{kg} / \mathrm{hr}$ & 0 & 7 & 0 & 0 & 7 & 0 & 0 & 7 & 0 & 0 & 7 \\
\hline Temperature & $\mathrm{K}$ & 298 & 298 & 298 & 298 & 298 & 298 & 298 & 298 & 298 & 298 & 298 \\
\hline Pressure & $\mathrm{atm}$ & 1 & 1 & 1 & 1 & 1 & 1 & 1 & 1 & 1 & 1 & 1 \\
\hline Vapor Frac & & 0 & 0 & 0 & 0 & 0 & 0 & 0 & 0 & 0 & 0 & 0 \\
\hline
\end{tabular}


Table G-2. (continued)

\begin{tabular}{lcrrrrrrr}
\hline \multicolumn{1}{c}{ Component } & unit & $\begin{array}{c}\text { DML- } \\
\mathbf{2 8}\end{array}$ & MC-28 & BMOUT28 & DML-29 & MC-29 & BMOUT29 \\
\hline $\begin{array}{l}\text { Overall Flow } \\
\text { (moisture and dry } \\
\text { matter) }\end{array}$ & $\mathrm{kg} / \mathrm{hr}$ & 0 & 581 & 29,633 & 0 & 581 & 29,633 \\
\hline Moisture Flow & $\mathrm{kg} / \mathrm{hr}$ & 0 & 581 & 3,419 & 0 & 581 & 3,419 \\
\hline $\begin{array}{l}\text { Total Flow (dry } \\
\text { matter) }\end{array}$ & $\mathrm{kg} / \mathrm{hr}$ & 0 & 0 & 26,214 & 0 & 0 & 26,214 \\
\hline C6 & $\mathrm{kg} / \mathrm{hr}$ & 0 & 0 & 9,946 & 0 & 0 & 9,946 \\
\hline C5 & $\mathrm{kg} / \mathrm{hr}$ & 0 & 0 & 5,086 & 0 & 0 & 5,086 \\
\hline LIGNIN & $\mathrm{kg} / \mathrm{hr}$ & 0 & 0 & 4,159 & 0 & 0 & 4,159 \\
\hline ASH & $\mathrm{kg} / \mathrm{hr}$ & 0 & 0 & 3,225 & 0 & 0 & 3,225 \\
\hline PROTEIN & $\mathrm{kg} / \mathrm{hr}$ & 0 & 0 & 769 & 0 & 0 & 769 \\
\hline EXTRACTIVES & $\mathrm{kg} / \mathrm{hr}$ & 0 & 0 & 3,022 & 0 & 0 & 3,022 \\
\hline OTHERS & $\mathrm{kg} / \mathrm{hr}$ & 0 & 0 & 7 & 0 & 0 & 7 \\
\hline Temperature & $\mathrm{K}$ & 298 & 298 & 298 & 298 & 298 & 298 \\
\hline Pressure & $\mathrm{atm}$ & 1 & 1 & 1 & 1 & 1 & 1 \\
\hline Vapor Frac & & 0 & 0 & 0 & 0 & 0 & 0 \\
\hline
\end{tabular}




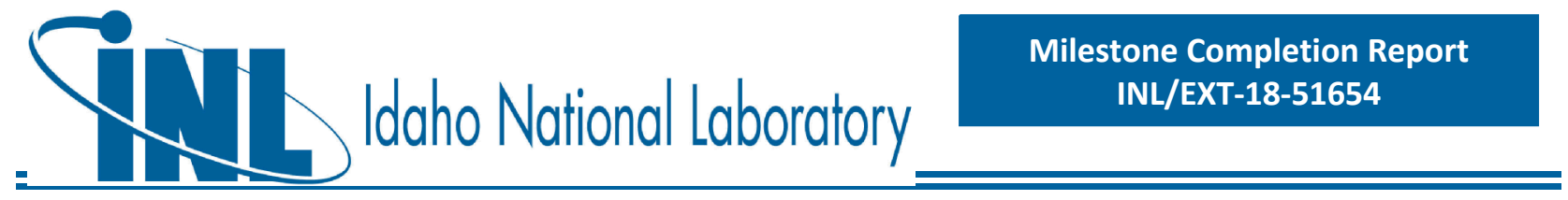

\section{G.2 Two-pass Corn Stover Blendstock}

High-level stream table information from Aspen Plus modeling output follows, for key streams associated with each process operation area. This is followed by high-level PFDs for the associated process areas. Space for stream tables was limited; below is a key to lumped components. As the stream table information focuses primarily on the high-level overall process and does not include every individual modeled stream within each process area, mass balance closure around a given unit area may not be $100 \%$.

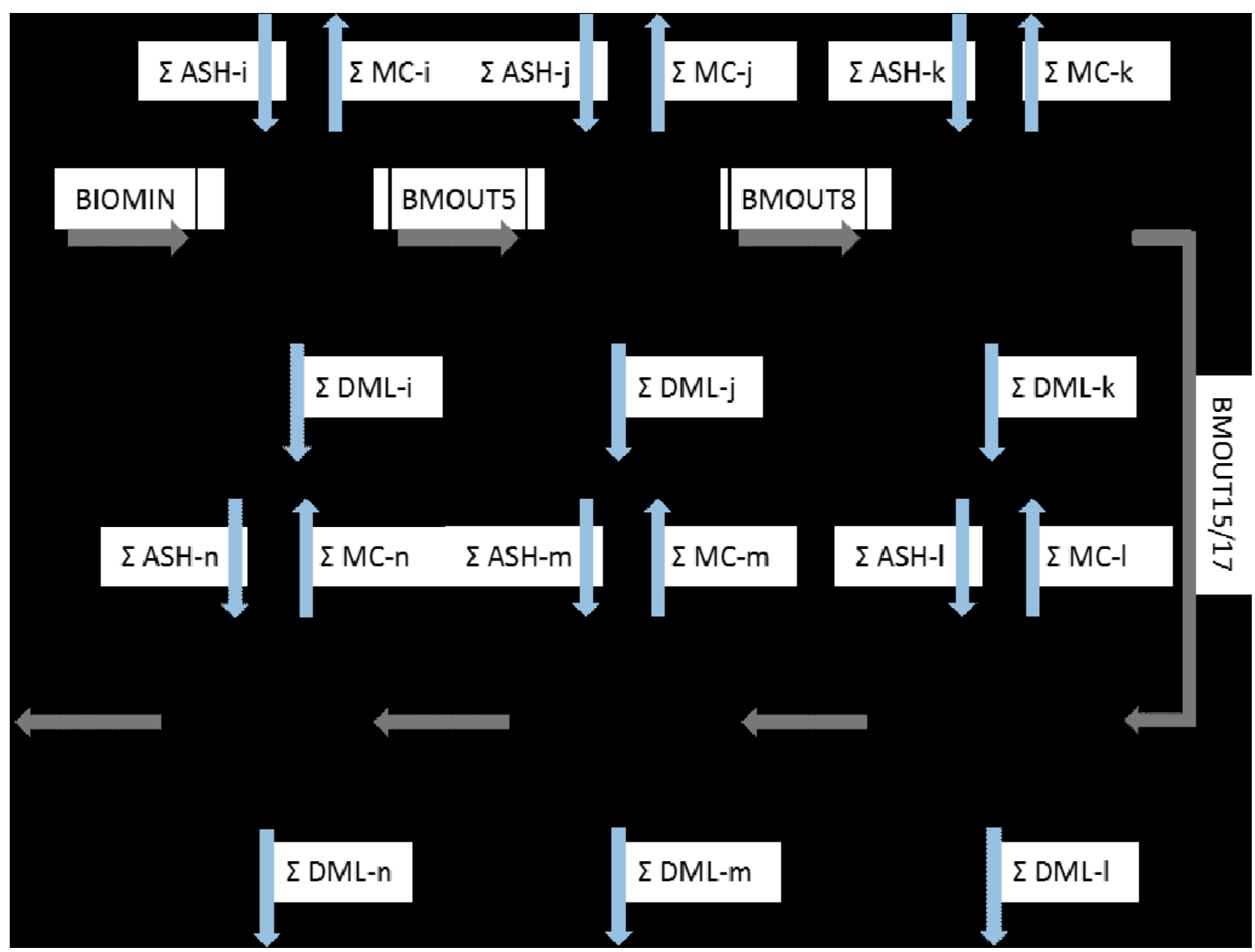

Figure G-8. High-level flowsheet showing key process areas for the two pass corn stover blendstock in the Exclusion of Grass Clippings from the Distributed Depot Case. 

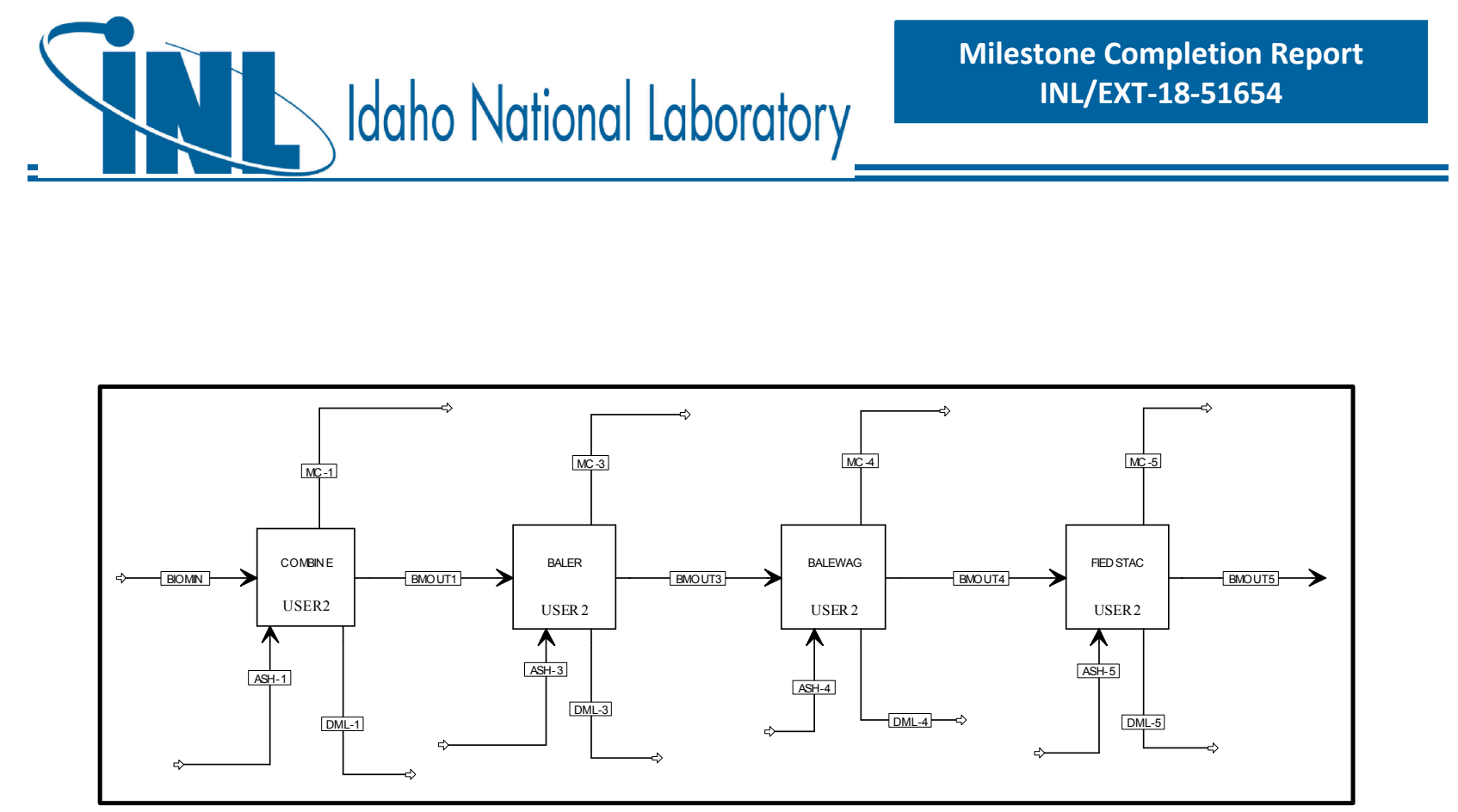

Figure G-9. Detailed process flow diagram for area B100 - Harvesting to Storage.

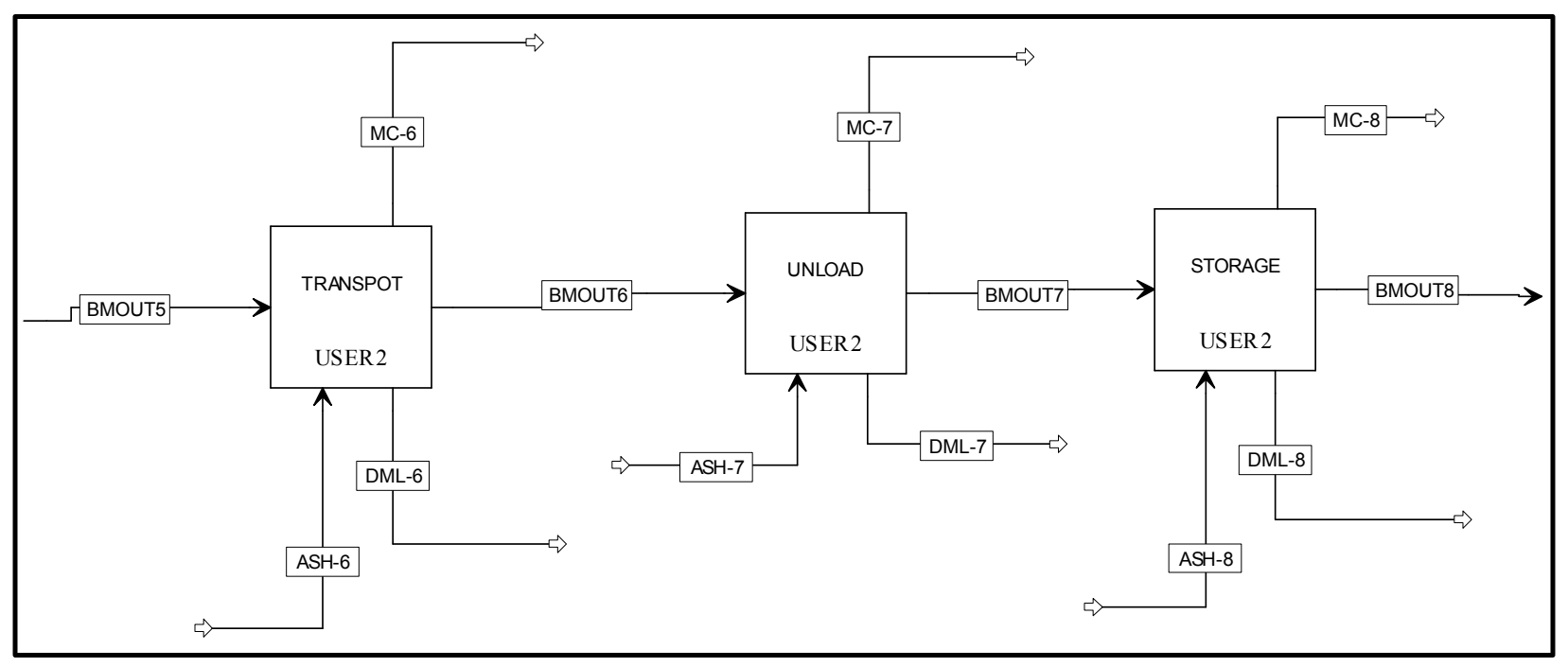

Figure G-10. Detailed process flow diagram for area B200 - Transport to Depot \& Handling. 


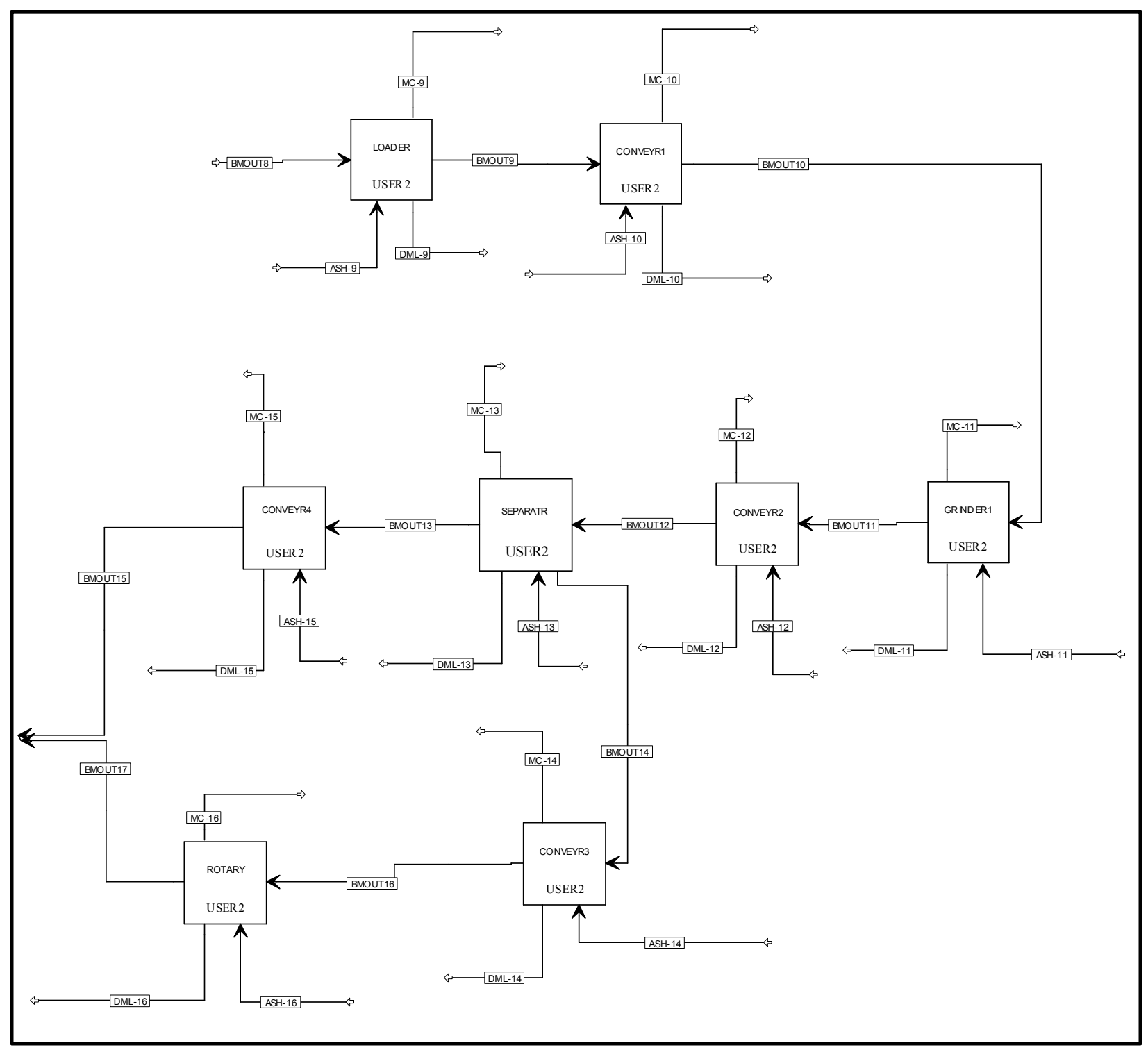

Figure G-11. Detailed process flow diagram for area B300 - Preprocessing - Size Reduction. 

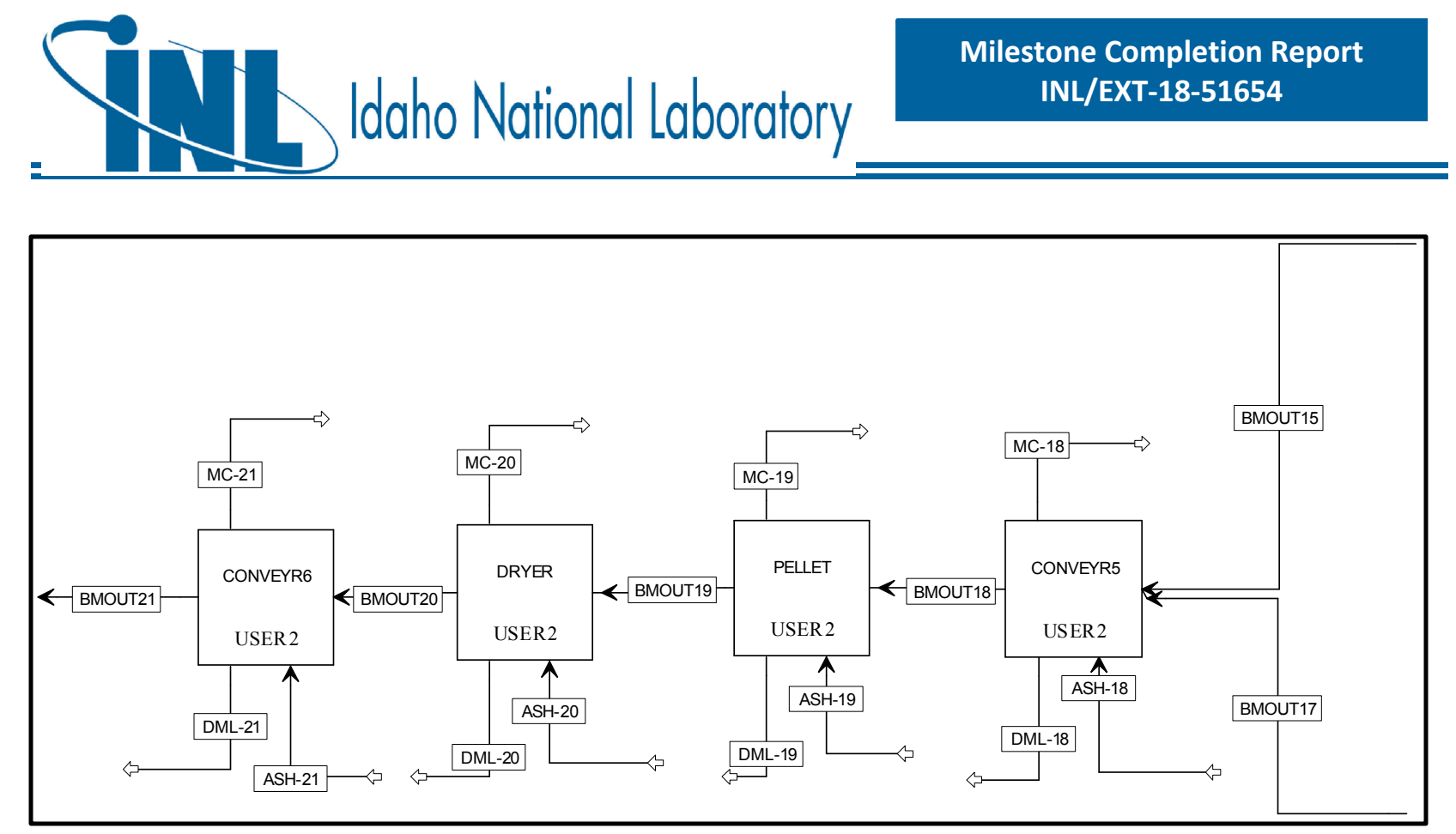

Figure G-12. Detailed process flow diagram for area B400 - Preprocessing - Pelleting.

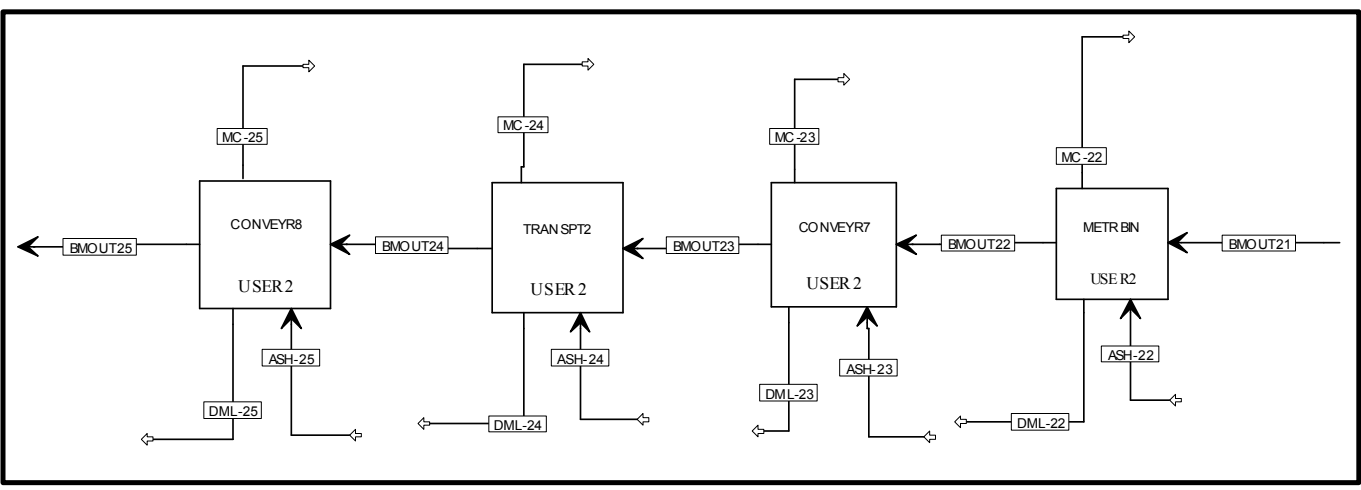

Figure G-13. Detailed process flow diagram for area B500 - Transport to Biorefinery. 

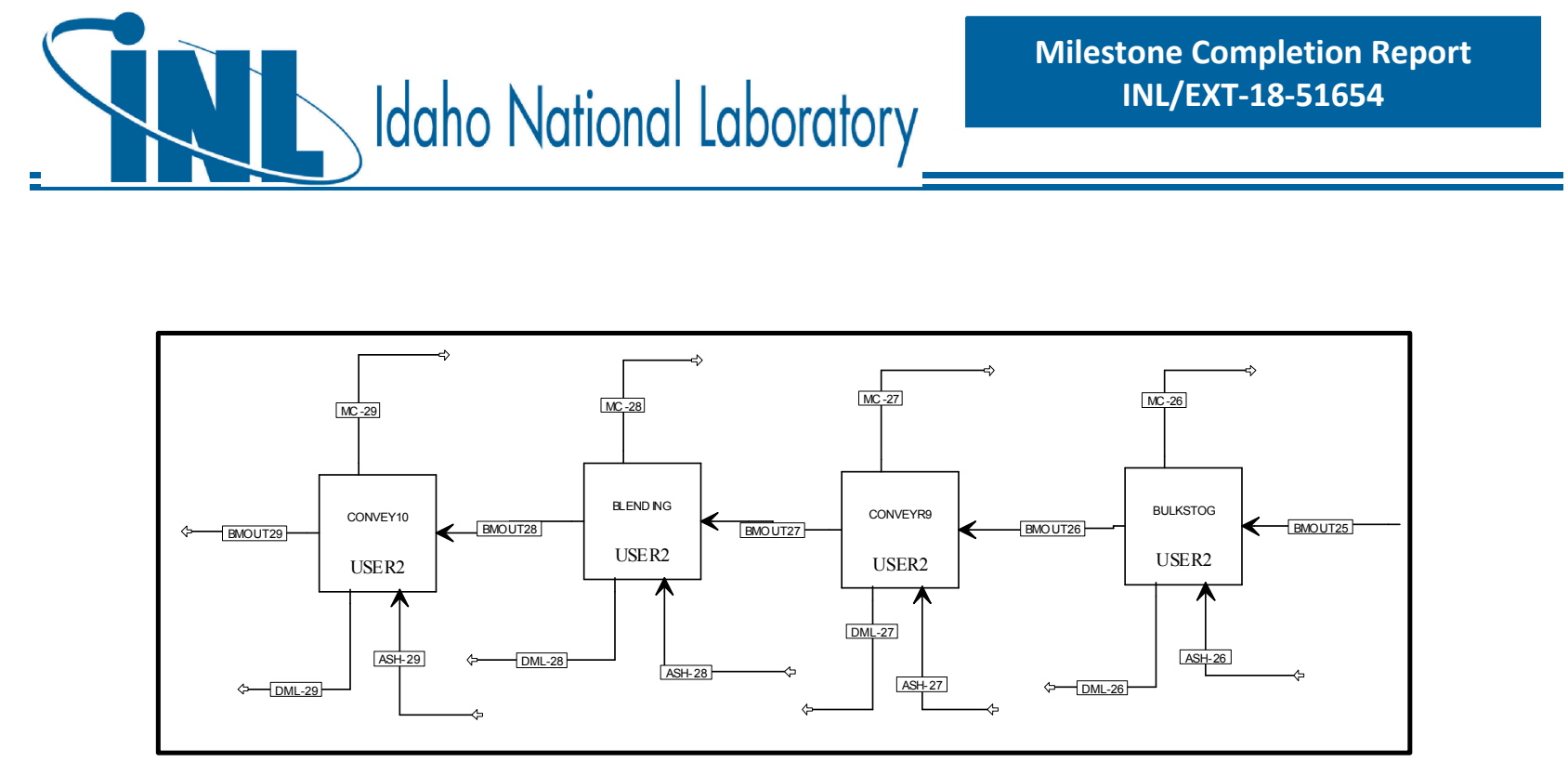

Figure G-14. Detailed process flow diagram for area B600-Feeding. 


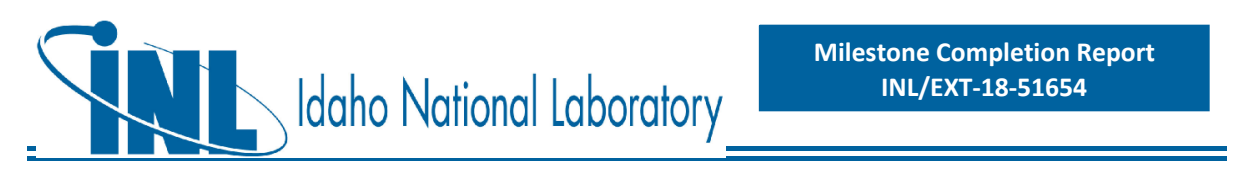

Table G-3. Aspen Plus mass balances from harvest to field-side storage (Area B100) for the two-pass corn stover blendstock in the Exclusion of Grass Clippings from the Distributed Depot Case. Harvest is assumed to take place within a 6 week period, working 14 hours/day, 6 days per week.

\begin{tabular}{|c|c|c|c|c|c|c|c|c|c|c|c|c|}
\hline Component & unit & BIOMIN & DML-1 & MC-1 & BMOUT1 & DML-3 & MC-3 & ASH-3 & BMOUT3 & DML-4 & MC-4 & BMOUT4 \\
\hline $\begin{array}{l}\text { Overall Flow } \\
\text { (moisture and } \\
\text { dry matter) }\end{array}$ & $\mathrm{kg} / \mathrm{hr}$ & $1,440,831$ & 0 & 0 & $1,440,831$ & 0 & 0 & 20,876 & $1,440,831$ & 0 & 0 & $1,440,831$ \\
\hline Moisture Flow & $\mathrm{kg} / \mathrm{hr}$ & 432,251 & 0 & 0 & 432,251 & 0 & 0 & 0 & 432,251 & 0 & 0 & 432,251 \\
\hline $\begin{array}{l}\text { Total Flow (dry } \\
\text { matter) }\end{array}$ & $\mathrm{kg} / \mathrm{hr}$ & $1,008,580$ & 0 & 0 & $1,008,580$ & 0 & 0 & 20,876 & $1,008,580$ & 0 & 0 & $1,008,580$ \\
\hline C6 & $\mathrm{kg} / \mathrm{hr}$ & 373,481 & 0 & 0 & 373,481 & 0 & 0 & 0 & 373,481 & 0 & 0 & 373,481 \\
\hline C5 & $\mathrm{kg} / \mathrm{hr}$ & 215,839 & 0 & 0 & 215,839 & 0 & 0 & 0 & 215,839 & 0 & 0 & 215,839 \\
\hline LIGNIN & $\mathrm{kg} / \mathrm{hr}$ & 155,724 & 0 & 0 & 155,724 & 0 & 0 & 0 & 155,724 & 0 & 0 & 155,724 \\
\hline ASH & $\mathrm{kg} / \mathrm{hr}$ & 49,720 & 0 & 0 & 49,720 & 0 & 0 & 20,876 & 70,597 & 0 & 0 & 70,597 \\
\hline PROTEIN & $\mathrm{kg} / \mathrm{hr}$ & 30,556 & 0 & 0 & 30,556 & 0 & 0 & 0 & 30,556 & 0 & 0 & 30,556 \\
\hline $\begin{array}{l}\text { EXTRACTIVE } \\
\text { S } \\
\end{array}$ & $\mathrm{kg} / \mathrm{hr}$ & 144,834 & 0 & 0 & 144,834 & 0 & 0 & 0 & 144,834 & 0 & 0 & 144,834 \\
\hline OTHERS & $\mathrm{kg} / \mathrm{hr}$ & 17,551 & 0 & 0 & 17,551 & 0 & 0 & 0 & 17,551 & 0 & 0 & 17,551 \\
\hline Temperature & $\mathrm{K}$ & 298 & 298 & 298 & 298 & 298 & 298 & 298 & 298 & 298 & 298 & 298 \\
\hline Pressure & $\mathrm{atm}$ & 1 & 1 & 1 & 1 & 1 & 1 & 1 & 1 & 1 & 1 & 1 \\
\hline Vapor Frac & & 0 & 0 & 0 & 0 & 0 & 0 & 0 & 0 & 0 & 0 & 0 \\
\hline
\end{tabular}




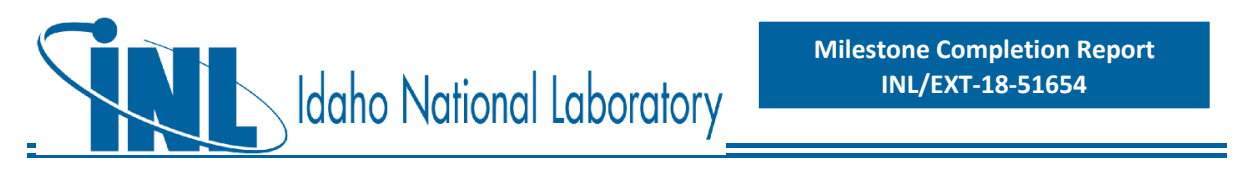

Table G-4. Aspen Plus mass balances from field-side storage to feeding (Areas B200-B600) for the two-pass corn stover blendstock in the Exclusion of Grass Clippings from the Distributed Depot Case. Depot operation is assumed to take place within 350 day period, working 24 hours/day, 7 days per week.

\begin{tabular}{|c|c|c|c|c|c|c|c|c|c|c|c|c|c|c|c|}
\hline Component & unit & MC-5 & DML-5 & BMOUT5 & $\begin{array}{c}\text { DML- } \\
6\end{array}$ & MC-6 & BMOUT6 & $\begin{array}{c}\text { DML- } \\
7\end{array}$ & MC-7 & BMOUT7 & $\begin{array}{c}\text { DML- } \\
8\end{array}$ & MC-8 & BMOUT8 & $\begin{array}{c}\text { DML- } \\
9\end{array}$ & $\begin{array}{c}\text { MC- } \\
9\end{array}$ \\
\hline $\begin{array}{l}\text { Overall Flow } \\
\text { (moisture and dry } \\
\text { matter) }\end{array}$ & $\mathrm{kg} / \mathrm{hr}$ & 8,169 & 7,262 & 71,018 & 0 & 0 & 71,018 & 0 & 0 & 71,018 & 0 & 0 & 71,018 & 0 & 0 \\
\hline Moisture Flow & $\mathrm{kg} / \mathrm{hr}$ & 8,169 & 0 & 17,766 & 0 & 0 & 17,766 & 0 & 0 & 17,766 & 0 & 0 & 17,766 & 0 & 0 \\
\hline $\begin{array}{l}\text { Total Flow (dry } \\
\text { matter) }\end{array}$ & $\mathrm{kg} / \mathrm{hr}$ & 0 & 7,262 & 53,253 & 0 & 0 & 53,253 & 0 & 0 & 53,253 & 0 & 0 & 53,253 & 0 & 0 \\
\hline C6 & $\mathrm{kg} / \mathrm{hr}$ & 0 & 1,340 & 21,068 & 0 & 0 & 21,068 & 0 & 0 & 21,068 & 0 & 0 & 21,068 & 0 & 0 \\
\hline $\mathrm{C} 5$ & $\mathrm{~kg} / \mathrm{hr}$ & 0 & 2,101 & 10,850 & 0 & 0 & 10,850 & 0 & 0 & 10,850 & 0 & 0 & 10,850 & 0 & 0 \\
\hline LIGNIN & $\mathrm{kg} / \mathrm{hr}$ & 0 & 468 & 8,876 & 0 & 0 & 8,876 & 0 & 0 & 8,876 & 0 & 0 & 8,876 & 0 & 0 \\
\hline ASH & $\mathrm{kg} / \mathrm{hr}$ & 0 & 0 & 4,236 & 0 & 0 & 4,236 & 0 & 0 & 4,236 & 0 & 0 & 4,236 & 0 & 0 \\
\hline PROTEIN & $\mathrm{kg} / \mathrm{hr}$ & 0 & 218 & 1,616 & 0 & 0 & 1,616 & 0 & 0 & 1,616 & 0 & 0 & 1,616 & 0 & 0 \\
\hline EXTRACTIVES & $\mathrm{kg} / \mathrm{hr}$ & 0 & 2,178 & 6,512 & 0 & 0 & 6,512 & 0 & 0 & 6,512 & 0 & 0 & 6,512 & 0 & 0 \\
\hline OTHERS & $\mathrm{kg} / \mathrm{hr}$ & 0 & 957 & 96 & 0 & 0 & 96 & 0 & 0 & 96 & 0 & 0 & 96 & 0 & 0 \\
\hline Temperature & $\mathrm{K}$ & 298 & 298 & 298 & 298 & 298 & 298 & 298 & 298 & 298 & 298 & 298 & 298 & 298 & 298 \\
\hline Pressure & $\mathrm{atm}$ & 1 & 1 & 1 & 1 & 1 & 1 & 1 & 1 & 1 & 1 & 1 & 1 & 1 & 1 \\
\hline Vapor Frac & & 0 & 0 & 0 & 0 & 0 & 0 & 0 & 0 & 0 & 0 & 0 & 0 & 0 & 0 \\
\hline
\end{tabular}


Table G-4. (continued)

\begin{tabular}{|c|c|c|c|c|c|c|c|c|c|c|c|}
\hline Component & unit & BMOUT9 & $\begin{array}{l}\text { DML- } \\
10\end{array}$ & MC-10 & BMOUT10 & DML-11 & MC-11 & BMOUT11 & DML-12 & $\begin{array}{l}\text { MC- } \\
12\end{array}$ & BMOUT12 \\
\hline $\begin{array}{l}\text { Overall Flow } \\
\text { (moisture and dry } \\
\text { matter) }\end{array}$ & $\mathrm{kg} / \mathrm{hr}$ & 71,018 & 0 & 0 & 71,018 & 533 & 4,384 & 66,102 & 0 & 0 & 66,102 \\
\hline Moisture Flow & $\mathrm{kg} / \mathrm{hr}$ & 17,766 & 0 & 0 & 17,766 & 0 & 4,384 & 13,382 & 0 & 0 & 13,382 \\
\hline $\begin{array}{l}\text { Total Flow (dry } \\
\text { matter) }\end{array}$ & $\mathrm{kg} / \mathrm{hr}$ & 53,253 & 0 & 0 & 53,253 & 533 & 0 & 52,720 & 0 & 0 & 52,720 \\
\hline C6 & $\mathrm{kg} / \mathrm{hr}$ & 21,068 & 0 & 0 & 21,068 & 148 & 0 & 20,921 & 0 & 0 & 20,921 \\
\hline $\mathrm{C} 5$ & $\mathrm{~kg} / \mathrm{hr}$ & 10,850 & 0 & 0 & 10,850 & 82 & 0 & 10,766 & 0 & 0 & 10,766 \\
\hline LIGNIN & $\mathrm{kg} / \mathrm{hr}$ & 8,876 & 0 & 0 & 8,876 & 103 & 0 & 8,772 & 0 & 0 & 8,772 \\
\hline ASH & $\mathrm{kg} / \mathrm{hr}$ & 4,236 & 0 & 0 & 4,236 & 133 & 0 & 4,103 & 0 & 0 & 4,103 \\
\hline PROTEIN & $\mathrm{kg} / \mathrm{hr}$ & 1,616 & 0 & 0 & 1,616 & 0 & 0 & 1,616 & 0 & 0 & 1,616 \\
\hline EXTRACTIVES & $\mathrm{kg} / \mathrm{hr}$ & 6,512 & 0 & 0 & 6,512 & 66 & 0 & 6,446 & 0 & 0 & 6,446 \\
\hline OTHERS & $\mathrm{kg} / \mathrm{hr}$ & 96 & 0 & 0 & 96 & 0 & 0 & 96 & 0 & 0 & 96 \\
\hline Temperature & $\mathrm{K}$ & 298 & 298 & 298 & 298 & 298 & 298 & 298 & 298 & 298 & 298 \\
\hline Pressure & $\mathrm{atm}$ & 1 & 1 & 1 & 1 & 1 & 1 & 1 & 1 & 1 & 1 \\
\hline Vapor Frac & & 0 & 0 & 0 & 0 & 0 & 0 & 0 & 0 & 0 & 0 \\
\hline
\end{tabular}




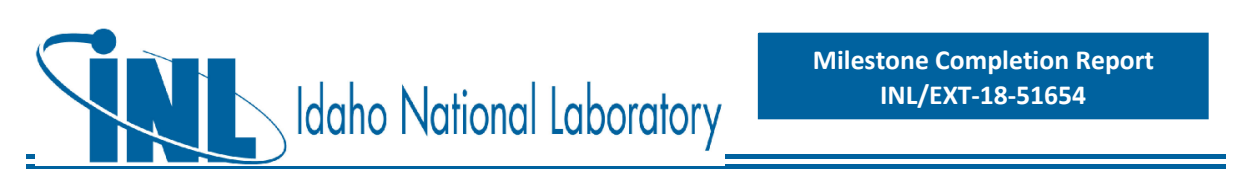

Table G-4. (continued)

\begin{tabular}{|c|c|c|c|c|c|c|c|c|c|c|c|c|}
\hline Component & unit & $\begin{array}{c}\text { DML- } \\
13\end{array}$ & MC-13 & BMOUT13 & BMOUT14 & DML-14 & MC-14 & DML-15 & MC-15 & BMOUT15 & $\begin{array}{c}\text { DML- } \\
16\end{array}$ & MC-16 \\
\hline $\begin{array}{l}\text { Overall Flow } \\
\text { (moisture and dry } \\
\text { matter) }\end{array}$ & $\mathrm{kg} / \mathrm{hr}$ & 1,618 & 0 & 28,624 & 35,859 & 0 & 0 & 0 & 0 & 28,624 & 294 & 65 \\
\hline Moisture Flow & $\mathrm{kg} / \mathrm{hr}$ & 1,618 & 0 & 5,222 & 6,541 & 0 & 0 & 0 & 0 & 5,222 & 0 & 65 \\
\hline $\begin{array}{l}\text { Total Flow (dry } \\
\text { matter) }\end{array}$ & $\mathrm{kg} / \mathrm{hr}$ & 0 & 0 & 23,402 & 29,318 & 0 & 0 & 0 & 0 & 23,402 & 294 & 0 \\
\hline C6 & $\mathrm{kg} / \mathrm{hr}$ & 0 & 0 & 9,286 & 11,634 & 0 & 0 & 0 & 0 & 9,286 & 82 & 0 \\
\hline $\mathrm{C} 5$ & $\mathrm{~kg} / \mathrm{hr}$ & 0 & 0 & 4,780 & 5,988 & 0 & 0 & 0 & 0 & 4,780 & 45 & 0 \\
\hline LIGNIN & $\mathrm{kg} / \mathrm{hr}$ & 0 & 0 & 3,894 & 4,878 & 0 & 0 & 0 & 0 & 3,894 & 57 & 0 \\
\hline ASH & $\mathrm{kg} / \mathrm{hr}$ & 0 & 0 & 1,822 & 2,282 & 0 & 0 & 0 & 0 & 1,822 & 73 & 0 \\
\hline PROTEIN & $\mathrm{kg} / \mathrm{hr}$ & 0 & 0 & 717 & 898 & 0 & 0 & 0 & 0 & 717 & 0 & 0 \\
\hline EXTRACTIVES & $\mathrm{kg} / \mathrm{hr}$ & 0 & 0 & 2,862 & 3,585 & 0 & 0 & 0 & 0 & 2,862 & 36 & 0 \\
\hline OTHERS & $\mathrm{kg} / \mathrm{hr}$ & 0 & 0 & 43 & 53 & 0 & 0 & 0 & 0 & 43 & 0 & 0 \\
\hline Temperature & K & 298 & 298 & 298 & 298 & 298 & 298 & 298 & 298 & 298 & 298 & 298 \\
\hline Pressure & atm & 1 & 1 & 1 & 1 & 1 & 1 & 1 & 1 & 1 & 1 & 1 \\
\hline Vapor Frac & & 0 & 0 & 0 & 0 & 0 & 0 & 0 & 0 & 0 & 0 & 0 \\
\hline
\end{tabular}


Table G-4. (continued)

\begin{tabular}{|c|c|c|c|c|c|c|c|c|c|c|c|}
\hline Component & unit & BMOUT16 & BMOUT17 & DML-18 & MC-18 & BMOUT18 & DML-19 & MC-19 & BMOUT19 & $\begin{array}{c}\text { DML- } \\
20\end{array}$ & MC-20 \\
\hline $\begin{array}{l}\begin{array}{l}\text { Overall Flow } \\
\text { (moisture and dry } \\
\text { matter) }\end{array} \\
\end{array}$ & $\mathrm{kg} / \mathrm{hr}$ & 35,859 & 35,501 & 0 & 0 & 64,125 & 0 & 3,697 & 60,427 & 0 & 1,162 \\
\hline Moisture Flow & $\mathrm{kg} / \mathrm{hr}$ & 6,541 & 6,476 & 0 & 0 & 11,698 & 0 & 3,697 & 8,000 & 0 & 1,162 \\
\hline $\begin{array}{l}\text { Total Flow (dry } \\
\text { matter) }\end{array}$ & $\mathrm{kg} / \mathrm{hr}$ & 29,318 & 29,024 & 0 & 0 & 52,427 & 0 & 0 & 52,427 & 0 & 0 \\
\hline C6 & $\mathrm{kg} / \mathrm{hr}$ & 11,634 & 11,553 & 0 & 0 & 20,839 & 0 & 0 & 20,839 & 0 & 0 \\
\hline C5 & $\mathrm{kg} / \mathrm{hr}$ & 5,988 & 5,941 & 0 & 0 & 10,721 & 0 & 0 & 10,721 & 0 & 0 \\
\hline LIGNIN & $\mathrm{kg} / \mathrm{hr}$ & 4,878 & 4,821 & 0 & 0 & 8,715 & 0 & 0 & 8,715 & 0 & 0 \\
\hline ASH & $\mathrm{kg} / \mathrm{hr}$ & 2,282 & 2,209 & 0 & 0 & 4,029 & 0 & 0 & 4,029 & 0 & 0 \\
\hline PROTEIN & $\mathrm{kg} / \mathrm{hr}$ & 898 & 898 & 0 & 0 & 1,616 & 0 & 0 & 1,616 & 0 & 0 \\
\hline EXTRACTIVES & $\mathrm{kg} / \mathrm{hr}$ & 3,585 & 3,549 & 0 & 0 & 6,410 & 0 & 0 & 6,410 & 0 & 0 \\
\hline OTHERS & $\mathrm{kg} / \mathrm{hr}$ & 53 & 53 & 0 & 0 & 96 & 0 & 0 & 96 & 0 & 0 \\
\hline Temperature & $\mathrm{K}$ & 298 & 298 & 298 & 298 & 298 & 298 & 298 & 298 & 298 & 298 \\
\hline Pressure & atm & 1 & 1 & 1 & 1 & 1 & 1 & 1 & 1 & 1 & 1 \\
\hline Vapor Frac & & 0 & 0 & 0 & 0 & 0 & 0 & 0 & 0 & 0 & 0 \\
\hline
\end{tabular}


Table G-4. (continued)

\begin{tabular}{|c|c|c|c|c|c|c|c|c|c|c|}
\hline Component & unit & BMOUT20 & DML-21 & MC-21 & BMOUT21 & DML-22 & MC-22 & BMOUT22 & DML-23 & $\begin{array}{l}\text { MC- } \\
23\end{array}$ \\
\hline $\begin{array}{l}\text { Overall Flow } \\
\text { (moisture and dry } \\
\text { matter) }\end{array}$ & $\mathrm{kg} / \mathrm{hr}$ & 59,265 & 0 & 0 & 59,265 & 0 & 0 & 59,265 & 0 & 0 \\
\hline Moisture Flow & $\mathrm{kg} / \mathrm{hr}$ & 6,839 & 0 & 0 & 6,839 & 0 & 0 & 6,839 & 0 & 0 \\
\hline $\begin{array}{l}\text { Total Flow (dry } \\
\text { matter) }\end{array}$ & $\mathrm{kg} / \mathrm{hr}$ & 52,427 & 0 & 0 & 52,427 & 0 & 0 & 52,427 & 0 & 0 \\
\hline C6 & $\mathrm{kg} / \mathrm{hr}$ & 20,839 & 0 & 0 & 20,839 & 0 & 0 & 20,839 & 0 & 0 \\
\hline C5 & $\mathrm{kg} / \mathrm{hr}$ & 10,721 & 0 & 0 & 10,721 & 0 & 0 & 10,721 & 0 & 0 \\
\hline LIGNIN & $\mathrm{kg} / \mathrm{hr}$ & 8,715 & 0 & 0 & 8,715 & 0 & 0 & 8,715 & 0 & 0 \\
\hline ASH & $\mathrm{kg} / \mathrm{hr}$ & 4,029 & 0 & 0 & 4,029 & 0 & 0 & 4,029 & 0 & 0 \\
\hline PROTEIN & $\mathrm{kg} / \mathrm{hr}$ & 1,616 & 0 & 0 & 1,616 & 0 & 0 & 1,616 & 0 & 0 \\
\hline EXTRACTIVES & $\mathrm{kg} / \mathrm{hr}$ & 6,410 & 0 & 0 & 6,410 & 0 & 0 & 6,410 & 0 & 0 \\
\hline OTHERS & $\mathrm{kg} / \mathrm{hr}$ & 96 & 0 & 0 & 96 & 0 & 0 & 96 & 0 & 0 \\
\hline Temperature & K & 298 & 298 & 298 & 298 & 298 & 298 & 298 & 298 & 298 \\
\hline Pressure & atm & 1 & 1 & 1 & 1 & 1 & 1 & 1 & 1 & 1 \\
\hline Vapor Frac & & 0 & 0 & 0 & 0 & 0 & 0 & 0 & 0 & 0 \\
\hline
\end{tabular}


Table G-4. (continued)

\begin{tabular}{|c|c|c|c|c|c|c|c|c|c|c|c|}
\hline Component & unit & BMOUT23 & DML-24 & MC-24 & BMOUT24 & DML-25 & MC-25 & BMOUT25 & DML-26 & $\begin{array}{l}\text { MC- } \\
26\end{array}$ & BMOUT26 \\
\hline $\begin{array}{l}\text { Overall Flow } \\
\text { (moisture and dry } \\
\text { matter) }\end{array}$ & $\mathrm{kg} / \mathrm{hr}$ & 59,265 & 0 & 0 & 59,265 & 0 & 0 & 59,265 & 0 & 0 & 59,265 \\
\hline Moisture Flow & $\mathrm{kg} / \mathrm{hr}$ & 6,839 & 0 & 0 & 6,839 & 0 & 0 & 6,839 & 0 & 0 & 6,839 \\
\hline $\begin{array}{l}\text { Total Flow (dry } \\
\text { matter) }\end{array}$ & $\mathrm{kg} / \mathrm{hr}$ & 52,427 & 0 & 0 & 52,427 & 0 & 0 & 52,427 & 0 & 0 & 52,427 \\
\hline C6 & $\mathrm{kg} / \mathrm{hr}$ & 20,839 & 0 & 0 & 20,839 & 0 & 0 & 20,839 & 0 & 0 & 20,839 \\
\hline C5 & $\mathrm{kg} / \mathrm{hr}$ & 10,721 & 0 & 0 & 10,721 & 0 & 0 & 10,721 & 0 & 0 & 10,721 \\
\hline LIGNIN & $\mathrm{kg} / \mathrm{hr}$ & 8,715 & 0 & 0 & 8,715 & 0 & 0 & 8,715 & 0 & 0 & 8,715 \\
\hline ASH & $\mathrm{kg} / \mathrm{hr}$ & 4,029 & 0 & 0 & 4,029 & 0 & 0 & 4,029 & 0 & 0 & 4,029 \\
\hline PROTEIN & $\mathrm{kg} / \mathrm{hr}$ & 1,616 & 0 & 0 & 1,616 & 0 & 0 & 1,616 & 0 & 0 & 1,616 \\
\hline EXTRACTIVES & $\mathrm{kg} / \mathrm{hr}$ & 6,410 & 0 & 0 & 6,410 & 0 & 0 & 6,410 & 0 & 0 & 6,410 \\
\hline OTHERS & $\mathrm{kg} / \mathrm{hr}$ & 96 & 0 & 0 & 96 & 0 & 0 & 96 & 0 & 0 & 96 \\
\hline Temperature & K & 298 & 298 & 298 & 298 & 298 & 298 & 298 & 298 & 298 & 298 \\
\hline Pressure & atm & 1 & 1 & 1 & 1 & 1 & 1 & 1 & 1 & 1 & 1 \\
\hline Vapor Frac & & 0 & 0 & 0 & 0 & 0 & 0 & 0 & 0 & 0 & 0 \\
\hline
\end{tabular}


a daho National Laboratory

Table G-4. (continued)

\begin{tabular}{|c|c|c|c|c|c|c|c|c|c|c|}
\hline Component & unit & $\begin{array}{c}\text { DML- } \\
27\end{array}$ & MC-27 & BMOUT27 & DML-28 & MC-28 & BMOUT28 & DML-29 & MC-29 & BMOUT29 \\
\hline $\begin{array}{l}\text { Overall Flow } \\
\text { (moisture and dry } \\
\text { matter) }\end{array}$ & $\mathrm{kg} / \mathrm{hr}$ & 0 & 0 & 59,265 & 0 & 0 & 59,265 & 0 & 0 & 59,265 \\
\hline Moisture Flow & $\mathrm{kg} / \mathrm{hr}$ & 0 & 0 & 6,839 & 0 & 0 & 6,839 & 0 & 0 & 6,839 \\
\hline $\begin{array}{l}\text { Total Flow (dry } \\
\text { matter) }\end{array}$ & $\mathrm{kg} / \mathrm{hr}$ & 0 & 0 & 52,427 & 0 & 0 & 52,427 & 0 & 0 & 52,427 \\
\hline C6 & $\mathrm{kg} / \mathrm{hr}$ & 0 & 0 & 20,839 & 0 & 0 & 20,839 & 0 & 0 & 20,839 \\
\hline C5 & $\mathrm{kg} / \mathrm{hr}$ & 0 & 0 & 10,721 & 0 & 0 & 10,721 & 0 & 0 & 10,721 \\
\hline LIGNIN & $\mathrm{kg} / \mathrm{hr}$ & 0 & 0 & 8,715 & 0 & 0 & 8,715 & 0 & 0 & 8,715 \\
\hline ASH & $\mathrm{kg} / \mathrm{hr}$ & 0 & 0 & 4,029 & 0 & 0 & 4,029 & 0 & 0 & 4,029 \\
\hline PROTEIN & $\mathrm{kg} / \mathrm{hr}$ & 0 & 0 & 1,616 & 0 & 0 & 1,616 & 0 & 0 & 1,616 \\
\hline EXTRACTIVES & $\mathrm{kg} / \mathrm{hr}$ & 0 & 0 & 6,410 & 0 & 0 & 6,410 & 0 & 0 & 6,410 \\
\hline OTHERS & $\mathrm{kg} / \mathrm{hr}$ & 0 & 0 & 96 & 0 & 0 & 96 & 0 & 0 & 96 \\
\hline Temperature & K & 298 & 298 & 298 & 298 & 298 & 298 & 298 & 298 & 298 \\
\hline Pressure & atm & 1 & 1 & 1 & 1 & 1 & 1 & 1 & 1 & 1 \\
\hline Vapor Frac & & 0 & 0 & 0 & 0 & 0 & 0 & 0 & 0 & 0 \\
\hline
\end{tabular}




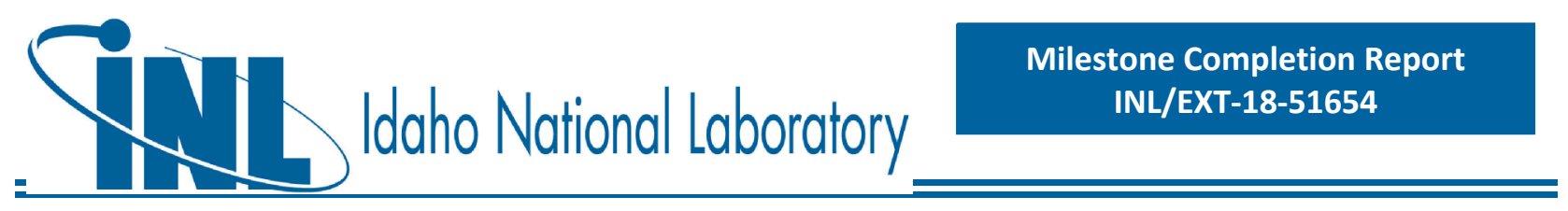

\section{APPENDIX H - Process Flow Diagrams and Mass Balances for the Primary Depot Co-located with the Biorefinery Case}

\section{H.1 Three-pass Corn Stover Blendstock}

High-level stream table information from Aspen Plus modeling output follows, for key streams associated with each process operation area. This is followed by high-level PFDs for the associated process areas. Space for stream tables was limited; below is a key to lumped components. As the stream table information focuses primarily on the high-level overall process and does not include every individual modeled stream within each process area, mass balance closure around a given unit area may not be $100 \%$.

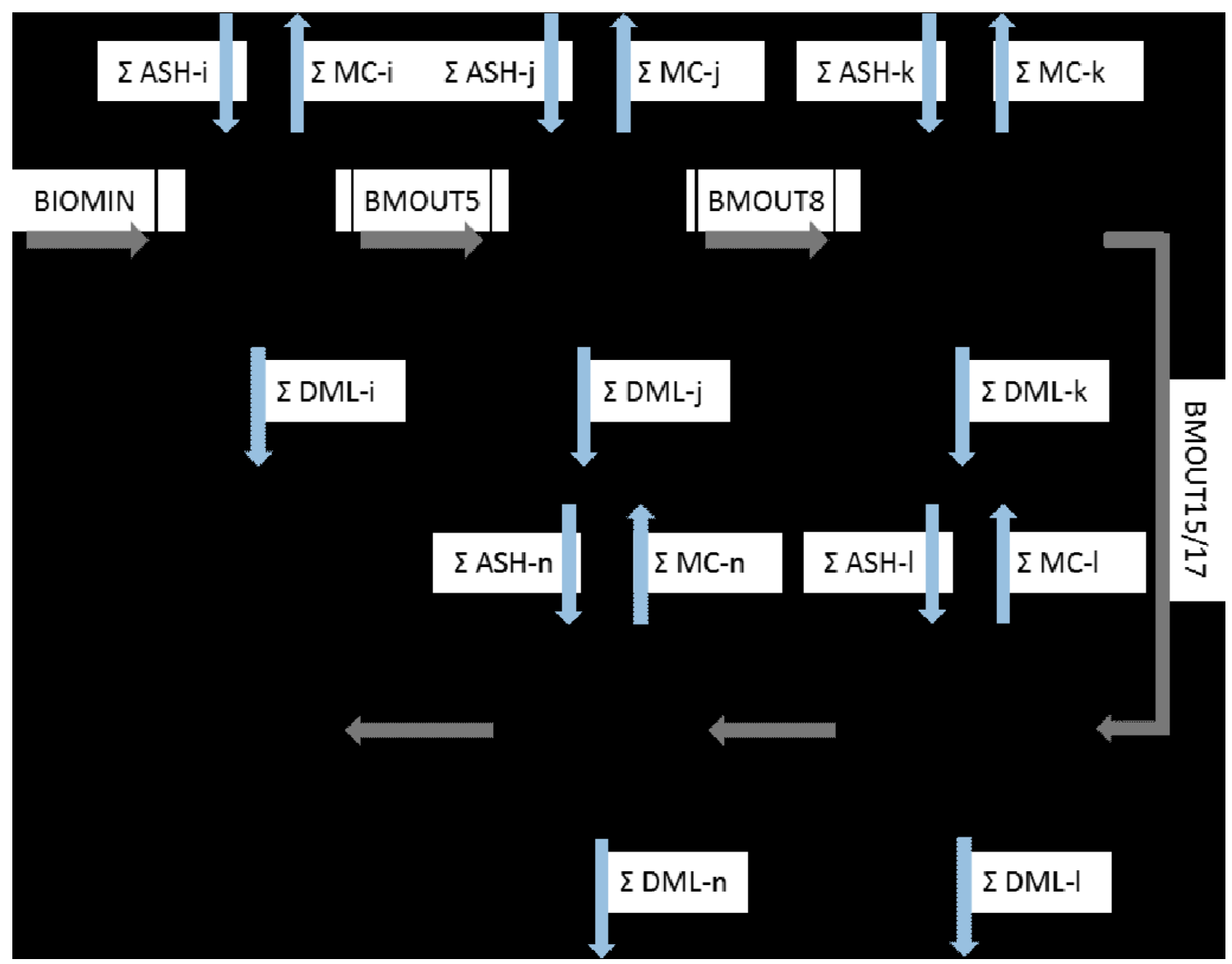

Figure H-1. High-level flowsheet showing key process areas for the three-pass corn stover blendstock in the Primary Depot Co-located with the Biorefinery Case. 


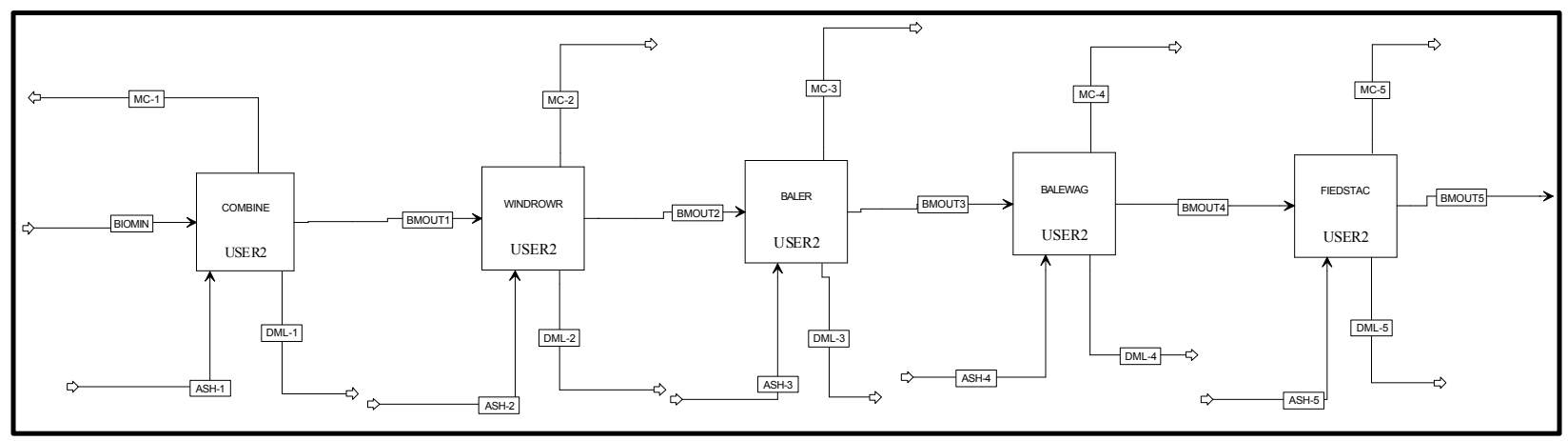

Figure H-2. Detailed process flow diagram for area A100 - Harvesting to Storage.

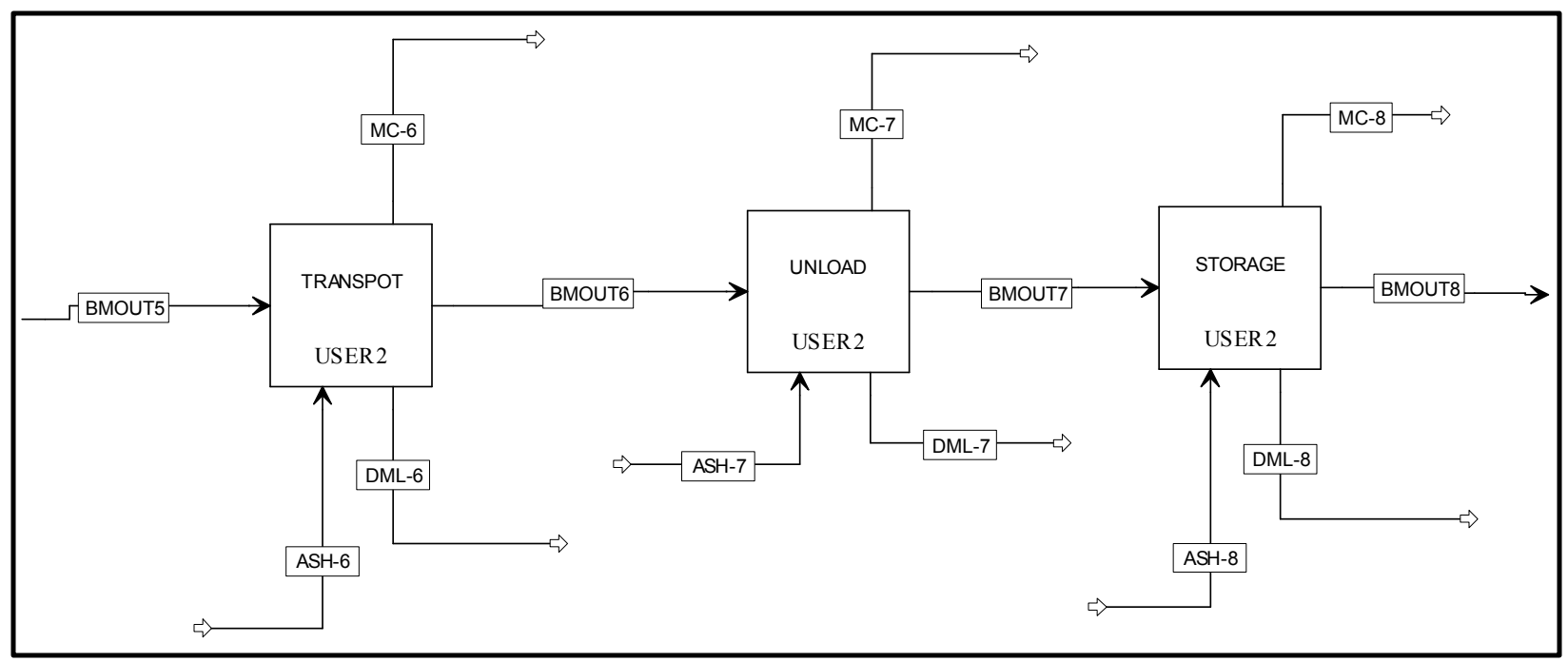

Figure H-3. Detailed process flow diagram for area A200 - Transport to Biorefinery \& Handling. 

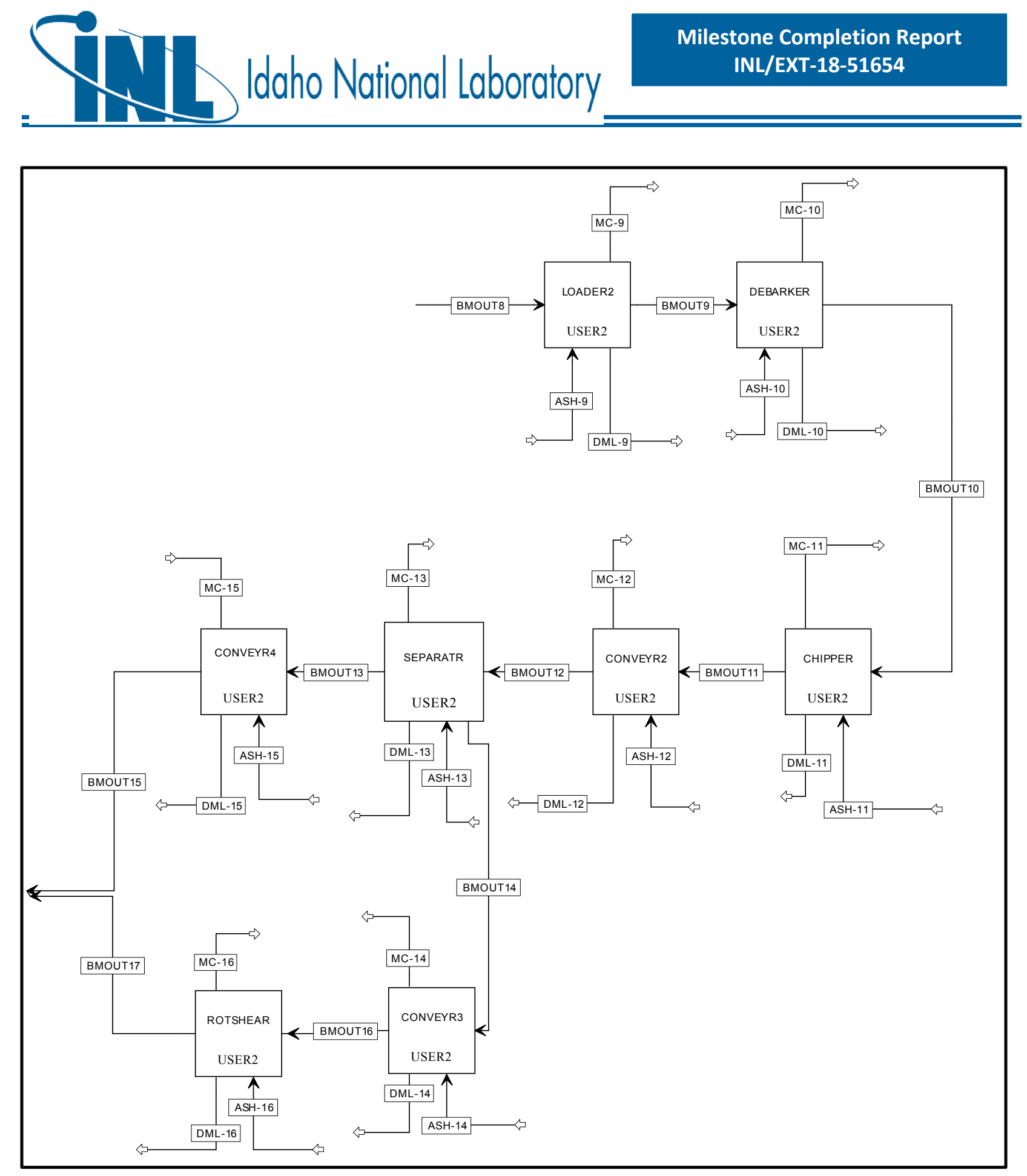

Figure H-4. Detailed process flow diagram for area A300 - Preprocessing - Size Reduction. 

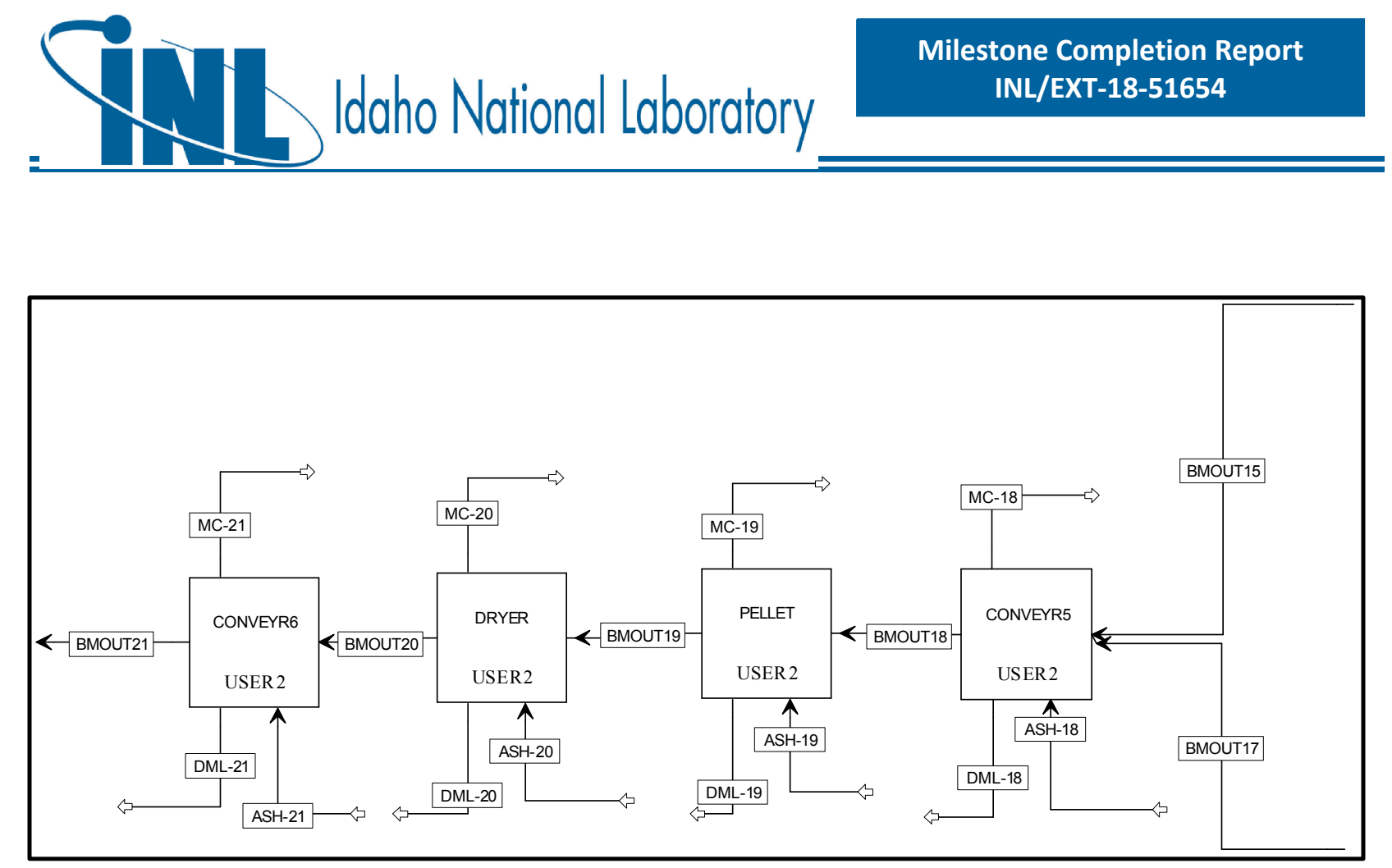

Figure H-5. Detailed process flow diagram for area A400 - Preprocessing - Pelleting.

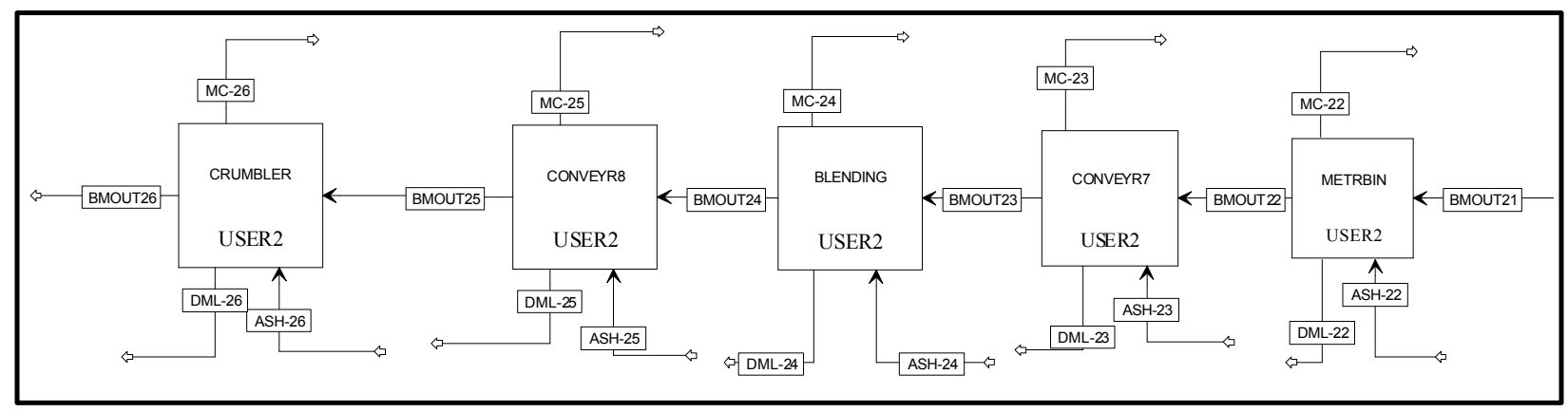

Figure H-6. Detailed process flow diagram for area A500 - Feeding. 


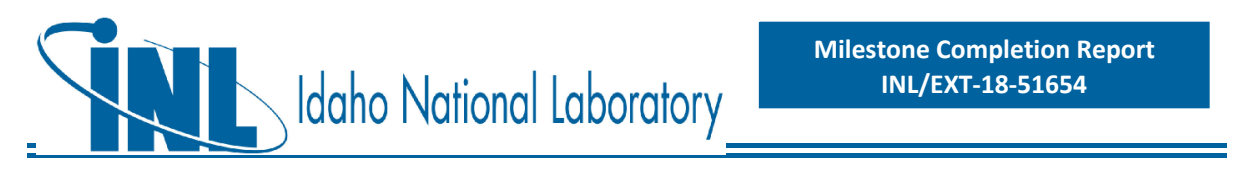

Table H-1. Aspen Plus mass balances from harvest to field-side storage (Area A100) for the three-pass corn stover blendstock in the Primary Depot Co-located with the Biorefinery Case. Harvest is assumed to take place within a 6 week period, working 14 hours/day, 6 days per week.

\begin{tabular}{|c|c|c|c|c|c|c|c|c|c|c|c|c|c|c|c|}
\hline Component & unit & BIOMIN & $\begin{array}{c}\text { DML- } \\
1\end{array}$ & MC-1 & BMOUT1 & $\begin{array}{l}\text { DML- } \\
2\end{array}$ & $\begin{array}{c}\text { MC- } \\
2\end{array}$ & BMOUT2 & $\begin{array}{l}\text { DML- } \\
3\end{array}$ & $\begin{array}{c}\text { MC- } \\
3\end{array}$ & ASH-3 & BMOUT3 & DML-4 & MC-4 & BMOUT4 \\
\hline $\begin{array}{l}\begin{array}{l}\text { Overall Flow } \\
\text { (moisture and } \\
\text { dry matter) }\end{array} \\
\end{array}$ & $\mathrm{kg} / \mathrm{hr}$ & 796,410 & 0 & 6 & 796,404 & 0 & 0 & 796,404 & 0 & 0 & 33,839 & 796,404 & 0 & 0 & 796,404 \\
\hline Moisture Flow & $\mathrm{kg} / \mathrm{hr}$ & 238,927 & 0 & 6 & 238,921 & 0 & 0 & 238,921 & 0 & 0 & 0 & 238,921 & 0 & 0 & 238,921 \\
\hline $\begin{array}{l}\text { Total Flow (dry } \\
\text { matter) }\end{array}$ & $\mathrm{kg} / \mathrm{hr}$ & 557,483 & 0 & 0 & 557,483 & 0 & 0 & 557,483 & 0 & 0 & 33,839 & 557,483 & 0 & 0 & 557,483 \\
\hline $\mathrm{C} 6$ & $\mathrm{~kg} / \mathrm{hr}$ & 197,706 & 0 & 0 & 197,706 & 0 & 0 & 197,706 & 0 & 0 & 0 & 197,706 & 0 & 0 & 197,706 \\
\hline C5 & $\mathrm{kg} / \mathrm{hr}$ & 114,240 & 0 & 0 & 114,240 & 0 & 0 & 114,240 & 0 & 0 & 0 & 114,240 & 0 & 0 & 114,240 \\
\hline LIGNIN & $\mathrm{kg} / \mathrm{hr}$ & 82,418 & 0 & 0 & 82,418 & 0 & 0 & 82,418 & 0 & 0 & 0 & 82,418 & 0 & 0 & 82,418 \\
\hline ASH & $\mathrm{kg} / \mathrm{hr}$ & 27,484 & 0 & 0 & 27,484 & 0 & 0 & 27,484 & 0 & 0 & 33,839 & 61,323 & 0 & 0 & 61,323 \\
\hline PROTEIN & $\mathrm{kg} / \mathrm{hr}$ & 16,167 & 0 & 0 & 16,167 & 0 & 0 & 16,167 & 0 & 0 & 0 & 16,167 & 0 & 0 & 16,167 \\
\hline $\begin{array}{l}\text { EXTRACTIVE } \\
\text { S } \\
\end{array}$ & $\mathrm{kg} / \mathrm{hr}$ & 76,682 & 0 & 0 & 76,682 & 0 & 0 & 76,682 & 0 & 0 & 0 & 76,682 & 0 & 0 & 76,682 \\
\hline OTHERS & $\mathrm{kg} / \mathrm{hr}$ & 8,947 & 0 & 0 & 8,947 & 0 & 0 & 8,947 & 0 & 0 & 0 & 8,947 & 0 & 0 & 8,947 \\
\hline Temperature & K & 298 & 298 & 298 & 298 & 298 & 298 & 298 & 298 & 298 & 298 & 298 & 298 & 298 & 298 \\
\hline Pressure & atm & 1 & 1 & 1 & 1 & 1 & 1 & 1 & 1 & 1 & 1 & 1 & 1 & 1 & 1 \\
\hline Vapor Frac & & 0 & 0 & 0 & 0 & 0 & 0 & 0 & 0 & 0 & 0 & 0 & 0 & 0 & 0 \\
\hline
\end{tabular}


Table H-2. Aspen Plus mass balances from field-side storage to feeding (Areas A200-A500) for the three-pass corn stover blendstock in the Primary Depot Co-located with the Biorefinery Case. Depot operation is assumed to take place within 350 day period, working 24 hours/day, 7 days per week.

\begin{tabular}{|c|c|c|c|c|c|c|c|c|c|c|c|c|c|}
\hline Component & unit & DML-5 & MC-5 & BMOUT5 & DML-6 & MC-6 & BMOUT6 & DML-7 & MC-7 & BMOUT7 & DML-8 & MC-8 & BMOUT8 \\
\hline $\begin{array}{l}\text { Overall Flow } \\
\text { (moisture and dry } \\
\text { matter) }\end{array}$ & $\mathrm{kg} / \mathrm{hr}$ & 4,014 & 4,515 & 39,255 & 0 & 0 & 39,255 & 0 & 0 & 39,255 & 0 & 0 & 39,255 \\
\hline Moisture Flow & $\mathrm{kg} / \mathrm{hr}$ & 0 & 4,515 & 9,820 & 0 & 0 & 9,820 & 0 & 0 & 9,820 & 0 & 0 & 9,820 \\
\hline $\begin{array}{l}\text { Total Flow (dry } \\
\text { matter) }\end{array}$ & $\mathrm{kg} / \mathrm{hr}$ & 4,014 & 0 & 29,435 & 0 & 0 & 29,435 & 0 & 0 & 29,435 & 0 & 0 & 29,435 \\
\hline C6 & $\mathrm{kg} / \mathrm{hr}$ & 741 & 0 & 11,121 & 0 & 0 & 11,121 & 0 & 0 & 11,121 & 0 & 0 & 11,121 \\
\hline C5 & $\mathrm{kg} / \mathrm{hr}$ & 1,162 & 0 & 5,693 & 0 & 0 & 5,693 & 0 & 0 & 5,693 & 0 & 0 & 5,693 \\
\hline LIGNIN & $\mathrm{kg} / \mathrm{hr}$ & 259 & 0 & 4,687 & 0 & 0 & 4,687 & 0 & 0 & 4,687 & 0 & 0 & 4,687 \\
\hline ASH & $\mathrm{kg} / \mathrm{hr}$ & 0 & 0 & 3,679 & 0 & 0 & 3,679 & 0 & 0 & 3,679 & 0 & 0 & 3,679 \\
\hline PROTEIN & $\mathrm{kg} / \mathrm{hr}$ & 120 & 0 & 850 & 0 & 0 & 850 & 0 & 0 & 850 & 0 & 0 & 850 \\
\hline EXTRACTIVES & $\mathrm{kg} / \mathrm{hr}$ & 1,204 & 0 & 3,397 & 0 & 0 & 3,397 & 0 & 0 & 3,397 & 0 & 0 & 3,397 \\
\hline OTHERS & $\mathrm{kg} / \mathrm{hr}$ & 529 & 0 & 8 & 0 & 0 & 8 & 0 & 0 & 8 & 0 & 0 & 8 \\
\hline Temperature & $\mathrm{K}$ & 298 & 298 & 298 & 298 & 298 & 298 & 298 & 298 & 298 & 298 & 298 & 298 \\
\hline Pressure & $\mathrm{atm}$ & 1 & 1 & 1 & 1 & 1 & 1 & 1 & 1 & 1 & 1 & 1 & 1 \\
\hline
\end{tabular}


Table H-2. (continued)

\begin{tabular}{|c|c|c|c|c|c|c|c|c|c|c|c|c|c|}
\hline Component & unit & DML-9 & MC-9 & BMOUT9 & DML-10 & MC-10 & BMOUT10 & DML-11 & MC-11 & BMOUT11 & $\begin{array}{c}\text { DML- } \\
12\end{array}$ & $\begin{array}{l}\text { MC- } \\
12\end{array}$ & BMOUT12 \\
\hline $\begin{array}{l}\text { Overall Flow } \\
\text { (moisture and dry } \\
\text { matter) }\end{array}$ & $\mathrm{kg} / \mathrm{hr}$ & 0 & 0 & 39,255 & 0 & 0 & 39,255 & 294 & 2,423 & 36,537 & 0 & 0 & 36,537 \\
\hline Moisture Flow & $\mathrm{kg} / \mathrm{hr}$ & 0 & 0 & 9,820 & 0 & 0 & 9,820 & 0 & 2,423 & 7,396 & 0 & 0 & 7,396 \\
\hline $\begin{array}{l}\text { Total Flow (dry } \\
\text { matter) }\end{array}$ & $\mathrm{kg} / \mathrm{hr}$ & 0 & 0 & 29,435 & 0 & 0 & 29,435 & 294 & 0 & 29,140 & 0 & 0 & 29,140 \\
\hline C6 & $\mathrm{kg} / \mathrm{hr}$ & 0 & 0 & 11,121 & 0 & 0 & 11,121 & 82 & 0 & 11,040 & 0 & 0 & 11,040 \\
\hline C5 & $\mathrm{kg} / \mathrm{hr}$ & 0 & 0 & 5,693 & 0 & 0 & 5,693 & 45 & 0 & 5,647 & 0 & 0 & 5,647 \\
\hline LIGNIN & $\mathrm{kg} / \mathrm{hr}$ & 0 & 0 & 4,687 & 0 & 0 & 4,687 & 57 & 0 & 4,629 & 0 & 0 & 4,629 \\
\hline ASH & $\mathrm{kg} / \mathrm{hr}$ & 0 & 0 & 3,679 & 0 & 0 & 3,679 & 73 & 0 & 3,606 & 0 & 0 & 3,606 \\
\hline PROTEIN & $\mathrm{kg} / \mathrm{hr}$ & 0 & 0 & 850 & 0 & 0 & 850 & 0 & 0 & 850 & 0 & 0 & 850 \\
\hline EXTRACTIVES & $\mathrm{kg} / \mathrm{hr}$ & 0 & 0 & 3,397 & 0 & 0 & 3,397 & 36 & 0 & 3,361 & 0 & 0 & 3,361 \\
\hline OTHERS & $\mathrm{kg} / \mathrm{hr}$ & 0 & 0 & 8 & 0 & 0 & 8 & 0 & 0 & 8 & 0 & 0 & 8 \\
\hline Temperature & K & 298 & 298 & 298 & 298 & 298 & 298 & 298 & 298 & 298 & 298 & 298 & 298 \\
\hline Pressure & $\mathrm{atm}$ & 1 & 1 & 1 & 1 & 1 & 1 & 1 & 1 & 1 & 1 & 1 & 1 \\
\hline Vapor Frac & & 0 & 0 & 0 & 0 & 0 & 0 & 0 & 0 & 0 & 0 & 0 & 0 \\
\hline
\end{tabular}


- lano National Laboratory

Table H-2. (continued)

\begin{tabular}{|c|c|c|c|c|c|c|c|c|c|c|c|c|c|}
\hline Component & unit & $\begin{array}{c}\text { DML- } \\
13\end{array}$ & MC-13 & BMOUT13 & $\begin{array}{c}\text { DML- } \\
14\end{array}$ & MC-14 & BMOUT14 & DML-15 & MC-15 & BMOUT15 & $\begin{array}{c}\text { DML- } \\
16\end{array}$ & MC-16 & BMOUT16 \\
\hline $\begin{array}{l}\begin{array}{l}\text { Overall Flow } \\
\text { (moisture and dry } \\
\text { matter) }\end{array} \\
\end{array}$ & $\mathrm{kg} / \mathrm{hr}$ & 895 & 0 & 15,821 & 0 & 0 & 19,821 & 0 & 0 & 15,821 & 162 & 36 & 19,821 \\
\hline Moisture Flow & $\mathrm{kg} / \mathrm{hr}$ & 895 & 0 & 2,887 & 0 & 0 & 3,616 & 0 & 0 & 2,887 & 0 & 36 & 3,616 \\
\hline $\begin{array}{l}\text { Total Flow (dry } \\
\text { matter) }\end{array}$ & $\mathrm{kg} / \mathrm{hr}$ & 0 & 0 & 12,936 & 0 & 0 & 16,205 & 0 & 0 & 12,936 & 162 & 0 & 16,205 \\
\hline C6 & $\mathrm{kg} / \mathrm{hr}$ & 0 & 0 & 4,901 & 0 & 0 & 6,139 & 0 & 0 & 4,901 & 45 & 0 & 6,139 \\
\hline LIGNIN & $\mathrm{kg} / \mathrm{hr}$ & 0 & 0 & 2,055 & 0 & 0 & 2,574 & 0 & 0 & 2,055 & 31 & 0 & 2,574 \\
\hline ASH & $\mathrm{kg} / \mathrm{hr}$ & 0 & 0 & 1,600 & 0 & 0 & 2,006 & 0 & 0 & 1,600 & 40 & 0 & 2,006 \\
\hline PROTEIN & $\mathrm{kg} / \mathrm{hr}$ & 0 & 0 & 377 & 0 & 0 & 473 & 0 & 0 & 377 & 0 & 0 & 473 \\
\hline EXTRACTIVES & $\mathrm{kg} / \mathrm{hr}$ & 0 & 0 & 1,492 & 0 & 0 & 1,869 & 0 & 0 & 1,492 & 20 & 0 & 1,869 \\
\hline OTHERS & $\mathrm{kg} / \mathrm{hr}$ & 0 & 0 & 3 & 0 & 0 & 4 & 0 & 0 & 3 & 0 & 0 & 4 \\
\hline Temperature & $\mathrm{K}$ & 298 & 298 & 298 & 298 & 298 & 298 & 298 & 298 & 298 & 298 & 298 & 298 \\
\hline Pressure & $\mathrm{atm}$ & 1 & 1 & 1 & 1 & 1 & 1 & 1 & 1 & 1 & 1 & 1 & 1 \\
\hline Vapor Frac & & 0 & 0 & 0 & 0 & 0 & 0 & 0 & 0 & 0 & 0 & 0 & 0 \\
\hline
\end{tabular}




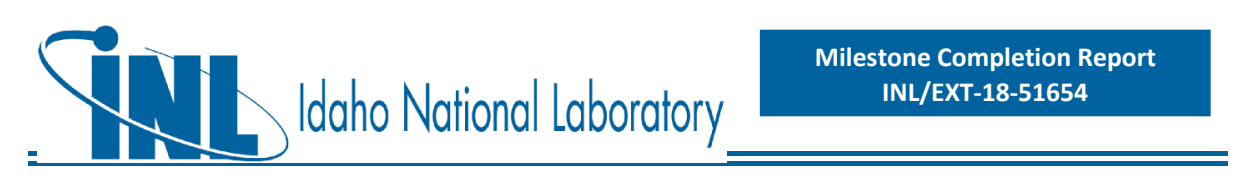

Table H-2. (continued)

\begin{tabular}{|c|c|c|c|c|c|c|c|c|c|c|c|}
\hline Component & unit & BMOUT17 & DML-18 & MC-18 & BMOUT18 & DML-19 & MC-19 & BMOUT19 & DML-20 & $\begin{array}{c}\text { MC- } \\
20\end{array}$ & BMOUT20 \\
\hline $\begin{array}{l}\text { Overall Flow } \\
\text { (moisture and dry } \\
\text { matter) }\end{array}$ & $\mathrm{kg} / \mathrm{hr}$ & 19,623 & 0 & 0 & 35,444 & 0 & 2,043 & 33,401 & 0 & 643 & 32,758 \\
\hline Moisture Flow & $\mathrm{kg} / \mathrm{hr}$ & 3,580 & 0 & 0 & 6,466 & 0 & 2,043 & 4,422 & 0 & 643 & 3,780 \\
\hline $\begin{array}{l}\text { Total Flow (dry } \\
\text { matter) }\end{array}$ & $\mathrm{kg} / \mathrm{hr}$ & 16,043 & 0 & 0 & 28,979 & 0 & 0 & 28,979 & 0 & 0 & 28,979 \\
\hline C6 & $\mathrm{kg} / \mathrm{hr}$ & 6,094 & 0 & 0 & 10,995 & 0 & 0 & 10,995 & 0 & 0 & 10,995 \\
\hline $\mathrm{C} 5$ & $\mathrm{~kg} / \mathrm{hr}$ & 3,115 & 0 & 0 & 5,622 & 0 & 0 & 5,622 & 0 & 0 & 5,622 \\
\hline LIGNIN & $\mathrm{kg} / \mathrm{hr}$ & 2,543 & 0 & 0 & 4,598 & 0 & 0 & 4,598 & 0 & 0 & 4,598 \\
\hline ASH & $\mathrm{kg} / \mathrm{hr}$ & 1,964 & 0 & 0 & 3,566 & 0 & 0 & 3,566 & 0 & 0 & 3,566 \\
\hline PROTEIN & $\mathrm{kg} / \mathrm{hr}$ & 473 & 0 & 0 & 850 & 0 & 0 & 850 & 0 & 0 & 850 \\
\hline EXTRACTIVES & $\mathrm{kg} / \mathrm{hr}$ & 1,849 & 0 & 0 & 3,341 & 0 & 0 & 3,341 & 0 & 0 & 3,341 \\
\hline OTHERS & $\mathrm{kg} / \mathrm{hr}$ & 4 & 0 & 0 & 8 & 0 & 0 & 8 & 0 & 0 & 8 \\
\hline Temperature & $\mathrm{K}$ & 298 & 298 & 298 & 298 & 298 & 298 & 298 & 298 & 298 & 298 \\
\hline Pressure & atm & 1 & 1 & 1 & 1 & 1 & 1 & 1 & 1 & 1 & 1 \\
\hline Vapor Frac & & 0 & 0 & 0 & 0 & 0 & 0 & 0 & 0 & 0 & 0 \\
\hline
\end{tabular}


lacho National Laboratory

Table H-2. (continued)

\begin{tabular}{|c|c|c|c|c|c|c|c|c|c|c|c|}
\hline Component & unit & $\begin{array}{c}\text { DML- } \\
21\end{array}$ & MC-21 & BMOUT21 & DML-22 & MC-22 & BMOUT22 & DML-23 & MC-23 & BMOUT23 & $\begin{array}{c}\text { DML- } \\
24\end{array}$ \\
\hline $\begin{array}{l}\text { Overall Flow } \\
\text { (moisture and dry } \\
\text { matter) }\end{array}$ & $\mathrm{kg} / \mathrm{hr}$ & 0 & 0 & 32,758 & 0 & 0 & 32,758 & 0 & 0 & 32,758 & 0 \\
\hline Moisture Flow & $\mathrm{kg} / \mathrm{hr}$ & 0 & 0 & 3,780 & 0 & 0 & 3,780 & 0 & 0 & 3,780 & 0 \\
\hline $\begin{array}{l}\text { Total Flow (dry } \\
\text { matter) }\end{array}$ & $\mathrm{kg} / \mathrm{hr}$ & 0 & 0 & 28,979 & 0 & 0 & 28,979 & 0 & 0 & 28,979 & 0 \\
\hline C6 & $\mathrm{kg} / \mathrm{hr}$ & 0 & 0 & 10,995 & 0 & 0 & 10,995 & 0 & 0 & 10,995 & 0 \\
\hline C5 & $\mathrm{kg} / \mathrm{hr}$ & 0 & 0 & 5,622 & 0 & 0 & 5,622 & 0 & 0 & 5,622 & 0 \\
\hline LIGNIN & $\mathrm{kg} / \mathrm{hr}$ & 0 & 0 & 4,598 & 0 & 0 & 4,598 & 0 & 0 & 4,598 & 0 \\
\hline ASH & $\mathrm{kg} / \mathrm{hr}$ & 0 & 0 & 3,566 & 0 & 0 & 3,566 & 0 & 0 & 3,566 & 0 \\
\hline PROTEIN & $\mathrm{kg} / \mathrm{hr}$ & 0 & 0 & 850 & 0 & 0 & 850 & 0 & 0 & 850 & 0 \\
\hline EXTRACTIVES & $\mathrm{kg} / \mathrm{hr}$ & 0 & 0 & 3,341 & 0 & 0 & 3,341 & 0 & 0 & 3,341 & 0 \\
\hline OTHERS & $\mathrm{kg} / \mathrm{hr}$ & 0 & 0 & 8 & 0 & 0 & 8 & 0 & 0 & 8 & 0 \\
\hline Temperature & K & 298 & 298 & 298 & 298 & 298 & 298 & 298 & 298 & 298 & 298 \\
\hline Pressure & atm & 1 & 1 & 1 & 1 & 1 & 1 & 1 & 1 & 1 & 1 \\
\hline Vapor Frac & & 0 & 0 & 0 & 0 & 0 & 0 & 0 & 0 & 0 & 0 \\
\hline
\end{tabular}


- lano National Laboratory

Table H-2. (continued)

\begin{tabular}{lcrrrrrrrr}
\hline \multicolumn{1}{c}{ Component } & unit & $\begin{array}{c}\text { MC- } \\
\mathbf{2 4}\end{array}$ & BMOUT24 & DML-25 & MC-25 & BMOUT25 & DML-26 & MC-26 & BMOUT26 \\
\hline $\begin{array}{l}\text { Overall Flow } \\
\text { (moisture and dry } \\
\text { matter) }\end{array}$ & $\mathrm{kg} / \mathrm{hr}$ & 0 & 32,758 & 0 & 0 & 32,758 & 0 & 0 & 32,758 \\
\hline Moisture Flow & $\mathrm{kg} / \mathrm{hr}$ & 0 & 3,780 & 0 & 0 & 3,780 & 0 & 0 & 3,780 \\
\hline $\begin{array}{l}\text { Total Flow (dry } \\
\text { matter) }\end{array}$ & $\mathrm{kg} / \mathrm{hr}$ & 0 & 28,979 & 0 & 0 & 28,979 & 0 & 0 & 28,979 \\
\hline C6 & $\mathrm{kg} / \mathrm{hr}$ & 0 & 10,995 & 0 & 0 & 10,995 & 0 & 0 & 10,995 \\
\hline C5 & $\mathrm{kg} / \mathrm{hr}$ & 0 & 5,622 & 0 & 0 & 5,622 & 0 & 0 & 5,622 \\
\hline LIGNIN & $\mathrm{kg} / \mathrm{hr}$ & 0 & 4,598 & 0 & 0 & 4,598 & 0 & 0 & 4,598 \\
\hline ASH & $\mathrm{kg} / \mathrm{hr}$ & 0 & 3,566 & 0 & 0 & 3,566 & 0 & 0 & 3,566 \\
\hline PROTEIN & $\mathrm{kg} / \mathrm{hr}$ & 0 & 850 & 0 & 0 & 850 & 0 & 0 & 850 \\
\hline EXTRACTIVES & $\mathrm{kg} / \mathrm{hr}$ & 0 & 3,341 & 0 & 0 & 3,341 & 0 & 0 & 3,341 \\
\hline OTHERS & $\mathrm{kg} / \mathrm{hr}$ & 0 & 8 & 0 & 0 & 8 & 0 & 0 & 8 \\
\hline Temperature & $\mathrm{K}$ & 298 & 298 & 298 & 298 & 298 & 298 & 298 & 298 \\
\hline Pressure & $\mathrm{atm}$ & 1 & 1 & 1 & 1 & 1 & 1 & 1 & 1 \\
\hline Vapor Frac & & 0 & 0 & 0 & 0 & 0 & 0 & 0 & 0 \\
\hline
\end{tabular}




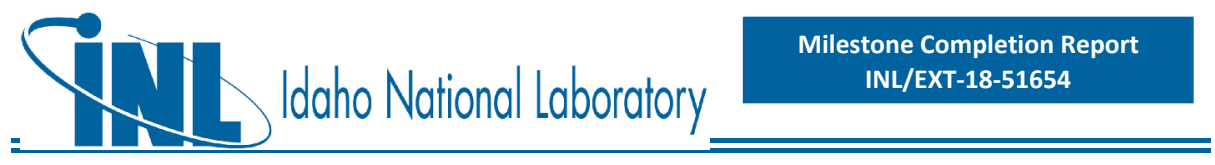




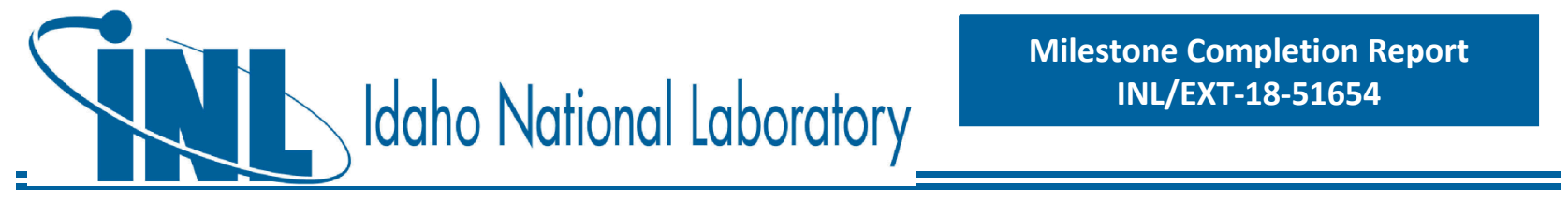

\section{H.2 Two-pass Corn Stover Blendstock}

High-level stream table information from Aspen Plus modeling output follows, for key streams associated with each process operation area. This is followed by high-level PFDs for the associated process areas. Space for stream tables was limited; below is a key to lumped components. As the stream table information focuses primarily on the high-level overall process and does not include every individual modeled stream within each process area, mass balance closure around a given unit area may not be $100 \%$.

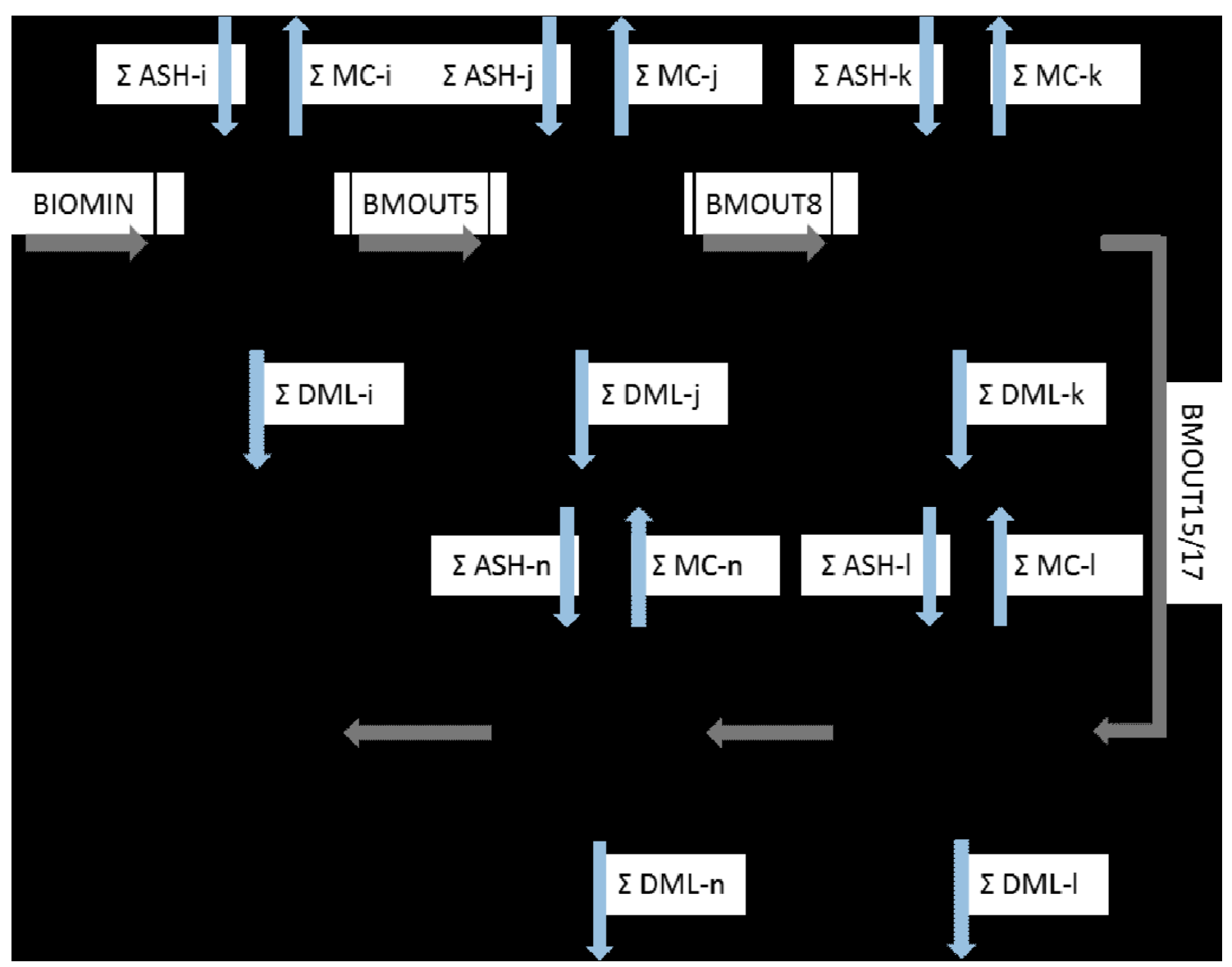

Figure H-7. High-level flowsheet showing key process areas for the two pass corn stover blendstock in the Primary Depot Co-located with the Biorefinery Case. 

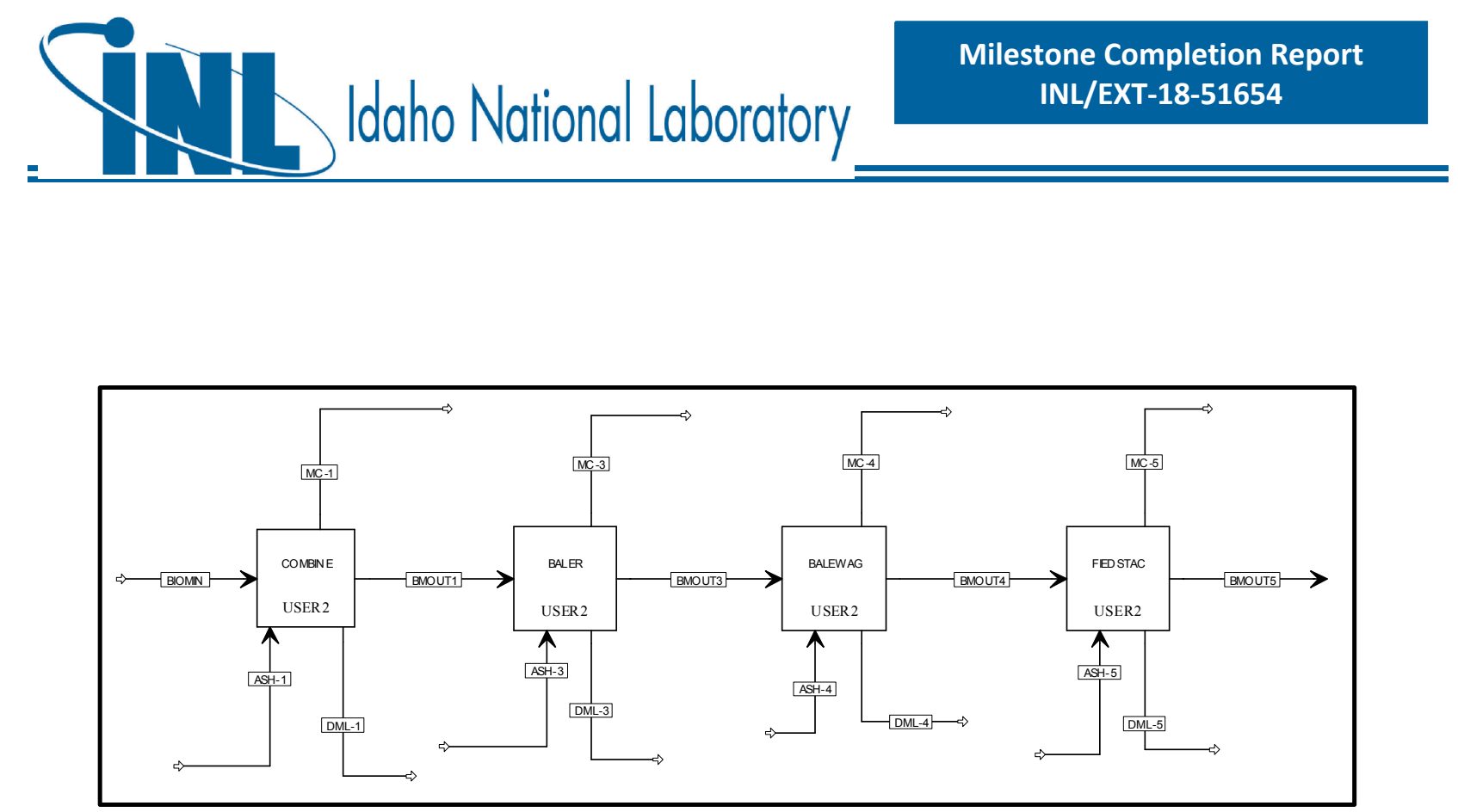

Figure H-8. Detailed process flow diagram for area B100 - Harvesting to Storage.

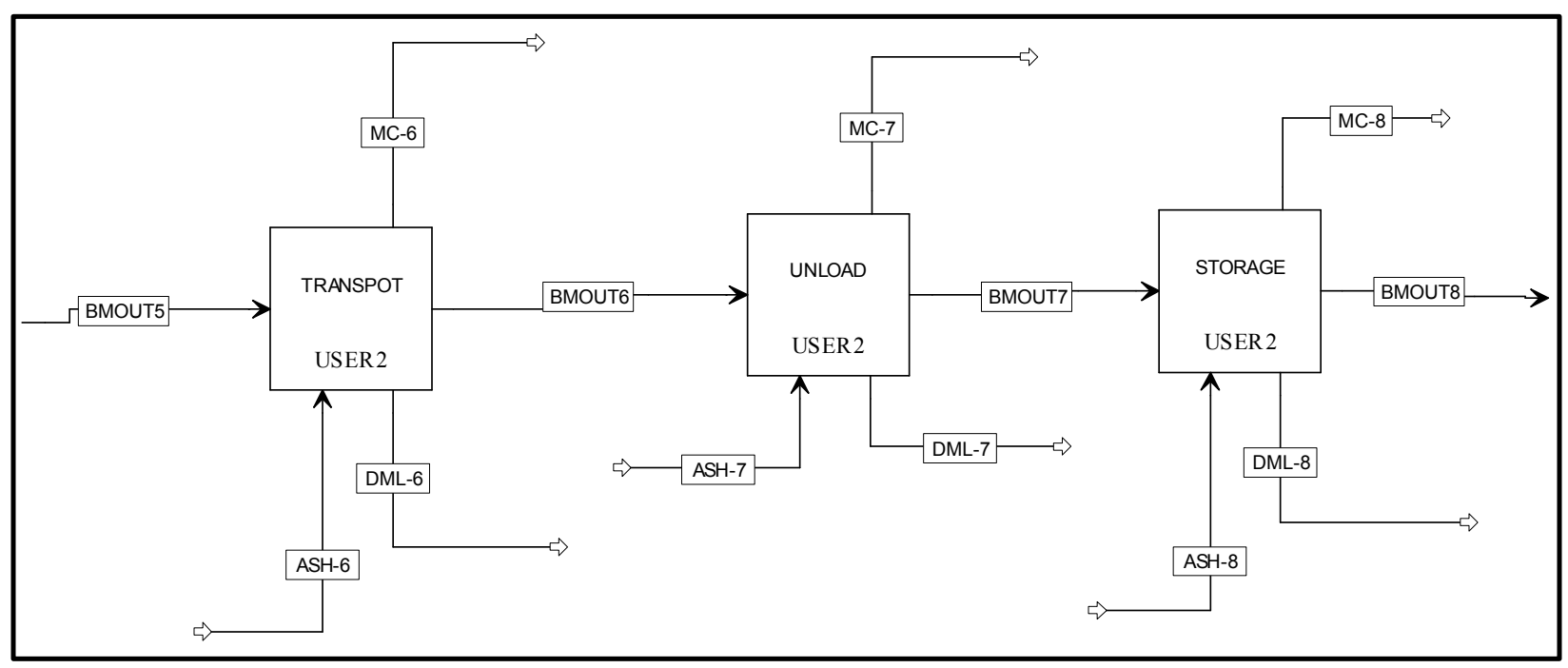

Figure H-9. Detailed process flow diagram for area B200 - Transport to Biorefinery \& Handling. 

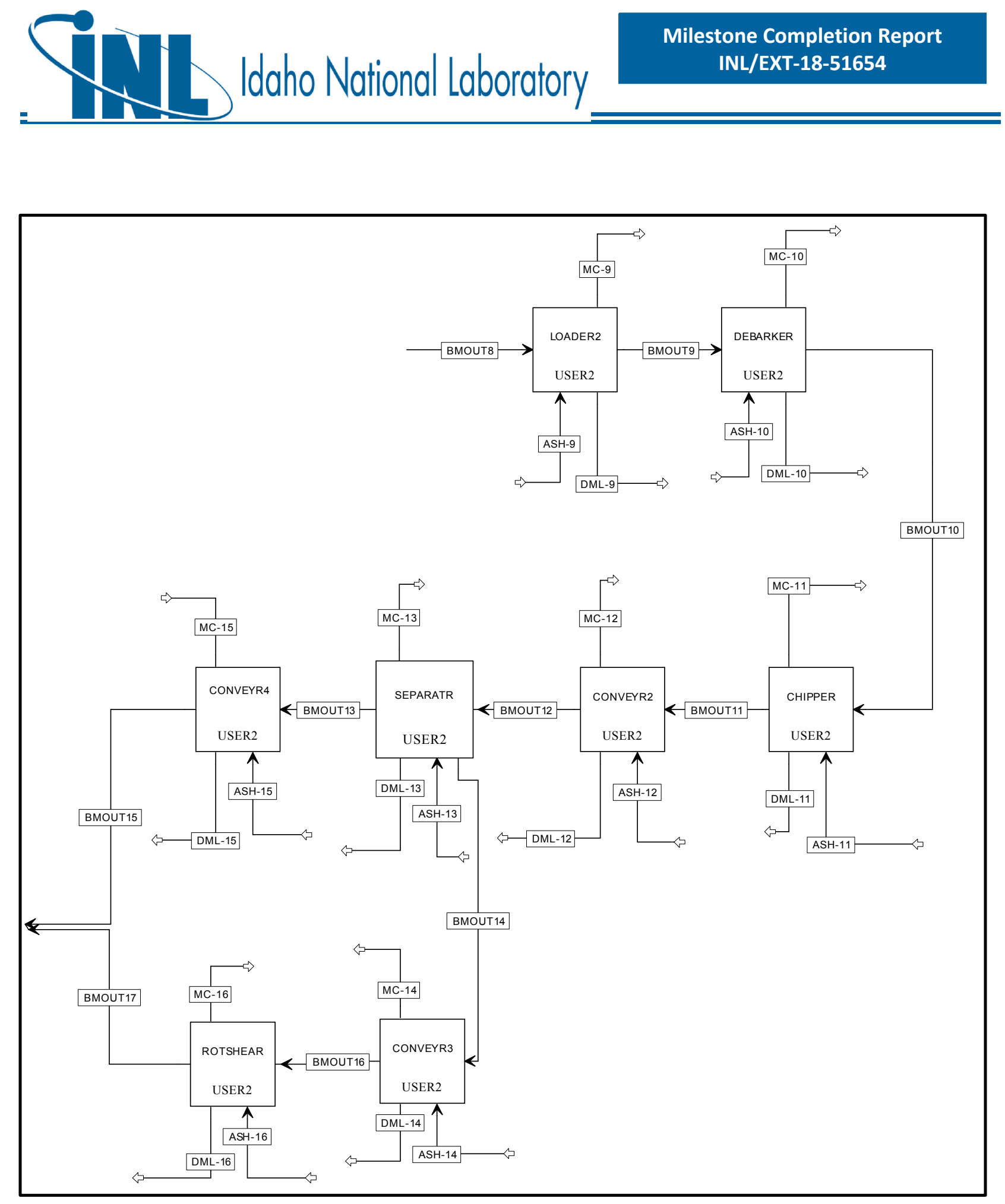

Figure H-10. Detailed process flow diagram for area B300 - Preprocessing - Size Reduction. 

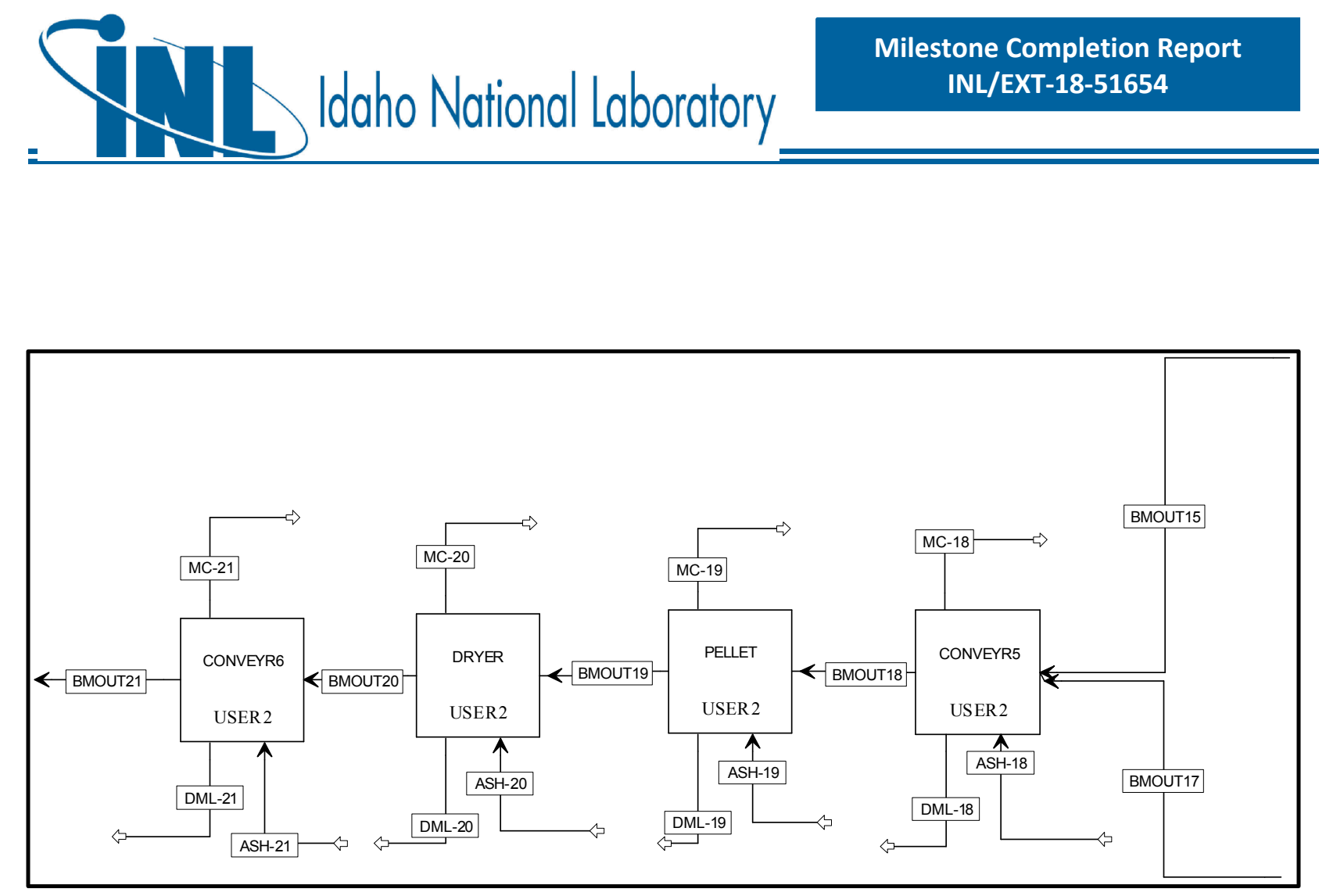

Figure H-11. Detailed process flow diagram for area B400 - Preprocessing - Pelleting.

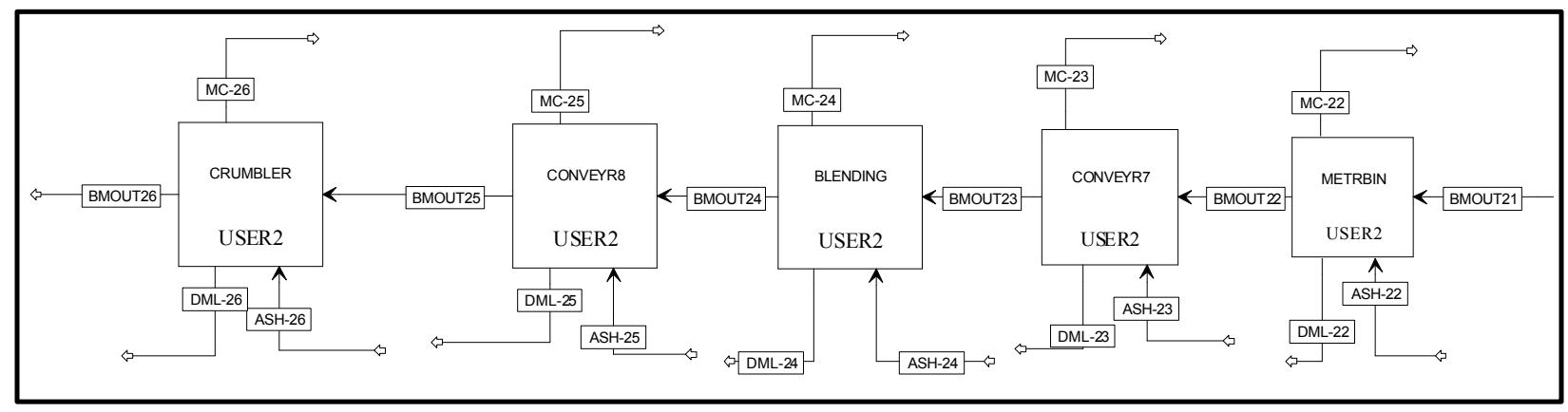

Figure H-12. Detailed process flow diagram for area B500 - Feeding. 


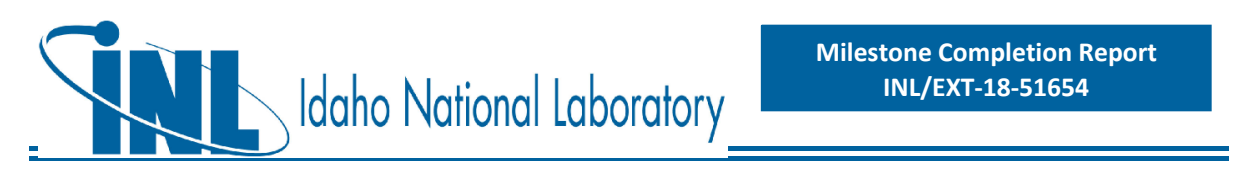

Table H-3. Aspen Plus mass balances from harvest to field-side storage (Area B100) for the two-pass corn stover blendstock in the Primary Depot Co-located with the Biorefinery Case. Harvest is assumed to take place within a 6 week period, working 14 hours/day, 6 days per week.

\begin{tabular}{|c|c|c|c|c|c|c|c|c|c|c|c|c|}
\hline Component & unit & BIOMIN & DML-1 & MC-1 & BMOUT1 & DML-3 & MC-3 & ASH-3 & BMOUT3 & DML-4 & MC-4 & BMOUT4 \\
\hline $\begin{array}{l}\text { Overall Flow } \\
\text { (moisture and } \\
\text { dry matter) }\end{array}$ & $\mathrm{kg} / \mathrm{hr}$ & $1,106,530$ & 0 & 16 & $1,106,514$ & 0 & 0 & 16,032 & $1,106,514$ & 0 & 0 & $1,106,514$ \\
\hline Moisture Flow & $\mathrm{kg} / \mathrm{hr}$ & 331,967 & 0 & 16 & 331,952 & 0 & 0 & 0 & 331,952 & 0 & 0 & 331,952 \\
\hline $\begin{array}{l}\text { Total Flow (dry } \\
\text { matter) }\end{array}$ & $\mathrm{kg} / \mathrm{hr}$ & 774,564 & 0 & 0 & 774,564 & 0 & 0 & 16,032 & 774,564 & 0 & 0 & 774,564 \\
\hline C6 & $\mathrm{kg} / \mathrm{hr}$ & 286,818 & 0 & 0 & 286,818 & 0 & 0 & 0 & 286,818 & 0 & 0 & 286,818 \\
\hline C5 & $\mathrm{kg} / \mathrm{hr}$ & 165,758 & 0 & 0 & 165,758 & 0 & 0 & 0 & 165,758 & 0 & 0 & 165,758 \\
\hline LIGNIN & $\mathrm{kg} / \mathrm{hr}$ & 119,585 & 0 & 0 & 119,585 & 0 & 0 & 0 & 119,585 & 0 & 0 & 119,585 \\
\hline ASH & $\mathrm{kg} / \mathrm{hr}$ & 38,181 & 0 & 0 & 38,181 & 0 & 0 & 16,032 & 54,213 & 0 & 0 & 54,213 \\
\hline PROTEIN & $\mathrm{kg} / \mathrm{hr}$ & 23,467 & 0 & 0 & 23,467 & 0 & 0 & 0 & 23,467 & 0 & 0 & 23,467 \\
\hline $\begin{array}{l}\text { EXTRACTIVE } \\
\text { S } \\
\end{array}$ & $\mathrm{kg} / \mathrm{hr}$ & 111,235 & 0 & 0 & 111,235 & 0 & 0 & 0 & 111,235 & 0 & 0 & 111,235 \\
\hline OTHERS & $\mathrm{kg} / \mathrm{hr}$ & 13,472 & 0 & 0 & 13,472 & 0 & 0 & 0 & 13,472 & 0 & 0 & 13,472 \\
\hline Temperature & $\mathrm{K}$ & 298 & 298 & 298 & 298 & 298 & 298 & 298 & 298 & 298 & 298 & 298 \\
\hline Pressure & $\mathrm{atm}$ & 1 & 1 & 1 & 1 & 1 & 1 & 1 & 1 & 1 & 1 & 1 \\
\hline Vapor Frac & & 0 & 0 & 0 & 0 & 0 & 0 & 0 & 0 & 0 & 0 & 0 \\
\hline
\end{tabular}


Table H-4. Aspen Plus mass balances from field-side storage to feeding (Areas B200-B500) for the two-pass corn stover blendstock in the Primary Depot Co-located with the Biorefinery Case. Depot operation is assumed to take place within 350 day period, working 24 hours/day, 7 days per week.

\begin{tabular}{|c|c|c|c|c|c|c|c|c|c|c|c|c|c|}
\hline Component & unit & DML-5 & MC-5 & BMOUT5 & DML-6 & MC-6 & BMOUT6 & $\begin{array}{c}\text { DML- } \\
7\end{array}$ & MC-7 & BMOUT7 & DML-8 & MC-8 & BMOUT8 \\
\hline $\begin{array}{l}\text { Overall Flow } \\
\text { (moisture and dry } \\
\text { matter) }\end{array}$ & $\mathrm{kg} / \mathrm{hr}$ & 5,577 & 6,274 & 54,540 & 0 & 0 & 54,540 & 0 & 0 & 54,540 & 0 & 0 & 54,540 \\
\hline Moisture Flow & $\mathrm{kg} / \mathrm{hr}$ & 0 & 6,274 & 13,644 & 0 & 0 & 13,643 & 0 & 0 & 13,643 & 0 & 0 & 13,643 \\
\hline $\begin{array}{l}\text { Total Flow (dry } \\
\text { matter) }\end{array}$ & $\mathrm{kg} / \mathrm{hr}$ & 5,577 & 0 & 40,897 & 0 & 0 & 40,897 & 0 & 0 & 40,897 & 0 & 0 & 40,897 \\
\hline C6 & $\mathrm{kg} / \mathrm{hr}$ & 1,029 & 0 & 16,180 & 0 & 0 & 16,180 & 0 & 0 & 16,180 & 0 & 0 & 16,180 \\
\hline C5 & $\mathrm{kg} / \mathrm{hr}$ & 1,614 & 0 & 8,332 & 0 & 0 & 8,332 & 0 & 0 & 8,332 & 0 & 0 & 8,332 \\
\hline LIGNIN & $\mathrm{kg} / \mathrm{hr}$ & 359 & 0 & 6,816 & 0 & 0 & 6,816 & 0 & 0 & 6,816 & 0 & 0 & 6,816 \\
\hline ASH & $\mathrm{kg} / \mathrm{hr}$ & 0 & 0 & 3,253 & 0 & 0 & 3,253 & 0 & 0 & 3,253 & 0 & 0 & 3,253 \\
\hline PROTEIN & $\mathrm{kg} / \mathrm{hr}$ & 168 & 0 & 1,240 & 0 & 0 & 1,240 & 0 & 0 & 1,240 & 0 & 0 & 1,240 \\
\hline EXTRACTIVES & $\mathrm{kg} / \mathrm{hr}$ & 1,672 & 0 & 5,001 & 0 & 0 & 5,001 & 0 & 0 & 5,001 & 0 & 0 & 5,001 \\
\hline OTHERS & $\mathrm{kg} / \mathrm{hr}$ & 735 & 0 & 74 & 0 & 0 & 74 & 0 & 0 & 74 & 0 & 0 & 74 \\
\hline Temperature & $\mathrm{K}$ & 298 & 298 & 298 & 298 & 298 & 298 & 298 & 298 & 298 & 298 & 298 & 298 \\
\hline Pressure & atm & 1 & 1 & 1 & 1 & 1 & 1 & 1 & 1 & 1 & 1 & 1 & 1 \\
\hline Vapor Frac & & 0 & 0 & 0 & 0 & 0 & 0 & 0 & 0 & 0 & 0 & 0 & 0 \\
\hline
\end{tabular}


lacho National Laboratory

Table H-4. (continued)

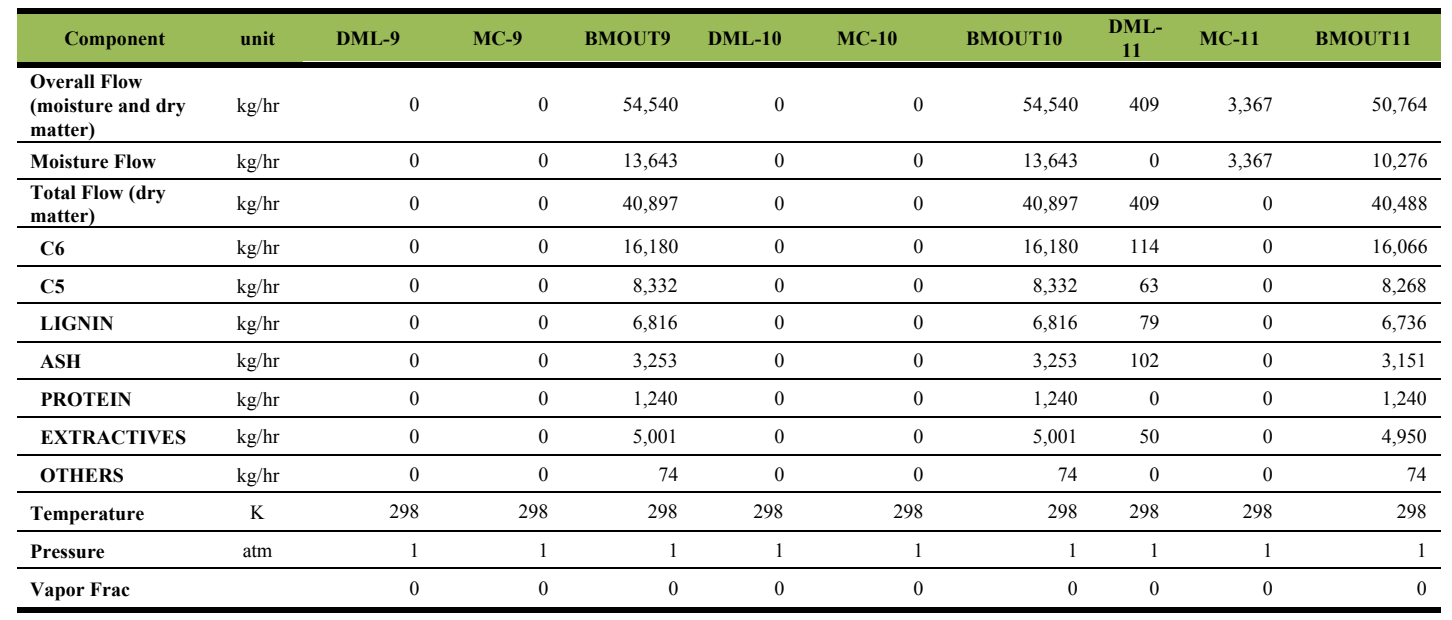


lacho National Laboratory

Table H-4. (continued)

\begin{tabular}{|c|c|c|c|c|c|c|c|c|c|c|}
\hline Component & unit & $\begin{array}{l}\text { DML- } \\
12\end{array}$ & $\begin{array}{l}\text { MC- } \\
12\end{array}$ & BMOUT12 & $\begin{array}{c}\text { DML- } \\
13\end{array}$ & MC-13 & BMOUT13 & DML-14 & MC-14 & BMOUT14 \\
\hline $\begin{array}{l}\text { Overall Flow } \\
\text { (moisture and dry } \\
\text { matter) }\end{array}$ & $\mathrm{kg} / \mathrm{hr}$ & 0 & 0 & 50,764 & 0 & 1,242 & 21,983 & 0 & 0 & 27,539 \\
\hline Moisture Flow & $\mathrm{kg} / \mathrm{hr}$ & 0 & 0 & 10,276 & 0 & 1,242 & 4,010 & 0 & 0 & 5,024 \\
\hline $\begin{array}{l}\text { Total Flow (dry } \\
\text { matter) }\end{array}$ & $\mathrm{kg} / \mathrm{hr}$ & 0 & 0 & 40,488 & 0 & 0 & 17,973 & 0 & 0 & 22,515 \\
\hline C6 & $\mathrm{kg} / \mathrm{hr}$ & 0 & 0 & 16,066 & 0 & 0 & 7,132 & 0 & 0 & 8,934 \\
\hline C5 & $\mathrm{kg} / \mathrm{hr}$ & 0 & 0 & 8,268 & 0 & 0 & 3,670 & 0 & 0 & 4,598 \\
\hline LIGNIN & $\mathrm{kg} / \mathrm{hr}$ & 0 & 0 & 6,736 & 0 & 0 & 2,990 & 0 & 0 & 3,746 \\
\hline ASH & $\mathrm{kg} / \mathrm{hr}$ & 0 & 0 & 3,151 & 0 & 0 & 1,399 & 0 & 0 & 1,753 \\
\hline PROTEIN & $\mathrm{kg} / \mathrm{hr}$ & 0 & 0 & 1,240 & 0 & 0 & 550 & 0 & 0 & 690 \\
\hline EXTRACTIVES & $\mathrm{kg} / \mathrm{hr}$ & 0 & 0 & 4,950 & 0 & 0 & 2,198 & 0 & 0 & 2,753 \\
\hline OTHERS & $\mathrm{kg} / \mathrm{hr}$ & 0 & 0 & 74 & 0 & 0 & 33 & 0 & 0 & 41 \\
\hline Temperature & K & 298 & 298 & 298 & 298 & 298 & 298 & 298 & 298 & 298 \\
\hline Pressure & atm & 1 & 1 & 1 & 1 & 1 & 1 & 1 & 1 & 1 \\
\hline Vapor Frac & & 0 & 0 & 0 & 0 & 0 & 0 & 0 & 0 & 0 \\
\hline
\end{tabular}


Table H-4. (continued)

\begin{tabular}{|c|c|c|c|c|c|c|c|c|}
\hline Component & unit & DML-15 & MC-15 & BMOUT15 & DML-16 & MC-16 & BMOUT16 & BMOUT17 \\
\hline $\begin{array}{l}\text { Overall Flow } \\
\text { (moisture and dry } \\
\text { matter) }\end{array}$ & $\mathrm{kg} / \mathrm{hr}$ & 0 & 0 & 21,983 & 225 & 50 & 27,539 & 27,264 \\
\hline Moisture Flow & $\mathrm{kg} / \mathrm{hr}$ & 0 & 0 & 4,010 & 0 & 50 & 5,024 & 4,974 \\
\hline $\begin{array}{l}\text { Total Flow (dry } \\
\text { matter) }\end{array}$ & $\mathrm{kg} / \mathrm{hr}$ & 0 & 0 & 17,973 & 225 & 0 & 22,515 & 22,290 \\
\hline C6 & $\mathrm{kg} / \mathrm{hr}$ & 0 & 0 & 7,132 & 62 & 0 & 8,934 & 8,872 \\
\hline C5 & $\mathrm{kg} / \mathrm{hr}$ & 0 & 0 & 3,670 & 35 & 0 & 4,598 & 4,563 \\
\hline LIGNIN & $\mathrm{kg} / \mathrm{hr}$ & 0 & 0 & 2,990 & 44 & 0 & 3,746 & 3,703 \\
\hline ASH & $\mathrm{kg} / \mathrm{hr}$ & 0 & 0 & 1,399 & 56 & 0 & 1,753 & 1,696 \\
\hline PROTEIN & $\mathrm{kg} / \mathrm{hr}$ & 0 & 0 & 550 & 0 & 0 & 690 & 690 \\
\hline EXTRACTIVES & $\mathrm{kg} / \mathrm{hr}$ & 0 & 0 & 2,198 & 28 & 0 & 2,753 & 2,726 \\
\hline OTHERS & $\mathrm{kg} / \mathrm{hr}$ & 0 & 0 & 33 & 0 & 0 & 41 & 41 \\
\hline Temperature & K & 298 & 298 & 298 & 298 & 298 & 298 & 298 \\
\hline Pressure & $\mathrm{atm}$ & 1 & 1 & 1 & 1 & 1 & 1 & 1 \\
\hline Vapor Frac & & 0 & 0 & 0 & 0 & 0 & 0 & 0 \\
\hline
\end{tabular}


Waho National Laboratory

Table H-4. (continued)

\begin{tabular}{|c|c|c|c|c|c|c|c|c|c|c|c|c|c|}
\hline Component & unit & DML-18 & MC-18 & BMOUT18 & $\begin{array}{l}\text { DML- } \\
19\end{array}$ & MC-19 & BMOUT19 & DML-20 & MC-20 & $\begin{array}{c}\text { BMOUT2 } \\
0\end{array}$ & DML-21 & MC-21 & BMOUT21 \\
\hline $\begin{array}{l}\text { Overall Flow } \\
\text { (moisture and dry } \\
\text { matter) }\end{array}$ & $\mathrm{kg} / \mathrm{hr}$ & 0 & 0 & 49,246 & 0 & 2,839 & 46,407 & 0 & 892 & 45,515 & 0 & 0 & 45,515 \\
\hline Moisture Flow & $\mathrm{kg} / \mathrm{hr}$ & 0 & 0 & 8,984 & 0 & 2,839 & 6,144 & 0 & 892 & 5,252 & 0 & 0 & 5,252 \\
\hline $\begin{array}{l}\text { Total Flow (dry } \\
\text { matter) }\end{array}$ & $\mathrm{kg} / \mathrm{hr}$ & 0 & 0 & 40,263 & 0 & 0 & 40,263 & 0 & 0 & 40,263 & 0 & 0 & 40,263 \\
\hline C6 & $\mathrm{kg} / \mathrm{hr}$ & 0 & 0 & 16,004 & 0 & 0 & 16,004 & 0 & 0 & 16,004 & 0 & 0 & 16,004 \\
\hline C5 & $\mathrm{kg} / \mathrm{hr}$ & 0 & 0 & 8,233 & 0 & 0 & 8,233 & 0 & 0 & 8,233 & 0 & 0 & 8,233 \\
\hline LIGNIN & $\mathrm{kg} / \mathrm{hr}$ & 0 & 0 & 6,693 & 0 & 0 & 6,693 & 0 & 0 & 6,693 & 0 & 0 & 6,693 \\
\hline ASH & $\mathrm{kg} / \mathrm{hr}$ & 0 & 0 & 3,094 & 0 & 0 & 3,094 & 0 & 0 & 3,094 & 0 & 0 & 3,094 \\
\hline PROTEIN & $\mathrm{kg} / \mathrm{hr}$ & 0 & 0 & 1,240 & 0 & 0 & 1,240 & 0 & 0 & 1,240 & 0 & 0 & 1,240 \\
\hline EXTRACTIVES & $\mathrm{kg} / \mathrm{hr}$ & 0 & 0 & 4,922 & 0 & 0 & 4,922 & 0 & 0 & 4,922 & 0 & 0 & 4,922 \\
\hline OTHERS & $\mathrm{kg} / \mathrm{hr}$ & 0 & 0 & 74 & 0 & 0 & 74 & 0 & 0 & 74 & 0 & 0 & 74 \\
\hline Temperature & K & 298 & 298 & 298 & 298 & 298 & 298 & 298 & 298 & 298 & 298 & 298 & 298 \\
\hline Pressure & atm & 1 & 1 & 1 & 1 & 1 & 1 & 1 & 1 & 1 & 1 & 1 & 1 \\
\hline Vapor Frac & & 0 & 0 & 0 & 0 & 0 & 0 & 0 & 0 & 0 & 0 & 0 & 0 \\
\hline
\end{tabular}


Table H-4. (continued)

\begin{tabular}{|c|c|c|c|c|c|c|c|c|c|c|c|c|c|}
\hline Component & unit & $\begin{array}{l}\text { DML- } \\
22\end{array}$ & $\begin{array}{l}\text { MC- } \\
22\end{array}$ & BMOUT22 & $\begin{array}{c}\text { DML- } \\
23\end{array}$ & $\begin{array}{l}\text { MC- } \\
23\end{array}$ & BMOUT23 & DML-24 & MC-24 & BMOUT24 & DML-25 & MC-25 & BMOUT25 \\
\hline $\begin{array}{l}\text { Overall Flow } \\
\text { (moisture and dry } \\
\text { matter) }\end{array}$ & $\mathrm{kg} / \mathrm{hr}$ & 0 & 0 & 45,515 & 0 & 0 & 45,515 & 0 & 0 & 45,515 & 0 & 0 & 45,515 \\
\hline Moisture Flow & $\mathrm{kg} / \mathrm{hr}$ & 0 & 0 & 5,252 & 0 & 0 & 5,252 & 0 & 0 & 5,252 & 0 & 0 & 5,252 \\
\hline $\begin{array}{l}\text { Total Flow (dry } \\
\text { matter) }\end{array}$ & $\mathrm{kg} / \mathrm{hr}$ & 0 & 0 & 40,263 & 0 & 0 & 40,263 & 0 & 0 & 40,263 & 0 & 0 & 40,263 \\
\hline C6 & $\mathrm{kg} / \mathrm{hr}$ & 0 & 0 & 16,004 & 0 & 0 & 16,004 & 0 & 0 & 16,004 & 0 & 0 & 16,004 \\
\hline C5 & $\mathrm{kg} / \mathrm{hr}$ & 0 & 0 & 8,233 & 0 & 0 & 8,233 & 0 & 0 & 8,233 & 0 & 0 & 8,233 \\
\hline LIGNIN & $\mathrm{kg} / \mathrm{hr}$ & 0 & 0 & 6,693 & 0 & 0 & 6,693 & 0 & 0 & 6,693 & 0 & 0 & 6,693 \\
\hline ASH & $\mathrm{kg} / \mathrm{hr}$ & 0 & 0 & 3,094 & 0 & 0 & 3,094 & 0 & 0 & 3,094 & 0 & 0 & 3,094 \\
\hline PROTEIN & $\mathrm{kg} / \mathrm{hr}$ & 0 & 0 & 1,240 & 0 & 0 & 1,240 & 0 & 0 & 1,240 & 0 & 0 & 1,240 \\
\hline EXTRACTIVES & $\mathrm{kg} / \mathrm{hr}$ & 0 & 0 & 4,922 & 0 & 0 & 4,922 & 0 & 0 & 4,922 & 0 & 0 & 4,922 \\
\hline OTHERS & $\mathrm{kg} / \mathrm{hr}$ & 0 & 0 & 74 & 0 & 0 & 74 & 0 & 0 & 74 & 0 & 0 & 74 \\
\hline Temperature & K & 298 & 298 & 298 & 298 & 298 & 298 & 298 & 298 & 298 & 298 & 298 & 298 \\
\hline Pressure & atm & 1 & 1 & 1 & 1 & 1 & 1 & 1 & 1 & 1 & 1 & 1 & 1 \\
\hline Vapor Frac & & 0 & 0 & 0 & 0 & 0 & 0 & 0 & 0 & 0 & 0 & 0 & 0 \\
\hline
\end{tabular}


Table H-4. (continued)

\begin{tabular}{lcccr}
\hline \multicolumn{1}{c}{ Component } & unit & DML-26 & MC-26 & BMOUT26 \\
\hline $\begin{array}{l}\text { Overall Flow } \\
\text { (moisture and dry } \\
\text { matter) }\end{array}$ & $\mathrm{kg} / \mathrm{hr}$ & 0 & 0 & 45,515 \\
\hline Moisture Flow & $\mathrm{kg} / \mathrm{hr}$ & 0 & 0 & 5,252 \\
\hline $\begin{array}{l}\text { Total Flow }(\mathrm{dry} \\
\text { matter) }\end{array}$ & $\mathrm{kg} / \mathrm{hr}$ & 0 & 0 & 40,263 \\
\hline C6 & $\mathrm{kg} / \mathrm{hr}$ & 0 & 0 & 16,004 \\
\hline C5 & $\mathrm{kg} / \mathrm{hr}$ & 0 & 0 & 8,233 \\
\hline LIGNIN & $\mathrm{kg} / \mathrm{hr}$ & 0 & 0 & 6,693 \\
\hline ASH & $\mathrm{kg} / \mathrm{hr}$ & 0 & 0 & 3,094 \\
\hline PROTEIN & $\mathrm{kg} / \mathrm{hr}$ & 0 & 0 & 1,240 \\
\hline EXTRACTIVES & $\mathrm{kg} / \mathrm{hr}$ & 0 & 0 & 4,922 \\
\hline OTHERS & $\mathrm{kg} / \mathrm{hr}$ & 0 & 0 & 74 \\
\hline Temperature & $\mathrm{K}$ & 298 & 298 & 298 \\
\hline Pressure & $\mathrm{atm}$ & 1 & 1 & 1 \\
\hline Vapor Frac & & 0 & 0 & 0 \\
\hline
\end{tabular}




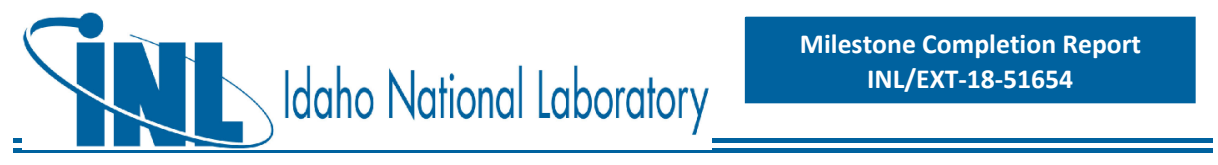




\section{H.3 Switchgrass Blendstock}

High-level stream table information from Aspen Plus modeling output follows, for key streams associated with each process operation area. This is followed by high-level PFDs for the associated process areas. Space for stream tables was limited; below is a key to lumped components. As the stream table information focuses primarily on the high-level overall process and does not include every individual modeled stream within each process area, mass balance closure around a given unit area may not be $100 \%$.

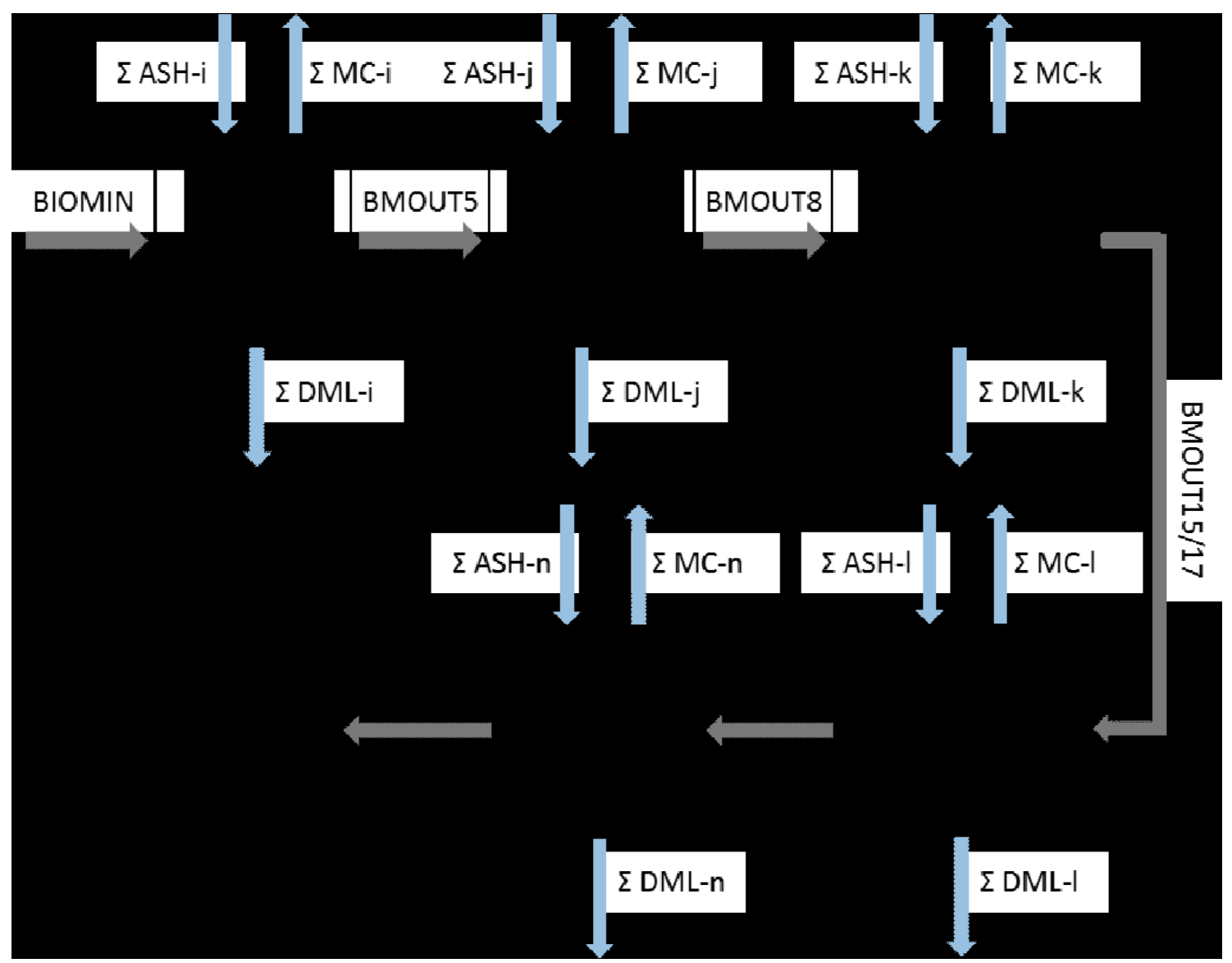

Figure H-13. High-level flowsheet showing key process areas for the switchgrass blendstock in the Primary Depot Co-located with the Biorefinery Case. 

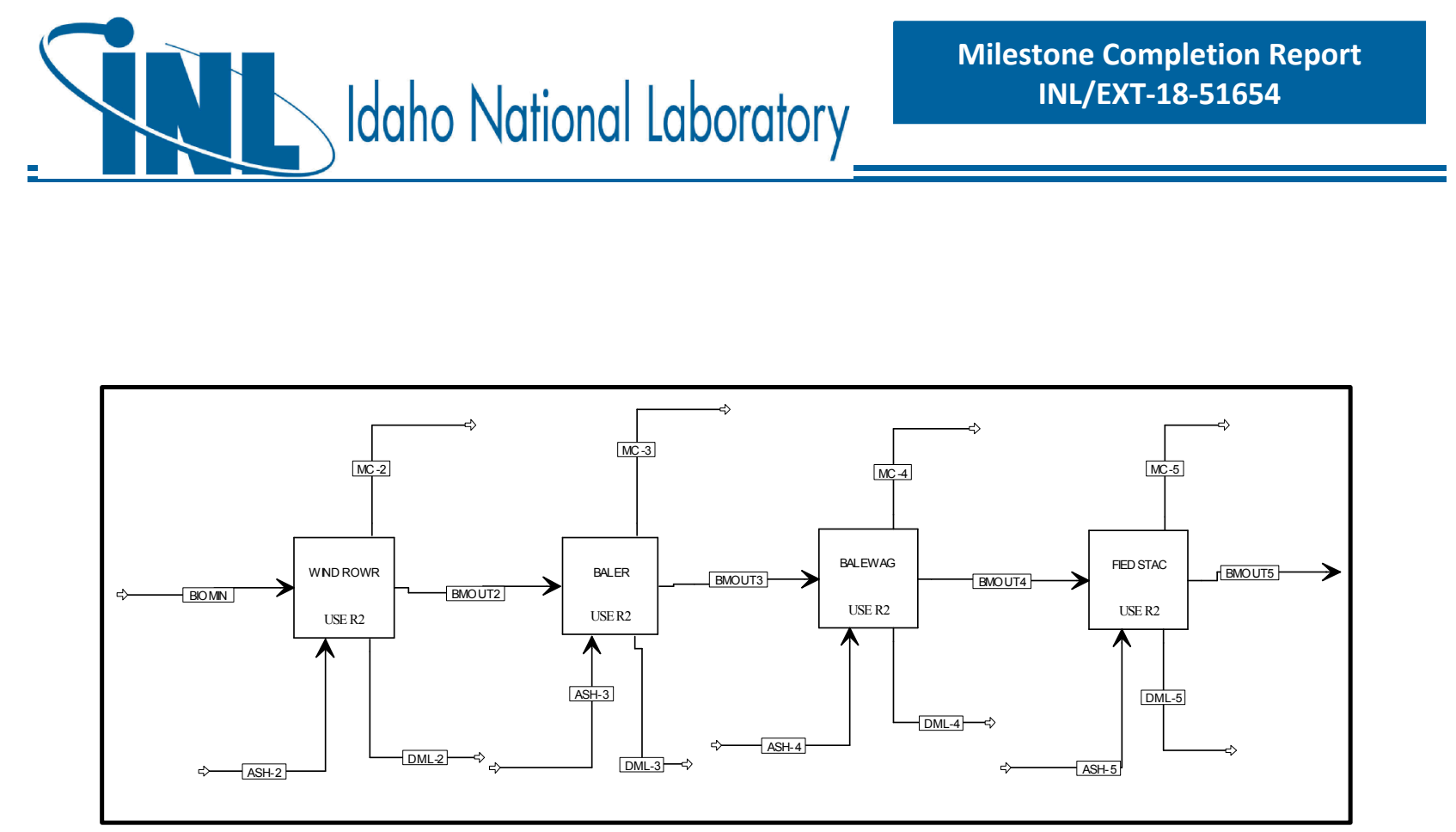

Figure H-14. Detailed process flow diagram for area C100 - Harvesting to Storage.

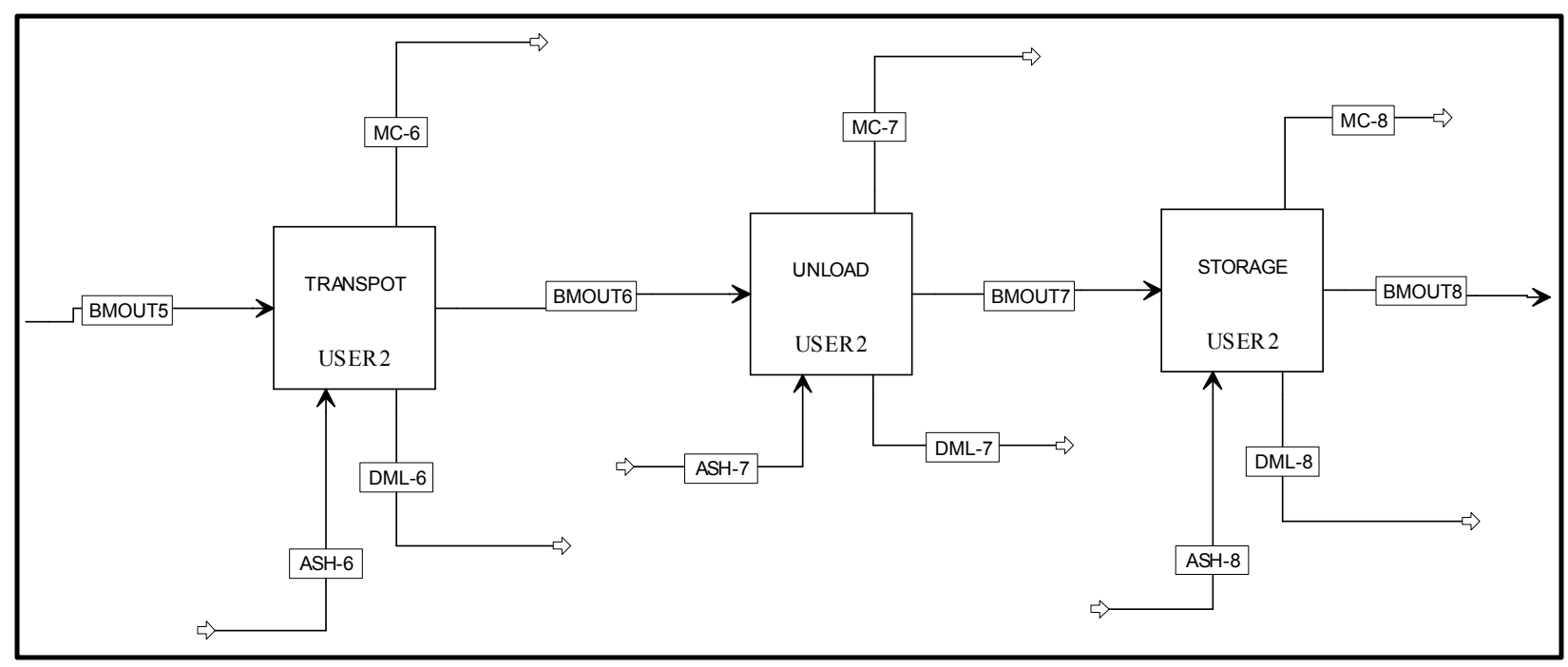

Figure H-15. Detailed process flow diagram for area C200 - Transport to Biorefinery \& Handling. 


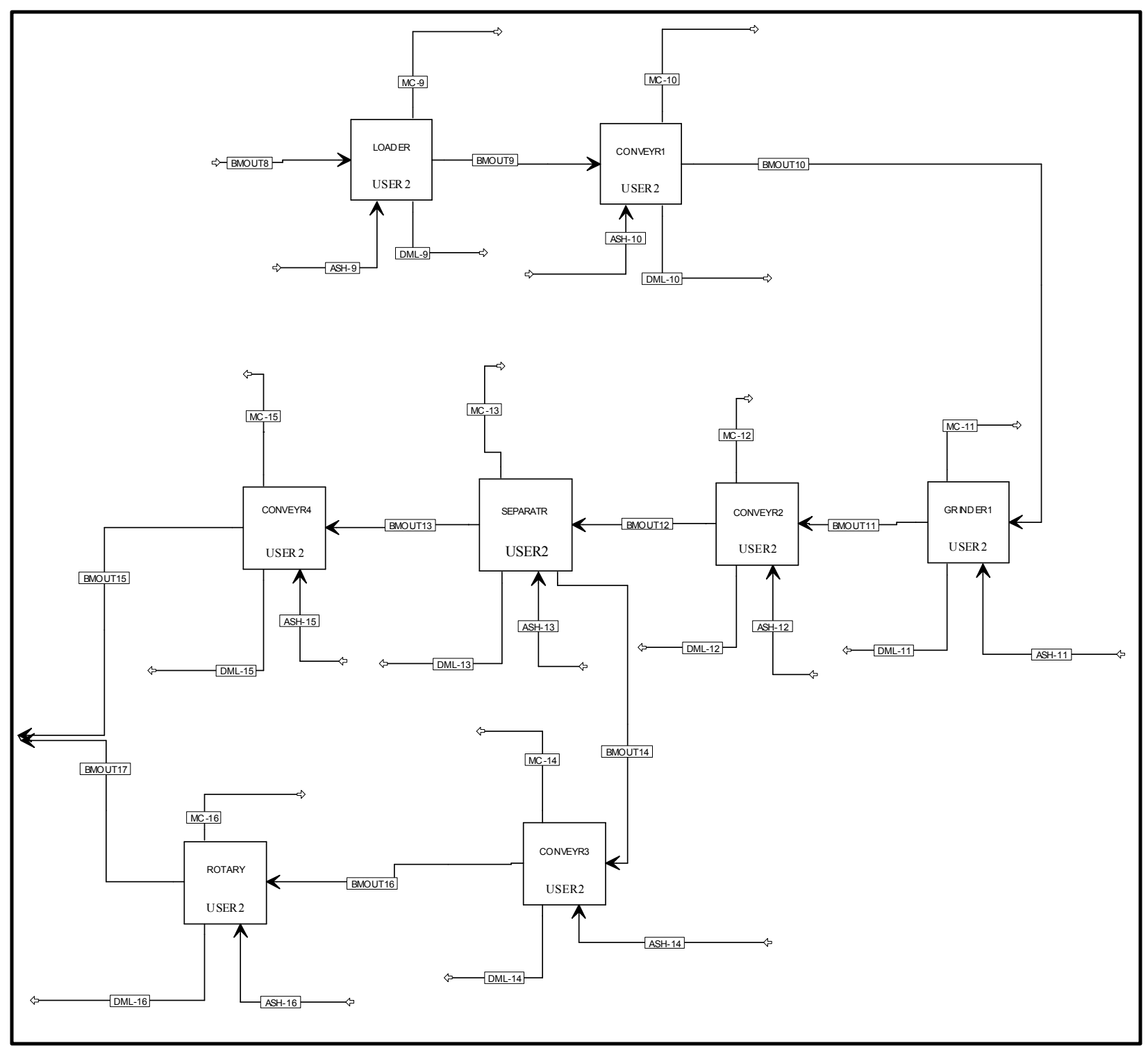

Figure H-16. Detailed process flow diagram for area C300 - Preprocessing - Size Reduction. 

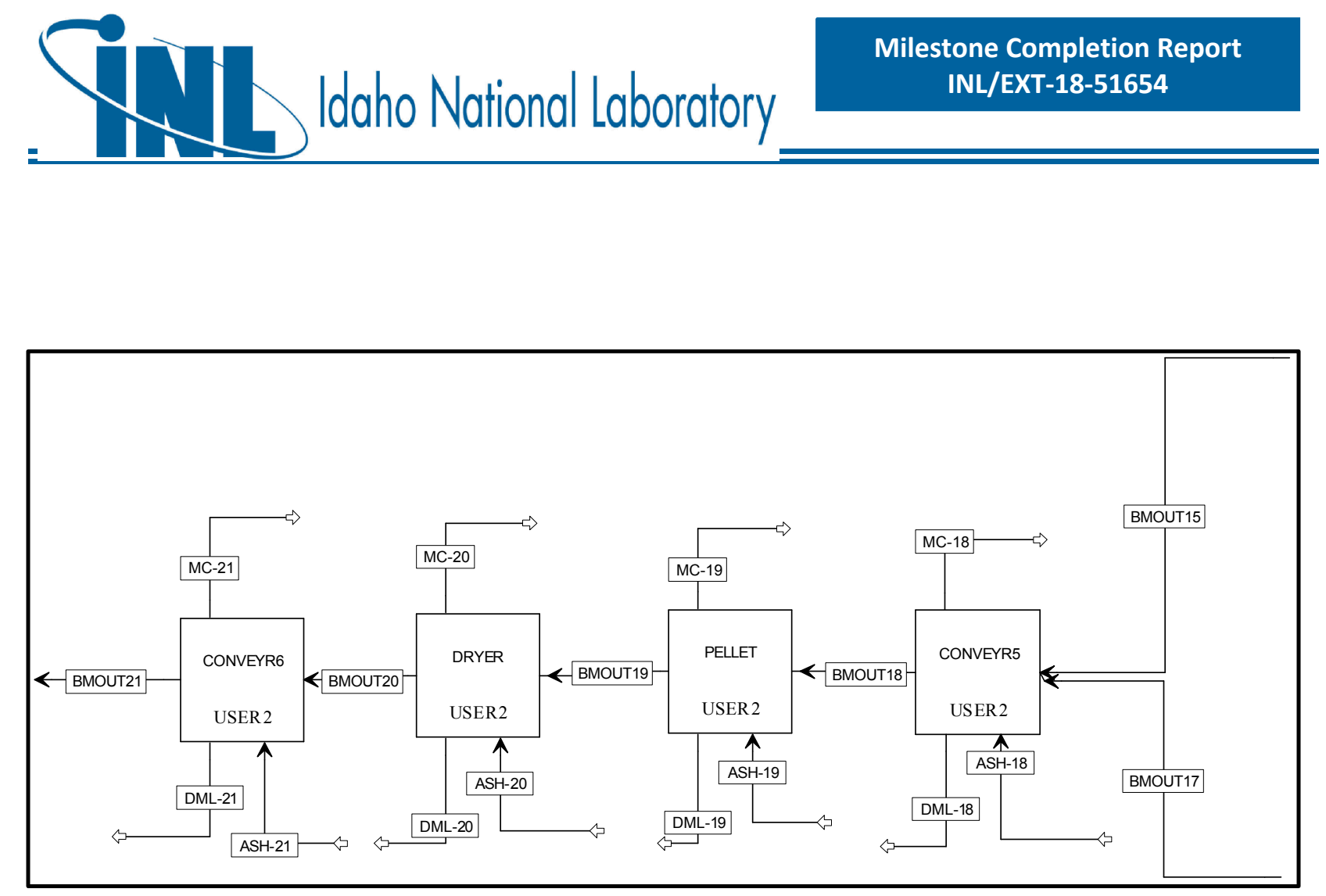

Figure H-17. Detailed process flow diagram for area C400 - Preprocessing - Pelleting.

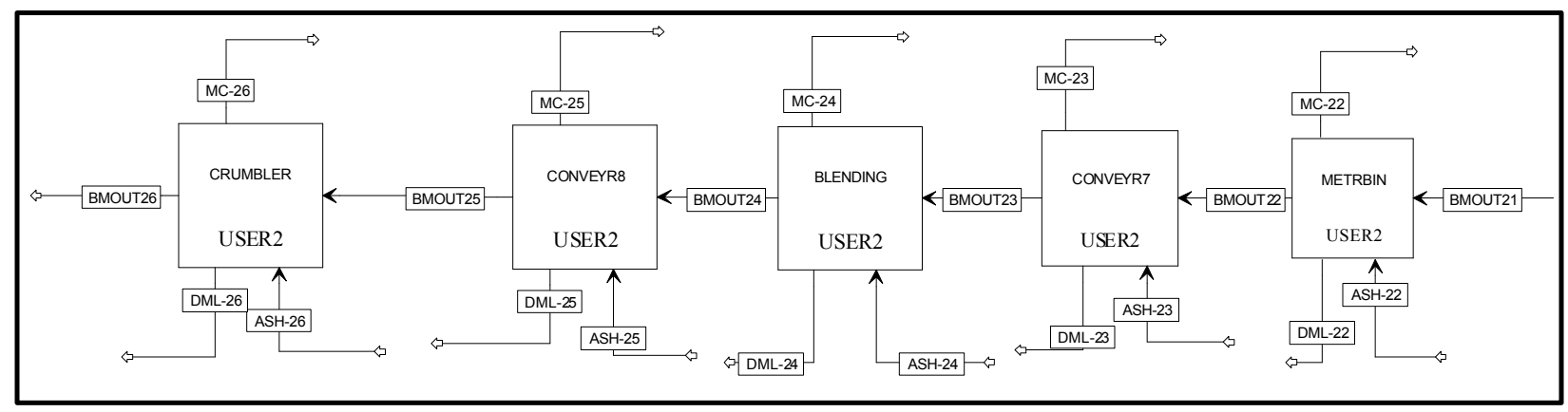

Figure H-18. Detailed process flow diagram for area C500 - Feeding. 
Table H-5. Aspen Plus mass balances from harvest to field-side storage (Area C100) for the switchgrass blendstock in the Primary Depot Colocated with the Biorefinery Case. Harvest is assumed to take place within a 6 week period, working 14 hours/day, 6 days per week.

\begin{tabular}{|c|c|c|c|c|c|c|c|c|c|c|c|c|c|}
\hline Component & unit & BIOMIN & DML-2 & MC-2 & & BMOUT2 & DML-3 & MC-3 & & BMOUT3 & DML-4 & MC-4 & BMOUT4 \\
\hline $\begin{array}{l}\text { Overall Flow } \\
\text { (moisture and } \\
\text { dry matter) }\end{array}$ & $\mathrm{kg} / \mathrm{hr}$ & 181,400 & 0 & & 0 & 181,400 & 0 & & 0 & 181,400 & 0 & 0 & 181,400 \\
\hline Moisture Flow & $\mathrm{kg} / \mathrm{hr}$ & 36,283 & 0 & & 0 & 36,283 & 0 & & 0 & 36,283 & 0 & 0 & 36,283 \\
\hline $\begin{array}{l}\text { Total Flow (dry } \\
\text { matter) }\end{array}$ & $\mathrm{kg} / \mathrm{hr}$ & 145,117 & 0 & & 0 & 145,117 & 0 & & 0 & 145,117 & 0 & 0 & 145,117 \\
\hline C6 & $\mathrm{kg} / \mathrm{hr}$ & 51,633 & 0 & & 0 & 51,633 & 0 & & 0 & 51,633 & 0 & 0 & 51,633 \\
\hline C5 & $\mathrm{kg} / \mathrm{hr}$ & 42,233 & 0 & & 0 & 42,233 & 0 & & 0 & 42,233 & 0 & 0 & 42,233 \\
\hline LIGNIN & $\mathrm{kg} / \mathrm{hr}$ & 25,783 & 0 & & 0 & 25,783 & 0 & & 0 & 25,783 & 0 & 0 & 25,783 \\
\hline ASH & $\mathrm{kg} / \mathrm{hr}$ & 9,000 & 0 & & 0 & 9,000 & 0 & & 0 & 9,000 & 0 & 0 & 9,000 \\
\hline PROTEIN & $\mathrm{kg} / \mathrm{hr}$ & 0 & & 0 & 0 & 0 & & 0 & 0 & 0 & c & 0 & 0 \\
\hline $\begin{array}{l}\text { EXTRACTIVE } \\
\text { S }\end{array}$ & $\mathrm{kg} / \mathrm{hr}$ & 16,467 & 0 & & 0 & 16,467 & 0 & & 0 & 16,467 & 0 & 0 & 16,467 \\
\hline OTHERS & $\mathrm{kg} / \mathrm{hr}$ & 0 & c & 0 & 0 & 0 & & 0 & 0 & 0 & 0 & 0 & 0 \\
\hline Temperature & $\mathrm{K}$ & 298 & 298 & & 298 & 298 & 298 & & 298 & 298 & 298 & 298 & 298 \\
\hline Pressure & atm & 1 & 1 & & 1 & 1 & 1 & & 1 & 1 & 1 & 1 & 1 \\
\hline Vapor Frac & & 0 & 0 & & 0 & 0 & 0 & 0 & 0 & 0 & 0 & 0 & 0 \\
\hline
\end{tabular}


Table H-6. Aspen Plus mass balances from field-side storage to feeding (Areas C200-C500) for the switchgrass blendstock in the Primary Depot Co-located with the Biorefinery Case. Depot operation is assumed to take place within 350 day period, working 24 hours/day, 7 days per week.

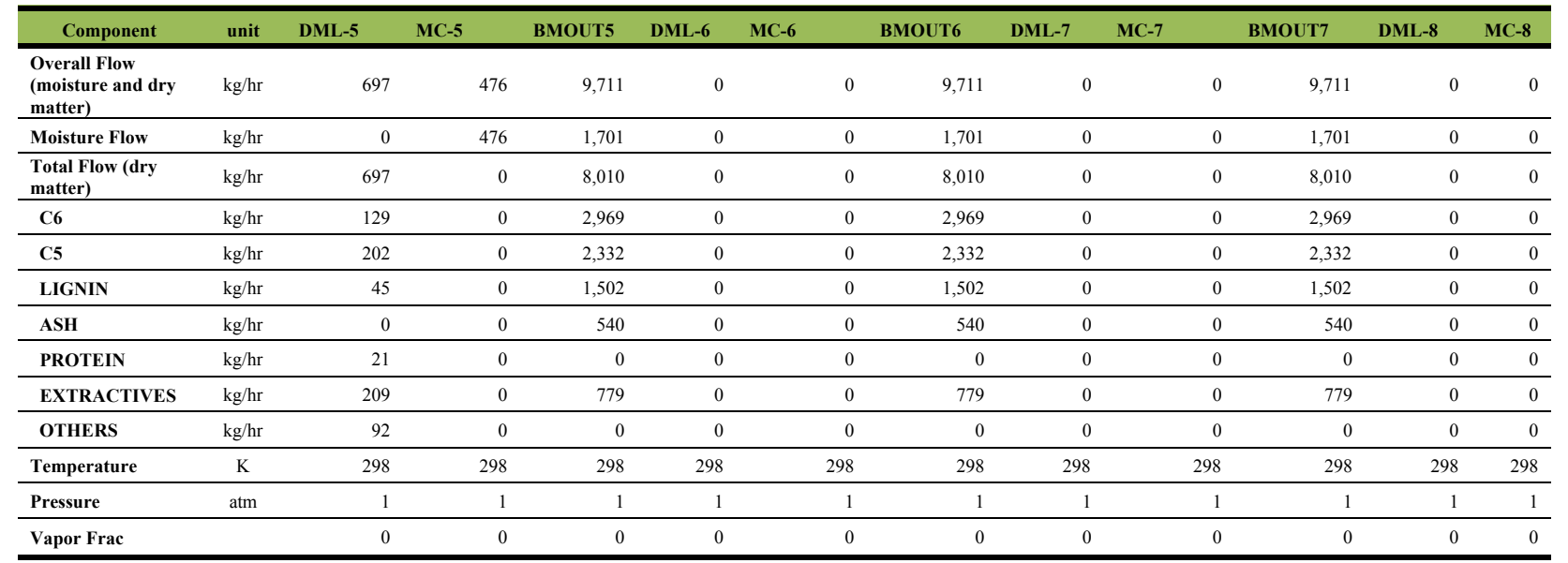


Table H-6. (continued)

\begin{tabular}{|c|c|c|c|c|c|c|c|c|c|c|c|}
\hline Component & unit & BMOUT8 & DML-9 & MC-9 & BMOUT9 & DML-10 & MC-10 & BMOUT10 & DML-11 & MC-11 & BMOUT11 \\
\hline $\begin{array}{l}\text { Overall Flow (moisture } \\
\text { and dry matter) }\end{array}$ & $\mathrm{kg} / \mathrm{hr}$ & 9,711 & 0 & 0 & 9,711 & 0 & 0 & 9,711 & 68 & 355 & 9,288 \\
\hline Moisture Flow & $\mathrm{kg} / \mathrm{hr}$ & 1,701 & 0 & 0 & 1,701 & 0 & 0 & 1,701 & 0 & 355 & 1,346 \\
\hline Total Flow (dry matter) & $\mathrm{kg} / \mathrm{hr}$ & 8,010 & 0 & 0 & 8,010 & 0 & 0 & 8,010 & 68 & 0 & 7,942 \\
\hline C6 & $\mathrm{kg} / \mathrm{hr}$ & 2,969 & 0 & 0 & 2,969 & 0 & 0 & 2,969 & 24 & 0 & 2,946 \\
\hline C5 & $\mathrm{kg} / \mathrm{hr}$ & 2,332 & 0 & 0 & 2,332 & 0 & 0 & 2,332 & 1 & 0 & 2,331 \\
\hline LIGNIN & $\mathrm{kg} / \mathrm{hr}$ & 1,502 & 0 & 0 & 1,502 & 0 & 0 & 1,502 & 15 & 0 & 1,487 \\
\hline ASH & $\mathrm{kg} / \mathrm{hr}$ & 540 & 0 & 0 & 540 & 0 & 0 & 540 & 20 & 0 & 520 \\
\hline PROTEIN & $\mathrm{kg} / \mathrm{hr}$ & 0 & 0 & 0 & 0 & 0 & 0 & 0 & 0 & 0 & 0 \\
\hline EXTRACTIVES & $\mathrm{kg} / \mathrm{hr}$ & 779 & 0 & 0 & 779 & 0 & 0 & 779 & 8 & 0 & 772 \\
\hline OTHERS & $\mathrm{kg} / \mathrm{hr}$ & 0 & 0 & 0 & 0 & 0 & 0 & 0 & 0 & 0 & 0 \\
\hline Temperature & K & 298 & 298 & 298 & 298 & 298 & 298 & 298 & 298 & 298 & 298 \\
\hline Pressure & $\mathrm{atm}$ & 1 & 1 & 1 & 1 & 1 & 1 & 1 & 1 & 1 & 1 \\
\hline Vapor Frac & & 0 & 0 & 0 & 0 & 0 & 0 & 0 & 0 & 0 & 0 \\
\hline
\end{tabular}


Lano National Laboratory

Table H-6. (continued)

\begin{tabular}{|c|c|c|c|c|c|c|c|c|c|c|c|c|c|}
\hline Component & unit & $\begin{array}{l}\text { DML- } \\
12\end{array}$ & $\begin{array}{l}\text { MC- } \\
12\end{array}$ & BMOUT12 & $\begin{array}{l}\text { DML- } \\
13\end{array}$ & MC-13 & BMOUT13 & DML-14 & MC-14 & BMOUT14 & DML-15 & $\begin{array}{l}\text { MC- } \\
15\end{array}$ & BMOUT15 \\
\hline $\begin{array}{l}\text { Overall Flow } \\
\text { (moisture and dry } \\
\text { matter) }\end{array}$ & $\mathrm{kg} / \mathrm{hr}$ & 0 & 0 & 9,289 & 106 & 0 & 4,130 & 0 & 0 & 5,052 & 0 & 0 & 4,130 \\
\hline Moisture Flow & $\mathrm{kg} / \mathrm{hr}$ & 0 & 0 & 1,347 & 106 & 0 & 558 & 0 & 0 & 683 & 0 & 0 & 558 \\
\hline $\begin{array}{l}\text { Total Flow (dry } \\
\text { matter) }\end{array}$ & $\mathrm{kg} / \mathrm{hr}$ & 0 & 0 & 7,942 & 0 & 0 & 3,572 & 0 & 0 & 4,370 & 0 & 0 & 3,572 \\
\hline C6 & $\mathrm{kg} / \mathrm{hr}$ & 0 & 0 & 2,946 & 0 & 0 & 1,325 & 0 & 0 & 1,621 & 0 & 0 & 1,325 \\
\hline LIGNIN & $\mathrm{kg} / \mathrm{hr}$ & 0 & 0 & 1,487 & 0 & 0 & 669 & 0 & 0 & 818 & 0 & 0 & 669 \\
\hline ASH & $\mathrm{kg} / \mathrm{hr}$ & 0 & 0 & 520 & 0 & 0 & 234 & 0 & 0 & 286 & 0 & 0 & 234 \\
\hline PROTEIN & $\mathrm{kg} / \mathrm{hr}$ & 0 & 0 & 0 & 0 & 0 & 0 & 0 & 0 & 0 & 0 & 0 & 0 \\
\hline EXTRACTIVES & $\mathrm{kg} / \mathrm{hr}$ & 0 & 0 & 772 & 0 & 0 & 347 & 0 & 0 & 425 & 0 & 0 & 347 \\
\hline OTHERS & $\mathrm{kg} / \mathrm{hr}$ & 0 & 0 & 0 & 0 & 0 & 0 & 0 & 0 & 0 & 0 & 0 & 0 \\
\hline Temperature & $\mathrm{K}$ & 298 & 298 & 298 & 298 & 298 & 298 & 298 & 298 & 298 & 298 & 298 & 298 \\
\hline Pressure & $\mathrm{atm}$ & 1 & 1 & 1 & 1 & 1 & 1 & 1 & 1 & 1 & 1 & 1 & 1 \\
\hline
\end{tabular}


Table H-6. (continued)

\begin{tabular}{|c|c|c|c|c|c|c|c|c|c|c|c|c|c|}
\hline Component & unit & $\begin{array}{l}\text { DML- } \\
16\end{array}$ & $\begin{array}{l}\text { MC- } \\
16\end{array}$ & BMOUT16 & BMOUT17 & DML-18 & MC-18 & & BMOUT18 & DML-19 & MC-19 & & BMOUT19 \\
\hline $\begin{array}{l}\text { Overall Flow } \\
\text { (moisture and dry } \\
\text { matter) }\end{array}$ & $\mathrm{kg} / \mathrm{hr}$ & 48 & 7 & 5,052 & 4,998 & 0 & & 0 & 9,128 & 0 & & 356 & 8,772 \\
\hline Moisture Flow & $\mathrm{kg} / \mathrm{hr}$ & 0 & 7 & 683 & 676 & 0 & & 0 & 1,234 & 0 & & 356 & 878 \\
\hline $\begin{array}{l}\text { Total Flow (dry } \\
\text { matter) }\end{array}$ & $\mathrm{kg} / \mathrm{hr}$ & 48 & 0 & 4,370 & 4,322 & 0 & & 0 & 7,894 & 0 & & 0 & 7,894 \\
\hline C6 & $\mathrm{kg} / \mathrm{hr}$ & 13 & 0 & 1,621 & 1,608 & 0 & & 0 & 2,933 & 0 & & 0 & 2,933 \\
\hline C5 & $\mathrm{kg} / \mathrm{hr}$ & 7 & 0 & 1,282 & 1,275 & 0 & & 0 & 2,324 & 0 & & 0 & 2,324 \\
\hline LIGNIN & $\mathrm{kg} / \mathrm{hr}$ & 8 & 0 & 818 & 810 & 0 & & 0 & 1,478 & 0 & & 0 & 1,478 \\
\hline ASH & $\mathrm{kg} / \mathrm{hr}$ & 11 & 0 & 286 & 275 & 0 & & 0 & 509 & 0 & & 0 & 509 \\
\hline PROTEIN & $\mathrm{kg} / \mathrm{hr}$ & 0 & 0 & 0 & 0 & 0 & & 0 & 0 & 0 & & 0 & 0 \\
\hline EXTRACTIVES & $\mathrm{kg} / \mathrm{hr}$ & 8 & 0 & 425 & 416 & 0 & & 0 & 763 & 0 & & 0 & 763 \\
\hline OTHERS & $\mathrm{kg} / \mathrm{hr}$ & 0 & 0 & 0 & 0 & 0 & & 0 & 0 & 0 & & 0 & 0 \\
\hline Temperature & K & 298 & 298 & 298 & 298 & 298 & & 298 & 298 & 298 & & 298 & 298 \\
\hline Pressure & atm & 1 & 1 & 1 & 1 & 1 & & 1 & 1 & 1 & & 1 & 1 \\
\hline Vapor Frac & & 0 & 0 & 0 & 0 & 0 & & 0 & 0 & 0 & & 0 & 0 \\
\hline
\end{tabular}


Table H-6. (continued)

\begin{tabular}{|c|c|c|c|c|c|c|c|c|c|c|}
\hline Component & unit & DML-20 & MC-20 & BMOUT20 & DML-21 & MC-21 & BMOUT21 & DML-22 & MC-22 & BMOUT22 \\
\hline $\begin{array}{l}\text { Overall Flow } \\
\text { (moisture and dry } \\
\text { matter) }\end{array}$ & $\mathrm{kg} / \mathrm{hr}$ & 0 & 96 & 8,676 & 0 & 0 & 8,676 & 0 & 0 & 8,676 \\
\hline Moisture Flow & $\mathrm{kg} / \mathrm{hr}$ & 0 & 96 & 781 & 0 & 0 & 781 & 0 & 0 & 781 \\
\hline $\begin{array}{l}\text { Total Flow (dry } \\
\text { matter) }\end{array}$ & $\mathrm{kg} / \mathrm{hr}$ & 0 & 0 & 7,894 & 0 & 0 & 7,894 & 0 & 0 & 7,894 \\
\hline C6 & $\mathrm{kg} / \mathrm{hr}$ & 0 & 0 & 2,933 & 0 & 0 & 2,933 & 0 & 0 & 2,933 \\
\hline C5 & $\mathrm{kg} / \mathrm{hr}$ & 0 & 0 & 2,324 & 0 & 0 & 2,324 & 0 & 0 & 2,324 \\
\hline LIGNIN & $\mathrm{kg} / \mathrm{hr}$ & 0 & 0 & 1,478 & 0 & 0 & 1,478 & 0 & 0 & 1,478 \\
\hline ASH & $\mathrm{kg} / \mathrm{hr}$ & 0 & 0 & 509 & 0 & 0 & 509 & 0 & 0 & 509 \\
\hline PROTEIN & $\mathrm{kg} / \mathrm{hr}$ & 0 & 0 & 0 & 0 & 0 & 0 & 0 & 0 & 0 \\
\hline EXTRACTIVES & $\mathrm{kg} / \mathrm{hr}$ & 0 & 0 & 763 & 0 & 0 & 763 & 0 & 0 & 763 \\
\hline OTHERS & $\mathrm{kg} / \mathrm{hr}$ & 0 & 0 & 0 & 0 & 0 & 0 & 0 & 0 & 0 \\
\hline Temperature & $\mathrm{K}$ & 298 & 298 & 298 & 298 & 298 & 298 & 298 & 298 & 298 \\
\hline Pressure & $\mathrm{atm}$ & 1 & 1 & 1 & 1 & 1 & 1 & 1 & 1 & 1 \\
\hline Vapor Frac & & 0 & 0 & 0 & 0 & 0 & 0 & 0 & 0 & 0 \\
\hline
\end{tabular}


Table H-6. (continued)

\begin{tabular}{|c|c|c|c|c|c|c|c|c|c|c|}
\hline Component & unit & DML-23 & MC-23 & BMOUT23 & DML-24 & MC-24 & BMOUT24 & DML-25 & MC-25 & BMOUT25 \\
\hline $\begin{array}{l}\text { Overall Flow } \\
\text { (moisture and dry } \\
\text { matter) }\end{array}$ & $\mathrm{kg} / \mathrm{hr}$ & 0 & 0 & 8,676 & 0 & 0 & 8,676 & 0 & 0 & 8,676 \\
\hline Moisture Flow & $\mathrm{kg} / \mathrm{hr}$ & 0 & 0 & 781 & 0 & 0 & 781 & 0 & 0 & 781 \\
\hline $\begin{array}{l}\text { Total Flow (dry } \\
\text { matter) }\end{array}$ & $\mathrm{kg} / \mathrm{hr}$ & 0 & 0 & 7,894 & 0 & 0 & 7,894 & 0 & 0 & 7,894 \\
\hline C6 & $\mathrm{kg} / \mathrm{hr}$ & 0 & 0 & 2,933 & 0 & 0 & 2,933 & 0 & 0 & 2,933 \\
\hline C5 & $\mathrm{kg} / \mathrm{hr}$ & 0 & 0 & 2,324 & 0 & 0 & 2,324 & 0 & 0 & 2,324 \\
\hline LIGNIN & $\mathrm{kg} / \mathrm{hr}$ & 0 & 0 & 1,478 & 0 & 0 & 1,478 & 0 & 0 & 1,478 \\
\hline ASH & $\mathrm{kg} / \mathrm{hr}$ & 0 & 0 & 509 & 0 & 0 & 509 & 0 & 0 & 509 \\
\hline PROTEIN & $\mathrm{kg} / \mathrm{hr}$ & 0 & 0 & 0 & 0 & 0 & 0 & 0 & 0 & 0 \\
\hline EXTRACTIVES & $\mathrm{kg} / \mathrm{hr}$ & 0 & 0 & 763 & 0 & 0 & 763 & 0 & 0 & 763 \\
\hline OTHERS & $\mathrm{kg} / \mathrm{hr}$ & 0 & 0 & 0 & 0 & 0 & 0 & 0 & 0 & 0 \\
\hline Temperature & $\mathrm{K}$ & 298 & 298 & 298 & 298 & 298 & 298 & 298 & 298 & 298 \\
\hline Pressure & $\mathrm{atm}$ & 1 & 1 & 1 & 1 & 1 & 1 & 1 & 1 & 1 \\
\hline Vapor Frac & & 0 & 0 & 0 & 0 & 0 & 0 & 0 & 0 & 0 \\
\hline
\end{tabular}


Table H-6. (continued)

\begin{tabular}{lccrr}
\hline \multicolumn{1}{c}{ Component } & unit & DML-26 & MC-26 & BMOUT26 \\
\hline $\begin{array}{l}\text { Overall Flow } \\
\text { (moisture and dry } \\
\text { matter) }\end{array}$ & $\mathrm{kg} / \mathrm{hr}$ & 0 & 0 & 8,676 \\
\hline Moisture Flow & $\mathrm{kg} / \mathrm{hr}$ & 0 & 0 & 781 \\
\hline $\begin{array}{l}\text { Total Flow (dry } \\
\text { matter) }\end{array}$ & $\mathrm{kg} / \mathrm{hr}$ & 0 & 0 & 7,894 \\
\hline C6 & $\mathrm{kg} / \mathrm{hr}$ & 0 & 0 & 2,933 \\
\hline C5 & $\mathrm{kg} / \mathrm{hr}$ & 0 & 0 & 2,324 \\
\hline LIGNIN & $\mathrm{kg} / \mathrm{hr}$ & 0 & 0 & 1,478 \\
\hline ASH & $\mathrm{kg} / \mathrm{hr}$ & 0 & 0 & 509 \\
\hline PROTEIN & $\mathrm{kg} / \mathrm{hr}$ & 0 & 0 & 0 \\
\hline EXTRACTIVES & $\mathrm{kg} / \mathrm{hr}$ & 0 & 0 & 763 \\
\hline OTHERS & $\mathrm{kg} / \mathrm{hr}$ & 0 & 0 & 0 \\
\hline Temperature & $\mathrm{K}$ & 298 & 298 & 298 \\
\hline Pressure & $\mathrm{atm}$ & 1 & 1 & 1 \\
\hline Vapor Frac & & 0 & 0 & 0 \\
\hline
\end{tabular}




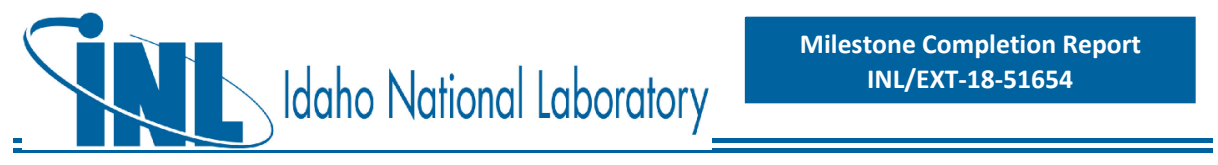




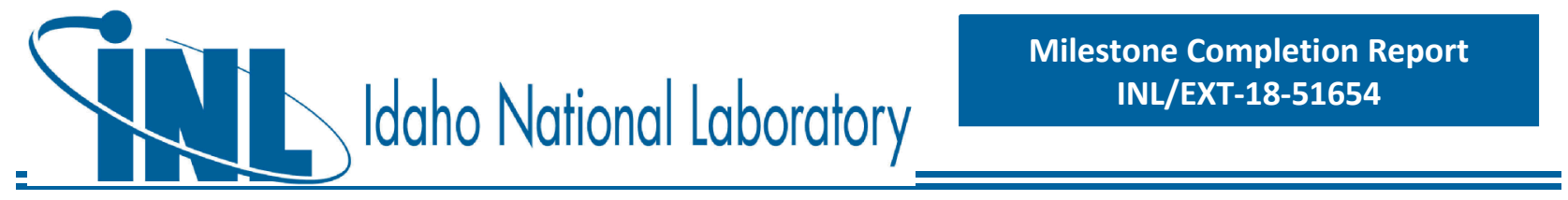

\section{H.4 Grass Clippings Blendstock}

High-level stream table information from Aspen Plus modeling output follows, for key streams associated with each process operation area. This is followed by high-level PFDs for the associated process areas. Space for stream tables was limited; below is a key to lumped components. As the stream table information focuses primarily on the high-level overall process and does not include every individual modeled stream within each process area, mass balance closure around a given unit area may not be $100 \%$.

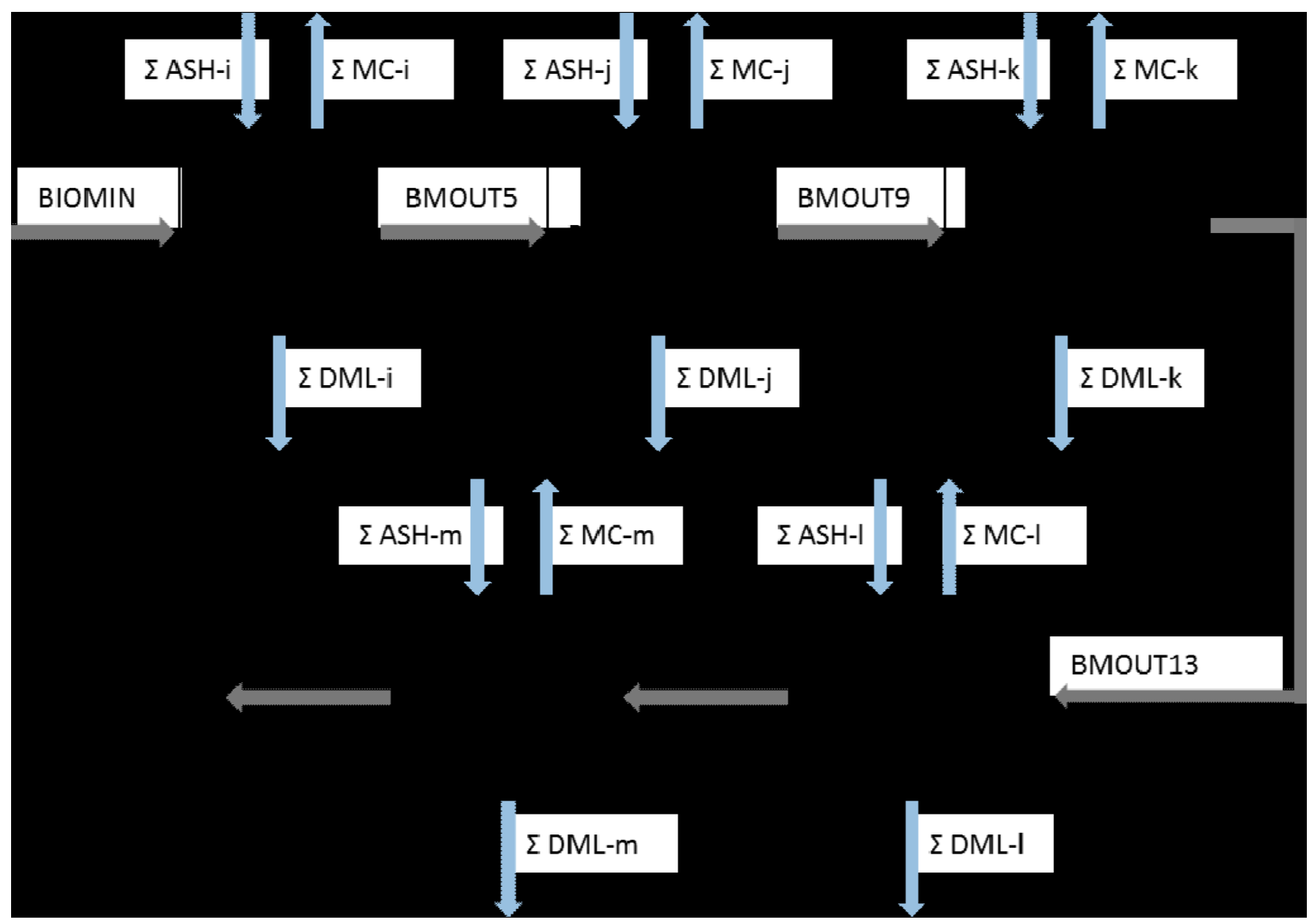

Figure H-19. High-level flowsheet showing key process areas for the grass clippings blendstock in the Primary Depot Co-located with the Biorefinery Case. 

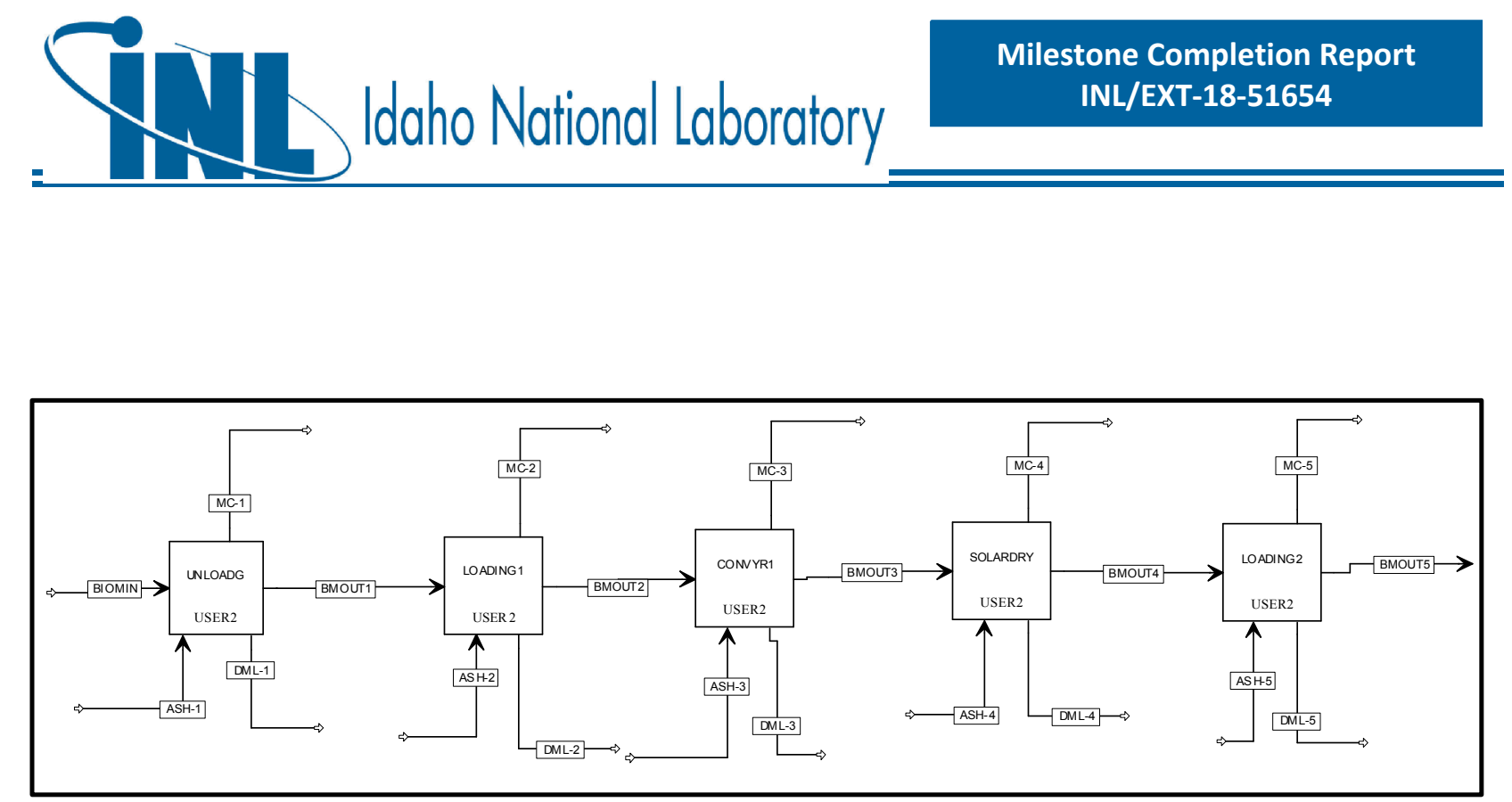

Figure H-20. Detailed process flow diagram for area D100 - Solar Drying.

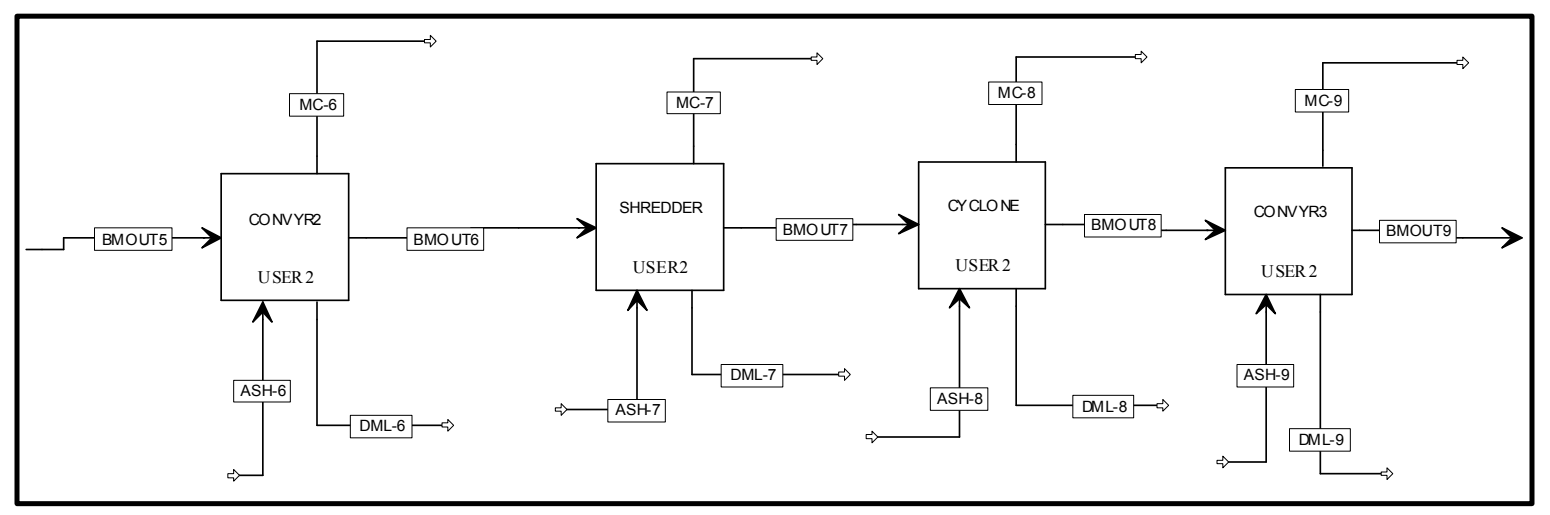

Figure H-21. Detailed process flow diagram for area D200 - Preprocessing - Size Reduction.

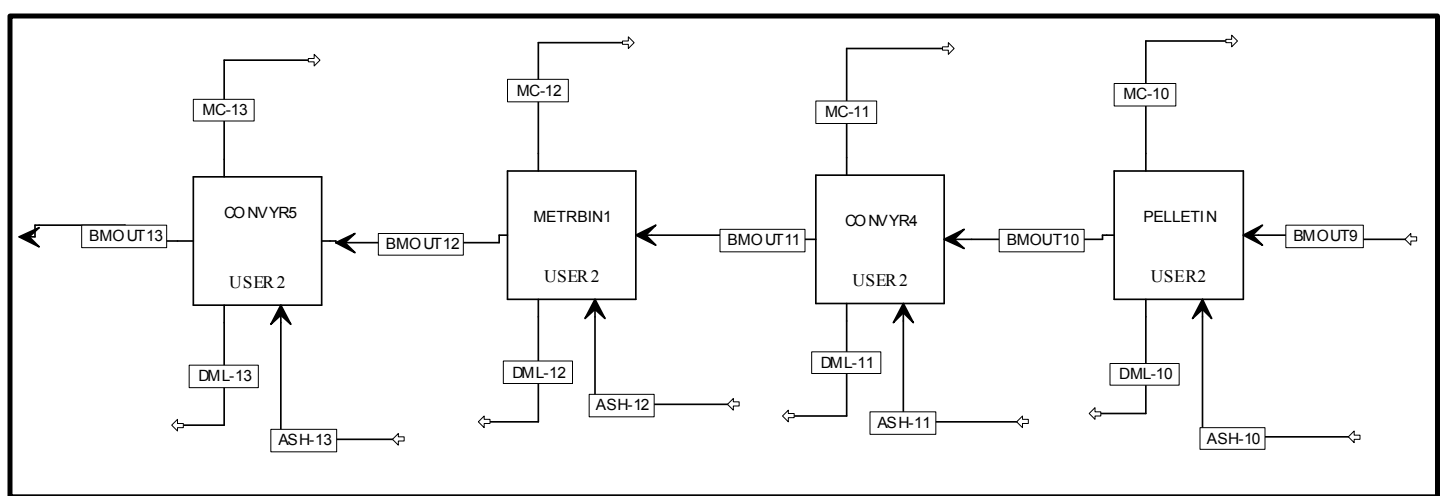

Figure H-22. Detailed process flow diagram for area D300 - Preprocessing - Pelleting. 


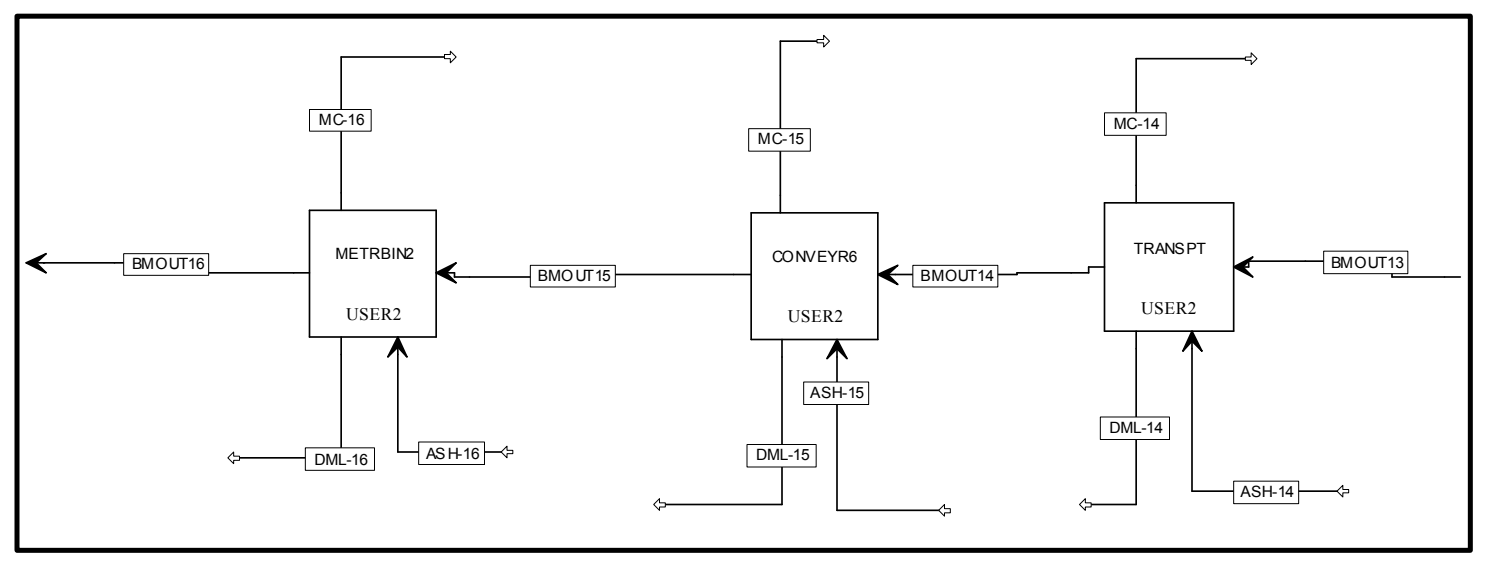

Figure H-23. Detailed process flow diagram for area D400 - Transportation to Biorefinery.

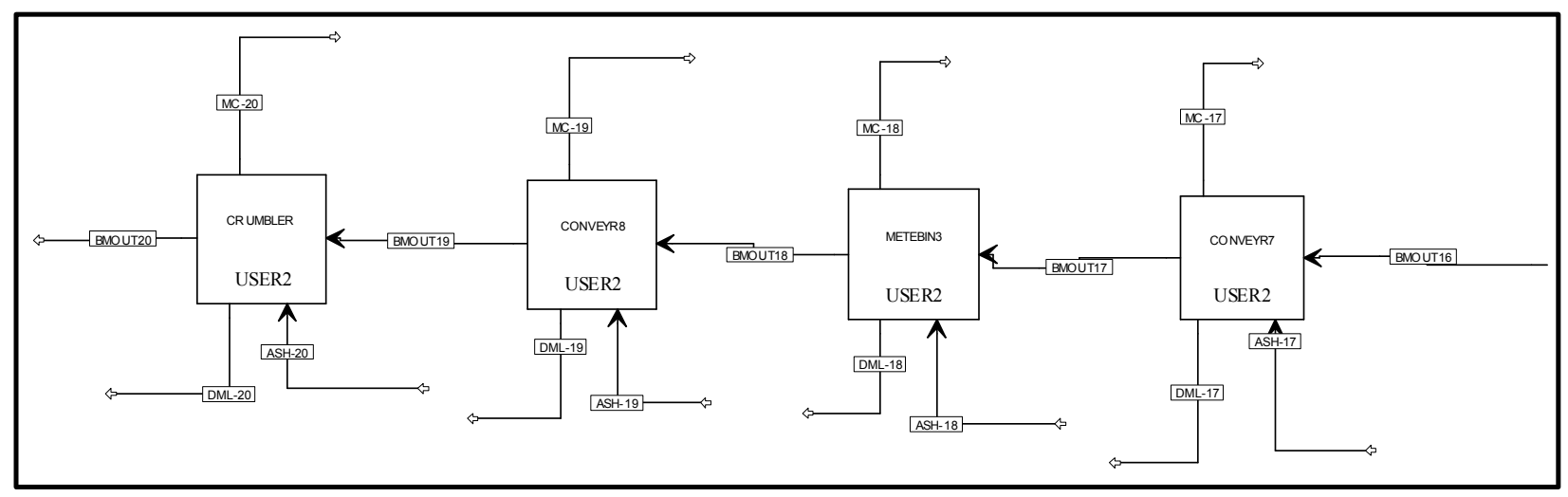

Figure H-24. Detailed process flow diagram for area D500 - Feeding. 


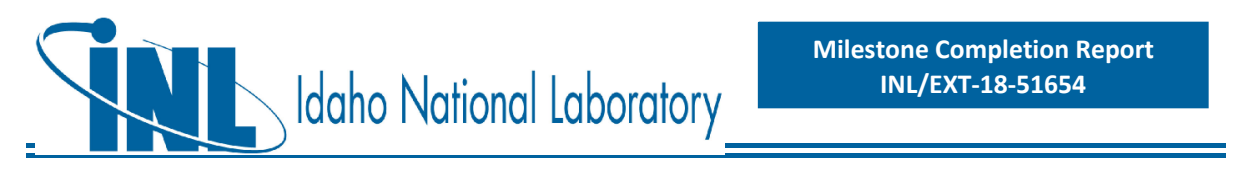

Table H-7. Aspen Plus mass and energy balances for the grass clippings blendstock in the Primary Depot Co-located with the Biorefinery Case. Depot operation is assumed to take place within a 25 week period, working 24 hours/day, 7 days per week.

\begin{tabular}{|c|c|c|c|c|c|c|c|c|c|c|c|c|c|}
\hline Component & unit & BIOMIN & DML-1 & MC-1 & BMOUT1 & DML-2 & MC-2 & BMOUT2 & DML-3 & MC-3 & BMOUT3 & DML-4 & MC-4 \\
\hline $\begin{array}{l}\text { Overall Flow } \\
\text { (moisture and } \\
\text { dry matter) }\end{array}$ & $\mathrm{kg} / \mathrm{hr}$ & 10,301 & 0 & 0 & 10,301 & 0 & 0 & 10,301 & 0 & 0 & 10,301 & 19 & 6,669 \\
\hline Moisture Flow & $\mathrm{kg} / \mathrm{hr}$ & 7,211 & 0 & 0 & 7,211 & 0 & 0 & 7,211 & 0 & 0 & 7,211 & 0 & 6,669 \\
\hline $\begin{array}{l}\text { Total Flow (dry } \\
\text { matter) }\end{array}$ & $\mathrm{kg} / \mathrm{hr}$ & 3,090 & 0 & 0 & 3,090 & 0 & 0 & 3,090 & 0 & 0 & 3,090 & 19 & 0 \\
\hline C6 & $\mathrm{kg} / \mathrm{hr}$ & 605 & 0 & 0 & 605 & 0 & 0 & 605 & 0 & 0 & 605 & 0 & 0 \\
\hline C5 & $\mathrm{kg} / \mathrm{hr}$ & 264 & 0 & 0 & 264 & 0 & 0 & 264 & 0 & 0 & 264 & 0 & 0 \\
\hline LIGNIN & $\mathrm{kg} / \mathrm{hr}$ & 515 & 0 & 0 & 515 & 0 & 0 & 515 & 0 & 0 & 515 & 0 & 0 \\
\hline ASH & $\mathrm{kg} / \mathrm{hr}$ & 394 & 0 & 0 & 394 & 0 & 0 & 394 & 0 & 0 & 394 & 0 & 0 \\
\hline PROTEIN & $\mathrm{kg} / \mathrm{hr}$ & 315 & 0 & 0 & 315 & 0 & 0 & 315 & 0 & 0 & 315 & 0 & 0 \\
\hline $\begin{array}{l}\text { EXTRACTIVE } \\
\text { S }\end{array}$ & $\mathrm{kg} / \mathrm{hr}$ & 668 & 0 & 0 & 668 & 0 & 0 & 668 & 0 & 0 & 668 & 19 & 0 \\
\hline OTHERS & $\mathrm{kg} / \mathrm{hr}$ & 327 & 0 & 0 & 327 & 0 & 0 & 327 & 0 & 0 & 327 & 0 & 0 \\
\hline Temperature & $\mathrm{K}$ & 298 & 298 & 298 & 298 & 298 & 298 & 298 & 298 & 298 & 298 & 298 & 298 \\
\hline Pressure & atm & 1 & 1 & 1 & 1 & 1 & 1 & 1 & 1 & 1 & 1 & 1 & 1 \\
\hline Vapor Frac & & 0 & 0 & 0 & 0 & 0 & 0 & 0 & 0 & 0 & 0 & 0 & 0 \\
\hline
\end{tabular}


lacho National Laboratory

Table H-7. (continued)

\begin{tabular}{|c|c|c|c|c|c|c|c|c|c|c|c|c|c|c|}
\hline Component & unit & BMOUT4 & DML-5 & MC-5 & BMOUT5 & DML-6 & MC-6 & BMOUT6 & DML-7 & MC-7 & BMOUT7 & $\begin{array}{l}\text { DML- } \\
8\end{array}$ & MC-8 & BMOUT8 \\
\hline $\begin{array}{l}\begin{array}{l}\text { Overall Flow } \\
\text { (moisture and } \\
\text { dry matter) }\end{array} \\
\end{array}$ & $\mathrm{kg} / \mathrm{hr}$ & 3,613 & 0 & 0 & 3,613 & 0 & 0 & 3,613 & 15 & 85 & 3,513 & 0 & 0 & 3,513 \\
\hline Moisture Flow & $\mathrm{kg} / \mathrm{hr}$ & 542 & 0 & 0 & 542 & 0 & 0 & 542 & 0 & 85 & 457 & 0 & 0 & 457 \\
\hline $\begin{array}{l}\text { Total Flow (dry } \\
\text { matter) }\end{array}$ & $\mathrm{kg} / \mathrm{hr}$ & 3,071 & 0 & 0 & 3,071 & 0 & 0 & 3,071 & 15 & 0 & 3,056 & 0 & 0 & 3,056 \\
\hline C6 & $\mathrm{kg} / \mathrm{hr}$ & 605 & 0 & 0 & 605 & 0 & 0 & 605 & 2 & 0 & 603 & 0 & 0 & 603 \\
\hline C5 & $\mathrm{kg} / \mathrm{hr}$ & 264 & 0 & 0 & 264 & 0 & 0 & 264 & 0 & 0 & 261 & 0 & 0 & 261 \\
\hline LIGNIN & $\mathrm{kg} / \mathrm{hr}$ & 515 & 0 & 0 & 515 & 0 & 0 & 515 & 2 & 0 & 513 & 0 & 0 & 513 \\
\hline ASH & $\mathrm{kg} / \mathrm{hr}$ & 394 & 0 & 0 & 394 & 0 & 0 & 394 & 5 & 0 & 392 & 0 & 0 & 392 \\
\hline PROTEIN & $\mathrm{kg} / \mathrm{hr}$ & 315 & 0 & 0 & 315 & 0 & 0 & 315 & 2 & 0 & 315 & 0 & 0 & 315 \\
\hline $\begin{array}{l}\text { EXTRACTIVE } \\
\text { S } \\
\end{array}$ & $\mathrm{kg} / \mathrm{hr}$ & 648 & 0 & 0 & 648 & 0 & 0 & 648 & 2 & 0 & 646 & 0 & 0 & 646 \\
\hline OTHERS & $\mathrm{kg} / \mathrm{hr}$ & 327 & 0 & 0 & 327 & 0 & 0 & 327 & 2 & 0 & 327 & 0 & 0 & 327 \\
\hline Temperature & K & 298 & 298 & 298 & 298 & 298 & 298 & 298 & 298 & 298 & 298 & 298 & 298 & 298 \\
\hline Pressure & atm & 1 & 1 & 1 & 1 & 1 & 1 & 1 & 1 & 1 & 1 & 1 & 1 & 1 \\
\hline Vapor Frac & & 0 & 0 & 0 & 0 & 0 & 0 & 0 & 0 & 0 & 0 & 0 & 0 & 0 \\
\hline
\end{tabular}


Table H-7. (continued)

\begin{tabular}{|c|c|c|c|c|c|c|c|c|c|c|c|c|c|c|}
\hline Component & unit & $\begin{array}{l}\text { DML- } \\
9\end{array}$ & $\begin{array}{c}\text { MC- } \\
9\end{array}$ & BMOUT9 & $\begin{array}{c}\text { DML- } \\
10\end{array}$ & $\begin{array}{l}\text { MC- } \\
10\end{array}$ & BMOUT10 & DML-11 & MC-11 & BMOUT11 & DML-12 & MC-12 & BMOUT12 & DML-13 \\
\hline $\begin{array}{l}\text { Overall Flow } \\
\text { (moisture and } \\
\text { dry matter) }\end{array}$ & $\mathrm{kg} / \mathrm{hr}$ & 0 & 0 & 3,513 & 0 & 116 & 3,395 & 0 & 0 & 3,395 & 0 & 0 & 3,395 & 0 \\
\hline Moisture Flow & $\mathrm{kg} / \mathrm{hr}$ & 0 & 0 & 457 & 0 & 116 & 339 & 0 & 0 & 339 & 0 & 0 & 339 & 0 \\
\hline $\begin{array}{l}\text { Total Flow (dry } \\
\text { matter) }\end{array}$ & $\mathrm{kg} / \mathrm{hr}$ & 0 & 0 & 3,056 & 0 & 0 & 3,056 & 0 & 0 & 3,056 & 0 & 0 & 3,056 & 0 \\
\hline C6 & $\mathrm{kg} / \mathrm{hr}$ & 0 & 0 & 603 & 0 & 0 & 603 & 0 & 0 & 603 & 0 & 0 & 603 & 0 \\
\hline $\mathrm{C5}$ & $\mathrm{kg} / \mathrm{hr}$ & 0 & 0 & 261 & 0 & 0 & 261 & 0 & 0 & 261 & 0 & 0 & 261 & 0 \\
\hline LIGNIN & $\mathrm{kg} / \mathrm{hr}$ & 0 & 0 & 513 & 0 & 0 & 513 & 0 & 0 & 513 & 0 & 0 & 513 & 0 \\
\hline ASH & $\mathrm{kg} / \mathrm{hr}$ & 0 & 0 & 392 & 0 & 0 & 392 & 0 & 0 & 392 & 0 & 0 & 392 & 0 \\
\hline PROTEIN & $\mathrm{kg} / \mathrm{hr}$ & 0 & 0 & 315 & 0 & 0 & 315 & 0 & 0 & 315 & 0 & 0 & 315 & 0 \\
\hline $\begin{array}{l}\text { EXTRACTIVE } \\
\text { S }\end{array}$ & $\mathrm{kg} / \mathrm{hr}$ & 0 & 0 & 646 & 0 & 0 & 646 & 0 & 0 & 646 & 0 & 0 & 646 & 0 \\
\hline OTHERS & $\mathrm{kg} / \mathrm{hr}$ & 0 & 0 & 327 & 0 & 0 & 327 & 0 & 0 & 327 & 0 & 0 & 327 & 0 \\
\hline Temperature & K & 298 & 298 & 298 & 298 & 298 & 298 & 298 & 298 & 298 & 298 & 298 & 298 & 298 \\
\hline Pressure & $\mathrm{atm}$ & 1 & 1 & 1 & 1 & 1 & 1 & 1 & 1 & 1 & 1 & 1 & 1 & 1 \\
\hline Vapor Frac & & 0 & 0 & 0 & 0 & 0 & 0 & 0 & 0 & 0 & 0 & 0 & 0 & 0 \\
\hline
\end{tabular}


Table H-7. (continued)

\begin{tabular}{|c|c|c|c|c|c|c|c|c|c|c|c|c|c|}
\hline Component & unit & MC-13 & BMOUT13 & DML-14 & MC-14 & BMOUT14 & DML-15 & MC-15 & BMOUT15 & DML-16 & MC-16 & BMOUT16 & DML-17 \\
\hline $\begin{array}{l}\text { Overall Flow } \\
\text { (moisture and } \\
\text { dry matter) }\end{array}$ & $\mathrm{kg} / \mathrm{hr}$ & 0 & 3,395 & 0 & 0 & 3,395 & 0 & 0 & 3,395 & 0 & 0 & 3,395 & 0 \\
\hline Moisture Flow & $\mathrm{kg} / \mathrm{hr}$ & 0 & 339 & 0 & 0 & 339 & 0 & 0 & 339 & 0 & 0 & 339 & 0 \\
\hline $\begin{array}{l}\text { Total Flow (dry } \\
\text { matter) }\end{array}$ & $\mathrm{kg} / \mathrm{hr}$ & 0 & 3,056 & 0 & 0 & 3,056 & 0 & 0 & 3,056 & 0 & 0 & 3,056 & 0 \\
\hline C6 & $\mathrm{kg} / \mathrm{hr}$ & 0 & 603 & 0 & 0 & 603 & 0 & 0 & 603 & 0 & 0 & 603 & 0 \\
\hline C5 & $\mathrm{kg} / \mathrm{hr}$ & 0 & 261 & 0 & 0 & 261 & 0 & 0 & 261 & 0 & 0 & 261 & 0 \\
\hline LIGNIN & $\mathrm{kg} / \mathrm{hr}$ & 0 & 513 & 0 & 0 & 513 & 0 & 0 & 513 & 0 & 0 & 513 & 0 \\
\hline ASH & $\mathrm{kg} / \mathrm{hr}$ & 0 & 392 & 0 & 0 & 392 & 0 & 0 & 392 & 0 & 0 & 392 & 0 \\
\hline PROTEIN & $\mathrm{kg} / \mathrm{hr}$ & 0 & 315 & 0 & 0 & 315 & 0 & 0 & 315 & 0 & 0 & 315 & 0 \\
\hline $\begin{array}{l}\text { EXTRACTIVE } \\
\text { S }\end{array}$ & $\mathrm{kg} / \mathrm{hr}$ & 0 & 646 & 0 & 0 & 646 & 0 & 0 & 646 & 0 & 0 & 646 & 0 \\
\hline OTHERS & $\mathrm{kg} / \mathrm{hr}$ & 0 & 327 & 0 & 0 & 327 & 0 & 0 & 327 & 0 & 0 & 327 & 0 \\
\hline Temperature & K & 298 & 298 & 298 & 298 & 298 & 298 & 298 & 298 & 298 & 298 & 298 & 298 \\
\hline Pressure & atm & 1 & 1 & 1 & 1 & 1 & 1 & 1 & 1 & 1 & 1 & 1 & 1 \\
\hline Vapor Frac & & 0 & 0 & 0 & 0 & 0 & 0 & 0 & 0 & 0 & 0 & 0 & 0 \\
\hline
\end{tabular}


Table H-7. (continued)

\begin{tabular}{|c|c|c|c|c|c|c|c|c|c|c|c|c|}
\hline Component & unit & MC-17 & BMOUT17 & DML-18 & MC-18 & BMOUT18 & DML-19 & MC-19 & BMOUT19 & DML-20 & MC-20 & BMOUT20 \\
\hline $\begin{array}{l}\text { Overall Flow } \\
\text { (moisture and } \\
\text { dry matter) }\end{array}$ & $\mathrm{kg} / \mathrm{hr}$ & 0 & 3,395 & 0 & 0 & 3,395 & 0 & 0 & 3,395 & 0 & 0 & 3,395 \\
\hline Moisture Flow & $\mathrm{kg} / \mathrm{hr}$ & 0 & 339 & 0 & 0 & 339 & 0 & 0 & 339 & 0 & 0 & 339 \\
\hline $\begin{array}{l}\text { Total Flow (dry } \\
\text { matter) }\end{array}$ & $\mathrm{kg} / \mathrm{hr}$ & 0 & 3,056 & 0 & 0 & 3,056 & 0 & 0 & 3,056 & 0 & 0 & 3,056 \\
\hline C6 & $\mathrm{kg} / \mathrm{hr}$ & 0 & 603 & 0 & 0 & 603 & 0 & 0 & 603 & 0 & 0 & 603 \\
\hline C5 & $\mathrm{kg} / \mathrm{hr}$ & 0 & 261 & 0 & 0 & 261 & 0 & 0 & 261 & 0 & 0 & 261 \\
\hline LIGNIN & $\mathrm{kg} / \mathrm{hr}$ & 0 & 513 & 0 & 0 & 513 & 0 & 0 & 513 & 0 & 0 & 513 \\
\hline ASH & $\mathrm{kg} / \mathrm{hr}$ & 0 & 392 & 0 & 0 & 392 & 0 & 0 & 392 & 0 & 0 & 392 \\
\hline PROTEIN & $\mathrm{kg} / \mathrm{hr}$ & 0 & 315 & 0 & 0 & 315 & 0 & 0 & 315 & 0 & 0 & 315 \\
\hline $\begin{array}{l}\text { EXTRACTIVE } \\
\text { S }\end{array}$ & $\mathrm{kg} / \mathrm{hr}$ & 0 & 646 & 0 & 0 & 646 & 0 & 0 & 646 & 0 & 0 & 646 \\
\hline OTHERS & $\mathrm{kg} / \mathrm{hr}$ & 0 & 327 & 0 & 0 & 327 & 0 & 0 & 327 & 0 & 0 & 327 \\
\hline Temperature & K & 298 & 298 & 298 & 298 & 298 & 298 & 298 & 298 & 298 & 298 & 298 \\
\hline Pressure & $\mathrm{atm}$ & 1 & 1 & 1 & 1 & 1 & 1 & 1 & 1 & 1 & 1 & 1 \\
\hline Vapor Frac & & 0 & 0 & 0 & 0 & 0 & 0 & 0 & 0 & 0 & 0 & 0 \\
\hline
\end{tabular}




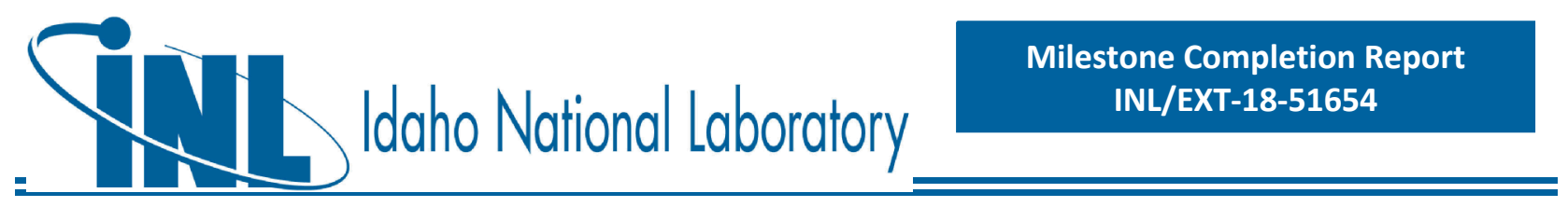

\section{APPENDIX I - Process Flow Diagrams and Mass Balances for the Exclusion of Grass Clippings from the Centralized Depot Case}

\section{I.1 Three-pass Corn Stover Blendstock}

High-level stream table information from Aspen Plus modeling output follows, for key streams associated with each process operation area. This is followed by high-level PFDs for the associated process areas. Space for stream tables was limited; below is a key to lumped components. As the stream table information focuses primarily on the high-level overall process and does not include every individual modeled stream within each process area, mass balance closure around a given unit area may not be $100 \%$.

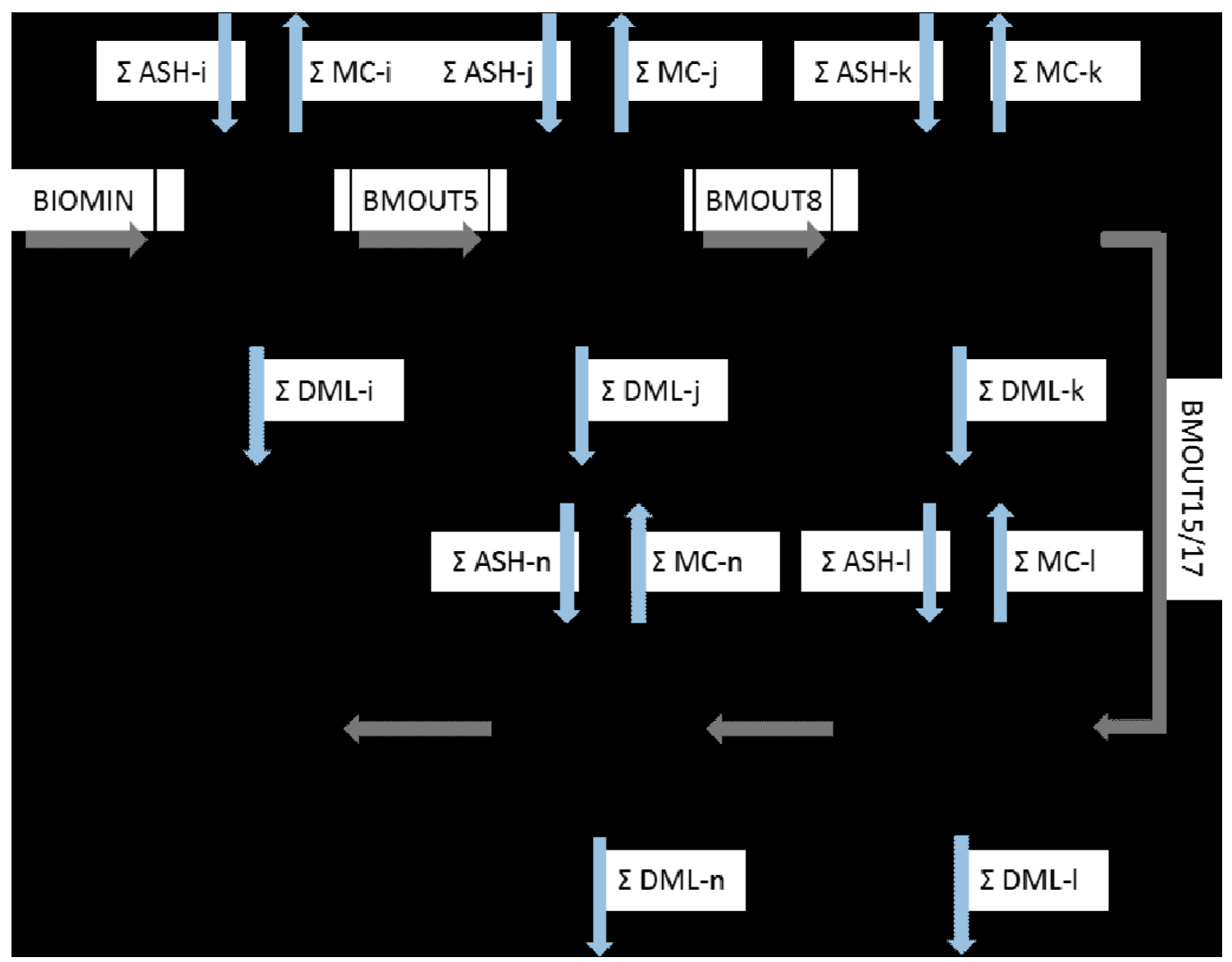

Figure I-1. High-level flowsheet showing key process areas for the three-pass corn stover blendstock in the Exclusion of Grass Clippings from the Centralized Depot Case. 


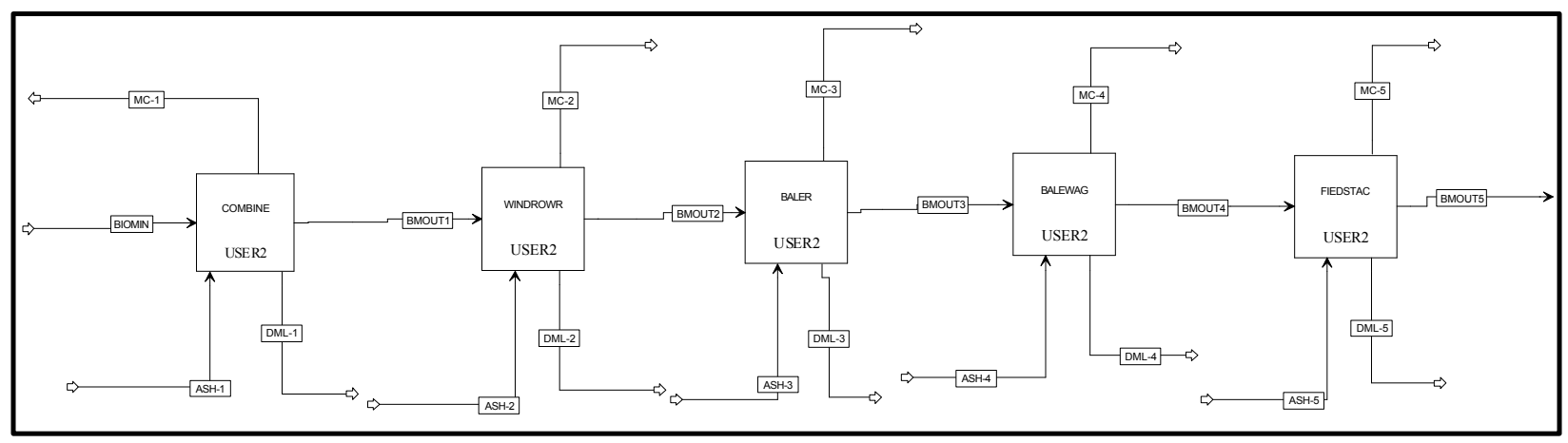

Figure I-2. Detailed process flow diagram for area A100 - Harvesting to Storage.

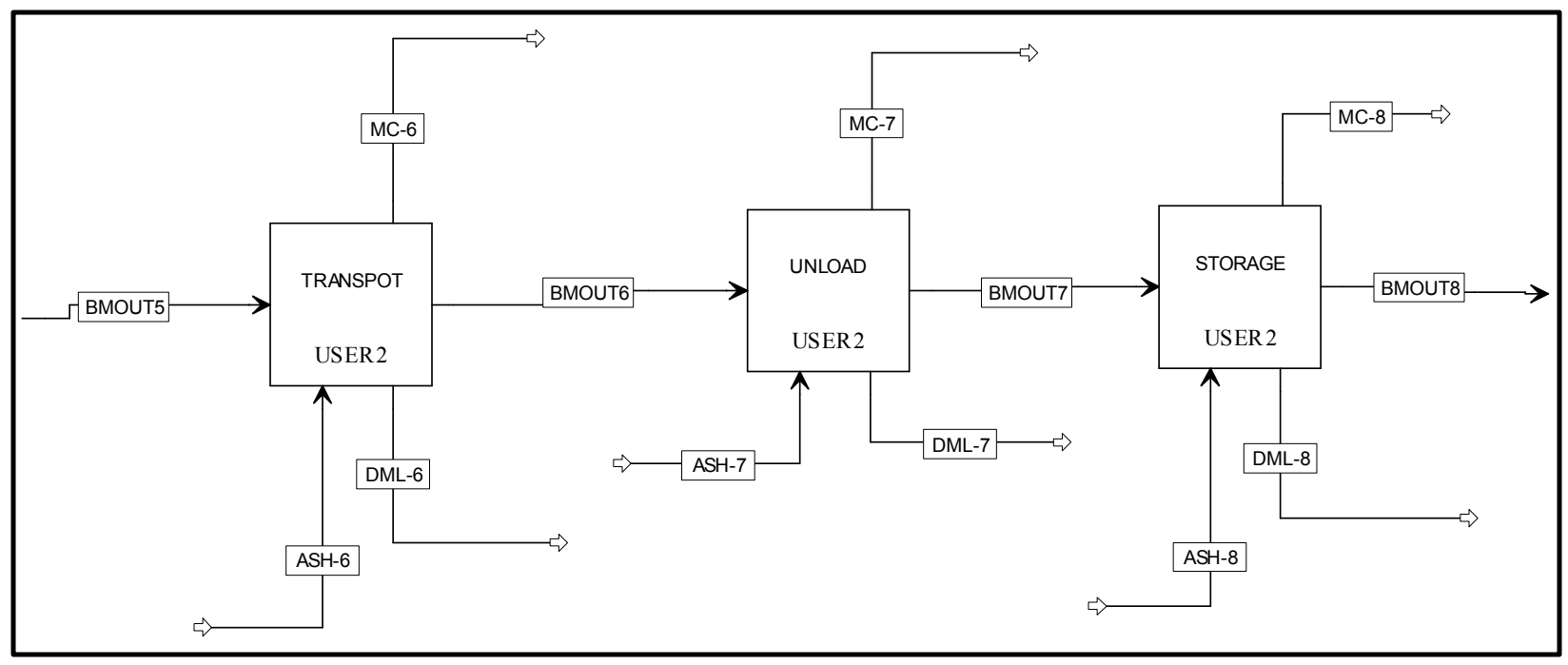

Figure I-3. Detailed process flow diagram for area A200 - Transport to Biorefinery \& Handling. 

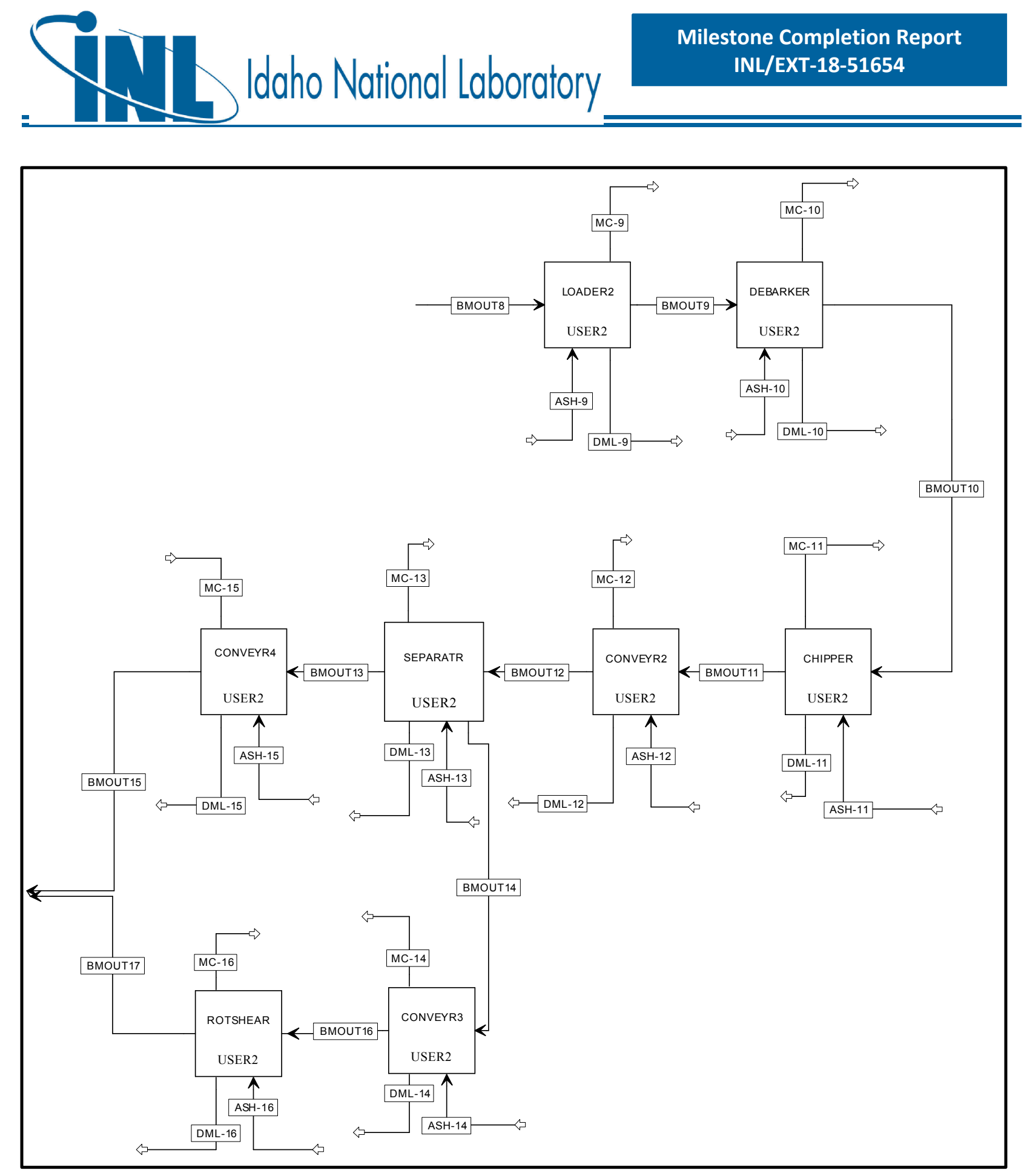

Figure I-4. Detailed process flow diagram for area A300 - Preprocessing - Size Reduction. 

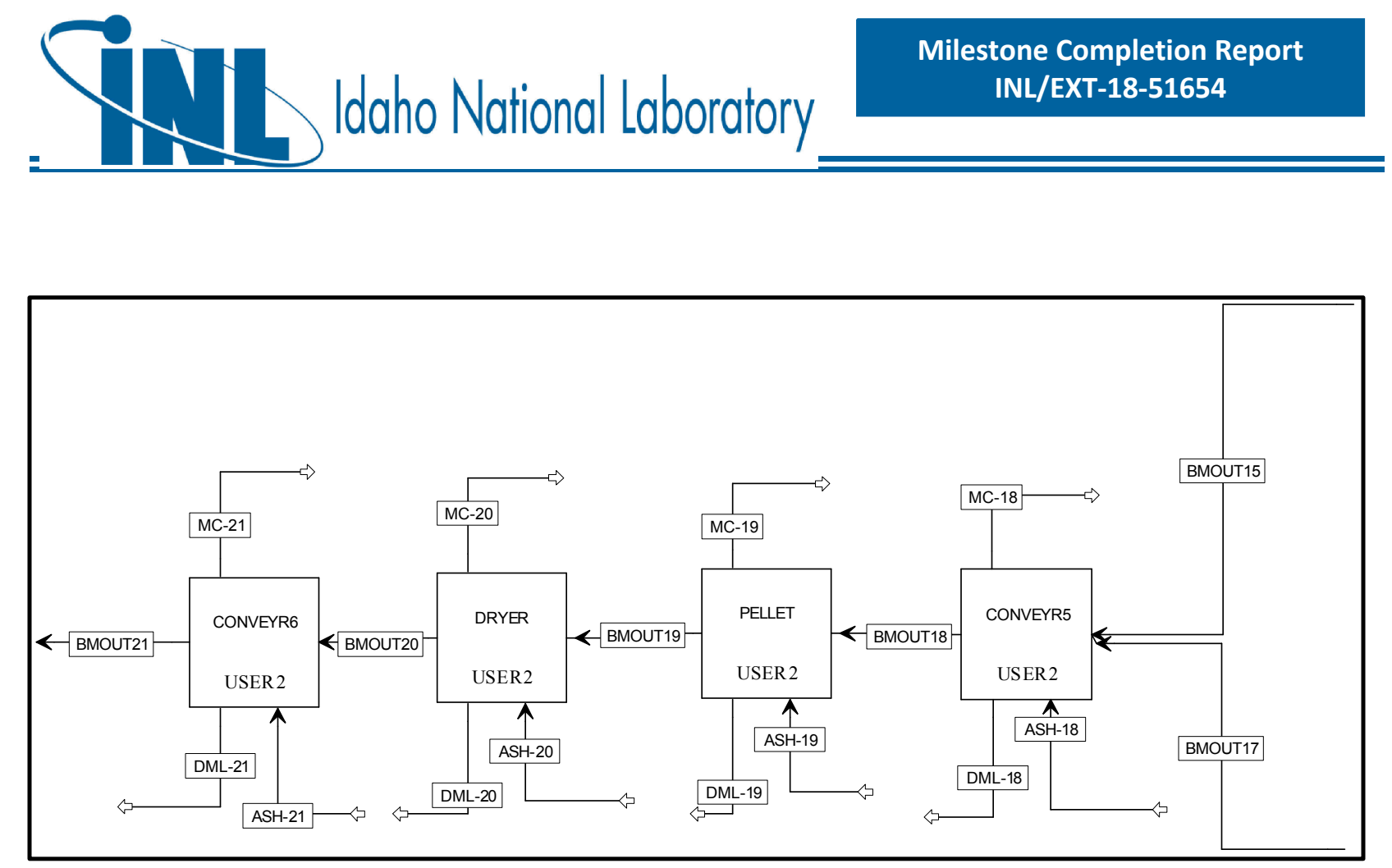

Figure I-5. Detailed process flow diagram for area A400 - Preprocessing - Pelleting.

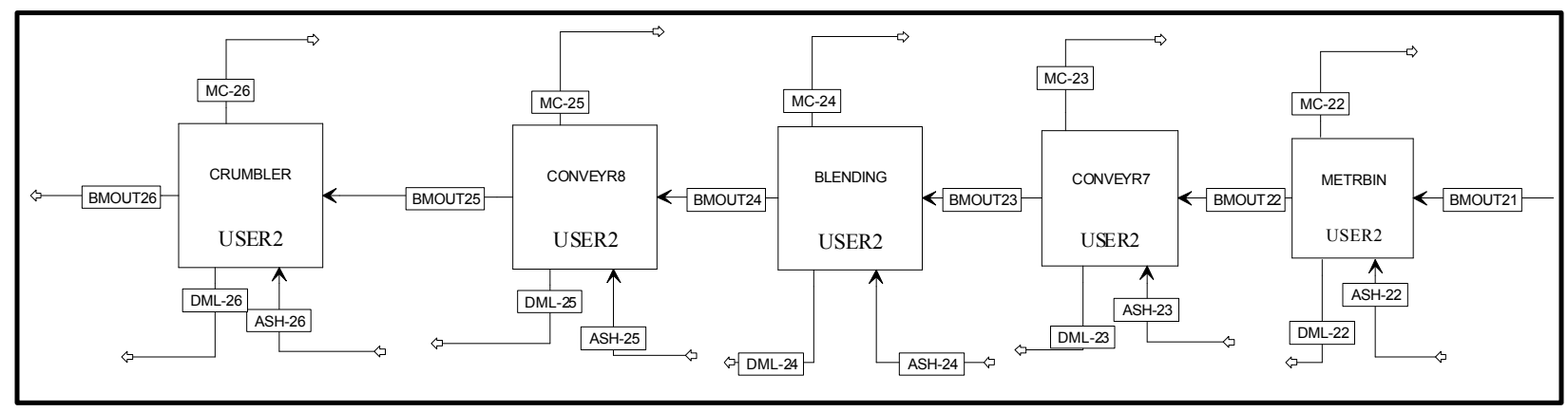

Figure I-6. Detailed process flow diagram for area A500 - Feeding. 
Table I-1. Aspen Plus mass balances from harvest to field-side storage (Area A100) for the three-pass corn stover blendstock in the Exclusion of Grass Clippings from the Centralized Depot Case. Harvest is assumed to take place within a 6 week period, working 14 hours/day, 6 days per week.

\begin{tabular}{|c|c|c|c|c|c|c|c|c|c|c|c|c|c|c|c|}
\hline Component & unit & BIOMIN & $\begin{array}{c}\text { DML- } \\
1\end{array}$ & $\begin{array}{c}\text { MC- } \\
1\end{array}$ & BMOUT1 & $\begin{array}{c}\text { DML- } \\
2\end{array}$ & $\begin{array}{c}\text { MC- } \\
2\end{array}$ & BMOUT2 & $\begin{array}{c}\text { DML- } \\
3\end{array}$ & $\begin{array}{c}\text { MC- } \\
\mathbf{3}\end{array}$ & ASH-3 & BMOUT3 & DML-4 & MC-4 & BMOUT4 \\
\hline $\begin{array}{l}\begin{array}{l}\text { Overall Flow } \\
\text { (moisture and } \\
\text { dry matter) }\end{array} \\
\end{array}$ & $\mathrm{kg} / \mathrm{hr}$ & $1,110,294$ & 0 & 4 & $1,110,289$ & 0 & 0 & $1,110,289$ & 0 & 0 & 47,176 & $1,110,289$ & 0 & 0 & $1,110,289$ \\
\hline Moisture Flow & $\mathrm{kg} / \mathrm{hr}$ & 333,091 & 0 & 4 & 333,087 & 0 & 0 & 333,087 & 0 & 0 & 0 & 333,087 & 0 & 0 & 333,087 \\
\hline $\begin{array}{l}\text { Total Flow (dry } \\
\text { matter) }\end{array}$ & $\mathrm{kg} / \mathrm{hr}$ & 777,202 & 0 & 0 & 777,202 & 0 & 0 & 777,202 & 0 & 0 & 47,176 & 777,202 & 0 & 0 & 777,202 \\
\hline C6 & $\mathrm{kg} / \mathrm{hr}$ & 275,627 & 0 & 0 & 275,627 & 0 & 0 & 275,627 & 0 & 0 & 0 & 275,627 & 0 & 0 & 275,627 \\
\hline $\mathrm{C5}$ & $\mathrm{kg} / \mathrm{hr}$ & 159,265 & 0 & 0 & 159,265 & 0 & 0 & 159,265 & 0 & 0 & 0 & 159,265 & 0 & 0 & 159,265 \\
\hline LIGNIN & $\mathrm{kg} / \mathrm{hr}$ & 114,902 & 0 & 0 & 114,902 & 0 & 0 & 114,902 & 0 & 0 & 0 & 114,902 & 0 & 0 & 114,902 \\
\hline ASH & $\mathrm{kg} / \mathrm{hr}$ & 38,316 & 0 & 0 & 38,316 & 0 & 0 & 38,316 & 0 & 0 & 47,176 & 85,493 & 0 & 0 & 85,493 \\
\hline PROTEIN & $\mathrm{kg} / \mathrm{hr}$ & 22,539 & 0 & 0 & 22,539 & 0 & 0 & 22,539 & 0 & 0 & 0 & 22,539 & 0 & 0 & 22,539 \\
\hline $\begin{array}{l}\text { EXTRACTIVE } \\
\text { S }\end{array}$ & $\mathrm{kg} / \mathrm{hr}$ & 106,904 & 0 & 0 & 106,904 & 0 & 0 & 106,904 & 0 & 0 & 0 & 106,904 & 0 & 0 & 106,904 \\
\hline OTHERS & $\mathrm{kg} / \mathrm{hr}$ & 12,474 & 0 & 0 & 12,474 & 0 & 0 & 12,474 & 0 & 0 & 0 & 12,474 & 0 & 0 & 12,474 \\
\hline Temperature & K & 298 & 298 & 298 & 298 & 298 & 298 & 298 & 298 & 298 & 298 & 298 & 298 & 298 & 298 \\
\hline Pressure & $\mathrm{atm}$ & 1 & 1 & 1 & 1 & 1 & 1 & 1 & 1 & 1 & 1 & 1 & 1 & 1 & 1 \\
\hline Vapor Frac & & 0 & 0 & 0 & 0 & 0 & 0 & 0 & 0 & 0 & 0 & 0 & 0 & 0 & 0 \\
\hline
\end{tabular}


Table I-2. Aspen Plus mass balances from field-side storage to feeding (Areas A200-A500) for the three-pass corn stover blendstock in the Exclusion of Grass Clippings from the Centralized Depot Case. Depot operation is assumed to take place within 350 day period, working 24 hours/day, 7 days per week.

\begin{tabular}{|c|c|c|c|c|c|c|c|c|c|c|c|c|c|}
\hline Component & unit & DML-5 & MC-5 & BMOUT5 & DML-6 & MC-6 & BMOUT6 & DML-7 & MC-7 & BMOUT7 & DML-8 & MC-8 & BMOUT8 \\
\hline $\begin{array}{l}\text { Overall Flow } \\
\text { (moisture and dry } \\
\text { matter) }\end{array}$ & $\mathrm{kg} / \mathrm{hr}$ & 5,596 & 6,295 & 54,726 & 0 & 0 & 54,726 & 0 & 0 & 54,726 & 0 & 0 & 54,726 \\
\hline Moisture Flow & $\mathrm{kg} / \mathrm{hr}$ & 0 & 6,295 & 13,690 & 0 & 0 & 13,690 & 0 & 0 & 13,690 & 0 & 0 & 13,690 \\
\hline $\begin{array}{l}\text { Total Flow (dry } \\
\text { matter) }\end{array}$ & $\mathrm{kg} / \mathrm{hr}$ & 5,596 & 0 & 41,036 & 0 & 0 & 41,036 & 0 & 0 & 41,036 & 0 & 0 & 41,036 \\
\hline C6 & $\mathrm{kg} / \mathrm{hr}$ & 1,033 & 0 & 15,505 & 0 & 0 & 15,505 & 0 & 0 & 15,505 & 0 & 0 & 15,505 \\
\hline C5 & $\mathrm{kg} / \mathrm{hr}$ & 1,619 & 0 & 7,937 & 0 & 0 & 7,937 & 0 & 0 & 7,937 & 0 & 0 & 7,937 \\
\hline LIGNIN & $\mathrm{kg} / \mathrm{hr}$ & 361 & 0 & 6,533 & 0 & 0 & 6,533 & 0 & 0 & 6,533 & 0 & 0 & 6,533 \\
\hline ASH & $\mathrm{kg} / \mathrm{hr}$ & 0 & 0 & 5,130 & 0 & 0 & 5,130 & 0 & 0 & 5,130 & 0 & 0 & 5,130 \\
\hline PROTEIN & $\mathrm{kg} / \mathrm{hr}$ & 168 & 0 & 1,185 & 0 & 0 & 1,185 & 0 & 0 & 1,185 & 0 & 0 & 1,185 \\
\hline EXTRACTIVES & $\mathrm{kg} / \mathrm{hr}$ & 1,678 & 0 & 4,736 & 0 & 0 & 4,736 & 0 & 0 & 4,736 & 0 & 0 & 4,736 \\
\hline OTHERS & $\mathrm{kg} / \mathrm{hr}$ & 737 & 0 & 11 & 0 & 0 & 11 & 0 & 0 & 11 & 0 & 0 & 11 \\
\hline Temperature & $\mathrm{K}$ & 298 & 298 & 298 & 298 & 298 & 298 & 298 & 298 & 298 & 298 & 298 & 298 \\
\hline Pressure & $\mathrm{atm}$ & 1 & 1 & 1 & 1 & 1 & 1 & 1 & 1 & 1 & 1 & 1 & 1 \\
\hline
\end{tabular}


Table I-2. (continued)

\begin{tabular}{|c|c|c|c|c|c|c|c|c|c|c|c|c|c|}
\hline Component & unit & DML-9 & MC-9 & BMOUT9 & DML-10 & MC-10 & BMOUT10 & DML-11 & MC-11 & BMOUT11 & $\begin{array}{c}\text { DML- } \\
12\end{array}$ & $\begin{array}{l}\text { MC- } \\
12\end{array}$ & BMOUT12 \\
\hline $\begin{array}{l}\text { Overall Flow } \\
\text { (moisture and dry } \\
\text { matter) }\end{array}$ & $\mathrm{kg} / \mathrm{hr}$ & 0 & 0 & 54,726 & 0 & 0 & 54,726 & 411 & 3,379 & 50,937 & 0 & 0 & 50,937 \\
\hline Moisture Flow & $\mathrm{kg} / \mathrm{hr}$ & 0 & 0 & 13,690 & 0 & 0 & 13,690 & 0 & 3,379 & 10,312 & 0 & 0 & 10,312 \\
\hline $\begin{array}{l}\text { Total Flow (dry } \\
\text { matter) }\end{array}$ & $\mathrm{kg} / \mathrm{hr}$ & 0 & 0 & 41,036 & 0 & 0 & 41,036 & 411 & 0 & 40,625 & 0 & 0 & 40,625 \\
\hline C6 & $\mathrm{kg} / \mathrm{hr}$ & 0 & 0 & 15,505 & 0 & 0 & 15,505 & 113 & 0 & 15,391 & 0 & 0 & 15,391 \\
\hline C5 & $\mathrm{kg} / \mathrm{hr}$ & 0 & 0 & 7,937 & 0 & 0 & 7,937 & 64 & 0 & 7,873 & 0 & 0 & 7,873 \\
\hline LIGNIN & $\mathrm{kg} / \mathrm{hr}$ & 0 & 0 & 6,533 & 0 & 0 & 6,533 & 79 & 0 & 6,454 & 0 & 0 & 6,454 \\
\hline ASH & $\mathrm{kg} / \mathrm{hr}$ & 0 & 0 & 5,130 & 0 & 0 & 5,130 & 103 & 0 & 5,027 & 0 & 0 & 5,027 \\
\hline PROTEIN & $\mathrm{kg} / \mathrm{hr}$ & 0 & 0 & 1,185 & 0 & 0 & 1,185 & 0 & 0 & 1,185 & 0 & 0 & 1,185 \\
\hline EXTRACTIVES & $\mathrm{kg} / \mathrm{hr}$ & 0 & 0 & 4,736 & 0 & 0 & 4,736 & 51 & 0 & 4,685 & 0 & 0 & 4,685 \\
\hline OTHERS & $\mathrm{kg} / \mathrm{hr}$ & 0 & 0 & 11 & 0 & 0 & 11 & 0 & 0 & 11 & 0 & 0 & 11 \\
\hline Temperature & K & 298 & 298 & 298 & 298 & 298 & 298 & 298 & 298 & 298 & 298 & 298 & 298 \\
\hline Pressure & atm & 1 & 1 & 1 & 1 & 1 & 1 & 1 & 1 & 1 & 1 & 1 & 1 \\
\hline Vapor Frac & & 0 & 0 & 0 & 0 & 0 & 0 & 0 & 0 & 0 & 0 & 0 & 0 \\
\hline
\end{tabular}


adaho National Laboratory

Table I-2. (continued)

\begin{tabular}{|c|c|c|c|c|c|c|c|c|c|c|c|c|c|}
\hline Component & unit & $\begin{array}{l}\text { DML- } \\
13\end{array}$ & MC-13 & BMOUT13 & DML-14 & MC-14 & BMOUT14 & DML-15 & $\begin{array}{l}\text { MC- } \\
15\end{array}$ & BMOUT15 & $\begin{array}{l}\text { DML- } \\
16\end{array}$ & $\begin{array}{l}\text { MC- } \\
16\end{array}$ & BMOUT16 \\
\hline $\begin{array}{l}\text { Overall Flow } \\
\text { (moisture and dry } \\
\text { matter) }\end{array}$ & $\mathrm{kg} / \mathrm{hr}$ & 1,246 & 0 & 22,057 & 0 & 0 & 27,633 & 0 & 0 & 22,057 & 226 & 51 & 27,633 \\
\hline Moisture Flow & $\mathrm{kg} / \mathrm{hr}$ & 1,246 & 0 & 4,024 & 0 & 0 & 5,041 & 0 & 0 & 4,024 & 0 & 51 & 5,041 \\
\hline $\begin{array}{l}\text { Total Flow (dry } \\
\text { matter) }\end{array}$ & $\mathrm{kg} / \mathrm{hr}$ & 0 & 0 & 18,034 & 0 & 0 & 22,592 & 0 & 0 & 18,034 & 226 & 0 & 22,592 \\
\hline C6 & $\mathrm{kg} / \mathrm{hr}$ & 0 & 0 & 6,832 & 0 & 0 & 8,559 & 0 & 0 & 6,832 & 63 & 0 & 8,559 \\
\hline C5 & $\mathrm{kg} / \mathrm{hr}$ & 0 & 0 & 3,494 & 0 & 0 & 4,378 & 0 & 0 & 3,494 & 35 & 0 & 4,378 \\
\hline LIGNIN & $\mathrm{kg} / \mathrm{hr}$ & 0 & 0 & 2,865 & 0 & 0 & 3,589 & 0 & 0 & 2,865 & 44 & 0 & 3,589 \\
\hline ASH & $\mathrm{kg} / \mathrm{hr}$ & 0 & 0 & 2,231 & 0 & 0 & 2,795 & 0 & 0 & 2,231 & 57 & 0 & 2,795 \\
\hline PROTEIN & $\mathrm{kg} / \mathrm{hr}$ & 0 & 0 & 526 & 0 & 0 & 659 & 0 & 0 & 526 & 0 & 0 & 659 \\
\hline EXTRACTIVES & $\mathrm{kg} / \mathrm{hr}$ & 0 & 0 & 2,080 & 0 & 0 & 2,605 & 0 & 0 & 2,080 & 28 & 0 & 2,605 \\
\hline OTHERS & $\mathrm{kg} / \mathrm{hr}$ & 0 & 0 & 5 & 0 & 0 & 6 & 0 & 0 & 5 & 0 & 0 & 6 \\
\hline Temperature & K & 298 & 298 & 298 & 298 & 298 & 298 & 298 & 298 & 298 & 298 & 298 & 298 \\
\hline Pressure & $\mathrm{atm}$ & 1 & 1 & 1 & 1 & 1 & 1 & 1 & 1 & 1 & 1 & 1 & 1 \\
\hline Vapor Frac & & 0 & 0 & 0 & 0 & 0 & 0 & 0 & 0 & 0 & 0 & 0 & 0 \\
\hline
\end{tabular}




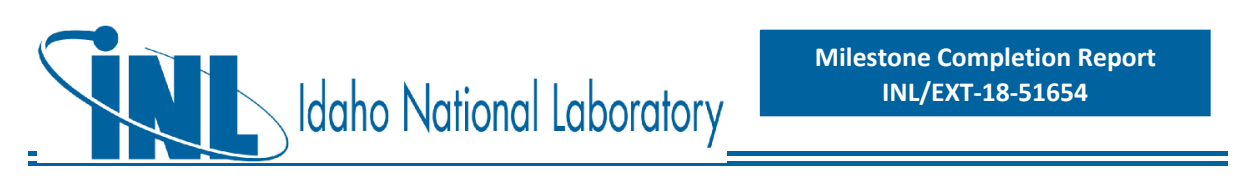

Table I-2. (continued)

\begin{tabular}{|c|c|c|c|c|c|c|c|c|c|c|c|}
\hline Component & unit & BMOUT17 & DML-18 & MC-18 & BMOUT18 & DML-19 & MC-19 & BMOUT19 & DML-20 & $\begin{array}{l}\text { MC- } \\
20\end{array}$ & BMOUT20 \\
\hline $\begin{array}{l}\text { Overall Flow } \\
\text { (moisture and dry } \\
\text { matter) }\end{array}$ & $\mathrm{kg} / \mathrm{hr}$ & 27,356 & 0 & 0 & 49,414 & 0 & 2,849 & 46,565 & 0 & 895 & 45,669 \\
\hline Moisture Flow & $\mathrm{kg} / \mathrm{hr}$ & 4,990 & 0 & 0 & 9,015 & 0 & 2,849 & 6,165 & 0 & 895 & 5,269 \\
\hline $\begin{array}{l}\text { Total Flow (dry } \\
\text { matter) }\end{array}$ & $\mathrm{kg} / \mathrm{hr}$ & 22,366 & 0 & 0 & 40,400 & 0 & 0 & 40,400 & 0 & 0 & 40,400 \\
\hline C6 & $\mathrm{kg} / \mathrm{hr}$ & 8,496 & 0 & 0 & 15,328 & 0 & 0 & 15,328 & 0 & 0 & 15,328 \\
\hline $\mathrm{C} 5$ & $\mathrm{~kg} / \mathrm{hr}$ & 4,343 & 0 & 0 & 7,838 & 0 & 0 & 7,838 & 0 & 0 & 7,838 \\
\hline LIGNIN & $\mathrm{kg} / \mathrm{hr}$ & 3,545 & 0 & 0 & 6,410 & 0 & 0 & 6,410 & 0 & 0 & 6,410 \\
\hline ASH & $\mathrm{kg} / \mathrm{hr}$ & 2,739 & 0 & 0 & 4,970 & 0 & 0 & 4,970 & 0 & 0 & 4,970 \\
\hline PROTEIN & $\mathrm{kg} / \mathrm{hr}$ & 659 & 0 & 0 & 1,185 & 0 & 0 & 1,185 & 0 & 0 & 1,185 \\
\hline EXTRACTIVES & $\mathrm{kg} / \mathrm{hr}$ & 2,577 & 0 & 0 & 4,657 & 0 & 0 & 4,657 & 0 & 0 & 4,657 \\
\hline OTHERS & $\mathrm{kg} / \mathrm{hr}$ & 6 & 0 & 0 & 11 & 0 & 0 & 11 & 0 & 0 & 11 \\
\hline Temperature & K & 298 & 298 & 298 & 298 & 298 & 298 & 298 & 298 & 298 & 298 \\
\hline Pressure & $\mathrm{atm}$ & 1 & 1 & 1 & 1 & 1 & 1 & 1 & 1 & 1 & 1 \\
\hline Vapor Frac & & 0 & 0 & 0 & 0 & 0 & 0 & 0 & 0 & 0 & 0 \\
\hline
\end{tabular}


lacho National Laboratory

Table I-2. (continued)

\begin{tabular}{|c|c|c|c|c|c|c|c|c|c|c|c|}
\hline Component & unit & $\begin{array}{l}\text { DML- } \\
21\end{array}$ & MC-21 & BMOUT21 & DML-22 & MC-22 & BMOUT22 & DML-23 & MC-23 & BMOUT23 & $\begin{array}{c}\text { DML- } \\
24\end{array}$ \\
\hline $\begin{array}{l}\text { Overall Flow } \\
\text { (moisture and dry } \\
\text { matter) }\end{array}$ & $\mathrm{kg} / \mathrm{hr}$ & 0 & 0 & 45,669 & 0 & 0 & 45,669 & 0 & 0 & 45,669 & 0 \\
\hline Moisture Flow & $\mathrm{kg} / \mathrm{hr}$ & 0 & 0 & 5,269 & 0 & 0 & 5,269 & 0 & 0 & 5,269 & 0 \\
\hline $\begin{array}{l}\text { Total Flow (dry } \\
\text { matter) }\end{array}$ & $\mathrm{kg} / \mathrm{hr}$ & 0 & 0 & 40,400 & 0 & 0 & 40,400 & 0 & 0 & 40,400 & 0 \\
\hline C6 & $\mathrm{kg} / \mathrm{hr}$ & 0 & 0 & 15,328 & 0 & 0 & 15,328 & 0 & 0 & 15,328 & 0 \\
\hline C5 & $\mathrm{kg} / \mathrm{hr}$ & 0 & 0 & 7,838 & 0 & 0 & 7,838 & 0 & 0 & 7,838 & 0 \\
\hline LIGNIN & $\mathrm{kg} / \mathrm{hr}$ & 0 & 0 & 6,410 & 0 & 0 & 6,410 & 0 & 0 & 6,410 & 0 \\
\hline ASH & $\mathrm{kg} / \mathrm{hr}$ & 0 & 0 & 4,970 & 0 & 0 & 4,970 & 0 & 0 & 4,970 & 0 \\
\hline PROTEIN & $\mathrm{kg} / \mathrm{hr}$ & 0 & 0 & 1,185 & 0 & 0 & 1,185 & 0 & 0 & 1,185 & 0 \\
\hline EXTRACTIVES & $\mathrm{kg} / \mathrm{hr}$ & 0 & 0 & 4,657 & 0 & 0 & 4,657 & 0 & 0 & 4,657 & 0 \\
\hline OTHERS & $\mathrm{kg} / \mathrm{hr}$ & 0 & 0 & 11 & 0 & 0 & 11 & 0 & 0 & 11 & 0 \\
\hline Temperature & K & 298 & 298 & 298 & 298 & 298 & 298 & 298 & 298 & 298 & 298 \\
\hline Pressure & atm & 1 & 1 & 1 & 1 & 1 & 1 & 1 & 1 & 1 & 1 \\
\hline Vapor Frac & & 0 & 0 & 0 & 0 & 0 & 0 & 0 & 0 & 0 & 0 \\
\hline
\end{tabular}


Table I-2. (continued)

\begin{tabular}{lccrrrrrrrr}
\hline \multicolumn{1}{c}{ Component } & unit & $\begin{array}{c}\text { MC- } \\
\mathbf{2 4}\end{array}$ & BMOUT24 & DML-25 & MC-25 & BMOUT25 & DML-26 & MC-26 & BMOUT26 \\
\hline $\begin{array}{l}\text { Overall Flow } \\
\text { (moisture and dry } \\
\text { matter) }\end{array}$ & $\mathrm{kg} / \mathrm{hr}$ & 0 & 45,669 & 0 & 0 & 45,669 & 0 & 0 & 45,669 \\
\hline Moisture Flow & $\mathrm{kg} / \mathrm{hr}$ & 0 & 5,269 & 0 & 0 & 5,269 & 0 & 0 & 5,269 \\
\hline $\begin{array}{l}\text { Total Flow (dry } \\
\text { matter) }\end{array}$ & $\mathrm{kg} / \mathrm{hr}$ & 0 & 40,400 & 0 & 0 & 40,400 & 0 & 0 & 40,400 \\
\hline C6 & $\mathrm{kg} / \mathrm{hr}$ & 0 & 15,328 & 0 & 0 & 15,328 & 0 & 0 & 15,328 \\
\hline C5 & $\mathrm{kg} / \mathrm{hr}$ & 0 & 7,838 & 0 & 0 & 7,838 & 0 & 0 & 7,838 \\
\hline LIGNIN & $\mathrm{kg} / \mathrm{hr}$ & 0 & 6,410 & 0 & 0 & 6,410 & 0 & 0 & 6,410 \\
\hline ASH & $\mathrm{kg} / \mathrm{hr}$ & 0 & 4,970 & 0 & 0 & 4,970 & 0 & 0 & 4,970 \\
\hline PROTEIN & $\mathrm{kg} / \mathrm{hr}$ & 0 & 1,185 & 0 & 0 & 1,185 & 0 & 0 & 1,185 \\
\hline EXTRACTIVES & $\mathrm{kg} / \mathrm{hr}$ & 0 & 4,657 & 0 & 0 & 4,657 & 0 & 0 & 4,657 \\
\hline OTHERS & $\mathrm{kg} / \mathrm{hr}$ & 0 & 11 & 0 & 0 & 11 & 0 & 0 & 11 \\
\hline Temperature & $\mathrm{K}$ & 298 & 298 & 298 & 298 & 298 & 298 & 298 & 1 \\
\hline Pressure & $\mathrm{atm}$ & 1 & 1 & 1 & 1 & 1 & 1 & 1 \\
\hline Vapor Frac & & 0 & 0 & 0 & 0 & 0 & 0 & 0 & 1 \\
\hline
\end{tabular}




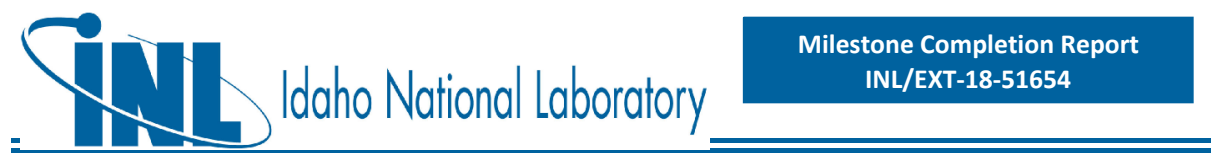




\section{I.2 Two-pass Corn Stover Blendstock}

High-level stream table information from Aspen Plus modeling output follows, for key streams associated with each process operation area. This is followed by high-level PFDs for the associated process areas. Space for stream tables was limited; below is a key to lumped components. As the stream table information focuses primarily on the high-level overall process and does not include every individual modeled stream within each process area, mass balance closure around a given unit area may not be $100 \%$.

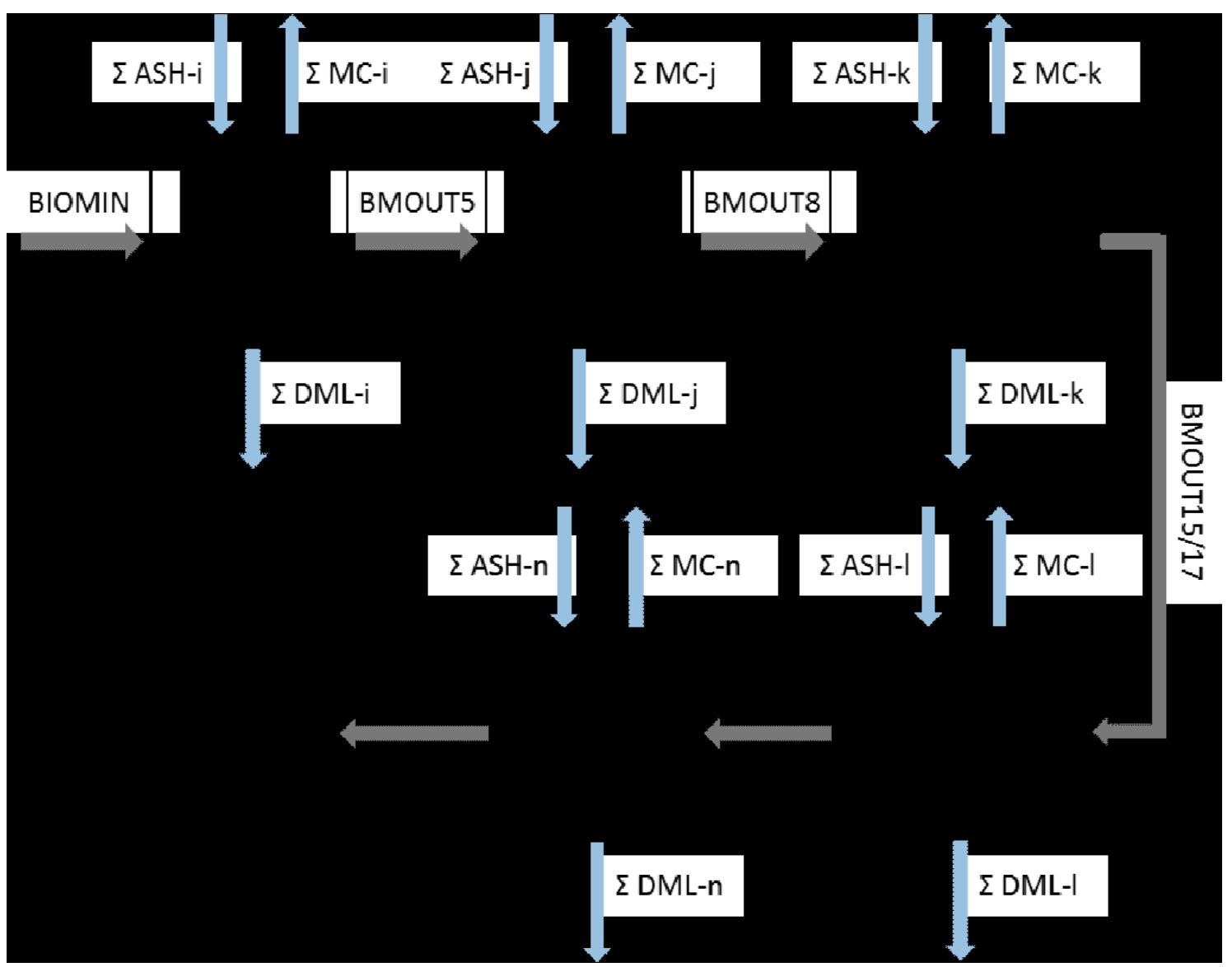

Figure I-7. High-level flowsheet showing key process areas for the two pass corn stover blendstock in the Exclusion of Grass Clippings from the Centralized Depot Case. 

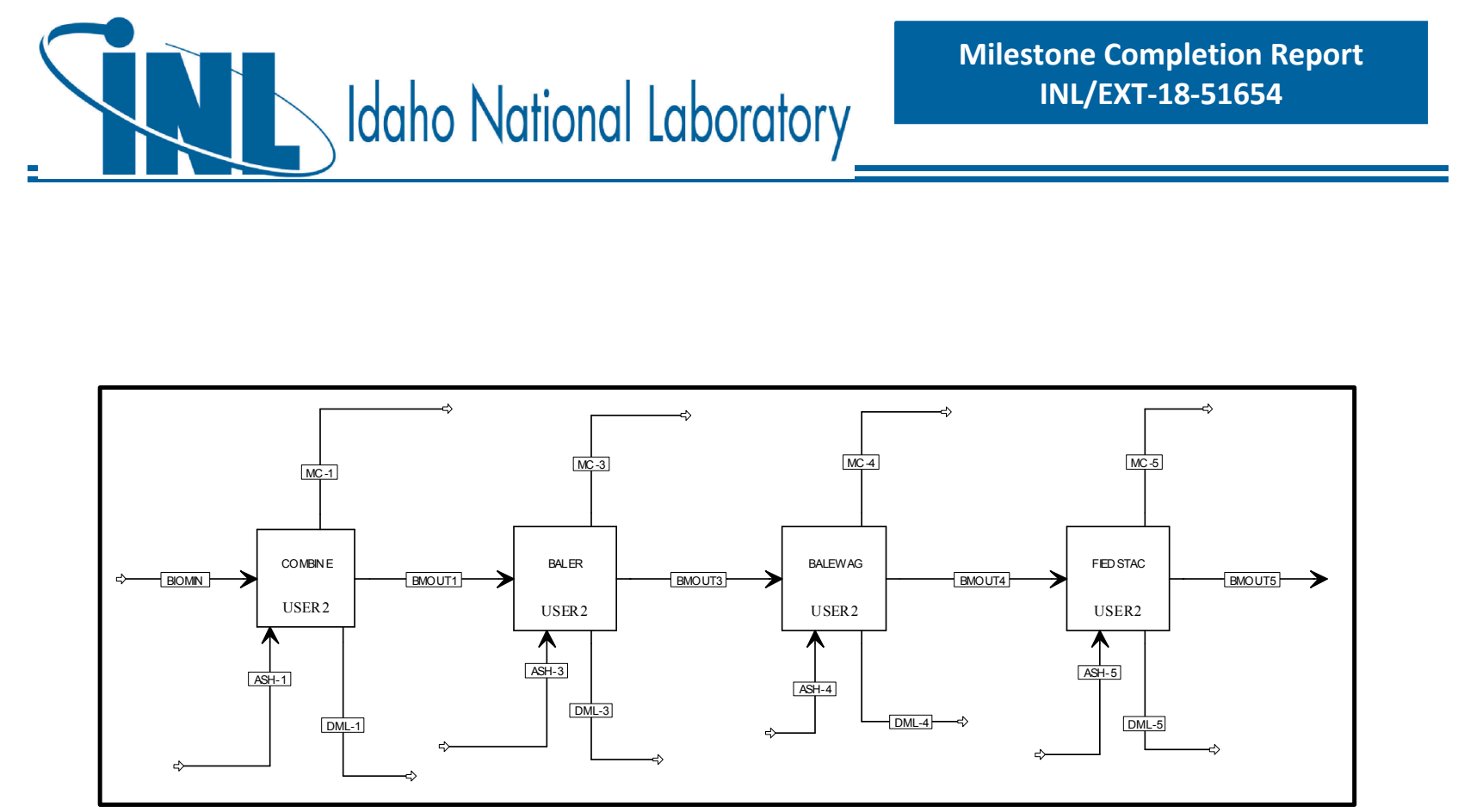

Figure I-8. Detailed process flow diagram for area B100 - Harvesting to Storage.

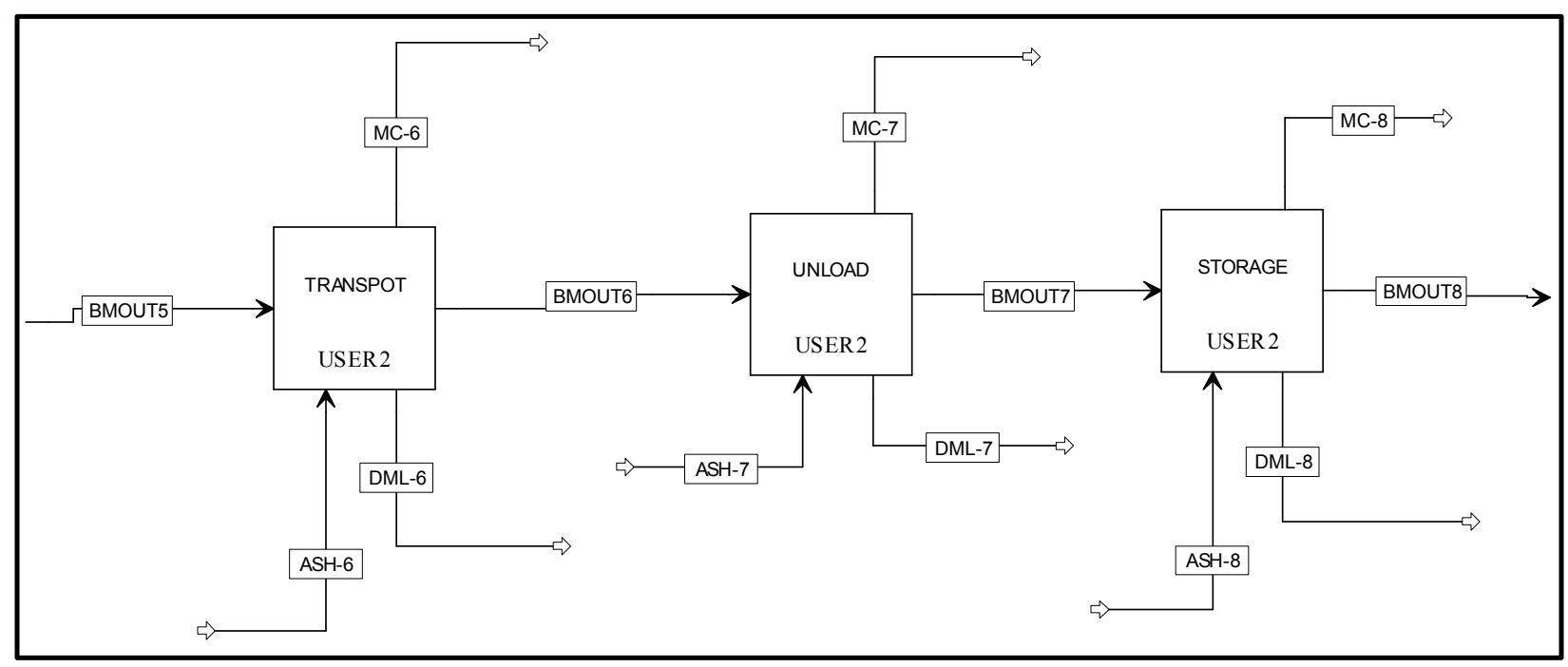

Figure I-9. Detailed process flow diagram for area B200 - Transport to Biorefinery \& Handling. 

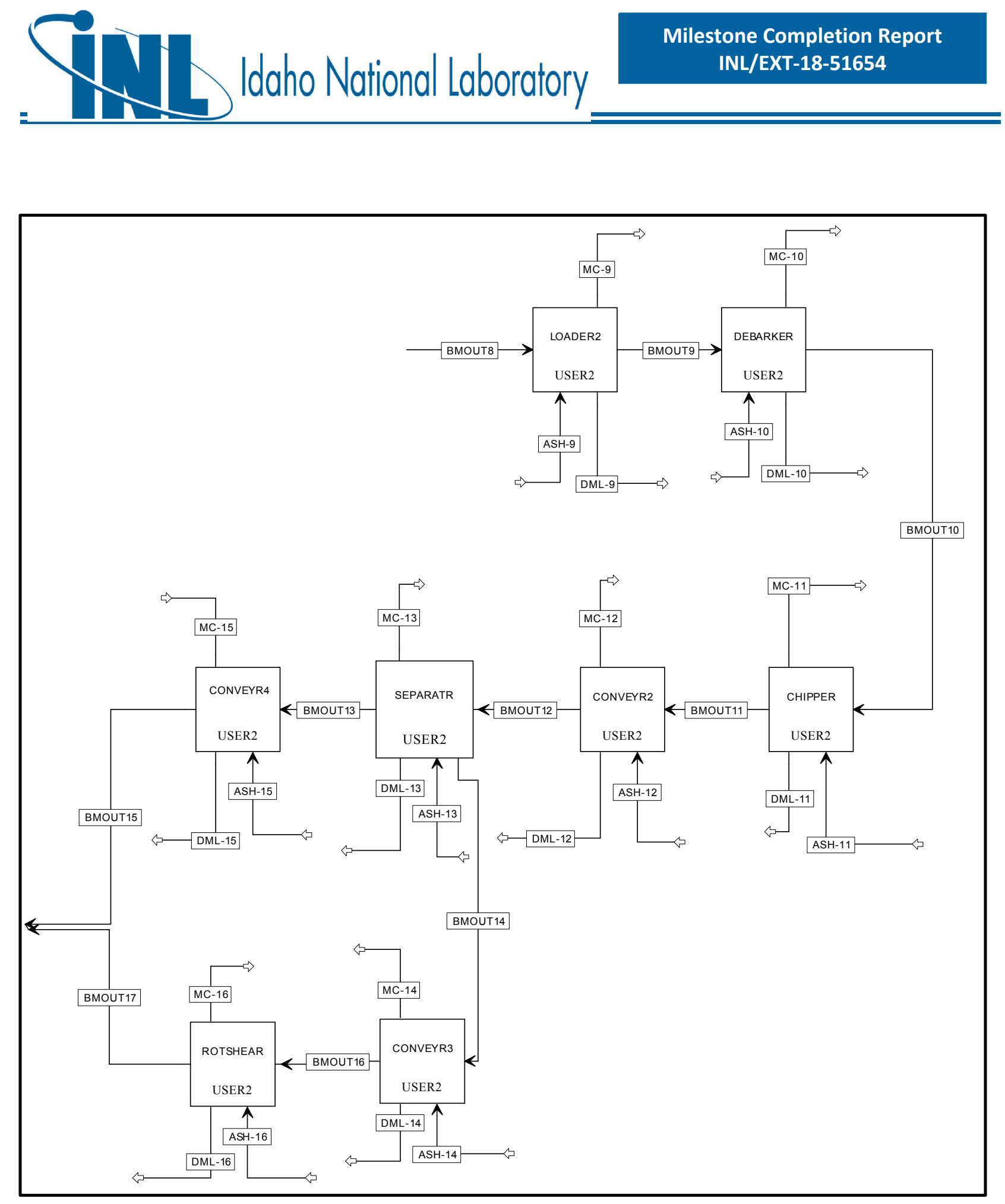

Figure I-10. Detailed process flow diagram for area B300 - Preprocessing - Size Reduction. 

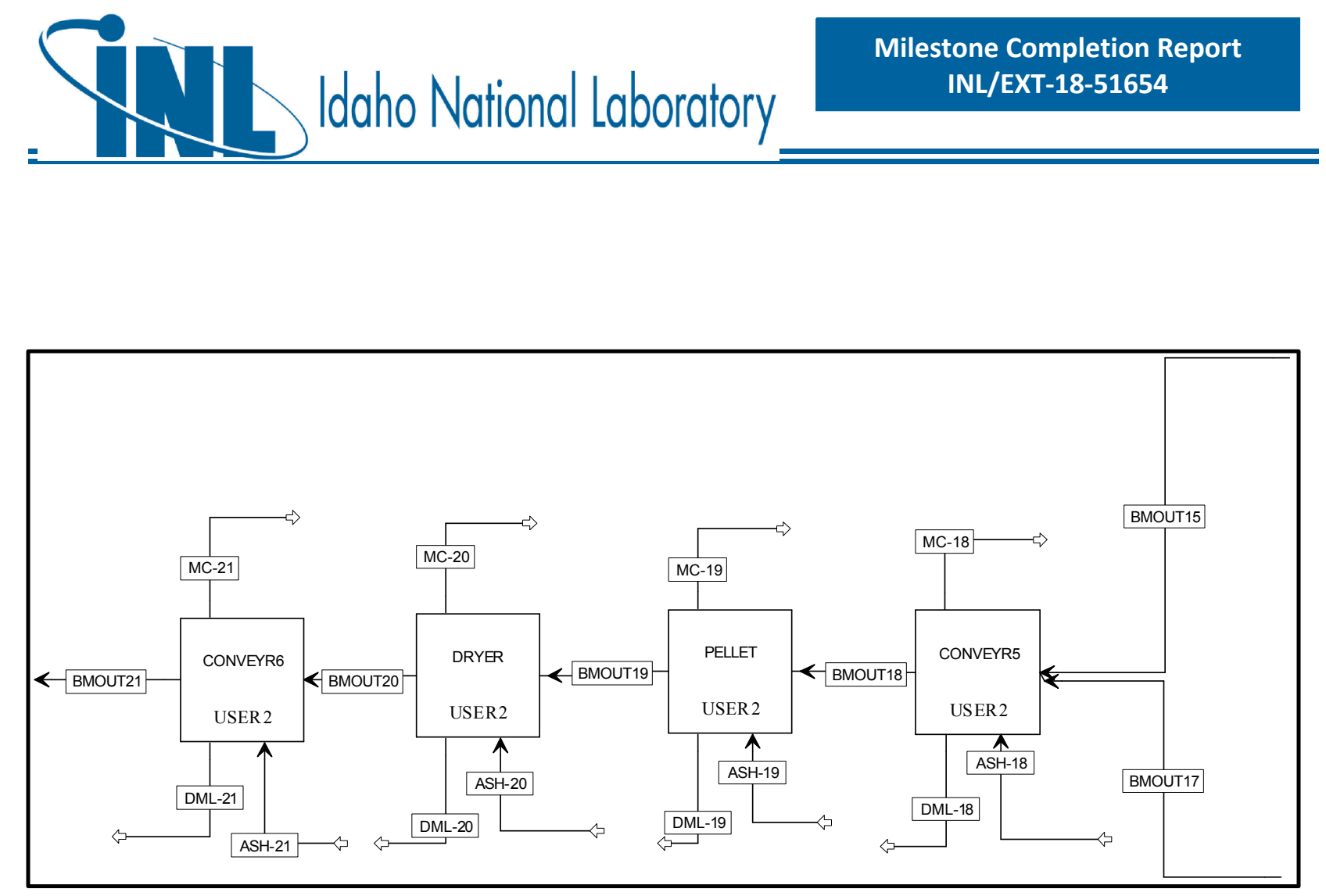

Figure I-11. Detailed process flow diagram for area B400 - Preprocessing - Pelleting.

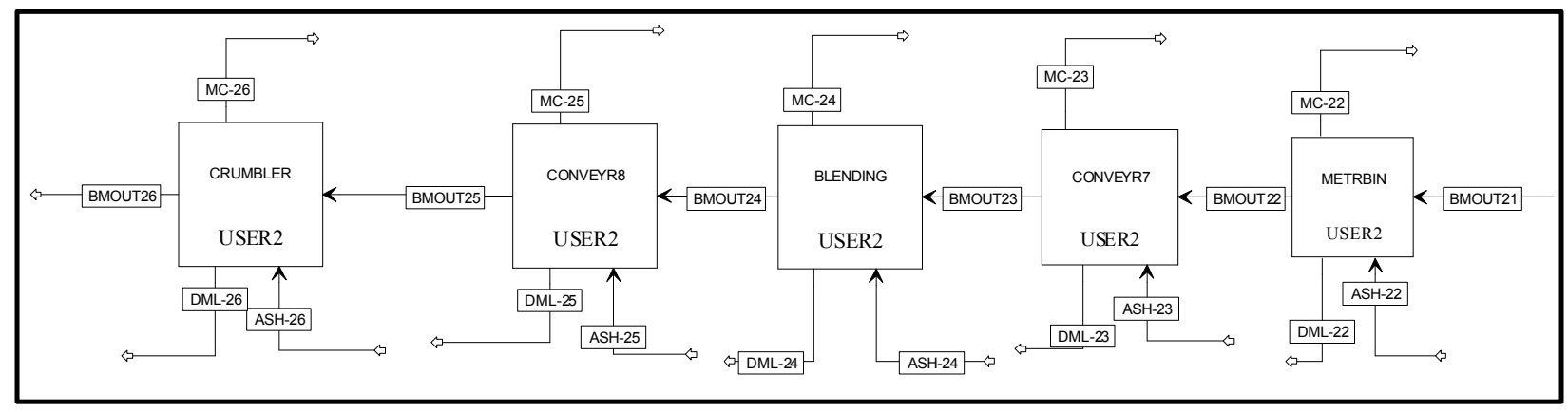

Figure I-12. Detailed process flow diagram for area B500 - Feeding. 


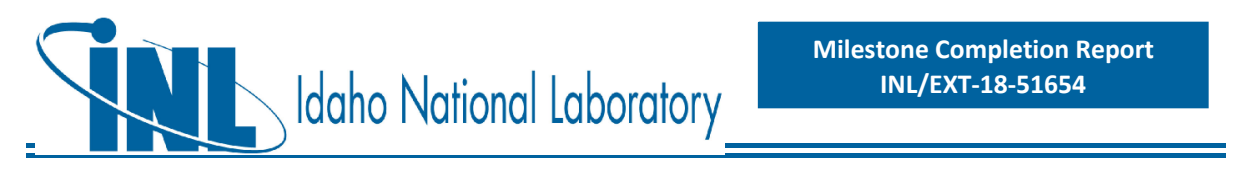

Table I-3. Aspen Plus mass balances from harvest to field-side storage (Area B100) for the two-pass corn stover blendstock in the Exclusion of Grass Clippings from the Centralized Depot Case. Harvest is assumed to take place within a 6 week period, working 14 hours/day, 6 days per week.

\begin{tabular}{|c|c|c|c|c|c|c|c|c|c|c|c|c|}
\hline Component & unit & BIOMIN & DML-1 & MC-1 & BMOUT1 & DML-3 & MC-3 & ASH-3 & BMOUT3 & DML-4 & MC-4 & BMOUT4 \\
\hline $\begin{array}{l}\text { Overall Flow } \\
\text { (moisture and } \\
\text { dry matter) }\end{array}$ & $\mathrm{kg} / \mathrm{hr}$ & 883,881 & 0 & 17 & 883,864 & 0 & 0 & 12,806 & 883,864 & 0 & 0 & 883,864 \\
\hline Moisture Flow & $\mathrm{kg} / \mathrm{hr}$ & 265,171 & 0 & 17 & 265,154 & 0 & 0 & 0 & 265,154 & 0 & 0 & 265,154 \\
\hline $\begin{array}{l}\text { Total Flow (dry } \\
\text { matter) }\end{array}$ & $\mathrm{kg} / \mathrm{hr}$ & 618,710 & 0 & 0 & 618,710 & 0 & 0 & 12,806 & 618,710 & 0 & 0 & 618,710 \\
\hline C6 & $\mathrm{kg} / \mathrm{hr}$ & 229,101 & 0 & 0 & 229,101 & 0 & 0 & 0 & 229,101 & 0 & 0 & 229,101 \\
\hline C5 & $\mathrm{kg} / \mathrm{hr}$ & 132,406 & 0 & 0 & 132,406 & 0 & 0 & 0 & 132,406 & 0 & 0 & 132,406 \\
\hline LIGNIN & $\mathrm{kg} / \mathrm{hr}$ & 95,524 & 0 & 0 & 95,524 & 0 & 0 & 0 & 95,524 & 0 & 0 & 95,524 \\
\hline ASH & $\mathrm{kg} / \mathrm{hr}$ & 30,500 & 0 & 0 & 30,500 & 0 & 0 & 12,806 & 43,306 & 0 & 0 & 43,306 \\
\hline PROTEIN & $\mathrm{kg} / \mathrm{hr}$ & 18,751 & 0 & 0 & 18,751 & 0 & 0 & 0 & 18,751 & 0 & 0 & 18,751 \\
\hline $\begin{array}{l}\text { EXTRACTIVE } \\
\text { S }\end{array}$ & $\mathrm{kg} / \mathrm{hr}$ & 88,840 & 0 & 0 & 88,840 & 0 & 0 & 0 & 88,840 & 0 & 0 & 88,840 \\
\hline OTHERS & $\mathrm{kg} / \mathrm{hr}$ & 10,765 & 0 & 0 & 10,765 & 0 & 0 & 0 & 10,765 & 0 & 0 & 10,765 \\
\hline Temperature & K & 298 & 298 & 298 & 298 & 298 & 298 & 298 & 298 & 298 & 298 & 298 \\
\hline Pressure & $\mathrm{atm}$ & 1 & 1 & 1 & 1 & 1 & 1 & 1 & 1 & 1 & 1 & 1 \\
\hline Vapor Frac & & 0 & 0 & 0 & 0 & 0 & 0 & 0 & 0 & 0 & 0 & 0 \\
\hline
\end{tabular}


Table I-4. Aspen Plus mass balances from field-side storage to feeding (Areas B200-B500) for the two-pass corn stover blendstock in the Exclusion of Grass Clippings from the Centralized Depot Case. Depot operation is assumed to take place within 350 day period, working 24 hours/day, 7 days per week.

\begin{tabular}{|c|c|c|c|c|c|c|c|c|c|c|c|}
\hline Component & unit & DML-5 & MC-5 & BMOUT5 & DML-6 & MC-6 & BMOUT6 & DML-7 & MC-7 & BMOUT7 & DML-8 \\
\hline $\begin{array}{l}\text { Overall Flow } \\
\text { (moisture and dry } \\
\text { matter) }\end{array}$ & $\mathrm{kg} / \mathrm{hr}$ & 5,011 & 4,455 & 43,566 & 0 & 0 & 43,566 & 0 & 0 & 43,566 & 0 \\
\hline Moisture Flow & $\mathrm{kg} / \mathrm{hr}$ & 5,011 & 0 & 10,899 & 0 & 0 & 10,899 & 0 & 0 & 10,899 & 0 \\
\hline $\begin{array}{l}\text { Total Flow (dry } \\
\text { matter) }\end{array}$ & $\mathrm{kg} / \mathrm{hr}$ & 0 & 4,455 & 32,667 & 0 & 0 & 32,667 & 0 & 0 & 32,667 & 0 \\
\hline C6 & $\mathrm{kg} / \mathrm{hr}$ & 0 & 823 & 12,925 & 0 & 0 & 12,925 & 0 & 0 & 12,925 & 0 \\
\hline C5 & $\mathrm{kg} / \mathrm{hr}$ & 0 & 1,289 & 6,655 & 0 & 0 & 6,655 & 0 & 0 & 6,655 & 0 \\
\hline LIGNIN & $\mathrm{kg} / \mathrm{hr}$ & 0 & 287 & 5,445 & 0 & 0 & 5,445 & 0 & 0 & 5,445 & 0 \\
\hline ASH & $\mathrm{kg} / \mathrm{hr}$ & 0 & 0 & 2,598 & 0 & 0 & 2,598 & 0 & 0 & 2,598 & 0 \\
\hline PROTEIN & $\mathrm{kg} / \mathrm{hr}$ & 0 & 134 & 991 & 0 & 0 & 991 & 0 & 0 & 991 & 0 \\
\hline EXTRACTIVES & $\mathrm{kg} / \mathrm{hr}$ & 0 & 1,336 & 3,995 & 0 & 0 & 3,995 & 0 & 0 & 3,995 & 0 \\
\hline OTHERS & $\mathrm{kg} / \mathrm{hr}$ & 0 & 587 & 59 & 0 & 0 & 59 & 0 & 0 & 59 & 0 \\
\hline Temperature & $\mathrm{K}$ & 298 & 298 & 298 & 298 & 298 & 298 & 298 & 298 & 298 & 298 \\
\hline Pressure & $\mathrm{atm}$ & 1 & 1 & 1 & 1 & 1 & 1 & 1 & 1 & 1 & 1 \\
\hline Vapor Frac & & 0 & 0 & 0 & 0 & 0 & 0 & 0 & 0 & 0 & 0 \\
\hline
\end{tabular}


Table I-4. (continued)

\begin{tabular}{|c|c|c|c|c|c|c|c|c|c|c|}
\hline Component & unit & MC-8 & BMOUT8 & DML-9 & MC-9 & BMOUT9 & DML-10 & MC-10 & BMOUT10 & DML-11 \\
\hline $\begin{array}{l}\text { Overall Flow } \\
\text { (moisture and dry } \\
\text { matter) }\end{array}$ & $\mathrm{kg} / \mathrm{hr}$ & 0 & 43,566 & 0 & 0 & 43,566 & 0 & 0 & 43,566 & 327 \\
\hline Moisture Flow & $\mathrm{kg} / \mathrm{hr}$ & 0 & 10,899 & 0 & 0 & 10,899 & 0 & 0 & 10,899 & 0 \\
\hline $\begin{array}{l}\text { Total Flow (dry } \\
\text { matter) }\end{array}$ & $\mathrm{kg} / \mathrm{hr}$ & 0 & 32,667 & 0 & 0 & 32,667 & 0 & 0 & 32,667 & 327 \\
\hline C6 & $\mathrm{kg} / \mathrm{hr}$ & 0 & 12,925 & 0 & 0 & 12,925 & 0 & 0 & 12,925 & 91 \\
\hline C5 & $\mathrm{kg} / \mathrm{hr}$ & 0 & 6,655 & 0 & 0 & 6,655 & 0 & 0 & 6,655 & 51 \\
\hline LIGNIN & $\mathrm{kg} / \mathrm{hr}$ & 0 & 5,445 & 0 & 0 & 5,445 & 0 & 0 & 5,445 & 63 \\
\hline ASH & $\mathrm{kg} / \mathrm{hr}$ & 0 & 2,598 & 0 & 0 & 2,598 & 0 & 0 & 2,598 & 82 \\
\hline PROTEIN & $\mathrm{kg} / \mathrm{hr}$ & 0 & 991 & 0 & 0 & 991 & 0 & 0 & 991 & 0 \\
\hline EXTRACTIVES & $\mathrm{kg} / \mathrm{hr}$ & 0 & 3,995 & 0 & 0 & 3,995 & 0 & 0 & 3,995 & 40 \\
\hline OTHERS & $\mathrm{kg} / \mathrm{hr}$ & 0 & 59 & 0 & 0 & 59 & 0 & 0 & 59 & 0 \\
\hline Temperature & $\mathrm{K}$ & 298 & 298 & 298 & 298 & 298 & 298 & 298 & 298 & 298 \\
\hline Pressure & $\mathrm{atm}$ & 1 & 1 & 1 & 1 & 1 & 1 & 1 & 1 & 1 \\
\hline Vapor Frac & & 0 & 0 & 0 & 0 & 0 & 0 & 0 & 0 & 0 \\
\hline
\end{tabular}


- lacho National Laboratory

Table I-4. (continued)

\begin{tabular}{|c|c|c|c|c|c|c|c|c|c|c|c|c|}
\hline Component & unit & MC-11 & BMOUT11 & $\begin{array}{c}\text { DML- } \\
12\end{array}$ & $\begin{array}{c}\text { MC- } \\
12\end{array}$ & BMOUT12 & $\begin{array}{c}\text { DML- } \\
13\end{array}$ & MC-13 & BMOUT13 & DML-14 & MC-14 & BMOUT14 \\
\hline $\begin{array}{l}\text { Overall Flow } \\
\text { (moisture and dry } \\
\text { matter) }\end{array}$ & $\mathrm{kg} / \mathrm{hr}$ & 2,690 & 40,549 & 0 & 0 & 40,549 & 0 & 992 & 17,559 & 0 & 0 & 21,998 \\
\hline Moisture Flow & $\mathrm{kg} / \mathrm{hr}$ & 2,690 & 8,209 & 0 & 0 & 8,209 & 0 & 992 & 3,203 & 0 & 0 & 4,013 \\
\hline $\begin{array}{l}\text { Total Flow (dry } \\
\text { matter) }\end{array}$ & $\mathrm{kg} / \mathrm{hr}$ & 0 & 32,341 & 0 & 0 & 32,341 & 0 & 0 & 14,356 & 0 & 0 & 17,985 \\
\hline C6 & $\mathrm{kg} / \mathrm{hr}$ & 0 & 12,834 & 0 & 0 & 12,834 & 0 & 0 & 5,697 & 0 & 0 & 7,136 \\
\hline C5 & $\mathrm{kg} / \mathrm{hr}$ & 0 & 6,605 & 0 & 0 & 6,605 & 0 & 0 & 2,932 & 0 & 0 & 3,673 \\
\hline LIGNIN & $\mathrm{kg} / \mathrm{hr}$ & 0 & 5,381 & 0 & 0 & 5,381 & 0 & 0 & 2,389 & 0 & 0 & 2,993 \\
\hline ASH & $\mathrm{kg} / \mathrm{hr}$ & 0 & 2,517 & 0 & 0 & 2,517 & 0 & 0 & 1,117 & 0 & 0 & 1,399 \\
\hline PROTEIN & $\mathrm{kg} / \mathrm{hr}$ & 0 & 991 & 0 & 0 & 991 & 0 & 0 & 440 & 0 & 0 & 551 \\
\hline EXTRACTIVES & $\mathrm{kg} / \mathrm{hr}$ & 0 & 3,955 & 0 & 0 & 3,955 & 0 & 0 & 1,755 & 0 & 0 & 2,199 \\
\hline OTHERS & $\mathrm{kg} / \mathrm{hr}$ & 0 & 59 & 0 & 0 & 59 & 0 & 0 & 26 & 0 & 0 & 33 \\
\hline Temperature & K & 298 & 298 & 298 & 298 & 298 & 298 & 298 & 298 & 298 & 298 & 298 \\
\hline Pressure & atm & 1 & 1 & 1 & 1 & 1 & 1 & 1 & 1 & 1 & 1 & 1 \\
\hline Vapor Frac & & 0 & 0 & 0 & 0 & 0 & 0 & 0 & 0 & 0 & 0 & 0 \\
\hline
\end{tabular}


Table I-4. (continued)

\begin{tabular}{|c|c|c|c|c|c|c|c|c|c|c|}
\hline Component & unit & DML-15 & MC-15 & BMOUT15 & DML-16 & MC-16 & BMOUT16 & BMOUT17 & DML-18 & MC-18 \\
\hline $\begin{array}{l}\text { Overall Flow } \\
\text { (moisture and dry } \\
\text { matter) }\end{array}$ & $\mathrm{kg} / \mathrm{hr}$ & 0 & 0 & 17,559 & 40 & 180 & 21,998 & 21,778 & 0 & 0 \\
\hline Moisture Flow & $\mathrm{kg} / \mathrm{hr}$ & 0 & 0 & 3,203 & 40 & 0 & 4,013 & 3,973 & 0 & 0 \\
\hline $\begin{array}{l}\text { Total Flow (dry } \\
\text { matter) }\end{array}$ & $\mathrm{kg} / \mathrm{hr}$ & 0 & 0 & 14,356 & 0 & 180 & 17,985 & 17,805 & 0 & 0 \\
\hline C6 & $\mathrm{kg} / \mathrm{hr}$ & 0 & 0 & 5,697 & 0 & 50 & 7,136 & 7,087 & 0 & 0 \\
\hline $\mathrm{C} 5$ & $\mathrm{~kg} / \mathrm{hr}$ & 0 & 0 & 2,932 & 0 & 28 & 3,673 & 3,645 & 0 & 0 \\
\hline LIGNIN & $\mathrm{kg} / \mathrm{hr}$ & 0 & 0 & 2,389 & 0 & 35 & 2,993 & 2,957 & 0 & 0 \\
\hline ASH & $\mathrm{kg} / \mathrm{hr}$ & 0 & 0 & 1,117 & 0 & 45 & 1,399 & 1,354 & 0 & 0 \\
\hline PROTEIN & $\mathrm{kg} / \mathrm{hr}$ & 0 & 0 & 440 & 0 & 0 & 551 & 551 & 0 & 0 \\
\hline EXTRACTIVES & $\mathrm{kg} / \mathrm{hr}$ & 0 & 0 & 1,755 & 0 & 22 & 2,199 & 2,177 & 0 & 0 \\
\hline OTHERS & $\mathrm{kg} / \mathrm{hr}$ & 0 & 0 & 26 & 0 & 0 & 33 & 33 & 0 & 0 \\
\hline Temperature & $\mathrm{K}$ & 298 & 298 & 298 & 298 & 298 & 298 & 298 & 298 & 298 \\
\hline Pressure & atm & 1 & 1 & 1 & 1 & 1 & 1 & 1 & 1 & 1 \\
\hline Vapor Frac & & 0 & 0 & 0 & 0 & 0 & 0 & 0 & 0 & 0 \\
\hline
\end{tabular}


lacho National Laboratory

Table I-4. (continued)

\begin{tabular}{|c|c|c|c|c|c|c|c|c|c|c|c|}
\hline Component & unit & BMOUT18 & $\begin{array}{c}\text { DML- } \\
19\end{array}$ & MC-19 & BMOUT19 & $\begin{array}{c}\text { DML- } \\
20\end{array}$ & MC-20 & BMOUT20 & DML-21 & MC-21 & BMOUT21 \\
\hline $\begin{array}{l}\text { Overall Flow } \\
\text { (moisture and dry } \\
\text { matter) }\end{array}$ & $\mathrm{kg} / \mathrm{hr}$ & 39,338 & 0 & 2,269 & 37,069 & 0 & 713 & 36,356 & 0 & 0 & 36,356 \\
\hline Moisture Flow & $\mathrm{kg} / \mathrm{hr}$ & 7,176 & 0 & 2,269 & 4,908 & 0 & 713 & 4,195 & 0 & 0 & 4,195 \\
\hline $\begin{array}{l}\text { Total Flow (dry } \\
\text { matter) }\end{array}$ & $\mathrm{kg} / \mathrm{hr}$ & 32,161 & 0 & 0 & 32,161 & 0 & 0 & 32,161 & 0 & 0 & 32,161 \\
\hline C6 & $\mathrm{kg} / \mathrm{hr}$ & 12,784 & 0 & 0 & 12,784 & 0 & 0 & 12,784 & 0 & 0 & 12,784 \\
\hline C5 & $\mathrm{kg} / \mathrm{hr}$ & 6,576 & 0 & 0 & 6,576 & 0 & 0 & 6,576 & 0 & 0 & 6,576 \\
\hline LIGNIN & $\mathrm{kg} / \mathrm{hr}$ & 5,346 & 0 & 0 & 5,346 & 0 & 0 & 5,346 & 0 & 0 & 5,346 \\
\hline ASH & $\mathrm{kg} / \mathrm{hr}$ & 2,472 & 0 & 0 & 2,472 & 0 & 0 & 2,472 & 0 & 0 & 2,472 \\
\hline PROTEIN & $\mathrm{kg} / \mathrm{hr}$ & 991 & 0 & 0 & 991 & 0 & 0 & 991 & 0 & 0 & 991 \\
\hline EXTRACTIVES & $\mathrm{kg} / \mathrm{hr}$ & 3,932 & 0 & 0 & 3,932 & 0 & 0 & 3,932 & 0 & 0 & 3,932 \\
\hline OTHERS & $\mathrm{kg} / \mathrm{hr}$ & 59 & 0 & 0 & 59 & 0 & 0 & 59 & 0 & 0 & 59 \\
\hline Temperature & K & 298 & 298 & 298 & 298 & 298 & 298 & 298 & 298 & 298 & 298 \\
\hline Pressure & atm & 1 & 1 & 1 & 1 & 1 & 1 & 1 & 1 & 1 & 1 \\
\hline Vapor Frac & & 0 & 0 & 0 & 0 & 0 & 0 & 0 & 0 & 0 & 0 \\
\hline
\end{tabular}


Table I-4. (continued)

\begin{tabular}{|c|c|c|c|c|c|c|c|c|c|c|}
\hline Component & unit & DML-22 & MC-22 & BMOUT22 & DML-23 & MC-23 & BMOUT23 & DML-24 & MC-24 & BMOUT24 \\
\hline $\begin{array}{l}\text { Overall Flow } \\
\text { (moisture and dry } \\
\text { matter) }\end{array}$ & $\mathrm{kg} / \mathrm{hr}$ & 0 & 0 & 36,356 & 0 & 0 & 36,356 & 0 & 0 & 36,356 \\
\hline $\begin{array}{l}\text { Total Flow (dry } \\
\text { matter) }\end{array}$ & $\mathrm{kg} / \mathrm{hr}$ & 0 & 0 & 32,161 & 0 & 0 & 32,161 & 0 & 0 & 32,161 \\
\hline C6 & $\mathrm{kg} / \mathrm{hr}$ & 0 & 0 & 12,784 & 0 & 0 & 12,784 & 0 & 0 & 12,784 \\
\hline LIGNIN & $\mathrm{kg} / \mathrm{hr}$ & 0 & 0 & 5,346 & 0 & 0 & 5,346 & 0 & 0 & 5,346 \\
\hline ASH & $\mathrm{kg} / \mathrm{hr}$ & 0 & 0 & 2,472 & 0 & 0 & 2,472 & 0 & 0 & 2,472 \\
\hline PROTEIN & $\mathrm{kg} / \mathrm{hr}$ & 0 & 0 & 991 & 0 & 0 & 991 & 0 & 0 & 991 \\
\hline EXTRACTIVES & $\mathrm{kg} / \mathrm{hr}$ & 0 & 0 & 3,932 & 0 & 0 & 3,932 & 0 & 0 & 3,932 \\
\hline OTHERS & $\mathrm{kg} / \mathrm{hr}$ & 0 & 0 & 59 & 0 & 0 & 59 & 0 & 0 & 59 \\
\hline
\end{tabular}


Table I-4. (continued)

\begin{tabular}{lcrrrrrrr}
\hline \multicolumn{1}{c}{ Component } & unit & $\begin{array}{c}\text { DML- } \\
\mathbf{2 5}\end{array}$ & $\begin{array}{c}\text { MC- } \\
\mathbf{2 5}\end{array}$ & BMOUT25 & $\begin{array}{c}\text { DML- } \\
\mathbf{2 6}\end{array}$ & $\begin{array}{c}\text { MC- } \\
\mathbf{2 6}\end{array}$ & BMOUT26 \\
\hline $\begin{array}{l}\text { Overall Flow } \\
\text { (moisture and dry } \\
\text { matter) }\end{array}$ & $\mathrm{kg} / \mathrm{hr}$ & 0 & 0 & 36,356 & 0 & 0 & 36,356 \\
\hline Moisture Flow & $\mathrm{kg} / \mathrm{hr}$ & 0 & 0 & 4,195 & 0 & 0 & 4,195 \\
\hline $\begin{array}{l}\text { Total Flow (dry } \\
\text { matter) }\end{array}$ & $\mathrm{kg} / \mathrm{hr}$ & 0 & 0 & 32,161 & 0 & 0 & 32,161 \\
\hline C6 & $\mathrm{kg} / \mathrm{hr}$ & 0 & 0 & 12,784 & 0 & 0 & 12,784 \\
\hline C5 & $\mathrm{kg} / \mathrm{hr}$ & 0 & 0 & 6,576 & 0 & 0 & 6,576 \\
\hline LIGNIN & $\mathrm{kg} / \mathrm{hr}$ & 0 & 0 & 5,346 & 0 & 0 & 5,346 \\
\hline ASH & $\mathrm{kg} / \mathrm{hr}$ & 0 & 0 & 2,472 & 0 & 0 & 2,472 \\
\hline PROTEIN & $\mathrm{kg} / \mathrm{hr}$ & 0 & 0 & 991 & 0 & 0 & 991 \\
\hline EXTRACTIVES & $\mathrm{kg} / \mathrm{hr}$ & 0 & 0 & 3,932 & 0 & 0 & 3,932 \\
\hline OTHERS & $\mathrm{kg} / \mathrm{hr}$ & 0 & 0 & 59 & 0 & 0 & 59 \\
\hline Temperature & $\mathrm{K}$ & 298 & 298 & 298 & 298 & 298 & 298 \\
\hline Pressure & $\mathrm{atm}$ & 1 & 1 & 1 & 1 & 1 & 1 \\
\hline Vapor Frac & & 0 & 0 & 0 & 0 & 0 & 0 \\
\hline
\end{tabular}




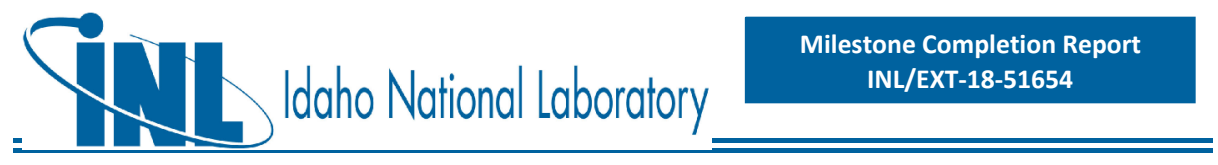




\section{Idaho National Laboratory}

\section{I.3 Switchgrass Blendstock}

High-level stream table information from Aspen Plus modeling output follows, for key streams associated with each process operation area. This is followed by high-level PFDs for the associated process areas. Space for stream tables was limited; below is a key to lumped components. As the stream table information focuses primarily on the high-level overall process and does not include every individual modeled stream within each process area, mass balance closure around a given unit area may not be $100 \%$.

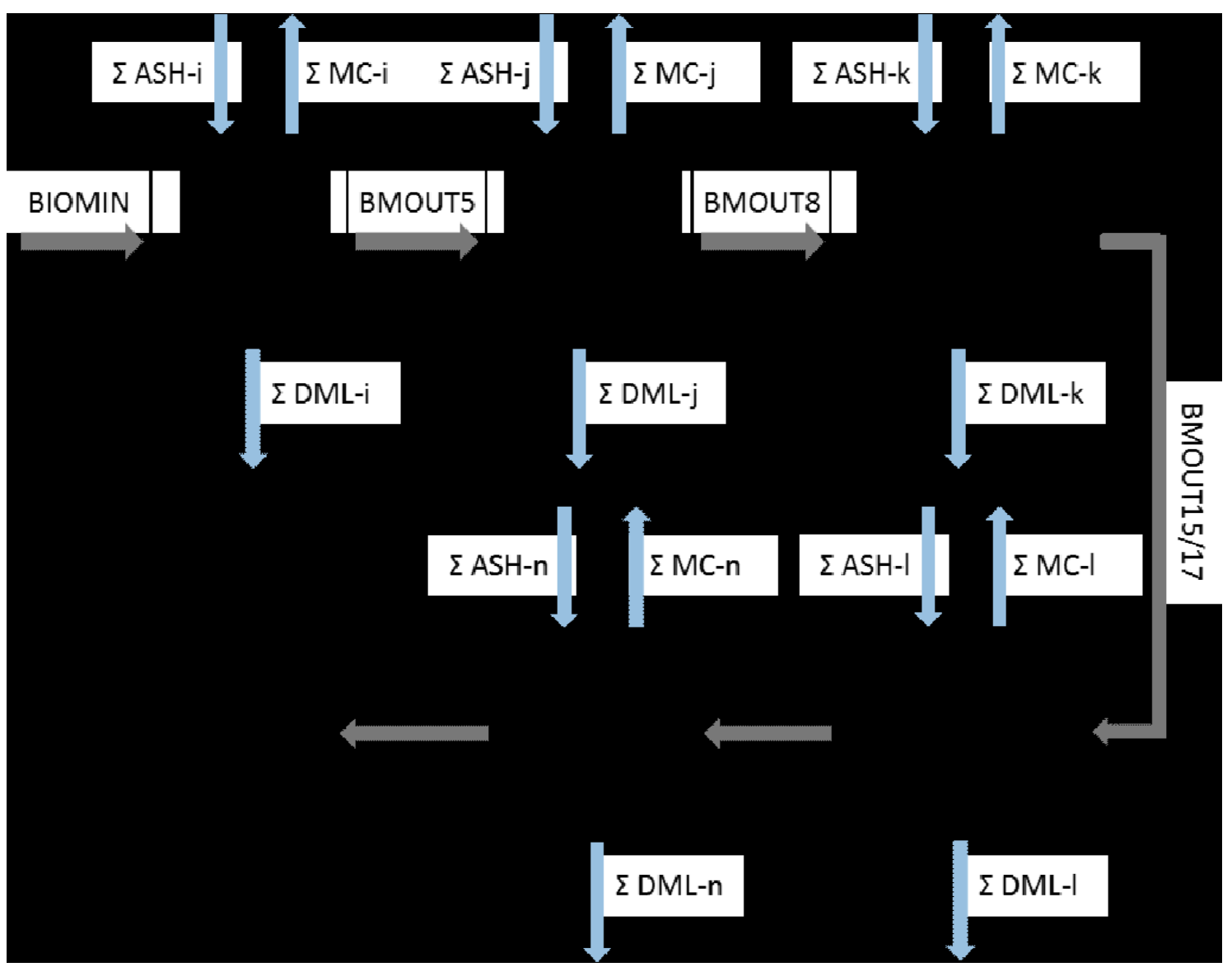

Figure I-13. High-level flowsheet showing key process areas for the switchgrass blendstock in the 2018 Herbaceous SOT. 

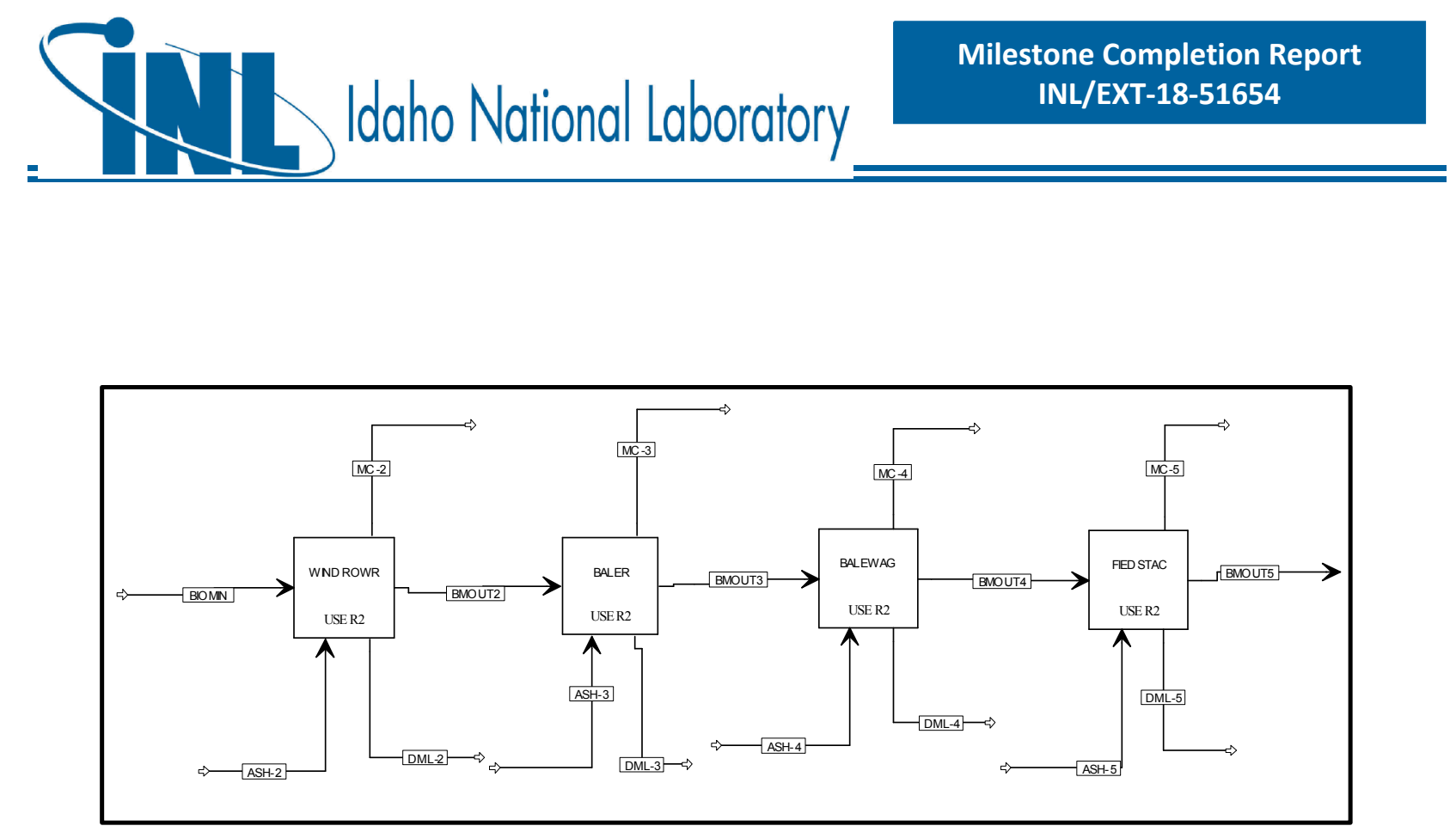

Figure I-14. Detailed process flow diagram for area C100 - Harvesting to Storage.

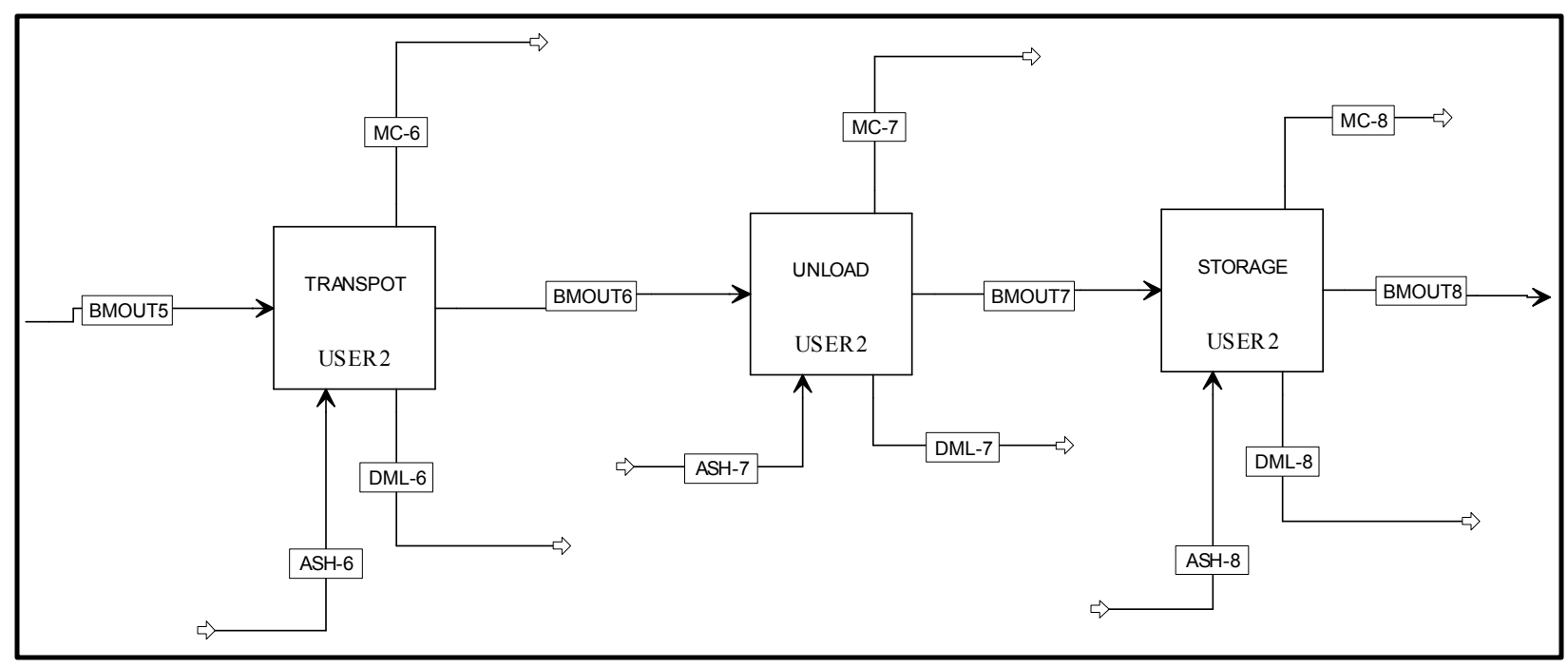

Figure I-15. Detailed process flow diagram for area C200 - Transport to Biorefinery \& Handling. 


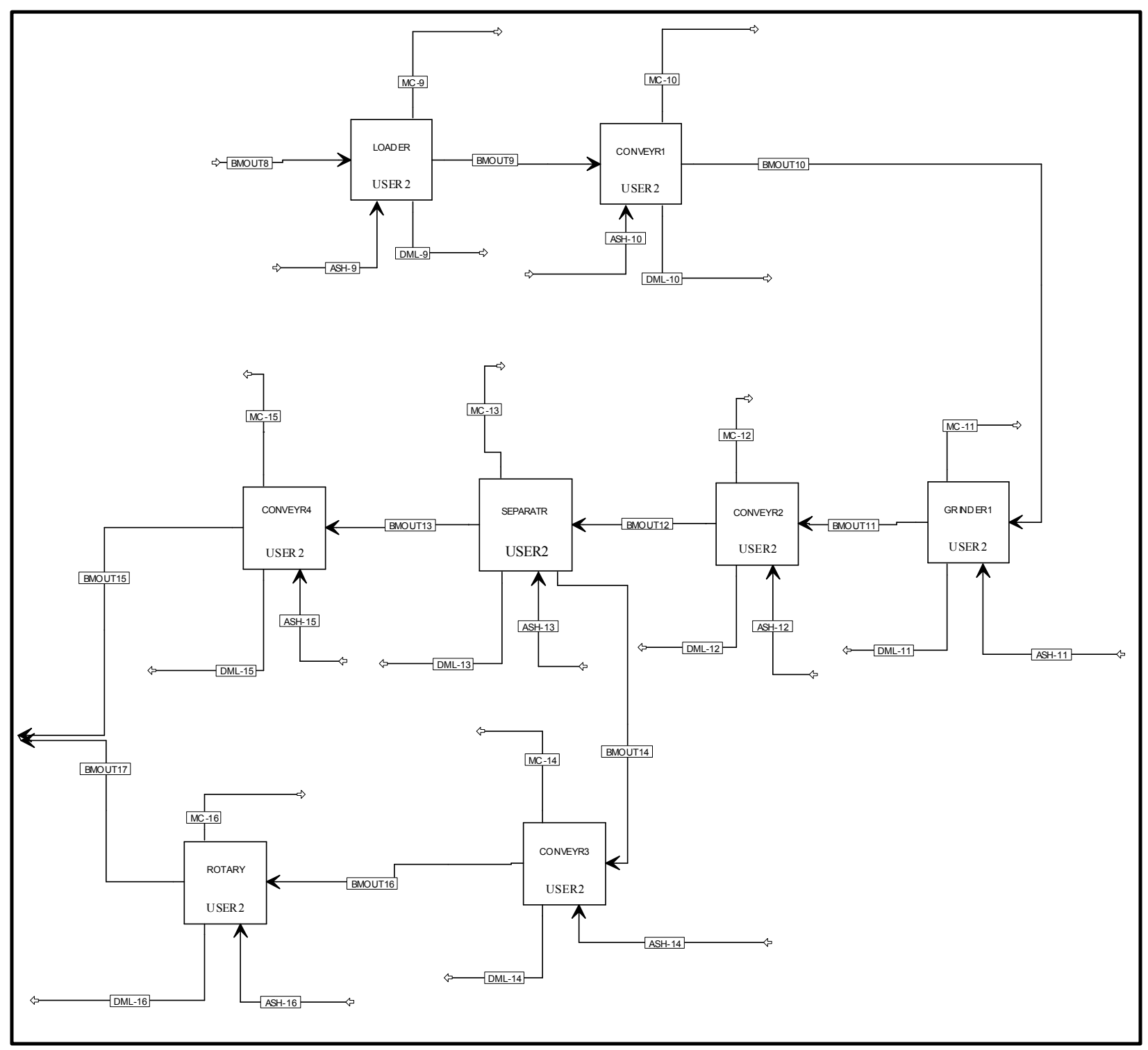

Figure I-16. Detailed process flow diagram for area C300 - Preprocessing - Size Reduction. 

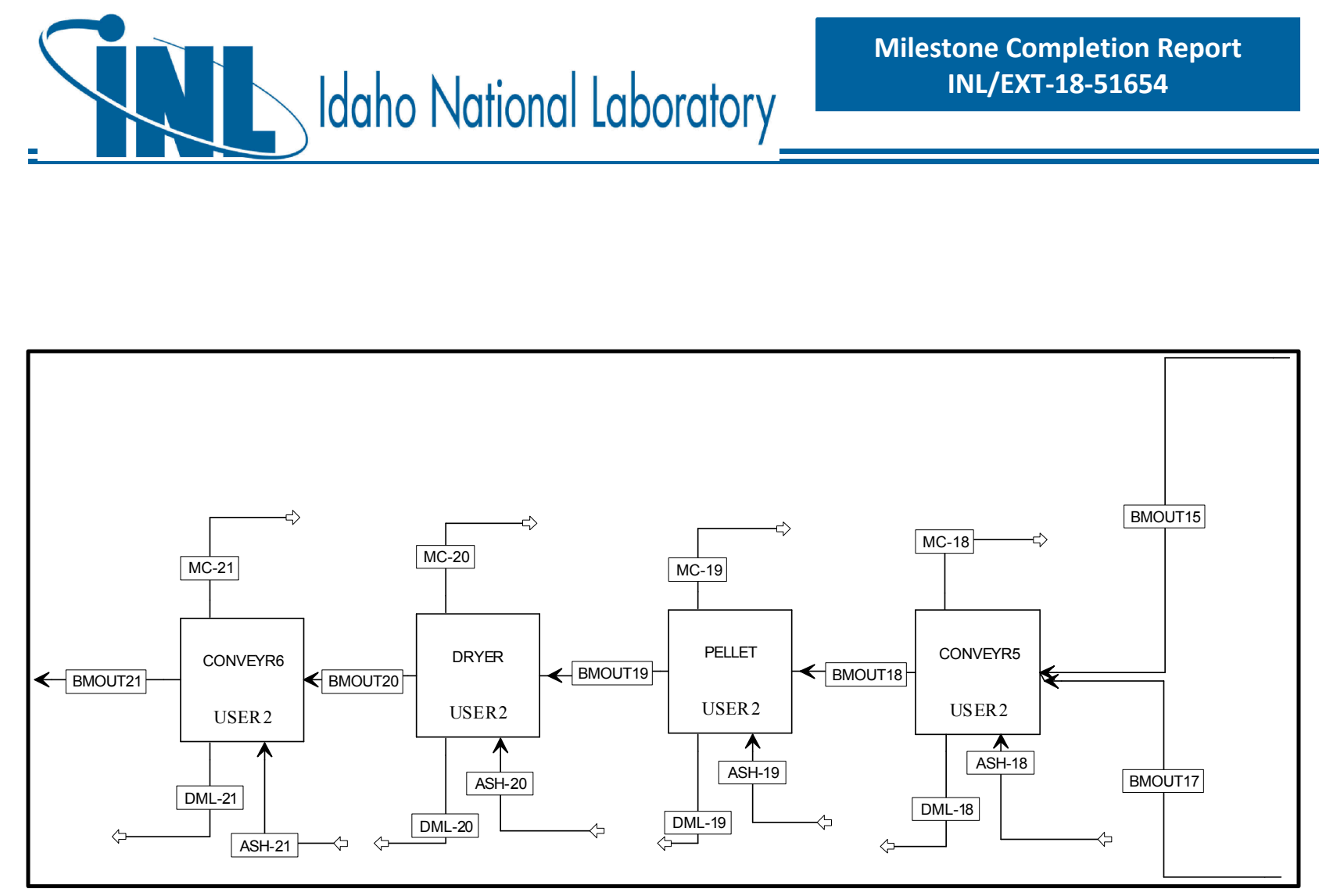

Figure I-17. Detailed process flow diagram for area C400 - Preprocessing - Pelleting.

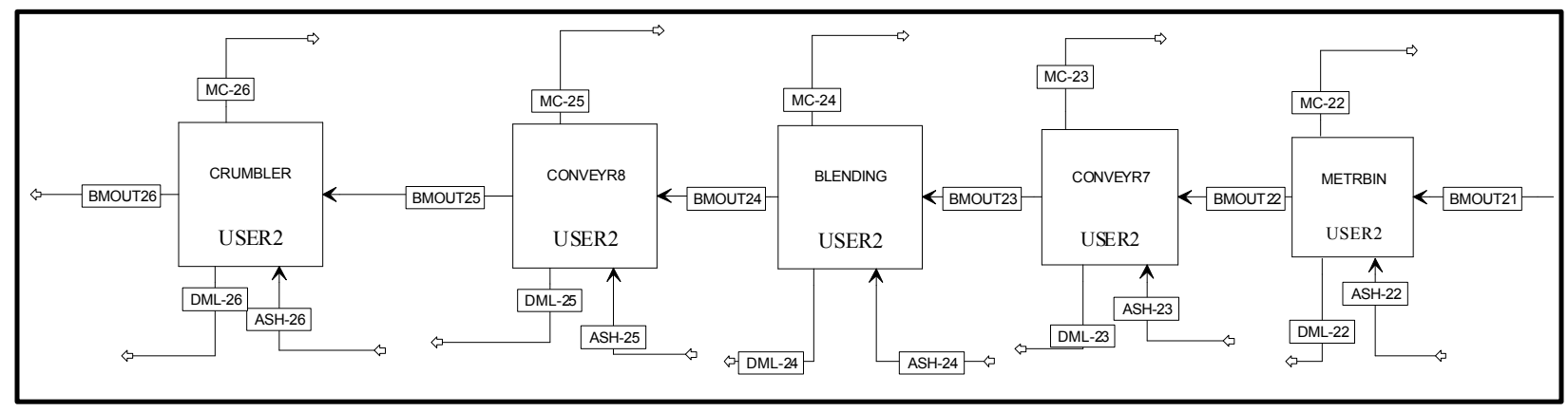

Figure I-18. Detailed process flow diagram for area C500 - Feeding. 


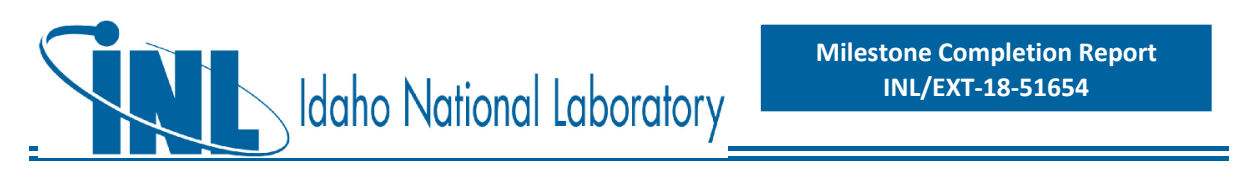

Table I-5. Aspen Plus mass balances from harvest to field-side storage (Area C100) for the switchgrass blendstock in the Exclusion of Grass Clippings from the Centralized Depot Case. Harvest is assumed to take place within a 6 week period, working 14 hours/day, 6 days per week.

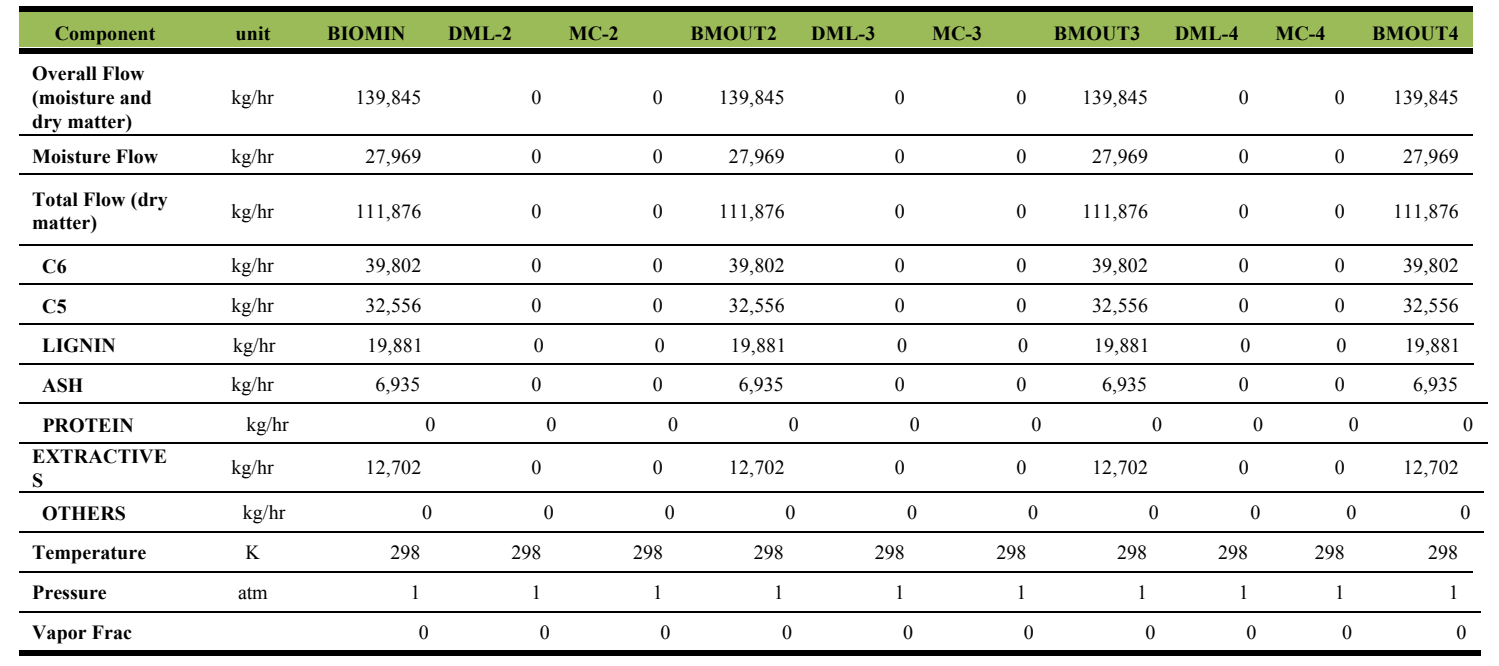


Table I-6. Aspen Plus mass balances from field-side storage to feeding (Areas C200-C500) for the switchgrass blendstock in the Exclusion of Grass Clippings from the Centralized Depot Case. Depot operation is assumed to take place within 350 day period, working 24 hours/day, 7 days per week.

\begin{tabular}{|c|c|c|c|c|c|c|c|c|c|c|c|c|}
\hline Component & unit & DML-5 & MC-5 & BMOUT5 & DML-6 & MC-6 & & BMOUT6 & DML-7 & MC-7 & & BMOUT7 \\
\hline $\begin{array}{l}\begin{array}{l}\text { Overall Flow } \\
\text { (moisture and dry } \\
\text { matter) }\end{array} \\
\end{array}$ & $\mathrm{kg} / \mathrm{hr}$ & 537 & 367 & 7,487 & 0 & & 0 & 7,487 & 0 & & 0 & 7,487 \\
\hline Moisture Flow & $\mathrm{kg} / \mathrm{hr}$ & 0 & 367 & 1,311 & 0 & & 0 & 1,311 & 0 & & 0 & 1,311 \\
\hline $\begin{array}{l}\text { Total Flow (dry } \\
\text { matter) }\end{array}$ & $\mathrm{kg} / \mathrm{hr}$ & 537 & 0 & 6,175 & 0 & & 0 & 6,175 & 0 & & 0 & 6,175 \\
\hline C6 & $\mathrm{kg} / \mathrm{hr}$ & 99 & 0 & 2,289 & 0 & & 0 & 2,289 & 0 & & 0 & 2,289 \\
\hline C5 & $\mathrm{kg} / \mathrm{hr}$ & 156 & 0 & 1,798 & 0 & & 0 & 1,798 & 0 & & 0 & 1,798 \\
\hline LIGNIN & $\mathrm{kg} / \mathrm{hr}$ & 35 & 0 & 1,158 & 0 & & 0 & 1,158 & 0 & & 0 & 1,158 \\
\hline ASH & $\mathrm{kg} / \mathrm{hr}$ & 0 & 0 & 416 & 0 & & 0 & 416 & 0 & & 0 & 416 \\
\hline PROTEIN & $\mathrm{kg} / \mathrm{hr}$ & 16 & 0 & 0 & 0 & & 0 & 0 & 0 & & 0 & 0 \\
\hline EXTRACTIVES & $\mathrm{kg} / \mathrm{hr}$ & 161 & 0 & 601 & 0 & & 0 & 601 & 0 & & 0 & 601 \\
\hline OTHERS & $\mathrm{kg} / \mathrm{hr}$ & 71 & 0 & 0 & 0 & & 0 & 0 & 0 & & 0 & 0 \\
\hline Temperature & $\mathrm{K}$ & 298 & 298 & 298 & 298 & & 298 & 298 & 298 & & 298 & 298 \\
\hline Pressure & $\mathrm{atm}$ & 1 & 1 & 1 & 1 & & 1 & 1 & 1 & & 1 & 1 \\
\hline Vapor Frac & & 0 & 0 & 0 & 0 & & 0 & 0 & 0 & & 0 & 0 \\
\hline
\end{tabular}


Table I-6. (continued)

\begin{tabular}{|c|c|c|c|c|c|c|c|c|c|c|c|c|c|}
\hline Component & unit & DML-8 & MC-8 & & BMOUT8 & DML-9 & MC-9 & & BMOUT9 & DML-10 & MC-10 & & BMOUT10 \\
\hline $\begin{array}{l}\text { Overall Flow } \\
\text { (moisture and dry } \\
\text { matter) }\end{array}$ & $\mathrm{kg} / \mathrm{hr}$ & & 0 & 0 & 7,487 & & 0 & 0 & 7,487 & 0 & & 0 & 7,487 \\
\hline Moisture Flow & $\mathrm{kg} / \mathrm{hr}$ & & 0 & 0 & 1,311 & & 0 & 0 & 1,311 & 0 & & 0 & 1,311 \\
\hline $\begin{array}{l}\text { Total Flow (dry } \\
\text { matter) }\end{array}$ & $\mathrm{kg} / \mathrm{hr}$ & & 0 & 0 & 6,175 & & 0 & 0 & 6,175 & 0 & & 0 & 6,175 \\
\hline C6 & $\mathrm{kg} / \mathrm{hr}$ & & 0 & 0 & 2,289 & & 0 & 0 & 2,289 & 0 & & 0 & 2,289 \\
\hline $\mathrm{C5}$ & $\mathrm{kg} / \mathrm{hr}$ & & 0 & 0 & 1,798 & & 0 & 0 & 1,798 & 0 & & 0 & 1,798 \\
\hline LIGNIN & $\mathrm{kg} / \mathrm{hr}$ & & 0 & 0 & 1,158 & & 0 & 0 & 1,158 & 0 & & 0 & 1,158 \\
\hline ASH & $\mathrm{kg} / \mathrm{hr}$ & & 0 & 0 & 416 & & 0 & 0 & 416 & 0 & & 0 & 416 \\
\hline PROTEIN & $\mathrm{kg} / \mathrm{hr}$ & & 0 & 0 & 0 & & 0 & 0 & 0 & 0 & & 0 & 0 \\
\hline EXTRACTIVES & $\mathrm{kg} / \mathrm{hr}$ & & 0 & 0 & 601 & & 0 & 0 & 601 & 0 & & 0 & 601 \\
\hline OTHERS & $\mathrm{kg} / \mathrm{hr}$ & & 0 & 0 & 0 & & 0 & 0 & 0 & 0 & & 0 & 0 \\
\hline Temperature & K & & 298 & 298 & 298 & & 298 & 298 & 298 & 298 & & 298 & 298 \\
\hline Pressure & atm & & 1 & 1 & 1 & & 1 & 1 & 1 & 1 & & 1 & 1 \\
\hline Vapor Frac & & & 0 & 0 & 0 & & 0 & 0 & 0 & 0 & & 0 & 0 \\
\hline
\end{tabular}


latano National Laboratory

Table I-6. (continued)

\begin{tabular}{|c|c|c|c|c|c|c|c|c|c|c|c|c|c|}
\hline Component & unit & $\begin{array}{l}\text { DML- } \\
11\end{array}$ & $\begin{array}{l}\text { MC- } \\
11\end{array}$ & BMOUT11 & $\begin{array}{l}\text { DML- } \\
12\end{array}$ & $\begin{array}{l}\text { MC- } \\
12\end{array}$ & BMOUT12 & $\begin{array}{l}\text { DML- } \\
13\end{array}$ & MC-13 & BMOUT13 & DML-14 & MC-14 & BMOUT14 \\
\hline $\begin{array}{l}\text { Overall Flow } \\
\text { (moisture and dry } \\
\text { matter) }\end{array}$ & $\mathrm{kg} / \mathrm{hr}$ & 53 & 274 & 7,160 & 0 & 0 & 7,161 & 82 & 0 & 3,185 & 0 & 0 & 3,895 \\
\hline Moisture Flow & $\mathrm{kg} / \mathrm{hr}$ & 0 & 274 & 1,037 & 0 & 0 & 1,038 & 82 & 0 & 430 & 0 & 0 & 526 \\
\hline $\begin{array}{l}\text { Total Flow (dry } \\
\text { matter) }\end{array}$ & $\mathrm{kg} / \mathrm{hr}$ & 53 & 0 & 6,123 & 0 & 0 & 6,123 & 0 & 0 & 2,754 & 0 & 0 & 3,369 \\
\hline C6 & $\mathrm{kg} / \mathrm{hr}$ & 19 & 0 & 2,271 & 0 & 0 & 2,271 & 0 & 0 & 1,021 & 0 & 0 & 1,249 \\
\hline C5 & $\mathrm{kg} / \mathrm{hr}$ & 1 & 0 & 1,797 & 0 & 0 & 1,797 & 0 & 0 & 809 & 0 & 0 & 988 \\
\hline LIGNIN & $\mathrm{kg} / \mathrm{hr}$ & 12 & 0 & 1,146 & 0 & 0 & 1,146 & 0 & 0 & 515 & 0 & 0 & 631 \\
\hline ASH & $\mathrm{kg} / \mathrm{hr}$ & 15 & 0 & 401 & 0 & 0 & 401 & 0 & 0 & 180 & 0 & 0 & 221 \\
\hline PROTEIN & $\mathrm{kg} / \mathrm{hr}$ & 0 & 0 & 0 & 0 & 0 & 0 & 0 & 0 & 0 & 0 & 0 & 0 \\
\hline EXTRACTIVES & $\mathrm{kg} / \mathrm{hr}$ & 6 & 0 & 595 & 0 & 0 & 595 & 0 & 0 & 268 & 0 & 0 & 327 \\
\hline OTHERS & $\mathrm{kg} / \mathrm{hr}$ & 0 & 0 & 0 & 0 & 0 & 0 & 0 & 0 & 0 & 0 & 0 & 0 \\
\hline Temperature & K & 298 & 298 & 298 & 298 & 298 & 298 & 298 & 298 & 298 & 298 & 298 & 298 \\
\hline Pressure & $\mathrm{atm}$ & 1 & 1 & 1 & 1 & 1 & 1 & 1 & 1 & 1 & 1 & 1 & 1 \\
\hline Vapor Frac & & 0 & 0 & 0 & 0 & 0 & 0 & 0 & 0 & 0 & 0 & 0 & 0 \\
\hline
\end{tabular}


Table I-6. (continued)

\begin{tabular}{|c|c|c|c|c|c|c|c|c|c|c|}
\hline Component & unit & DML-15 & MC-15 & & BMOUT15 & DML-16 & MC-16 & & BMOUT16 & BMOUT17 \\
\hline $\begin{array}{l}\text { Overall Flow } \\
\text { (moisture and dry } \\
\text { matter) }\end{array}$ & $\mathrm{kg} / \mathrm{hr}$ & & 0 & 0 & 3,185 & & 37 & 5 & 3,895 & 3,853 \\
\hline Moisture Flow & $\mathrm{kg} / \mathrm{hr}$ & & 0 & 0 & 430 & & 0 & 5 & 526 & 521 \\
\hline $\begin{array}{l}\text { Total Flow (dry } \\
\text { matter) } \\
\end{array}$ & $\mathrm{kg} / \mathrm{hr}$ & & 0 & 0 & 2,754 & & 37 & 0 & 3,369 & 3,332 \\
\hline C6 & $\mathrm{kg} / \mathrm{hr}$ & & 0 & 0 & 1,021 & & 10 & 0 & 1,249 & 1,239 \\
\hline C5 & $\mathrm{kg} / \mathrm{hr}$ & & 0 & 0 & 809 & & 6 & 0 & 988 & 983 \\
\hline LIGNIN & $\mathrm{kg} / \mathrm{hr}$ & & 0 & 0 & 515 & & 7 & 0 & 631 & 625 \\
\hline ASH & $\mathrm{kg} / \mathrm{hr}$ & & 0 & 0 & 180 & & 8 & 0 & 221 & 212 \\
\hline PROTEIN & $\mathrm{kg} / \mathrm{hr}$ & & 0 & 0 & 0 & & 0 & 0 & 0 & 0 \\
\hline EXTRACTIVES & $\mathrm{kg} / \mathrm{hr}$ & & 0 & 0 & 268 & & 7 & 0 & 327 & 321 \\
\hline OTHERS & $\mathrm{kg} / \mathrm{hr}$ & & 0 & 0 & 0 & & 0 & 0 & 0 & 0 \\
\hline Temperature & $\mathrm{K}$ & & 298 & 298 & 298 & & 298 & 298 & 298 & 298 \\
\hline Pressure & $\mathrm{atm}$ & & 1 & 1 & 1 & & 1 & 1 & 1 & 1 \\
\hline Vapor Frac & & & 0 & 0 & 0 & & 0 & 0 & 0 & 0 \\
\hline
\end{tabular}


Table I-6. (continued)

\begin{tabular}{|c|c|c|c|c|c|c|c|c|c|c|c|c|c|}
\hline Component & unit & DML-18 & MC-18 & & BMOUT18 & DML-19 & MC-19 & & BMOUT19 & DML-20 & MC-20 & & BMOUT20 \\
\hline $\begin{array}{l}\text { Overall Flow } \\
\text { (moisture and dry } \\
\text { matter) }\end{array}$ & $\mathrm{kg} / \mathrm{hr}$ & & 0 & 0 & 7,037 & & 0 & 274 & 6,763 & & 0 & 74 & 6,688 \\
\hline Moisture Flow & $\mathrm{kg} / \mathrm{hr}$ & & 0 & 0 & 951 & & 0 & 274 & 677 & & 0 & 74 & 603 \\
\hline $\begin{array}{l}\text { Total Flow (dry } \\
\text { matter) }\end{array}$ & $\mathrm{kg} / \mathrm{hr}$ & & 0 & 0 & 6,086 & & 0 & 0 & 6,086 & & 0 & 0 & 6,086 \\
\hline C6 & $\mathrm{kg} / \mathrm{hr}$ & & 0 & 0 & 2,261 & & 0 & 0 & 2,261 & & 0 & 0 & 2,261 \\
\hline C5 & $\mathrm{kg} / \mathrm{hr}$ & & 0 & 0 & 1,791 & & 0 & 0 & 1,791 & & 0 & 0 & 1,791 \\
\hline LIGNIN & $\mathrm{kg} / \mathrm{hr}$ & & 0 & 0 & 1,140 & & 0 & 0 & 1,140 & & 0 & 0 & 1,140 \\
\hline ASH & $\mathrm{kg} / \mathrm{hr}$ & & 0 & 0 & 392 & & 0 & 0 & 392 & & 0 & 0 & 392 \\
\hline PROTEIN & $\mathrm{kg} / \mathrm{hr}$ & & 0 & 0 & 0 & & 0 & 0 & 0 & & 0 & 0 & 0 \\
\hline EXTRACTIVES & $\mathrm{kg} / \mathrm{hr}$ & & 0 & 0 & 589 & & 0 & 0 & 589 & & 0 & 0 & 589 \\
\hline OTHERS & $\mathrm{kg} / \mathrm{hr}$ & & 0 & 0 & 0 & & 0 & 0 & 0 & & 0 & 0 & 0 \\
\hline Temperature & $\mathrm{K}$ & & 298 & 298 & 298 & & 298 & 298 & 298 & & 298 & 298 & 298 \\
\hline Pressure & atm & & 1 & 1 & 1 & & 1 & 1 & 1 & & 1 & 1 & 1 \\
\hline
\end{tabular}


Table I-6. (continued)

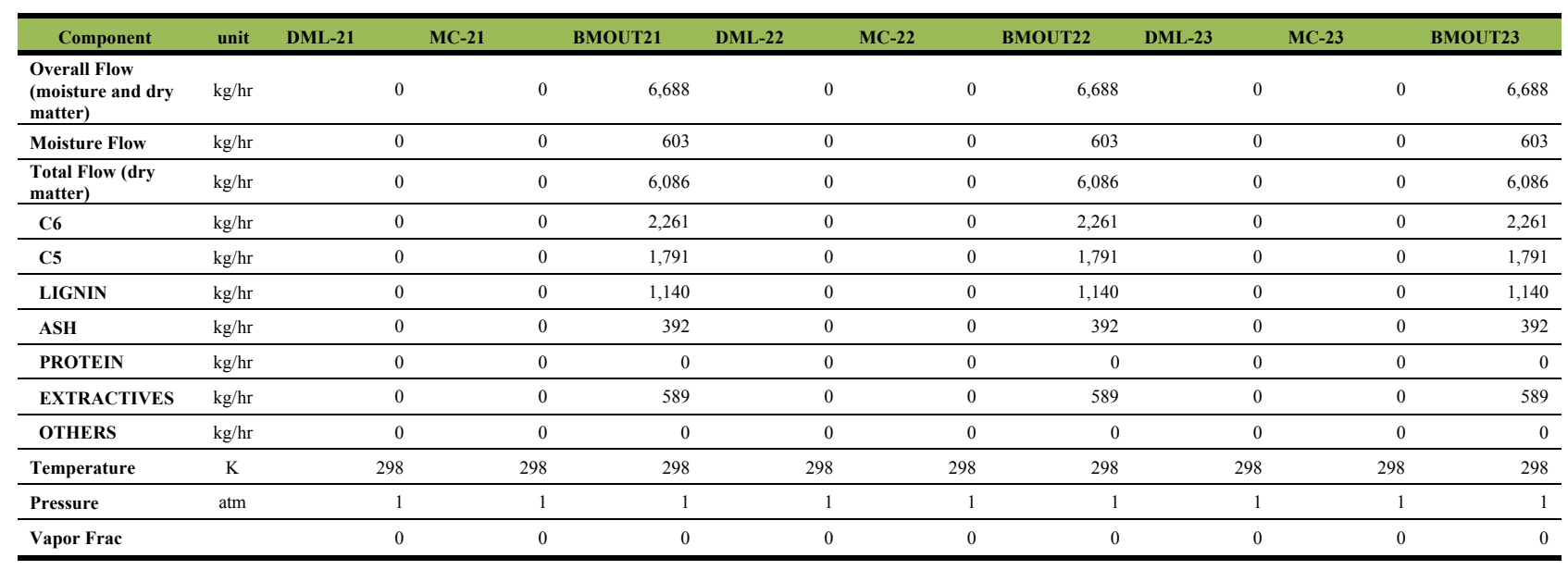


Table I-6. (continued)

\begin{tabular}{lccrrrrrrrrr}
\hline \multicolumn{1}{c}{ Component } & unit & $\begin{array}{l}\text { DML- } \\
\mathbf{2 4}\end{array}$ & $\begin{array}{l}\text { MC- } \\
\mathbf{2 4}\end{array}$ & BMOUT24 & $\begin{array}{l}\text { DML- } \\
\mathbf{2 5}\end{array}$ & $\begin{array}{l}\text { MC- } \\
\mathbf{2 5}\end{array}$ & BMOUT25 & $\begin{array}{l}\text { DML- } \\
\mathbf{2 6}\end{array}$ & $\begin{array}{l}\text { MC- } \\
\mathbf{2 6}\end{array}$ & BMOUT26 \\
\hline $\begin{array}{l}\text { Overall Flow } \\
\text { (moisture and dry } \\
\text { matter) }\end{array}$ & $\mathrm{kg} / \mathrm{hr}$ & 0 & 0 & 6,688 & 0 & 0 & 6,688 & 0 & 0 & 6,688 \\
\hline Moisture Flow & $\mathrm{kg} / \mathrm{hr}$ & 0 & 0 & 603 & 0 & 0 & 603 & 0 & 0 & 603 \\
\hline $\begin{array}{l}\text { Total Flow (dry } \\
\text { matter) }\end{array}$ & $\mathrm{kg} / \mathrm{hr}$ & 0 & 0 & 6,086 & 0 & 0 & 6,086 & 0 & 0 & 6,086 \\
\hline C6 & $\mathrm{kg} / \mathrm{hr}$ & 0 & 0 & 2,261 & 0 & 0 & 2,261 & 0 & 0 & 2,261 \\
\hline C5 & $\mathrm{kg} / \mathrm{hr}$ & 0 & 0 & 1,791 & 0 & 0 & 1,791 & 0 & 0 & 1,791 \\
\hline LIGNIN & $\mathrm{kg} / \mathrm{hr}$ & 0 & 0 & 1,140 & 0 & 0 & 1,140 & 0 & 0 & 1,140 \\
\hline ASH & $\mathrm{kg} / \mathrm{hr}$ & 0 & 0 & 392 & 0 & 0 & 392 & 0 & 0 & 392 \\
\hline PROTEIN & $\mathrm{kg} / \mathrm{hr}$ & 0 & 0 & 0 & 0 & 0 & 0 & 0 & 0 & 0 \\
\hline EXTRACTIVES & $\mathrm{kg} / \mathrm{hr}$ & 0 & 0 & 589 & 0 & 0 & 589 & 0 & 0 & 589 \\
\hline OTHERS & $\mathrm{kg} / \mathrm{hr}$ & 0 & 0 & 0 & 0 & 0 & 0 & 0 & 0 & 0 \\
\hline Temperature & $\mathrm{K}$ & 298 & 298 & 298 & 298 & 298 & 298 & 298 & 298 & 298 \\
\hline Pressure & $\mathrm{atm}$ & 1 & 1 & 1 & 1 & 1 & 1 & 1 & 1 & 1 \\
\hline Vapor Frac & & 0 & 0 & 0 & 0 & 0 & 0 & 0 & 0 & 0 \\
\hline
\end{tabular}




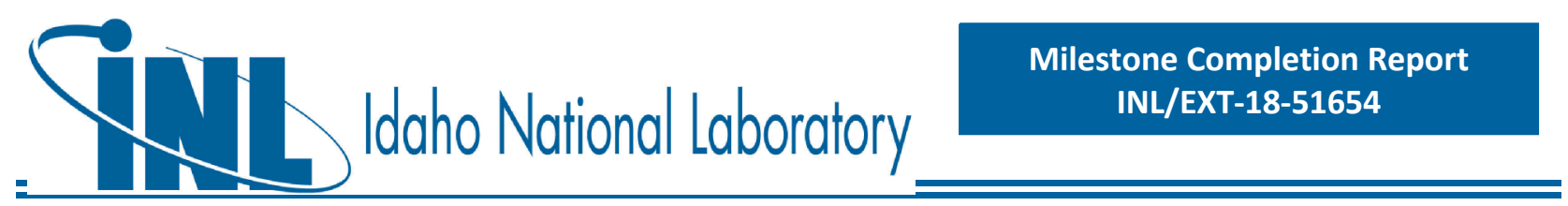

\section{APPENDIX J - Process Flow Diagrams and Mass Balances for the 2022 Herbaceous Projection}

\section{J.1 Three-pass Corn Stover Blendstock}

High-level stream table information from Aspen Plus modeling output follows, for key streams associated with each process operation area. This is followed by high-level PFDs for the associated process areas. Space for stream tables was limited; below is a key to lumped components. As the stream table information focuses primarily on the high-level overall process and does not include every individual modeled stream within each process area, mass balance closure around a given unit area may not be $100 \%$.

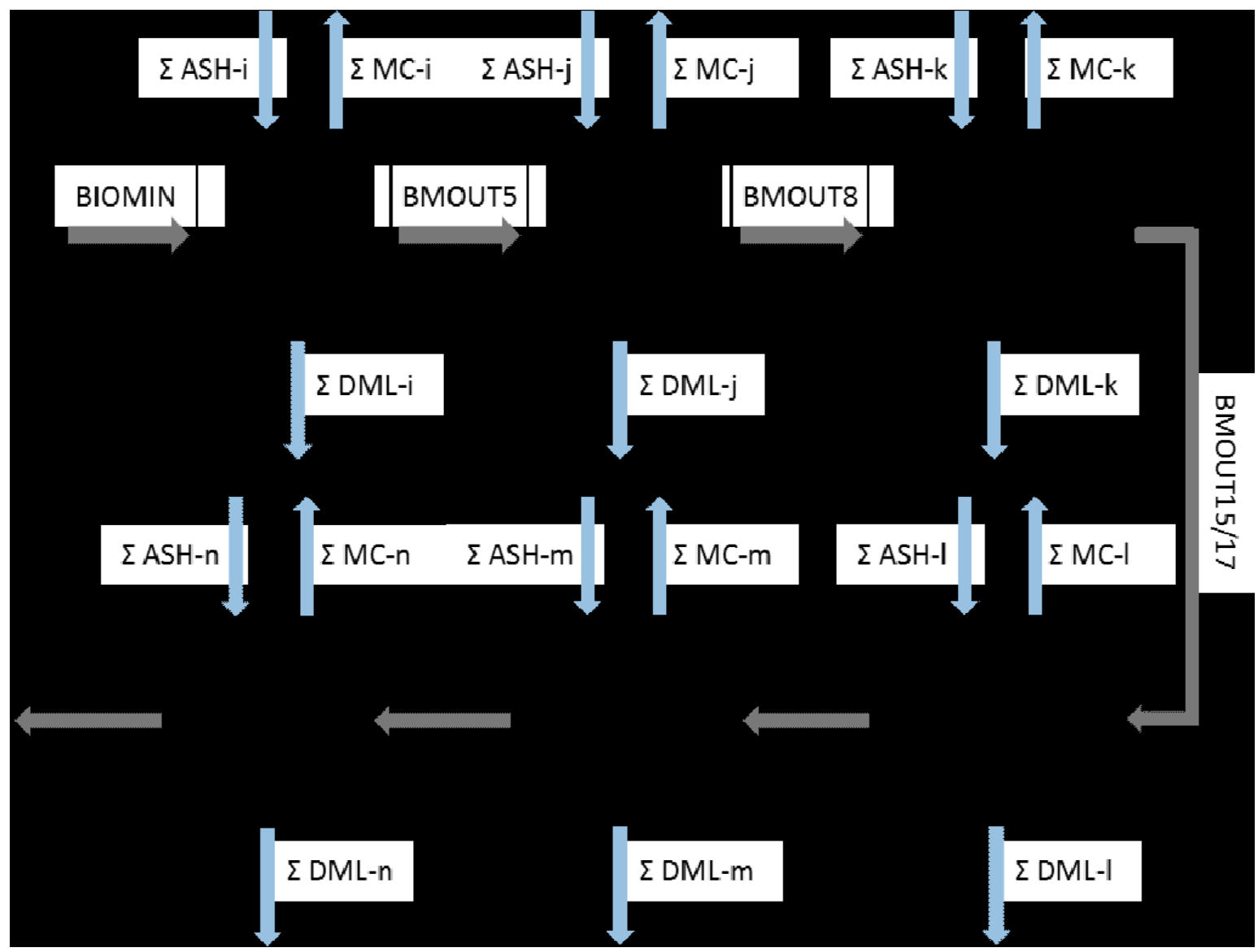

Figure J-1. High-level flowsheet showing key process areas for the three-pass corn stover blendstock in the 2022 Herbaceous Projection. 


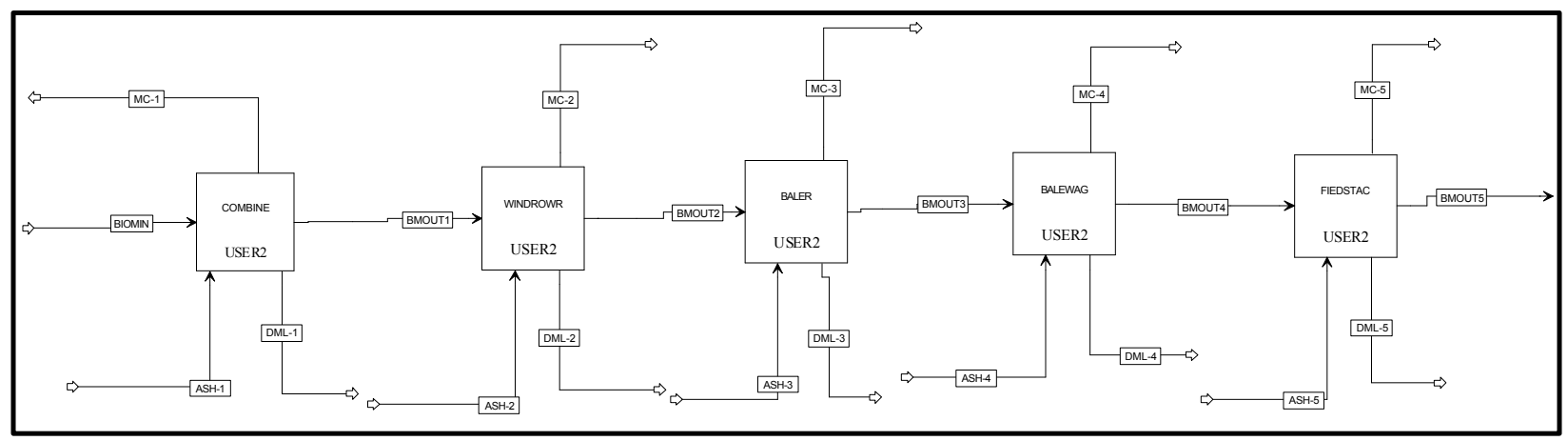

Figure J-2. Detailed process flow diagram for area A100 - Harvesting to Storage.

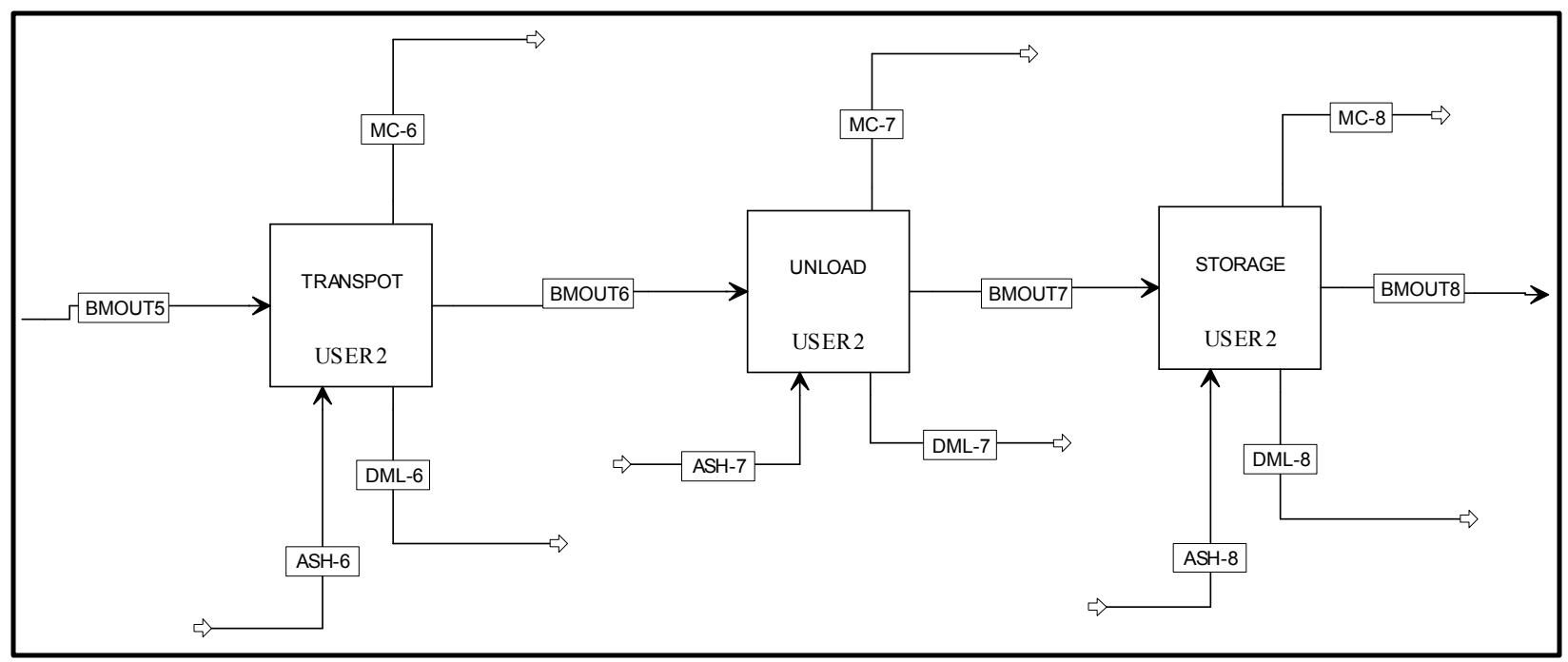

Figure J-3. Detailed process flow diagram for area A200 - Transport to Depot \& Handling. 


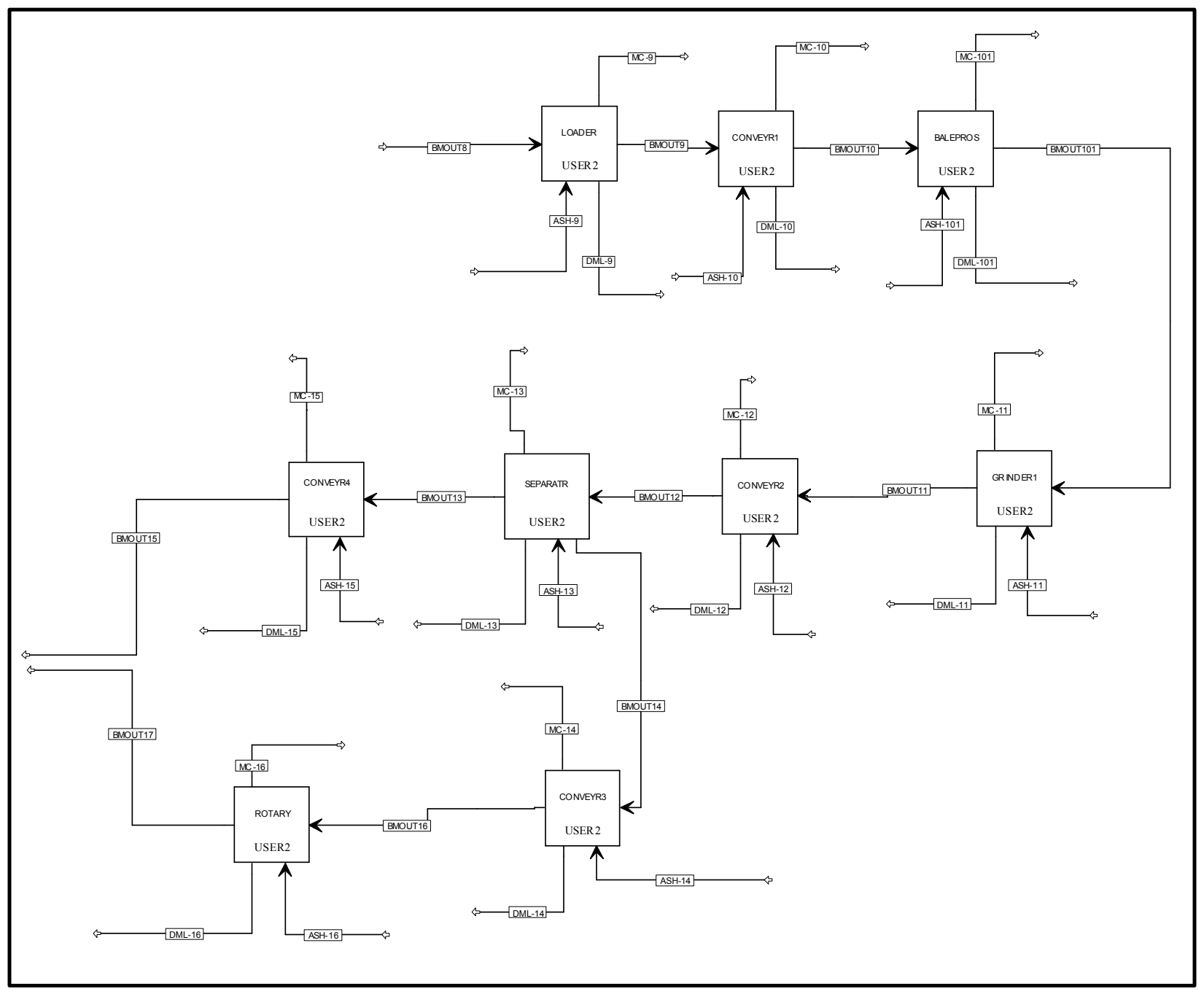

Figure J-4. Detailed process flow diagram for area A300 - Preprocessing - Size Reduction. 

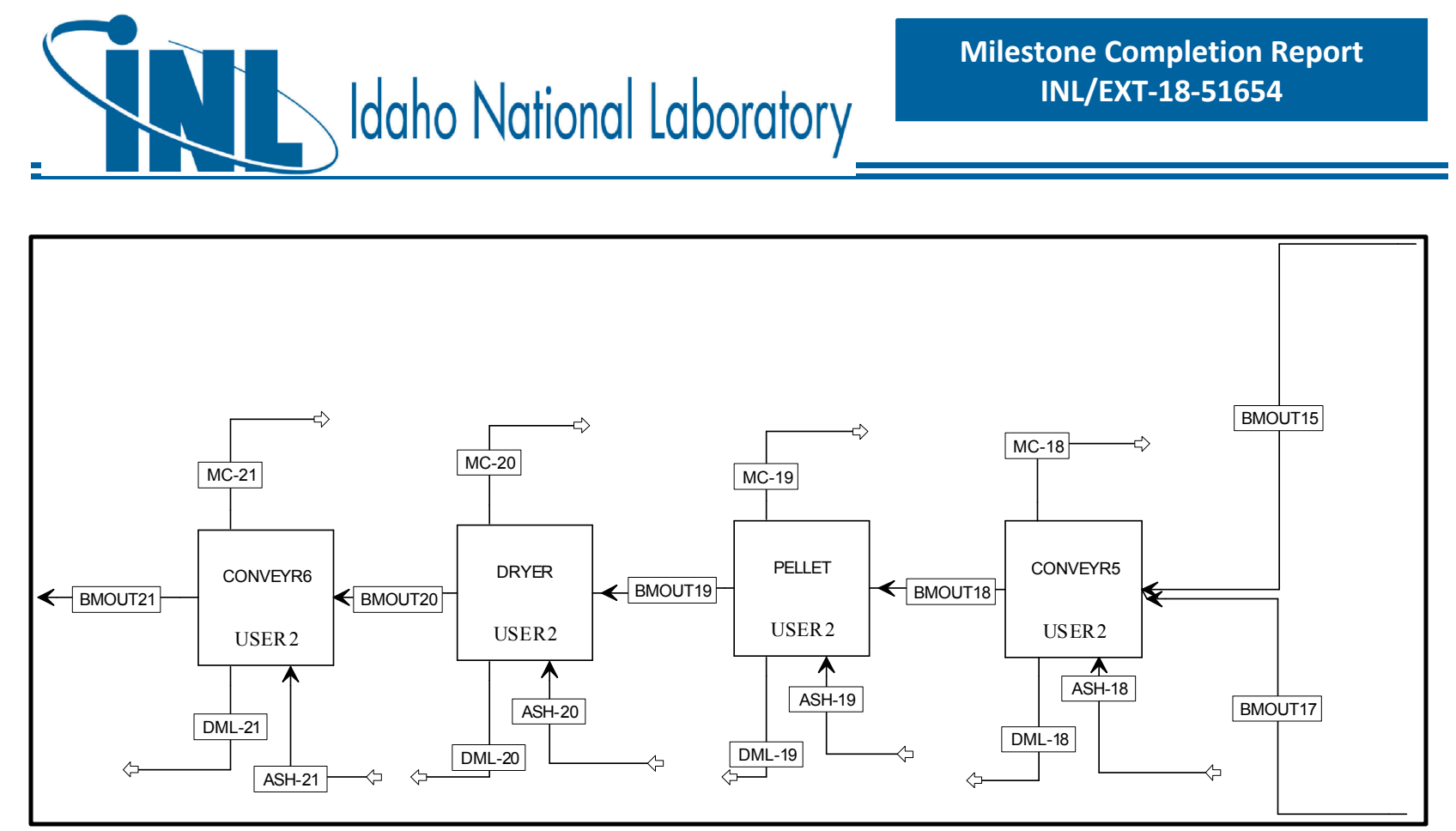

Figure J-5. Detailed process flow diagram for area A400 - Preprocessing - Pelleting.

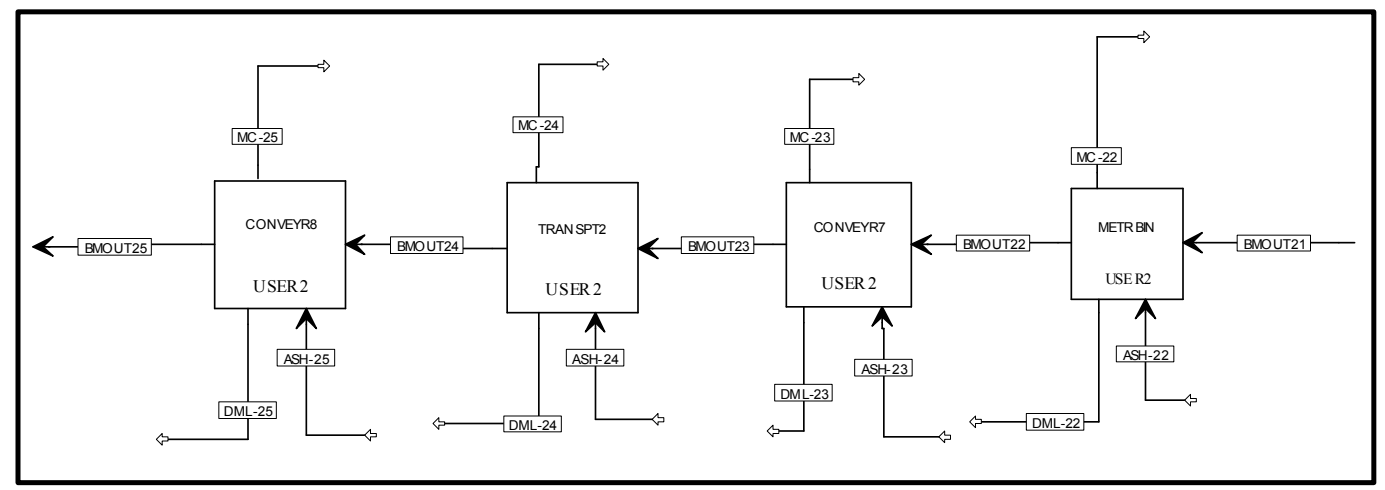

Figure J-6. Detailed process flow diagram for area A500 - Transport to Biorefinery. 

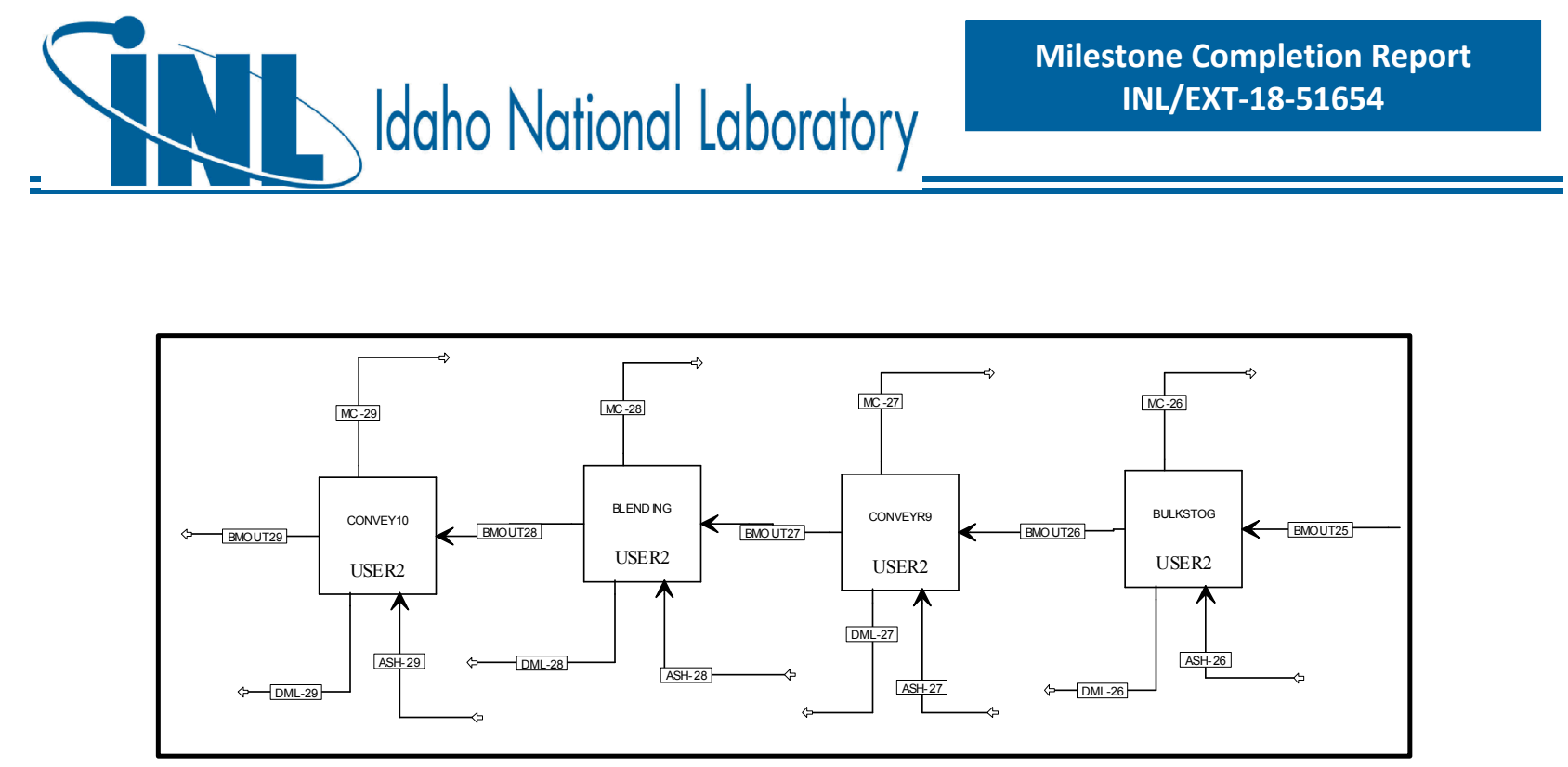

Figure J-7. Detailed process flow diagram for area A600 - Feeding. 


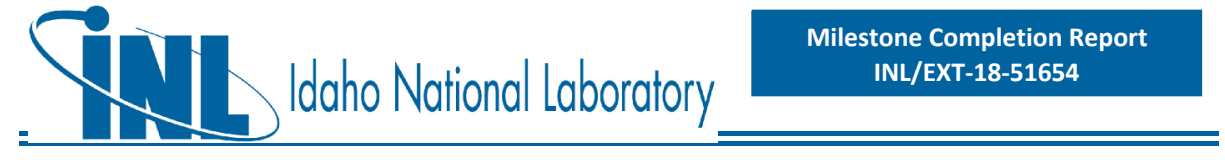

Table J-1. Aspen Plus mass balances from harvest to field-side storage (Area A100) for the three-pass corn stover blendstock in the 2022 Herbaceous Projection. Harvest is assumed to take place within a 6 week period, working 14 hours/day, 6 days per week.

\begin{tabular}{|c|c|c|c|c|c|c|c|c|c|c|c|c|c|c|}
\hline Component & unit & BIOMIN & $\begin{array}{c}\text { DML- } \\
1\end{array}$ & MC-1 & $\begin{array}{c}\text { BMOUT } \\
1\end{array}$ & DML-2 & MC-2 & $\begin{array}{c}\text { BMOUT } \\
2\end{array}$ & $\begin{array}{c}\text { DML- } \\
3\end{array}$ & MC-3 & BMOUT3 & $\begin{array}{c}\text { DML- } \\
4\end{array}$ & $\begin{array}{c}\text { MC- } \\
4\end{array}$ & BMOUT4 \\
\hline $\begin{array}{l}\text { Overall Flow } \\
\text { (moisture and dry } \\
\text { matter) }\end{array}$ & $\mathrm{kg} / \mathrm{hr}$ & 61,389 & 0 & 0 & 61389 & 0 & 0 & 61,389 & 0 & 0 & 61,389 & 0 & 0 & 61,389 \\
\hline Moisture Flow & $\mathrm{kg} / \mathrm{hr}$ & 18,417 & 0 & 0 & 18417 & 0 & 0 & 18,417 & 0 & 0 & 18,417 & 0 & 0 & 18,417 \\
\hline $\begin{array}{l}\text { Total Flow (dry } \\
\text { matter) }\end{array}$ & $\mathrm{kg} / \mathrm{hr}$ & 42,972 & 0 & 0 & 42972 & 0 & 0 & 42,972 & 0 & 0 & 42,972 & 0 & 0 & 42,972 \\
\hline C6 & $\mathrm{kg} / \mathrm{hr}$ & 15,240 & 0 & 0 & 15240 & 0 & 0 & 15,240 & 0 & 0 & 15,240 & 0 & 0 & 15,240 \\
\hline C5 & $\mathrm{kg} / \mathrm{hr}$ & 8,806 & 0 & 0 & 8806 & 0 & 0 & 8,806 & 0 & 0 & 8,806 & 0 & 0 & 8,806 \\
\hline LIGNIN & $\mathrm{kg} / \mathrm{hr}$ & 6,353 & 0 & 0 & 6353 & 0 & 0 & 6,353 & 0 & 0 & 6,353 & 0 & 0 & 6,353 \\
\hline ASH & $\mathrm{kg} / \mathrm{hr}$ & 4,727 & 0 & 0 & 4727 & 0 & 0 & 4,727 & 0 & 0 & 4,727 & 0 & 0 & 4,727 \\
\hline PROTEIN & $\mathrm{kg} / \mathrm{hr}$ & 1,246 & 0 & 0 & 1246 & 0 & 0 & 1,246 & 0 & 0 & 1,246 & 0 & 0 & 1,246 \\
\hline EXTRACTIVES & $\mathrm{kg} / \mathrm{hr}$ & 5,911 & 0 & 0 & 5911 & 0 & 0 & 5,911 & 0 & 0 & 5,911 & 0 & 0 & 5,911 \\
\hline OTHERS & $\mathrm{kg} / \mathrm{hr}$ & 690 & 0 & 0 & 690 & 0 & 0 & 690 & 0 & 0 & 690 & 0 & 0 & 690 \\
\hline Temperature & K & 298 & 298 & 298 & 298 & 298 & 298 & 298 & 298 & 298 & 298 & 298 & 298 & 298 \\
\hline Pressure & $\mathrm{atm}$ & 1 & 1 & 1 & 1 & 1 & 1 & 1 & 1 & 1 & 1 & 1 & 1 & 1 \\
\hline Vapor Frac & & 0 & 0 & 0 & 0 & 0 & 0 & 0 & 0 & 0 & 0 & 0 & 0 & 0 \\
\hline
\end{tabular}




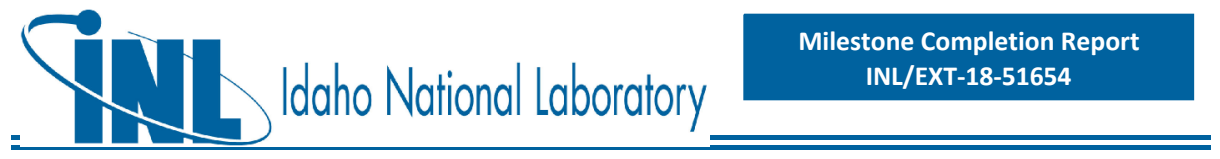

Table J-2. Aspen Plus mass balances from field-side storage to feeding (Areas A200-A600) for the three-pass corn stover blendstock in the 2022 Herbaceous Projection. Depot operation is assumed to take place within 350 day period, working 24 hours/day, 7 days per week.

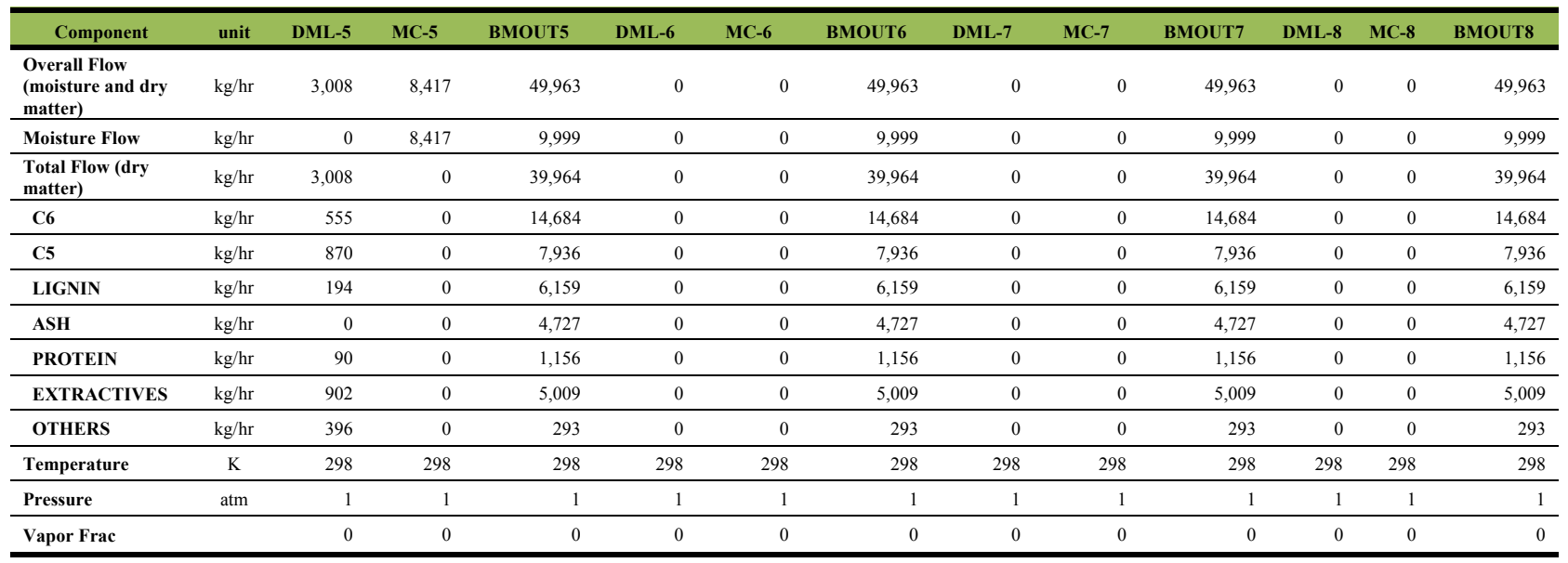

283 


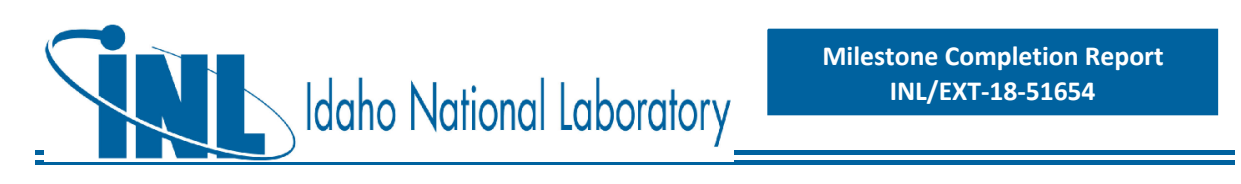

Table J-2. (continued)

\begin{tabular}{|c|c|c|c|c|c|c|c|c|c|c|c|c|c|}
\hline Component & unit & DML-9 & MC-9 & BMOUT9 & DML-10 & MC-10 & BMOUT10 & $\begin{array}{l}\text { DML- } \\
101\end{array}$ & MC-101 & BMOUT101 & $\begin{array}{l}\text { DML- } \\
11\end{array}$ & $\begin{array}{l}\text { MC- } \\
11\end{array}$ & BMOUT11 \\
\hline $\begin{array}{l}\text { Overall Flow } \\
\text { (moisture and dry } \\
\text { matter) }\end{array}$ & $\mathrm{kg} / \mathrm{hr}$ & 0 & 0 & 49,963 & 0 & 0 & 49,963 & 0 & 0 & 49,963 & 799 & 2,433 & 46,731 \\
\hline Moisture Flow & $\mathrm{kg} / \mathrm{hr}$ & 0 & 0 & 9,999 & 0 & 0 & 9,999 & 0 & 0 & 9,999 & 0 & 2,433 & 7,566 \\
\hline $\begin{array}{l}\text { Total Flow (dry } \\
\text { matter) }\end{array}$ & $\mathrm{kg} / \mathrm{hr}$ & 0 & 0 & 39,964 & 0 & 0 & 39,964 & 0 & 0 & 39,964 & 799 & 0 & 39,165 \\
\hline C6 & $\mathrm{kg} / \mathrm{hr}$ & 0 & 0 & 14,684 & 0 & 0 & 14,684 & 0 & 0 & 14,684 & 221 & 0 & 14,463 \\
\hline C5 & $\mathrm{kg} / \mathrm{hr}$ & 0 & 0 & 7,936 & 0 & 0 & 7,936 & 0 & 0 & 7,936 & 124 & 0 & 7,811 \\
\hline LIGNIN & $\mathrm{kg} / \mathrm{hr}$ & 0 & 0 & 6,159 & 0 & 0 & 6,159 & 0 & 0 & 6,159 & 155 & 0 & 6,004 \\
\hline ASH & $\mathrm{kg} / \mathrm{hr}$ & 0 & 0 & 4,727 & 0 & 0 & 4,727 & 0 & 0 & 4,727 & 200 & 0 & 4,527 \\
\hline PROTEIN & $\mathrm{kg} / \mathrm{hr}$ & 0 & 0 & 1,156 & 0 & 0 & 1,156 & 0 & 0 & 1,156 & 0 & 0 & 1,156 \\
\hline EXTRACTIVES & $\mathrm{kg} / \mathrm{hr}$ & 0 & 0 & 5,009 & 0 & 0 & 5,009 & 0 & 0 & 5,009 & 99 & 0 & 4,910 \\
\hline OTHERS & $\mathrm{kg} / \mathrm{hr}$ & 0 & 0 & 293 & 0 & 0 & 293 & 0 & 0 & 293 & 0 & 0 & 293 \\
\hline Temperature & $\mathrm{K}$ & 298 & 298 & 298 & 298 & 298 & 298 & 298 & 298 & 298 & 298 & 298 & 298 \\
\hline Pressure & atm & 1 & 1 & 1 & 1 & 1 & 1 & 1 & 1 & 1 & 1 & 1 & 1 \\
\hline Vapor Frac & & 0 & 0 & 0 & 0 & 0 & 0 & 0 & 0 & 0 & 0 & 0 & 0 \\
\hline
\end{tabular}




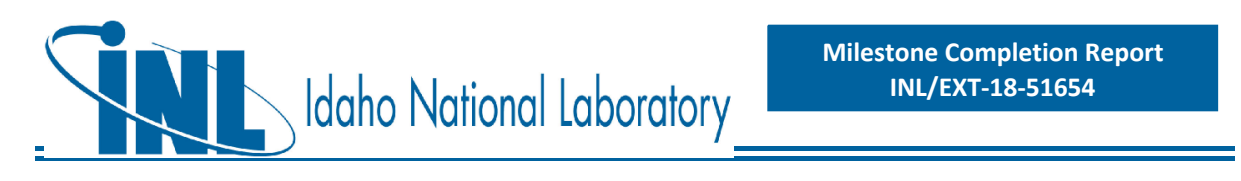

Table J-2. (continued)

\begin{tabular}{|c|c|c|c|c|c|c|c|c|c|c|c|c|}
\hline Component & unit & $\begin{array}{l}\text { DML- } \\
12\end{array}$ & MC-12 & BMOUT12 & DML-13 & MC-13 & BMOUT13 & BMOUT14 & $\begin{array}{c}\text { DML- } \\
15\end{array}$ & $\begin{array}{l}\text { MC- } \\
15\end{array}$ & BMOUT15 & $\begin{array}{c}\text { DML- } \\
14\end{array}$ \\
\hline $\begin{array}{l}\text { Overall Flow } \\
\text { (moisture and dry } \\
\text { matter) }\end{array}$ & $\mathrm{kg} / \mathrm{hr}$ & 0 & 0 & 46,731 & 0 & 0 & 20,744 & 25,987 & 0 & 389 & 20,355 & 0 \\
\hline Moisture Flow & $\mathrm{kg} / \mathrm{hr}$ & 0 & 0 & 7,566 & 0 & 0 & 3,359 & 4,208 & 0 & 389 & 2,970 & 0 \\
\hline $\begin{array}{l}\text { Total Flow (dry } \\
\text { matter) }\end{array}$ & $\mathrm{kg} / \mathrm{hr}$ & 0 & 0 & 39,165 & 0 & 0 & 17,385 & 21,779 & 0 & 0 & 17,385 & 0 \\
\hline $\mathrm{C} 6$ & $\mathrm{~kg} / \mathrm{hr}$ & 0 & 0 & 14,463 & 0 & 0 & 6,420 & 8,043 & 0 & 0 & 6,420 & 0 \\
\hline $\mathrm{C5}$ & $\mathrm{kg} / \mathrm{hr}$ & 0 & 0 & 7,811 & 0 & 0 & 3,467 & 4,344 & 0 & 0 & 3,467 & 0 \\
\hline LIGNIN & $\mathrm{kg} / \mathrm{hr}$ & 0 & 0 & 6,004 & 0 & 0 & 2,665 & 3,339 & 0 & 0 & 2,665 & 0 \\
\hline ASH & $\mathrm{kg} / \mathrm{hr}$ & 0 & 0 & 4,527 & 0 & 0 & 2,010 & 2,518 & 0 & 0 & 2,010 & 0 \\
\hline PROTEIN & $\mathrm{kg} / \mathrm{hr}$ & 0 & 0 & 1,156 & 0 & 0 & 513 & 643 & 0 & 0 & 513 & 0 \\
\hline EXTRACTIVES & $\mathrm{kg} / \mathrm{hr}$ & 0 & 0 & 4,910 & 0 & 0 & 2,180 & 2,730 & 0 & 0 & 2,180 & 0 \\
\hline OTHERS & $\mathrm{kg} / \mathrm{hr}$ & 0 & 0 & 293 & 0 & 0 & 130 & 163 & 0 & 0 & 130 & 0 \\
\hline Temperature & $\mathrm{K}$ & 298 & 298 & 298 & 298 & 298 & 298 & 298 & 298 & 298 & 298 & 298 \\
\hline Pressure & $\mathrm{atm}$ & 1 & 1 & 1 & 1 & 1 & 1 & 1 & 1 & 1 & 1 & 1 \\
\hline Vapor Frac & & 0 & 0 & 0 & 0 & 0 & 0 & 0 & 0 & 0 & 0 & 0 \\
\hline
\end{tabular}




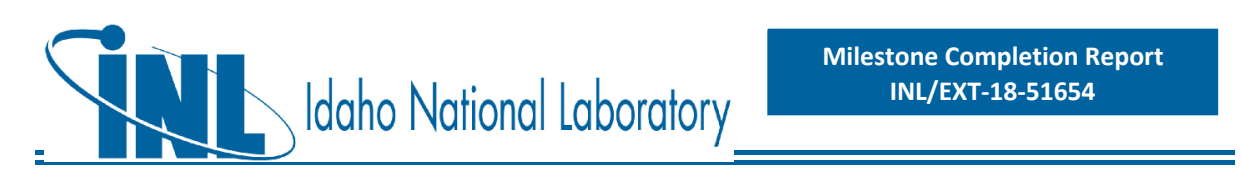

Table J-2. (continued)

\begin{tabular}{|c|c|c|c|c|c|c|c|c|c|c|c|c|}
\hline Component & unit & $\begin{array}{l}\text { MC- } \\
14\end{array}$ & BMOUT16 & DML-16 & MC-16 & BMOUT17 & DML-18 & MC-18 & BMOUT18 & DML-19 & $\begin{array}{c}\text { MC- } \\
19\end{array}$ & BMOUT19 \\
\hline $\begin{array}{l}\text { Overall Flow } \\
\text { (moisture and dry } \\
\text { matter) }\end{array}$ & $\mathrm{kg} / \mathrm{hr}$ & 0 & 25,987 & 0 & 487 & 25,500 & 0 & 0 & 45,855 & 0 & 1,055 & 44,800 \\
\hline Moisture Flow & $\mathrm{kg} / \mathrm{hr}$ & 0 & 4,208 & 0 & 487 & 3,721 & 0 & 0 & 6,691 & 0 & 1,055 & 5,636 \\
\hline $\begin{array}{l}\text { Total Flow (dry } \\
\text { matter) }\end{array}$ & $\mathrm{kg} / \mathrm{hr}$ & 0 & 21,779 & 0 & 0 & 21,779 & 0 & 0 & 39,165 & 0 & 0 & 39,165 \\
\hline C6 & $\mathrm{kg} / \mathrm{hr}$ & 0 & 8,043 & 0 & 0 & 8,043 & 0 & 0 & 14,463 & 0 & 0 & 14,463 \\
\hline C5 & $\mathrm{kg} / \mathrm{hr}$ & 0 & 4,344 & 0 & 0 & 4,344 & 0 & 0 & 7,811 & 0 & 0 & 7,811 \\
\hline LIGNIN & $\mathrm{kg} / \mathrm{hr}$ & 0 & 3,339 & 0 & 0 & 3,339 & 0 & 0 & 6,004 & 0 & 0 & 6,004 \\
\hline ASH & $\mathrm{kg} / \mathrm{hr}$ & 0 & 2,518 & 0 & 0 & 2,518 & 0 & 0 & 4,527 & 0 & 0 & 4,527 \\
\hline PROTEIN & $\mathrm{kg} / \mathrm{hr}$ & 0 & 643 & 0 & 0 & 643 & 0 & 0 & 1,156 & 0 & 0 & 1,156 \\
\hline EXTRACTIVES & $\mathrm{kg} / \mathrm{hr}$ & 0 & 2,730 & 0 & 0 & 2,730 & 0 & 0 & 4,910 & 0 & 0 & 4,910 \\
\hline OTHERS & $\mathrm{kg} / \mathrm{hr}$ & 0 & 163 & 0 & 0 & 163 & 0 & 0 & 293 & 0 & 0 & 293 \\
\hline Temperature & $\mathrm{K}$ & 298 & 298 & 298 & 298 & 298 & 298 & 298 & 298 & 298 & 298 & 298 \\
\hline Pressure & atm & 1 & 1 & 1 & 1 & 1 & 1 & 1 & 1 & 1 & 1 & 1 \\
\hline Vapor Frac & & 0 & 0 & 0 & 0 & 0 & 0 & 0 & 0 & 0 & 0 & 0 \\
\hline
\end{tabular}




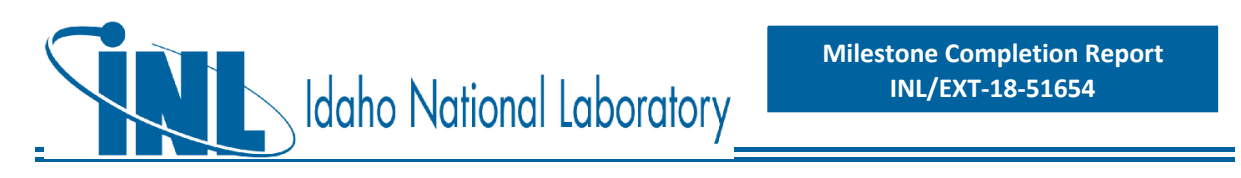

Table J-2. (continued)

\begin{tabular}{|c|c|c|c|c|c|c|c|c|c|c|c|}
\hline Component & unit & $\begin{array}{l}\text { DML- } \\
20\end{array}$ & MC-20 & BMOUT20 & DML-21 & MC-21 & BMOUT21 & DML-22 & MC-22 & BMOUT22 & $\begin{array}{c}\text { DML- } \\
23\end{array}$ \\
\hline $\begin{array}{l}\text { Overall Flow } \\
\text { (moisture and dry } \\
\text { matter) }\end{array}$ & $\mathrm{kg} / \mathrm{hr}$ & 0 & 1,008 & 43,792 & 0 & 0 & 43,792 & 0 & 0 & 43,792 & 0 \\
\hline Moisture Flow & $\mathrm{kg} / \mathrm{hr}$ & 0 & 1,008 & 4,628 & 0 & 0 & 4,628 & 0 & 0 & 4,628 & 0 \\
\hline $\begin{array}{l}\text { Total Flow (dry } \\
\text { matter) }\end{array}$ & $\mathrm{kg} / \mathrm{hr}$ & 0 & 0 & 39,165 & 0 & 0 & 39,165 & 0 & 0 & 39,165 & 0 \\
\hline C6 & $\mathrm{kg} / \mathrm{hr}$ & 0 & 0 & 14,463 & 0 & 0 & 14,463 & 0 & 0 & 14,463 & 0 \\
\hline C5 & $\mathrm{kg} / \mathrm{hr}$ & 0 & 0 & 7,811 & 0 & 0 & 7,811 & 0 & 0 & 7,811 & 0 \\
\hline LIGNIN & $\mathrm{kg} / \mathrm{hr}$ & 0 & 0 & 6,004 & 0 & 0 & 6,004 & 0 & 0 & 6,004 & 0 \\
\hline ASH & $\mathrm{kg} / \mathrm{hr}$ & 0 & 0 & 4,527 & 0 & 0 & 4,527 & 0 & 0 & 4,527 & 0 \\
\hline PROTEIN & $\mathrm{kg} / \mathrm{hr}$ & 0 & 0 & 1,156 & 0 & 0 & 1,156 & 0 & 0 & 1,156 & 0 \\
\hline EXTRACTIVES & $\mathrm{kg} / \mathrm{hr}$ & 0 & 0 & 4,910 & 0 & 0 & 4,910 & 0 & 0 & 4,910 & 0 \\
\hline OTHERS & $\mathrm{kg} / \mathrm{hr}$ & 0 & 0 & 293 & 0 & 0 & 293 & 0 & 0 & 293 & 0 \\
\hline Temperature & $\mathrm{K}$ & 298 & 298 & 298 & 298 & 298 & 298 & 298 & 298 & 298 & 298 \\
\hline Pressure & $\mathrm{atm}$ & 1 & 1 & 1 & 1 & 1 & 1 & 1 & 1 & 1 & 1 \\
\hline Vapor Frac & & 0 & 0 & 0 & 0 & 0 & 0 & 0 & 0 & 0 & 0 \\
\hline
\end{tabular}


Milestone Completion Report

INL/EXT-18-51654

Idaho National Laboratory

Table J-2. (continued)

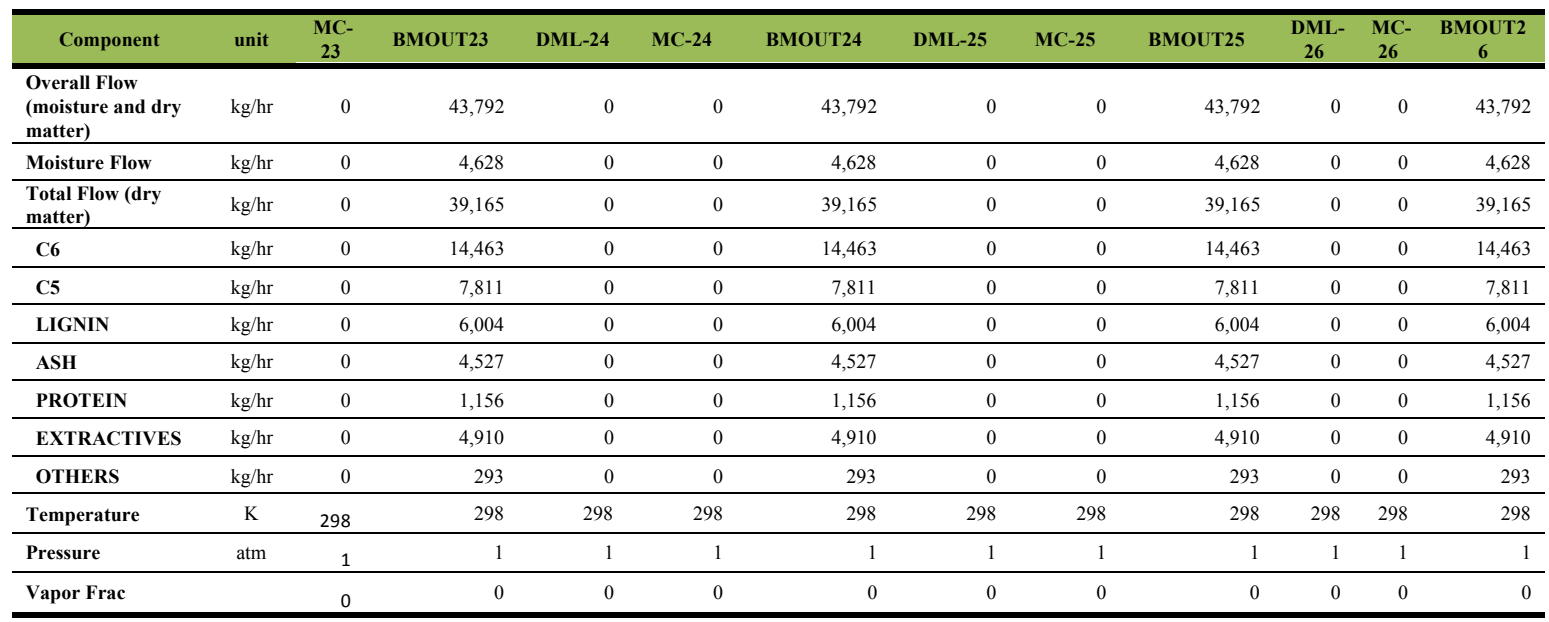

288 


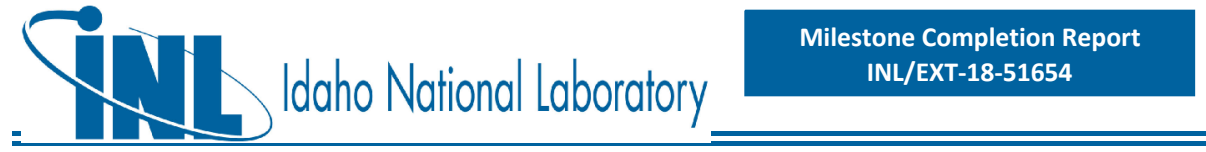

Table J-2. (continued)

\begin{tabular}{|c|c|c|c|c|c|c|c|c|c|c|}
\hline Component & unit & $\begin{array}{l}\text { DML- } \\
27\end{array}$ & MC-27 & BMOUT27 & DML-28 & MC-28 & BMOUT28 & DML-29 & MC-29 & BMOUT29 \\
\hline $\begin{array}{l}\text { Overall Flow } \\
\text { (moisture and dry } \\
\text { matter) }\end{array}$ & $\mathrm{kg} / \mathrm{hr}$ & 0 & 0 & 43,792 & 0 & 0 & 43,792 & 0 & 0 & 43,792 \\
\hline Moisture Flow & $\mathrm{kg} / \mathrm{hr}$ & 0 & 0 & 4,628 & 0 & 0 & 4,628 & 0 & 0 & 4,628 \\
\hline $\begin{array}{l}\text { Total Flow (dry } \\
\text { matter) }\end{array}$ & $\mathrm{kg} / \mathrm{hr}$ & 0 & 0 & 39,165 & 0 & 0 & 39,165 & 0 & 0 & 39,165 \\
\hline C6 & $\mathrm{kg} / \mathrm{hr}$ & 0 & 0 & 14,463 & 0 & 0 & 14,463 & 0 & 0 & 14,463 \\
\hline $\mathrm{C5}$ & $\mathrm{kg} / \mathrm{hr}$ & 0 & 0 & 7,811 & 0 & 0 & 7,811 & 0 & 0 & 7,811 \\
\hline LIGNIN & $\mathrm{kg} / \mathrm{hr}$ & 0 & 0 & 6,004 & 0 & 0 & 6,004 & 0 & 0 & 6,004 \\
\hline ASH & $\mathrm{kg} / \mathrm{hr}$ & 0 & 0 & 4,527 & 0 & 0 & 4,527 & 0 & 0 & 4,527 \\
\hline PROTEIN & $\mathrm{kg} / \mathrm{hr}$ & 0 & 0 & 1,156 & 0 & 0 & 1,156 & 0 & 0 & 1,156 \\
\hline EXTRACTIVES & $\mathrm{kg} / \mathrm{hr}$ & 0 & 0 & 4,910 & 0 & 0 & 4,910 & 0 & 0 & 4,910 \\
\hline OTHERS & $\mathrm{kg} / \mathrm{hr}$ & 0 & 0 & 293 & 0 & 0 & 293 & 0 & 0 & 293 \\
\hline Temperature & $\mathrm{K}$ & 298 & 298 & 298 & 298 & 298 & 298 & 298 & 298 & 298 \\
\hline Pressure & atm & 1 & 1 & 1 & 1 & 1 & 1 & 1 & 1 & 1 \\
\hline Vapor Frac & & 0 & 0 & 0 & 0 & 0 & 0 & 0 & 0 & 0 \\
\hline
\end{tabular}




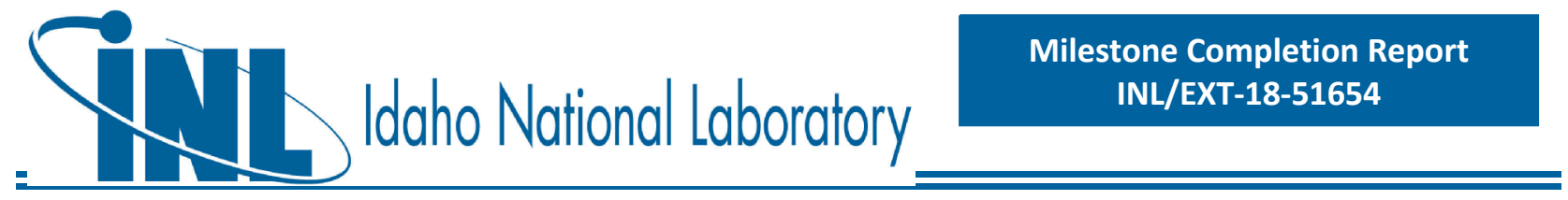

\section{J.2 Two-pass Corn Stover Blendstock}

High-level stream table information from Aspen Plus modeling output follows, for key streams associated with each process operation area. This is followed by high-level PFDs for the associated process areas. Space for stream tables was limited; below is a key to lumped components. As the stream table information focuses primarily on the high-level overall process and does not include every individual modeled stream within each process area, mass balance closure around a given unit area may not be $100 \%$.

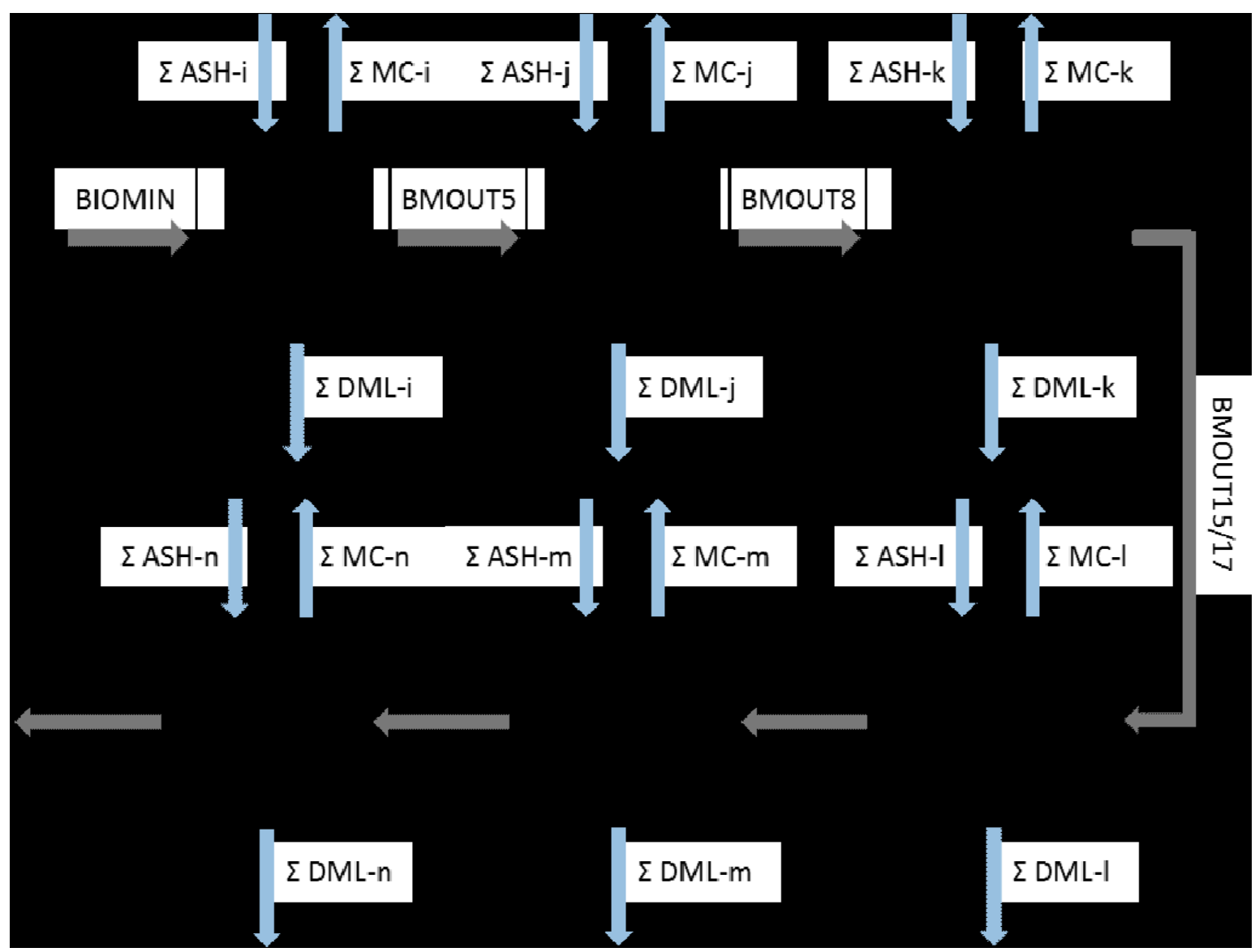

Figure J-8. High-level flowsheet showing key process areas for the two pass corn stover blendstock in the 2022 Herbaceous Projection. 

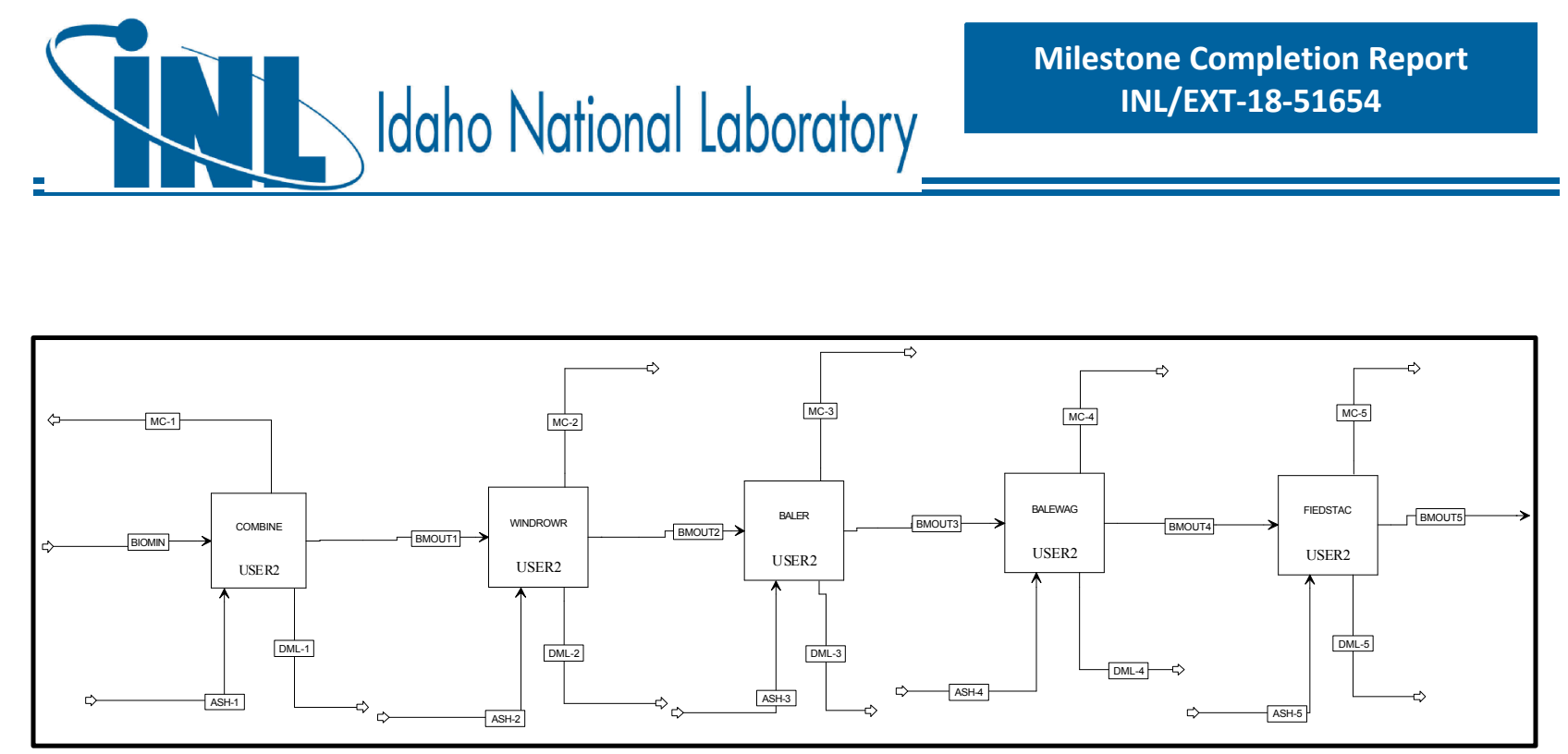

Figure J-9. Detailed process flow diagram for area B100 - Harvesting to Storage.

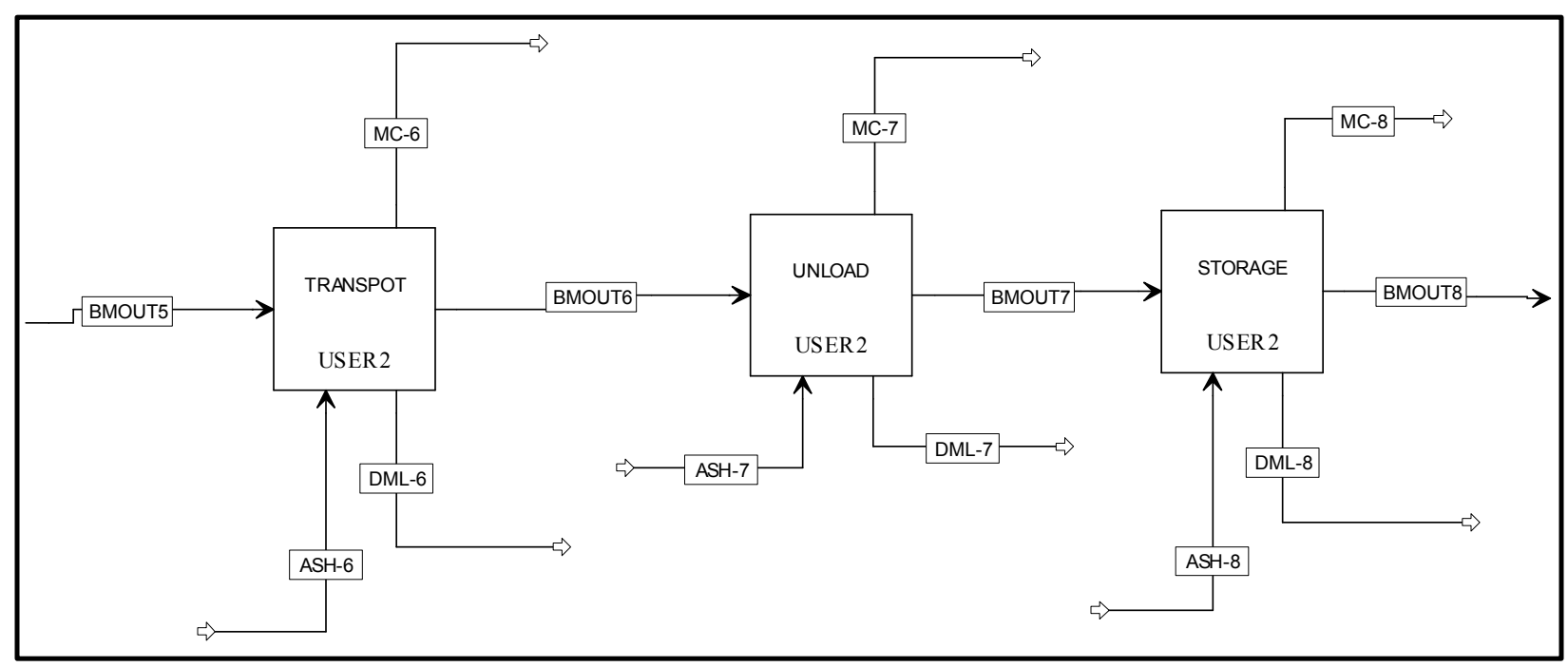

Figure J-10. Detailed process flow diagram for area B200 - Transport to Depot \& Handling. 


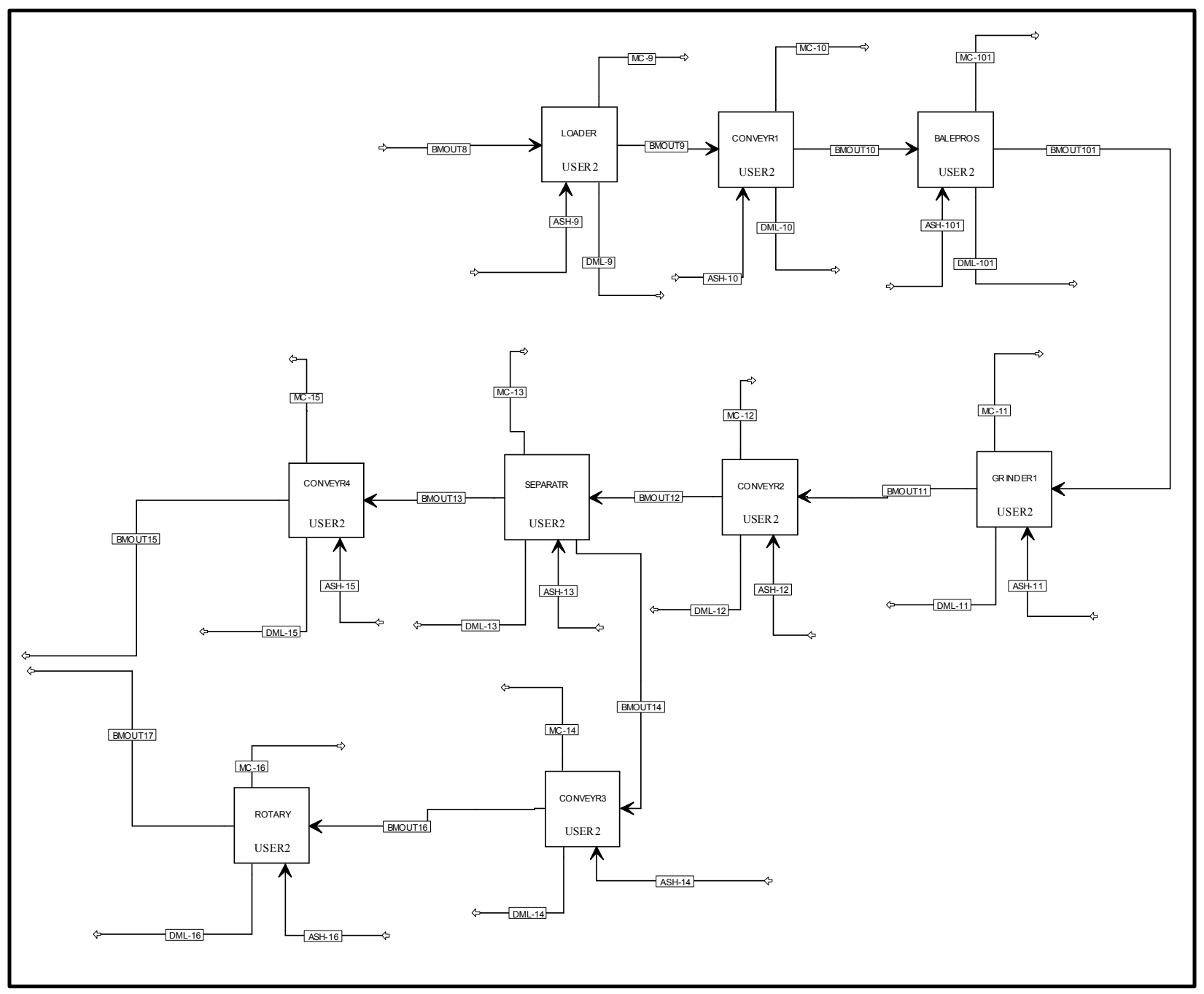

Figure J-11. Detailed process flow diagram for area B300 - Preprocessing - Size Reduction. 

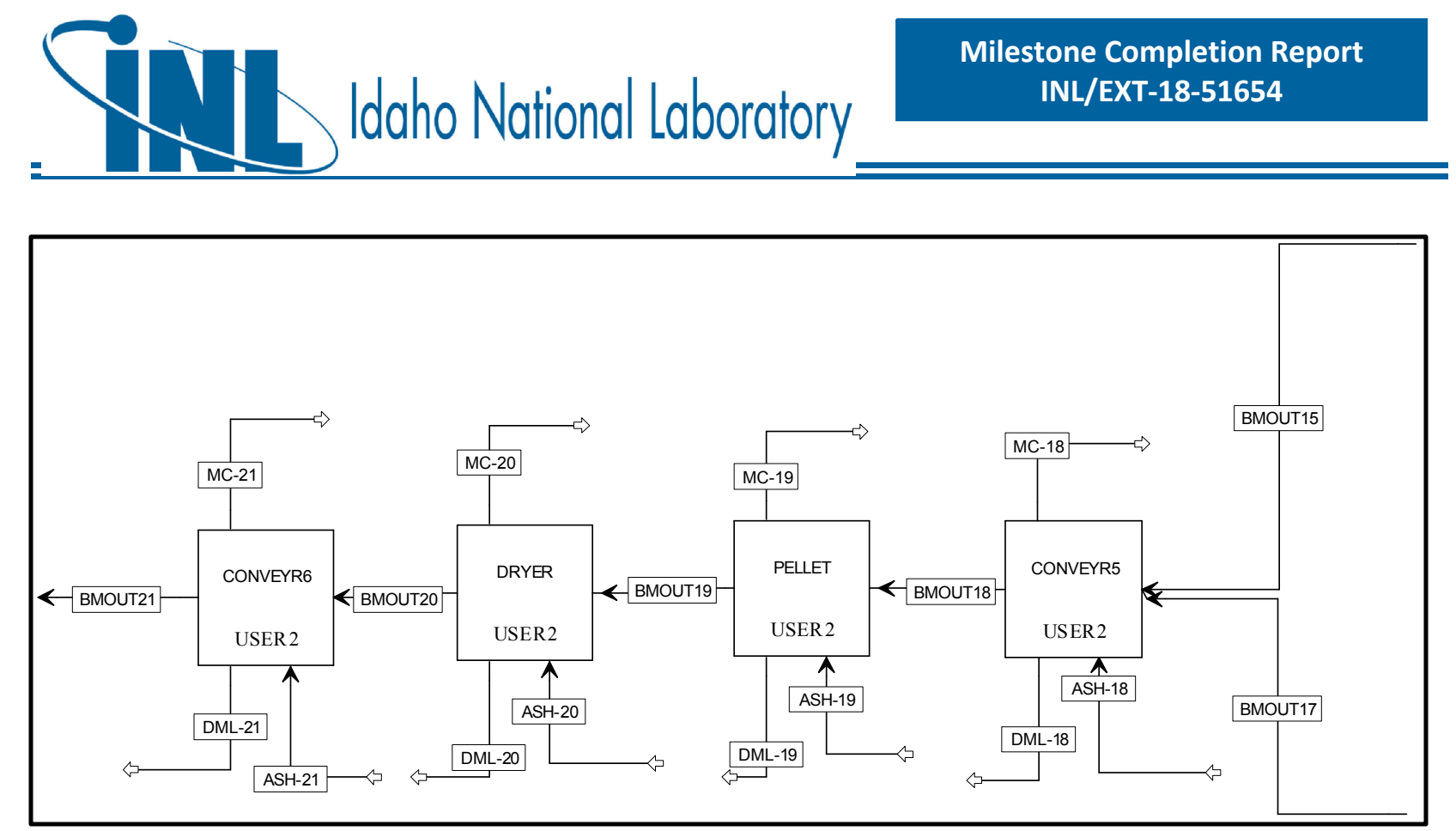

Figure J-12. Detailed process flow diagram for area B400 - Preprocessing - Pelleting.

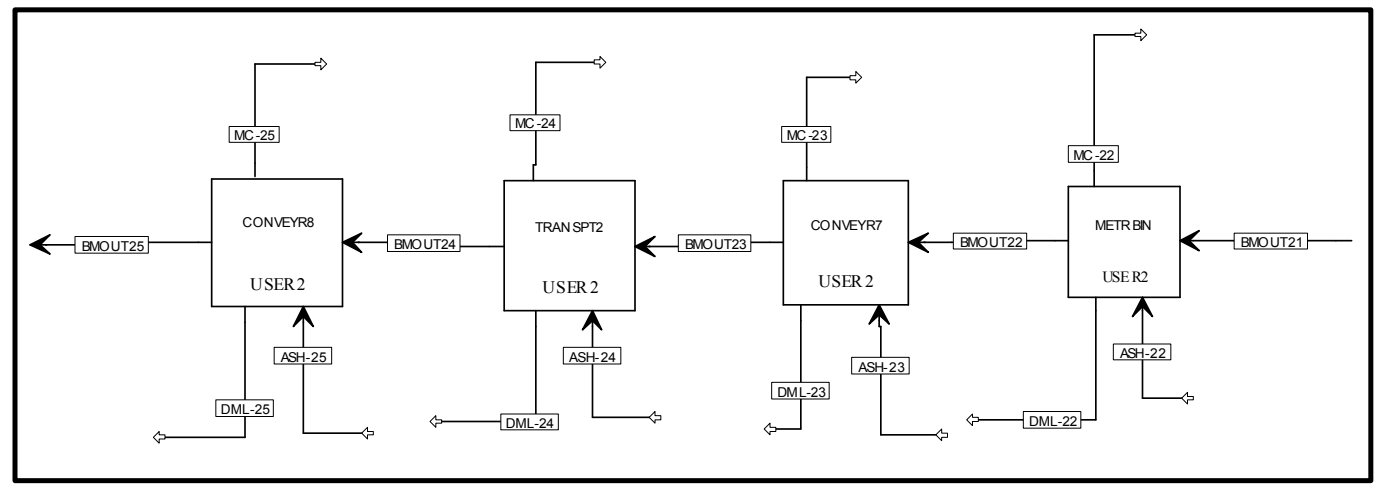

Figure J-13. Detailed process flow diagram for area B500 - Transport to Biorefinery. 

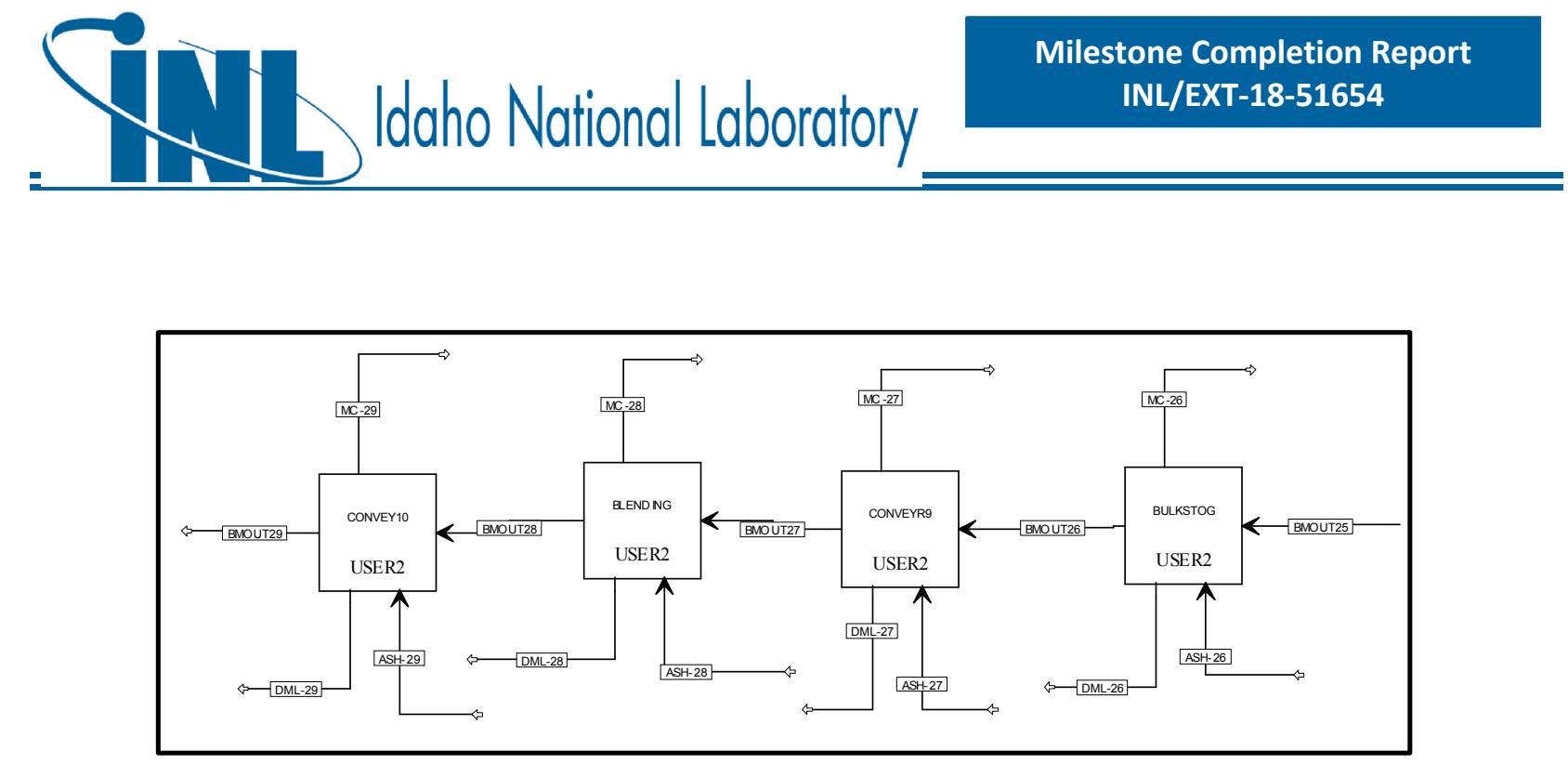

Figure J-14. Detailed process flow diagram for area B600 - Feeding. 
Table J-3. Aspen Plus mass balances from harvest to field-side storage (Area J100) for the two-pass corn stover blendstock in the 2022 Herbaceous Projection. Harvest is assumed to take place within a 6 week period, working 14 hours/day, 6 days per week.

\begin{tabular}{|c|c|c|c|c|c|c|c|c|c|c|c|c|c|c|}
\hline Component & unit & BIOMIN & $\begin{array}{c}\text { DML- } \\
1\end{array}$ & MC-1 & $\begin{array}{c}\text { BMOUT } \\
1\end{array}$ & DML-2 & MC-2 & $\begin{array}{c}\text { BMOUT } \\
2\end{array}$ & $\begin{array}{c}\text { DML- } \\
3\end{array}$ & MC-3 & BMOUT3 & $\begin{array}{c}\text { DML- } \\
4\end{array}$ & $\begin{array}{c}\text { MC- } \\
4\end{array}$ & BMOUT4 \\
\hline $\begin{array}{l}\text { Overall Flow } \\
\text { (moisture and dry } \\
\text { matter) }\end{array}$ & $\mathrm{kg} / \mathrm{hr}$ & 15,029 & 0 & 0 & 15,029 & 0 & 0 & 15,029 & 0 & 0 & 15,029 & 0 & 0 & 15,029 \\
\hline Moisture Flow & $\mathrm{kg} / \mathrm{hr}$ & 4,509 & 0 & 0 & 4,509 & 0 & 0 & 4,509 & 0 & 0 & 4,509 & 0 & 0 & 4,509 \\
\hline $\begin{array}{l}\text { Total Flow (dry } \\
\text { matter) }\end{array}$ & $\mathrm{kg} / \mathrm{hr}$ & 10,520 & 0 & 0 & 10,520 & 0 & 0 & 10,520 & 0 & 0 & 10,520 & 0 & 0 & 10,520 \\
\hline C6 & $\mathrm{kg} / \mathrm{hr}$ & 3,896 & 0 & 0 & 3,896 & 0 & 0 & 3,896 & 0 & 0 & 3,896 & 0 & 0 & 3,896 \\
\hline $\mathrm{C} 5$ & $\mathrm{~kg} / \mathrm{hr}$ & 2,251 & 0 & 0 & 2,251 & 0 & 0 & 2,251 & 0 & 0 & 2,251 & 0 & 0 & 2,251 \\
\hline LIGNIN & $\mathrm{kg} / \mathrm{hr}$ & 1,624 & 0 & 0 & 1,624 & 0 & 0 & 1,624 & 0 & 0 & 1,624 & 0 & 0 & 1,624 \\
\hline ASH & $\mathrm{kg} / \mathrm{hr}$ & 736 & 0 & 0 & 736 & 0 & 0 & 736 & 0 & 0 & 736 & 0 & 0 & 736 \\
\hline PROTEIN & $\mathrm{kg} / \mathrm{hr}$ & 319 & 0 & 0 & 319 & 0 & 0 & 319 & 0 & 0 & 319 & 0 & 0 & 319 \\
\hline EXTRACTIVES & $\mathrm{kg} / \mathrm{hr}$ & 1,511 & 0 & 0 & 1,511 & 0 & 0 & 1,511 & 0 & 0 & 1,511 & 0 & 0 & 1,511 \\
\hline OTHERS & $\mathrm{kg} / \mathrm{hr}$ & 183 & 0 & 0 & 183 & 0 & 0 & 183 & 0 & 0 & 183 & 0 & 0 & 183 \\
\hline Temperature & K & 298 & 298 & 298 & 298 & 298 & 298 & 298 & 298 & 298 & 298 & 298 & 298 & 298 \\
\hline Pressure & atm & 1 & 1 & 1 & 1 & 1 & 1 & 1 & 1 & 1 & 1 & 1 & 1 & 1 \\
\hline Vapor Frac & & 0 & 0 & 0 & 0 & 0 & 0 & 0 & 0 & 0 & 0 & 0 & 0 & 0 \\
\hline
\end{tabular}




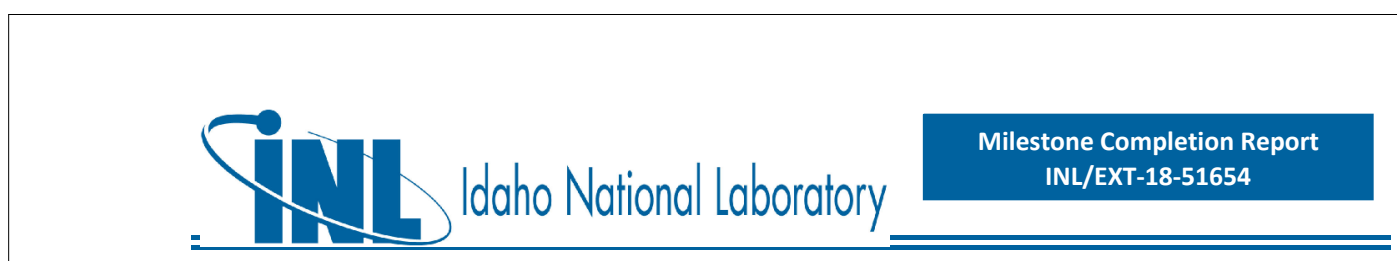

Table J-4. Aspen Plus mass balances from field-side storage to feeding (Areas B200-B600) for the two-pass corn stover blendstock in the 2022 Herbaceous Projection. Depot operation is assumed to take place within 350 day period, working 24 hours/day, 7 days per week.

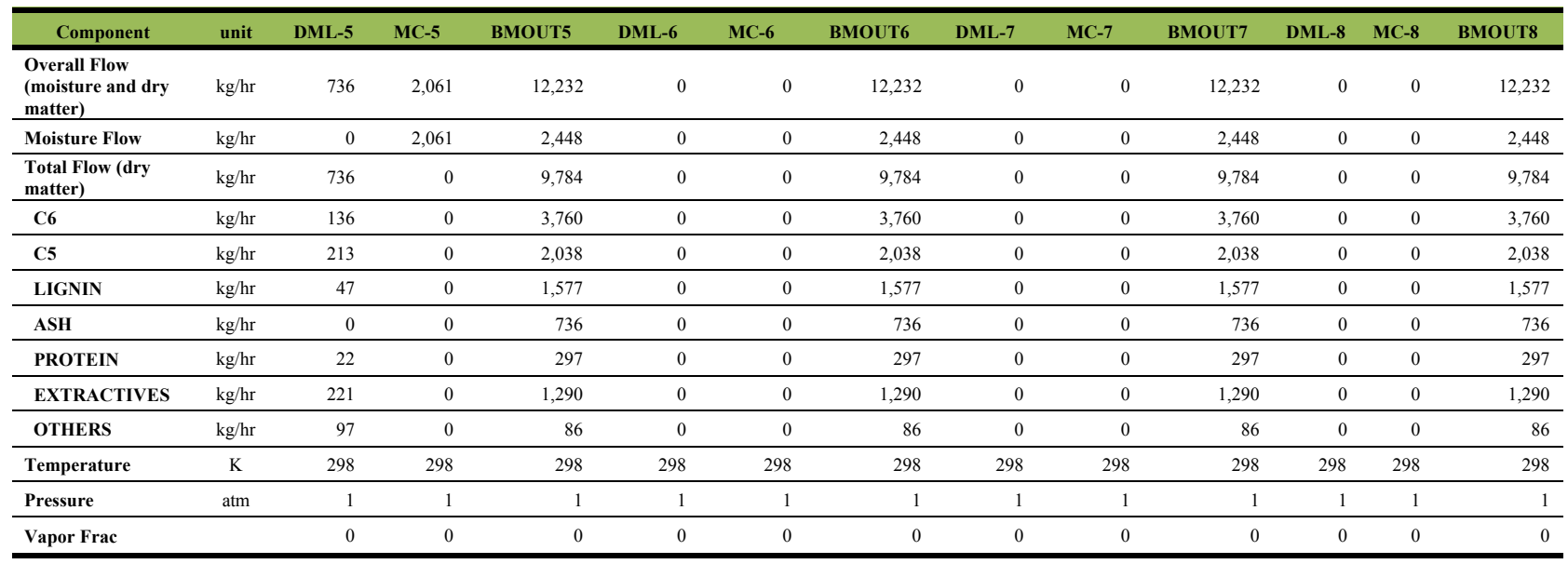

296 
Table J-4. (continued)

\begin{tabular}{|c|c|c|c|c|c|c|c|c|c|c|c|c|c|}
\hline Component & unit & DML-9 & MC-9 & BMOUT9 & DML-10 & MC-10 & BMOUT10 & $\begin{array}{l}\text { DML- } \\
101\end{array}$ & MC-101 & BMOUT101 & $\begin{array}{l}\text { DML- } \\
11\end{array}$ & $\begin{array}{l}\text { MC- } \\
11\end{array}$ & BMOUT11 \\
\hline $\begin{array}{l}\text { Overall Flow } \\
\text { (moisture and dry } \\
\text { matter) }\end{array}$ & $\mathrm{kg} / \mathrm{hr}$ & 0 & 0 & 12,232 & 0 & 0 & 12,232 & 0 & 0 & 12,232 & 196 & 596 & 11,440 \\
\hline Moisture Flow & $\mathrm{kg} / \mathrm{hr}$ & 0 & 0 & 2,448 & 0 & 0 & 2,448 & 0 & 0 & 2,448 & 0 & 596 & 1,852 \\
\hline $\begin{array}{l}\text { Total Flow (dry } \\
\text { matter) }\end{array}$ & $\mathrm{kg} / \mathrm{hr}$ & 0 & 0 & 9,784 & 0 & 0 & 9,784 & 0 & 0 & 9,784 & 196 & 0 & 9,588 \\
\hline C6 & $\mathrm{kg} / \mathrm{hr}$ & 0 & 0 & 3,760 & 0 & 0 & 3,760 & 0 & 0 & 3,760 & 54 & 0 & 3,705 \\
\hline C5 & $\mathrm{kg} / \mathrm{hr}$ & 0 & 0 & 2,038 & 0 & 0 & 2,038 & 0 & 0 & 2,038 & 30 & 0 & 2,008 \\
\hline LIGNIN & $\mathrm{kg} / \mathrm{hr}$ & 0 & 0 & 1,577 & 0 & 0 & 1,577 & 0 & 0 & 1,577 & 38 & 0 & 1,539 \\
\hline ASH & $\mathrm{kg} / \mathrm{hr}$ & 0 & 0 & 736 & 0 & 0 & 736 & 0 & 0 & 736 & 49 & 0 & 687 \\
\hline PROTEIN & $\mathrm{kg} / \mathrm{hr}$ & 0 & 0 & 297 & 0 & 0 & 297 & 0 & 0 & 297 & 0 & 0 & 297 \\
\hline EXTRACTIVES & $\mathrm{kg} / \mathrm{hr}$ & 0 & 0 & 1,290 & 0 & 0 & 1,290 & 0 & 0 & 1,290 & 24 & 0 & 1,266 \\
\hline OTHERS & $\mathrm{kg} / \mathrm{hr}$ & 0 & 0 & 86 & 0 & 0 & 86 & 0 & 0 & 86 & 0 & 0 & 86 \\
\hline Temperature & K & 298 & 298 & 298 & 298 & 298 & 298 & 298 & 298 & 298 & 298 & 298 & 298 \\
\hline Pressure & atm & 1 & 1 & 1 & 1 & 1 & 1 & 1 & 1 & 1 & 1 & 1 & 1 \\
\hline Vapor Frac & & 0 & 0 & 0 & 0 & 0 & 0 & 0 & 0 & 0 & 0 & 0 & 0 \\
\hline
\end{tabular}


Iano National Laboratory

Table J-4. (continued)

\begin{tabular}{|c|c|c|c|c|c|c|c|c|c|c|c|c|}
\hline Component & unit & $\begin{array}{c}\text { DML- } \\
12\end{array}$ & MC-12 & BMOUT12 & DML-13 & MC-13 & BMOUT13 & BMOUT14 & $\begin{array}{l}\text { DML- } \\
15\end{array}$ & $\begin{array}{l}\text { MC- } \\
15\end{array}$ & BMOUT15 & $\begin{array}{c}\text { DML- } \\
14\end{array}$ \\
\hline $\begin{array}{l}\text { Overall Flow } \\
\text { (moisture and dry } \\
\text { matter) }\end{array}$ & $\mathrm{kg} / \mathrm{hr}$ & 0 & 0 & 11,440 & 0 & 0 & 5,078 & 6,362 & 0 & 95 & 4,983 & 0 \\
\hline Moisture Flow & $\mathrm{kg} / \mathrm{hr}$ & 0 & 0 & 1,852 & 0 & 0 & 822 & 1,030 & 0 & 95 & 727 & 0 \\
\hline $\begin{array}{l}\text { Total Flow (dry } \\
\text { matter) }\end{array}$ & $\mathrm{kg} / \mathrm{hr}$ & 0 & 0 & 9,588 & 0 & 0 & 4,256 & 5,332 & 0 & 0 & 4,256 & 0 \\
\hline C6 & $\mathrm{kg} / \mathrm{hr}$ & 0 & 0 & 3,705 & 0 & 0 & 1,645 & 2,061 & 0 & 0 & 1,645 & 0 \\
\hline C5 & $\mathrm{kg} / \mathrm{hr}$ & 0 & 0 & 2,008 & 0 & 0 & 891 & 1,117 & 0 & 0 & 891 & 0 \\
\hline LIGNIN & $\mathrm{kg} / \mathrm{hr}$ & 0 & 0 & 1,539 & 0 & 0 & 683 & 856 & 0 & 0 & 683 & 0 \\
\hline ASH & $\mathrm{kg} / \mathrm{hr}$ & 0 & 0 & 687 & 0 & 0 & 305 & 382 & 0 & 0 & 305 & 0 \\
\hline PROTEIN & $\mathrm{kg} / \mathrm{hr}$ & 0 & 0 & 297 & 0 & 0 & 132 & 165 & 0 & 0 & 132 & 0 \\
\hline EXTRACTIVES & $\mathrm{kg} / \mathrm{hr}$ & 0 & 0 & 1,266 & 0 & 0 & 562 & 704 & 0 & 0 & 562 & 0 \\
\hline OTHERS & $\mathrm{kg} / \mathrm{hr}$ & 0 & 0 & 86 & 0 & 0 & 38 & 48 & 0 & 0 & 38 & 0 \\
\hline Temperature & K & 298 & 298 & 298 & 298 & 298 & 298 & 298 & 298 & 298 & 298 & 298 \\
\hline Pressure & atm & 1 & 1 & 1 & 1 & 1 & 1 & 1 & 1 & 1 & 1 & 1 \\
\hline Vapor Frac & & 0 & 0 & 0 & 0 & 0 & 0 & 0 & 0 & 0 & 0 & 0 \\
\hline
\end{tabular}


lacho National Laboratory

Table J-4. (continued)

\begin{tabular}{|c|c|c|c|c|c|c|c|c|c|c|c|c|}
\hline Component & unit & $\begin{array}{l}\text { MC- } \\
14\end{array}$ & BMOUT16 & DML-16 & MC-16 & BMOUT17 & DML-18 & MC-18 & BMOUT18 & DML-19 & $\begin{array}{l}\text { MC- } \\
19\end{array}$ & BMOUT19 \\
\hline $\begin{array}{l}\text { Overall Flow } \\
\text { (moisture and dry } \\
\text { matter) }\end{array}$ & $\mathrm{kg} / \mathrm{hr}$ & 0 & 6,362 & 0 & 119 & 6,243 & 0 & 0 & 11,226 & 0 & 258 & 10,968 \\
\hline Moisture Flow & $\mathrm{kg} / \mathrm{hr}$ & 0 & 1,030 & 0 & 119 & 911 & 0 & 0 & 1,638 & 0 & 258 & 1,380 \\
\hline $\begin{array}{l}\text { Total Flow (dry } \\
\text { matter) }\end{array}$ & $\mathrm{kg} / \mathrm{hr}$ & 0 & 5,332 & 0 & 0 & 5,332 & 0 & 0 & 9,588 & 0 & 0 & 9,588 \\
\hline C6 & $\mathrm{kg} / \mathrm{hr}$ & 0 & 2,061 & 0 & 0 & 2,061 & 0 & 0 & 3,705 & 0 & 0 & 3,705 \\
\hline C5 & $\mathrm{kg} / \mathrm{hr}$ & 0 & 1,117 & 0 & 0 & 1,117 & 0 & 0 & 2,008 & 0 & 0 & 2,008 \\
\hline LIGNIN & $\mathrm{kg} / \mathrm{hr}$ & 0 & 856 & 0 & 0 & 856 & 0 & 0 & 1,539 & 0 & 0 & 1,539 \\
\hline ASH & $\mathrm{kg} / \mathrm{hr}$ & 0 & 382 & 0 & 0 & 382 & 0 & 0 & 687 & 0 & 0 & 687 \\
\hline PROTEIN & $\mathrm{kg} / \mathrm{hr}$ & 0 & 165 & 0 & 0 & 165 & 0 & 0 & 297 & 0 & 0 & 297 \\
\hline EXTRACTIVES & $\mathrm{kg} / \mathrm{hr}$ & 0 & 704 & 0 & 0 & 704 & 0 & 0 & 1,266 & 0 & 0 & 1,266 \\
\hline OTHERS & $\mathrm{kg} / \mathrm{hr}$ & 0 & 48 & 0 & 0 & 48 & 0 & 0 & 86 & 0 & 0 & 86 \\
\hline Temperature & K & 298 & 298 & 298 & 298 & 298 & 298 & 298 & 298 & 298 & 298 & 298 \\
\hline Pressure & $\mathrm{atm}$ & 1 & 1 & 1 & 1 & 1 & 1 & 1 & 1 & 1 & 1 & 1 \\
\hline Vapor Frac & & 0 & 0 & 0 & 0 & 0 & 0 & 0 & 0 & 0 & 0 & 0 \\
\hline
\end{tabular}


lacho National Laboratory

Table J-4. (continued)

\begin{tabular}{|c|c|c|c|c|c|c|c|c|c|c|c|}
\hline Component & unit & $\begin{array}{l}\text { DML- } \\
20\end{array}$ & MC-20 & BMOUT20 & DML-21 & MC-21 & BMOUT21 & DML-22 & MC-22 & BMOUT22 & $\begin{array}{c}\text { DML- } \\
23\end{array}$ \\
\hline $\begin{array}{l}\text { Overall Flow } \\
\text { (moisture and dry } \\
\text { matter) }\end{array}$ & $\mathrm{kg} / \mathrm{hr}$ & 0 & 247 & 10,721 & 0 & 0 & 10,721 & 0 & 0 & 10,721 & 0 \\
\hline Moisture Flow & $\mathrm{kg} / \mathrm{hr}$ & 0 & 247 & 1,133 & 0 & 0 & 1,133 & 0 & 0 & 1,133 & 0 \\
\hline $\begin{array}{l}\text { Total Flow (dry } \\
\text { matter) }\end{array}$ & $\mathrm{kg} / \mathrm{hr}$ & 0 & 0 & 9,588 & 0 & 0 & 9,588 & 0 & 0 & 9,588 & 0 \\
\hline C6 & $\mathrm{kg} / \mathrm{hr}$ & 0 & 0 & 3,705 & 0 & 0 & 3,705 & 0 & 0 & 3,705 & 0 \\
\hline C5 & $\mathrm{kg} / \mathrm{hr}$ & 0 & 0 & 2,008 & 0 & 0 & 2,008 & 0 & 0 & 2,008 & 0 \\
\hline LIGNIN & $\mathrm{kg} / \mathrm{hr}$ & 0 & 0 & 1,539 & 0 & 0 & 1,539 & 0 & 0 & 1,539 & 0 \\
\hline ASH & $\mathrm{kg} / \mathrm{hr}$ & 0 & 0 & 687 & 0 & 0 & 687 & 0 & 0 & 687 & 0 \\
\hline PROTEIN & $\mathrm{kg} / \mathrm{hr}$ & 0 & 0 & 297 & 0 & 0 & 297 & 0 & 0 & 297 & 0 \\
\hline EXTRACTIVES & $\mathrm{kg} / \mathrm{hr}$ & 0 & 0 & 1,266 & 0 & 0 & 1,266 & 0 & 0 & 1,266 & 0 \\
\hline OTHERS & $\mathrm{kg} / \mathrm{hr}$ & 0 & 0 & 86 & 0 & 0 & 86 & 0 & 0 & 86 & 0 \\
\hline Temperature & K & 298 & 298 & 298 & 298 & 298 & 298 & 298 & 298 & 298 & 298 \\
\hline Pressure & atm & 1 & 1 & 1 & 1 & 1 & 1 & 1 & 1 & 1 & 1 \\
\hline Vapor Frac & & 0 & 0 & 0 & 0 & 0 & 0 & 0 & 0 & 0 & 0 \\
\hline
\end{tabular}


lacho National Laboratory

Table J-4. (continued)

\begin{tabular}{|c|c|c|c|c|c|c|c|c|c|c|c|c|}
\hline Component & unit & $\begin{array}{l}\text { MC- } \\
23\end{array}$ & BMOUT23 & DML-24 & MC-24 & BMOUT24 & DML-25 & MC-25 & BMOUT25 & $\begin{array}{c}\text { DML- } \\
26\end{array}$ & $\begin{array}{l}\text { MC- } \\
26\end{array}$ & $\begin{array}{c}\text { BMOUT- } \\
26\end{array}$ \\
\hline $\begin{array}{l}\text { Overall Flow } \\
\text { (moisture and dry } \\
\text { matter) }\end{array}$ & $\mathrm{kg} / \mathrm{hr}$ & 0 & 10,721 & 0 & 0 & 10,721 & 0 & 0 & 10,721 & 0 & 0 & 10,721 \\
\hline Moisture Flow & $\mathrm{kg} / \mathrm{hr}$ & 0 & 1,133 & 0 & 0 & 1,133 & 0 & 0 & 1,133 & 0 & 0 & 1,133 \\
\hline $\begin{array}{l}\text { Total Flow (dry } \\
\text { matter) }\end{array}$ & $\mathrm{kg} / \mathrm{hr}$ & 0 & 9,588 & 0 & 0 & 9,588 & 0 & 0 & 9,588 & 0 & 0 & 9,588 \\
\hline C6 & $\mathrm{kg} / \mathrm{hr}$ & 0 & 3,705 & 0 & 0 & 3,705 & 0 & 0 & 3,705 & 0 & 0 & 3,705 \\
\hline C5 & $\mathrm{kg} / \mathrm{hr}$ & 0 & 2,008 & 0 & 0 & 2,008 & 0 & 0 & 2,008 & 0 & 0 & 2,008 \\
\hline LIGNIN & $\mathrm{kg} / \mathrm{hr}$ & 0 & 1,539 & 0 & 0 & 1,539 & 0 & 0 & 1,539 & 0 & 0 & 1,539 \\
\hline ASH & $\mathrm{kg} / \mathrm{hr}$ & 0 & 687 & 0 & 0 & 687 & 0 & 0 & 687 & 0 & 0 & 687 \\
\hline PROTEIN & $\mathrm{kg} / \mathrm{hr}$ & 0 & 297 & 0 & 0 & 297 & 0 & 0 & 297 & 0 & 0 & 297 \\
\hline EXTRACTIVES & $\mathrm{kg} / \mathrm{hr}$ & 0 & 1,266 & 0 & 0 & 1,266 & 0 & 0 & 1,266 & 0 & 0 & 1,266 \\
\hline OTHERS & $\mathrm{kg} / \mathrm{hr}$ & 0 & 86 & 0 & 0 & 86 & 0 & 0 & 86 & 0 & 0 & 86 \\
\hline Temperature & K & 298 & 298 & 298 & 298 & 298 & 298 & 298 & 298 & 298 & 298 & 298 \\
\hline Pressure & atm & 1 & 1 & 1 & 1 & 1 & 1 & 1 & 1 & 1 & 1 & 1 \\
\hline Vapor Frac & & 0 & 0 & 0 & 0 & 0 & 0 & 0 & 0 & 0 & 0 & 0 \\
\hline
\end{tabular}


a daho National Laboratory

Table J-4. (continued)

\begin{tabular}{|c|c|c|c|c|c|c|c|c|c|c|}
\hline Component & unit & $\begin{array}{c}\text { DML- } \\
27\end{array}$ & MC-27 & BMOUT27 & DML-28 & MC-28 & BMOUT28 & DML-29 & MC-29 & BMOUT29 \\
\hline $\begin{array}{l}\text { Overall Flow } \\
\text { (moisture and dry } \\
\text { matter) }\end{array}$ & $\mathrm{kg} / \mathrm{hr}$ & 0 & 0 & 10,721 & 0 & 0 & 10,721 & 0 & 0 & 10,721 \\
\hline Moisture Flow & $\mathrm{kg} / \mathrm{hr}$ & 0 & 0 & 1,133 & 0 & 0 & 1,133 & 0 & 0 & 1,133 \\
\hline $\begin{array}{l}\text { Total Flow (dry } \\
\text { matter) }\end{array}$ & $\mathrm{kg} / \mathrm{hr}$ & 0 & 0 & 9,588 & 0 & 0 & 9,588 & 0 & 0 & 9,588 \\
\hline C6 & $\mathrm{kg} / \mathrm{hr}$ & 0 & 0 & 3,705 & 0 & 0 & 3,705 & 0 & 0 & 3,705 \\
\hline C5 & $\mathrm{kg} / \mathrm{hr}$ & 0 & 0 & 2,008 & 0 & 0 & 2,008 & 0 & 0 & 2,008 \\
\hline LIGNIN & $\mathrm{kg} / \mathrm{hr}$ & 0 & 0 & 1,539 & 0 & 0 & 1,539 & 0 & 0 & 1,539 \\
\hline ASH & $\mathrm{kg} / \mathrm{hr}$ & 0 & 0 & 687 & 0 & 0 & 687 & 0 & 0 & 687 \\
\hline PROTEIN & $\mathrm{kg} / \mathrm{hr}$ & 0 & 0 & 297 & 0 & 0 & 297 & 0 & 0 & 297 \\
\hline EXTRACTIVES & $\mathrm{kg} / \mathrm{hr}$ & 0 & 0 & 1,266 & 0 & 0 & 1,266 & 0 & 0 & 1,266 \\
\hline OTHERS & $\mathrm{kg} / \mathrm{hr}$ & 0 & 0 & 86 & 0 & 0 & 86 & 0 & 0 & 86 \\
\hline Temperature & K & 298 & 298 & 298 & 298 & 298 & 298 & 298 & 298 & 298 \\
\hline Pressure & atm & 1 & 1 & 1 & 1 & 1 & 1 & 1 & 1 & 1 \\
\hline Vapor Frac & & 0 & 0 & 0 & 0 & 0 & 0 & 0 & 0 & 0 \\
\hline
\end{tabular}




\section{J.3 Switchgrass Blendstock}

High-level stream table information from Aspen Plus modeling output follows, for key streams associated with each process operation area. This is followed by high-level PFDs for the associated process areas. Space for stream tables was limited; below is a key to lumped components. As the stream table information focuses primarily on the high-level overall process and does not include every individual modeled stream within each process area, mass balance closure around a given unit area may not be $100 \%$.

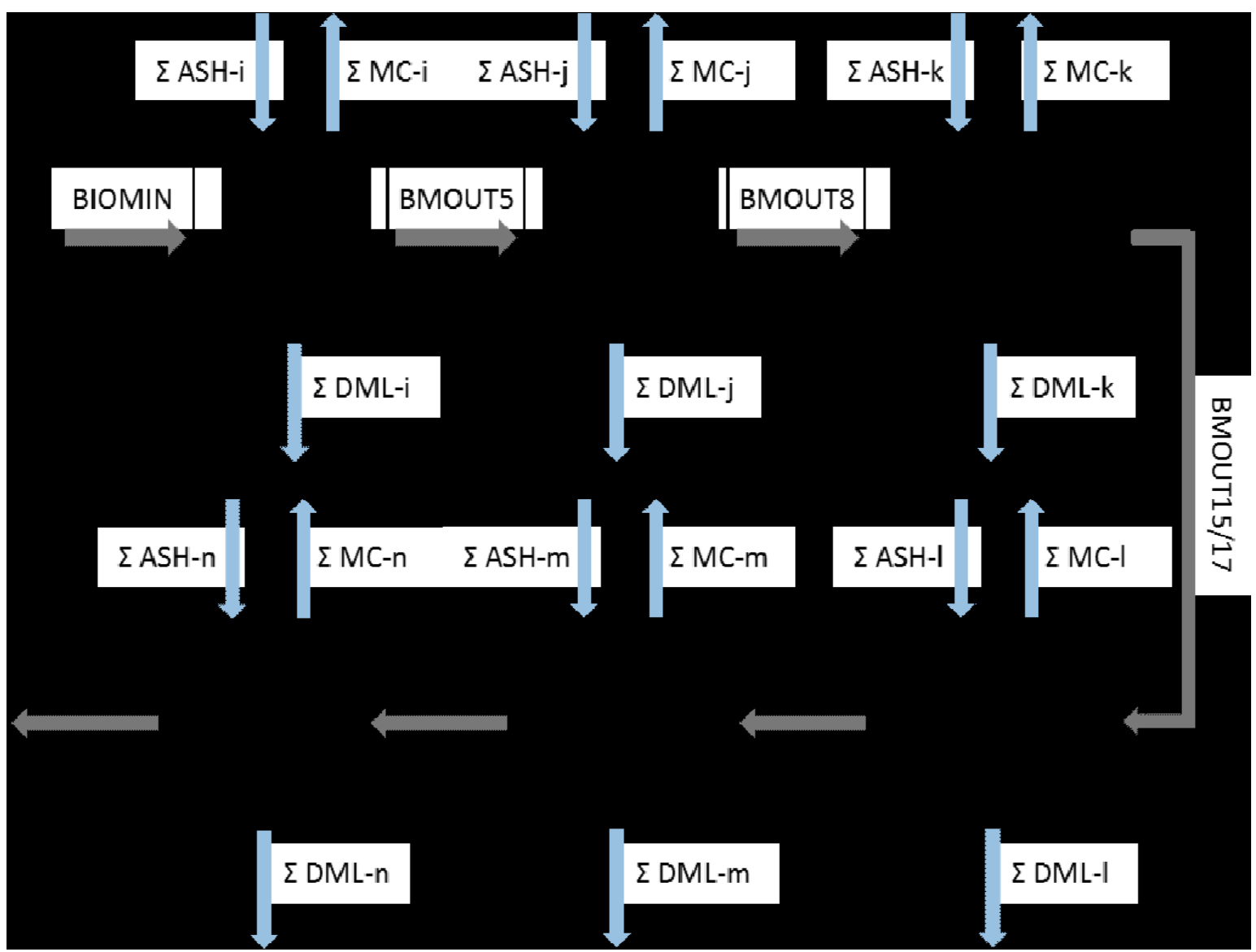

Figure J-15. High-level flowsheet showing key process areas for the switchgrass blendstock in the 2022 Herbaceous Projection. 


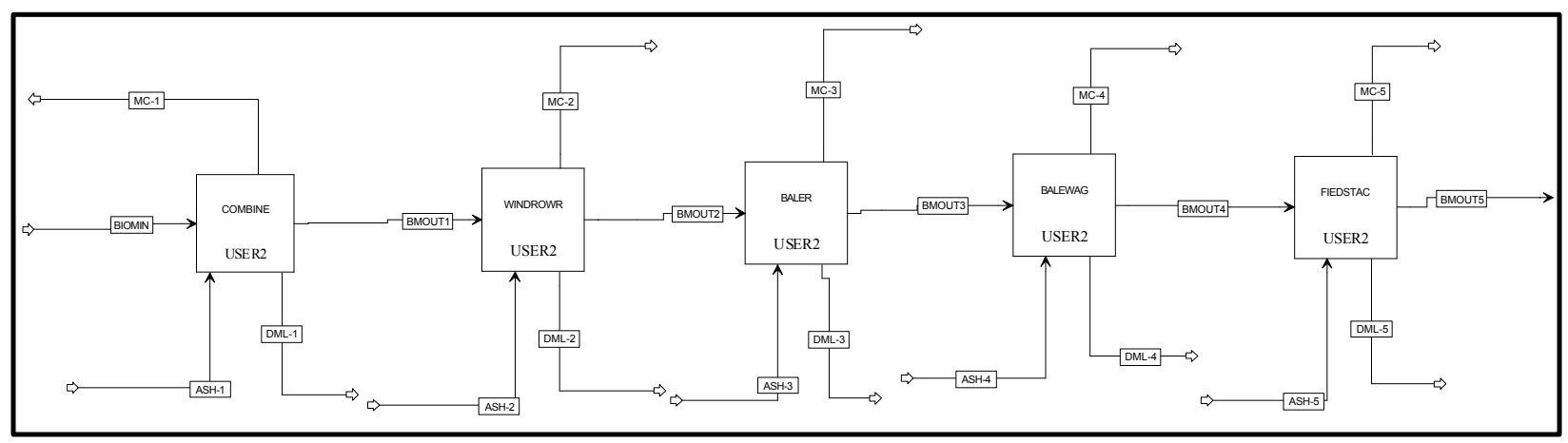

Figure J-16. Detailed process flow diagram for area C100 - Harvesting to Storage.

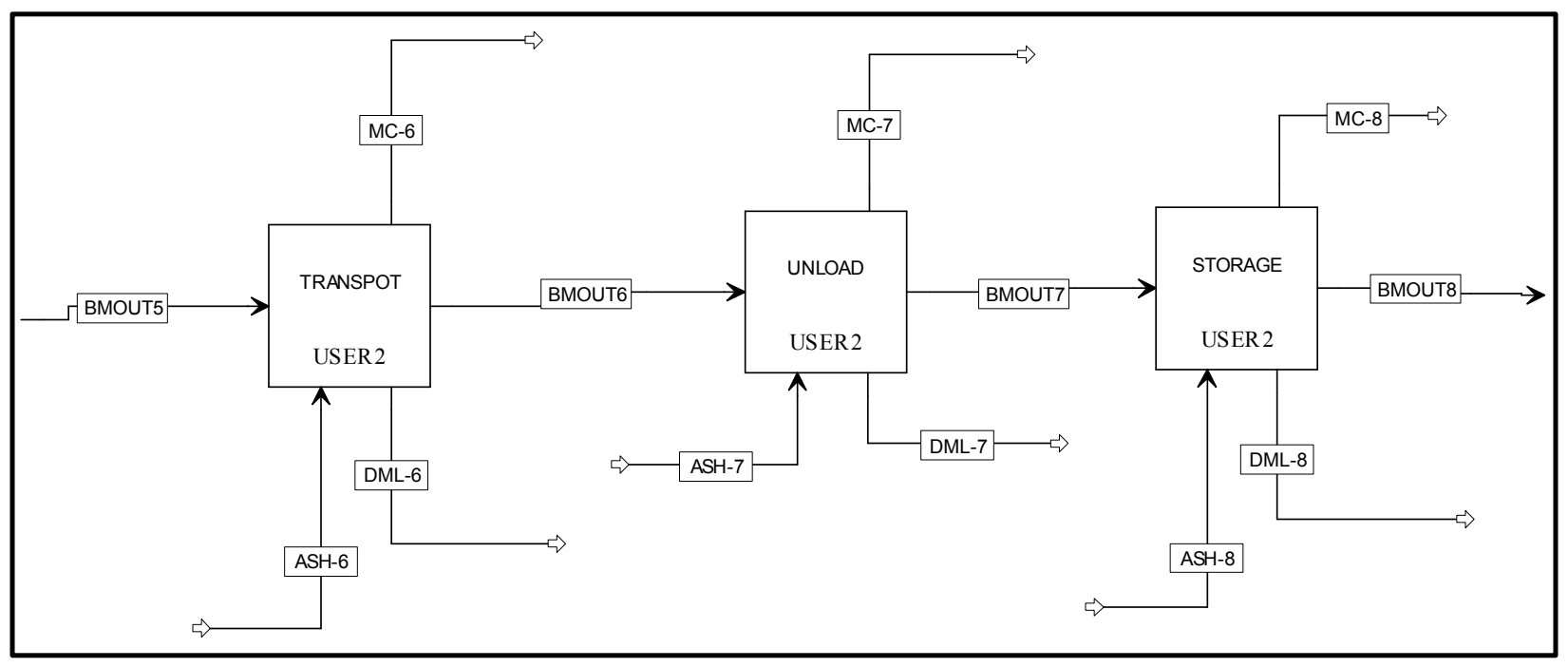

Figure J-17. Detailed process flow diagram for area C200 - Transport to Depot \& Handling. 


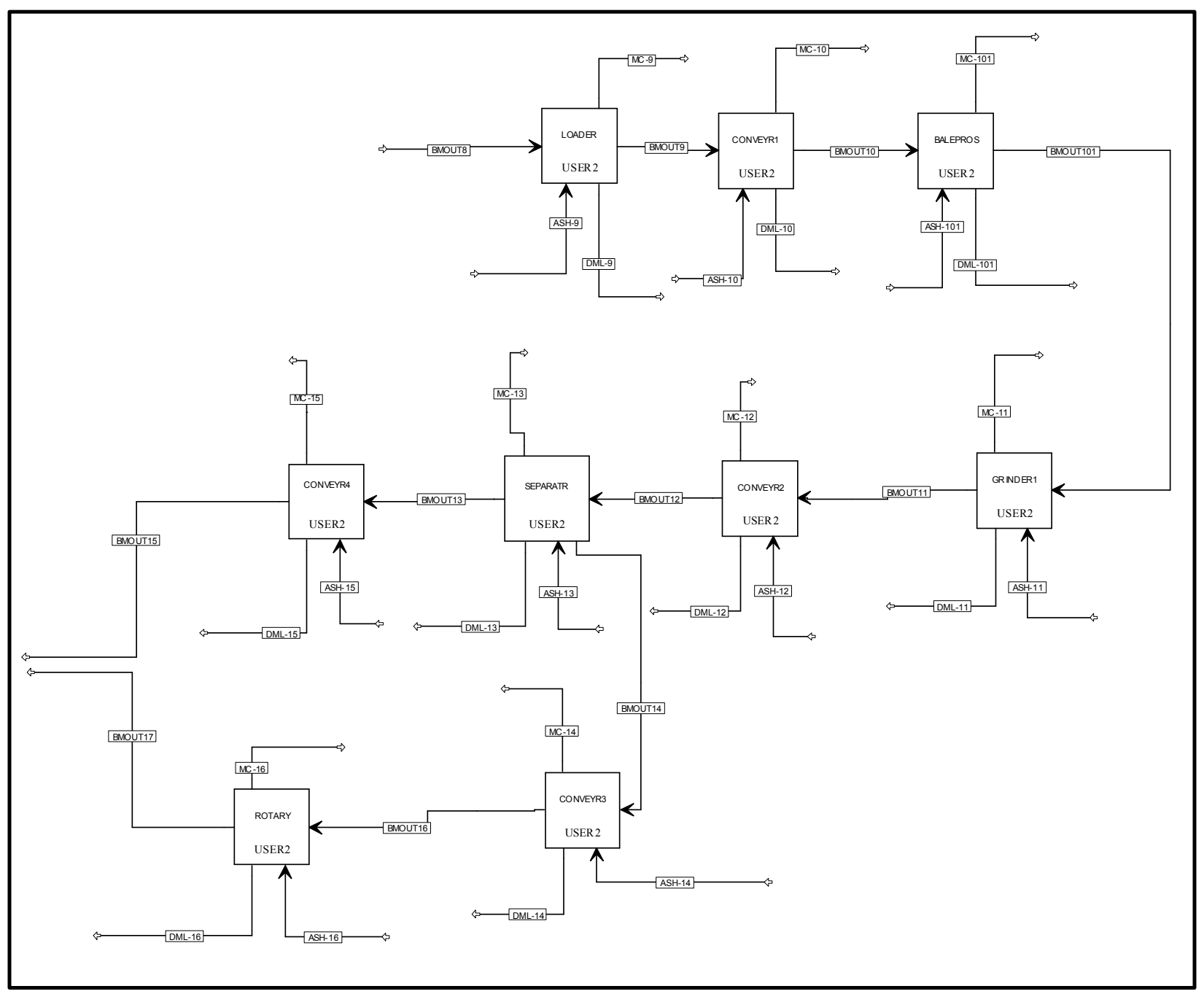

Figure J-18. Detailed process flow diagram for area C300 - Preprocessing - Size Reduction. 

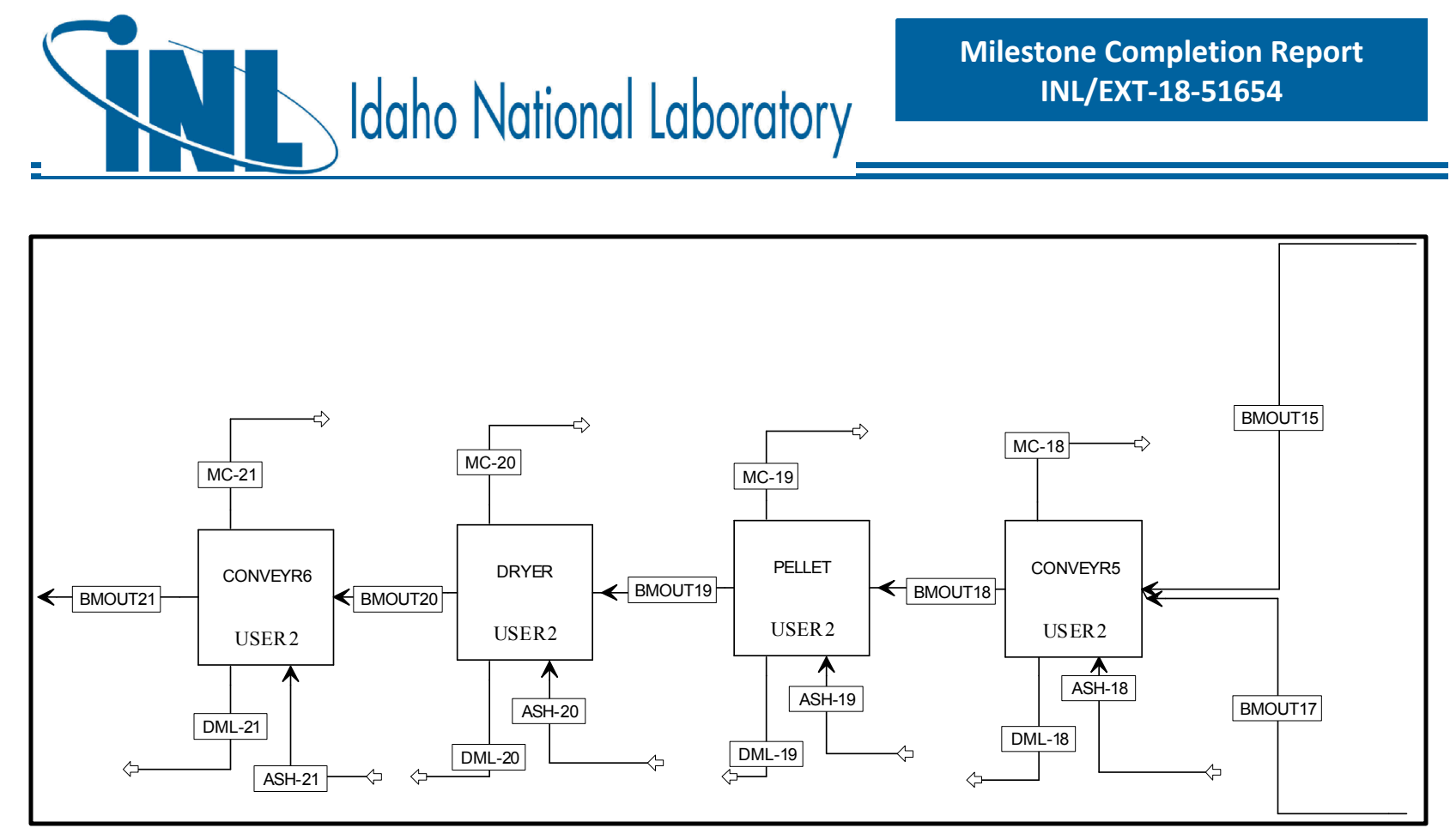

Figure J-19. Detailed process flow diagram for area C400 - Preprocessing - Pelleting.

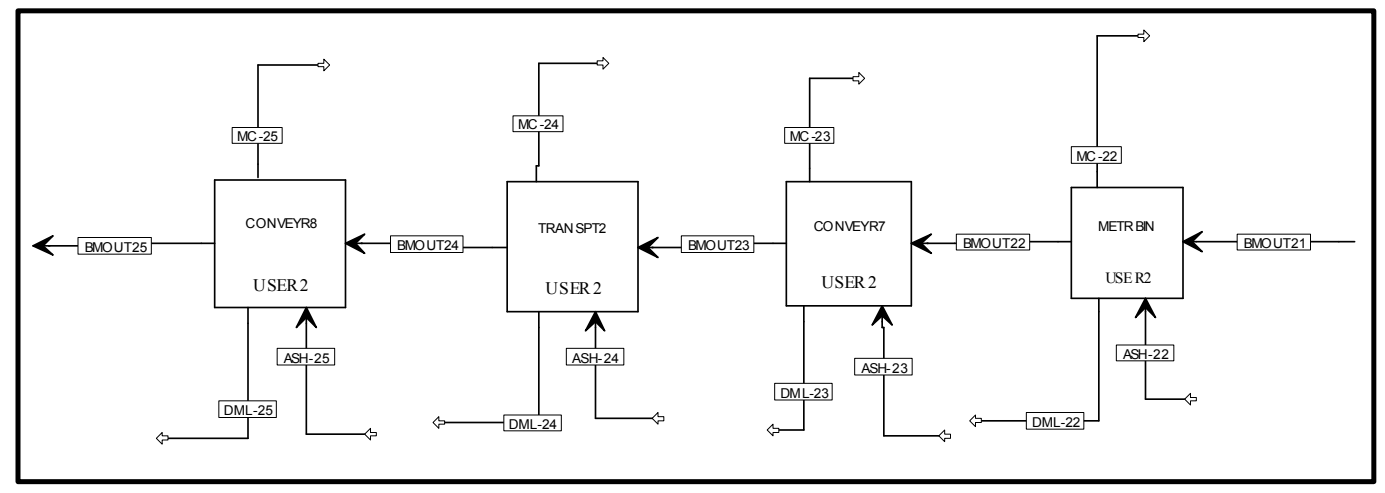

Figure J-20. Detailed process flow diagram for area C500 - Transport to Biorefinery. 

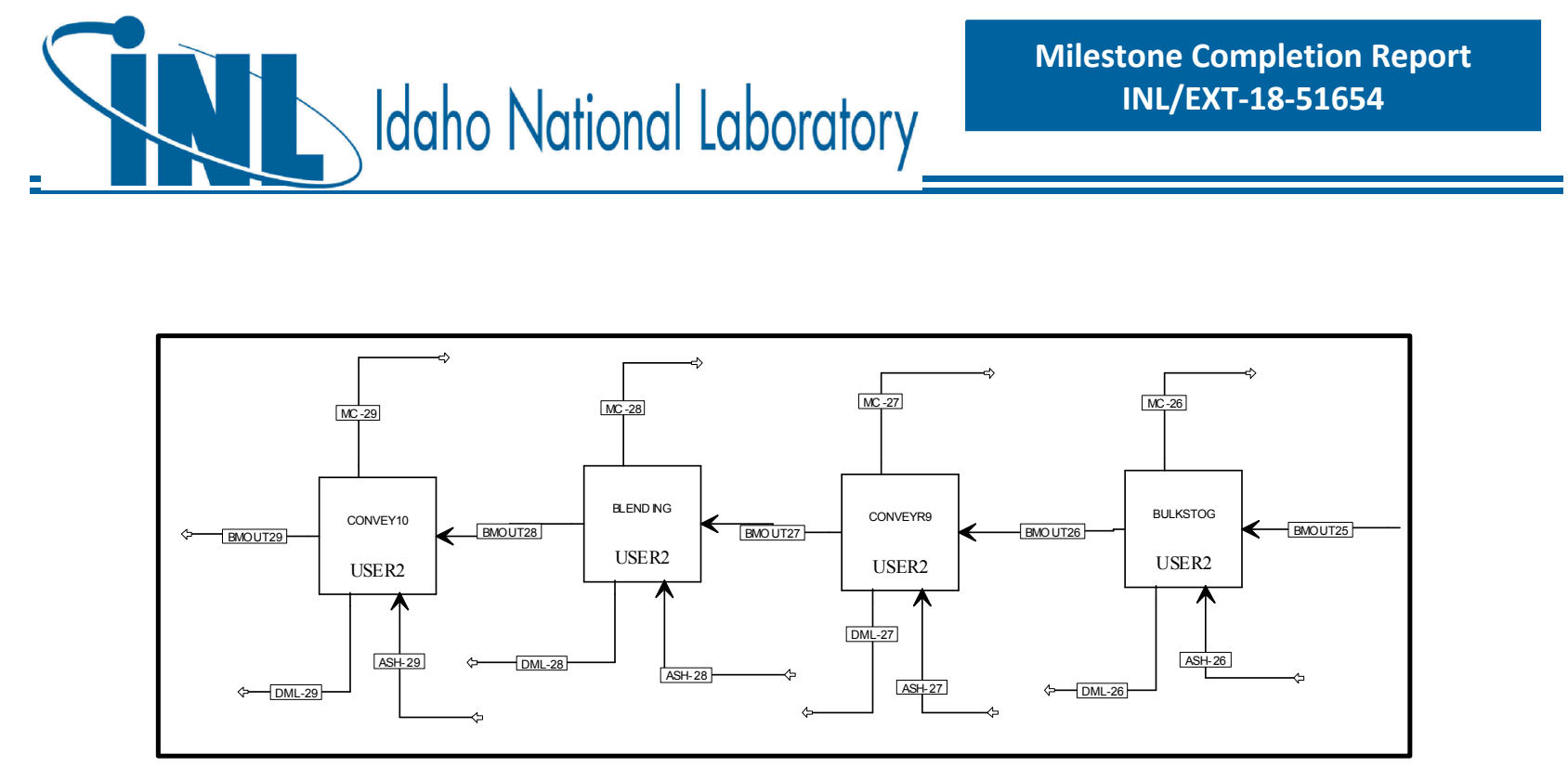

Figure J-21. Detailed process flow diagram for area C600 - Feeding. 
Table J-5. Aspen Plus mass balances from harvest to field-side storage (Area B100) for the switchgrass blendstock in the 2022 Herbaceous Projection. Harvest is assumed to take place within a 6 week period, working 14 hours/day, 6 days per week.

\begin{tabular}{|c|c|c|c|c|c|c|c|c|c|c|c|c|c|c|}
\hline Component & unit & BIOMIN & $\begin{array}{c}\text { DML- } \\
1\end{array}$ & MC-1 & $\begin{array}{c}\text { BMOUT } \\
1\end{array}$ & DML-2 & MC-2 & $\begin{array}{c}\text { BMOUT } \\
2\end{array}$ & $\begin{array}{c}\text { DML- } \\
3\end{array}$ & MC-3 & BMOUT3 & $\begin{array}{c}\text { DML- } \\
4\end{array}$ & $\begin{array}{c}\text { MC- } \\
4\end{array}$ & BMOUT4 \\
\hline $\begin{array}{l}\text { Overall Flow } \\
\text { (moisture and dry } \\
\text { matter) }\end{array}$ & $\mathrm{kg} / \mathrm{hr}$ & 35,520 & 0 & 0 & 35,520 & 0 & 0 & 35,520 & 0 & 0 & 35,520 & 0 & 0 & 35,520 \\
\hline Moisture Flow & $\mathrm{kg} / \mathrm{hr}$ & 7,104 & 0 & 0 & 7,104 & 0 & 0 & 7,104 & 0 & 0 & 7,104 & 0 & 0 & 7,104 \\
\hline $\begin{array}{l}\text { Total Flow (dry } \\
\text { matter) }\end{array}$ & $\mathrm{kg} / \mathrm{hr}$ & 28,416 & 0 & 0 & 28,416 & 0 & 0 & 28,416 & 0 & 0 & 28,416 & 0 & 0 & 28,416 \\
\hline C6 & $\mathrm{kg} / \mathrm{hr}$ & 10,110 & 0 & 0 & 10,110 & 0 & 0 & 10,110 & 0 & 0 & 10,110 & 0 & 0 & 10,110 \\
\hline C5 & $\mathrm{kg} / \mathrm{hr}$ & 8,269 & 0 & 0 & 8,269 & 0 & 0 & 8,269 & 0 & 0 & 8,269 & 0 & 0 & 8,269 \\
\hline LIGNIN & $\mathrm{kg} / \mathrm{hr}$ & 5,047 & 0 & 0 & 5,047 & 0 & 0 & 5,047 & 0 & 0 & 5,047 & 0 & 0 & 5,047 \\
\hline ASH & $\mathrm{kg} / \mathrm{hr}$ & 1,762 & 0 & 0 & 1,762 & 0 & 0 & 1,762 & 0 & 0 & 1,762 & 0 & 0 & 1,762 \\
\hline PROTEIN & $\mathrm{kg} / \mathrm{hr}$ & 0 & 0 & 0 & 0 & 0 & 0 & 0 & 0 & 0 & 0 & 0 & 0 & 0 \\
\hline EXTRACTIVES & $\mathrm{kg} / \mathrm{hr}$ & 3,228 & 0 & 0 & 3,228 & 0 & 0 & 3,228 & 0 & 0 & 3,228 & 0 & 0 & 3,228 \\
\hline OTHERS & $\mathrm{kg} / \mathrm{hr}$ & 0 & 0 & 0 & 0 & 0 & 0 & 0 & 0 & 0 & 0 & 0 & 0 & 0 \\
\hline Temperature & $\mathrm{K}$ & 298 & 298 & 298 & 298 & 298 & 298 & 298 & 298 & 298 & 298 & 298 & 298 & 298 \\
\hline Pressure & atm & 1 & 1 & 1 & 1 & 1 & 1 & 1 & 1 & 1 & 1 & 1 & 1 & 1 \\
\hline Vapor Frac & & 0 & 0 & 0 & 0 & 0 & 0 & 0 & 0 & 0 & 0 & 0 & 0 & 0 \\
\hline
\end{tabular}




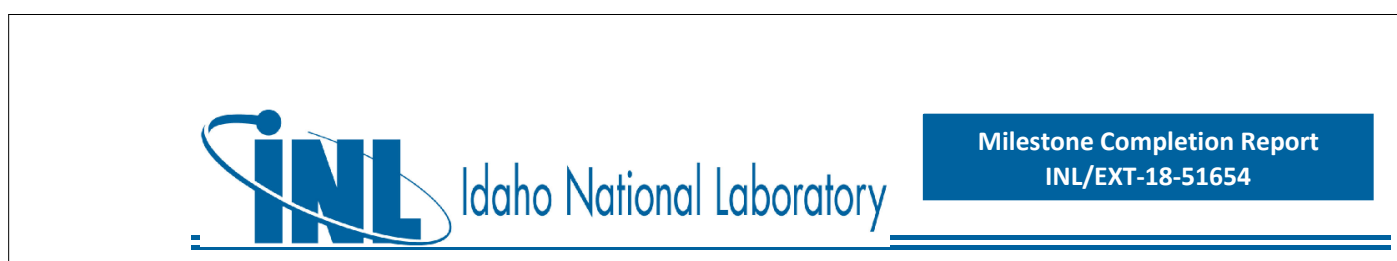

Table J-6. Aspen Plus mass balances from field-side storage to feeding (Areas B200-B600) for the witchgrass blendstock in the 2022 Herbaceous Projection. Depot operation is assumed to take place within 350 day period, working 24 hours/day, 7 days per week.

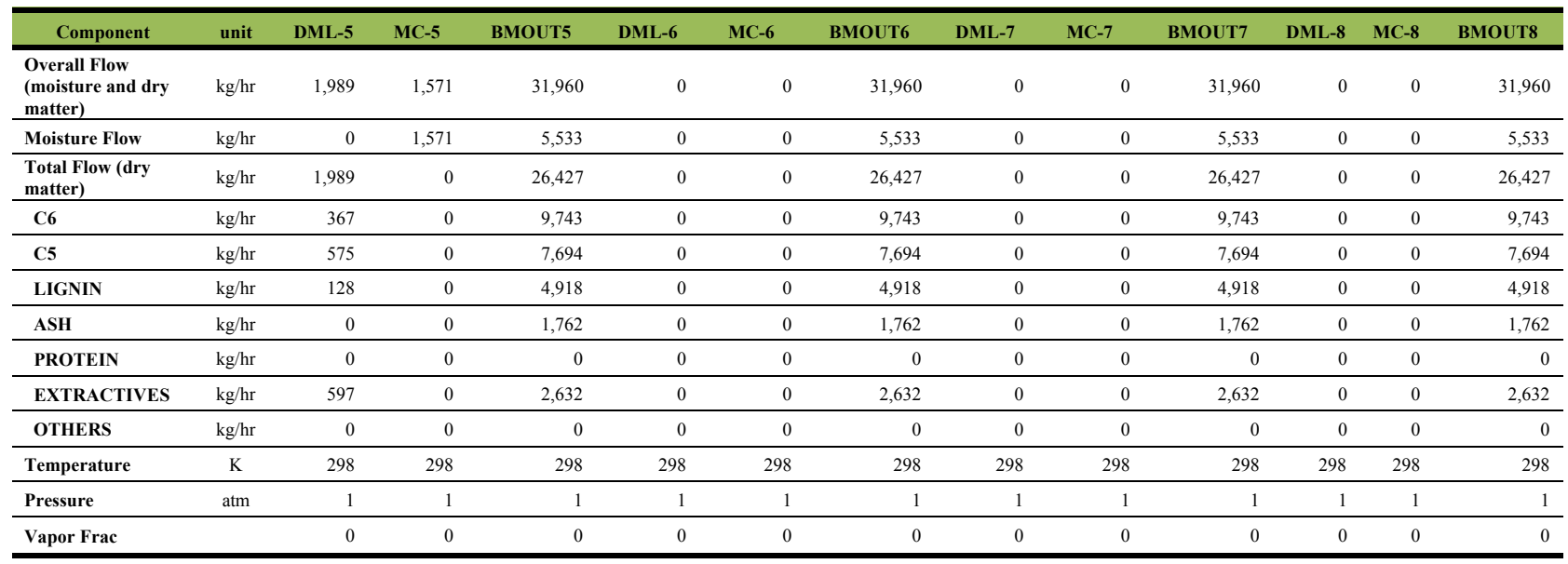

309 
Table J-6. (continued)

\begin{tabular}{|c|c|c|c|c|c|c|c|c|c|c|c|c|c|}
\hline Component & unit & DML-9 & MC-9 & BMOUT9 & DML-10 & MC-10 & BMOUT10 & $\begin{array}{l}\text { DML- } \\
101\end{array}$ & MC-101 & BMOUT101 & $\begin{array}{l}\text { DML- } \\
11\end{array}$ & $\begin{array}{l}\text { MC- } \\
11\end{array}$ & BMOUT11 \\
\hline $\begin{array}{l}\text { Overall Flow } \\
\text { (moisture and dry } \\
\text { matter) }\end{array}$ & $\mathrm{kg} / \mathrm{hr}$ & 0 & 0 & 31,960 & 0 & 0 & 31,960 & 0 & 0 & 31,960 & 529 & 1,197 & 30,234 \\
\hline Moisture Flow & $\mathrm{kg} / \mathrm{hr}$ & 0 & 0 & 5,533 & 0 & 0 & 5,533 & 0 & 0 & 5,533 & 0 & 1,197 & 4,336 \\
\hline $\begin{array}{l}\text { Total Flow (dry } \\
\text { matter) }\end{array}$ & $\mathrm{kg} / \mathrm{hr}$ & 0 & 0 & 26,427 & 0 & 0 & 26,427 & 0 & 0 & 26,427 & 529 & 0 & 25,898 \\
\hline C6 & $\mathrm{kg} / \mathrm{hr}$ & 0 & 0 & 9,743 & 0 & 0 & 9,743 & 0 & 0 & 9,743 & 146 & 0 & 9,597 \\
\hline C5 & $\mathrm{kg} / \mathrm{hr}$ & 0 & 0 & 7,694 & 0 & 0 & 7,694 & 0 & 0 & 7,694 & 82 & 0 & 7,611 \\
\hline LIGNIN & $\mathrm{kg} / \mathrm{hr}$ & 0 & 0 & 4,918 & 0 & 0 & 4,918 & 0 & 0 & 4,918 & 103 & 0 & 4,816 \\
\hline ASH & $\mathrm{kg} / \mathrm{hr}$ & 0 & 0 & 1,762 & 0 & 0 & 1,762 & 0 & 0 & 1,762 & 132 & 0 & 1,630 \\
\hline PROTEIN & $\mathrm{kg} / \mathrm{hr}$ & 0 & 0 & 0 & 0 & 0 & 0 & 0 & 0 & 0 & 0 & 0 & 0 \\
\hline EXTRACTIVES & $\mathrm{kg} / \mathrm{hr}$ & 0 & 0 & 2,632 & 0 & 0 & 2,632 & 0 & 0 & 2,632 & 65 & 0 & 2,566 \\
\hline OTHERS & $\mathrm{kg} / \mathrm{hr}$ & 0 & 0 & 0 & 0 & 0 & 0 & 0 & 0 & 0 & 0 & 0 & 0 \\
\hline Temperature & K & 298 & 298 & 298 & 298 & 298 & 298 & 298 & 298 & 298 & 298 & 298 & 298 \\
\hline Pressure & atm & 1 & 1 & 1 & 1 & 1 & 1 & 1 & 1 & 1 & 1 & 1 & 1 \\
\hline Vapor Frac & & 0 & 0 & 0 & 0 & 0 & 0 & 0 & 0 & 0 & 0 & 0 & 0 \\
\hline
\end{tabular}


- lano National Laboratory

Table J-6. (continued)

\begin{tabular}{|c|c|c|c|c|c|c|c|c|c|c|c|c|}
\hline Component & unit & $\begin{array}{c}\text { DML- } \\
12\end{array}$ & MC-12 & BMOUT12 & DML-13 & MC-13 & BMOUT13 & BMOUT14 & $\begin{array}{l}\text { DML- } \\
15\end{array}$ & $\begin{array}{l}\text { MC- } \\
15\end{array}$ & BMOUT15 & $\begin{array}{c}\text { DML- } \\
14\end{array}$ \\
\hline $\begin{array}{l}\text { Overall Flow } \\
\text { (moisture and dry } \\
\text { matter) }\end{array}$ & $\mathrm{kg} / \mathrm{hr}$ & 0 & 0 & 30,234 & 0 & 0 & 13,421 & 16,813 & 0 & 153 & 13,267 & 0 \\
\hline Moisture Flow & $\mathrm{kg} / \mathrm{hr}$ & 0 & 0 & 4,336 & 0 & 0 & 1,925 & 2,411 & 0 & 153 & 1,771 & 0 \\
\hline $\begin{array}{l}\text { Total Flow (dry } \\
\text { matter) }\end{array}$ & $\mathrm{kg} / \mathrm{hr}$ & 0 & 0 & 25,898 & 0 & 0 & 11,496 & 14,402 & 0 & 0 & 11,496 & 0 \\
\hline C6 & $\mathrm{kg} / \mathrm{hr}$ & 0 & 0 & 9,597 & 0 & 0 & 4,260 & 5,337 & 0 & 0 & 4,260 & 0 \\
\hline C5 & $\mathrm{kg} / \mathrm{hr}$ & 0 & 0 & 7,611 & 0 & 0 & 3,379 & 4,233 & 0 & 0 & 3,379 & 0 \\
\hline LIGNIN & $\mathrm{kg} / \mathrm{hr}$ & 0 & 0 & 4,816 & 0 & 0 & 2,138 & 2,678 & 0 & 0 & 2,138 & 0 \\
\hline ASH & $\mathrm{kg} / \mathrm{hr}$ & 0 & 0 & 1,630 & 0 & 0 & 723 & 906 & 0 & 0 & 723 & 0 \\
\hline PROTEIN & $\mathrm{kg} / \mathrm{hr}$ & 0 & 0 & 0 & 0 & 0 & 0 & 0 & 0 & 0 & 0 & 0 \\
\hline EXTRACTIVES & $\mathrm{kg} / \mathrm{hr}$ & 0 & 0 & 2,566 & 0 & 0 & 1,139 & 1,427 & 0 & 0 & 1,139 & 0 \\
\hline OTHERS & $\mathrm{kg} / \mathrm{hr}$ & 0 & 0 & 0 & 0 & 0 & 0 & 0 & 0 & 0 & 0 & 0 \\
\hline Temperature & K & 298 & 298 & 298 & 298 & 298 & 298 & 298 & 298 & 298 & 298 & 298 \\
\hline Pressure & atm & 1 & 1 & 1 & 1 & 1 & 1 & 1 & 1 & 1 & 1 & 1 \\
\hline Vapor Frac & & 0 & 0 & 0 & 0 & 0 & 0 & 0 & 0 & 0 & 0 & 0 \\
\hline
\end{tabular}


- lano National Laboratory

Table J-6. (continued)

\begin{tabular}{|c|c|c|c|c|c|c|c|c|c|c|c|c|}
\hline Component & unit & $\begin{array}{l}\text { MC- } \\
14\end{array}$ & BMOUT16 & DML-16 & MC-16 & BMOUT17 & DML-18 & MC-18 & BMOUT18 & DML-19 & $\begin{array}{c}\text { MC- } \\
19\end{array}$ & BMOUT19 \\
\hline $\begin{array}{l}\text { Overall Flow } \\
\text { (moisture and dry } \\
\text { matter) }\end{array}$ & $\mathrm{kg} / \mathrm{hr}$ & 0 & 16,813 & 0 & 192 & 16,621 & 0 & 0 & 29888 & 0 & 585 & 29,303 \\
\hline Moisture Flow & $\mathrm{kg} / \mathrm{hr}$ & 0 & 2,411 & 0 & 192 & 2,219 & 0 & 0 & 3,990 & 0 & 585 & 3,405 \\
\hline $\begin{array}{l}\text { Total Flow (dry } \\
\text { matter) }\end{array}$ & $\mathrm{kg} / \mathrm{hr}$ & 0 & 14,402 & 0 & 0 & 14,402 & 0 & 0 & 25,898 & 0 & 0 & 25,898 \\
\hline C6 & $\mathrm{kg} / \mathrm{hr}$ & 0 & 5,337 & 0 & 0 & 5,337 & 0 & 0 & 9,597 & 0 & 0 & 9,597 \\
\hline $\mathrm{C} 5$ & $\mathrm{~kg} / \mathrm{hr}$ & 0 & 4,233 & 0 & 0 & 4,233 & 0 & 0 & 7,611 & 0 & 0 & 7,611 \\
\hline LIGNIN & $\mathrm{kg} / \mathrm{hr}$ & 0 & 2,678 & 0 & 0 & 2,678 & 0 & 0 & 4,816 & 0 & 0 & 4,816 \\
\hline ASH & $\mathrm{kg} / \mathrm{hr}$ & 0 & 906 & 0 & 0 & 906 & 0 & 0 & 1,630 & 0 & 0 & 1,630 \\
\hline PROTEIN & $\mathrm{kg} / \mathrm{hr}$ & 0 & 0 & 0 & 0 & 0 & 0 & 0 & 0 & 0 & 0 & 0 \\
\hline EXTRACTIVES & $\mathrm{kg} / \mathrm{hr}$ & 0 & 1,427 & 0 & 0 & 1,427 & 0 & 0 & 2,566 & 0 & 0 & 2,566 \\
\hline OTHERS & $\mathrm{kg} / \mathrm{hr}$ & 0 & 0 & 0 & 0 & 0 & 0 & 0 & 0 & 0 & 0 & 0 \\
\hline Temperature & $\mathrm{K}$ & 298 & 298 & 298 & 298 & 298 & 298 & 298 & 298 & 298 & 298 & 298 \\
\hline Pressure & $\mathrm{atm}$ & 1 & 1 & 1 & 1 & 1 & 1 & 1 & 1 & 1 & 1 & 1 \\
\hline Vapor Frac & & 0 & 0 & 0 & 0 & 0 & 0 & 0 & 0 & 0 & 0 & 0 \\
\hline
\end{tabular}


lacho National Laboratory

Table J-6. (continued)

\begin{tabular}{|c|c|c|c|c|c|c|c|c|c|c|c|}
\hline Component & unit & $\begin{array}{l}\text { DML- } \\
20\end{array}$ & MC-20 & BMOUT20 & DML-21 & MC-21 & BMOUT21 & DML-22 & MC-22 & BMOUT22 & $\begin{array}{c}\text { DML- } \\
23\end{array}$ \\
\hline $\begin{array}{l}\text { Overall Flow } \\
\text { (moisture and dry } \\
\text { matter) }\end{array}$ & $\mathrm{kg} / \mathrm{hr}$ & 0 & 563 & 28,740 & 0 & 0 & 28,740 & 0 & 0 & 28,740 & 0 \\
\hline Moisture Flow & $\mathrm{kg} / \mathrm{hr}$ & 0 & 563 & 2,842 & 0 & 0 & 2,842 & 0 & 0 & 2,842 & 0 \\
\hline $\begin{array}{l}\text { Total Flow (dry } \\
\text { matter) }\end{array}$ & $\mathrm{kg} / \mathrm{hr}$ & 0 & 0 & 25,898 & 0 & 0 & 25,898 & 0 & 0 & 25,898 & 0 \\
\hline C6 & $\mathrm{kg} / \mathrm{hr}$ & 0 & 0 & 9,597 & 0 & 0 & 9,597 & 0 & 0 & 9,597 & 0 \\
\hline C5 & $\mathrm{kg} / \mathrm{hr}$ & 0 & 0 & 7,611 & 0 & 0 & 7,611 & 0 & 0 & 7,611 & 0 \\
\hline LIGNIN & $\mathrm{kg} / \mathrm{hr}$ & 0 & 0 & 4,816 & 0 & 0 & 4,816 & 0 & 0 & 4,816 & 0 \\
\hline ASH & $\mathrm{kg} / \mathrm{hr}$ & 0 & 0 & 1,630 & 0 & 0 & 1,630 & 0 & 0 & 1,630 & 0 \\
\hline PROTEIN & $\mathrm{kg} / \mathrm{hr}$ & 0 & 0 & 0 & 0 & 0 & 0 & 0 & 0 & 0 & 0 \\
\hline EXTRACTIVES & $\mathrm{kg} / \mathrm{hr}$ & 0 & 0 & 2,566 & 0 & 0 & 2,566 & 0 & 0 & 2,566 & 0 \\
\hline OTHERS & $\mathrm{kg} / \mathrm{hr}$ & 0 & 0 & 0 & 0 & 0 & 0 & 0 & 0 & 0 & 0 \\
\hline Temperature & K & 298 & 298 & 298 & 298 & 298 & 298 & 298 & 298 & 298 & 298 \\
\hline Pressure & atm & 1 & 1 & 1 & 1 & 1 & 1 & 1 & 1 & 1 & 1 \\
\hline Vapor Frac & & 0 & 0 & 0 & 0 & 0 & 0 & 0 & 0 & 0 & 0 \\
\hline
\end{tabular}


lacho National Laboratory

Table J-6. (continued)

\begin{tabular}{|c|c|c|c|c|c|c|c|c|c|c|c|c|}
\hline Component & unit & $\begin{array}{l}\text { MC- } \\
23\end{array}$ & BMOUT23 & DML-24 & MC-24 & BMOUT24 & DML-25 & MC-25 & BMOUT25 & $\begin{array}{c}\text { DML- } \\
26\end{array}$ & $\begin{array}{l}\text { MC- } \\
26\end{array}$ & $\begin{array}{c}\text { BMOUT- } \\
26\end{array}$ \\
\hline $\begin{array}{l}\text { Overall Flow } \\
\text { (moisture and dry } \\
\text { matter) }\end{array}$ & $\mathrm{kg} / \mathrm{hr}$ & 0 & 28,740 & 0 & 0 & 28,740 & 0 & 0 & 28,740 & 0 & 0 & 28,740 \\
\hline Moisture Flow & $\mathrm{kg} / \mathrm{hr}$ & 0 & 2,842 & 0 & 0 & 2,842 & 0 & 0 & 2,842 & 0 & 0 & 2,842 \\
\hline $\begin{array}{l}\text { Total Flow (dry } \\
\text { matter) }\end{array}$ & $\mathrm{kg} / \mathrm{hr}$ & 0 & 25,898 & 0 & 0 & 25,898 & 0 & 0 & 25,898 & 0 & 0 & 25,898 \\
\hline C6 & $\mathrm{kg} / \mathrm{hr}$ & 0 & 9,597 & 0 & 0 & 9,597 & 0 & 0 & 9,597 & 0 & 0 & 9,597 \\
\hline C5 & $\mathrm{kg} / \mathrm{hr}$ & 0 & 7,611 & 0 & 0 & 7,611 & 0 & 0 & 7,611 & 0 & 0 & 7,611 \\
\hline LIGNIN & $\mathrm{kg} / \mathrm{hr}$ & 0 & 4,816 & 0 & 0 & 4,816 & 0 & 0 & 4,816 & 0 & 0 & 4,816 \\
\hline ASH & $\mathrm{kg} / \mathrm{hr}$ & 0 & 1,630 & 0 & 0 & 1,630 & 0 & 0 & 1,630 & 0 & 0 & 1,630 \\
\hline PROTEIN & $\mathrm{kg} / \mathrm{hr}$ & 0 & 0 & 0 & 0 & 0 & 0 & 0 & 0 & 0 & 0 & 0 \\
\hline EXTRACTIVES & $\mathrm{kg} / \mathrm{hr}$ & 0 & 2,566 & 0 & 0 & 2,566 & 0 & 0 & 2,566 & 0 & 0 & 2,566 \\
\hline OTHERS & $\mathrm{kg} / \mathrm{hr}$ & 0 & 0 & 0 & 0 & 0 & 0 & 0 & 0 & 0 & 0 & 0 \\
\hline Temperature & K & 298 & 298 & 298 & 298 & 298 & 298 & 298 & 298 & 298 & 298 & 298 \\
\hline Pressure & atm & 1 & 1 & 1 & 1 & 1 & 1 & 1 & 1 & 1 & 1 & 1 \\
\hline Vapor Frac & & 0 & 0 & 0 & 0 & 0 & 0 & 0 & 0 & 0 & 0 & 0 \\
\hline
\end{tabular}


a daho National Laboratory

Table J-6. (continued)

\begin{tabular}{|c|c|c|c|c|c|c|c|c|c|c|}
\hline Component & unit & $\begin{array}{c}\text { DML- } \\
27\end{array}$ & MC-27 & BMOUT27 & DML-28 & MC-28 & BMOUT28 & DML-29 & MC-29 & BMOUT29 \\
\hline $\begin{array}{l}\text { Overall Flow } \\
\text { (moisture and dry } \\
\text { matter) }\end{array}$ & $\mathrm{kg} / \mathrm{hr}$ & 0 & 0 & 28,740 & 0 & 0 & 28,740 & 0 & 0 & 28,740 \\
\hline Moisture Flow & $\mathrm{kg} / \mathrm{hr}$ & 0 & 0 & 2,842 & 0 & 0 & 2,842 & 0 & 0 & 2,842 \\
\hline $\begin{array}{l}\text { Total Flow (dry } \\
\text { matter) }\end{array}$ & $\mathrm{kg} / \mathrm{hr}$ & 0 & 0 & 25,898 & 0 & 0 & 25,898 & 0 & 0 & 25,898 \\
\hline C6 & $\mathrm{kg} / \mathrm{hr}$ & 0 & 0 & 9,597 & 0 & 0 & 9,597 & 0 & 0 & 9,597 \\
\hline C5 & $\mathrm{kg} / \mathrm{hr}$ & 0 & 0 & 7,611 & 0 & 0 & 7,611 & 0 & 0 & 7,611 \\
\hline LIGNIN & $\mathrm{kg} / \mathrm{hr}$ & 0 & 0 & 4,816 & 0 & 0 & 4,816 & 0 & 0 & 4,816 \\
\hline ASH & $\mathrm{kg} / \mathrm{hr}$ & 0 & 0 & 1,630 & 0 & 0 & 1,630 & 0 & 0 & 1,630 \\
\hline PROTEIN & $\mathrm{kg} / \mathrm{hr}$ & 0 & 0 & 0 & 0 & 0 & 0 & 0 & 0 & 0 \\
\hline EXTRACTIVES & $\mathrm{kg} / \mathrm{hr}$ & 0 & 0 & 2,566 & 0 & 0 & 2,566 & 0 & 0 & 2,566 \\
\hline OTHERS & $\mathrm{kg} / \mathrm{hr}$ & 0 & 0 & 0 & 0 & 0 & 0 & 0 & 0 & 0 \\
\hline Temperature & K & 298 & 298 & 298 & 298 & 298 & 298 & 298 & 298 & 298 \\
\hline Pressure & atm & 1 & 1 & 1 & 1 & 1 & 1 & 1 & 1 & 1 \\
\hline Vapor Frac & & 0 & 0 & 0 & 0 & 0 & 0 & 0 & 0 & 0 \\
\hline
\end{tabular}




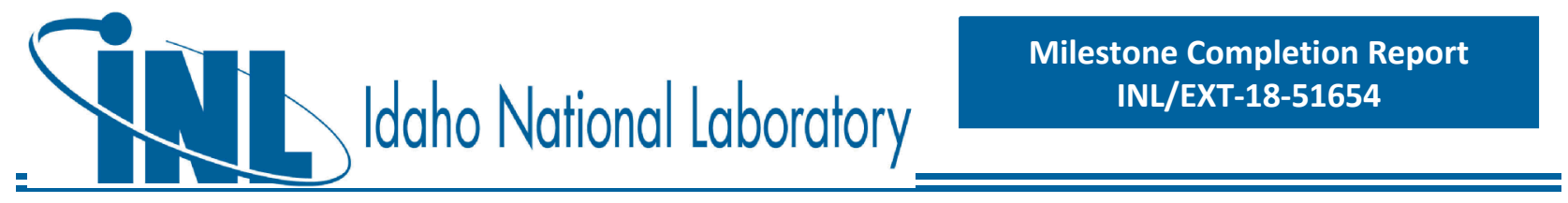

\section{J.4 Grass Clippings Blendstock}

High-level stream table information from Aspen Plus modeling output follows, for key streams associated with each process operation area. This is followed by high-level PFDs for the associated process areas. Space for stream tables was limited; below is a key to lumped components. As the stream table information focuses primarily on the high-level overall process and does not include every individual modeled stream within each process area, mass balance closure around a given unit area may not be $100 \%$.

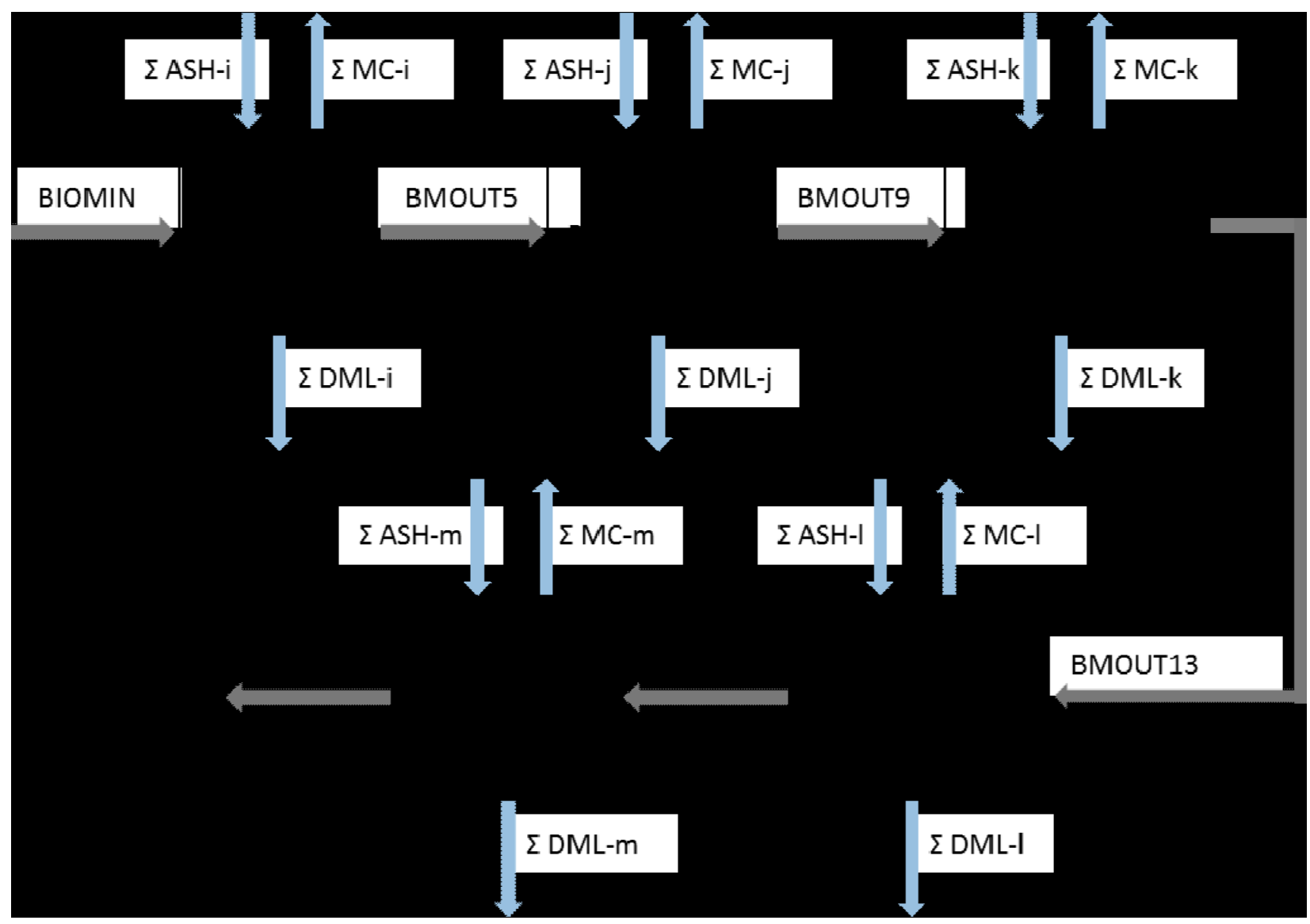

Figure J-22. High-level flowsheet showing key process areas for the grass clippings blendstock in the 2022 Herbaceous Projection. 

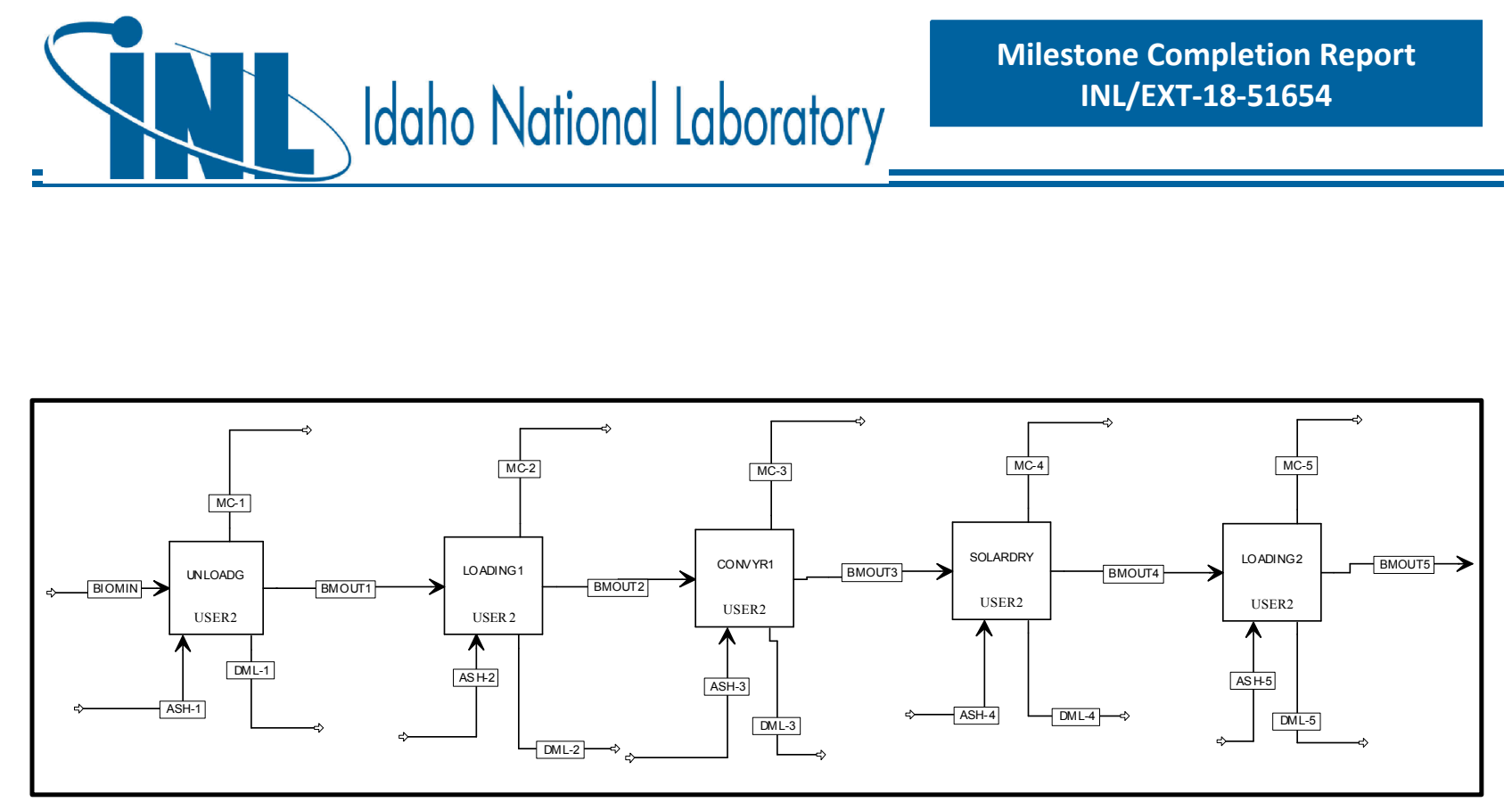

Figure J-23. Detailed process flow diagram for area D100 - Solar Drying.

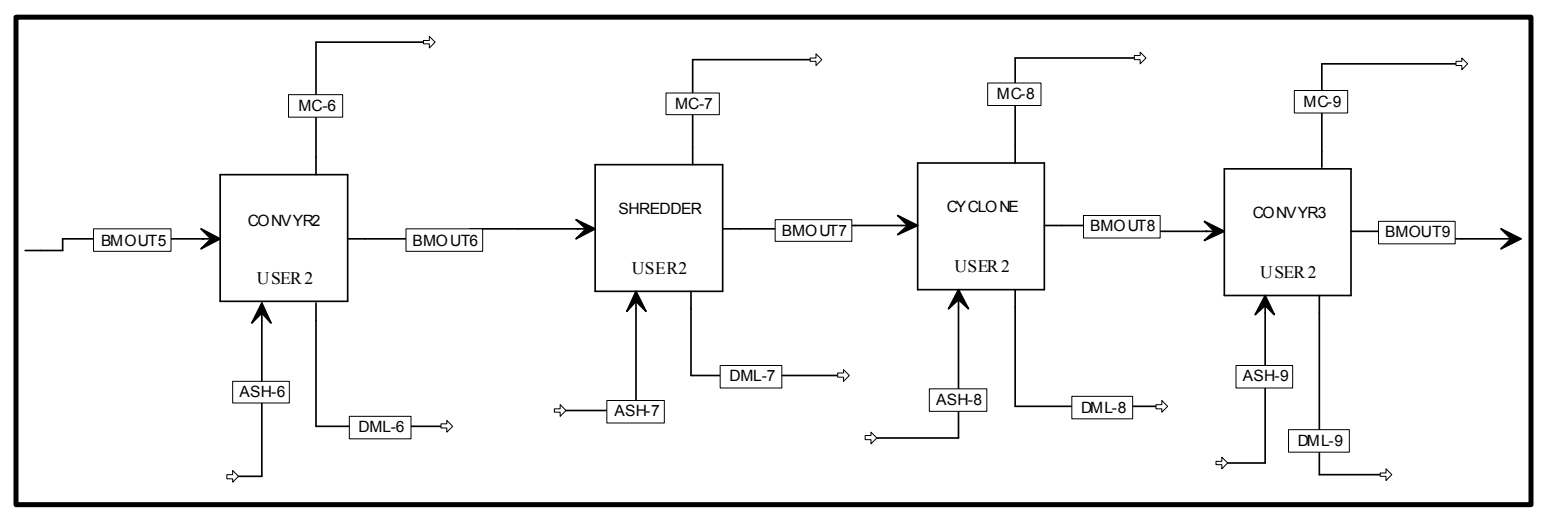

Figure J-24. Detailed process flow diagram for area D200 - Preprocessing - Size Reduction.

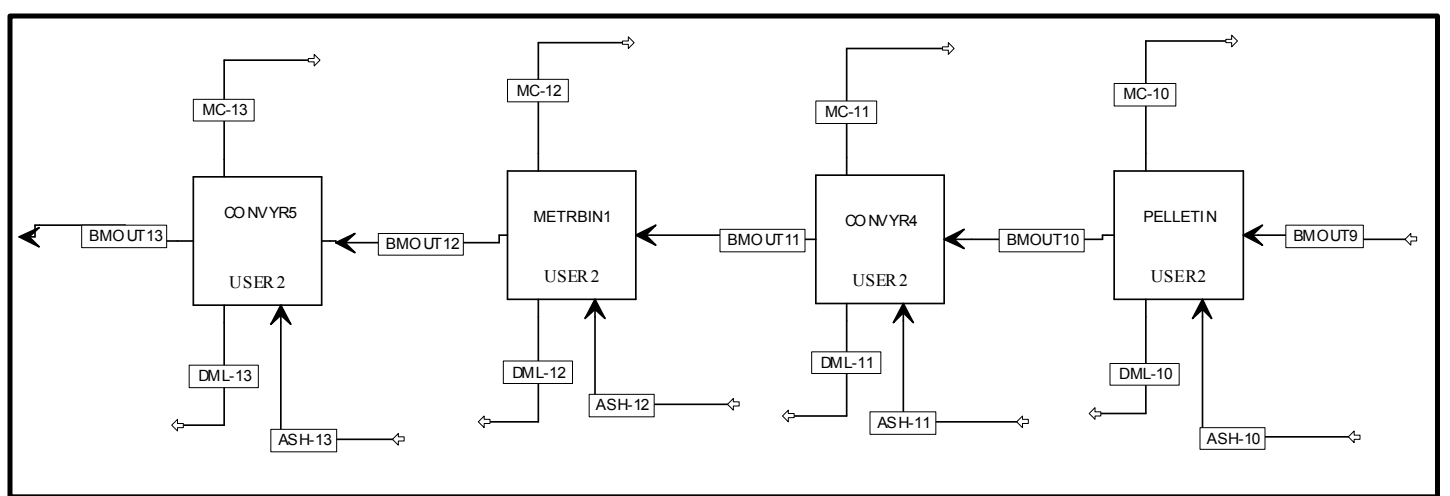

Figure J-25. Detailed process flow diagram for area D300 - Preprocessing - Pelleting. 


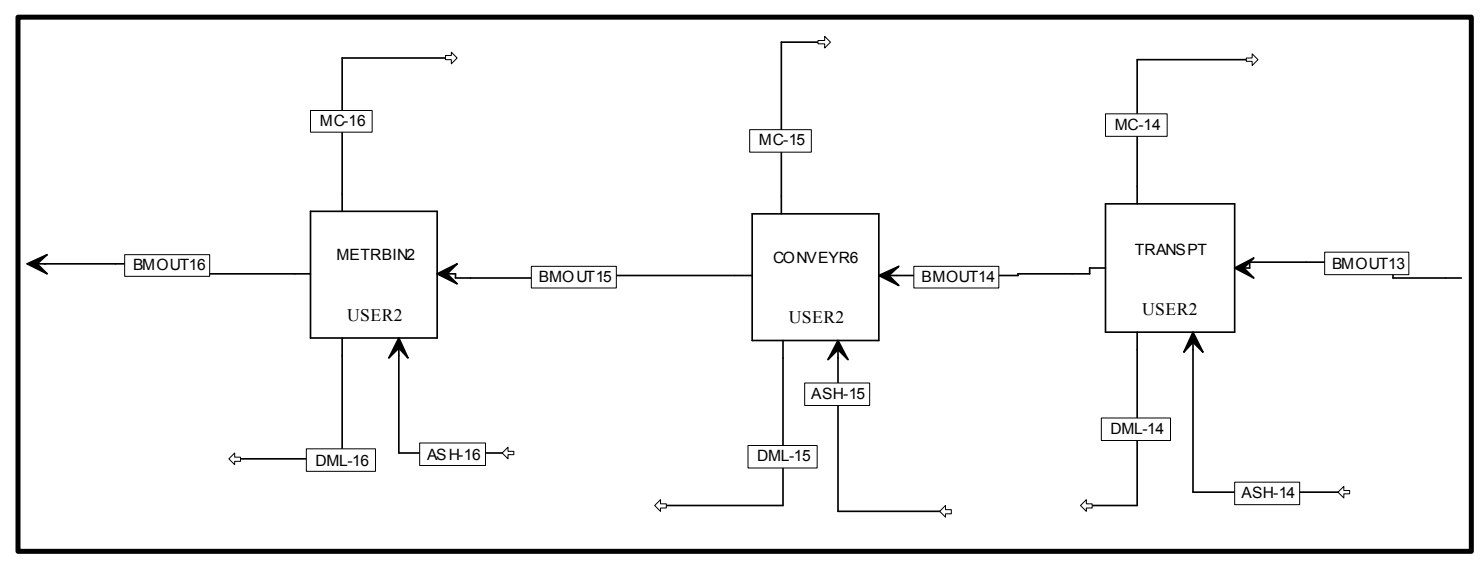

Figure J-26. Detailed process flow diagram for area D400 - Transportation to Biorefinery.

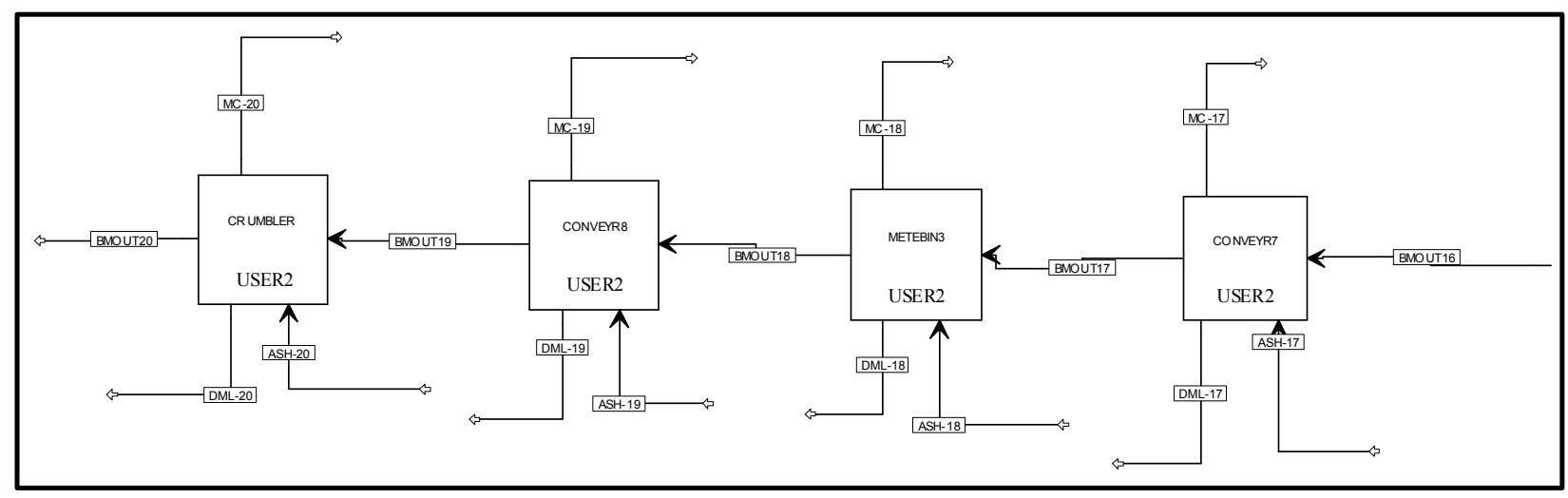

Figure J-27. Detailed process flow diagram for area D500 - Feeding. 


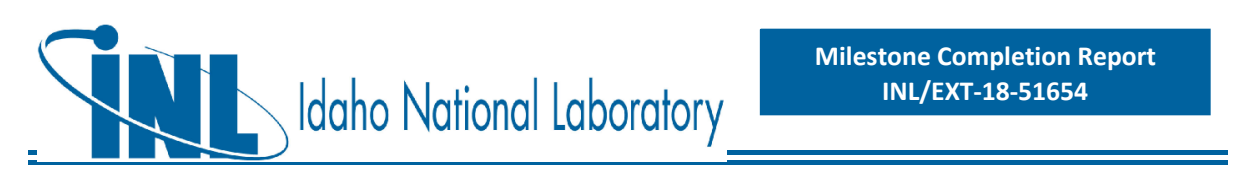

Table J-7. Aspen Plus mass balances for the grass clippings blendstock in the 2022 Herbaceous Projection. Depot operation is assumed to take place within a 25 week period, working 24 hours/day, 7 days per week.

\begin{tabular}{|c|c|c|c|c|c|c|c|c|c|c|c|c|c|}
\hline Component & unit & BIOMIN & DML-1 & MC-1 & BMOUT1 & DML-2 & MC-2 & BMOUT2 & DML-3 & MC-3 & BMOUT3 & DML-4 & MC-4 \\
\hline $\begin{array}{l}\text { Overall Flow } \\
\text { (moisture and } \\
\text { dry matter) }\end{array}$ & $\mathrm{kg} / \mathrm{hr}$ & 49,803 & 0 & 0 & 49,803 & 0 & 0 & 49,803 & 0 & 0 & 49,803 & 90 & 32,242 \\
\hline Moisture Flow & $\mathrm{kg} / \mathrm{hr}$ & 34,862 & 0 & 0 & 34,862 & 0 & 0 & 34,862 & 0 & 0 & 34,862 & 0 & 32,242 \\
\hline $\begin{array}{l}\text { Total Flow (dry } \\
\text { matter) }\end{array}$ & $\mathrm{kg} / \mathrm{hr}$ & 14,941 & 0 & 0 & 14,941 & 0 & 0 & 14,941 & 0 & 0 & 14,941 & 90 & 0 \\
\hline C6 & $\mathrm{kg} / \mathrm{hr}$ & 2,928 & 0 & 0 & 2,928 & 0 & 0 & 2,928 & 0 & 0 & 2,928 & 0 & 0 \\
\hline C5 & $\mathrm{kg} / \mathrm{hr}$ & 1,270 & 0 & 0 & 1,270 & 0 & 0 & 1,270 & 0 & 0 & 1,270 & 0 & 0 \\
\hline LIGNIN & $\mathrm{kg} / \mathrm{hr}$ & 2,495 & 0 & 0 & 2,495 & 0 & 0 & 2,495 & 0 & 0 & 2,495 & 0 & 0 \\
\hline ASH & $\mathrm{kg} / \mathrm{hr}$ & 1,912 & 0 & 0 & 1,912 & 0 & 0 & 1,912 & 0 & 0 & 1,912 & 0 & 0 \\
\hline PROTEIN & $\mathrm{kg} / \mathrm{hr}$ & 1,524 & 0 & 0 & 1,524 & 0 & 0 & 1,524 & 0 & 0 & 1,524 & 0 & 0 \\
\hline $\begin{array}{l}\text { EXTRACTIVE } \\
\text { S }\end{array}$ & $\mathrm{kg} / \mathrm{hr}$ & 3,227 & 0 & 0 & 3,227 & 0 & 0 & 3,227 & 0 & 0 & 3,227 & 90 & 0 \\
\hline OTHERS & $\mathrm{kg} / \mathrm{hr}$ & 1,584 & 0 & 0 & 1,584 & 0 & 0 & 1,584 & 0 & 0 & 1,584 & 0 & 0 \\
\hline Temperature & $\mathrm{K}$ & 298 & 298 & 298 & 298 & 298 & 298 & 298 & 298 & 298 & 298 & 298 & 298 \\
\hline Pressure & atm & 1 & 1 & 1 & 1 & 1 & 1 & 1 & 1 & 1 & 1 & 1 & 1 \\
\hline Vapor Frac & & 0 & 0 & 0 & 0 & 0 & 0 & 0 & 0 & 0 & 0 & 0 & 0 \\
\hline
\end{tabular}


Laho National Laboratory

Table J-7. (continued)

\begin{tabular}{|c|c|c|c|c|c|c|c|c|c|c|c|c|c|c|}
\hline Component & unit & BMOUT4 & DML-5 & MC-5 & BMOUT5 & DML-6 & MC-6 & BMOUT6 & $\begin{array}{l}\text { DML- } \\
7\end{array}$ & MC-7 & BMOUT7 & $\begin{array}{l}\text { DML- } \\
8\end{array}$ & MC-8 & BMOUT8 \\
\hline $\begin{array}{l}\text { Overall Flow } \\
\text { (moisture and } \\
\text { dry matter) }\end{array}$ & $\mathrm{kg} / \mathrm{hr}$ & 17,472 & 0 & 0 & 17,472 & 0 & 0 & 17,472 & 74 & 413 & 16,985 & 0 & 0 & 16,985 \\
\hline Moisture Flow & $\mathrm{kg} / \mathrm{hr}$ & 2,621 & 0 & 0 & 2,621 & 0 & 0 & 2,621 & 0 & 413 & 2,208 & 0 & 0 & 2,208 \\
\hline $\begin{array}{l}\text { Total Flow (dry } \\
\text { matter) }\end{array}$ & $\mathrm{kg} / \mathrm{hr}$ & 14,851 & 0 & 0 & 14,851 & 0 & 0 & 14,851 & 74 & 0 & 14,777 & 0 & 0 & 14,777 \\
\hline C6 & $\mathrm{kg} / \mathrm{hr}$ & 2,928 & 0 & 0 & 2,928 & 0 & 0 & 2,928 & 13 & 0 & 2,916 & 0 & 0 & 2,916 \\
\hline C5 & $\mathrm{kg} / \mathrm{hr}$ & 1,270 & 0 & 0 & 1,270 & 0 & 0 & 1,270 & 5 & 0 & 1,265 & 0 & 0 & 1,265 \\
\hline LIGNIN & $\mathrm{kg} / \mathrm{hr}$ & 2,495 & 0 & 0 & 2,495 & 0 & 0 & 2,495 & 11 & 0 & 2,484 & 0 & 0 & 2,484 \\
\hline ASH & $\mathrm{kg} / \mathrm{hr}$ & 1,912 & 0 & 0 & 1,912 & 0 & 0 & 1,912 & 19 & 0 & 1,894 & 0 & 0 & 1,894 \\
\hline PROTEIN & $\mathrm{kg} / \mathrm{hr}$ & 1,524 & 0 & 0 & 1,524 & 0 & 0 & 1,524 & 7 & 0 & 1,517 & 0 & 0 & 1,517 \\
\hline $\begin{array}{l}\text { EXTRACTIVE } \\
\text { S }\end{array}$ & $\mathrm{kg} / \mathrm{hr}$ & 3,138 & 0 & 0 & 3,138 & 0 & 0 & 3,138 & 14 & 0 & 3,124 & 0 & 0 & 3,124 \\
\hline OTHERS & $\mathrm{kg} / \mathrm{hr}$ & 1,584 & 0 & 0 & 1,584 & 0 & 0 & 1,584 & 7 & 0 & 1,577 & 0 & 0 & 1,577 \\
\hline Temperature & $\mathrm{K}$ & 298 & 298 & 298 & 298 & 298 & 298 & 298 & 298 & 298 & 298 & 298 & 298 & 298 \\
\hline Pressure & $\mathrm{atm}$ & 1 & 1 & 1 & 1 & 1 & 1 & 1 & 1 & 1 & 1 & 1 & 1 & 1 \\
\hline Vapor Frac & & 0 & 0 & 0 & 0 & 0 & 0 & 0 & 0 & 0 & 0 & 0 & 0 & 0 \\
\hline
\end{tabular}


Table J-7. (continued)

\begin{tabular}{|c|c|c|c|c|c|c|c|c|c|c|c|c|c|c|}
\hline Component & unit & $\begin{array}{l}\text { DML- } \\
9\end{array}$ & MC-9 & BMOUT9 & DML-10 & MC-10 & BMOUT10 & DML-11 & MC-11 & BMOUT11 & DML-12 & MC-12 & BMOUT12 & DML-13 \\
\hline $\begin{array}{l}\begin{array}{l}\text { Overall Flow } \\
\text { (moisture and } \\
\text { dry matter) }\end{array} \\
\end{array}$ & $\mathrm{kg} / \mathrm{hr}$ & 0 & 0 & 16,985 & 0 & 382 & 16,604 & 0 & 184 & 16,419 & 0 & 0 & 16,419 & 0 \\
\hline Moisture Flow & $\mathrm{kg} / \mathrm{hr}$ & 0 & 0 & 2,208 & 0 & 382 & 1,826 & 0 & 184 & 1,642 & 0 & 0 & 1,642 & 0 \\
\hline $\begin{array}{l}\text { Total Flow (dry } \\
\text { matter) }\end{array}$ & $\mathrm{kg} / \mathrm{hr}$ & 0 & 0 & 14,777 & 0 & 0 & 14,777 & 0 & 0 & 14,777 & 0 & 0 & 14,777 & 0 \\
\hline C6 & $\mathrm{kg} / \mathrm{hr}$ & 0 & 0 & 2,916 & 0 & 0 & 2,916 & 0 & 0 & 2,916 & 0 & 0 & 2,916 & 0 \\
\hline $\mathrm{C} 5$ & $\mathrm{~kg} / \mathrm{hr}$ & 0 & 0 & 1,265 & 0 & 0 & 1,265 & 0 & 0 & 1,265 & 0 & 0 & 1,265 & 0 \\
\hline LIGNIN & $\mathrm{kg} / \mathrm{hr}$ & 0 & 0 & 2,484 & 0 & 0 & 2,484 & 0 & 0 & 2,484 & 0 & 0 & 2,484 & 0 \\
\hline ASH & $\mathrm{kg} / \mathrm{hr}$ & 0 & 0 & 1,894 & 0 & 0 & 1,894 & 0 & 0 & 1,894 & 0 & 0 & 1,894 & 0 \\
\hline PROTEIN & $\mathrm{kg} / \mathrm{hr}$ & 0 & 0 & 1,517 & 0 & 0 & 1,517 & 0 & 0 & 1,517 & 0 & 0 & 1,517 & 0 \\
\hline $\begin{array}{l}\text { EXTRACTIVE } \\
\text { S }\end{array}$ & $\mathrm{kg} / \mathrm{hr}$ & 0 & 0 & 3,124 & 0 & 0 & 3,124 & 0 & 0 & 3,124 & 0 & 0 & 3,124 & 0 \\
\hline OTHERS & $\mathrm{kg} / \mathrm{hr}$ & 0 & 0 & 1,577 & 0 & 0 & 1,577 & 0 & 0 & 1,577 & 0 & 0 & 1,577 & 0 \\
\hline Temperature & $\mathrm{K}$ & 298 & 298 & 298 & 298 & 298 & 298 & 298 & 298 & 298 & 298 & 298 & 298 & 298 \\
\hline Pressure & atm & 1 & 1 & 1 & 1 & 1 & 1 & 1 & 1 & 1 & 1 & 1 & 1 & 1 \\
\hline Vapor Frac & & 0 & 0 & 0 & 0 & 0 & 0 & 0 & 0 & 0 & 0 & 0 & 0 & 0 \\
\hline
\end{tabular}


Table J-7. (continued)

\begin{tabular}{|c|c|c|c|c|c|c|c|c|c|c|c|c|c|}
\hline Component & unit & MC-13 & BMOUT13 & DML-14 & MC-14 & BMOUT14 & DML-15 & MC-15 & BMOUT15 & DML-16 & MC-16 & BMOUT16 & DML-17 \\
\hline $\begin{array}{l}\text { Overall Flow } \\
\text { (moisture and } \\
\text { dry matter) }\end{array}$ & $\mathrm{kg} / \mathrm{hr}$ & 0 & 16,419 & 0 & 0 & 16,419 & 0 & 0 & 16,419 & 0 & 0 & 16,419 & 0 \\
\hline Moisture Flow & $\mathrm{kg} / \mathrm{hr}$ & 0 & 1,642 & 0 & 0 & 1,642 & 0 & 0 & 1,642 & 0 & 0 & 1,642 & 0 \\
\hline $\begin{array}{l}\text { Total Flow (dry } \\
\text { matter) }\end{array}$ & $\mathrm{kg} / \mathrm{hr}$ & 0 & 14,777 & 0 & 0 & 14,777 & 0 & 0 & 14,777 & 0 & 0 & 14,777 & 0 \\
\hline C6 & $\mathrm{kg} / \mathrm{hr}$ & 0 & 2,916 & 0 & 0 & 2,916 & 0 & 0 & 2,916 & 0 & 0 & 2,916 & 0 \\
\hline C5 & $\mathrm{kg} / \mathrm{hr}$ & 0 & 1,265 & 0 & 0 & 1,265 & 0 & 0 & 1,265 & 0 & 0 & 1,265 & 0 \\
\hline LIGNIN & $\mathrm{kg} / \mathrm{hr}$ & 0 & 2,484 & 0 & 0 & 2,484 & 0 & 0 & 2,484 & 0 & 0 & 2,484 & 0 \\
\hline ASH & $\mathrm{kg} / \mathrm{hr}$ & 0 & 1,894 & 0 & 0 & 1,894 & 0 & 0 & 1,894 & 0 & 0 & 1,894 & 0 \\
\hline PROTEIN & $\mathrm{kg} / \mathrm{hr}$ & 0 & 1,517 & 0 & 0 & 1,517 & 0 & 0 & 1,517 & 0 & 0 & 1,517 & 0 \\
\hline $\begin{array}{l}\text { EXTRACTIVE } \\
\text { S } \\
\end{array}$ & $\mathrm{kg} / \mathrm{hr}$ & 0 & 3,124 & 0 & 0 & 3,124 & 0 & 0 & 3,124 & 0 & 0 & 3,124 & 0 \\
\hline OTHERS & $\mathrm{kg} / \mathrm{hr}$ & 0 & 1,577 & 0 & 0 & 1,577 & 0 & 0 & 1,577 & 0 & 0 & 1,577 & 0 \\
\hline Temperature & K & 298 & 298 & 298 & 298 & 298 & 298 & 298 & 298 & 298 & 298 & 298 & 298 \\
\hline Pressure & atm & 1 & 1 & 1 & 1 & 1 & 1 & 1 & 1 & 1 & 1 & 1 & 1 \\
\hline Vapor Frac & & 0 & 0 & 0 & 0 & 0 & 0 & 0 & 0 & 0 & 0 & 0 & 0 \\
\hline
\end{tabular}


Table J-7. (continued)

\begin{tabular}{|c|c|c|c|c|c|c|c|c|c|c|c|c|}
\hline Component & unit & MC-17 & BMOUT17 & DML-18 & MC-18 & BMOUT18 & DML-19 & MC-19 & BMOUT19 & DML-20 & MC-20 & BMOUT20 \\
\hline $\begin{array}{l}\text { Overall Flow } \\
\text { (moisture and } \\
\text { dry matter) }\end{array}$ & $\mathrm{kg} / \mathrm{hr}$ & 0 & 16,419 & 0 & 0 & 16,419 & 0 & 0 & 16,419 & 0 & 0 & 16,419 \\
\hline Moisture Flow & $\mathrm{kg} / \mathrm{hr}$ & 0 & 1,642 & 0 & 0 & 1,642 & 0 & 0 & 1,642 & 0 & 0 & 1,642 \\
\hline $\begin{array}{l}\text { Total Flow (dry } \\
\text { matter) }\end{array}$ & $\mathrm{kg} / \mathrm{hr}$ & 0 & 14,777 & 0 & 0 & 14,777 & 0 & 0 & 14,777 & 0 & 0 & 14,777 \\
\hline C6 & $\mathrm{kg} / \mathrm{hr}$ & 0 & 2,916 & 0 & 0 & 2,916 & 0 & 0 & 2,916 & 0 & 0 & 2,916 \\
\hline $\mathrm{C} 5$ & $\mathrm{~kg} / \mathrm{hr}$ & 0 & 1,265 & 0 & 0 & 1,265 & 0 & 0 & 1,265 & 0 & 0 & 1,265 \\
\hline LIGNIN & $\mathrm{kg} / \mathrm{hr}$ & 0 & 2,484 & 0 & 0 & 2,484 & 0 & 0 & 2,484 & 0 & 0 & 2,484 \\
\hline ASH & $\mathrm{kg} / \mathrm{hr}$ & 0 & 1,894 & 0 & 0 & 1,894 & 0 & 0 & 1,894 & 0 & 0 & 1,894 \\
\hline PROTEIN & $\mathrm{kg} / \mathrm{hr}$ & 0 & 1,517 & 0 & 0 & 1,517 & 0 & 0 & 1,517 & 0 & 0 & 1,517 \\
\hline $\begin{array}{l}\text { EXTRACTIVE } \\
\mathrm{S} \\
\end{array}$ & $\mathrm{kg} / \mathrm{hr}$ & 0 & 3,124 & 0 & 0 & 3,124 & 0 & 0 & 3,124 & 0 & 0 & 3,124 \\
\hline OTHERS & $\mathrm{kg} / \mathrm{hr}$ & 0 & 1,577 & 0 & 0 & 1,577 & 0 & 0 & 1,577 & 0 & 0 & 1,577 \\
\hline Temperature & $\mathrm{K}$ & 298 & 298 & 298 & 298 & 298 & 298 & 298 & 298 & 298 & 298 & 298 \\
\hline Pressure & $\mathrm{atm}$ & 1 & 1 & 1 & 1 & 1 & 1 & 1 & 1 & 1 & 1 & 1 \\
\hline Vapor Frac & & 0 & 0 & 0 & 0 & 0 & 0 & 0 & 0 & 0 & 0 & 0 \\
\hline
\end{tabular}




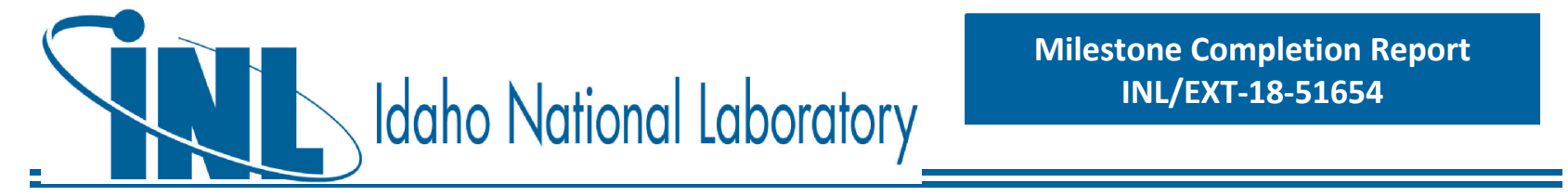

